九州大学学術情報リポジトリ

Kyushu University Institutional Repository

Systematic Study on the Genus Bafrisoplisus and its Allied Genera from Japan (Coleoptera, Pse laphidae)

Nomura, Shuhe i

https://doi.org/10.5109/2550

出版情報: ESAKIA. 30，pp.1-462，1991-05-31. Entomological Laboratory，Faculty of Agriculture， Kyushu University

バージョン：

権利関係 : 


\title{
Systematic Study on the Genus Bafrisoplisus and its Allied Genera from Japan (Coleoptera, Pselaphidae) $^{*}$
}

\author{
Shûhei NOMURA \\ Entomological Laboratory, Faculty of Agriculture, \\ Kyushu University, Fukuoka, 812 Japan
}

\begin{abstract}
A total number of 6 genera, 67 species and 8 subspecies of the Batrisocenus complex or the fifth division of the subtribe Batrisina occurring in Japan is revised.

Number of species and subspecies for each germs treated is as follows: 23 species and 1 subspecies in Batrisoplisus (including 18 new species and 1 new subspecies), 16 species and 1 subspecies in Batriscenellus (including 11 new species and 1 new combination), 7 species and 2 subspecies in Batriscenaulax (including 3 new species and 2 new subspecies), 3 species in Physomerinus (including 1 new species and 1 new combination), 16 species and 3 subspecies in Arthromelodes (including 14 new species, 3 new subspecies and 1 new combination) and 3 species in Batrisceniola (1 new species and 1 new combination). The genus Pseudobatriscenus Jeanne1 is synonymized with $\boldsymbol{A r}$ thromelodes. Descriptions of and keys to genera and species are presented and the important characters are illustrated for all species. Biological informations are noted for some species.

The characters and their polarities are discussed in detail from the view point of phylogenetic systematics. The dimorphisms of the wings and the male genitalia are noticed for the first time in this group on 13 and 6 species respectively.
\end{abstract}

* Contribution from the Entomological Laboratory, Faculty of Agriculture, Kyushu University, Fukuoka (Ser. 4, No. 26). 


\section{CONTENTS}

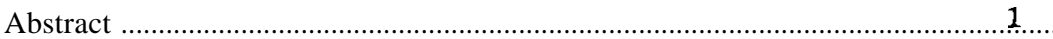

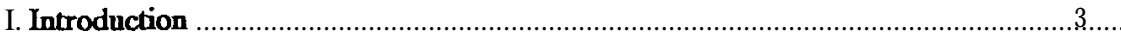

IL Materials and methods ...........................................................................................

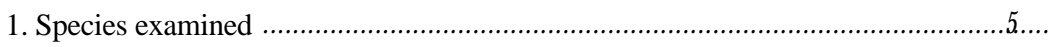

2. Methods of dissection and observation ............................................................6.

3. Methods of phyiogenetic reconstruction ………………...................................6.

III. General morphology ........................................................................................................

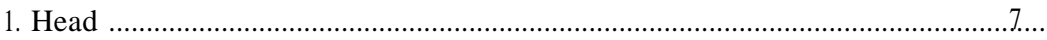

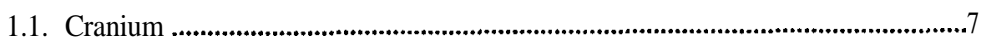

1.2. Appendages of the head ...................................................................................

2. Thorax ……

2.1. Structure of thoracic segments ……………………....................................11

2.2. wigs ................................................................................................................ 14

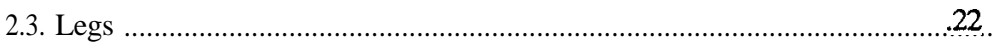

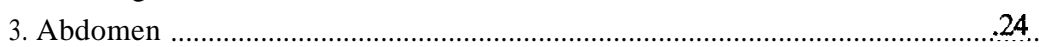

3.1. Basic structures of abdominal segments ........................................................24

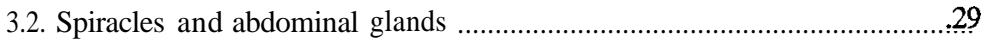

3.3. Male genitalia .................................................................................................... 31

3.4. Ovipositor ........................................................................................ 37.

4. Hairs and setiferous structures ..........................................................................?

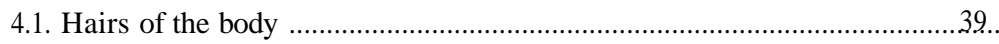

4.2. Non-sexual setiferous structure ……………………………………...........

4.3. Sexual patch ..................................................................................................4

IV. Phylogeny .....................................................................................................................48

1. Phylogenetic relationship of Japanese genera of the Batrisocenus complex and systematic position of the genus Cratna ................................................................4

2. Phylogenetic relationship among species-groups, species and subspecies of the genus Batrisoplisus .............................................................................................

3. Phylogenetic relationship among subgenera, species and subspecies of the genus Batriscenellus ....................................................................................................50

4. Phylogenetic relationship among species and subspecies of the genera Batriscenaulax, Physomerinus, Arthromelodes and Batrisceniola ..............................50

Appendix 1: Plesiomorphy and apomorphy of the characters used for a cladistic analysis of Batniocenus complex ................................................................52

Appendix 2: Character matrix used for a cladistic analysis of the Batniocenus

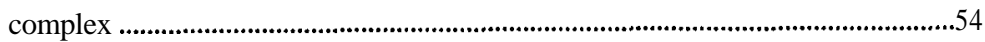

Figures for the chapters of general morphology and phylogeny (Figs. 1-106) .................58 
V. Systematics

A key to the genera of Batrisocenus complex from Japan (with some from the

Oriental region put in parentheses)

Genus Batrisoplisus Raffiray

A key to the species group, the species and the subspecies of the genus

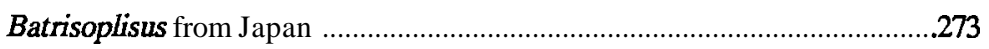

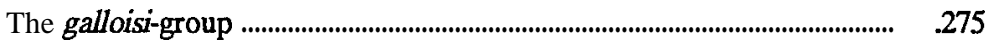

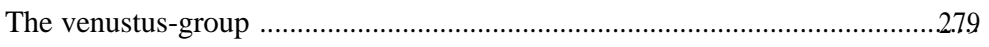

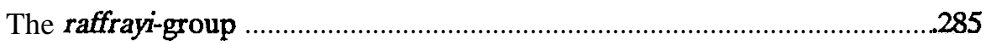

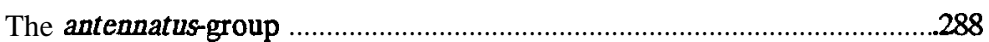

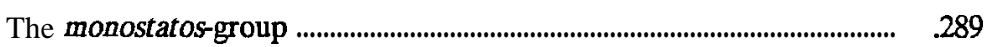

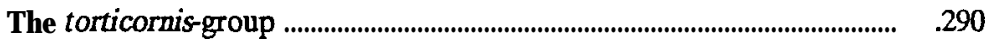

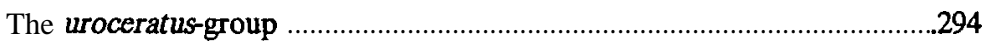

Genus Batriscenellus Jeannel ......................................................................299

A key to the subgenera of the genus Batriscenellus from Japan ...........................299

Subgenus Batriscenellus s. str. ........................................................................300

A key to the species and the subspecies of the subgenus Batriscenellus .........3 00

Subgenus Nipponoscenellus nov. ...............................................................

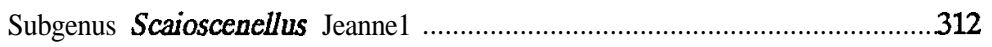

A key to the species of the subgenus Scaioscenellus from Japan ....................312

Subgenus Batriscenellinus nov. ....................................................................321

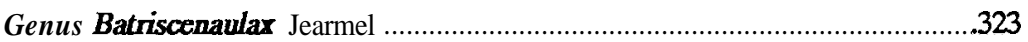

A key to the species and the subspecies of the genus Batriscenaulax from

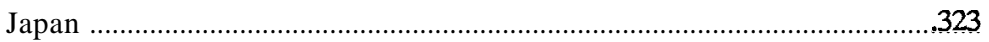

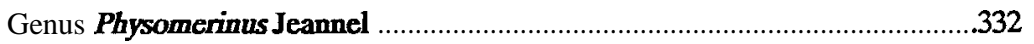

A key to the species of the genus Physomerinus from Japan ................................333

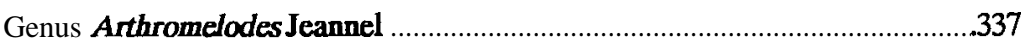

A key to the species and subspecies of the genus Arthromelodes from Japan

Act.............................................338

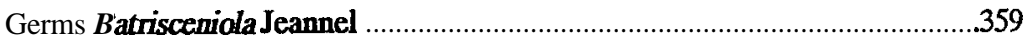

A key to the species of the genus Batrisceniola from Japan ..................................360

Figures for the chapter of systematics (Figs. 107-150) ……................................. .365

VI. Acknowiedgement ...................................................................................................453

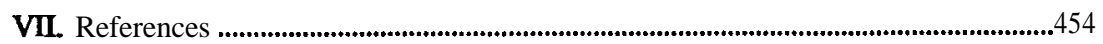

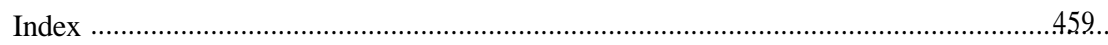

\section{INTRODUCTION}

The pselaphid beetles occur in leaf litter, rotten logs, and other habitats which contain decaying 
organic matter. Most species may be predators and some are known to be myrmecophilous. They are important not only as a component of the soil ecosystem as predators, but also as indicator species of the soil environment. This family is worldwide in distribution and greatly diversified in the tropics. Japanese fauna of the Pselaphidae contains about 170 species so far recorded, but no less than one thousand species could be estimated actually living in Japan upon my collecting data. Present paper is a first part of my study on Japanese pselaphids, containing the comparative morphology, phylogeny and systematics of the genus Batrisoplisus and its allies.

Jeanne1 $(1958,1959)$ divided the subtribe Batrisina belonging to the subfamily Batrisinae in the family Pselaphidae into five divisions; his fifth division is clearly defined group including 20 genera and 283 species all over the world. I called this division "the Batrisocenus complex" ( = BC) in the present study after a representative germs of this group widely used since Raffray (1903), etc. The genera and numbers of species included in this group from the world are enumerated as follows after Löbl (pers. comm.) and Newton \& Chandler (1989), with these on record from Japan are added in parentheses.

\section{The Batrisocenus complex}

1 Genus Batrisoplisus Raffray, 1908

2 Genus Batrisocenus Raffray, 1903

3 Genus Batrisceninus Jearmel, 1952

4 Genus Batriscenellus Jeannel, 1958

Subgenus Batriscenellus s. str.

Subgenus Scaioscenellus Jeannel, 1958

5 Genus Seydelites Jeannel, 1951

6 Genus Arthromelus Jeannel, 1949

Subgenus Arthromelus s. str.

Subgenus Scaiomelus Jeannel, 1951

Subgenus Euthiomelus Jeannel, 1957

7 Genus Batrisiella Raffray, 1904

8 Genus Cratna Raffray, 1890

9 Genus Physomerinus Jeannel, 1952

10 Genus Batriscenaulax Jeannel, 1958

11 Genus Arthromelodes Jeannel, 1953

12 Genus Pseudobatriscenus Jeannel, 1958

13 Genus Batriscenodes Jeannel, 1952

14 Genus Batristhenes Jeannel, 1960

15 Genus Plocamarthrus Jeannel, 1960

16 Genus Trisiniotus Jeannel, 1960

17 Genus Trisinarthrus Jeannel, 1960

18 Genus Batrisceniola Jearmel, 1958

19 Genus Eubatrisus Raffray, 1890

20 Genus Batriscenites Jeannel, 1952

$$
\begin{aligned}
& 5 \text { (5) spp. } \\
& 92 \text { (0) spp. } \\
& 5 \text { (0) spp. } \\
& 4 \text { (4) spp. }
\end{aligned}
$$

7 (0) spp.

110 (0) spp.
15 (2) spp.

13 (0) spp.

9 (1) spp.

4 (4) spp.

2 (1) spp.

1(1) sp.

5 (0) Spp.

$2(0)$ spp.

4 (0) spp.

$1(0) \mathrm{sp}$.

$1(0) \mathrm{sp}$.

1(1) sp.

1(0) sp.

$1(0) \mathrm{sp}$.

These species are mainly distributed in Oriental and Ethiopian regions. From Japan, 8 genera, 20 
species and 1 subspecies were described by Sharp (1874, 1883), Weise (1877), Raffray $(1909,1911)$, Kubota (1943), Jeanne1 (1958) and Löbl (1973). These genera are, however, necessary to be redefined, because every genus was almost defined only by the sexual character of the male which is inappropriate for the generic taxonomy in my opinion, causing impossibility for the identification of the females.

Many species of the BC are inhabitants in the litter of the forest floor; the others inhabit under bark of the rotten wood, in the sandy soil of the riverside or in the litter of the grassland. No symbionts of the ants, wasps or termites, and no cavernicolous species have been known in this group.

The morphological studies of the adult pselaphids have been presented by Kliiger (1910), Jeanne1 $(1950$, etc.) and Naomi $(1985 \mathrm{~b}$, etc.). Recently, the character evolution of the foveae of the thoracic ventrite is argued by Grigarick \& Schuster (1980), Carlton (1983) and Chandler (1988c); the internal processes of the abdominal integument were also documented by Ohishi (1986) in detail. But as for the BC, the male genital structure was discussed only by Jeanne1 (1951a). Referring to the phylogenetic position of the Pselaphidae in the superfamily Staphylinoidea, there is hot controversy by Lawrence \& Newton (1982), Thayer (1985), Naomi (1985) and Newton \& Thayer (1989). In the family Pselaphidae auct., the phylogenetic analyses have been made for the American genera of Euplectini by Grigarick \& Schuster (1980), for seven species of Conoplectus of Euplectinae by Carlton (1983), and for Nearctic Cylindrarctus and world genera of Tychini by Chandler (1988a, 1988b).

This study treats first the comparative morphology and the polymorphism of the adult pselaphids. Then, the phylogenetic relationship among the genera and species occurring in Japan are inferred mainly on the characters of the external structures by the cladistic method. Furthermore, a total number of 67 species and 8 subspecies are newly described and redefined in 6 genera in this study, of which 47 species and 7 subspecies are new to science, together with illustrations of the important characters and notes on the biological informations.

\section{MATERIALS AND METHODS}

1. Species Examined

In the course of this study, I have dissected and examined the following 72 species and 6 subspecies including 8 exotic species (the latter localities are parenthesized in the list) of the $\mathrm{BC}$, and about 20 species of the out-groups for the purpose of determining the polarity of the morphocline for the cladistic analyses in addition.

A. The Batrisocenus complex

The genus Batrisoplisus Raffray: sagamianus sp. nov.; galloisi sp. nov.; sawadai sp. nov.; satsumazus sp. nov.; subtilis sp. nov.; veoustus Jeannel; tenuiformis sp. nov.; esakii sp. nov.; tosanus sp. nov.; tanabei sp. nov.; okamotoisp. nov.; raffrayi Jeannel; torticornis sp. nov.; tamino sp. nov.; constrictus sp. nov.; monostatos sp. nov.; volucaninsulanus sp. nov.; uroceratus uroceratus sp. et subsp. nov.; u. brevispinis sp. et subsp. nov.; inermis sp. nov.; parallelus sp. nov.

The genus Batriscenellus Jeannel: The subgenus Batriscenelluss. str.: japonicusjaponicus (Sharp); j. vicarius Löbl; punctatus sp. nov.; fallax(Sharp); omogensis sp. nov.; kujumontanus sp. nov.; 
fragilis (Sharp); nodulifer sp. nov.

The subgenus Nipponoscenellus nov.: transformis sp. nov.

The subgenus Scaioscenellus Jeannel: similis (Sharp); shiranui sp. nov.; ohishii sp. nov.; insulicola sp. nov.; orientalis (Löbl); pilosellus sp. nov.; sakaii sp. nov.

The subgenus Batriscenellinus nov.: uenoisp. nov.

The genus Physomerinus Jeannel: pedator (Sharp); schenklingi (Raffray); hasegawai sp. nov.

The genus Batriscenaulax Jeannel: modestus (Sharp); longipes longipes Jeannel; 1. kumaso subsp. nov.; 1. hayato subsp. nov.; furuhatai (Kubota); kleinzach sp. nov.; kunigamensis sp. nov.; nagensis sp. nov.

The genus Arthromelodes Jeannel: cariei Jeanne1 (MADAGASCAR); punctifrons sp. nov.; giganteus sp. nov.; pilicollis sp. nov.; kiiensis sp. nov.; gyoja sp. nov.; thysanoventris sp. nov.; corniventris sp. nov.; mercurius sp. nov.; hikosanus sp. nov.; loebli sp. nov.; dilatatus daibosatsuanus subsp. nov.; d. shiranemontanus subsp. nov.; d. fujimontanus subsp. nov.; sinuatipes sp. nov.; aizuanus sp. nov.; saikaiensis sp. nov.; crucifer sp. nov.

The genus Batrisceniola Jeannel: dissimilis (Sharp); hiranoisp. nov.; semipunctulata (Raffray).

The genus Cratna Raffray: abdominalis Löbl (TAIWAN); torticornis Raffray (MALAYSIA); denticornis Löbl (SINGAPORE); 2 species undetermined (TAIWAN, N. SUMATRA).

The genus Trisiniotus Jeannel: 1 species undetermined (N. SUMATRA).

The genus Arthromelus Jeannel: Iabiatus Jeannel (BELGIAN CONGO).

The genus Seiderites Jeannel: affinis Leleup (COTE D'IVOIRE).

B. The out-groups

Batrisinae: Batrisoschema euplectiforme (Sharp); Coryphomodes spinicollis (Sharp); Mina elegans Raffray; Batristilbus politus (Sharp); Tribasoditespicticornis Nomura; Tribasodes longicornis (Sharp); Basitrodes sp.; Batrisodes (Excavodes) dorsalis Jeannel; Batrisodes? quinquesulcatus (Raffray); Batrisodellus risor Tanabe \& Nakane.

Goniacerinae: Barbiera sp.; Takaorites torticornis Jeannel; T. spp.; Nipponobythus omissus Löbl; N. spp.; Batraxis splendida Nomura; B. sp.; Bryaxis spp.

Euplectinae: Euplectus sp.; Acetalius dubius Sharp; Philoscotus spp.

\section{Methods of Dissection and Observation}

Most of the specimens examined were extracted from soil by using the Berlese funnel and by handshifting methods; some specimens were captured by light trap. They were preserved in $70 \%$ ethanol. They were dissected in glycerin or in $70 \%$ ethanol and were observed with both a stereoscopic microscope under $10 \mathrm{X}$ to $80 \mathrm{X}$ magnification and a compound microscope under $100 \mathrm{X}$ to $400 \mathrm{X}$ magnification according to sizes of the structures. Surface structures of the integument and the vestures are examined in detail by a scanning electron microscope under $50 \mathrm{X}$ to $10000 \mathrm{X}$ magnification.

3. Methods of Phylogenetic Reconstruction 
In the present study, phylogenetic relationships of the $\mathrm{BC}$ are documented in the chapter IV on the basis of the general morphology argued in the chapter III. The methods of the cladistic analyses by Hennig (1966) and Wiley (1981) were adopted in the course of this study in principle. For the purpose of determining the polarity of the character transformation series, "out-group comparison" by Watrous \& Wheeler (1981) was adopted. Any phylogenetic character (autapomorphy and synapomorphy) used in the cladistic analyses must be a result of the evolutionary event once occurred in the common ancestor of the taxa. As the policy of this cladistic analyses, any apomorphic character of the atrophied or rudimentary organs and the relative reduction in any quantity are omitted from the cladistic analysis in the chapter IV. Such characters often tend to mislead us to incorrect phylogenetic system, because not only each of them is easily occurred more than once in the course of the evolutionary process, but also it has no identity as a single character state. The cladograms illustrated in this study have some polychotomous branching points. These mean no phylogenetic event but the diapomorphic conditions derived from a single plesiomorphic character state or the poor phylogenetic information in the group. The apomorphic character unique to one species or subspecies is not treated in the cladistic study, but it is important for determining the polarity of the character transformation series.

\section{GENERAL M ORPHOLOGY}

The morphology of the Batrisocenus complex and the discussion on the phylogeny are treated in this chapter. Each of the structures from head to abdomen and the setiferous structures is argued about 1) the general structure, 2) the variation within the group in question, 3) comparison to the out-groups and 4) determination of the polarity and phylogenetic evaluation.

\section{H ead}

1.1. Cranium

\subsubsection{Structure of cranium (Figs. 1-7)}

The cranium is thick and ovoid to quadrangular in dorsal view, sloping from the frons to the clypeus in anterodorsal part. Naomi (1987a) pointed out that the head sutures are almost lost in Pselaphidae; even the gular sutures are reduced at the anterior part in the BC. Thus each part of the cranium called clypeus, frons, vertex and gena in description is not demarcated by suture.

The clypeofrontal area is the anterior margin of the cranium including the sloping area, and is arcuately expanded anteriorly and marginate in some species. The frons is highest at both sides and flat or weakly concave in the median part with a pair of foveae at the bases of the antennae; there is a transverse sulcus in the median part of the frons. The vertex is convex and has a pair of distinct foveae which are identified with dorsal tentorial pits; between these foveae, there is usually a longitudinal ridge running from the middle of the frontal sulcus to the base of the occiput. The postgenae are short in general and flat or weakly rounded in dorsal view. The occiput defined by the occipital constriction from the gena is subcylindrical and bears a pair of posteriorly divergent sutures. 
The clypeus is strongly expanded anteriorly and the posterior part of the cranium from the frons to the postgenae is short and transverse in Batrisceniola. This character is useful to key out this genus from the others, but it is observed in some out-groups (Takaorites, Nipponobythus: Goniacerinae, Tanypleurim).

The paired frontal foveae (Fig. 2B) are indistinct or absent in the most of the BC except for Batrisoplisus, in which these foveae are distinctly observed. Although this distinct condition is unique for $\mathbf{B a}$ trisoplisus in the $\mathrm{BC}$, the polarity of this character cannot be determined by the following two reasons: 1) those foveae are very small structure, and poorly known in the out-groups, 2) whereas they are located at the points where the anterior arms of the tentorium are attached to their internal surface in the other staphylinoid groups, the anterior tentorial arms are not distinctly recognized in the $\mathrm{BC}$. In short, the frontal foveae may be the rudiment of certain primitive organ.

The frontal sulcus is variously modified in the BC; it is reverse U-shaped connecting the dorsal tentorial pits in Batrisoplisus, reverse U-shaped and indistinct near the tentorial pits in Physomerinus and Batriscenaulax kleinzach, horizontal to flatly V-shaped distant from the tentorial pits in some species of Batrisceoaulax, Batriscenellus, Arthromelodes and Batrisceniola, clearly inverse T-shaped in Cratna. The last condition is unique and clearly autapomorphic for Cratna.

The vertex has a raised ridge in the most species of the $\mathrm{BC}$ as a fine structure, but it is completely lost in Batriscenaulax longipes, B. kleinzach and Arthromelodesgiganteus. In Cratna abdominalis, this vertical ridge is replaced by the sulcus in its posterior $1 / 3$.

The cranium bears a pair of horns on both anterolateral sides exterior to the maxillae in Batrisoplisus (Fig. 2C). This characteristic horns are recognized as an autapomorphic character. This character state is different from the similar structure occurred in Acetalius dubius of Euplectinae by absence of the dense setae on the horns (Fig. 2D).

The division V ( = BC) of the subtribe Batrisina was characterized by the short postgenae and the elytron with two foveae. The short postgenae means the short distance between each eye and the occipital constriction. Such condition is generally occurred in the BC, but the long postgena is observed in a few species of the BC, for example, Arthromefodes dilatatus. On the other hand, some species have short postgenae in the out-groups of Batrisina. The short postgena is considered to be a secondary reduction, and such character is inappropriate for the key character nor autapomorphy.

\subsubsection{Gular area and tentorium}

The anterior part of the gular area is reduced to a posteroventral fovea. The posterior part of the gula is broadened posteriorly to form a triangular plate posterior to the occipital constriction. It is clearly demarcated from the occiput by a pair of divergent gular sutures. The tentorium, namely the endoskeleton of the cranium, is V-shaped or inverse A-shaped in posterior view, which is derived from the posterolateral foveae, and the dorsal tentorial arms reach pass dorsally to become attached to the internal surface of the vertical foveae, sometimes together with a thin transverse bridge at the basal part. The anterior tentorial arms are not recognized. The structure and the shape of the gula and tentorium are hardly varied among the genera and the species.

\subsubsection{Postocciput and cervix}

The postocciput is recognized behind the occiput and demarcated by the postoccipital suture. This 
plate is observed in some species of the $\mathrm{BC}$ as an indistinct ring-shaped sclerite (Fig. 2E). The cervix between the postocciput and the pronotum is completely membranous and no cervical sclerite is present. These characters are of little importance for the phylogenetic study.

\subsubsection{Eyes}

The compound eyes are each ovoid and convex, and composed of 10 to 40 semispherical facets in the BC. Each eye of the male is a little larger in number of the facets than that of the female in general. In the dimorphic species, the macropterous male has many facets than the apterous one in the Acetaliina (Nomura, 1988a-c); but those are hardly different between the macropterous and the brachypterous males in each species of the BC.

\subsection{Appendages of the Head}

The antennae and the mouthparts are treated in this chapter.

\subsubsection{Antennae (Fig. 8)}

The antennae are eleven-segmented in all species of the BC. The first antennal segment called the scape is generally thicker than any segment of the flagellum; this segment is articulated with the cranium at the ventral face of the excavation of anteroventral side, and is strongly curved anteriorly, subcylindrical at the apical part and is excavated at apex. The second segment called the pedicel is articulated to the first segment at its apical excavation, and is elongately ovoid to subcylindrical. The third to eighth segments are each ovoid to subcylindrical conjointly forming the slender flagellum. The ninth to eleventh segments are thicker than the flagellum, which are united to form an indistinct club; the ninth to tenth segments are each ovoid to subglobose, and the eleventh segment is largest in general, and is subspherical at base and is narrowed apically.

The antennae are usually covered with dense pubescence and setae; the distribution of the setae are treated in the paragraph 4.1.2. In some species, the sexual feature like the sexual patch and the nonsexual setiferous structure are present in the antenna, they are shown in the chapter 4 . The ninth segment of the male is thicker than that of the female in four species of the uroceratus-group of the genus Batrisoplisus. The similar feature is also observed in the eighth to tenth segments of the male of Arthromelodes gyoja.

\subsubsection{Labrum (Fig. 9C)}

The labrum is a thick and transverse plate, which is narrowed apically and angulate basilaterally; its basal part hidden below the clypeus is narrower than the apical part and subparallel-sided. The labrum bears several long bristles at the anterolateral parts, and one or two pairs of bold setae each with round apex on the anteromedian margin.

In Batrisoplisus and Physomerinus, the labrum has a pair of bold setae, whereas these are two paired in the other Japanese genera of the BC. But the both conditions are widely observed in the outgroups as already illustrated by Raffray (1908), hence the polarity of these characters cannot be determined. 


\subsubsection{Mandibles (Figs. 9D-F)}

The mandible is broad and thick at base and sharpened apically. It bears three to five inner teeth in the apical half, and a bold bristle arisen from near the middle of the outer margin reaching near the apex of the ramus. The right mandible has a slight difference from the left in shape that the most apical tooth is closer to the ramus. These characters are generally observed in Batrisina.

The uroceratus-group of the genus Batrisoplisus is extremely unique in having a large projection in the right mandible just outside the bristle in the male (Fig. 9E, F). This projection is not found in the other group of the $\mathrm{BC}$ nor the out-group as shown in B. torticornis (Fig. 9D), and is recognized to be autapomorphic.

\subsubsection{Maxillae (Fig. 10)}

The maxillae are each divided into five parts, cardo, stipes, maxillary palpus, lacinia and galea. The cardo is a transverse and thick plate situated at base of the maxilla; the ventral surface of it is almost glabrous and flat, but there are a few short setae in the outer part. The basal part of the stipes is divided into two sclerites; the inner sclerite is broad and triangular articulating with the cardo at the posterior margin, and has a seta in the outer part in some species; the elongate outer sclerite is termed the palpifer, and bears a few long setae in many cases. The maxillary palpus is 4-segmented in appearance since the fifth segment is completely invisible; the first segment is short, with subcylindrical to subconical apical part; the second segment is elongate and is distally thickened; the third segment is small and subcylindrical, and shortened on the inner side; the fourth is a large fusiform segment swollen near the middle. The lacinia bears hyaline dense hairs at the apical part. The galea is indistinctly demarcated into 2 parts, the proximal part is the subgalea, which is sclerotized and articulated to the inner sclerite of the stipes, and the distal part which is similar to the lacinia in shape and structure is located on the inner side of the lacinia. The lacinia and the apical part of the galea are mostly concealed by the labium in ventral view.

The cardo bears a patch with dense pores on the basilateral side in all genera of the BC except for Batrisoplisus. This character is also observed in the divisions II and IV of Batrisina; but it is difficult to determine the polarity, because this very minute structure is visible only by SEM and has not been studied enough in the out-groups.

The maxillary palpi are modified in some groups as follows: These are uniquely elongate in all segments, and bear many long setae in Cratna. This is not only a practical key character of the genus but also a good autapomorphy. In the exotic genera, Batriscenites, Batriscenodes and Batrisceninus, the fourth segment of the maxillary palpus is pedonculate according to Jeanne1 (1952), but this character is indistinct in Japanese species and is not useful for their classification. The fourth segment is broad and flattened in the internal surface in the galloisi-, venustus- and raffrayi-groups of the genus Batrisoplisus, this segment is expanded basilaterally in the male of Physomerinus hasegawai. These two characters are unique for the group and the species, respectively, and they are regarded to be autapomorphic characters.

\subsection{Labium (Fig. 11)}

The labium is composed of mentum + submentum, prementum, labial palpi and ligula. The 
mentum is fused with submentum to form the postmentum; the postmentum is an apically broadened or round-sided large plate and has two or three pairs of short setae near the middle of the ventral surface. The prementum is mostly membranous bearing a pair of small sclerites called palpiger; the latter bears two or three setae. The labial palpi are s-segmented; the first segment is very short and subcylindrical, with a short seta at the basilateral part in some species; the second segment is elongate and thick, which is weakly carinate on the anterior side in some species, and bears a long and bold bristle at apex; the third segment is very slender and bristle-like, but it is clearly stouter than the surrounding bristle or hairs, and bears a short bristle at the base and three to four small swellings at the apex. The ligula ("synglossa" in Naomi, 1988b) is bilobate, each lobe is elongately tongue-shaped and densely hairy in the apical part of the anterior margin.

These characters of the labium are of little variations not only within the $\mathrm{BC}$ but also the subtribe Batrisina in general, and are consequently regarded to have little importance for phylogenetic study.

\section{Thorax}

\subsection{Structure of Thoracic Segments}

The dorsolateral part of the tergum and the dorsal part of the pleuron covered by the elytra in the pterothorax are more or less reduced to be membranous. Each plate or suture is partially visible, and these characters have not been described nor discussed in detail in Pselaphidae. These plates therefore cannot be argued in their homology nor phylogenetic evaluation. In this study, the lateral and dorsal plates of the meso- and matathoraces and the flying armatures (furca, axilla and veins) are observed in detail on the following five species: Batrisoplisus raffrayi Jeannel, Batriscenellus kujumontanus sp. nov., Batriscenaulax longipes Jeannel, Cratna abdominalis Löbl and Batrisceniola dissimilis (Sharp).

\subsubsection{Prothorax (Figs. 12-15)}

The prothorax is a large tube composed of pronotum, paired hypomera and prosternum together with endostemites (profurca), and is emarginated in the posteroventral part forming the procoxal cavity.

The pronotum is a large semitubular plate, it bears four sulci, a pair of dorsal carinae, two pairs of lateral foveae and two pairs of antebasal foveae at most as follows: the median longitudinal sulcus varies in length, but it is not completely lost in all Japanese species of the BC. According to Jeanne1 (1951, 1952, 1960), it is absent in the component species of the genera Seiderites, Trisiniotus, Batristhenes, Batrisceninus, Batrisceoodes and Batriscenites. In fact, such character state is observed in Trisiniotus sp. from Sumatra; that sulcus tends to be lost in some genera of Batrisina as Mina of the division II in various degree. Thus the efface of the median longitudinal sulcus is evidently secondary, hence it must not be a practical key character.

Each of the paired lateral sulci is U-shaped and surrounds the lateral expansion of the pronotum posteriorly connecting two lateral foveae on each side. This character is constantly present in all species of the BC. and rarely effaces. These sulci are rudimentary in Batriscenites according to Tanokuchi (1989), however Jeanne1 (1960) considered them to be absent. In the out-groups of the subtribe Batrisi- 
ni, there is no species having a U-shaped lateral sulcus on each side connecting with two lateral foveae.

The transverse sulcus connects the dorsolateral foveae across the median longitudinal sulcus; it is shallow in Batrisoplisus, or medially broken in Cratna abdominalis, but is not so distinctly occurred in the other Batrisina. The U-shaped lateral sulci and the transverse sulcus are considered to be an autapomorphy. As the similar condition is known in some genera of Euplectinae (Paraplectus, etc.). These two states are seemed to be evolved independently in Euplectinae and Batrisinae.

The paired dorsal carinae are indistinct in Batrisoplisus, and completely obliterated in the other genera of the BC. This character is present more distinctly in some out-group species of the division II or IV, and is consequently regarded as a plesiomorphic to the Batrisina.

The lateral foveae include the dorsolateral and ventrolateral pairs; they are located on both sides of the pronotum in the basal constriction.

The antebasal foveae near the posterodorsal margin are two-paired in most cases. These foveae are distinct in Batriscenellus, Batriscenaulaxand Physomerinus in the $\mathrm{BC}$, and indistinct in the rest genera and some out-groups of Batrisina. They are not important for the phylogenetic study by their variability in out-groups.

The hypomera are glabrous plates forming the lateral walls of the procoxal cavity, but are indistinctly demarcated from the prostemum. This parts are scarcely modified in the BC.

The prosternum is transverse and densely pubescent in the anterior part, and glabrous forming anterior wall of the procoxal cavity in the posterior part. There are a pair of large foveae just anterior to the coxal cavity, and a pair of small ones each within the anterior wall of the coxal cavity; the former are called the antecoxal foveae and the latter are the subcoxal foveae in the present study.

The profurca (endosternite) extends internally from the antecoxal foveae, which is bisinuate above the base of coxae and from the middle of each arch, vertically stalked to reach the middle height of the prothorax. The phragmata of the prothorax is well-developed on the anterior and posterior margins, but are indistinctly continued to the lamelar endosternites inside of the thoracic wall.

\subsubsection{Mesothorax (Figs. 16-21)}

The well-defined mesosternum of the $\mathrm{BC}$ is composed of the anteriorly narrowed mesonotum and anteriorly narrowed large ventral plate (mesopleura and mesosternum). However the mesothorax is fused with metathorax ventrolaterally and incompletely demarcated from it in some groups of Pselaphidae (especially in Macroscelides, as Naomi, 1988 shown in Lasinus).

The mesonotum (Figs. 16,17) is very small and its posterior part is exposed between the elytra; its anterior part appears when the articulation between the pro- and mesothoraces is relaxed. In the anterior part of the mesonotum, the prescutum is reduced to be indefinable. The main sclerite of the mesonotum is occupied by the scutum + scutellum, and is articulated with each elytron by the anterior arm and the laterally extending ligament from the posterolateral side of the scutum; phragmata are not recognized.

In the mesothoracic ventrite of many pselaphids including the $\mathrm{BC}$, the distinct anapleural sutures divide the anepisterna and the composite ventral plate. The anterior part of the ventral sclerite is a crescent collar so-called prepectus, and defmed by the narrow membranous part or suture. The pleural sutures are absent (completely present in Eupfectus), and the epimeron and the anepisternum are united to form a large glabrous ventrolateral plate on each side together with a lateral sulcus where the elytron 
are attached. The composite ventral plate is divergent posteriorly and pubescent forming the anterior wall of the mesocoxal cavity together with an angular posteromedian projection between the mesocoxae. In Batrisoplisus, this posteromedian projection has a pair of small processes (Fig. 19A-D); this character is unique and constantly observed in this genus, hence it is regarded as an autapomorphic character of this genus.

The foveation of the thoracic ventrite in the BC almost corresponds with that of American Euplectinae reported by Grigarick \& Schuster (1980) in the structure and the arrangement (Fig. 16A). In their terminology, there are two sorts of mesothoracic foveae: first is the forked median mesosternal fovea at the mediobasal part of the composite ventral plate, and second is a pair of lateral mesosternal foveae located on both sides of the former foveae each of which is forked into two.

The mesofurca is represented by a pair of slender endosternites which originate from the paired small foveae at the bottom of the mesocoxal cavities (named subcoxal mesosternal foveae in this study). Each has a very thin dorsal arm reaching close to the lateral base of the elytron.

The shape and the structure of the mesothorax have little variation within the $\mathrm{BC}$ and Batrisina, and not so important phylogenetically except for the antecoxal processes of Batrisoplisus.

\subsubsection{Metathorax (Figs. 19-2.5)}

In Pselaphidae the metathorax except for the hind wing is wider than the mesothorax in general, it is posteriorly broadened and connected with the membranous first segment of the abdomen. It is divided into large and weakly sclerotized metanotum, a pair of more or less membranous metapleura supporting the hind wings at the anterior part, and strongly sclerotized metasternum. Since the metathorax has the flight muscles, the metanotal and the metapleural sclerites differ among the macropterous male, the brachypterous male and the brachypterous female. The sclerotization and shape of the muscle attachment as the muscle discs are also varied according to the length of the hind wing.

The metanotum (Figs. 22-25) is weakly sclerotized in the macropterous male; the acrotergite is indistinct or very short; the antecostal suture is arcuate together with large phragma vertically hanging from the internal surface of the prescutum, which is transversely divided into two lobes, the semilunar dorsal lobe and the bilobate ventral one; the prescutum is transverse and is bordered by a narrow membranous area at the posterior margin; the prescutal muscle discs are paired and each composed of two sclerites located on the lateral end of the prescutum; the scutum is very broad and divided by the scutellum into two large pieces, each tapers posteriorly and is provided with the well-convex alacrista at the anteromedian part, the well-demarcated suralare at the humeral angle and the medially punctuated transverse suture at its lateral and median sides; the scutellum is triangular and posteriorly broadened; the postnotum is broad and transverse, divided into a median and a pair of lateral pieces by a pair of oblique sutures in some species; the postnotum protrudes anteriorly on each side to form the postnotal wmg process reaching the subalare, and laterally to adjoin the posterior part of the epimeron.

In the brachypterous male, the metanotal sclerites are almost of the same in structure and shape as those of the macropterous male except for the flatter antecosta, the smaller anterior phragma and the reduced prescutal muscle discs. In the brachypterous female, the metanotal sclerites are fused to form a less sclerotized large plate; its suralare and scutellum are distinct in Batrisceniola dissimilis and broadly membranous without the sclerotized suralare in Batrisoplisus raffrayi and Batriscenellus kujumontanus.

The metapleuron (Figs. 18, 22) is composed of weakly sclerotized metepimeron and strongly sclero- 
tized metepistemum and exposed on the ventral side. The elongate metepimeron is usually concealed by the elytron and angularly protrudes to the metanotal postnotum. The metepimeron is divided into two parts, the notepimeron and the sternepimeron by the sternepimeral line according to Blackwelder (1936); the medial part along the sternepimeral line is well-sclerotized in pselaphids. Its anterior end is nodulated to form the pleural wing process.

The metepisternum is indistinctly demarcated from the composite ventral plate, and is elongate and narrowed posteriorly. The pleural suture probably corresponds posteriorly with the lateral ridge of the ventrite to which the elytron is attached, but in the anterior part, it is indistinct that the pleural suture fits with the lateral ridge. The basalare is represented as a tubercle anterior to the epimeron distant from the composite ventral plate.

The anapleural cleft runs from the posterolateral angle to the metacoxa in Euplectus dividing the metapleuron and the matasternum, which is indistinct in many pselaphids (Fig. 18C). In the BC, the metathorax bears three pairs of indistinct lateral sutures or border lines on the ventrite. As compared with the out-group species having many plesiomorphic characters, such as Batrisoschema euplectiforme, the most inner pair may be the anapleural clefts, and the outer two pairs may be the secondary sutures (Fig. 18B).

The composite ventral plate is usually represented by a very large, transverse and posteriorly broadened plate occupying the ventrite of the metathorax. Adopting the terminology of Grigarick and Schuster (1980), it bears two pairs of foveae, the outer pair is the mesocoxal foveae located on both sides of the mesocoxal cavities, and the inner pair is the metasternal foveae lying posterior to the mesocoxal cavities. The composite ventral plate is flattened or concave on the median part in the male of many species in various shape and structure, and its phylogenetic importance cannot be evaluated. The sexual patches often arise at this part in some species as treated in the chapter 4. The posteromedian part of the composite ventral plate between the matacoxae is broad and posteriorly truncate in Batrisoplisus, or arcuately expanded and medially notched at the apex together with a short and shallow longitudinal groove in front of the notch in the other genera of the BC. Both character states are observed in the other pselaphid groups. The distant metacoxae by the posterior extension of the metasternum is regarded to be an apomorphic condition. A large conical spine between the metacoxae is unique in the male of Batriscenellus transformis. This character is recognized as a good autapomorphy of the subgenus Nipponoscenellus.

\section{2. wings}

\subsubsection{Structure of the elytra (fore wings) (Figs. 26-28)}

The elytra cover generally the dorsal surface of the meso- and metathoraces and the first to third abdominal tergites in Pselaphidae. They are more or less narrowed anteriorly, rounded on both sides and convex dorsally, and intraspecific variation is observed in shape and length such as the elytra are generally larger in the male than in the female and more narrowed anteriorly in the brachypterous individual than in the macropterous one. As epipleural ridge is always absent in the $\mathrm{BC}$, the epipleuron is not demarcated. The inner surface of the elytra is lined with membrane, and provided with several pits for setting them on the dorsum, which are argued in the next paragraph. Each elytron has two basidor- 
sal foveae and a basilateral fovea, each of which is accompanied posteriorly by a shallow longitudinal sulcus.

The divisions of Batrisina were defined by Jeanne1 $(1958,1959,1960,1961)$ mostly on the conditions of foveae; namely the divisions III, IV and V were defined by having two pairs of the elytral foveae (two pairs of the basidorsal foveae in the present study), whereas they are three paired in the divisions I and II. In Coryphomodes spinicollis belonging the division IV, however the most inner fovea is composed of two small foveae in the observation by SEM (Fig. 27F). This character state means evidently the presence of three pairs of the basidorsal foveae on the elytra exclusive to the definition. With the exception of the elytral foveae, Coryphomodes is very similar to those of division II in many characters. As a consequence, the character state that have two pairs of simple elytral foveae on the elytra may not be treated as a synapomorphy in the $\mathrm{BC}$, but a reductive apomorphy, because there is no evidence denying that the character state with two pairs of the basidorsal foveae arise from that with three pairs of the foveae by reduction. Chandler (1988a) treated such reduction of the elytral foveae as an autapomorphy in his cladistic analyses, but I exclude it in this study.

The basilateral foveae are absent in Arthromelodesgiganteus, A. saikaiensis, A. mercurius, $A$. thysanoventris, A. dilatatus and Cratna abdominalis. This character state is regarded as a parallelism due to atrophy.

\subsubsection{Axillae of the elytra (Figs. 16, 17)}

The axillae of the elytra are very small and difficult to observe. The first axillary sclerite is a distinct subspherical sclerite appearing at just inside the anterior joint between the outer process of the elytron and the prealar arm of the mesonotum. The second axillary is an elongate sclerite which is larger than the first, medially membranous, and is located between the inner process of the elytral base and the lateral expansion of the mesoscutum. The third axillary is the smallest sclerite located at the lateral end of the ligament (axillary cord) extending from the posterolateral part of the scutum to the inner base of the elytron when it is present; or it is hardly distinguished from the ligament. The axillae are scarcely varied in the shape and arrangement within the $\mathrm{BC}$, and have little importance for phylogenetic analyses.

\subsubsection{Locking device of the elytra (Fig. 29)}

The locking device of the elytra of Ips typographus in Scolytidae is represented by two processes in each mesopleuron and the corresponding two concavities on the anterolateral margin of each elytron (Larsen, 1966). In Pselaphidae, the position and the structure of the locking device are very unique among Coleoptera as follows.

The locking device of each elytron of the $\mathrm{BC}$ is represented by the following seven pairs of locking processes and the receiving pits (Fig. 29A-I). In the mesonotum, the lateral nodules of the scutellum each fits the concavity at the anterior end of the inner margin of the elytron (Fig. 29A); the two mesopleural processes pointed out by Larsen (1966) are almost atrophied, but the corresponding two pits are present on internal side of the anterolateral margin of the elytron where the expansions of the wing base may be filled in (Fig. 29B, C); a shallow longitudinal groove is present on the anterior inner margin of the elytron for receiving the inner ridge of the metanotal alacrista (Fig. 29D); the thickened hind margin of the elytra is inserted into the transverse groove between the third and the fourth abdominal tergites (Fig. 29E); the anterior margin of the third abdominal segment is convex anterodorsally, it is received 
into the transverse groove along the inner posterior margin of the elytron (Fig. 29F); a large and deep concavity at the posterolateral angle of the elytron receives the anterolateral nodule of the third abdominal tergite which is composed of many semihyaline bristles (Fig. 29G); an inner nodule and an outer excavation interior of the posterolateral corner of the elytron are caught into the short lateral ridge and the proximal deep groove at the anterolateral part of the fourth abdominal tergite respectively (Fig. $29 \mathrm{H}$, I). Along the sutural line, the longitudinal ridge and groove of one elytron engage with the groove and ridge of the other.

These locking processes and pits are developed in the brachypterous individuals than the macropterous ones as shown in Fig. 30. These characters are broadly distributed within Pselaphidae.

\subsubsection{Hind wings (Fig. 31)}

In some species of the pselaphids, there are two male forms on the hind wings, the macropterous form with very long hind wings and the brachypterous one with short wings; the female is uniformly brachypterous having short wings which are shorter than those of the brachypterous male in general. In some species of the $\mathrm{BC}$, especially the dimorphic species, the wing length (abbreviated WL as below) and the body length ( = BL) are measured and the histograms of the relative length of the wing (WL/BL) are made. Obtained result shows two peaks on the relative length separated by a point about $\mathrm{WL} / \mathrm{BL}=0.9$. The value is constant for separating the two forms among the species examined and used fully for sorting the specimens into forms in this study.

The hind wing is longer than whole body length in many macropterous individuals, dilated apically, broadest near the middle and is gradually narrowed basally without distinct vannal region. It is ciliate along the hind margin from its base to near the apex. The veins are mostly thin and short, mainly consisting of costa, subcosta, radius, media, cubitus + posterior cubitus and anal vein (as for the hind wing venation, the terminology of Morimoto (1983) is adopted). The costa (C) is short, broad and strongly sclerotized covering the anterior part of the wing base. The subcosta ( $\mathrm{S} \mathrm{C}_{\mathrm{C}}$ is strongly sclerotized behind the costa, broadened and weakly sclerotized in its apical part. The radius $(\mathrm{R})$ is thin at base, and broadened distally reaching the basal $1 / 4$ to $1 / 5$ of the wing; the apical end of which is weakly sclerotized to form an indistinct stigma where the longitudinal foldings are concentrated. The media (M) is very thin, distant from axilla and sometimes fused with the cubitus at base. The cubitus and the posterior cubitus $(\mathrm{C}+\mathrm{PCu})$ are united to form a weakly sclerotized bold vein which is bifurcate in its apical part; the anal vein (A) is short, broadened and weakly sclerotized at base, and obsolescent towards the hind margin of the wing. The hind wing is folded longitudinally three to four times and transversely about seven times in the macropterous male of Batrisceniola dissimilis.

In the brachypterous male, the hind wing is usually 0.2 to 0.7 times as long as the body, short and elongate. Each veins of the brachypterous male is defmite, however it is shorter than that of the macropterous male. The hind wing is folded transversely two to four times without longitudinal fold in the brachypterous male of Batrisceniola dissimilis. In the brachypterous female, the hind wing sometimes tapers or wrinkles clinging to the metanotum, and is 0.1 to 0.3 times as long as the body in general. The veins are rarely recognized in the female except for the very short $\mathrm{C}+\mathrm{Sc}$ ? at the base.

\subsubsection{Axillae of the hind wings (Figs. 22-25)}

The axilla of the hind wing is composed of three sclerites, to which the flight muscles are inserted in 
the macropterous form of the BC. The first axillary sclerite $(1 \mathrm{Ax})$ is tapered anteriorly and curved distally and broadened posteriorly; it is connected with the subcostal vein at the anterior end and associated with the suralare internally. The second axillary $(2 \mathrm{Ax})$ is articulated with the under side of the $1 \mathrm{Ax}$, and is nearly T-shaped; its anterior arm is attached to the internal end of the radius and the inner posterior arm is articulated with'the pleural wing process. The third axillary ( $3 A x)$ is elongate, weakly sclerotized and located posterior to the $2 \mathrm{Ax}$ at a distance; its basal end is connected with the postnotal wing process and the apical end is associated with the base of the anal vein.

In the brachypterous male, all axillary sclerites are clearly defined, but is shorter than those in the macropterous male. But in the brachypterous female, they are fused each other to form a very small sclerite, or indistinguishable from the costa or the metathoracic wing processes.

\subsection{Dimorphism of the hind wings (Figs. 32-34)}

The phenomena that the long-winged individual and the flightless one with rudimentary hind wings are mixed in the same taxon or species are observed in some Coleoptera. In some groups of Pselaphidae including the $\mathrm{BC}$, such wing dimorphism occurs in the male. The macropterous male (Mm), the brachypterous male $(\mathrm{Bm})$ and the brachypterous female $(\mathrm{Bf})$ are observed in the $\mathrm{BC}$. Each species of them has the $\mathrm{Mm}+\mathrm{Bf}$, the $\mathrm{Bm}+\mathrm{Bf}$ or dimorphic $(\mathrm{Mm}+\mathrm{Bm})+\mathrm{Bf}$. The female is monomorphic and brachypterous in all species. The ratio of the $\mathrm{Bm}$ in the population is shown in Table 3-1 on the species of the BC examined.

The wing reduction in the male of each genus is summarized as follows. In Batrisoplisus, four macropterous and seven brachypterous species are monomorphic, five species are dimorphic, and no macropterous individual is found in four species of the uroceratus-group. In Batriscenellus, seven species are macropterous and three species are dimorphic. No brachypterous individual was occurred in Physomerinus. Brachyptery is dominant in Batriscenaulaxwhich includes three dimorphic species and three brachypterous species. All males in Arthromelodes are brachypterous without exception. In Batrisceniola, two species are dimorphic and the rest one, B. semipunctulata is always macropterous.

Furthermore, for the purpose of observing the correlation between the wing size and the body length and their frequency, the following six species from 10 local populations are measured on the body length (BL) and wing length (WL):

Batriscenellus kujumontanus. Mt.Kurodake, Kuju, Oita Pref.(KUJU).

Batriscenaulax longipes: Mt. Haigamine, Kure City, Hiroshima Pref. (KURE).

B. furuhatar: Kamagari-cho, Hiroshima Pref. (KAMAGARI).

Bartisceniola dissimilis. Mt. Towari, Towada lakeside, Aomori Pref. (TOWADA); Futakuchi vall., Miyagi Pref. (FUTAKUCHI); Chuzenji lakeside, Nikko, Tochigi Pref. (NIKKO); Mt. Ogasa,

Daito-machi, Shizuoka Pref. (OGASA); Kamagari-cho, Hiroshima Pref. (KAMAGARI).

B. hiranot: Kurose-machi, Hiroshima Pref. (KLJROSE).

B. semipunctulata: Higashi-Onuma, Oshima, Hokkaido Pref. (ONUMA).

The measurements are shown in Table 3-2 and the frequency distributions of the relative wing length are shown in Table 3-3, and the ratios of the macroptery and the brachyptery in some local populations of Batriscenaulax longipes and Battisceniola dissimilis are illustrated in Fig. 32 and the 
Table 3-1. The ratio of the brachypterous male to the total male on each species of the Batrisocenus

\begin{tabular}{|c|c|c|c|c|}
\hline species & $\mathrm{N}$ & $\mathrm{Bm}$ & $\mathrm{Mm}$ & $\mathrm{Bm} / \mathrm{N}(\%)$ \\
\hline \multicolumn{5}{|l|}{ Batrisoplisus } \\
\hline B. sagamianus & 1 & 1 & 0 & 100 \\
\hline B. galloisi & 10 & 1 & $9^{*}$ & 10 \\
\hline B. sawadai & 1 & 1 & 0 & 100 \\
\hline B. venustus & 11 & 3 & 8 & 27 \\
\hline B. esakii & 3 & 1 & 2 & 33 \\
\hline B. tosanus & 10 & 0 & 10 & 0 \\
\hline B. tanabei & 1 & 0 & 1 & 0 \\
\hline B. okamotoi & 23 & 4 & 19 & 17 \\
\hline B. raffrayi & 2 & 0 & 2 & 0 \\
\hline B. monostatos & 4 & 0 & $4^{*}$ & 0 \\
\hline B. torticomis & 4 & 2 & 2 & 50 \\
\hline B. wnstrictus & 1 & 1 & 0 & 100 \\
\hline B. volucaninsulanus & 1 & 1 & 0 & 100 \\
\hline B. uroceratus urocaratus & 2 & 2 & 0 & 100 \\
\hline B. inermis & 1 & 1 & 0 & 100 \\
\hline B. parallelus & 8 & 8 & 0 & 100 \\
\hline \multicolumn{5}{|l|}{ Batriscenellus } \\
\hline B. japonicus japonicus & 3 & 0 & $3^{*}$ & 0 \\
\hline B. japonicus vicarius & & 0 & 1 & 0 \\
\hline B. punctatus & 2 & 0 & 2 & 0 \\
\hline B. fallax & 2 & 0 & 2 & 0 \\
\hline B. kujumontanus & 67 & 9 & 58 & 13 \\
\hline B. fragilis & 2 & 0 & 2 & 0 \\
\hline B. transformis & 9 & 2 & 7 & 22 \\
\hline B. similis & 10 & 6 & 4 & 60 \\
\hline B. ohishii & 2 & 0 & 2 & 0 \\
\hline B. pilosellus & 5 & 0 & $5^{*}$ & 0 \\
\hline \multicolumn{5}{|l|}{ Physomerinus } \\
\hline P. schenklingi & 21 & 0 & $21^{*} ?$ & 0 \\
\hline P. hasega wai & 2 & 0 & $2 * ?$ & 0 \\
\hline
\end{tabular}

$\mathrm{N}$ : total number of the male examined, BP: brachypterous; MP: macropterous; *: a few specimens (all 
complex examined.

\begin{tabular}{llllll}
\hline species & $\mathrm{N}$ & $\mathrm{Bm}$ & $\mathrm{Mm}$ & $\mathrm{Bm} / \mathrm{N}(\%)$ \\
\hline
\end{tabular}

Batriscenaulax

$\begin{array}{lrrrr}\text { B. longipes longipes } & 49 & 46 & 3 & 94 \\ \text { B. } \text { l. kumaso } & 8 & 5 & 3 & 63 \\ \text { B. } \text { l. hayato } & 3 & 3 & 0 & 100 \\ \text { B. furuhatai } & 45 & 42 & 3 & 93 \\ \text { B. kleinzach } & 4 & 4 & 0 & 100 \\ \text { B. kunigamensis } & 1 & 1 & 0 & 100\end{array}$

Arthromelodes

$\begin{array}{lllll}\text { A. punctifrons } & 1 & 1 & 0 & 100 \\ \text { A. giganteus } & 4 & 4 & 0 & 100 \\ \text { A. pilicollis } & 1 & 1 & 0 & 100 \\ \text { A. } \text { kiiensis } & 8 & 8 & 0 & 100 \\ \text { A. thysanoventris } & 7 & 7 & 0 & 100 \\ \text { A. corniventris } & 1 & 1 & 0 & 100 \\ \text { A. } \text { loebli } & 9 & 9 & 0 & 100 \\ \text { A. dilatatus daibosatsuanus } & 3 & 3 & 0 & 100 \\ \text { A. } \text { d. shiranemontanus } & 3 & 3 & 0 & 100 \\ \text { A. d. fujimontanus } & 3 & 3 & 0 & 100 \\ \text { A. sinuatipes } & 2 & 2 & 0 & 100 \\ \text { A. aizuanus } & 1 & 1 & 0 & 100 \\ \text { A. saikaiensis } & 3 & 3 & 0 & 100 \\ \text { A. crucifer } & 4 & 4 & 0 & 100\end{array}$

Batrisceniola

$\begin{array}{lrrrr}\text { B. dissimilis } & 293 & 285 & 8 & 97 \\ \text { B. hiranoi } & 40 & 25 & 15 & 63 \\ \text { B. semipunctulata } & 25 & 0 & 25 & 0\end{array}$

macropterous) caught by light trap. 
Table 3-2. Measurements of body length, wing length and relative length of wing on 6 species of the Batrisocenus complex in 10 populations

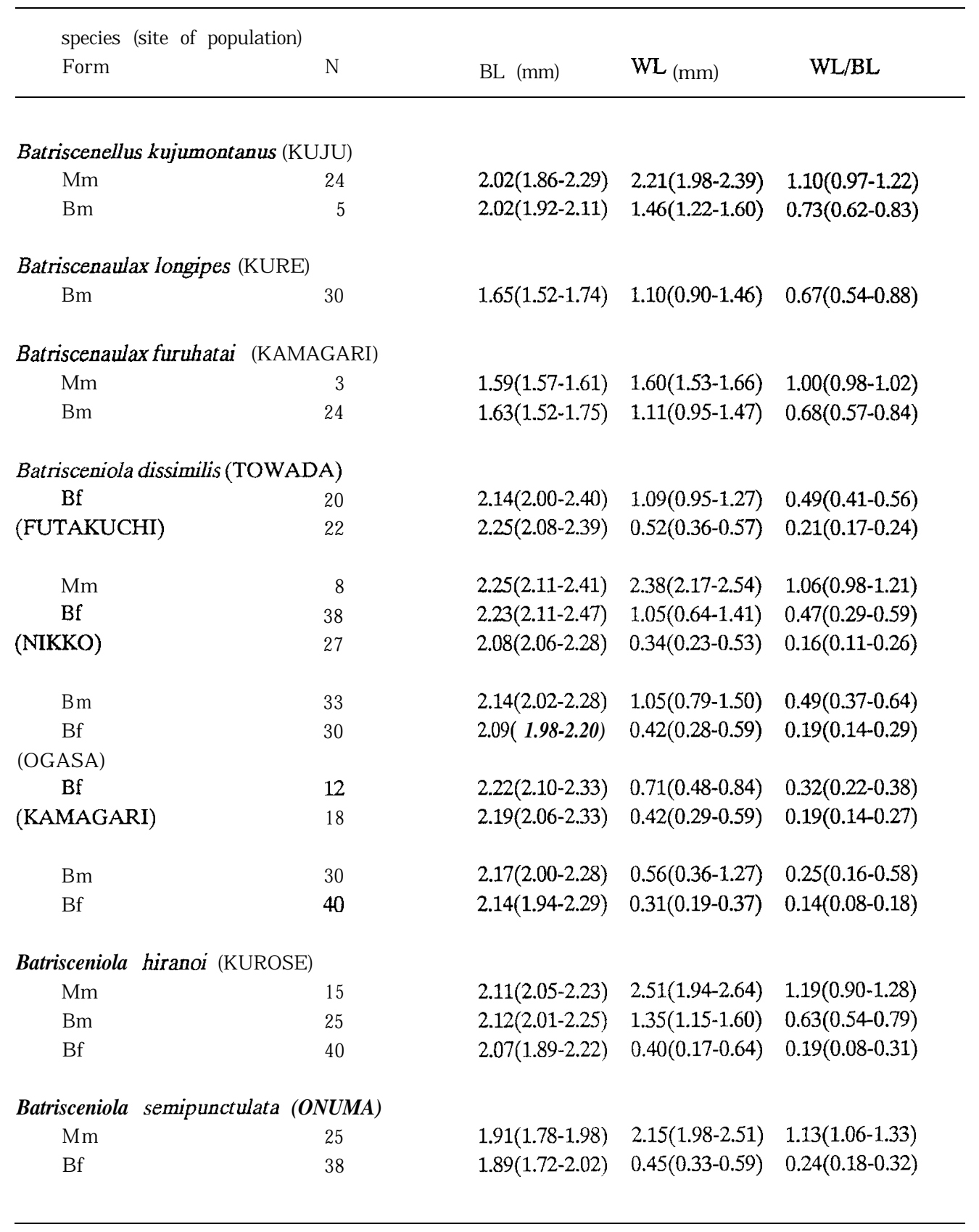

M: macropterous; B: brachypterous; m: male; f: female; N: number; BL: body length; WL: wing length; WL/BL: relative length of wing. 
Table 3-3. Frequency distribution of the relative wing length of 6 species of the Batrisocenus complex in 10 populations.

\begin{tabular}{|c|c|c|c|c|c|c|c|c|c|c|c|c|c|c|c|}
\hline species(site) & from & 0 & .1 & .2 & .3 & .4 & .5 & .6 & .7 & .8 & .9 & 1.0 & .1 & .2 & .3 \\
\hline sex & to & .1 & .2 & .3 & .4 & .5 & 6 & .7 & .8 & .9 & 1.0 & .1 & .2 & .3 & .4 \\
\hline
\end{tabular}

\section{Batriscenellus kujumontanus (KUJU)}

male

$$
\begin{array}{lllllll}
2 & 2 & 1 & 4 & 7 & 11 & 2
\end{array}
$$

\section{Batriscenaulax longipes (KURE)}

male

$$
\begin{array}{llll}
2 & 21 & 6 & 1
\end{array}
$$

\section{B. furuhatai (KAMAGARI)}

male

$\begin{array}{llllll}3 & 12 & 7 & 2 & 1 & 2\end{array}$

\section{Batrisceniola dissimilis(TOWADA)}

male

female

(FUTAKUCHI)

male

female

(NIKKO)

male

female

(OGASA)

male

female

(KAMAGARI)

male

female

$5 \quad 17$

$\begin{array}{llll}1 & 6 & 15 & 16\end{array}$

243

B. hiranoi (KUROSE)

male

female

$\begin{array}{llll}1 & 21 & 17 & 1\end{array}$

B. semipunctulata (ONUMA)

male

female

$\begin{array}{lll}5 & 32 & 1\end{array}$ 
histograms of the relative wing length are shown in Figs. 33 and 34.

As a result of the observation, the following two can be pointed out:

1) Pattern of the frequency distribution of the relative wing lengths differs among several dimorphic species. For example, the distribution is continuous and the mean values of the macropterous and the brachypterous forms are close to each other in Batriscenellus kujumontanus and Batriscenaulax furuhatai, but in each of Batrisceniola dissimilis and $\boldsymbol{B}$. hiranoi, the distribution curve is clearly divided into two peaks.

2) The frequency distributions of the wing length varies among the local populations for each species. The monomorphic brachypterous and the dimorphic or monomorphic macropterous local populations are observed in the same species in the cases of Batriscenaulaxlongipes and Batrisceniola dissimilis. Furthermore, the distribution range of the relative wing length differs significantly among the brachypterous populations. This fact is also observed in the female populations of Batrisceniola dissimilis, while the differences are small.

The wing dimorphism has not been studied in detail in Pselaphidae, but that is well-studied from various aspects in Carabidae. In Carabidae, the genetic mechanism of the wing dimorphism was concluded by Lindroth (1946) that the brachyptery is single dominant and the macroptery is homozygote. The evolutionary processes related to natural selection of the hind wing atrophy have been argued by Darlington (1936), Den Boer et al. (1980) and Kavanaugh (1985). Darlington assumed that the wing dimorphism is an intermediate stage in the evolutionary process from the macroptery to the brachyptery and pointed out some dynamic factors of the atrophy. Den Boer et al. proposed a hypothesis that the environmental fluctuation results the selection of the intermediate individuals in wing length, and it accelerates the dimorphism and atrophy. Kavanaugh illustrated the process of atrophy from the viewpoint of morphology, and inferred that the wing atrophy occurs independently in many times in Nearctic Nebria, placing the wing-atrophied taxa on its phylogenetic tree.

The wing atrophy and the dimorphism are almost congruent with the case of Carabidae in Pselaphidae in phenomenal level. But the wing dimorphic pselaphids have a striking feature that the female is always flightless. The brachyptery is apparently an apomorphic character probably occurred in many times in the BC, and has poor phylogenetic importance.

\subsection{Legs}

The structure of the legs, especially of the coxae, trochanters and tarsi has ever been regarded as very important characters for the taxonomy of Pselaphidae and used for dividing it to Brachyscelides and Macroscelides. Each leg consists of coxa, trochanter, femur, tibia, tarsus and pretarsus. These structures are illustrated on Batriscenellus ohishii in Fig. 35.

\subsubsection{Coxae}

The coxa is the most basal segment located on the emargination of the hind margin of each thoracic segment. Originally, each coxa is articulated with the eutrochantin (coxopleurite) in its basal part, but which is often reduced or absent in Pselaphidae; then the original sutures of the coxae are hardly recognized. 
The fore coxa is elongate, protrudes ventrally and is constricted medially; its apical part is strongly sclerotized and ovoid being slightly narrowed posteriorly, and the basal part of which is weakly sclerotized and articulated with the eutrochantin. The eutrochantin is elongately lamelar, partially membranous and articulated with the coxa at two points.

The mid coxa is short, basally rounded and subconical in the apical part, and articulated with the lateral bottom of the coxal cavity; its articulate part is strongly constricted, but no eutrochantin was recognized at the base.

The hind coxa is articulated with metasternum at two points near the median line, is thickened medially, and its posterolateral angle is transverse. The coxae are distant from each other in Batrisoplisus, slightly close to each other in the other five genera studied. The latter state is not the same as that of Euplectinae bearing the contiguous hind coxae, because the coxae are evidently separated from each other by the notched metastemal expansion with a short longitudinal sulcus (see the paragraph 21.3.).

\subsubsection{Trochanters (Fig. 37)}

The trochanter is a short segment in Brachyscelides, articulated with the apex of the coxa, and is very close to the basal end of the femur. Each trochanter is shorter than its preceding coxa, and is triangular in ventral view or subconical having a semilunar lobe where the basal end of the femur is attached ventrally.

\subsubsection{Femora}

The femur is usually the largest segment in the leg, which is obliquely truncate at the basal articulate part and internally notched at the apex where the basal end of the tibia is inserted.

The fore femur is medially thickened and shorter than the posteriors in the $\mathrm{BC}$, and has a shallow excavation with pores and setae on the basal inner side. This setiferous organ was called the sensory pit by Grigarick \& Schuster (1980), and is argued here in the paragraph 4.2.3. The mid femur is usually longer and thickened in the more apical part than the fore one. The hind femur tapers longer in the basal part than the mid one.

\subsubsection{Tibiae (Figs. 38-40)}

The tibia is slender and internally curved near the basal end which is inserted into the apex of the femur together with the four tendons as follows: the internal tendons are paired, and each tendon is subcylindrical together with flexor muscles at the apex; the external tendon is short and weakly acuminate at apex; the middle tendon is very short and very weakly sclerotized. The latter two are probably associated with the extensor muscles. This structure is common with fore, mid and hind tibiae (Fig. 35B, D, F).

The fore tibia is usually shorter than the others and bears a very small denticle near apex in the male of some species of the galloisi, venustus and torricornis-groups of the genus Batrisoplisus. This delicate structure is not practical for taxonomy. The male of Batrisoplisus uroceratus uroceratus, $\boldsymbol{B}$. uroceratus brevispinis and $\boldsymbol{B}$. inermis is characteristic in having the conspicuous mucro at each apex of the fore tibiae, hence the latter character is proposed to be autapomorphic.

The mid tibia has a mucro at apex in the male of many species in the BC. In Pselaphidae, such male modification raised in the fore and mid tibiae, the mid femur and all of the trochanters. As these 
male features are various in pselaphids, they are difficult to be correctly graded.

The hind tibia is generally largest among the tibiae, weakly thickened in the apical part, and rarely mucronate in the BC. It is mucronate only in the male of Arthromelodes thysanoventris.

\subsubsection{Tarsi and pretarsi (Fig 36D, E)}

The tarsus is three-segmented in all species of Pselaphidae and has common structures as follows: the first segment is shortest and triangular or subconical, and is shortened on the upper side where the second segment is attached; the second segment is usually longest, slender and slightly thickened distally; the third segment is feebly shorter than the second or as long as it in general, slender and slightly narrowed distally. The hind tarsus is usually longest, and the mid one is longer than the shortest fore one.

The pretarsus is composed of a small empodium and two tarsal claws in the BC. The empodium is a very small hairless tubercle sometimes retracted into the inner base of the claws. One of the tarsal claw is articulated with the third tarsal segment making an acute angle and predominantly larger than the other one.

\section{Abdomen}

The abdomen is g-segmented in both sexes, basal three segments are covered by the elytra, fourth segment is predominantly large, fifth to eighth segments are each short, 9th segment (sternite) is partly exposed in the male, formed into ovipositor in the female.

\subsection{Basic Structures of Abdominal Segments}

\subsubsection{Fist to third segments}

The basal three segments are more or less reduced as in the other group of pselaphids. The first to second abdominal tergites are entirely membranous. The first to second sternites are atrophied to become a narrow membranous joint between the metasternum and third abdominal sternite. The third segment is short; third sternite is partially fused with the third tergite to form the posterior wall of the metacoxal cavity with a ventromedian process.

These basal segments are scarcely varied within Batrisina, and they have poor importance for phylogeny.

\subsection{External structure of fourth abdominal segment (Figs. 41-43)}

The fourth abdominal segment is conspicuously larger than any other abdominal segment, it is subcylindrical and shortened on ventral side especially in the male. The fourth tergite bears a short basimedian carina on each side between the dorsolateral fovea and the dorsomedian depression. When a pair of paratergites are demarcated from the tergite, they are bordered by a pair of lateral carinae each obliquely running from the outside of the dorsolateral fovea to the posterolateral corner of the dorsum. The tergite and sternite are more or less fused to each other; the suture between tergite (paratergite) and sternite is weakly carinate and is called tergosternal ridge at basilateral part in this study. 
The fourth sternite has a pair of ventrolateral carinae running subparallel or weakly dilated, each of which located between the ventromedian fovea and the ventrolateral fovea is narrow and straight in general; it is conglutinate with the third sternite at ventromedian part forming a broad nodule between the metacoxae.

The tergosternal ridges are distinct in the most species of Batrisoplisus and Batriscenellus, rudimentary in Batrisceniola and some species of Arthromelodes. The paratergites are clearly demarcated by the paratergal suture only in Batrisoplisus. The basimedian carinae are varied in length within Batrisina, for example, there are distinct carinae reaching the middle of the segment in Arthromelodes pilicollis, though they are entirely atrophied in its allied species. The metacoxae are broadly separated by the ventromedian nodule in Batrisoplisus. The ventrolateral carinae are modified to be triangular broad type in Batrisoplisus uroceratus.

In some groups of Pselaphidae, fusion of the fourth abdominal tergite and sternite appears in parallel in various degrees. The tergite and sternite are completely amalgamated in the terminal condition, and such is observed in the out-groups, for example, Acetalius of Euplectinae, Batraxis sp. of Goniacerinae, Mina and Batristilbus of Batrisina examined in the present study. Such a series of atrophies and reductions of the original structure are evidently apomorphic transformations, but they are useless for cladistic analyses, because of their parallel occurrences.

\subsubsection{Internal processes of the fourth abdominal segment (Figs. 44-46)}

The internal processes of the fourth abdominal segment of Pselaphidae are discussed by Ohishi (1986) for the first time. These processes are located behind the antecosta at the basal part of the fourth segment as Ohishi (1986) stated. These invaginations of the integument are connected to each other at their apices to form internal arches; each of which is visibly a depression or a fovea in the external appearance. The terminology of the internal processes by Ohishi (1986) corresponds to my terminology as follows:

Internal process

External appearance

Tergite

dorsomedian process (DMP)

— dorsomedian depression (DMD)

( = medial cavity by Ohishi, 1986)

dorsolateral process (DLP)

- dorsolateral fovea (DLF)

( = lateral cavity by Ohishi)

\section{Sternite}

ventrolateral process (VLP)

— ventrolateral fovea (VLF)

( = lateral process by Ohishi)

ventromedian process (VMP)

-- ventromedian fovea (VMF)

The structure of these processes are summarized in Table 3-4. Furthermore, the shape of each processes and relative width of each arches in some species of the BC are shown in Table 3-5. 
Table 3-4. Basic structure of the internal processes of 4th abdominal segment in the Batrisocenus complex

\begin{tabular}{|c|c|c|}
\hline internal process & structure & external appearance \\
\hline \multicolumn{3}{|l|}{$<$ Tergite > } \\
\hline \multirow[t]{2}{*}{ DMP } & bifurcate & DMD \\
\hline & arched: Acl & (paratergal carina) \\
\hline DLP & bifurcate, paired & DLF \\
\hline$<$ Stemite $>$ & arched: Ac2 & (tergostemal ridge) \\
\hline \multirow[t]{2}{*}{ VLP } & bifurcate, paired & VLF \\
\hline & arched: Ac3 & (ventrolateral carina) \\
\hline \multirow[t]{3}{*}{ VMP } & bifurcate or divided & \\
\hline & to 2 , paired & $\mathrm{VMF}$ \\
\hline & $\begin{array}{l}\text { arched with the } \\
\text { other one: Ac4 }\end{array}$ & (ventromedian nodule) \\
\hline
\end{tabular}


Table 3-5. Shapes of the internal processes and the relative widths of arches of 4th abdominal segment in the species of Batrisocenus complex.

\begin{tabular}{|c|c|c|c|c|c|c|c|c|}
\hline species & DMP & Acl & DLP & Ac2 & VLP & $\mathrm{Ac3}$ & V M P & Ac4 \\
\hline \multicolumn{9}{|l|}{ Batrisoplisus } \\
\hline B. raffrayi & bf & $\mathrm{L}$ & $\mathrm{n}$ & $\mathrm{L}$ & bf & $\mathrm{L}$ & bf & $\mathrm{L}$ \\
\hline B. parallelus & bf & $\mathrm{L}$ & $\mathbf{n}$ & $\mathrm{L}$ & bf & $\mathrm{L}$ & bf & $\mathrm{L}$ \\
\hline B. uroceratus & sp & M & bf & $\mathrm{L}$ & bf & $\mathrm{L}$ & bf & $\mathrm{L}$ \\
\hline \multicolumn{9}{|l|}{ Batriscenellus } \\
\hline B. kujumontanus & bf & $\mathrm{L}$ & bf & $\mathrm{L}$ & bf & $\mathrm{L}$ & bf & M \\
\hline B. uenoi & $\mathrm{sp}$ & $\mathrm{L}$ & bf & $\mathrm{L}$ & bf & $\mathrm{L}$ & bf & M \\
\hline \multicolumn{9}{|l|}{ Physomerinus } \\
\hline P. schenklingi & bf & S & bf & $\mathrm{L}$ & bf & M & $s p$ & S \\
\hline \multicolumn{9}{|l|}{ Batriscenaulax } \\
\hline B. furuhatai & bf & $\mathrm{L}$ & bf & M & $\mathrm{bf}$ & $\mathrm{M}$ & $\mathrm{sp}$ & $\mathrm{L}$ \\
\hline B. kleinzach & bf & M & bf & M & bf & M & $\mathrm{sp}$ & M \\
\hline \multicolumn{9}{|l|}{ Cratna } \\
\hline C. abdominalis & $\mathrm{sp}$ & M & bf & M & bf & S & $\mathrm{sp}$ & S \\
\hline \multicolumn{9}{|l|}{ Arthromelodes } \\
\hline A. punctifrons & bf & $\mathrm{L}$ & br & M & br & M & bf & $\mathrm{L}$ \\
\hline A. giganteus & bf & $\mathrm{R}$ & br & S & br & S & $\mathrm{sg}$ & $\mathrm{L}$ \\
\hline A. küensis & bf & S & bf & M & bf & $\mathrm{L}$ & bf & M \\
\hline A. thysanoventris & $\mathrm{sp}$ & M & bf & M & bf & $\mathrm{L}$ & bf & $\mathrm{L}$ \\
\hline A. mercurius & bf & M & bf & M & bf & M & $\mathrm{sg}$ & $\mathrm{M}$ \\
\hline A. saikaiensis & bf & S & bf & M & bf & $\mathrm{L}$ & bf & M \\
\hline A. crucifer & bf & $\mathrm{L}$ & bf & M & bf & $\mathrm{L}$ & bf & $\mathrm{L}$ \\
\hline \multicolumn{9}{|l|}{ Batrisceniola } \\
\hline B. dissimilis & bf & M & br & M & bf & M & sg & $\mathrm{R}$ \\
\hline B. semipunctulata & bf & $\mathrm{L}$ & bf & M & bf & $\mathrm{L}$ & bf & M \\
\hline
\end{tabular}

bf: bifurcate; br: broad; L: large; M: medium; n: narrow; R: reduced; S: small; sp: separated; sg: single. 
(1986) as the type Il. If the internal processes of Batrisoplisus raffrayi and B. parallelus having paratergites can be assumed a primitive condition, namely a ground plan of the $\mathrm{BC}$, the following character evolution can be suggested for the shape of each internal process: The separated DMP is derived from a bifurcate shape becoming the DMD shallow; this derived state appears in Batrisoplisusuroceratus, Batriscenellus uenoi, Cratna abdominalis and Arthromelodes thysanoveotris. The Acl formed by the lateral arms of the DMP and DLP is reduced in the apomorphic condition; this reduction also observed in some genus in various degree, but these arches are lost in Arthromelodesgiganteus. The DLP is narrow in primitive condition, from which the bifurcate form is derived and reduced to be the broad form; the terminal condition is found in Arthromelodespunctifrons and A. gigaoteuswhich is regarded as the most apomorphic type of the internal processes. The large Ac2 shows evidently primitive state because of the presence of the paratergite which originally has movable articulation; Ohishi (1986) concluded that the closed $\mathrm{Ac} 2$ of the $\mathrm{BC}$ was derived from the internally opened form as the paratergal articulation had become rigid. The primitive state of the Ac2 is found in Batrisoplisus, Batriscenellus and Physomerinus, and the apomorphic reduced form distinctly appears in Arthromelodes giganteus. The VLP is large and bifurcate in many species, but it is also reduced to be broad and shallow in $A r$ thromelodespunctifrons and A. giganteus. As for the VMP, the bifurcate form is evidently primitive, from which the separated and reduced single forms are derived; separated form is observed in Physomerinus, Batriscenaulax and Cratna abdominalis, and the single form appears in Arthromelodes giganteus, A. mercurius and Batrisceniola dissimilis. The Ac3 and Ac4 are each successively reduced in the derived condition, such as the other arches.

According to Ohishi (1986), the arrangements of the internal processes of 4th abdominal segments in Batrisina are classified into three types $(\mathrm{J}, \mathrm{I} 1, \mathrm{I} 2)$ and these conditions are not observed in the other subfamilies. In Batrisoschema, the dorsomedian process is absent (type 12 of Ohishi). But the most species of Batrisina have the same type of the internal processes in general. An evolutional tendency of the internal processes is apparent from the deep or bifurcate form to the shallow and broad form by gradual reduction. Additionally, the internal arches constructed by these processes are successively reduced or lost in the apomorphic state, which is typically arisen in Arthromelodesgiganteus. These series of reductions have little importance for cladistic analyses, not with standing the evolutionary process has been clearly documented.

\subsubsection{Fifth to seventh abdominal segments (Figs. 47-50)}

The fifth to seventh abdominal segments are conjointly tubular and more or less narrowed posteriorly. In each segment, the tergite and the sternite are demarcated from each other by the tergosternal ridge or suture on each side; the paratergites of fifth to seventh segments are sometimes indefinite. The fifth and sixth segments are often strongly shortened on the ventral side, especially in the male. The seventh segment is distinctly larger than the fifth or sixth segment in dorsal view. The seventh segment is enlarged in all species of this groups, but the fifth to eighth segments are successively shortened in the other groups of Batrisina. This is a heteronominal change of the segmentation, and considered to be apomorphic. But there is a problem whether it is an autapomorphy, because similar enlargement of the seventh abdominal segment is commonly observed in the subtribe Euplactina of Euplectinae, and sometimes occurred in the other division of Batrisina. If the enlarged seventh abdominal segment of the BC is homologous with that of Euplectina, it may be plesiomorphic character. This problem is the same as 
the pronotal sulci shown in the paragraph 2.1.1. Considering this fact, this character is tentatively considered to be an autapomorphy.

The internal processes are also present in lateral part of the fifth to seventh segments, and each of them is very small, subconical and connected with the antecosta of each plate. The tergal and the sternal processes are connected with each other at their apices. The internal processes appears as lateral foveae in the external view (lc: lateral cavities of Ohishi, 1986). A pair of median cavities are represented by rudimentary pits on median part of each sternite in the BC when they are present. These processes or cavities are clearly observed in the divisions II and IV of the subtribe Batrisina (Fig. 50E, F). Compared with the out-groups, the lateral cavities are assumed to be present in each plate of fifth to seventh segments and the median cavities are also in each stemite in the ancestral condition of Batrisina. The reduction of these structures must be occurred secondarily in the BC.

\subsubsection{Eighth to ninth abdominal segments}

The posterior end of the abdomen is a composite circular plate consisting of the eighth segment and the ninth sternite in male. The eighth tergite is emarginate at the posterior margin with a short internal folding. The eighth sternite is short and shallowly emarginate at the posteromedian margin. The ninth stemite is very small, the posterior part is exposed, and the basal part extends internally below the eighth sternite and asymmetrical in some species.

In Arthromelodes mercurius, the eighth tergite bears a transverse groove in the middle part (Fig. 49D-F). There are a pair of longitudinal carinae in all length of the eighth sternite in the subgenus Batriscenellus. The ninth stemite is absent in the male of Physomerinus pedator, etc. Each of these modifications being unique to each taxa or species is regarded as an autapomorphic character.

The eighth tergite and stemite form the pygidium in the female. The eighth tergite and stemite are similar in shape. The eighth tergite is internally folded at the posterior margin. The eighth tergite is uniquely convex in the female of three species of the uroceratus-group of the genus Batrisoplisus excepting $\boldsymbol{B}$. parallelus, namely, this tergite is short, but distinctly convex in $\boldsymbol{B}$. volucaninsulanus, projected to form a semispherical nodule in $\boldsymbol{B}$. inermis, and conically projected in Batrisoplisus uroceratus. The morphocline from the flat to projected conditions of the eighth sternite is recognized as a series of autapomorphies showing the phylogenetic relationship among these three species.

\subsection{Spiracles and Abdominal Glands}

\subsubsection{Abdominal spiracles (Figs. 51-53)}

The abdominal spiracles are present on the fourth to eighth abdominal segments, but are minute and almost invisible under the low magnification, and they are observed by the SEM in this study. These spiracles are located each on the lateral carina or suture between the paratergite and tergite in general. The spiracles of fourth abdominal segment (here in after denoted as spiracle 4 or Sp4) is each located on lateral carina, or if the carina is absent, it appears on dorsolateral part of the fourth segment behind of the dorsolateral foveae at a distance. The spiracle 4 is a very small and weakly tubercular simple hole or sometimes lost. Each of the spiracles 5 to 6 is also a simple hole and is located on each posterior end of the lateral carina. The spiracle 7 is larger than any other spiracle with swollen periphery. The spira- 
cle 8 lies at the basal part of the eighth tergite and concealed below the hind edge of the seventh segment.

Atrophy pattern of the spiracles 4 to 8 is varied in the species of Batrisina as shown in the Table 3-6. The spiracle 4 in the female has a tendency to become lost in general.

Table 3-6. Atrophy pattern of spiracles in fourth to eighth abdominal segments in Batrisina.

\begin{tabular}{|c|c|c|c|c|c|}
\hline species & Sp4 & Sp5 & Sp6 & Sp7 & Sp8 \\
\hline \multicolumn{6}{|l|}{ Batrisoplisus raffrayi } \\
\hline male & + & + & + & + & + \\
\hline \multicolumn{6}{|l|}{ Batriscenellus kujumontanus } \\
\hline male & + & + & + & + & + \\
\hline female & $\mathrm{R}$ & + & + & + & + \\
\hline \multicolumn{6}{|l|}{ B. ohishü } \\
\hline male & + & + & + & + & $?$ \\
\hline female & & + & + & + & $?$ \\
\hline \multicolumn{6}{|l|}{ Batriscenaulaxfuruhatai } \\
\hline male & + & + & + & + & $?$ \\
\hline female & & + & + & + & $?$ \\
\hline \multicolumn{6}{|l|}{ Batrisceniola dissimilis } \\
\hline male & & + & + & + & $?$ \\
\hline \multicolumn{6}{|l|}{ B. hiranoi } \\
\hline female & & + & + & + & + \\
\hline \multicolumn{6}{|l|}{ < out-group > } \\
\hline Batrisoschema euplectiforme & & & & & \\
\hline female & + & + & + & + & + \\
\hline
\end{tabular}

+ : present; -: absent; R: reduced; ?: not observed.

Lawrence \& Newton (1982) pointed out that the adult spiracles on the fourth to sixth abdominal 
segments are atrophied in Pselaphidae, Dasyceridae, Micropeplidae, and Neophoninae and Proteininae of Staphylinidae; Newton \& Thayer (1988) justified again this apomorphic character. But, Naomi (1989c) suggested that the spiracles are present on the first to eighth segments in Pselaphidae in principle, and tend to atrophy in various degree from the fourth to sixth segments.

In my observation, all spiracles on the fourth to eighth abdominal segments are basically present in Batrisina. If these spiracles retain their function, this fact produces a counterevidence to Lawrence \& Newton (1982) and their following studies, and support the consideration by Naomi (1989c). These series of atrophies cannot be evaluated in my cladistic analysis, however such atrophies are apomorphic and showing the various atrophy patterns.

\subsubsection{Abdominal defensive gland (Fig. 54)}

The defensive gland arises at the basimedian margin of the eighth abdominal sternite in some staphylinids (Omaliinae group of Lawrence \& Newton, 1982), and its secretory structure was studied in detail by Klinger \& Maschwitz (1977). This organ is also observed in some groups of Pselaphidae including the BC. It is very small and fragile structure fixed at the middle point of the basal margin of the eighth sternite in general; it cannot be recognized in the externalview (Fig. 54A). In Batriscenellus kujumontanus, this organ is a spoon-like vestige (Fig. 54B). It arises as a distinct nodule in Physomerinus schenklingi (Fig. 54D) and a large membranous sac in Batrisceniola dissimilis (Fig. 54E, F). This organ is rudimentary in Batriscenaulax furuhatai (Fig. 54C) or almost absent in Batrisoplisus raffrayi and Batriscenellus transformis etc.

This variously reduced defensive gland on the eighth sternite is regarded to be a positive apomorphic character. Lawrence and Newton (1982) pointed out that the defensive gland originally arose on the eighth sternite in some taxa of the Omaliinae group of Staphylinidae and Dasyceridae, but was absent in Pselaphidae. Thayer (1987) suggested that some pselaphids had the reduced abdominal defensive gland, but many ones had nothing, and she assumed that many pselaphids had lost this organ at the stage of the common ancestor. Although the defensive gland is reduced to small one, it is a synapomorphy justifying the Lawrence \& Newton system in my opinion. Thayer's hypothesis must be almost reasonable, but the more original type of the defensive gland in the $\mathrm{BC}$ proves that the reductions and atrophies of this organ had occurred in parallel in many times within Pselaphidae.

\subsection{Male Genitalia}

\subsubsection{Parameres}

The male genitalia have specialized structure of the trilobed type in the superfamily Staphylinoidea (Sharp and Muir, 1912, Blackwelder, 1935, Jeannel, 1955, Matsuda, 1976, Naomi, 1985b etc). In many groups of Staphylinoidea, the basal piece is reduced to tiny structure or absent, then the parameres are fixed at the basal foramen of the aedeagus (median lobe). Thus, parameres are the only component of the tegmen in Pselaphidae. But in Batrisinae, they are generally fused to each other forming a weakly sclerotized plate attached to the apical margin of the basal foramen of the aedeagus. The parameres are independent from the ejaculatory duct. Some muscles are inserted to the ventral side of the paramere in some cases (Batriscenaulaxlongipes etc.). These muscles may act the aedeagus to stome into the 
abdominal segments. This simple structure is shared by all species of the BC. The less reduced parameres than the BC are observed in Tribasodites picticornis, which is composed of three plates, and two pieces are identified as the rudiments of paired parameres.

\subsubsection{Aedeagus (Fig. 55)}

The aedeagus is composed only of well-sclerotized median lobe, and is clearly divided into the basal bulb and the dorsal apophysis in the $\mathrm{BC}$. This type of aedeagus is apparently asymmetrical without sclerotized endophallus. The basal bulb is bulbous or subconical always bearing a large and well-stalked projection called the ventral stalk in this study. The basal bulb is thick around the basal foramen, and adorned sometimes with a knob or projection called basal strut at the basal end. In some species, the apical foramen is covered with membrane and has two or three processes named articulate processes in this study to which the dorsal apophysis is articulated. The dorsal apophysis is various in shape, and bears membrane continued from the apical foramen of the basal bulb near to the apex. The muscles arise from the inner surface of the basal bulb and inserted into the base of the dorsal apophysis. The contraction of the muscles draws the apex of the dorsal apophysis near the apex of the ventral stalk, thus the articulated apparatus may act as the clasper or the fixer to the vulva.

In Batrisoplisus, the aedeagus is complicate in shape, and has an elongate basal bulb along the median axis, whose dorsal apophysis contains two or three sclerites being almost immovable. Each of the other Japanese species in the $\mathrm{BC}$ has such a movable dorsal apophysis that their apophyses are classified into four types by their shape as follows:

1) The Batriscenellus type. In the large genus Batriscenellus, the dorsal apophysis curves strongly at the basal part, and extends to the outside of the ventral stalk or sometimes crosses the apex of the ventral stalk.

2) The Physomerinus type. In Physomerinus and Batriscenaulax, the dorsal apophysis is articulated at one point, elongate and nearly straight in dorsal view, with a narrow membranous part along the internal side.

3) The Arthromelodes type. In many species of Arthromelodes, the dorsal apophysis is subconical to subtubular with apical spines or projections, and it is broadly covered by membrane arisen from its basal part.

4) The Batrisceniola type. The special type is observed in Batrisceniola. The dorsal apophysis is articulated to basal bulb at the distant two points, tapers, strongly curves and is surrounded by membrane in the basal part.

As for the origin of the dorsal apophysis, Jeanne1 (1949) suggested that it is formed from paired parameral plates after examining in some species of Batrisocenus from New Guinea. But this is doubtful in the following two points: 1) the dorsal apophysis is the most distant from the basal foramen in principle, 2) the rudimentary parameres are independently observed from the dorsal apophysis at the posterior margin of the basal foramen, for instance, the parameres appear evidently in Physomerinus schenkLingi and Tribasoditespicticornis. Later, Jeanne1 (1951a) denied his own hypothesis and correctly suggested about the formation of the dorsal apophysis that it originates in the dorsal wall of the median lobe.

The character transformation series of the dorsal apophysis in Batrisina are inferred from the observed morphocline and the polarity determined by out-group comparison in the present study as fol- 
lows:

Step 1: The male genitalia are in the shape of a jar with basal foramen on its side and sclerotized endophallus, and the parameres are reduced to a simple lobe. The aedeagi of many species in the divisions II and IV of Batrisina, especially the type of Batrisodes are derived from this step by reduction of the genital sclerite in the dorsal wall of the median lobe.

Step 2: The dorsal wall of the median lobe is broadly expanded apically to form an incomplete dorsal apophysis, and the endophallus is more or less reduced. Tribasodites picticornis, Tribasodes longicornis and Basitrodes sp. have the aedeagi of this step.

Step 3: The dorsal apophysis is almost immovable and broad or complicate in shape, for instance, it is represented by a shield-like plate in Batrisocenus spp. from New Guinea (Jeannel, 1949) or two or three pieces of sclerites in Batrisoplisus.

Step 4: The dorsal apophysis is movably articulated with the basal bulb having the clear muscles; and the endophallus is not sclerotized. This step shows the apomorphic condition observed in most species of the BC except for Batrisoplisus and Batrisocenus.

The character in the steps $3+4$ is treated as an autapomorphy supporting the monophyly of the $\mathrm{BC}$ in the present cladistic analysis, but there are following two problems: Jeanne1 (1951) pointed out that the dorsal apophyses are occurred in the aedeagi of the other groups, for example, Parabatrisus in the division II of Batrisina. Jeannel (1952) also described the male genitalia of Batriscenites morulus belonging to the $\mathrm{BC}$, which are similar to those of the step 1. Judging from literature on these species, the dorsal apophysis of the former species is probably not homologous with that of the $\mathrm{BC}$, and that the latter species is considered to have the step 4 of aedeagus according to Tanokuchi (1989).

\subsubsection{Dimorphism of the male genitalia (Figs. 56, 57)}

The male genitalia of this group are asymmetrical without exception. A type of the male genitalia with a dorsal apophysis on its right side of the basal bulb is named as the right-articulated type (RA) in this study, and the contrary type for the left side is named as the left-articulated one (LA) in the same way. The genitalia are allocated to RA and LA on each species of the BC as shown in the Table 3-7. In some species, both of the RA and LA are found in the same population of one species, which is denoted here as dimorphic (Fig. 56).

As a result of the comparison, the situation of the dorsal apophysis on the male genitalia of each genus is clarified as follows:

In Batrisoplisus, the dorsal apophysis is composed of two or three sclerites, and articulated at both sides. Judging from the situation of the ventral spine, one type of the genitalia with the spine on the left side must be the RA, and the other for the right side is the LA. In this way, every specimens examined excepting the torticornis-group is classified to the RA. The torticornis-group is composed of three species having a different type of genitalia respectively from the other species-groups, two of which are settled to the LA, and torticornis is dimorphic.

The dorsal apophysis of Batriscenellus is articulated on the left side of the basal bulb without exception, and curves rightward in the basal part to reach right side of the basal bulb.

In Physomerinus, $P$. shenklingi is uniformly LA, and the rest two species are settled to the RA; there is no dimorphic species. 
Table 3-7. Number of right- and left-articulated types of male genitalia in each species of the Batriso-

species
$\mathrm{N}$
LA

RA or LA

\section{Batrisoplisus}

B. sagamianus

B. galloisi

B. sawadai

B. satsumanus

B. subtilis

B. venustus

B. tenuiformis

B. esakii

B. tosanus

B. tanabei

B. okamotoi

B. raffrayi

B. amamianus

B. monostatos

B. torticornis

B. tamino

B. constrictus

B. volucaninsulanus

B. uroceratus uroceratus

B. uroceratus brevispinis

B. inermis

B. parallelus

2
3
2
1
1
5
1
4
1
2
2
9
1
6
10
1
1
1
2
1
1
8

2
3
2
1
1
5
1
4
1
2
2
9
1
6
4
0
0
1
2
1
1
8

RA

RA

RA

RA

RA

RA

RA

RA

$\mathrm{RA}$

RA

RA

RA

RA

RA

dimorphic

LA

LA

RA

RA

$\mathrm{RA}$

$\mathrm{RA}$

$\mathrm{RA}$

\section{Batriscenellus}

\begin{tabular}{|c|c|c|c|c|}
\hline B. japonicus japonicus & 1 & 0 & 1 & LA \\
\hline B. $j$. vicarius & 2 & 0 & 2 & $\overline{\mathrm{LA}}$ \\
\hline B. punctatus & 3 & 0 & 3 & LA \\
\hline B. fallax & 3 & 0 & 3 & LA \\
\hline B. omogensis & 1 & 0 & 1 & LA \\
\hline B. kujumontanus & 68 & 0 & 68 & LA \\
\hline B. fragilis & 1 & 0 & 1 & LA \\
\hline B. nodulifer & 1 & 0 & 1 & LA \\
\hline B. transformis & 10 & 0 & 10 & LA \\
\hline B. similis & 10 & 0 & 10 & LA \\
\hline B. ohishï & 4 & 0 & 4 & LA \\
\hline B. insulicola & 1 & 0 & 1 & LA \\
\hline B. orientalis & 1 & 0 & 1 & LA \\
\hline B. pilosellus & 1 & 0 & 1 & LA \\
\hline B. sakaii & 1 & 0 & 1 & LA \\
\hline B. иenoi & 4 & 0 & 4 & LA \\
\hline
\end{tabular}

$\mathrm{N}$ : number of males examined; RA: right-articulated type; LA: left-articulated type. 
cenus complex.

\begin{tabular}{|c|c|c|c|c|}
\hline species & $\mathrm{N}$ & $\mathrm{RA}$ & LA & RA or LA \\
\hline \multicolumn{5}{|l|}{ Physomerinus } \\
\hline P. pedator & 2 & 2 & 0 & RA \\
\hline P. schenklingi & 23 & 0 & 23 & LA \\
\hline P. hasegawai & 1 & 1 & 0 & $\overline{\mathrm{RA}}$ \\
\hline \multicolumn{5}{|l|}{ Batriscenaulax } \\
\hline B. modestus & 1 & 1 & 0 & RA \\
\hline B. longipes longipes & 49 & 0 & 49 & LA \\
\hline B. 1. kumaso & 8 & 0 & 8 & LA \\
\hline B. 1. hayato & 3 & 0 & 3 & LAA \\
\hline B. fiuuhatai & 27 & 0 & 27 & LA \\
\hline B. kleinzach & 5 & 5 & 0 & $\mathrm{RA}$ \\
\hline B. kunigamensis & 1 & 0 & 1 & LA \\
\hline B. nagensis & 1 & 0 & 1 & LA \\
\hline \multicolumn{5}{|l|}{ Arthromelodes } \\
\hline A. punctifrons & 1 & 0 & 1 & LA \\
\hline A. giganteus & 1 & 0 & 1 & LA \\
\hline A. pilicollis & 1 & 1 & 0 & RA \\
\hline A. kiiensis & 8 & 8 & 0 & $\mathrm{RA}$ \\
\hline A. gyoja & 1 & 1 & 0 & RA \\
\hline A. thysanoventris & 8 & 3 & 5 & dimorphic \\
\hline A. comiventris & 1 & 0 & 1 & LA \\
\hline A. mercurius & 1 & 1 & 0 & RA \\
\hline A. hikosanus & 1 & 1 & 0 & RA \\
\hline A. loebli & 8 & 5 & 3 & dimorphic \\
\hline A. dilatatus daibosatsuanus & 1 & 0 & 1 & LA \\
\hline A. d. shiranemontanus & 1 & 0 & 1 & LA \\
\hline A. d. fujimontanus & 1 & 0 & 1 & LA \\
\hline A. sinuatipes & 1 & 0 & 1 & LA \\
\hline A. aizuanus & 1 & 1 & 0 & RA \\
\hline A. saikaieasis & 4 & 0 & 4 & LA \\
\hline A. crucifer & 1 & 1 & 1 & dimorphic \\
\hline \multicolumn{5}{|l|}{ Batrisceniola } \\
\hline B. dissimilis & 293 & 184 & 109 & dimorphic \\
\hline B. hiranoi & 237 & 129 & 108 & dimorphic \\
\hline B. semipunctulata & 25 & 0 & 25 & LA \\
\hline
\end{tabular}


In Batriscenaulax, B. kleinzach and B. modestus are each RA and the rest four species and two subspecies are of the uniformly LA; but $\boldsymbol{B}$. longipes scarcely differs morphologically from $\boldsymbol{B}$. modestus in appearance and the structure of the male genitalia without the direction, hence these two species are suspected to be of two morphotypes of the same dimorphic species.

In Arthromelodes, six species and two subspecies are uniformly of LA, other six species are of RA, and three species, A. thysanoventris, A. Ioebli and A. crucifer are dimorphic.

Each of two species of Batrisceniola, B. dissimilis and B. hiranoi is dimorphic and the rest one is settled to the LA.

Furthermore, on some local populations of the dimorphic species, Batrisceniola dissimilis, the ratios of the RA and the LA were compared. These data are shown in Table 3-8 and Fig. 57.

Table 3-8. Number of right- and left- articulated types of male genitalia in the different populations of Batrisceniola dissimilis.

\begin{tabular}{|c|c|c|c|c|}
\hline localities & $\mathrm{N}$ & RA & LA & $\mathrm{RA} / \mathrm{N}(\%)$ \\
\hline TOWADA (Aomori Pref.) & 20 & 12 & 8 & 60 \\
\hline FUTAKUCHI (Miyagi Pref.) & 38 & 22 & 16 & 58 \\
\hline NIKKO (Tochigi Pref.) & 33 & 17 & 16 & 52 \\
\hline HAKONE (Kanagawa Pref.) & 14 & 0 & 14 & 0 \\
\hline OGASA (Shizuoka Pref.) & 12 & 7 & 5 & 58 \\
\hline HIKIMI (Shimane Pref.) & 24 & 19 & 5 & 79 \\
\hline KAMAGARI (Hiroshima Pref.) & 30 & 19 & 11 & 63 \\
\hline The other localities & 122 & 95 & 39 & \\
\hline Total & 293 & 184 & 109 & 63 \\
\hline
\end{tabular}

$\mathrm{N}$ : number of males examined; RA: right-articulated type; LA; left-articulated type.

The morphotypes of the RA and the LA are both observed and the ratio is a little larger for RA 
than the LA in most populations. The population in Hakone is an exception where fourteen males are all of LA.

Jeanne1 (1955) referred to the inversion of the asymmetrical male genitalia in the pselaphids and carabids in his review on the morphology of aedeagus, and regarded it as a mutation on the evolutionary process. But the "inversion" in his sense indicates interspecific or intersubspecific variation and never means intraspecific one. He explained an example of the inversion in Pterostichus rufipes of Carabidae as an intraspecific mutation and exceptional.

Concerning the dorsal apophysis of the BC, Jeanne1 (1951a) assumed that the LA was primitive and the RA was derived from the LA by the mutation based on the fact that RA was more generally observed in the BC than the LA (but some groups examined by Jeanne1 are excluded from the BC in my opinion). Thus, he classified the African genus Arthromelus into two subgenera on the types of the male genitalia, namely, Scaiomelus of the LA and Arthromelus s. str. of the RA. Additionally, he suggested that Arthromelodes cariei is most primitive because of its nearly symmetrical male genitalia. In short, he hypothesized the following evolutionary process of the male genitalia: Arthromelodes cariei (symmetriCal) - subgenus Scaiomelus (LA) - subgenus Arthromelus (RA).

But the present study evidently demonstrates that the change from the LA to the RA (or from the RA to the LA) is not an evolutionary event once occurred in the $\mathrm{BC}$, and his observation that the male genitalia of Arthromelodes cariei is symmetrical is inappropriate. The hypothesis that the symmetrical male genitalia are primitive in Batrisina is reasonable, but every genitalia having dorsal apophysis is clearly asymmetrical without exception in my observation. The dimorphism of the male genitalia as the RA or LA is not a result of the evolutionary event, but is probably a genetic variation occurred in parallel in some groups of the BC. Such dimorphic character should not be treated as a phyiogenetic character for the taxonomy.

\subsection{Ovipositor}

The ovipositor is composed of the ninth abdominal sternite and the genital plate in Batrisina. The vagina is located between two hemistemites of the ninth sternite (Fig. 58).

\subsubsection{Ninth abdominal stemite}

The ninth abdominal sternite is divided into two hemisternites by a narrow and transverse membranous part including the vagina. These hemisternites are named fore and hind lobes in this study. The apical margin of the hind lobe is connected with the ventral side of the anus. In four Japanese genera of the BC excepting Batrisoplisus and Batriscenellus, the hind lobe bears a transverse or ovoid median membranous area. The fore lobe of ninth sternite is more or less narrowed, and has a pair of ventral processes running in subparallel at the basal part in many species.

The internal structure of the female reproductive organ located anterior to the ninth sternite contains the bursa copulatrix, ovary, spermatheca and a pair of glandular vesicles (Jeannel, 1950). The bursa copulatrix is very large, and attached to the fore lobe containing ventral processes, and dorsally supported by the lateral arms when these are well-developed. The glandular vesicles was first reported in Claviger testaceus by Klüger (1910). The duct from the vesicles is attached each to lateral extension 
of the hind lobe at the basal margin in the $\mathrm{BC}$. The position and shape of the spermatheca and ovary of the $\mathrm{BC}$ are not examined in the present study.

In Batrisoplisus, the ninth stemite is almost membranous, and the fore and hind lobes are indefinite without ventral processes. The ninth sternite of Batriscenellus is weakly sclerotized, and the fore and hind lobes are clearly distinguishable and partially overlapped in the ventral view. Its hind lobe has no distinct median membranous area, and the fore lobe has a pair of small ventral processes. Every species of the other four genera Physomerinus, Batriscenaulax, Batrisceniola and Arthromelodes has the similar type of the ovipositor in having the median membranous area on the hind lobe and the well-developed ventral processes. Each of the two species of Cratna examined in this study also has the hind lobe of the same type, but bears no sclerotized ventral processes on the fore lobe. The ninth sternite of Arthromelodes punctifrons is very weakly sclerotized and has indistinct ventral processes, but this character is regarded due to a secondary reduction, because the sclerotized frame of that type of the sternite remains.

In many species of the division II of Batrisina, the ninth stemite is a weakly sclerotized single plate in general, which is probably the primitive condition of the ninth stemite in Batrisina. The divided ninth sternite shared by the five Japanese genera and Cratna is considered to be the derived condition. The fore lobe having a pair of well-developed ventral processes in four Japanese genera are regarded as apomorphic. The median membranous area of the hind lobe found in four Japanese genera and Cratna is regarded to be a derived character. Each of these three characters is unique to each group, hence it is recognized as a good autapomorphy.

\subsubsection{Genital plate}

The genital plate is a small sclerite located at the dorsomedian part of the bursa copulatrix; this sclerite is composed of a median wall and a pair of lateral walls in the general form. This plate in Probatrisus called "pièce papilionacée" was regarded to be homologous with the "plaque vaginale (apophyse vaginale)" (Jeannel, 1941) of Carabidae by Jeanne1 (1949). In some species of the BC, the genital plate is very large, strongly sclerotized and laterally extends to form a pair of robust arms, which are called the lateral arms in this study. In these species, muscles arise from the ventral processes and are inserted to the apical part of the lateral arms.

The genital plate of Batrisoplisus is weakly sclerotized and not laterally extended to form lateral arms. In Batriscenellus, the genital plate is small, slender and T-shaped, and its lateral arms are very short without distinct muscles. Similar T-shaped but large genital plate is present in two species of Cratna examined in this study. In the other four genera, the genital plate is large and strongly sclerotized with well-developed muscles, and the lateral arms are very long extending anterolaterally.

The genital plate of Batrisopfisusbelongs to the general type of Pselaphidae, which apparently shows primitive condition. The T-shaped genital plate of Batriscenellus and Cratna shows apomorphic state. Furthermore, the type with anterolaterally extending long lateral arms must be derived from the latter type. The latter two characters are each recognized as an autapomorphy. 


\section{Hairs and Setiferous Structures}

\subsection{Hairs of the Body}

\subsubsection{Normal hairs}

The normal hairs mean the hairs covering the integument of the body without distinct secretory pore nor modification as sensory pit in this study. Each hair is sharpened toward apex and furrowed longitudinally and its socket is simple. The direction of the hairs has the following manner. The hairs are anteriorly directed on clypeus, anteriorly or laterally on the frons, toward the center or anteriorly on the vertex, toward apex or erect on the antenna, toward the center on the pronotum, posteriorly on the elytra, laterally or posteriorly in the median part of the mesosternum, posteriorly on the metasternum, toward apex in general, but with some modification on the legs. On each of fourth to seventh abdominal segments, the hairs in the anterior part of the dorsum are directed toward the hind margin and turned internally on the posterior part. These are internally directed on the eighth tergite, and posteriorly on the eighth stemite. This principal direction of the hairs has some exceptions, for instance, in Batriscenioladissimilis and $\boldsymbol{B}$. hiranoi, the hairs on the frons are directed posteromedially. It is modified in accordance with the sexual patch on the frons.

The direction of the hairs is common to the most species in Batrisina or to some taxa in Pselaphidae.

\subsubsection{Suberect long hairs}

The suberect long hairs are distinctly longer than the surrounding hairs, erected on the integument and are paired symmetrically, but they are very similar in structure to the normal hairs. The suberect long hairs arise on the first, second, fifth, seventh and ninth to eleventh antennal segments in most species, sometimes on the lateral and dorsal sides of the pronotum and the dorsal side of the elytra or dorsal part of the fourth abdominal segment; a pair of those hairs are observed on each segment of fifth to eighth abdominal segments in many cases. They are observed in many species of Batrisinae.

In five species of Arthromelodes, the suberect hairs varied in number, position and length as shown in Fig. 59. The suberect hairs also densely arise on the postgenae in many species of Batrisina, but are not so developed in the BC.

\subsection{Non-Sexual Setiferous Structure}

\subsubsection{Trichome and allied structure of first antennal segment (Figs. 60-62)}

The first antennal segment has a trichome consisting of several bold and semihyaline setae on the outer apical part in both sexes of some species in the BC. This organ is developed to be a conical projection in all species of Batriscenellus (Fig. 60B-F); the same structure is present in the scape of $A r$ thromelus labiatus, and Seidelites affinis from Africa in my observation; there is a small trichome on the same position in some species of Arthromelodes, Batriscenaulaxand Batrisceniola; these setiferous 
structures are completely absent in Batrisoplisus and Physomerinus. In Cratna belonging to the BC from south-east Asia and Taiwan, the first antennal segment projects apically from the outer side, and the projection is truncate and unifoveate at the apex in both sexes (Fig. 61A, B).

Löbl (1986) pointed that the secretory organs are also present on the scape in male of many species of Batrisinae, but these non-sexual modifications are unique to Cratna. In my observation, the microstructure of these setiferous organs are presumably characteristic to each genus group or the genus within Batrisinae. Therefore, I recognize the conical trichome of Batriscenellus and allied genera, and the truncate and unifoveate projection of Cratna as an autapomorphy of each genus group or the genus, respectively.

\subsection{Trichome of maxillary palpus (Fig. 63)}

In both sexes of all species of the BC examined, a small trichome composed of several short and bold setae is observed at the outside of the fourth segment of the maxillary palpus. This structure is widely found in the subfamily Batrisinae, and was illustrated by Löbl(1979a, 19796) in Megabatrus and Sathytes (division II).

\subsubsection{Sensory pit of fore femur (Figs. 64-66)}

In many pselaphids, the fore femur has the setiferous organ or sculpture of the integument called "sensory pit" by Grigarick \& Schuster (1980) in the shallow groove on the inferior surface, which is observed by SEM in detail in this study. This organ comprises basically several setiferous units in a longitudinal lines on the internal side, and each unit is composed of a group of pores and a suberect seta. This basic structure and its modifications of the sensory pit are generally observed in some groups of Euplectinae and Batrisinae. This sensory pit is supposedly a trace of the evolutionary event that the subfamily Batrisinae are derived from a certain group of the subfamily Euplectinae.

This setiferous structure is completely absent or rudimentary in Batrisoplisus (Fig. 64A). Many pores densely arise and suberect setae are arranged at short distances in Batriscenellus (Fig. 64B, C). This organ has many short setae around the pores in Batriscenaulax and Physomerinus (Fig. 65A-E). In three species of Cratna examined, the basal part of this organ is similar to that in Batriscenellus, but each unit of the apical part bears a characteristic suberectseta, which is distinctly larger than those of basal units (Fig. 64D, E). This seta is longer and bolder than the around normal hair, and branched complexly, each branch of which is short and clavate (Fig. 64F, G).

The pores and the suberect setae are also observed in some species of the out-groups, for example Batrisodes (Excavodes) dorsalis (Fig. 66F). Then, the short setae surrounding the pores and the suberect setae are considered to be an autapomorphy of Physomerinus + Batriscenaulax because of the absence in the out-groups. Although the branched long setae uniquely observed in Cratna in the BC, the same character arises in some species of the division II of Batrisina (Batrisodes? quinquesulcatus, Batrisodellus risor, etc.). Such type of the setae may have been evolved at the genus Cratna and some outgroups in parallel.

\subsubsection{Setiferous structure of tibiae (Figs. 38-40)}

Through the observation by SEM, the tibia has the following five sorts of setae at most. First, the normal and pointed setae which are dense on the basal part of the tibia sparser apically; second, only 
one long and slender seta borne at the base of the ctenidia on the apex of each tibia. This is probably a kind of sensory organ, but it is very similar to the normal hair in structure; third, spatulate setae abundant on the apical part of the tibia, which are as bold as the normal hairs at the basal part, and are broadened apically and flattened or shallowly excavated; fourth, ctenidia arranged around the apex and live to ten in number, each ctenidium round at tip, and shorter and apparently bolder than the other sorts of setae; fifth, a group of secretory setae formed into pencil or spur, each seta is truncate or spatulate, and twisted at the apex.

The first four sorts of setae are present on almost all the tibiae in the $\mathrm{BC}$, but the last secretory setae are characteristic to the male of the four genera Batriscenaulax, Physomerinus, Arthromelodes and Batrisceniola. This type of seta is treated in the paragraph 4.3.2.

\subsubsection{Brush-like organ of seventh abdominal tergite (Fig. 67A-C)}

In both sexes of Batrisceniola, the seventh abdominal tergite bears a brush comprising of several short setae of round head. This is a good autapomorphy for this genus.

\subsubsection{Spatulate setae in the concavity of integument (Fig. 67D-G)}

The spatulate setae arise in the concavity of the integument, for instance, on the lateral cavities of the abdominal segment in many species. They are observed in a line in the outer dorsal sulci of the elytra and the lateral sulci of the pronotum in Physomerinus hasegawai and Cratna abdominalis (Fig. 67E, F), and are also present in the T-shaped sulcus of the frons in Cratna abdominalis (Fig. 67G).

Such setae are found in some species of the out-groups in parallel, for example, Grigarick \& Schuster (1980) showed this type of setae in the Nearctic Euplectinae. These setae are various in shape and position, and consequently difficult to evaluate the phylogenetic importance.

\subsection{Sexual Patch}

"Sexual patch" indicates a patch of the secretory organ and the accompanied structures occurred in the male and often containing secretory setae. It shows the complex appearance in many cases and is important for the practical taxonomy and the phylogeny of the BC.

\subsubsection{Position and macrostructure of the sexual patch}

The sexual patch occurs in the various position of the integument having the various macrostructures. This patch can be classified into the types $\mathrm{Al}$ to $\mathrm{A} 3$.

Al. Setiferous patch or acinous patch (S): the flattened area uniformly covered with many secretory setae or acinous glands.

A2. Excavation with setae (E): the large excavation containing a certain sort of secretory setae or pores.

A3. Fringe (F) and trichome (T): the brush-like structure consisting of several bold hairs or secretory setae, lined with setae $(\mathbf{F})$ or pencillate at a point $(\mathbf{T})$.

Furthermore, these structures are located and arranged as in the following B1 to B3:

B1. Siie structure above the median line (s). 
Table 3-9. Position, arrangement and macrostructure of the sexual patch in each species of the Batri

\begin{tabular}{|c|c|c|c|}
\hline species/position & $8 \mathrm{~A}$ & $9 \mathrm{~A}$ & MS \\
\hline \multicolumn{4}{|l|}{ Batrisoplisus } \\
\hline antenna nodiform type 14 spp.* & - & $(S+E) p$ & 一 \\
\hline \multicolumn{4}{|l|}{ B. torticornis-group } \\
\hline antenna nodiform type $2 \mathrm{spp}$. & $(S+E) p$ & - & $\mathrm{SC}$ \\
\hline B. constrictus & - & $\rightarrow$ & $S C$ \\
\hline antenna moniliform type 5 spp.** & - & 一 & 一 \\
\hline
\end{tabular}

*: B. galloisi, venustus and raffrayi-groups except for $\boldsymbol{B}$. coiffaiti.

**: B. monostatos and uroceratus-groups.

\begin{tabular}{lcccc}
\hline species/positions & MS & HF & 5T & 6T \\
\hline $\begin{array}{c}\text { Batriscenellus } \\
\text { Subgenus Batriscenellus 7 spp. }\end{array}$ & - & - & Fs + Sc & Es \\
B. transformis & - & - & Es + Sc & Es \\
B. similis etc. ${ }^{*}$ & SC & - & Es & SS \\
B. orientalis etc. ${ }^{*}$ & SC & - & SP & - \\
B.uenoi & - & &
\end{tabular}

*: B. similis and $\boldsymbol{B}$. shiranui.

**: B. orientali, ohishii, insulicola, pilosellus and sakaii.

8A-10A: dth-10th antennal segment; F: frons; MS: metasternum; EL: elytra; FT: fore tibia; MF: mid 
socenus complex.

species/positions

Physomerinus 3 spp.

Batriscenaulax6 spp.

B. kleinzach

Cratna

C. abdominalis

C. sp.

EL FT MF HF 4 T

$-\mathrm{Tp} \quad-\quad \mathrm{Ep}-$

$-\mathrm{Tp} \quad-\quad-\quad \mathrm{Es}+\mathrm{Sc}$

$\mathrm{Sp} \quad \mathrm{TP} \quad \mathrm{Sp} \quad \mathrm{Sp} \quad \mathrm{Es}+\mathrm{Sc}$

\begin{tabular}{llllllllll}
\hline species/positions & $9 \mathrm{~A}$ & $10 \mathrm{~A}$ & $\mathrm{~F}$ & $\mathrm{HF}$ & $\mathrm{HT}$ & $4 \mathrm{~T}$ & $7 \mathrm{~T}$ \\
\hline
\end{tabular}

\section{Arthromelodes}

\section{A. giganteus}

A. punctifrons, etc.*

A. thysanoventris, etc. ${ }^{* *}$

A. mercurius, etc.*

A dilatatus, etc. $* * * *$

\section{Batrisceniola}

B. semipunctulata

B. dissimilis and hiranoi
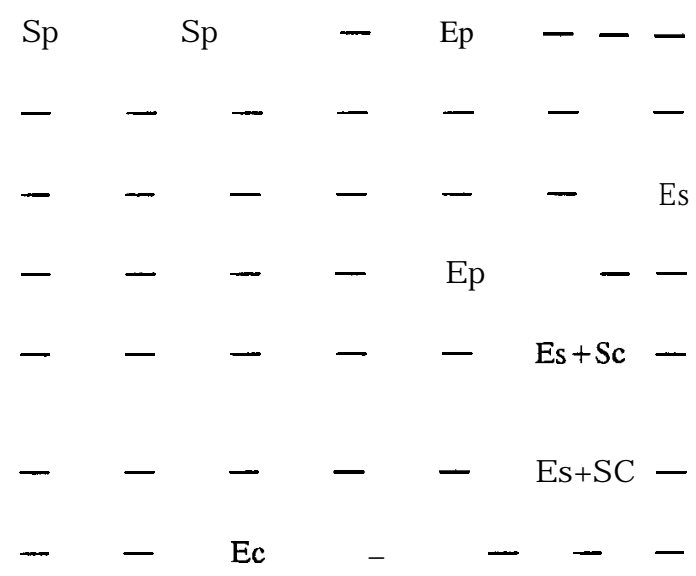

* : A. punctifrons, pilicollis küensis and gyoja.

**: A. thysanoventris and corniventris.

***: A. mercurius, loebli and hikosanus.

****: A. dilatatus, sinuatipes, aizuanus, saikaiensis and cruciter.

femur; HF: hind femur; HT: hind tibia; $4 \mathrm{~T}-\mathrm{TT}$ : 4 th to 7 th abdominal tergite. 


\section{B2. Coupled structures both located on the sides of the segment (c).}

\section{B3. A pair of structures located on the paired organs or appendages in each (p).}

These positions and the macrostructure of the sexual patch in all species of the BC from Japan are shown in the Table 3-9.

The sexual patch varies in the position and macrostructure within not only the $\mathrm{BC}$ but in some monophyletic taxa in the out-groups. Some arise similarly on the homologous organ among the distantly related taxa, for instance the fourth abdominal tergites of Batriscenaulax, Cratna sp., Batrisceniola semipunctulata, Arthromelodes dilatatus and the allied species. The sexual patches appear on the same position and with the same macrostructure, but they can be often classified into many character states. Hence, the position or macrostructure itself should not be identified as a single character state.

Additionally, the species with and without sexual patch are often present within the same genus or species-group, for example, the torticornis-group of the genus Batrisoplisus contains B. constrictus without secretory organ in the antenna and two species with complicate sexual patches. These phenomena are also observed generally in Batrisoplisus, Batriscenellus, typically in Cratna, and Arthromelodes. Therefore, any genus cannot be defined by the macrostructure and position of the sexual patch.

\subsubsection{Secretory setae and the related structure of the sexual patch}

The sexual patch accompanies a secretory organ containing the secretory setae, pores of gland or acinous gland. It differs apparently from the non-sexual secretory organ treated in the paragraph 4.2. or that of the myrmecophilous species. Such sexual patch is widely distributed in Coleoptera shown by Faustini and Halstead(1982), etc. The secretory setae in the sexual patch are varied in structure and size. In some cases, several sorts of setae arise within the sexual patch of one species. The form, the number and the position of the setae are strictly specific. The structure of the secretory setae and the related structure are classified as in the following $\mathrm{Cl}$ to $\mathrm{C4}$ for the convenience in this study:

Cl. Subtubular seta (A): the more or less tubular seta with a pore at the center. This seta consists of a basal socket and an apical lobe. The basal socket is ring-shaped or tubular with modifications as a concaved ringed at the base (Physomerinus schenklingi - Fig. 84A) or a tapering projection (Batriscenellus kujumontanus - Fig. 73F, etc. ). The apical lobe is slender, rounded at the apex and shoehorn-shaped or semitubular in many cases. It is broadened at the basal part and sharpened apically in Batriscenellus uenoi (Fig. 81A), and divided into three pieces in B. nodulifer (Fig. 76F).

C2. N on tubular seta (B): the seta pointed apically without tubular socket, and accompanies one or a few pores at the base, but the surface structure is various. In some species, it is striate longitudinally as in the normal hair, but usually bolder than the normal hair.

C3. Acinous gland (C): the granular area without pore or with very minute pores. The glands of this type are usually grouped together to form a granular patch, which is called the acinous patch in this study. This is observed on the ninth segment of the nodiform antenna of Batrisoplisus (Fig. 70A-C) and on both sides of the fourth abdominal tergite in Arthromelodes crucifer (Fig. 99F).

C4. Pore and secretory pit (P): the opening of the gland without seta. The opening of this type is uncommon in the secretory gland and observed on the hind femur of Arthromelodes giganteus (Fig. 93C, D) and the sixth abdominal tergite of the Batriscenellus nodulifer (Fig. 76G). In all species of Batriscenaulax, the pores are crowded to form some patches each surrounded by the other type of setae, which are located in the median concavity of the sexual patch on the fourth abdominal segment (Figs. 
87C, F, 88B, E, 91B, C).

Furthermore, secondary structures formed by a kind of the setae or the openings of the glands are denoted as in the following D1-4:

D1. Filament (M): one or a few pairs of the bold setae or the supporting structure of the small setae locating at the central part of the sexual patch.

D2 Setiferous patch and acinous patch $(\mathbf{P})$ : a certain area where a kind of setae or acinous glands are crowded.

D3. Fringe (F) and trichome (T): the same structure as A3 in the foregoing paragraph 4.3.1.

D4. The solitary seta and the sparse setae are denoted by the number of the setae in this study.

Combining the $\mathrm{Cl}-4$ and $\mathrm{Dl}-4$, the sorts and the secondary structures of the setae and glands are shown in the Table 3-10.

The sexual patches had evolved into the similar forms in parallel probably for the function as sensory or secretory organ, because the similar structures occur in the distant groups or on the non-homologous organs. Most of these non-homologous characters are certified by the discordance of their positions and types of the setae. The characters of Nos. 432-1-39 are proposed to be autapomorphic, the identity of these apomorphic characters is verified by the conformities of their positions and types of the setae of the sexual patch on a segment. 
Table 3-10. Position and structures of the setae and secretory organs in species of the Batrisocenus

\begin{tabular}{llll}
\hline \multicolumn{1}{c}{ species } & position & $\begin{array}{l}\text { setae and } \\
\text { secretory organ }\end{array}$ & $\begin{array}{c}\text { Code } \\
\text { apo }\end{array}$ \\
\hline Batrisoplisus & & & \\
B. galloisi & $9 \mathrm{~A}$ & $\mathrm{~A} 2+\mathrm{B} 3+\mathrm{CP}$ & $432-1$ \\
B. venustus & $9 \mathrm{~A}$ & $\mathrm{~A} 2+\mathrm{B} 12+\mathrm{BT}+\mathrm{CP}$ & $432-1$ \\
B. okamotoi & $9 \mathrm{~A}$ & $\mathrm{~A} 2+\mathrm{B} 15+\mathrm{CP}$ & $432-1$ \\
B. raffrayi & $9 \mathrm{~A}$ & $\mathrm{~A} 2+\mathrm{B} 12+\mathrm{B} 12$ & $432-1$ \\
B. torticornis & $8 \mathrm{~A}$ & $\mathrm{AP}+\mathrm{AM}+\mathrm{A} 2+\mathrm{B} 10$ & $432-2$ \\
& $9 \mathrm{~A}$ & $\mathrm{BT}$ & $432-3$ \\
B. constrictus & MS & BP & $432-4$ \\
B. monostatos & MS & BP & $432-4$ \\
& $7 \mathrm{~A}$ & AP & $432-5$ \\
& $8 \mathrm{~A}$ & AP & $432-6$ \\
& $9 \mathrm{~A}$ & & $432-7$
\end{tabular}

\section{Batriscenellus}

\begin{tabular}{|c|c|c|c|}
\hline B. kujumontanus & $\begin{array}{l}5 \mathrm{~T} \\
6 \mathrm{~T}\end{array}$ & $\begin{array}{l}\mathrm{AP}+\mathrm{BF} \\
\mathrm{AP}+\mathrm{AP}+\mathrm{AT}\end{array}$ & $\begin{array}{l}432-8 \\
432-9\end{array}$ \\
\hline B. fallax & $\begin{array}{l}5 \mathrm{~T} \\
6 \mathrm{~T}\end{array}$ & $\begin{array}{l}\mathrm{AP}+\mathrm{BF} \\
\mathrm{AP}+\mathrm{AP}+\mathrm{AT}\end{array}$ & $\begin{array}{l}432-8 \\
432-9\end{array}$ \\
\hline B. nodulifer & $\begin{array}{l}5 \mathrm{~T} \\
6 \mathrm{~T}\end{array}$ & $\begin{array}{l}\mathrm{AP}+\mathrm{BF} \\
\mathrm{AM}+\mathrm{BM}+\mathrm{BF}+\mathrm{P} 6\end{array}$ & $\begin{array}{l}432-8 \\
432-10\end{array}$ \\
\hline B. transformis & $6 \mathrm{~T}$ & $\mathrm{AM}+\mathrm{AP}+\mathrm{AT}$ & $432-11$ \\
\hline B. similis & $\begin{array}{l}5 \mathrm{~T} \\
6 \mathrm{~T} \\
\mathrm{MS}\end{array}$ & $\begin{array}{l}\mathrm{AP}+\mathrm{BM} \\
\mathrm{AP}+\mathrm{BT}+\mathrm{B} 10 \\
\mathrm{BP}\end{array}$ & $\begin{array}{l}432-12 \\
432-13 \\
432-14\end{array}$ \\
\hline B. ohishii & $\begin{array}{l}5 \mathrm{~T} \\
6 \mathrm{~T} \\
\mathrm{MS}\end{array}$ & $\begin{array}{l}\mathrm{AP} \\
\mathrm{AP} \\
\mathrm{BP}\end{array}$ & $\begin{array}{l}432-15 \\
432-16 \\
432-14\end{array}$ \\
\hline B. pilosellus & $\begin{array}{l}5 \mathrm{~T} \\
6 \mathrm{~T} \\
\mathrm{MS}\end{array}$ & $\begin{array}{l}\mathrm{AP} \\
\mathrm{AP} \\
\mathrm{BP}\end{array}$ & $\begin{array}{l}432-15 \\
432-16 \\
432-14\end{array}$ \\
\hline B. uenoi & $\mathrm{HF}$ & $\mathrm{AP}+\mathrm{AP}$ & $432-17$ \\
\hline
\end{tabular}

\section{Physomerinus}

$\begin{array}{llll}\text { P. pedator } & \mathrm{FT} & \mathrm{BT} & 432-18 \mathrm{a} \\ & \mathrm{MS} & \mathrm{B} 15 & 432-19 \\ & \mathrm{HF} & \mathrm{AP}+\mathrm{AP}+\mathrm{P} 10 & 432-20 \\ \text { P. schenklingi } & \mathrm{FT} & \mathrm{BT} & 432-18 \mathrm{a} \\ & \mathrm{HF} & \mathrm{AP}+\mathrm{B} 6+\mathrm{B} 10+\mathrm{P} 1 & 432-21 \\ \text { P. hasega wai } & \mathrm{FT} & \mathrm{BT} & 432-18 \\ & \mathrm{HF} & \mathrm{A} 4+\mathrm{AP}+\mathrm{B} 8+\mathrm{BT}+\mathrm{P} 2 & 432-22\end{array}$


complex.

\begin{tabular}{|c|c|c|c|}
\hline species & position & $\begin{array}{l}\text { setae and } \\
\text { secretory organ }\end{array}$ & $\begin{array}{l}\text { Code No. of } \\
\text { apomorphy }\end{array}$ \\
\hline
\end{tabular}

\section{Batriscenaulax}

B. longipes

FT

$\begin{array}{ll}\mathrm{BT} & \begin{array}{l}432-18 \mathrm{~b} \\ \mathrm{AP}\end{array}+(\mathrm{BF}+\mathrm{PP}) \\ \mathrm{PP} & +\mathrm{BT}+(\mathrm{BF}+\mathrm{BT}+23\end{array}$

B. furuhatai

FT

$\mathrm{PP})+\mathrm{BM}+\mathrm{BT}$

BT $432-18 \mathrm{~b}$

$\mathrm{AP}+(\mathrm{BF}+\mathrm{PP})+\mathrm{BT}+(\mathrm{BF}+\quad 432-23$

B. kleinzach

FT
EL
MF
HF

BT

AP

$432-18 \mathrm{~b}$

AP

$432-24$

$4 \mathrm{~T}$

$\mathrm{PP})+(\mathrm{B}+\mathrm{P}) \mathrm{M}+\mathrm{BT}$

Arthromelodes

A. giganteus

$\mathrm{FT}$
$8 \mathrm{~A}$
$9 \mathrm{~A}$

HF

BT

AP

$\mathrm{AP}+\mathrm{P} 1$

432-27

$432-28$

$432-29$

$432-30$

A. thysanoventris

BT

BT

432-27

$432-31$

BT

$432-32$

$432-33$

A. mercurius

FT

BT

432-27

BT $432-34$

A. dilatatus

FT

BT

$\mathrm{AP}+\mathrm{BM}+\mathrm{BT}+\mathrm{BT}$

$432-27$

$432-35$

A. saikaiensis

FT

$\begin{array}{ll}\mathrm{BT} & 432-27 \\ \mathrm{AP}+\mathrm{BM}+\mathrm{BT}+\mathrm{BT}+\mathrm{BT} & 432-36\end{array}$

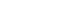

A. cruciter

FT

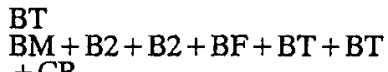

432-27

432-37

\section{Batrisceniola}
B. semipunctulata
FT
$\underset{\mathrm{BT}}{\mathrm{BP}}+\mathrm{BM}+\mathrm{B} 2+\mathrm{B} 2+\mathrm{BT}+\mathrm{BT}+\begin{array}{r}432-27 \\ \mathrm{BT}+ \\ 432-38\end{array}$
B. dissimilis
FT
AT
$432-27$
B. hiranoi
FT
BT
$432-39$
432-24
$432-36$ 


\section{PH YLOGENY}

The phylogenetic relationship of the genera and species of the $\mathrm{BC}$ is inferred from the characters evaluated in the chapter III. In this study, 6 genera, 67 species and 8 subspecies of the BC are treated from Japan, together with four species of the exotic genus Cratna from East Asia for comparison and also information in the literatures are consulted. The characters used for this analysis are tabulated and appended at the end of this chapter.

1. Phylogenetic relationship of Japanese genera of the Batrisocenus complex and systematic position of the genus Cratna (Fig. 103)

The short postgenae and the sulcate elytron with two dorsal foveae used as the key characters of the BC by Jeanne1 $(1958,1959$, etc.) are not appropriate for their autapomorphy as mentioned already (1.1.1., 2.2.1.). The apomorphic characters supporting the monophyly of the $\mathrm{BC}$ are the U-shaped lateral sulci and the transverse sulcus of the pronotum (2.1.1.) and the male genitalia with a distinct dorsal apophysis (3.3.2.). The relatively large seventh abdominal segment (3.1.3.) is proposed also an autapomorphy of the BC. But every autapomorphic character supporting the monophyly of the BC includes some problems about the homology or polarity as discussed in the foregoing chapter. As a result of the cladistic analysis, this monophyletic group is divided into the following five monophyletic subgroups: The genus Batrisoplisus, the genus Batrisceoellus, the genus Cratna, the genera Batriscenaulax + Physomerinus and the genera Arthromelodes + Batrisceniola.

The genus Batrisoplisushas many plesiomorphic characters as the well-demarcated abdominal paratergites, but it is a monophyletic group defined by the following two autapomorphic characters, the paired horns in the ventral surface of the cranium (1.1.1.) and the paired small processes between the mesocoxal cavities (2.1.2.). The remaining six genera are regarded as a monophyletic group on these characters, the well-sclerotized ninth abdominal sternite (3.4.1.), the T- or W-shaped genital plate (3.4.2.) and the dorsal apophysis of the male genitalia composed of a single sclerite and membrane (3.3.2.).

Among these six genera, Batriscenellus is defined as a monophyletic group by the first antenna1 segment with a conical setiferous organ (4.2.1.) and by the basally curved dorsal apophysis of the male genitalia (3.3.2.). In my observation, Arthromeluslabiatusand Seiderites affinis also have the same features, thus some species of these genera may join in this monophyletic group. The other five genera are proposed to be monophyletic by the ninth abdominal sternite with a transverse or ovoid membranous part in the female (3.4.1.).

The genus Cratna is a good monophyletic group defined by the elongate maxillary palpus with many long setae (1.2.4.); which also bears three distinct autapomorphic characters, the obliquely truncate projection of the first antennal segment with an apical pore (4.2.1.), the T-shaped frontal sulcus connected with the vertexal ridge (1.1.1.), and the fore femur with long, suberect and branched setae (4.2.3.). This genus is probably most allied to Batriscenaulax in having the similar small male genitalia with a short median lobe and the fourth abdominal segment with two pairs of separated ventromedian foveae, however they are not recognized as autapomorphic. 
The four genera, Batriscenaulax, Physomerinus, Arthromelodes and Batrisceniola are also regarded to form a monophyletic group on two autapomorphic characters, the fore tibia with twisted setae near the apex in the male (4.2.4.), and the female genital plate with a pair of anterolaterally extending long lateral arms to which muscles are inserted (3.4.2.). These four genera are divided into two and two; a group composed of Batriscenaulax and Physomerinus is monophyletic by the fore femur with long and short setae in the ventral surface (4.2.3.) and the spatulate and twisted setae of the fore tibia formed into a pencil (4.2.4.). The other comprising Arthromelodes and Batrisceniola is tentatively defined a monophyletic group by the fore tibia with an apical spur formed by the twisted setae (4.2.4.).

2. Phylogenetic relationship among species-groups, species and subspecies of the genus Batrisoplisus

(Fig. 104)

The endemic genus Batrisoplisus in Japan contains twenty-four species. Twenty-two species of them have been examined in this study excepting $\boldsymbol{B}$. antennatus and $\boldsymbol{B}$. coiffaiti. They are classified into following six species-groups: The uroceratus, monostatos-, torticomis-, raffrayi-, venustus- and galloisigroups.

First, the uroceratus-group is good monophyletic sharing an autapomorphy of the right mandible with a large external projection (1.2.3.) is a good monophyletic group. The four species constitute a sister group to $\boldsymbol{B}$. parallelus in this group on the convex eighth abdominal tergite in the female (3.1.4.). Another sister group comprising $\boldsymbol{B}$. uroceratus and $\boldsymbol{B}$. inermis is characteristic in having the more advanced apomorphic characters, the nodulate or conically projected eighth tergite in the femele (3.1.4.), the fore tibia with a mucro (2.3.4.), and the mid trochanter with a curved spine in the male. The two subspecies of $\boldsymbol{B}$. uroceratus are so similar to each other on the conical projection of the eighth abdominal tergite in the female and the long mucro of the fore tibia in the male.

Second, the monostatos-group contains one species, B. monostatos. This group is defined by the fifth abdominal sternite with a posteromedian ventral process in the male, but its cladistic position among those species-groups is unsettled.

Third, the torticornis-group containing three species is regarded as monophyletic by the sexual patch on the metasternum (432-4) and by the characteristic male genitalia composed of a rectangular basal bulb and a dorsal apophysis, the latter consists of three sclerites. In this species-group, B. torticor$\boldsymbol{n i s}$ and $\boldsymbol{B}$. tamino are closely related in having the sexual patch on eighth to ninth antennal segments (432-2, 432-3). B. constrictus has sister relationship with these two species on the absence of distinct sexual patch in the antenna.

The remaining three species-groups and probably B. antennatus are recognized as monophyletic by the sexual patch on the ninth antennal segment in the male (432-1). The cladistic relationship among this clade and the other three species-groups mentioned above is indefinite. The raffrayi-group is a monophyletic group containing three species (B. coiffaiti has not been examined), and characterized by the externally expanded ninth antennal segment in the male and the fourth abdominal sternite with a pair of ventral processes in the male. Its phylogenetic relationship is uncertain. The venustus-group comprising six species is tentatively regarded monophyletic supported by an autapomorphy, the fourth abdominal sternite with a posteromedian ventral process. This character is also shared with $\boldsymbol{B}$. parallefusof the uroceratus-group. This disagreement of the apomorphic character must be regarded as a parallelism from the viewpoint of parsimony, i. e. this apomorphic character is antagonistic to the two 
autapomorphic characters, the right mandible of the uroceratus-group and the ninth antennal segment of the sister group formed from the three species-groups. Within the venustus-group, the phylogenetic relationship among the species is not settled. The galloisi-group is characterized by the absence of the ventral process in the fourth abdominal sternite in the male, so this group may be paraphyletic containing live species of the undecided phylogenetic position.

3. Phylogenetic relationship among subgenera, species and subspecies of the genus Batriscenellus (Fig. 105)

The genus Batriscenellus contains 4 subgenera, 16 species and 1 subspecies and all of them is examined in the present study. This genus has been reported from Japan and North Korea, but may possibly be a synonym of Arthromelus or Batrisiella. At least some species described in Arthromelus, Batrisiella and Batrisocenus (sensu Raffray) may belong to Batriscenellus. Each of four subgenera has been represented by a monophyletic group, but their phylogenetic relationships are uncertain. The phylogenetic relationship among the species is partly hypothesized by the sort and arrangement of the secretory setae of the sexual patch as mentioned in the foregoing chapter (4.3.2.), etc.

The subgenus Batriscenellus composed of 8 species is defined by the autapomorphic character of the number 432-8 in the foregoing chapter, namely the fifth abdominal segment with two sorts of secretory setae. The seven species in this subgenus excluding $\boldsymbol{B}$. nodulifer constructs a sister group welldefined by the two autapomorphic characters, one of which is numbered 432-9, the other is the seventh to eighth abdominal sternites with a pair of longitudinal carinae. On the other hand, B. nodulifer is characteristic by the sexual patch on the sixth abdominal segment of the number 432-10. In the remaining seven species, B. kujumontanus and $\boldsymbol{B}$. fragilis are regarded as monophyletic by the shallow median depression on the sixth to seventh abdominal tergites. The other five species are paraphyletic and their phylogenetic relationships are undecided.

The subgenus Scaioscenellus described by Jeanne1 constructs a monophyletic group well-defmed by the sexual patch of the metasternum (432-14). In this subgenus, seven component species are classified into the group whether the fifth abdominal tergite is concave or not. The former group including $\boldsymbol{B}$. similis and $\boldsymbol{B}$. shiranui is regarded monophyletic by the autapomorphies of the sexual patches numbered 432-12 and 432-13. The rest of this subgenus have the sexual patch formed of a sort of the secretory setae, and are tentatively assumed monophyletic, because the character state of the sexual patch with many sorts of setae is possibly evolved from that with one sort $(432-15,432-16)$; in this case, the remaining live species may be invalid as a monophyletic group.

The subgenera Nipponoscenellus and Batriscenellinus each containing one species are neither closely related to the other clades. The genus Nipponoscenellus is characterized by the posteroventrally projected conical spine at the posterior end of the metasternum in the male (2.1.3.) and the sexual patch on the sixth abdominal tergite (432-11). The subgenus Batriscenellinus is different from the other subgenera by the sexual patch on the hind femur (432-17).

4. Phylogenetic relationship among species and subspecies of the genera Batriscenaulax, Physomerinus,

Arthromelodes and Batrisceniola (Fig. 106)

The genus Batriscenaulaxis endemic to Japan, consisting of seven species and two subspecies. Excepting one species, B. puncticollis unknown to me, the whole of this genus is regarded as a monophy- 
letic group supported by the character state of the sexual patch numbered 432-23. The shape of the secretory setae on the fore tibia is also characteristic to this genus (432-18b). There are some apomorphic characters each specific to one species, B. kleinzach, for instance, the characteristic sexual patch in the states numbered $432-24,432-25$ and $432-26$, but autapomorphic character for the relationship of the species is not found.

The genus Physomerinus contains three species from Japan and Taiwan and the generic type-species in Indochina but the type species was not examined in this study. According to the original description by Shaufuss (1877) and the redescription by Jeanne1 (1952), the type species of this genus is distant from the Japanese species on the structure of the male genitalia, etc. Concerning the three Japanese species, their monophyly is evident by the very slender and bent dorsal apophysis of the male genitalia, but their phylogenetic relationships within this sister group are not fixed.

By comparing the type species of the genus Arthromelodes, A. carieiwith Pseudobatriscenus dilatatus and allied Japanese species, they all should be grouped into one genus Arthromelodes. The species in this genus have not any evident autapomorphy, therefore they may be paraphyletic in disregard of their similarities on morphological and biological features. In this genus, A. thysanoventris and A. corniventris have close sister relationship characterized by the sexual patch (432-31, 432-32, 432-33); $\boldsymbol{A}$. mercurius, A. hikosanus and A. loebli constitute monophyletic group by 432-34 in the same way as above; $\boldsymbol{A}$. dilatatus containing four subspecies is also monophyletic by the characteristic lateral lobe of the fourth abdominal segment. Five species each having a large concavity and a pair of setiferous patch on the fourth abdominal segment are different from each other in the sorts and arrangement of the secretory setae, therefore their phylogenetic relationships cannot be inferred. Remaining five species without abdominal sexual patch are also uncertained for their phylogenetic relationships.

The genus Batrisceniola is a monophyletic group well-defmed by the seventh abdominal tergite with a brush-like organ in both sexes (4.2.5.). Within the component three species, B. dissimilis and $\boldsymbol{B}$. hiranoi are similar species sharing the frontal sexual patch numbered 432-39. B. semipunctulata is distant from them by the abdominal sexual patch named 432-38, but evidently belongs to this genus by having the brush-like organ on the seventh abdominal segment and the similar male genitalia. 
Appendix 1: Plesiomorphy and apomorphy of the characters used for a cladistic analysis of the Batrisoce-

\begin{tabular}{ll}
\hline Plesiomorphy & Apomorphy \\
\hline
\end{tabular}

1. cranium without horn

2. frons with a transverse sulcus

3. 9th antennal segment rounded rounded laterally in male

4. right mandible normal

5. maxillary palpus short

6. pronotum with longitudinal sulci

7. mesosternum normal

8. metasternum truncate or notched at posterior end

9. fore tibia without mucro

10. 4th tergite without lateral lobe in male

11. 4th stemite without ventral process

12. 5th stemite without ventral process

13. 6 th to 7 th tergites almost flat in median part

14. 7th tergite normal

15. 7 th to 8 th sternites without carinae

16. 8 th tergite slightly convex in female

17. male genitalia with a basally rounded basal bulb

18. male genitalia without distinct dorsal apophysis

19. dorsal apophysis composed of 2 sclerites 19a. dorsal apophysis composed of 3 sclerites

20. dorsal apophysis composed of 2 sclerites 21a. dorsal apophysis formed from a single sclerite and

21. dorsal apophysis erected on basal bulb

22. dorsal apophysis broadened at base

23. 9th sternite almost membranous in female

24. genital plate membranous membrane

\section{HEAD}

1a. cranium with a pair of horn on both sides of maxillae

2a. frons with a T-shaped sulcus

3a. 9th antennal segment expanded laterally in male

4a. right mandible with a large external projection

5a. maxillary palpus elongate with many long setae

\section{THORAX}

6a. pronotum with a pair of U-shaped and a transverse sulci

7a. mesosternum with a pair of small processes between mesocoxal cavities

8a. metasternum with a conical spine at posterior end in male

9a. fore tibia with a mucro at apex in male

$9 \mathrm{~b}$. fore tibia with a long mucro in male

\section{ABDOMEN}

10a. 4th tergite with a pair of lateral lobes in male 1la. 4th sternite with a pair of ventral processes in mate 1lb. 4th stemite with a median ventral process in male 12a. 5th sternite with a median ventral process in male 13a. 6th to 7 th tergites each depressed in median part

14a. 7th tergite distinctly longer than 6th

15a. 7th to 8th sternite with a pair of longitudinal carinae

17a. 8th tergite distinctly convex in female

16b. 8th tergite nodulate in female

16c. 8th tergite conically projected in female

17a. male genitalia with a rectangular basal bulb

18a. male genitalia with a distinct dorsal apophysis

21a. dorsal apophysis curved at basal part

22a. dorsal apophysis very slender and bent internally

23a. 9th sternite well-sclerotized in female

23b. 9th sternite with an ovoid or transverse membranous part

24a. genital plate well-sclerotized, $\mathrm{T}$ - or $\mathrm{W}$-shaped

24b. genital plate with a pair of anterolaterally extending lateral arms 


Plesiomorphy Apomorphy

\section{SETIFEROUS STRUCTURE}

25. 1st antennal segment without setiferous 25a. lst antennal segment with a conical setiferous organ organ

26. 1st antennal roundly expanded anterolaterally

26a. 1st antennal segment projected anterolaterally, truncate and with a pore at apex

27. fore femur with pores and long setae

27a. fore femur with pores, short and long setae

28. 7th abdominal tergite without brush-like $28 \mathrm{a}$. 7th abdominal tergite with a brush-like organ organ

29. frons without sexual patch

30. 8th to 9 th antennal segments without sexual patch

31. 9th antennal segment without sexual patch as 432-1

32. metasternum without setiferous patch on middle part

33. metastemum without setiferous patch between metacoxae

34. fore tibia without secretory setae

35. hind femur without sexual patch

36. hind tibia slender

37. 4th abdominal tergite without sexual patch as 432-23

38. 5th abdominal tergite without sexual patch as $432-12$

39. 5th abdominal tergite without sexual patch as $432-8$

40. 5th to 6 th abdominal tergite without sexual patch as $432-15$ nor $432-16$

41. 5th to 7 th abdominal tergite without sexual patch as $432-31,432-32$ nor 432-33

42. 6th abdominal tergite without sexual patch as 432-9

43. 6th abdominal tergite without sexual patch as $432-11$

29a. frons with a pair of deep excavations containing secretory setae (432-39)

30a. 8th to 9th antennal segments with sexual patch (432-2, 432-3)

31a. 9th antennal segment with sexual patch (432-1)

32a. metastemum with setiferous patch on middle part (432-4)

33a. metastemum with setiferous patch between metacoxae (432-14)

34a. fore tibia with a pencil composed of twisted setae near apex

34b. fore tibia with an apical spur formed from twisted setae $(432-27)$

35a. hind femur with sexual patch (432-17)

36a. hind tibia swollen, with an oblique groove and secretory setae (432-34)

37a. 4th abdominal tergite with sexual patch (432-23)

38a. 5th abdominal tergite with a shallow concavity and secretory setae (432-12)

39a. 5th abdominal tergite with a friie of bold setae and a pair of setiferous patches (432-8)

40a. 5th to 6th abdominal tergite covered with a sort of secretory setae (432-15, 432-16)

43a. 5th to 6th abdominal tergite with bold setae; 7 th with an excavation, a nodule and bold setae (432-31, 432-32, 432-33)

44a. 6th abdominal tergite with a semihmar excavation including secretory setae (432-9)

45a. 6th abdominal tergite with a transverse excavation and a pair of setiferous patches (432-11) 
Appendir 2: Charactermatrixusedfor a cladistis analysis of the Batrisocenus complex.

\begin{tabular}{|c|c|c|c|c|c|c|c|c|c|c|c|c|c|c|c|c|c|c|}
\hline species $\backslash$ No. of character & 1 & 2 & 3 & 4 & 5 & 6 & 7 & 8 & 9 & & & & 13 & & & & 171819 & 19202 \\
\hline \multicolumn{19}{|l|}{ Batrisoplisus } \\
\hline sagamianus & 1 & 0 & 0 & 0 & 0 & 1 & 1 & 0 & 0 & 0 & 0 & 0 & 0 & 1 & 0 & 0 & $\begin{array}{lll}0 & 1 & 0\end{array}$ & 00 \\
\hline galloisi & 1 & 0 & 0 & 0 & 0 & 1 & 1 & 0 & 0 & 0 & 0 & 0 & 0 & 1 & 0 & 0 & $\begin{array}{lll}0 & 1 & 0\end{array}$ & $\begin{array}{lll}0 & 0 & 0\end{array}$ \\
\hline sa wadai & 1 & 0 & 0 & 0 & 0 & 1 & 1 & 0 & 0 & 0 & 0 & 0 & 0 & 1 & 0 & $?$ & $\begin{array}{lll}0 & 1 & 0\end{array}$ & $\begin{array}{llll}0 & 0 & 0 & 0\end{array}$ \\
\hline satsumanus & 1 & 0 & 0 & 0 & 0 & 1 & 1 & 0 & 0 & 0 & 0 & 0 & 0 & 1 & 0 & $?$ & $\begin{array}{lll}0 & 1 & 0\end{array}$ & $\begin{array}{lll}0 & 0 & 0\end{array}$ \\
\hline subtilis & 1 & 0 & 0 & 0 & 0 & 1 & 1 & 0 & 0 & 0 & 0 & 0 & 0 & 1 & 0 & $?$ & $\begin{array}{lll}0 & 1 & 0\end{array}$ & $\begin{array}{llll}0 & 0 & 0 & 0\end{array}$ \\
\hline venustus & 1 & 0 & 0 & 0 & 0 & 1 & 1 & 0 & 0 & 0 & 1 & 0 & 0 & 1 & 0 & 0 & $\begin{array}{lll}0 & 1 & 0\end{array}$ & $\begin{array}{lll}0 & 0 & 0\end{array}$ \\
\hline tenuiformis & 1 & 0 & 0 & 0 & 0 & 1 & 1 & 0 & 0 & 0 & 1 & 0 & 0 & 1 & 0 & 0 & $\begin{array}{lll}0 & 1 & 0\end{array}$ & $\begin{array}{lll}0 & 0 & 0\end{array}$ \\
\hline esakü & 1 & 0 & 0 & 0 & 0 & 1 & 1 & 0 & 0 & 0 & 1 & 0 & 0 & 1 & 0 & $?$ & $\begin{array}{lll}0 & 1 & 0\end{array}$ & $\begin{array}{llll}0 & 0 & 0 & 0\end{array}$ \\
\hline tosanus & 1 & 0 & 0 & 0 & 0 & 1 & 1 & 0 & 0 & 0 & 1 & 0 & 0 & 1 & 0 & 0 & $\begin{array}{lll}0 & 1 & 0\end{array}$ & $\begin{array}{lll}0 & 0 & 0\end{array}$ \\
\hline tanabei & 1 & 0 & 0 & 0 & 0 & 1 & 1 & 0 & 0 & 0 & 1 & 0 & 0 & 1 & 0 & $?$ & $\begin{array}{lll}0 & 1 & 0\end{array}$ & $\begin{array}{llll}0 & 0 & 0 & 0\end{array}$ \\
\hline okamotoi & 1 & 0 & 0 & 0 & 0 & 1 & 1 & 0 & 0 & 0 & 1 & 0 & 0 & 1 & 0 & 0 & $\begin{array}{lll}0 & 1 & 0\end{array}$ & $\begin{array}{lll}0 & 0 & 0\end{array}$ \\
\hline raffrayi & 1 & 0 & 1 & 0 & 0 & 1 & 1 & 0 & 0 & 0 & 2 & 0 & 0 & 1 & 0 & 0 & $\begin{array}{lll}0 & 1 & 0\end{array}$ & $\begin{array}{lll}0 & 0 & 0\end{array}$ \\
\hline amamianus & 1 & 0 & 1 & 0 & 0 & 1 & 1 & 0 & 0 & 0 & 2 & 0 & 0 & 1 & 0 & 0 & $\begin{array}{lll}0 & 1 & 0\end{array}$ & 00 \\
\hline monostatos & 1 & 0 & 0 & 0 & 0 & 1 & 1 & 0 & 0 & 0 & 0 & 1 & 0 & 1 & 0 & 0 & $\begin{array}{lll}0 & 1 & 0\end{array}$ & 00 \\
\hline tortiwrnis & 1 & 0 & 0 & 0 & 0 & 1 & 1 & 0 & 0 & 0 & 0 & 0 & 0 & 1 & 0 & 0 & $\begin{array}{lll}1 & 1 & 1\end{array}$ & $\begin{array}{lll}0 & 0 & 0\end{array}$ \\
\hline tamino & 1 & 0 & 0 & 0 & 0 & 1 & 1 & 0 & 0 & 0 & 0 & 0 & 0 & 1 & 0 & 0 & $\begin{array}{lll}1 & 1 & 1\end{array}$ & $\begin{array}{lll}0 & 0 & 0\end{array}$ \\
\hline constrictus & 1 & 0 & 0 & 0 & 0 & 1 & 1 & 0 & 0 & 0 & 0 & 0 & 0 & 1 & 0 & 0 & $\begin{array}{lll}1 & 1 & 1\end{array}$ & 00 \\
\hline volucaninsulanus & 1 & 0 & 0 & 1 & 0 & 1 & 1 & 0 & 0 & 0 & 0 & 0 & 0 & 1 & 0 & 0 & $\begin{array}{lll}0 & 1 & 0\end{array}$ & 00 \\
\hline uroceratus uroceratus & 1 & 0 & 0 & 1 & 0 & 1 & 1 & 0 & 2 & 0 & 0 & 0 & 0 & 1 & 0 & 3 & $\begin{array}{lll}0 & 1 & 0\end{array}$ & 00 \\
\hline u. brevispinis & 1 & 0 & 0 & 1 & 0 & 1 & 1 & 0 & 2 & 0 & 0 & 0 & 0 & 1 & 0 & 2 & $\begin{array}{lll}0 & 1 & 0\end{array}$ & $\begin{array}{lll}0 & 0 & 0\end{array}$ \\
\hline inermis & 1 & 0 & 0 & 1 & 0 & 1 & 1 & 0 & 1 & 0 & 0 & 0 & 0 & 1 & 0 & 1 & $\begin{array}{lll}0 & 1 & 0\end{array}$ & $\begin{array}{lll}0 & 0 & 0\end{array}$ \\
\hline parallelus & 1 & 0 & 0 & 1 & 0 & 1 & 1 & 0 & 0 & 0 & 0 & 0 & 0 & 1 & 0 & 0 & $\begin{array}{lll}0 & 1 & 0\end{array}$ & $\begin{array}{lll}0 & 0 & 0\end{array}$ \\
\hline \multicolumn{19}{|l|}{ Batriscenellus } \\
\hline japonicus japonicus & 0 & 0 & 0 & 0 & 0 & 1 & 0 & 0 & 0 & 0 & 0 & 0 & 0 & 1 & 1 & ? & $\begin{array}{lll}0 & 1 & 0\end{array}$ & $\begin{array}{lll}1 & 1 & 0\end{array}$ \\
\hline$j$. vicarius & 0 & 0 & 0 & 0 & 0 & 1 & 0 & 0 & 0 & 0 & 0 & 0 & 0 & 1 & 1 & & $\begin{array}{lll}0 & 1 & 0\end{array}$ & $\begin{array}{lll}1 & 1 & 0\end{array}$ \\
\hline punctatus & 0 & 0 & 0 & 0 & 0 & 1 & 0 & 0 & 0 & 0 & 0 & 0 & 0 & 1 & 1 & & $\begin{array}{lll}0 & 1 & 0\end{array}$ & $\begin{array}{lll}1 & 1 & 0\end{array}$ \\
\hline fallax & 0 & 0 & 0 & 0 & 0 & 1 & 0 & 0 & 0 & 0 & 0 & 0 & 0 & 1 & 1 & 0 & $\begin{array}{lll}0 & 1 & 0\end{array}$ & $\begin{array}{lll}1 & 1 & 0\end{array}$ \\
\hline omogensis & 0 & 0 & 0 & 0 & 0 & 1 & 0 & 0 & 0 & 0 & 0 & 0 & 1 & 1 & 1 & ? & $\begin{array}{lll}0 & 1 & 0\end{array}$ & $\begin{array}{lll}1 & 1 & 0\end{array}$ \\
\hline kujumontanus & 0 & 0 & 0 & 0 & 0 & 1 & 0 & 0 & 0 & 0 & 0 & 0 & 1 & 1 & 1 & 0 & $\begin{array}{lll}0 & 1 & 0\end{array}$ & $\begin{array}{lll}1 & 1 & 0\end{array}$ \\
\hline fragilis & 0 & 0 & 0 & 0 & 0 & 1 & 0 & 0 & 0 & 0 & 0 & 0 & 0 & 1 & 1 & $?$ & $\begin{array}{lll}0 & 1 & 0\end{array}$ & 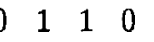 \\
\hline nodulifer & 0 & 0 & 0 & 0 & 0 & 1 & 0 & 0 & 0 & 0 & 0 & 0 & 0 & 1 & 0 & $?$ & $\begin{array}{lll}0 & 1 & 0\end{array}$ & 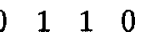 \\
\hline transformis & 0 & 0 & 0 & 0 & 0 & 1 & 0 & 1 & 0 & 0 & 0 & 0 & 0 & 1 & 0 & 0 & $\begin{array}{lll}0 & 1 & 0\end{array}$ & $\begin{array}{lll}1 & 1 & 0\end{array}$ \\
\hline similis & 0 & 0 & 0 & 0 & 0 & 1 & 0 & 0 & 0 & 0 & 0 & 0 & 0 & 1 & 0 & 0 & $\begin{array}{lll}0 & 1 & 0\end{array}$ & $\begin{array}{lll}1 & 1 & 0\end{array}$ \\
\hline shiranui & 0 & 0 & 0 & 0 & 0 & 1 & 0 & 0 & 0 & 0 & 0 & 0 & 0 & 1 & 0 & ? & $\begin{array}{lll}0 & 1 & 0\end{array}$ & $\begin{array}{llll}7 & 1 & 1 & 0\end{array}$ \\
\hline ohishï & 0 & 0 & 0 & 0 & 0 & 1 & 0 & 0 & 0 & 0 & 0 & 0 & 0 & 1 & 0 & 0 & $\begin{array}{lll}0 & 1 & 0\end{array}$ & $\begin{array}{lll}1 & 1 & 0\end{array}$ \\
\hline insulicola & 0 & 0 & 0 & 0 & 0 & 1 & 0 & 0 & 0 & 0 & 0 & 0 & 0 & 1 & 0 & ? & $\begin{array}{lll}0 & 1 & 0\end{array}$ & ) 110 \\
\hline orientalis & 0 & 0 & 0 & 0 & 0 & 1 & 0 & 0 & 0 & 0 & 0 & 0 & 0 & 1 & 0 & $?$ & $\begin{array}{lll}0 & 1 & 0\end{array}$ & ) 1110 \\
\hline pilosellus & 0 & 0 & 0 & 0 & 0 & 1 & 0 & 0 & 0 & 0 & 0 & 0 & 0 & 1 & 0 & 0 & $\begin{array}{lll}0 & 1 & 0\end{array}$ & $\begin{array}{lll}1 & 1 & 0\end{array}$ \\
\hline sakä̈ & 0 & 0 & 0 & 0 & 0 & 1 & 0 & 0 & 0 & 0 & 0 & 0 & 0 & 1 & 0 & 0 & 10 & $\begin{array}{lll}1 & 1 & 0\end{array}$ \\
\hline uenoi & 0 & & & & 0 & & & & & & 0 & & & & & & & $\begin{array}{lll}1 & 1 & 0\end{array}$ \\
\hline
\end{tabular}




\begin{tabular}{|c|c|c|c|c|c|c|c|c|c|c|c|c|c|c|c|c|c|c|c|c|}
\hline species $\backslash$ No. of character & 1 & 2 & 3 & 4 & 5 & 6 & 7 & 8 & 9 & 10 & & 12 & 13 & & 15 & 16 & 17 & & 192021 & 122 \\
\hline \multicolumn{21}{|l|}{ Cratna } \\
\hline abdominalis & $\mathbf{0}$ & $\mathbf{1}$ & $\mathbf{0}$ & $\mathbf{0}$ & $\mathbf{1}$ & $\mathbf{1}$ & $\mathbf{0}$ & $\mathbf{0}$ & $\mathbf{0}$ & $\mathbf{0}$ & $\mathbf{0}$ & $\mathbf{0}$ & $\mathbf{0}$ & & & $\mathbf{0}$ & & 10 & 10 & $\mathbf{0}$ \\
\hline torticornis & $\mathbf{0}$ & $\mathbf{1}$ & $\mathbf{0}$ & $\mathbf{0}$ & $\mathbf{1}$ & $\mathbf{1}$ & $\mathbf{0}$ & $\mathbf{0}$ & $\mathbf{0}$ & $\mathbf{0}$ & 0 & $\mathbf{0}$ & $\mathbf{0}$ & $\mathbf{1}$ & $\mathbf{0}$ & $\mathbf{0}$ & 01 & 10 & 10 & $\mathbf{0}$ \\
\hline sp. 1 & 0 & 1 & 0 & 0 & 1 & 1 & 0 & 0 & 0 & 0 & 0 & 0 & 0 & 1 & 0 & $?$ & 0 & 10 & $\begin{array}{lll}0 & 1 & 0\end{array}$ & $0 \quad 0$ \\
\hline sp. 2 & 0 & 1 & 0 & 0 & 1 & 1 & 0 & 0 & 0 & 0 & 0 & 0 & 0 & 1 & 0 & $?$ & 0 & 10 & $\begin{array}{lll}0 & 1 & 0\end{array}$ & 00 \\
\hline \multicolumn{21}{|l|}{ Physomerinus } \\
\hline pedator & $\mathbf{0}$ & $\mathbf{0}$ & $\mathbf{0}$ & $\mathbf{0}$ & $\mathbf{0}$ & $\mathbf{1}$ & $\mathbf{0}$ & $\mathbf{0}$ & $\mathbf{0}$ & $\mathbf{0}$ & 0 & $\mathbf{0}$ & $\mathbf{0}$ & & $\mathbf{0}$ & $\mathbf{0}$ & & 10 & 10 & $\mathbf{1}$ \\
\hline schenklingi & $\mathbf{0}$ & $\mathbf{0}$ & $\mathbf{0}$ & $\mathbf{0}$ & $\mathbf{0}$ & $\mathbf{1}$ & $\mathbf{0}$ & $\mathbf{0}$ & $\mathbf{0}$ & $\mathbf{0}$ & $\mathbf{0}$ & $\mathbf{0}$ & $\mathbf{0}$ & 1 & $\mathbf{0}$ & $\mathbf{0}$ & & 10 & 10 & 1 \\
\hline hasega wai & $\mathbf{0}$ & $\mathbf{0}$ & $\mathbf{0}$ & $\mathbf{0}$ & $\mathbf{0}$ & 1 & $\mathbf{0}$ & $\mathbf{0}$ & $\mathbf{0}$ & $\mathbf{0}$ & $\mathbf{0}$ & $\mathbf{0}$ & $\mathbf{0}$ & $\mathbf{1}$ & $\mathbf{0}$ & $\mathbf{0}$ & 01 & 10 & 10 & $\mathbf{1}$ \\
\hline \multicolumn{21}{|l|}{ Batriscenaulax } \\
\hline modestus & 0 & 0 & 0 & 0 & $\mathbf{0}$ & 1 & 0 & 0 & 0 & 0 & 0 & 0 & 0 & & 0 & ? & & & & 0 \\
\hline longipes longipes & $\mathbf{0}$ & $\mathbf{0}$ & $\mathbf{0}$ & $\mathbf{0}$ & $\mathbf{0}$ & 1 & $\mathbf{0}$ & $\mathbf{0}$ & $\mathbf{0}$ & $\mathbf{0}$ & $\mathbf{0}$ & $\mathbf{0}$ & $\mathbf{0}$ & 1 & & $\mathbf{0}$ & & 10 & 10 & $\mathbf{0}$ \\
\hline 1. kumaso & $\mathbf{0}$ & $\mathbf{0}$ & $\mathbf{0}$ & $\mathbf{0}$ & $\mathbf{0}$ & $\mathbf{1}$ & $\mathbf{0}$ & $\mathbf{0}$ & $\mathbf{0}$ & $\mathbf{0}$ & 0 & $\mathbf{0}$ & $\mathbf{0}$ & $\mathbf{1}$ & $\mathbf{0}$ & $\mathbf{0}$ & & 10 & 10 & $\mathbf{0}$ \\
\hline 1. hayato & $\mathbf{0}$ & $\mathbf{0}$ & $\mathbf{0}$ & $\mathbf{0}$ & $\mathbf{0}$ & 1 & $\mathbf{0}$ & $\mathbf{0}$ & $\mathbf{0}$ & $\mathbf{0}$ & 0 & $\mathbf{0}$ & $\mathbf{0}$ & $\mathbf{1}$ & $\mathbf{0}$ & $\mathbf{0}$ & & 10 & 10 & $\mathbf{0}$ \\
\hline furuhatai & $\mathbf{0}$ & $\mathbf{0}$ & $\mathbf{0}$ & $\mathbf{0}$ & $\mathbf{0}$ & $\mathbf{1}$ & $\mathbf{0}$ & $\mathbf{0}$ & $\mathbf{0}$ & $\mathbf{0}$ & 0 & $\mathbf{0}$ & $\mathbf{0}$ & $\mathbf{1}$ & $\mathbf{0}$ & $\mathbf{0}$ & & 10 & 10 & $\mathbf{0}$ \\
\hline kleinzach & $\mathbf{0}$ & $\mathbf{0}$ & $\mathbf{0}$ & $\mathbf{0}$ & $\mathbf{0}$ & $\mathbf{1}$ & $\mathbf{0}$ & $\mathbf{0}$ & $\mathbf{0}$ & $\mathbf{0}$ & 0 & $\mathbf{0}$ & $\mathbf{0}$ & 1 & $\mathbf{0}$ & $\mathbf{0}$ & & 10 & 10 & $\mathbf{0}$ \\
\hline kunigamensis & $\mathbf{0}$ & $\mathbf{0}$ & $\mathbf{0}$ & $\mathbf{0}$ & $\mathbf{0}$ & $\mathbf{1}$ & $\mathbf{0}$ & $\mathbf{0}$ & $\mathbf{0}$ & $\mathbf{0}$ & 0 & 0 & $\mathbf{0}$ & 1 & $\mathbf{0}$ & $\mathbf{0}$ & & 10 & 10 & $\mathbf{0}$ \\
\hline nagensis & 0 & 0 & 0 & 0 & 0 & 1 & 0 & 0 & 0 & 0 & 0 & 0 & 0 & 1 & 0 & $?$ & 0 & 10 & $\begin{array}{lll}0 & 1 & 0\end{array}$ & 0 \\
\hline \multicolumn{21}{|l|}{ Arthromelodes } \\
\hline pun\&irons & $\mathbf{0}$ & $\mathbf{0}$ & $\mathbf{0}$ & $\mathbf{0}$ & $\mathbf{0}$ & $\mathbf{1}$ & $\mathbf{0}$ & $\mathbf{0}$ & $\mathbf{0}$ & $\mathbf{0}$ & $\mathbf{0}$ & $\mathbf{0}$ & $\mathbf{0}$ & $\mathbf{1}$ & $\mathbf{0}$ & $\mathbf{0}$ & & 10 & 10 & $\mathbf{0}$ \\
\hline giganteus & $\mathbf{0}$ & $\mathbf{0}$ & $\mathbf{0}$ & $\mathbf{0}$ & $\mathbf{0}$ & $\mathbf{1}$ & $\mathbf{0}$ & $\mathbf{0}$ & $\mathbf{0}$ & $\mathbf{0}$ & 0 & 0 & $\mathbf{0}$ & $\mathbf{1}$ & $\mathbf{0}$ & $\mathbf{0}$ & 01 & 10 & 10 & $\mathbf{0}$ \\
\hline pilicollis & 0 & 0 & 0 & 0 & 0 & 1 & 0 & 0 & 0 & 0 & 0 & 0 & 0 & 1 & 0 & $?$ & & 10 & $\begin{array}{lll}0 & 1 & 0\end{array}$ & 0 \\
\hline küensis & $\mathbf{0}$ & $\mathbf{0}$ & $\mathbf{0}$ & 0 & $\mathbf{0}$ & 1 & o & 0 & 0 & 0 & 0 & 0 & $\mathbf{0}$ & 1 & 0 & 0 & $\begin{array}{ll}0 & 1 \\
0 & 1\end{array}$ & 10 & 10 & 0 \\
\hline gyoja & $\mathbf{0}$ & $\mathbf{0}$ & $\mathbf{0}$ & $\mathbf{0}$ & $\mathbf{0}$ & $\mathbf{1}$ & $\mathbf{0}$ & $\mathbf{0}$ & $\mathbf{0}$ & $\mathbf{0}$ & 0 & 0 & $\mathbf{0}$ & $\mathbf{1}$ & $\mathbf{0}$ & $\mathbf{0}$ & 01 & 10 & 10 & $\mathbf{0}$ \\
\hline thysanoventris & $\mathbf{0}$ & $\mathbf{0}$ & $\mathbf{0}$ & $\mathbf{0}$ & $\mathbf{0}$ & $\mathbf{1}$ & $\mathbf{0}$ & $\mathbf{0}$ & $\mathbf{0}$ & $\mathbf{0}$ & 0 & 0 & $\mathbf{0}$ & $\mathbf{1}$ & $\mathbf{0}$ & $\mathbf{0}$ & 01 & 10 & 10 & $\mathbf{0}$ \\
\hline corniventris & 0 & 0 & 0 & 0 & 0 & 1 & 0 & 0 & 0 & 0 & 0 & 0 & 0 & 1 & 0 & $?$ & & 10 & 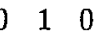 & 0 \\
\hline mercurius & $\mathbf{0}$ & $\mathbf{0}$ & $\mathbf{0}$ & $\mathbf{0}$ & $\mathbf{0}$ & $\mathbf{1}$ & $\mathbf{0}$ & $\mathbf{0}$ & $\mathbf{0}$ & $\mathbf{0}$ & $\mathbf{0}$ & 0 & $\mathbf{0}$ & $\mathbf{1}$ & $\mathbf{0}$ & $\mathbf{0}$ & 01 & 10 & 10 & $\mathbf{0}$ \\
\hline hikosanus & $\mathbf{0}$ & $\mathbf{0}$ & $\mathbf{0}$ & $\mathbf{0}$ & $\mathbf{0}$ & 1 & $\mathbf{0}$ & $\mathbf{0}$ & $\mathbf{0}$ & $\mathbf{0}$ & $\mathbf{0}$ & $\mathbf{0}$ & $\mathbf{0}$ & $\mathbf{1}$ & $\mathbf{0}$ & $\mathbf{0}$ & 01 & 10 & 10 & $\mathbf{0}$ \\
\hline loebli & $\mathbf{0}$ & $\mathbf{0}$ & $\mathbf{0}$ & $\mathbf{0}$ & $\mathbf{0}$ & 1 & $\mathbf{0}$ & $\mathbf{0}$ & $\mathbf{0}$ & $\mathbf{0}$ & 0 & 0 & $\mathbf{0}$ & $\mathbf{1}$ & $\mathbf{0}$ & $\mathbf{0}$ & 01 & 10 & 10 & $\mathbf{0}$ \\
\hline dilatatus daibosatsuanus & 0 & 0 & 0 & 0 & 0 & 1 & 0 & 0 & 0 & 1 & 0 & 0 & 0 & 1 & 0 & ? & 0 & 10 & 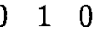 & 0 \\
\hline d. shiranemontanus & 0 & 0 & 0 & 0 & 0 & 1 & 0 & 0 & 0 & 1 & 0 & 0 & 0 & 1 & 0 & ? & 0 & 10 & $\begin{array}{ll}0 & 0\end{array}$ & 0 \\
\hline d. fujimontanus & 0 & 0 & 0 & 0 & 0 & 1 & 0 & 0 & 0 & 1 & 0 & 0 & 0 & 1 & 0 & $?$ & & 10 & 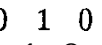 & 0 \\
\hline sinuatipes & $\mathbf{0}$ & $\mathbf{0}$ & $\mathbf{0}$ & $\mathbf{0}$ & $\mathbf{0}$ & 1 & $\mathbf{0}$ & $\mathbf{0}$ & $\mathbf{0}$ & $\mathbf{0}$ & $\mathbf{0}$ & $\mathbf{0}$ & $\mathbf{0}$ & 1 & $\mathbf{0}$ & $\mathbf{0}$ & & 10 & 10 & $\mathbf{0}$ \\
\hline aizuanus & $\mathbf{0}$ & $\mathbf{0}$ & $\mathbf{0}$ & $\mathbf{0}$ & $\mathbf{0}$ & $\mathbf{1}$ & $\mathbf{0}$ & $\mathbf{0}$ & $\mathbf{0}$ & $\mathbf{0}$ & 0 & 0 & $\mathbf{0}$ & 1 & $\mathbf{0}$ & $\mathbf{0}$ & 01 & 10 & 10 & $\mathbf{0}$ \\
\hline saikaiensis & $\mathbf{0}$ & $\mathbf{0}$ & $\mathbf{0}$ & $\mathbf{0}$ & $\mathbf{0}$ & $\mathbf{1}$ & $\mathbf{0}$ & $\mathbf{0}$ & $\mathbf{0}$ & $\mathbf{0}$ & $\mathbf{0}$ & $\mathbf{0}$ & $\mathbf{0}$ & $\mathbf{1}$ & $\mathbf{0}$ & $\mathbf{0}$ & 01 & 10 & 10 & $\mathbf{0}$ \\
\hline crucifer & $\mathbf{0}$ & $\mathbf{0}$ & $\mathbf{0}$ & $\mathbf{0}$ & $\mathbf{0}$ & 1 & $\mathbf{0}$ & $\mathbf{0}$ & $\mathbf{0}$ & $\mathbf{0}$ & 0 & $\mathbf{0}$ & $\mathbf{0}$ & $\mathbf{1}$ & & $\mathbf{0}$ & 01 & 10 & 10 & $\mathbf{0}$ \\
\hline \multicolumn{21}{|l|}{ Batrisceniola } \\
\hline dissimilis & $\mathbf{0}$ & $\mathbf{0}$ & $\mathbf{0}$ & $\mathbf{0}$ & $\mathbf{0}$ & $\mathbf{1}$ & $\mathbf{0}$ & $\mathbf{0}$ & 0 & 0 & 0 & $\mathbf{0}$ & $\mathbf{0}$ & $\mathbf{1}$ & $\mathbf{0}$ & $\mathbf{0}$ & 01 & 10 & 10 & \\
\hline hiranoi & $\mathbf{0}$ & $\mathbf{0}$ & $\mathbf{0}$ & $\mathbf{0}$ & $\mathbf{0}$ & $\mathbf{1}$ & $\mathbf{0}$ & $\mathbf{0}$ & $\mathbf{0}$ & 0 & 0 & 0 & $\mathbf{0}$ & $\mathbf{1}$ & $\mathbf{0}$ & $\mathbf{0}$ & 01 & 10 & 10 & $\mathbf{0}$ \\
\hline semipunctulata & $\mathbf{0}$ & $\mathbf{0}$ & $\mathbf{0}$ & $\mathbf{0}$ & $\mathbf{0}$ & $\mathbf{1}$ & $\mathbf{0}$ & $\mathbf{0}$ & 0 & 0 & $\mathbf{0}$ & 0 & $\mathbf{0}$ & $\mathbf{1}$ & $\mathbf{0}$ & 0 & 01 & 10 & 10 & $\mathbf{0}$ \\
\hline
\end{tabular}




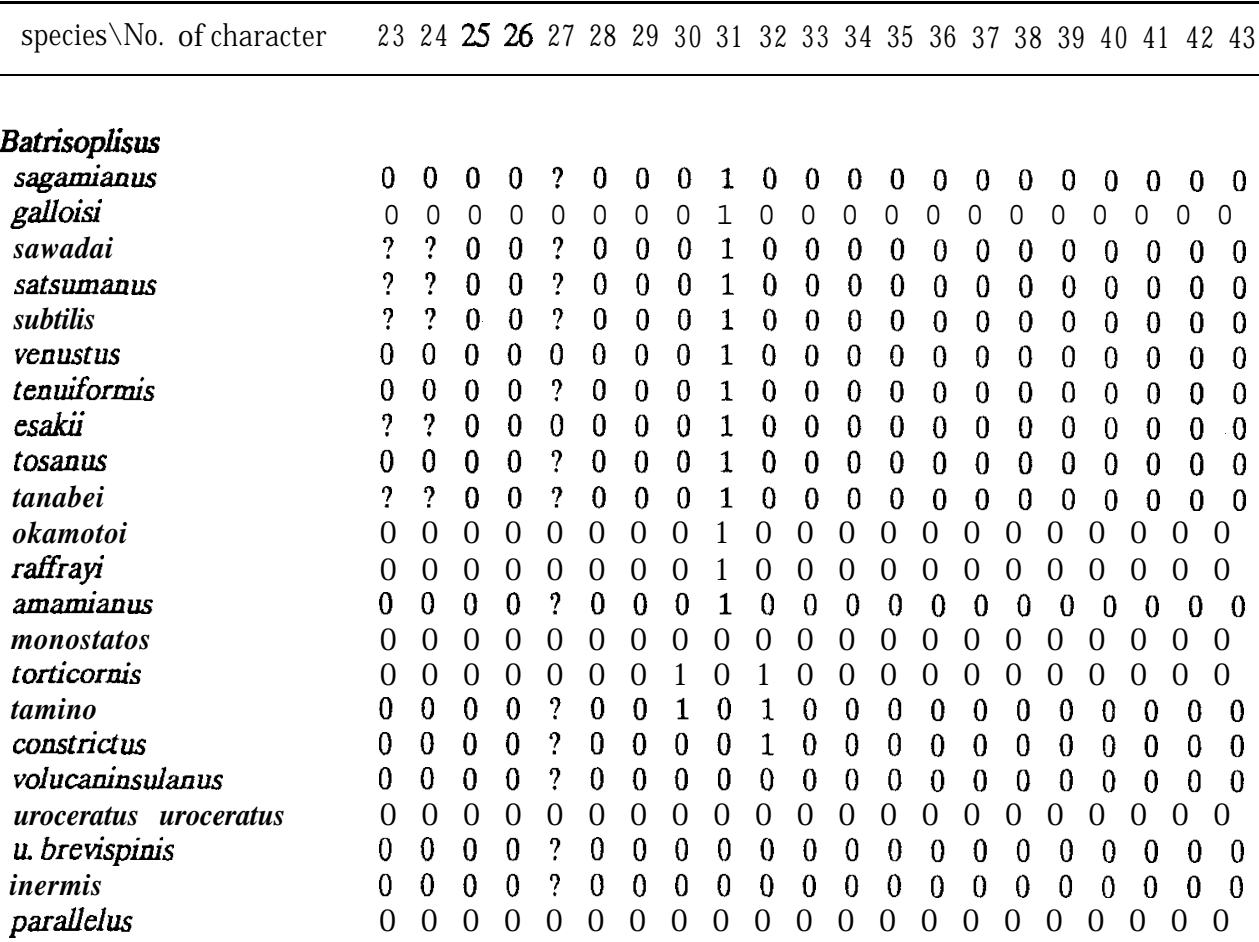

\section{Batriscenellus}

$\begin{array}{llllllllllllllllllllll}\text { japom'cus japonicus } & ? & ? & 1 & 0 & ? & 0 & 0 & 0 & 0 & 0 & 0 & 0 & 0 & 0 & 0 & 0 & 1 & 0 & 0 & 1 & 0 \\ \text { j. vicarius } & 1 & 1 & 1 & 0 & ? & 0 & 0 & 0 & 0 & 0 & 0 & 0 & 0 & 0 & 0 & 0 & 1 & 0 & 0 & 1 & 0 \\ \text { punctatus } & 1 & 1 & 1 & 0 & ? & 0 & 0 & 0 & 0 & 0 & 0 & 0 & 0 & 0 & 0 & 0 & 1 & 0 & 0 & 1 & 0 \\ \text { fallax } & 1 & 1 & 1 & 0 & 0 & 0 & 0 & 0 & 0 & 0 & 0 & 0 & 0 & 0 & 0 & 0 & 1 & 0 & 0 & 1 & 0 \\ \text { omogensis } & ? & ? & 1 & 0 & ? & 0 & 0 & 0 & 0 & 0 & 0 & 0 & 0 & 0 & 0 & 0 & 1 & 0 & 0 & 1 & 0 \\ \text { kujumontanus } & 1 & 1 & 1 & 0 & 0 & 0 & 0 & 0 & 0 & 0 & 0 & 0 & 0 & 0 & 0 & 0 & 1 & 0 & 0 & 1 & 0 \\ \text { fragilis } & ? & ? & 1 & 0 & ? & 0 & 0 & 0 & 0 & 0 & 0 & 0 & 0 & 0 & 0 & 0 & 1 & 0 & 0 & 1 & 0 \\ \text { nodulifer } & ? & ? & 1 & 0 & 0 & 0 & 0 & 0 & 0 & 0 & 0 & 0 & 0 & 0 & 0 & 0 & 1 & 0 & 0 & 0 & 0 \\ \text { transformis } & 1 & 1 & 1 & 0 & 0 & 0 & 0 & 0 & 0 & 0 & 0 & 0 & 0 & 0 & 0 & 0 & 0 & 0 & 0 & 0 & 1 \\ \text { similis } & 1 & 1 & 1 & 0 & 0 & 0 & 0 & 0 & 0 & 0 & 1 & 0 & 0 & 0 & 0 & 1 & 0 & 0 & 0 & 0 & 0 \\ \text { shiranui } & ? & ? & 1 & 0 & ? & 0 & 0 & 0 & 0 & 0 & 1 & 0 & 0 & 0 & 0 & 1 & 0 & 0 & 0 & 0 & 0 \\ \text { ohishii } & 1 & 1 & 1 & 0 & 0 & 0 & 0 & 0 & 0 & 0 & 1 & 0 & 0 & 0 & 0 & 0 & 0 & 1 & 0 & 0 & 0 \\ \text { insulicola } & ? & ? & 1 & 0 & ? & 0 & 0 & 0 & 0 & 0 & 1 & 0 & 0 & 0 & 0 & 0 & 0 & 1 & 0 & 0 & 0 \\ \text { orientalis } & ? & ? & 1 & 0 & ? & 0 & 0 & 0 & 0 & 0 & 1 & 0 & 0 & 0 & 0 & 0 & 0 & 1 & 0 & 0 & 0 \\ \text { pilosellus } & 1 & 1 & 1 & 0 & 0 & 0 & 0 & 0 & 0 & 0 & 1 & 0 & 0 & 0 & 0 & 0 & 0 & 1 & 0 & 0 & 0 \\ \text { sakaii } & 1 & 1 & 1 & 0 & ? & 0 & 0 & 0 & 0 & 0 & 1 & 0 & 0 & 0 & 0 & 0 & 0 & 1 & 0 & 0 & 0 \\ \text { uenoi } & 1 & 1 & 1 & 0 & 0 & 0 & 0 & 0 & 0 & 0 & 0 & 0 & 1 & 0 & 0 & 0 & 0 & 0 & 0 & 0 & 0\end{array}$




\begin{tabular}{|c|c|c|c|c|c|c|c|c|c|c|c|c|c|c|c|c|c|c|c|c|c|}
\hline species $\backslash$ No. of character & 23 & & 25 & 26 & & 28 & & 30 & & & 33 & 34 & & & & & & & & & \\
\hline \multicolumn{22}{|l|}{ Cratna } \\
\hline abdominalis & 2 & & 0 & 1 & 0 & 0 & 0 & 0 & 0 & 0 & 0 & 0 & 0 & 0 & 0 & 0 & & 0 & & & 0 \\
\hline torticornis & 2 & 1 & 0 & 1 & 0 & 0 & 0 & 0 & 0 & 0 & 0 & 0 & 0 & 0 & 0 & 0 & 0 & 0 & & & 0 \\
\hline sp. 1 & ? & $?$ & 0 & 1 & 0 & 0 & 0 & 0 & 0 & 0 & 0 & 0 & 0 & 0 & 0 & 0 & 0 & 0 & 0 & & 0 \\
\hline $\mathrm{sp} .2$ & $?$ & $?$ & 0 & 1 & 0 & 0 & 0 & 0 & 0 & 0 & 0 & 0 & 0 & 0 & 0 & 0 & 0 & 0 & 0 & 0 & 0 \\
\hline \multicolumn{22}{|l|}{ Physomerinus } \\
\hline pedator & 2 & 2 & 0 & 0 & 1 & 0 & 0 & 0 & 0 & 0 & 0 & 1 & 0 & 0 & 0 & 0 & 0 & 0 & 0 & & \\
\hline schenklingi & 2 & 2 & 0 & 0 & 1 & 0 & 0 & 0 & 0 & 0 & 0 & 1 & 0 & 0 & 0 & 0 & 0 & 0 & 0 & & 0 \\
\hline hasega wai & 2 & 2 & 0 & 0 & 1 & 0 & 0 & 0 & 0 & 0 & 0 & 1 & 0 & 0 & 0 & 0 & 0 & 0 & 0 & & 0 \\
\hline \multicolumn{22}{|l|}{ Batrixenaulax } \\
\hline modestus & $?$ & $?$ & 0 & 0 & ? & 0 & 0 & 0 & 0 & 0 & 0 & 1 & 0 & 0 & 1 & 0 & & & & & 0 \\
\hline long\&es longipes & 2 & 2 & 0 & 0 & 1 & 0 & 0 & 0 & 0 & 0 & 0 & 1 & 0 & 0 & 1 & 0 & 0 & & & & 0 \\
\hline L. kumaso & 2 & 2 & 0 & 0 & ? & 0 & 0 & 0 & 0 & 0 & 0 & 1 & 0 & 0 & 1 & 0 & 0 & 0 & 0 & & 0 \\
\hline 1. hayato & 2 & 2 & 0 & 0 & ? & 0 & 0 & 0 & 0 & 0 & 0 & 1 & 0 & 0 & 1 & 0 & 0 & 0 & 0 & & 0 \\
\hline furuhatai & 2 & 2 & 0 & 0 & 1 & 0 & 0 & 0 & 0 & 0 & 0 & 1 & 0 & 0 & 1 & 0 & 0 & 0 & & & 0 \\
\hline kleinzach & 2 & 2 & 0 & 0 & 1 & 0 & 0 & 0 & 0 & 0 & 0 & 1 & 0 & 0 & 1 & 0 & 0 & 0 & & & 0 \\
\hline kunigamensis & 2 & 2 & 0 & 0 & $?$ & 0 & 0 & 0 & 0 & 0 & 0 & 1 & 0 & 0 & 1 & 0 & 0 & 0 & 0 & & 0 \\
\hline nagensis & $?$ & $?$ & 0 & 0 & $?$ & 0 & 0 & 0 & 0 & 0 & 0 & 1 & 0 & 0 & 1 & 0 & 0 & 0 & 0 & 0 & 0 \\
\hline \multicolumn{22}{|l|}{ Arthromelodes } \\
\hline punctifrons & 2 & 2 & 0 & 0 & $?$ & 0 & 0 & 0 & 0 & 0 & 0 & 1 & 0 & 0 & 0 & 0 & 0 & & 0 & & 0 \\
\hline giganteus & 2 & 2 & 0 & 0 & 0 & 0 & 0 & 0 & 0 & 0 & 0 & 1 & 0 & 0 & 0 & 0 & 0 & 0 & 0 & & 0 \\
\hline pilicollis & ? & $?$ & 0 & 0 & ? & 0 & 0 & 0 & 0 & 0 & 0 & 1 & 0 & 0 & 0 & 0 & 0 & 0 & 0 & & 0 \\
\hline kiiensis & 2 & 2 & 0 & 0 & 0 & 0 & 0 & 0 & 0 & 0 & 0 & 1 & 0 & 0 & 0 & 0 & 0 & 0 & 0 & & 0 \\
\hline gyoja & 2 & 2 & 0 & 0 & $?$ & 0 & 0 & 0 & 0 & 0 & 0 & 1 & 0 & 0 & 0 & 0 & 0 & 0 & 0 & 0 & 0 \\
\hline thysanoventris & 2 & 2 & 0 & 0 & 0 & 0 & 0 & 0 & 0 & 0 & 0 & 1 & 0 & 0 & 0 & 0 & 0 & 0 & 0 & & 0 \\
\hline corniventris & $?$ & $?$ & 0 & 0 & $?$ & 0 & 0 & 0 & 0 & 0 & 0 & 1 & 0 & 0 & 0 & 0 & 0 & 0 & 0 & 1 & 0 \\
\hline mercurius & 2 & 2 & 0 & 0 & 0 & 0 & 0 & 0 & 0 & 0 & 0 & 1 & 0 & 1 & 0 & 0 & 0 & 0 & 0 & & 0 \\
\hline hikosanus & 2 & 2 & 0 & 0 & ? & 0 & 0 & 0 & 0 & 0 & 0 & 1 & 0 & 1 & 0 & 0 & 0 & 0 & 0 & 0 & 0 \\
\hline loebli & 2 & 2 & 0 & 0 & ? & 0 & 0 & 0 & 0 & 0 & 0 & 1 & 0 & 1 & 0 & 0 & 0 & 0 & 0 & 0 & 0 \\
\hline dilatatus daibosatsuanus & $?$ & $?$ & 0 & 0 & 0 & 0 & 0 & 0 & 0 & 0 & 0 & 1 & 0 & 0 & 0 & 0 & 0 & 0 & 0 & 0 & 0 \\
\hline d. shiranemontanus & $?$ & ? & 0 & 0 & ? & 0 & 0 & 0 & 0 & 0 & 0 & 1 & 0 & 0 & 0 & 0 & 0 & 0 & 0 & 0 & 0 \\
\hline d. fujimontanus & $?$ & $?$ & 0 & 0 & ? & 0 & 0 & 0 & 0 & 0 & 0 & 1 & 0 & 0 & 0 & 0 & 0 & 0 & 0 & 0 & 0 \\
\hline sinuatipes & $?$ & $?$ & 0 & 0 & $?$ & 0 & 0 & 0 & 0 & 0 & 0 & 1 & 0 & 0 & 0 & 0 & 0 & 0 & 0 & 0 & 0 \\
\hline aizuanus & $?$ & $?$ & 0 & 0 & $?$ & 0 & 0 & 0 & 0 & 0 & 0 & 1 & 0 & 0 & 0 & 0 & 0 & 0 & 0 & 0 & 0 \\
\hline saikaiensis & 2 & 2 & 0 & 0 & 0 & 0 & 0 & 0 & 0 & 0 & 0 & 1 & 0 & 0 & 0 & 0 & 0 & 0 & 0 & 0 & 0 \\
\hline crucifer & 2 & 2 & 0 & 0 & 0 & 0 & 0 & 0 & 0 & 0 & 0 & 1 & 0 & 0 & 0 & 0 & 0 & 0 & 0 & 0 & 0 \\
\hline \multicolumn{22}{|l|}{ Batrisceniola } \\
\hline dissimilis & 2 & 2 & 0 & 0 & 0 & 1 & 1 & 0 & 0 & 0 & 0 & 1 & 0 & 0 & 0 & 0 & 0 & 0 & 0 & 0 & 0 \\
\hline hiranoi & 2 & 2 & 0 & 0 & 0 & 1 & 1 & 0 & 0 & 0 & 0 & 1 & 0 & 0 & 0 & 0 & 0 & 0 & 0 & 0 & 0 \\
\hline semipunctulata & 2 & 2 & 0 & 0 & 0 & 1 & 0 & 0 & 0 & 0 & 0 & 1 & 0 & 0 & 0 & 0 & 0 & 0 & 0 & & 0 \\
\hline
\end{tabular}


S. NOMURA

FIGURES FOR THE CHAPTERS OF GENERAL MORPHOLOGY AND PHYLOGENY

(Figs. 1-106)

Fig. 1. Schemata of cranium.

A-C, Batrisceniola semipunctulata (Raffray).

A, dorsal view.

B, lateral view.

C, ventral view.

D, B. dissimilis (Sharp).

$\mathrm{D}$, internal view. 


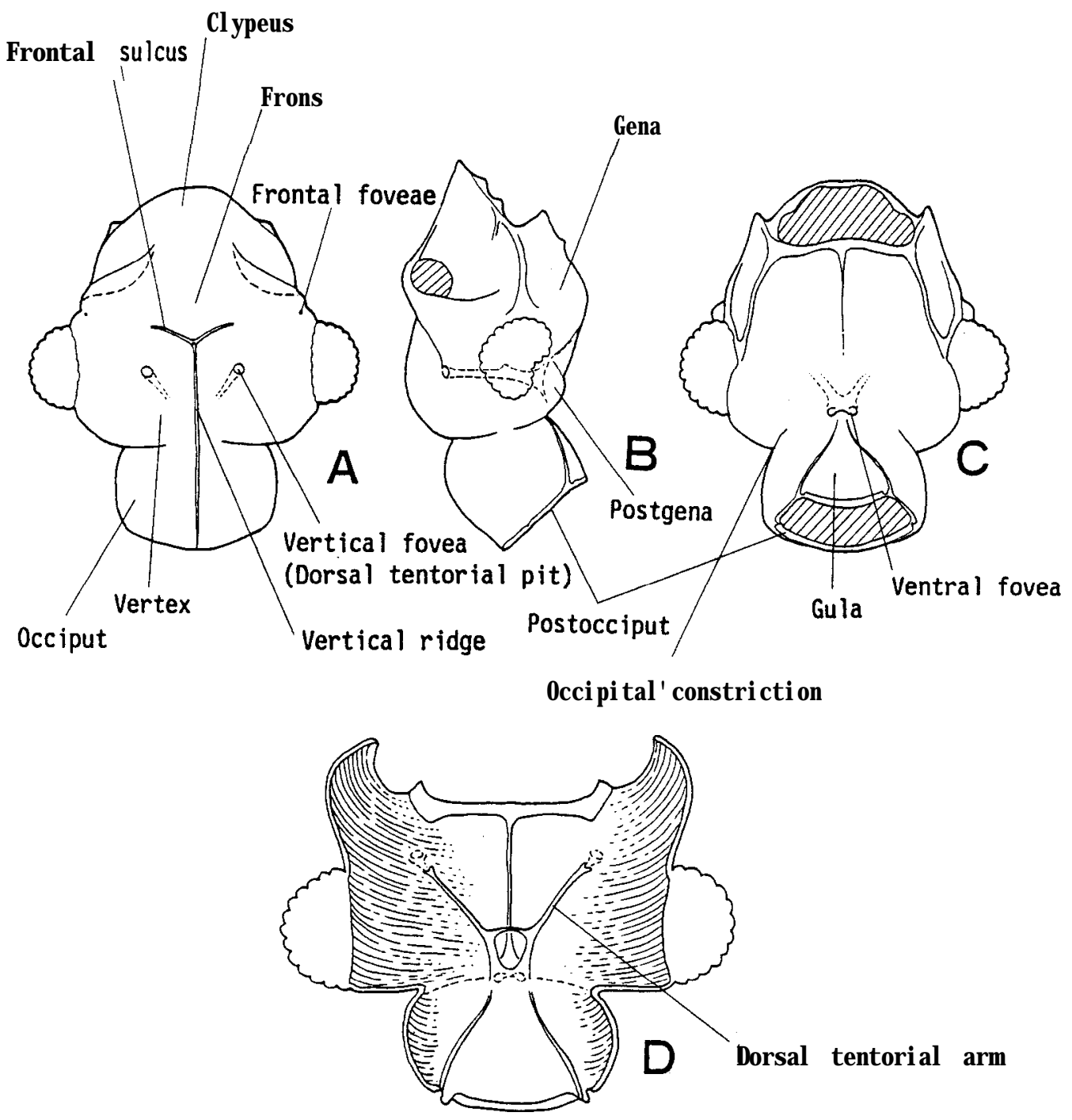


Fig. 2 Heads.

A, lateral view.

$\mathrm{B}$, frontal fovea.

C, D, anteroventral part of cranium.

E, occiput
A, B, Batrisceniola semipunctulata (Raffray).
C, Batrisoplisus parallelus sp. nov.
D, Acetalius dubius Sharp (out-group).
E, Batrisceniola dissimilis (Sharp). 
BATRISOPLISUS AND ITS ALLIES FROM JAPAN
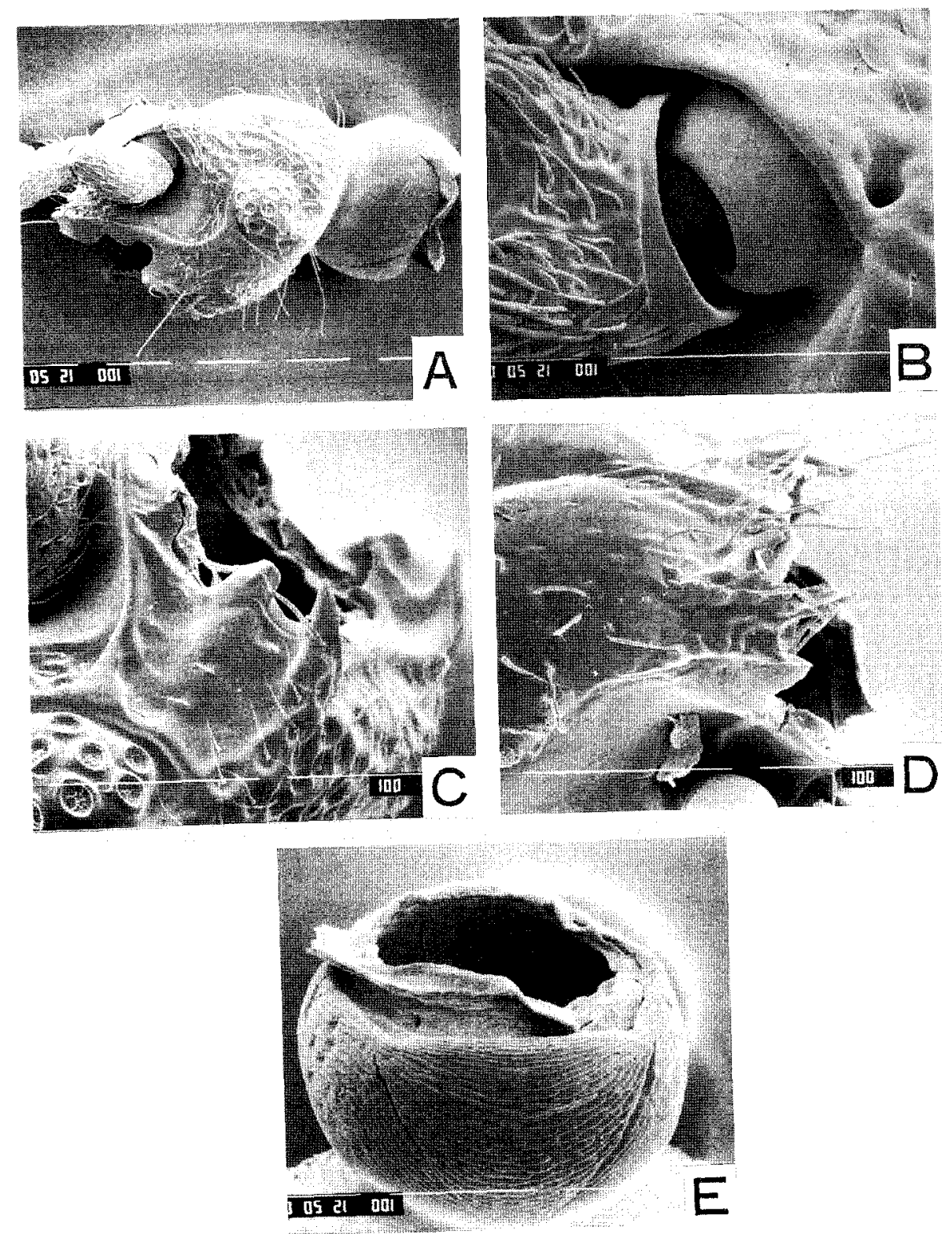
S. NOMURA

Fig. 3. Heads in dorsal view.

A, Batrisoplisus galloisi Jeannel, male.

B, B. torticornis sp. nov., male.

C, B. uroceratus uroceratus sp. et subsp. nov., male.

D, Batriscenellus kujumontanus sp. nov., female.

E, B. similis (Sharp), male.

F, B. ohishï sp. nov., female. 

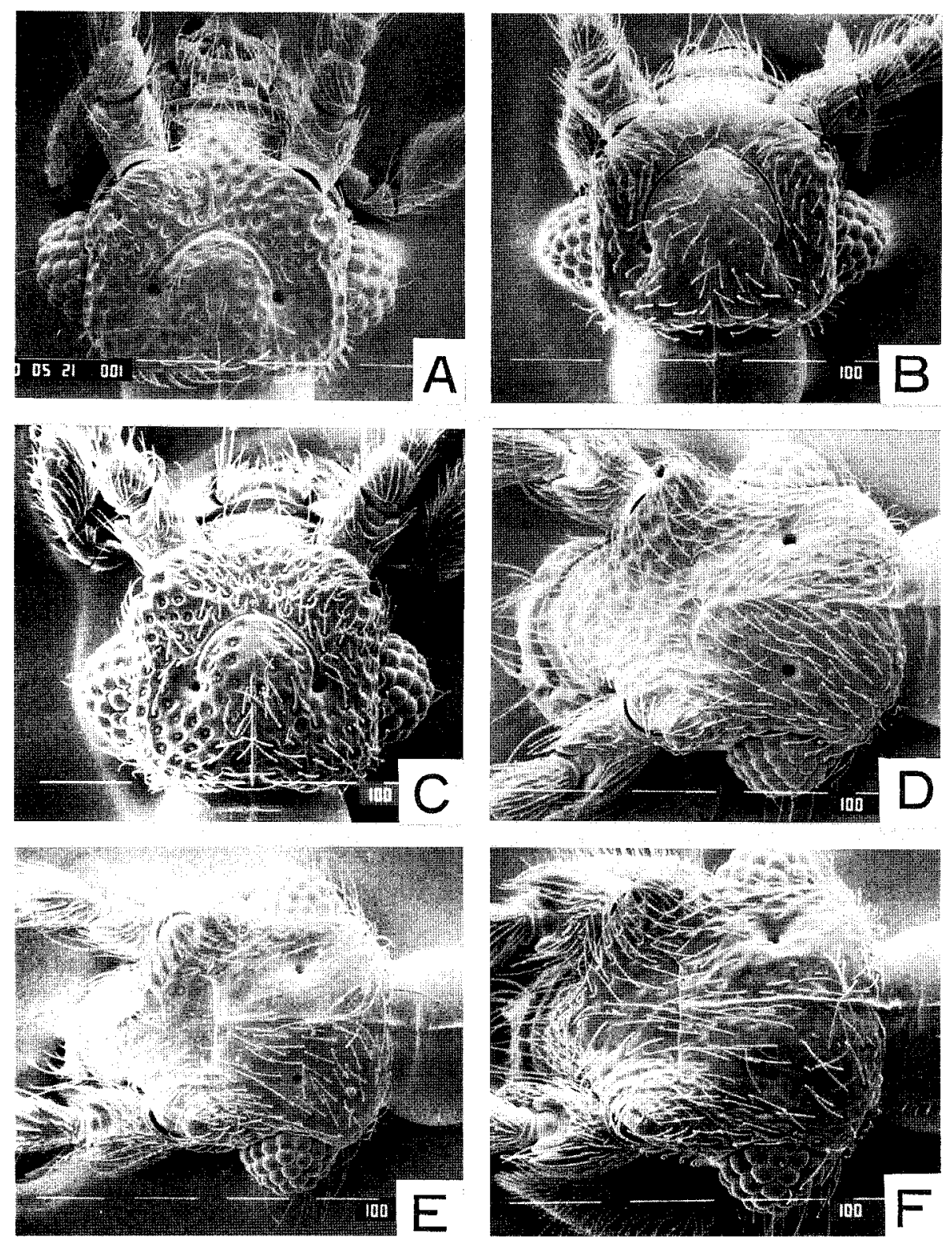
S. NOMURA

Fig. 4. Heads in dorsal view.

A, Cratna abdominalis Löbl, male.

B, Physomerinus schenklingi (Raffray), female.

C, P. pedator (Sharp), male.

$\mathrm{D}, P$. hasegawaisp. nov., male.

E, Batriscenaulax longipes longipes Jeannel, female.

F, B. kleinzach sp. nov., male. 

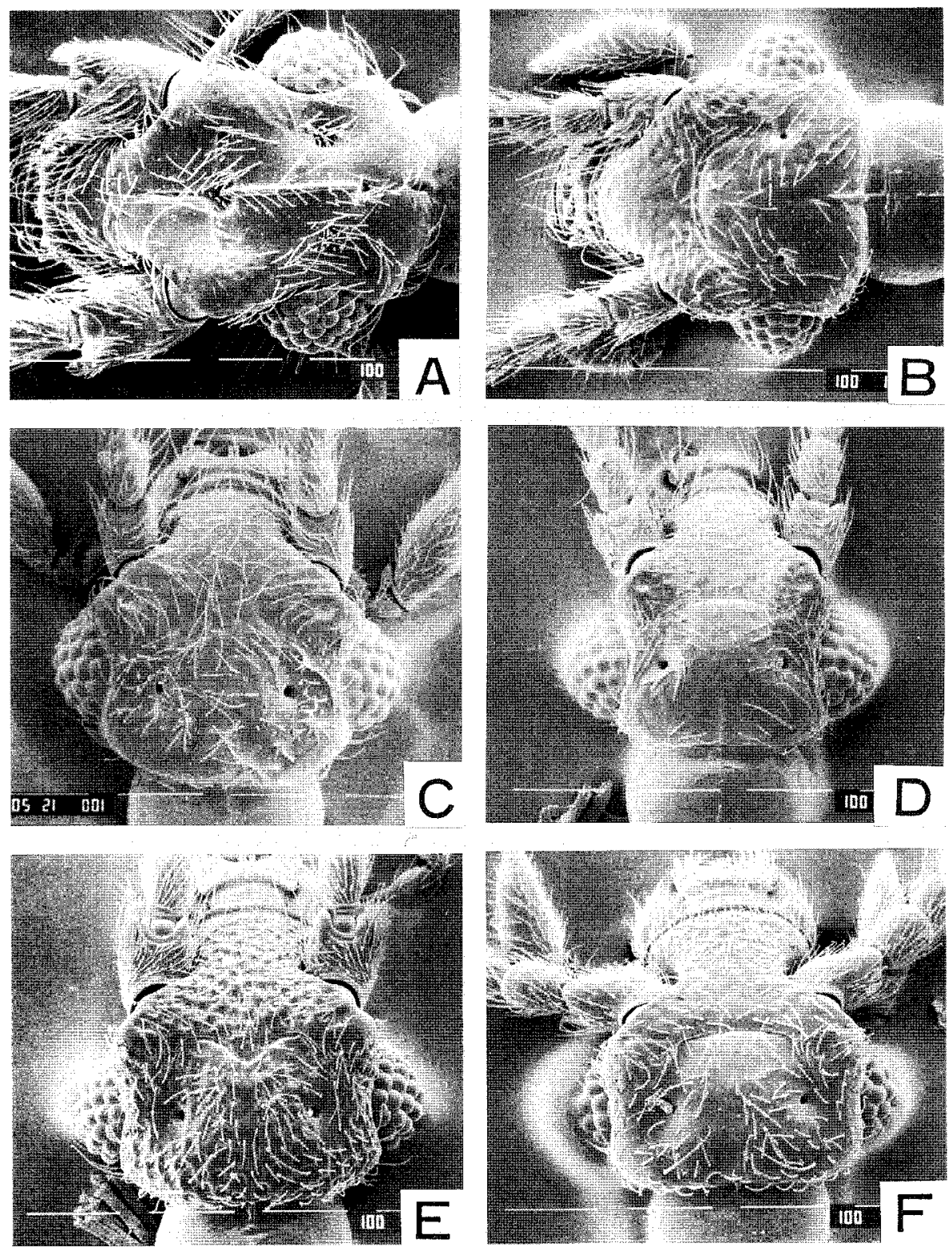
S. NOMURA

Fig. 5. H eads in dorsal view.

A, Arthromelodes giganteus sp. nov., male.

B, A. kiiensis sp. nov., male.

C, A. mercurius sp. nov., male.

D, A. dilatatus daibosatsuanus subsp. nov., male.

E, A. saikaiensis sp. nov., male.

F, Batrisceniola semipunctulata (Raffray), male. 

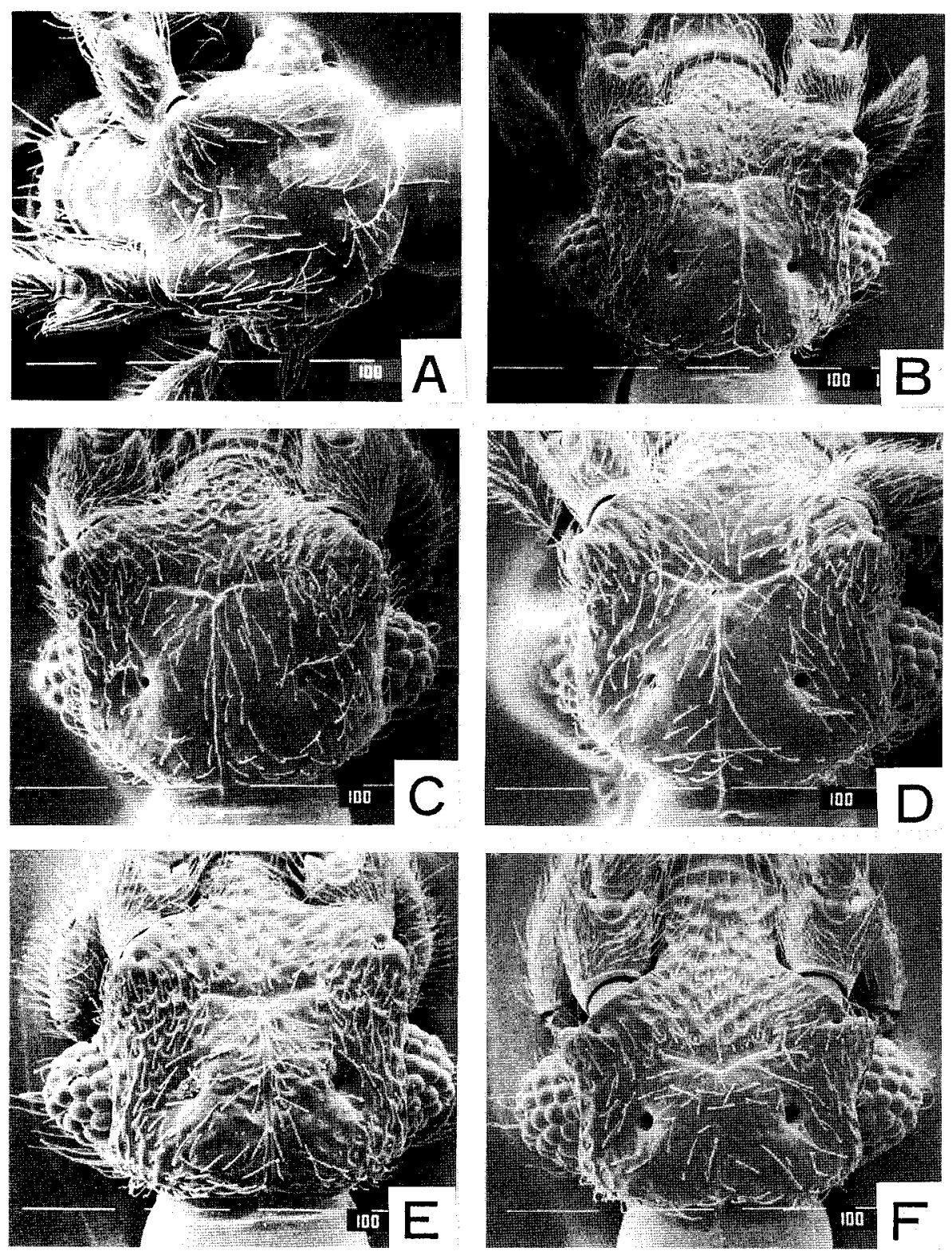
Fig. 6. Heads in ventral view.
A, Batrisoplisus raffrayi Jeannel, male.
B, B. torticornis sp. nov., male.
C, Batriscenellus kujumontanus sp. nov., male.
D, B. transformis sp. nov., male.
E, B. similis (Sharp), male.
F. Physomerinus schenklingi (Raffray), male. 

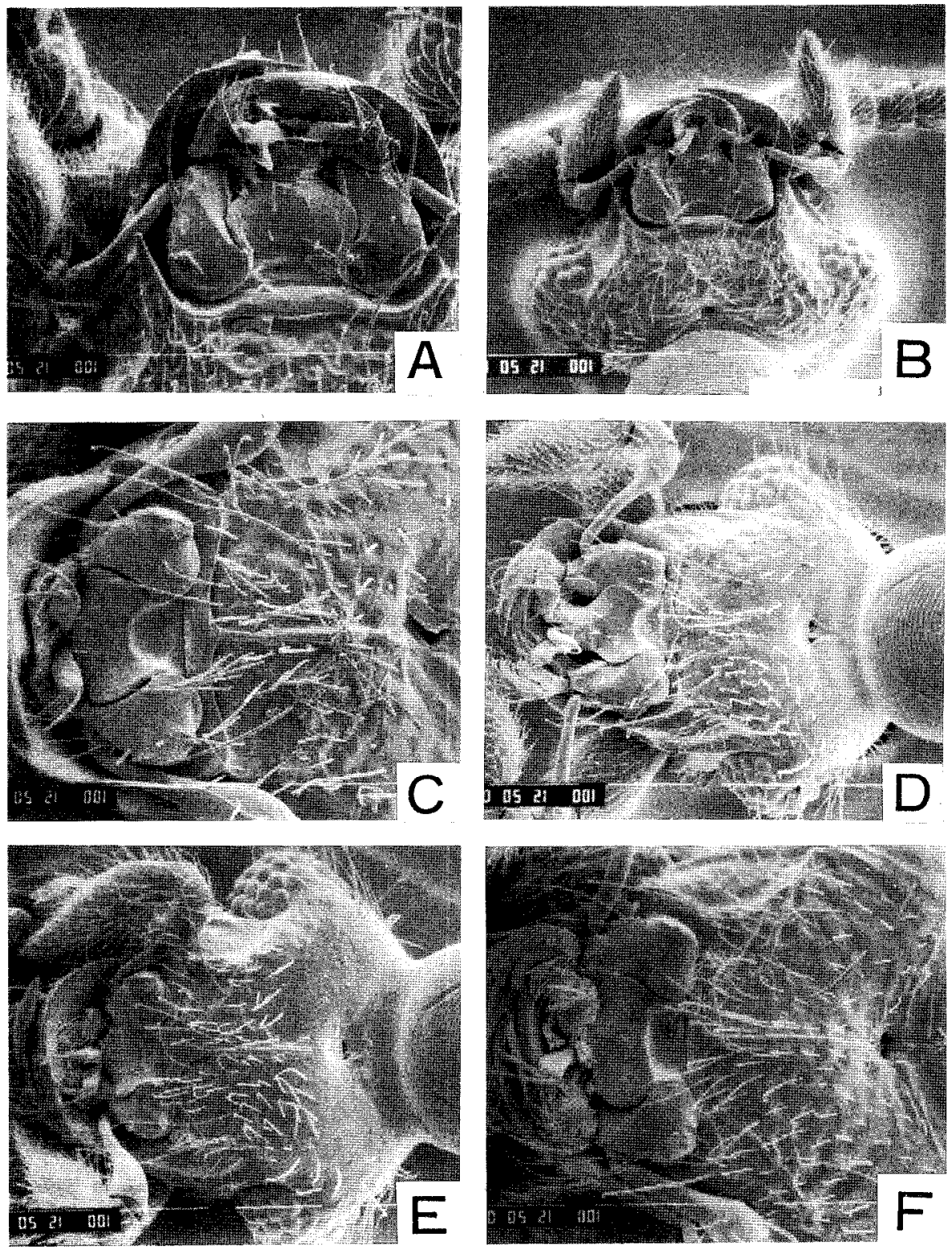
Fig. 7. Heads in ventral view.
A, Batriscenaulax furuhatai (Kubota), female.
B, B. kleinzach sp. nov., male.
C, Arthromelodes giganteus sp. nov., male.
D, A. küensis sp. nov., male.
E, A. saikaiensis sp. nov., male.
F, A. crucifer sp. nov., male. 

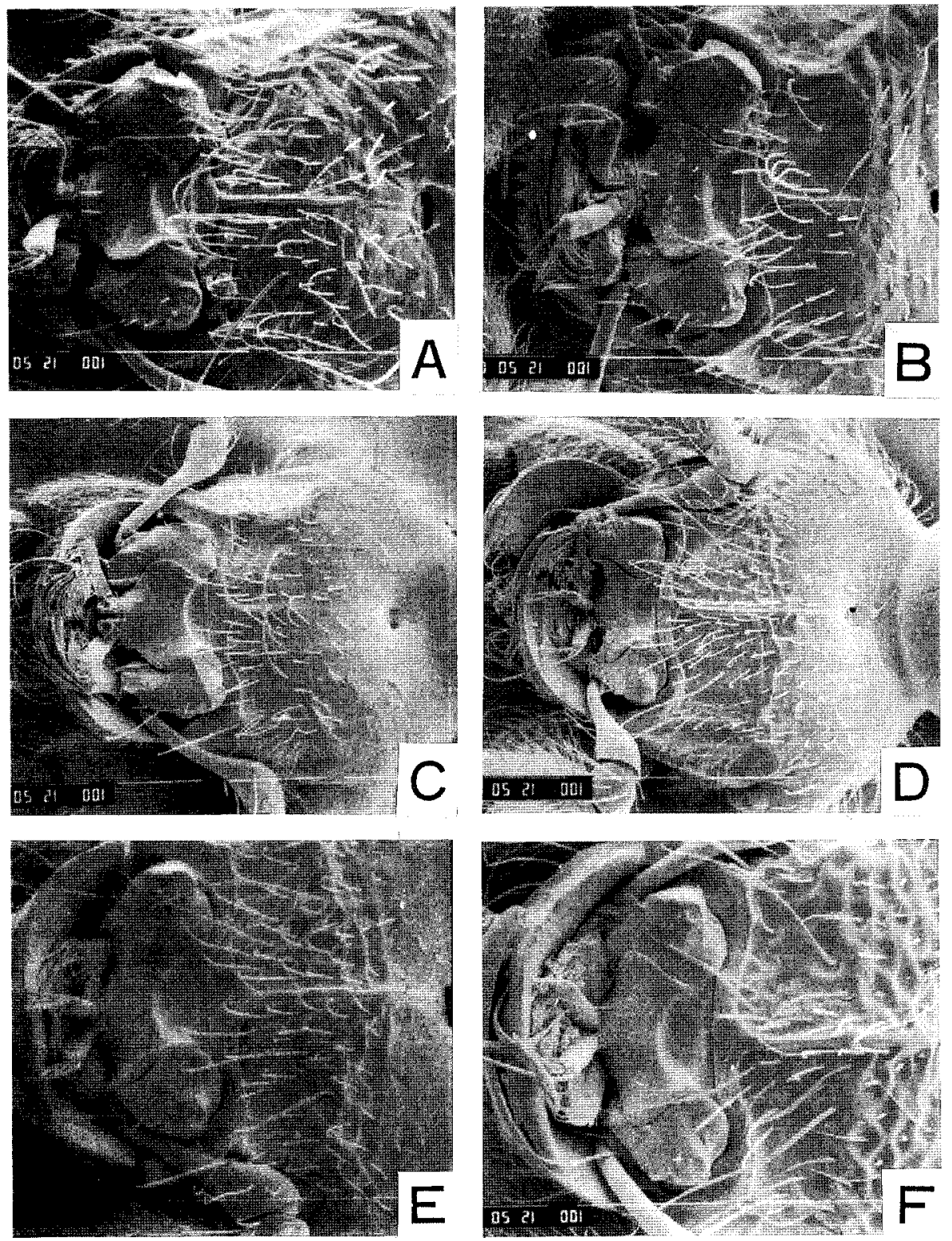
Fig. 8 Antennae.
A, 3rd to 11th segments.
B-D, 7th to 11th segments.
E, F, 1st antennal segment.

A, Batrisoplisus raffrayi Jeannel, male.

B, B. torticornis sp. nov., female.

$\mathrm{C}, \boldsymbol{B}$. uroceratus uroceratus sp. et subsp. nov., male.

$\mathrm{D}$, ditto, female.

E, B. parallelus sp. nov., male.

F, Physomerinus schenklingi(Raffray), female. 

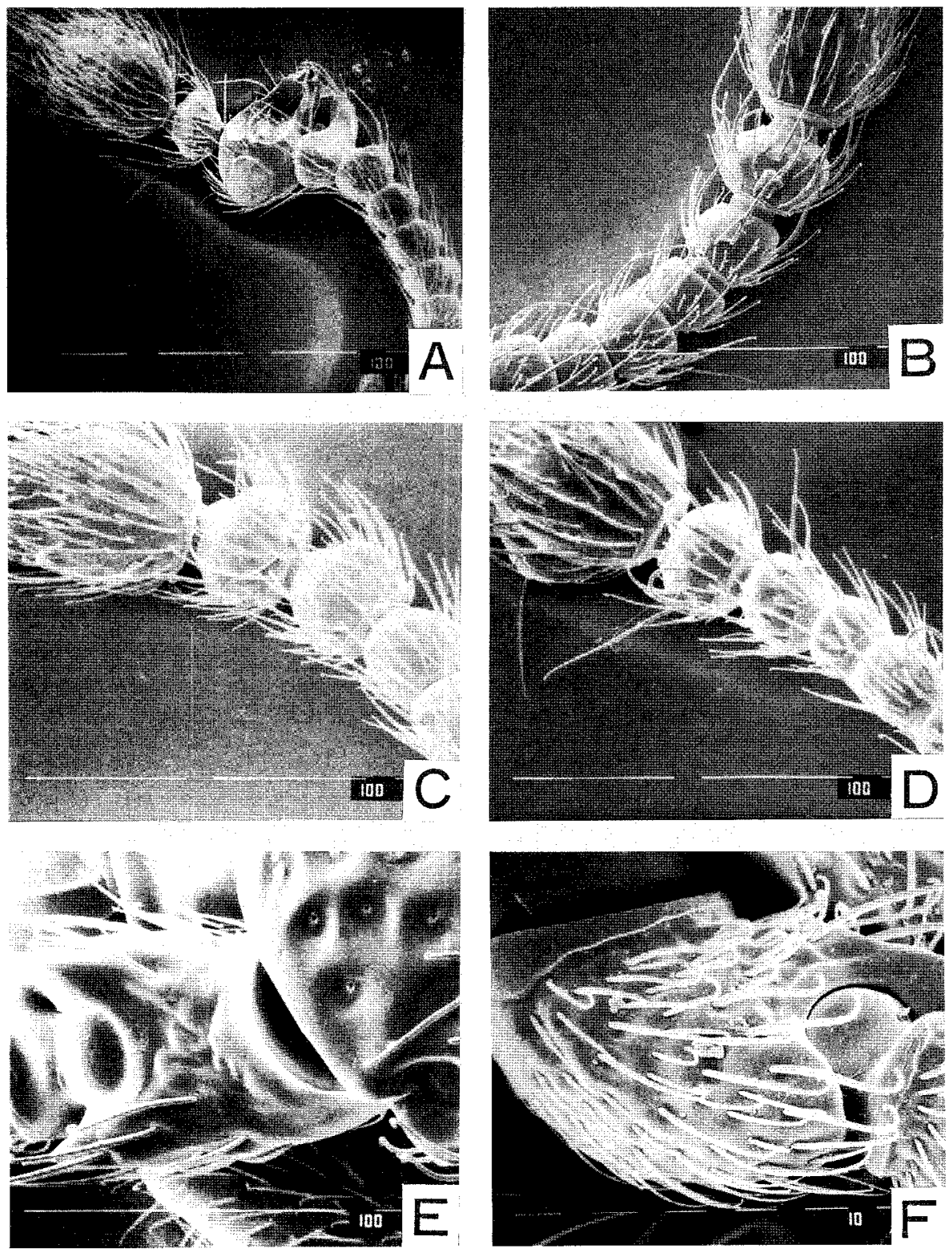


\section{S. NOMURA}

Fig. 9. Mouthparts.

A, B, mouthparts in ventral view.

$\mathrm{C}$, labrum in anterior view.

D-F, right mandible in ventral view.
A, Batrisceniola dissimilis (Sharp), male.
B, C, B. semipunctulata (Raffray), male.
D, Batrisoplisus torticornis sp. nov., male
E, B. uroceratus uroceratus sp. et subsp. nov., male
$\mathrm{F}, \boldsymbol{B}$. parallelus sp. nov. 

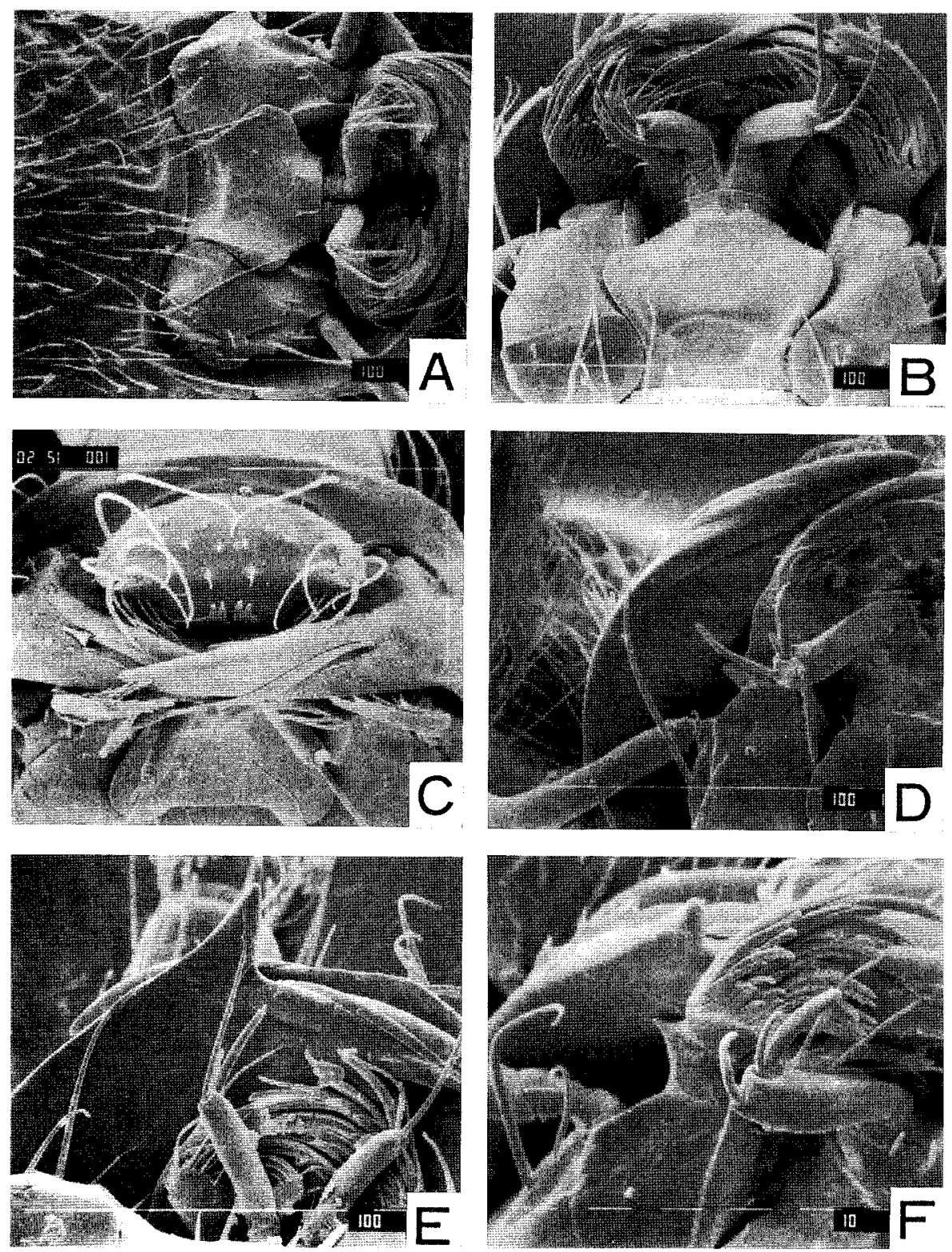
S. NOMURA

Fig. 10. Maxillae.
$\mathrm{A}, \mathrm{B}$, ventral view.
C-E, basal parts in ventral view.
$\mathrm{F}$, pores at basal part.
A, Batrisoplisus raffrayi Jeannel, male.
B, B. torticomis sp. nov., male.
C, Batriscenellus kujumontanus sp. nov., male.
D, Batriscenaulax furuhatai (Kubota), male.
E, Batrisoschema euplectiforme (Sharp), male (out-group)
F, Batriscenehs similis (Sharp), male. 

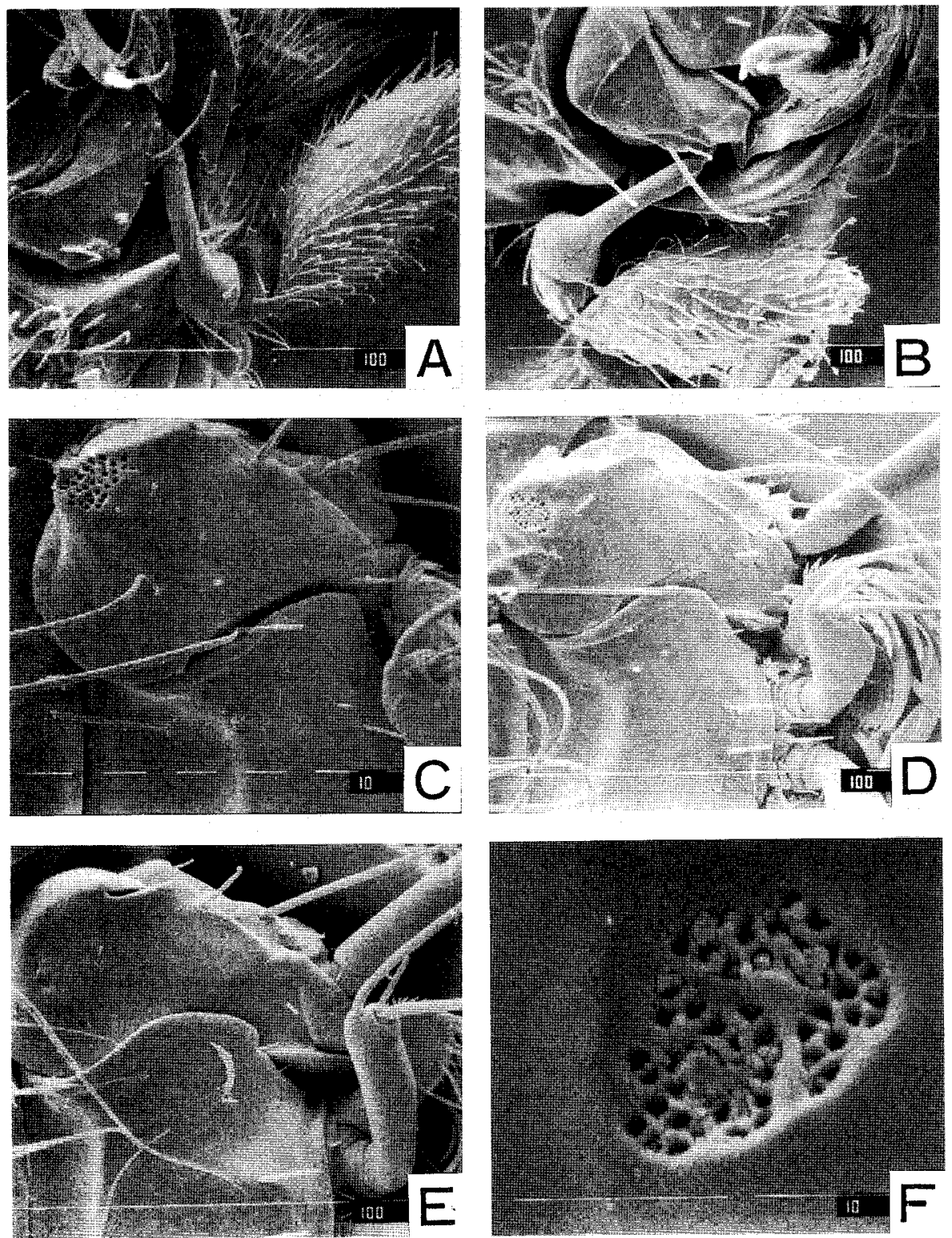
Fig. 11. Labium in ventral view.

A, B, Batrisceniola dissimilis (Sharp), male.

C, Batrisoplisus raffrayi Jeannel, male.

D, Arthromelodes giganteus sp. nov., male (labial palpi are lost). 

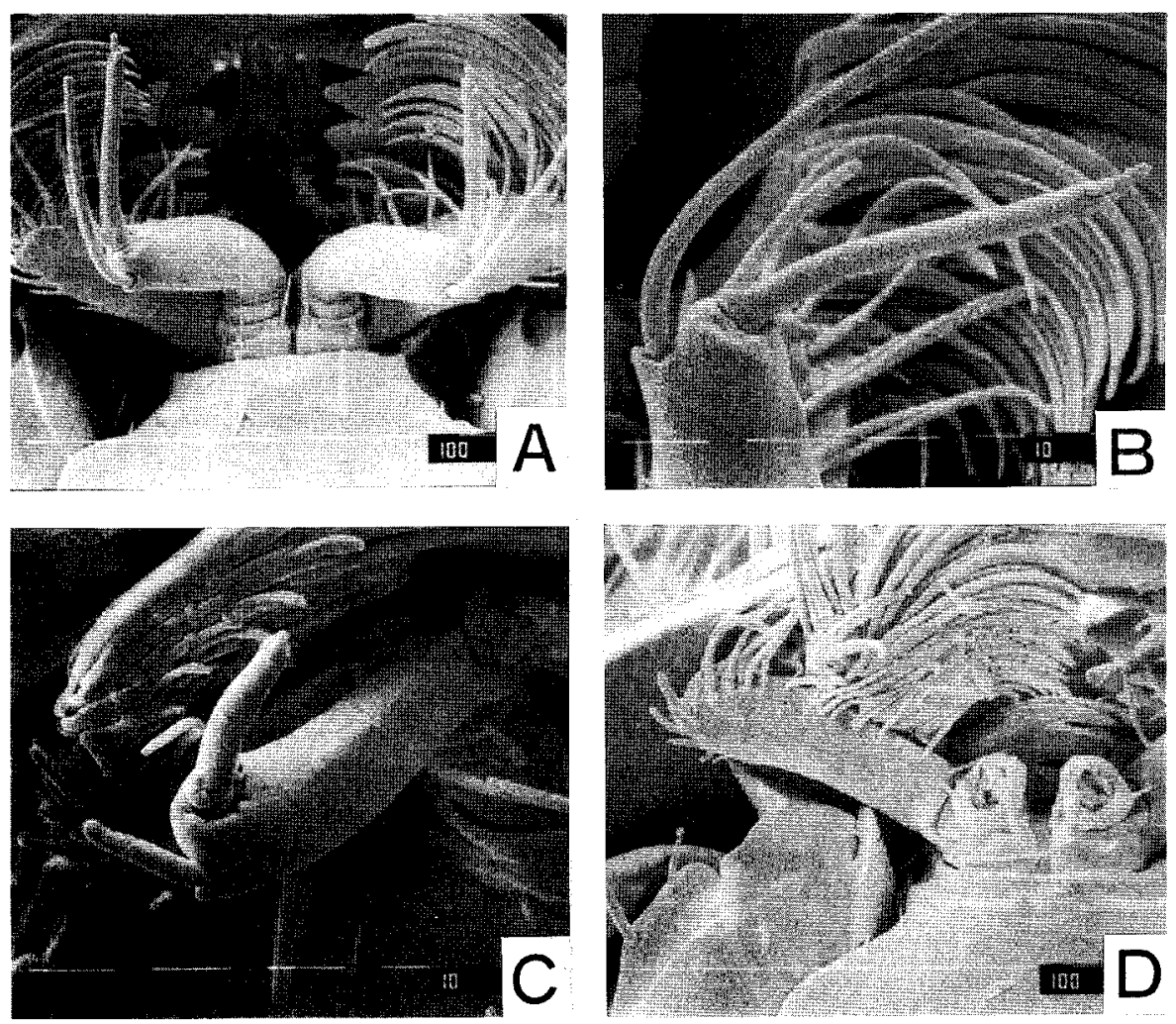
S. NOMURA

Fig. 12 Shemata of prothorax.

A, C, dorsal view.

$B$, ventral view.

$\mathrm{D}$, lateral view.

A, B, Batrisceniola semipunctulata (Raffray), male.

C, Batrisoplisus raffrayi Jeannel, male.

D, Batrisceniola dissimilis (Sharp). 


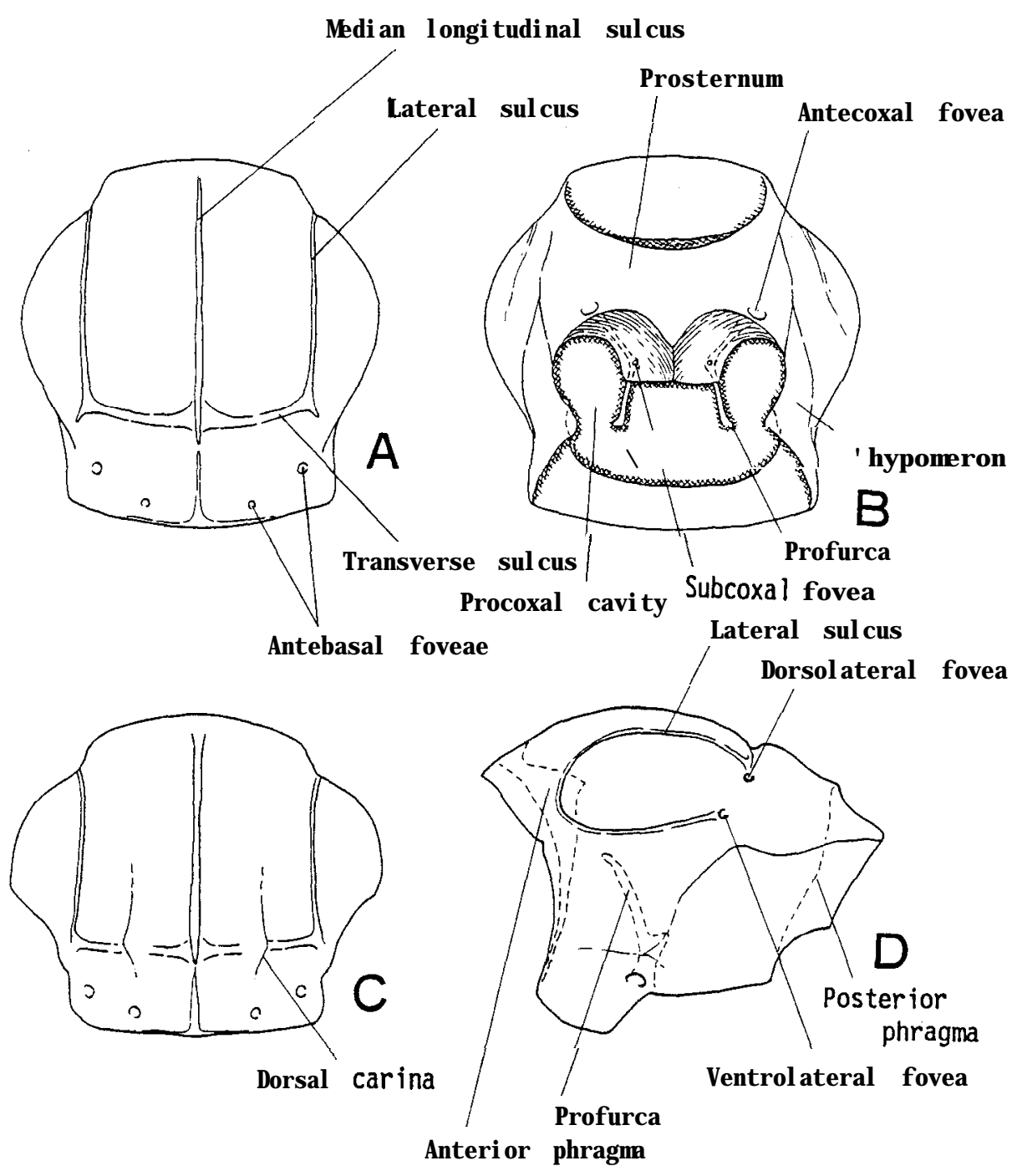


S. NOMURA

Fig. 13 Prothoraces in dorsal view.

A, Batrisoplisus venustus Jeannel, male.

B, B. parallelus sp. nov., male.

C, Batriscenellus kujumontanus sp. nov., male.

D, B. ohishiil sp. nov., female.

E, Cratna abdominalis Löbl, male.

F, Batriscenaulax longipes longipes Jeannel, male. 

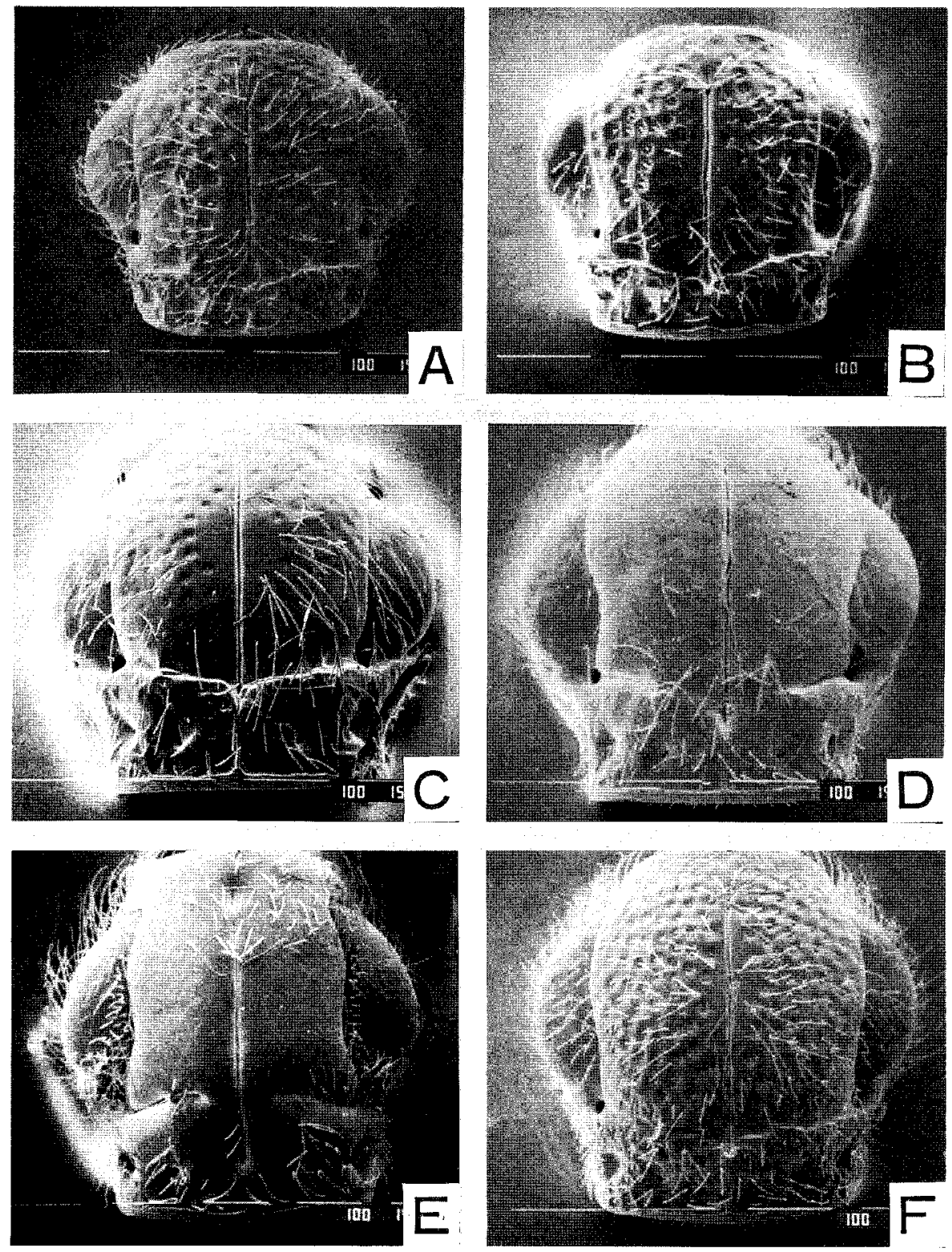
S. NOMURA

Fig. 14. Prothoraces in dorsal view.

A, B. kleinzach sp. nov., male.

B, Physomerinus pedator (Sharp), female.

C, Arthromelcdes giganteus sp. nov., male.

D, A. mercurius sp. nov., male.

E, A. saikaiensis sp. nov., male.

F, Batrisceniola semipunctulata (R affray), male. 

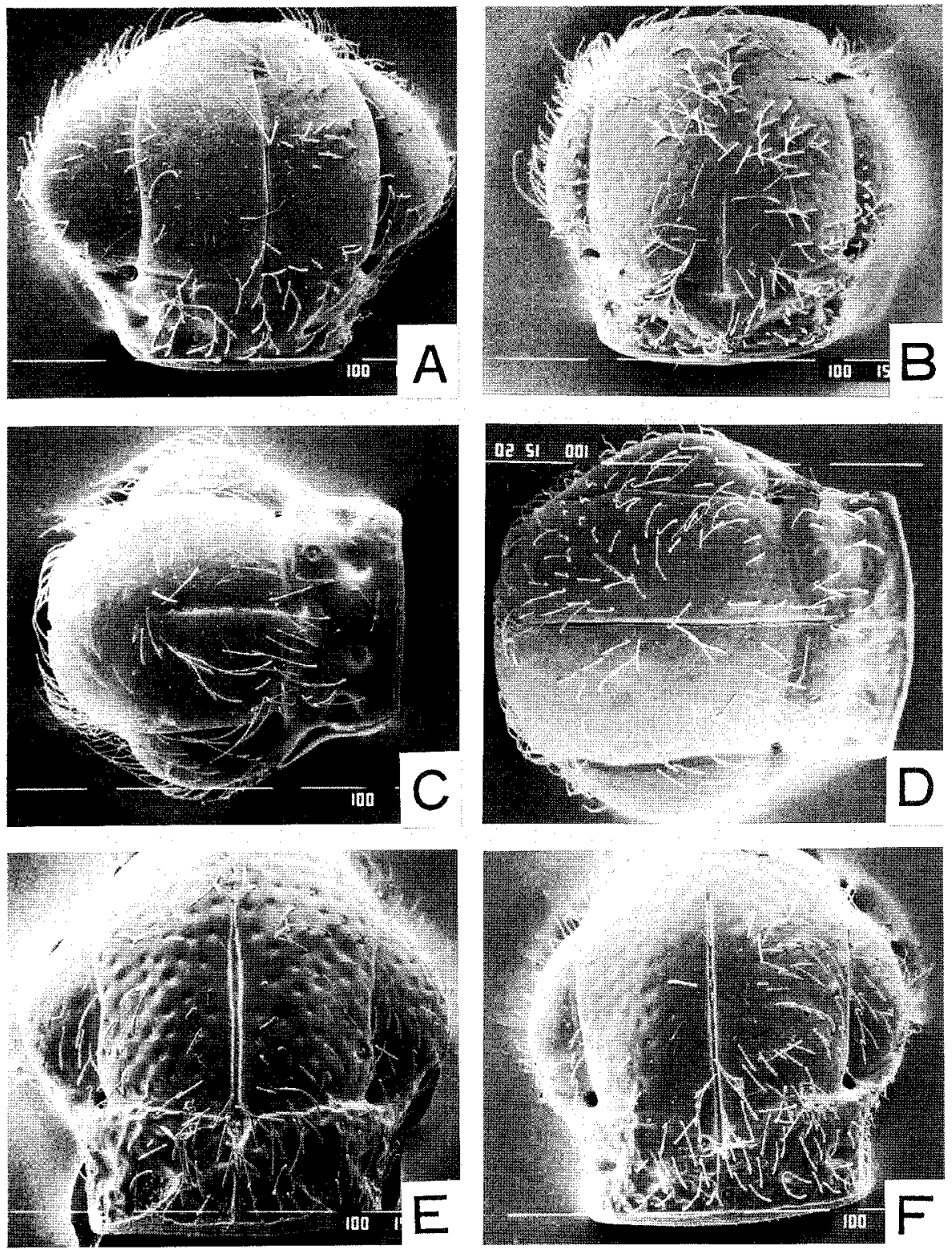
S. NOMURA

Fig. 15. Prothoraces in ventral view.

A, Batrisoplisus parallelus sp. nov., male.

$\mathrm{B}$, Batriscenellus kujumontanus sp. nov., male.

C, B. transformis sp. nov., male.

D, Batriscenaulax kleinzach sp. nov., male.

E, Arthromelodes saikaiensis sp. nov., male.

F, Batrisceniola semipunctulata (Raffray), male. 

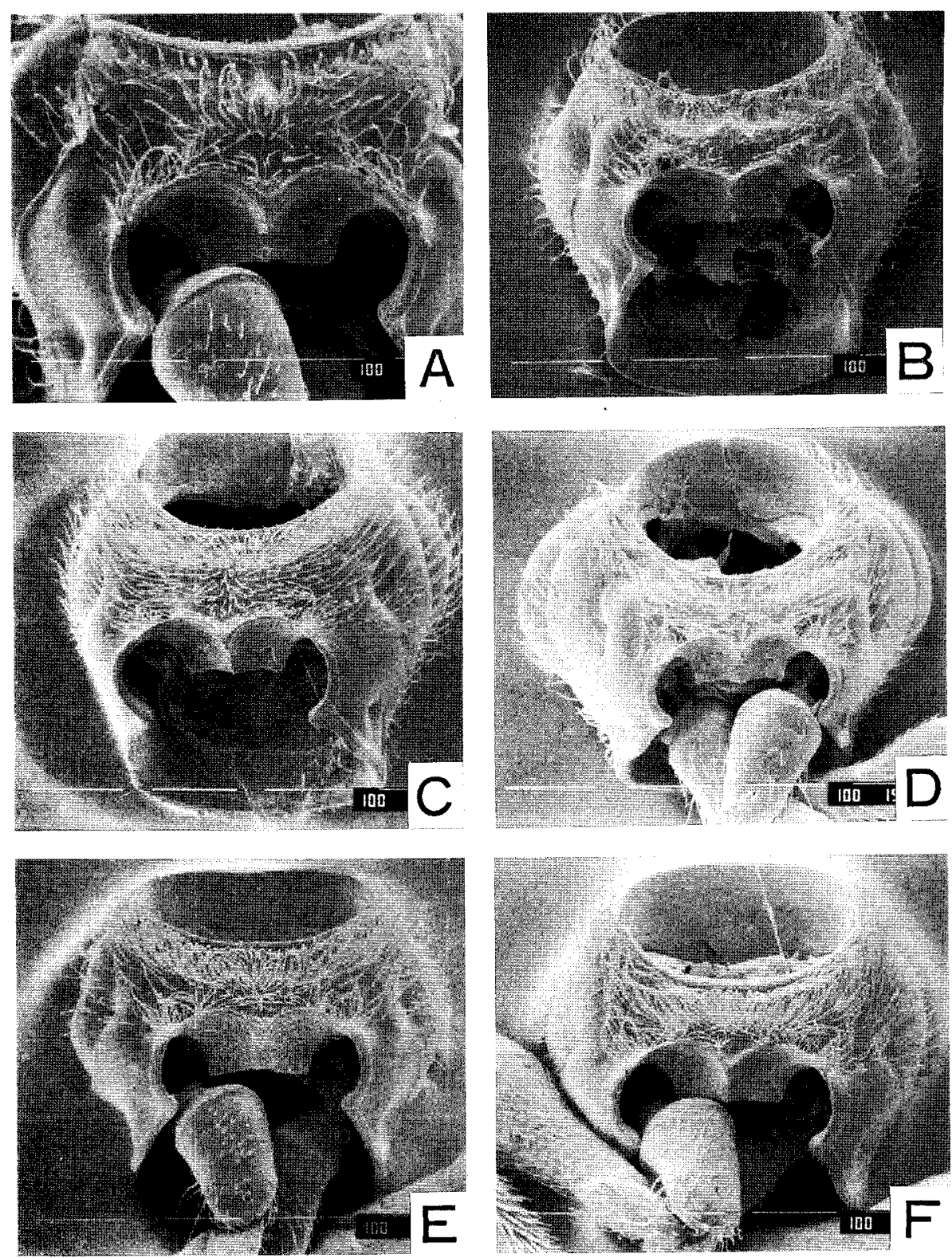
S. NOMURA

Fig. 16. Schemata of mesothorax

$A, B$, Batrisceniola semipunctulata (Raffray);

A, mesonotum in dorsal view.

B. mesothorax in anterior view. 


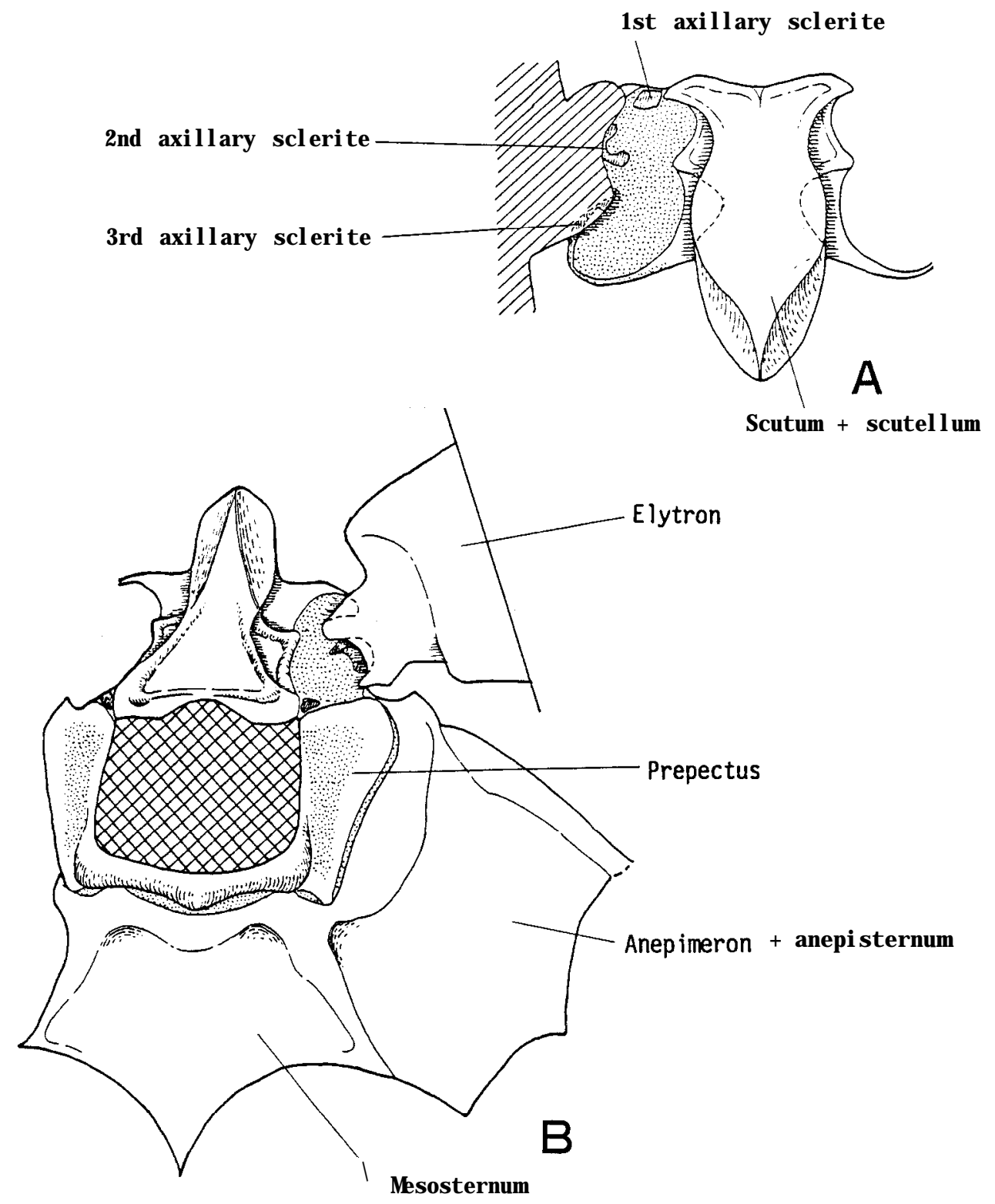


Fii 17. Mesonota in dorsal view.
A, Batrisoplisus raffrayi Jeannel, brachypterous male.
B, Batriscenaulax longipes longipes Jeannel, brachypterous male.
C, Batriscenellus kujumontanus sp. nov., brachypterous female.
$\mathrm{D}$, Batrisceniola dissimilis (Sharp), macropterous male,
E, ditto, brachypterous male.
$\mathrm{F}$, ditto, brachypterous female. 

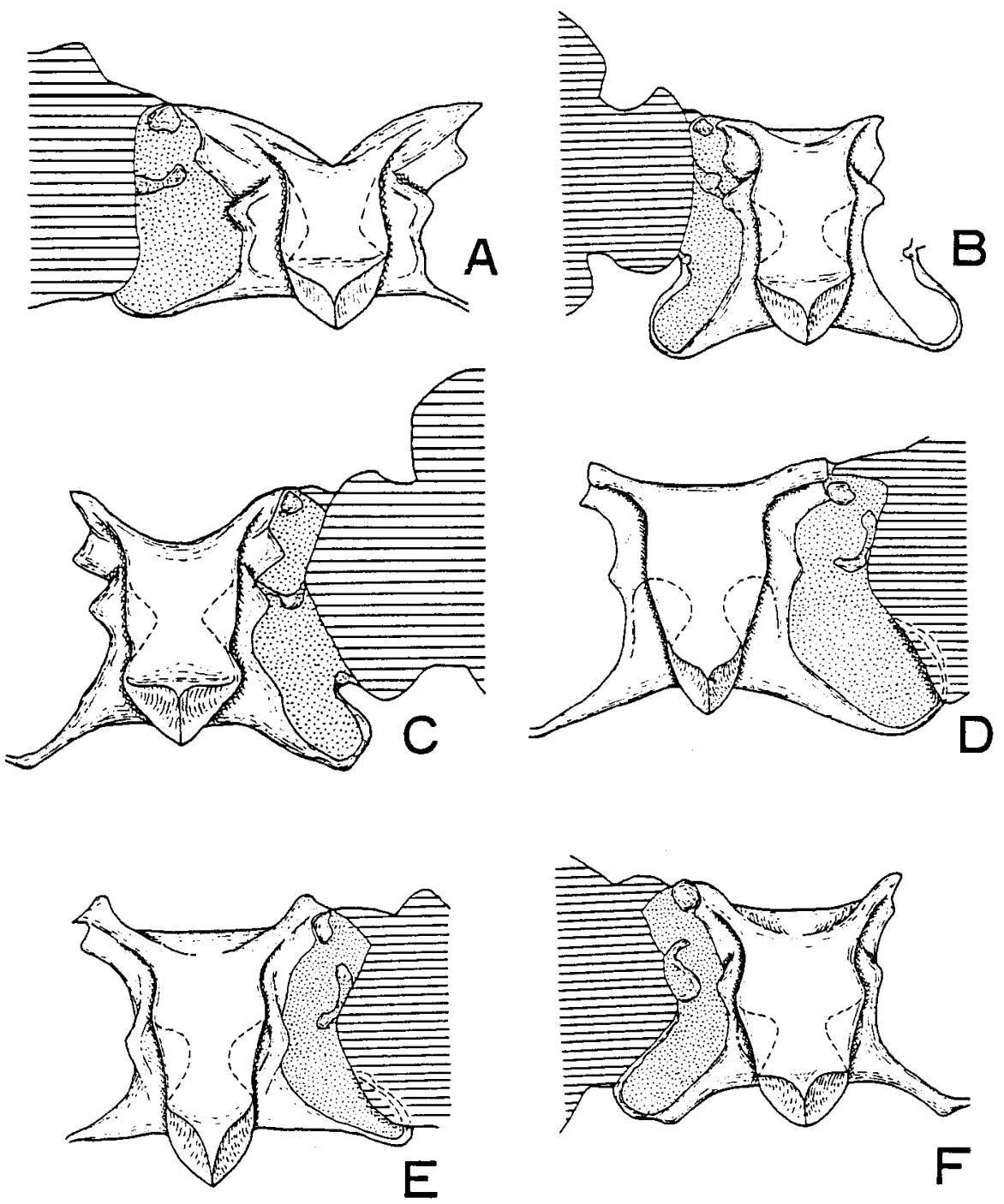
Fig. 18. Schemata of mesothoracic and metathoracic sterna in ventral view.
$A$, Batrisceniola semipunctulata (Raffray).
B, Batrisoschema euplectiforme (Sharp) (out-group).
C, Euplectus sp. (out-group). 

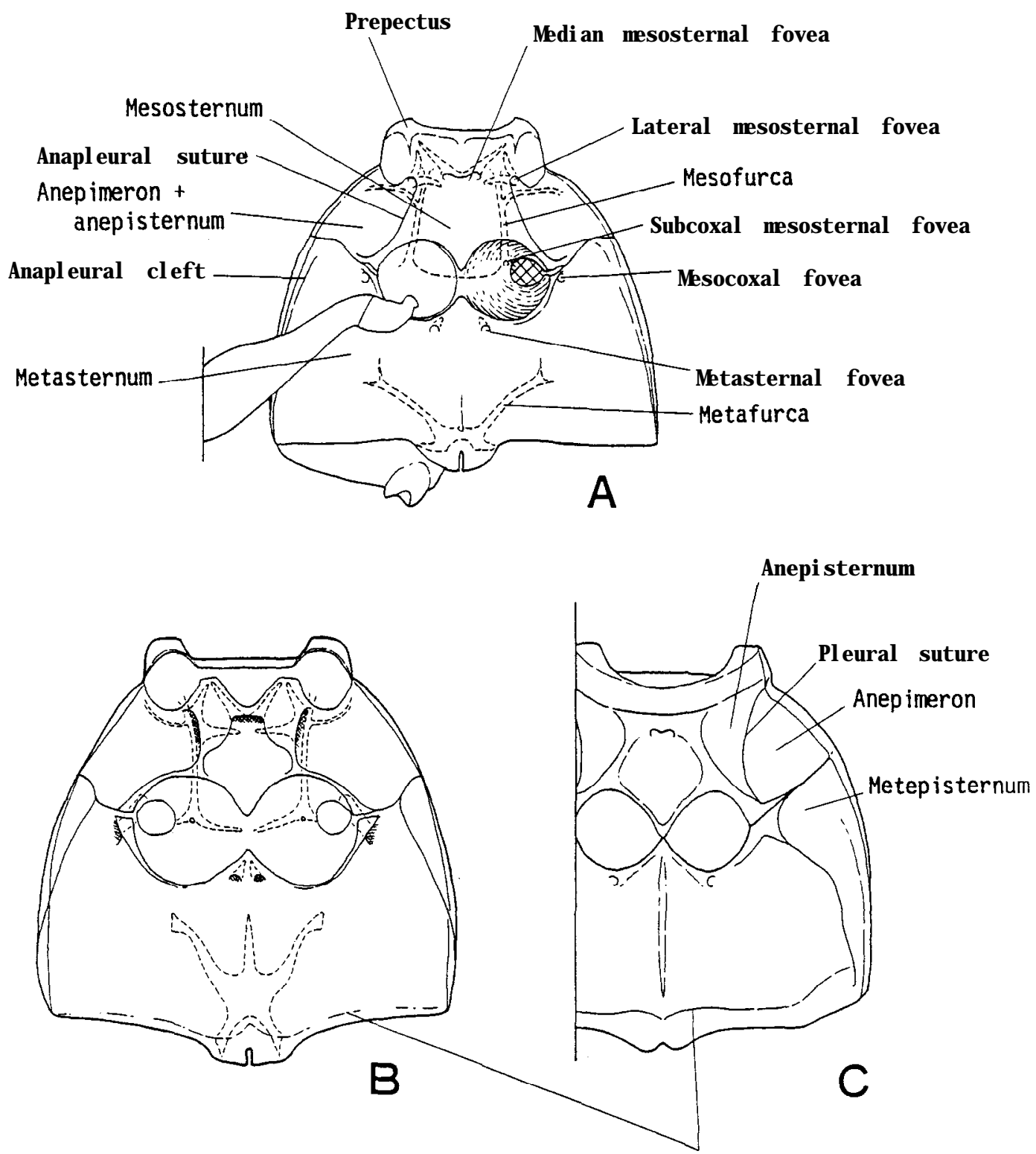

Paracoxal suture 
Fig. 19. Meso and Metathoraces.

A-D, ventral view.

$\mathrm{E}, \mathrm{F}$, posteromedian parts of metathoraces in ventral view.

A, Batrisoplisus galloisi Jeannel, male.

B, B. raffrayi Jeannel, male.

C, B. monostatos sp. nov., male.

D, F, B. parallelus sp. nov., male.

E, B. uroceratus uroceratus sp. et subsp. nov., male. 

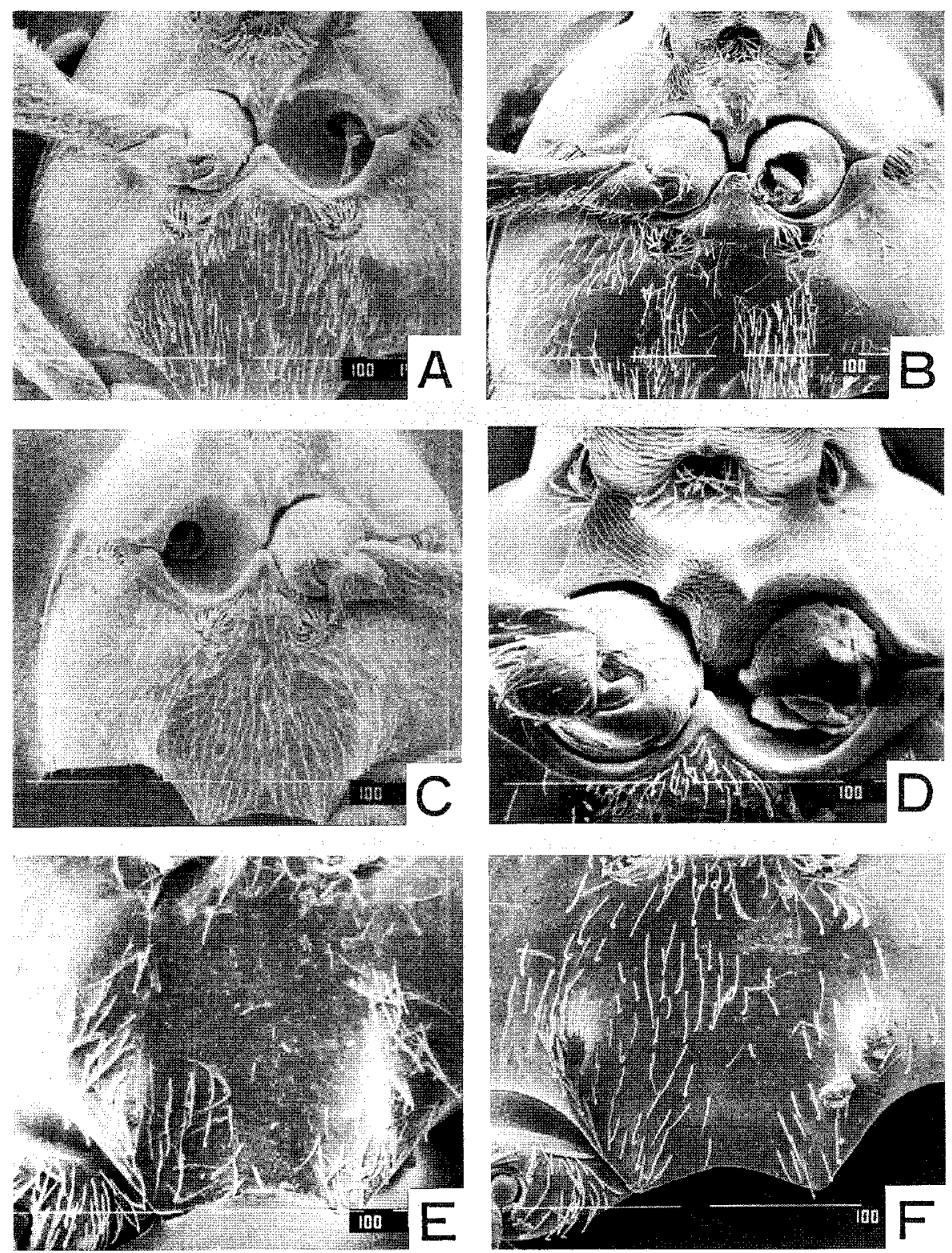
Fig. 20. Meso- and metathoraces in ventral view-
A, Batriscenellus kujumontanus sp. nov., male.
B, B. uenoi sp. nov., male.
C, B. ohishï sp. nov., female.
D, Cratna abdominalis Mbl, male.
E, Batriscenaulax furuhatai (Kubota), male.
F, Physomerinus pedator sp. nov., female. 

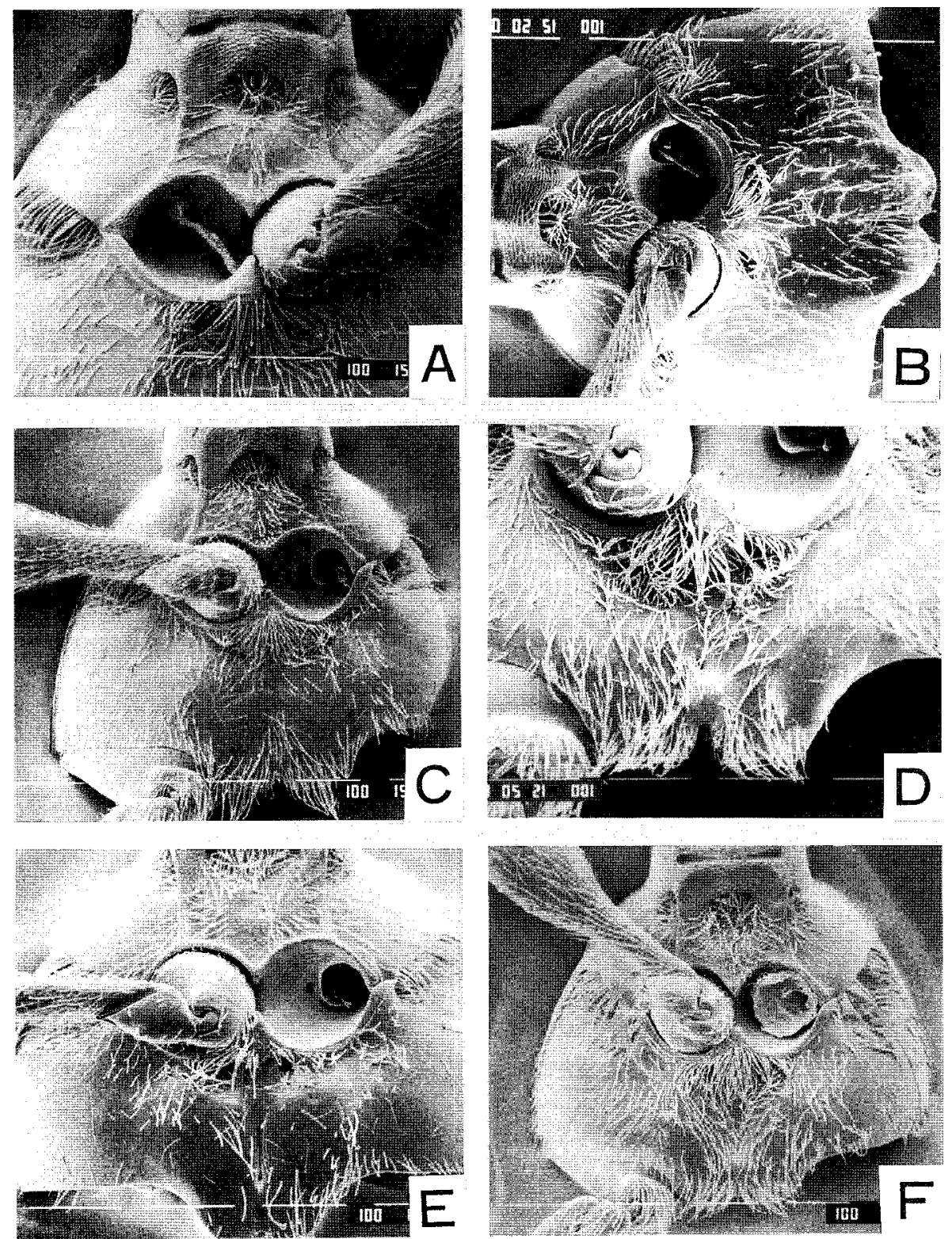
S. NOMURA

Fig. 2L Meso- and metathoraces in ventral view.
A, Arthromelodes giganteus sp. nov., male.
$\mathrm{B}, A$. küiensis sp. nov., male.
$C$, A. mercurius sp. nov., male.
$\mathrm{D}, \boldsymbol{A}$. saikaiensis sp. nov., female.
E, Batrisceniola dissimilis (Sharp), male.
F, B. semipunctulata (Raffray), male. 

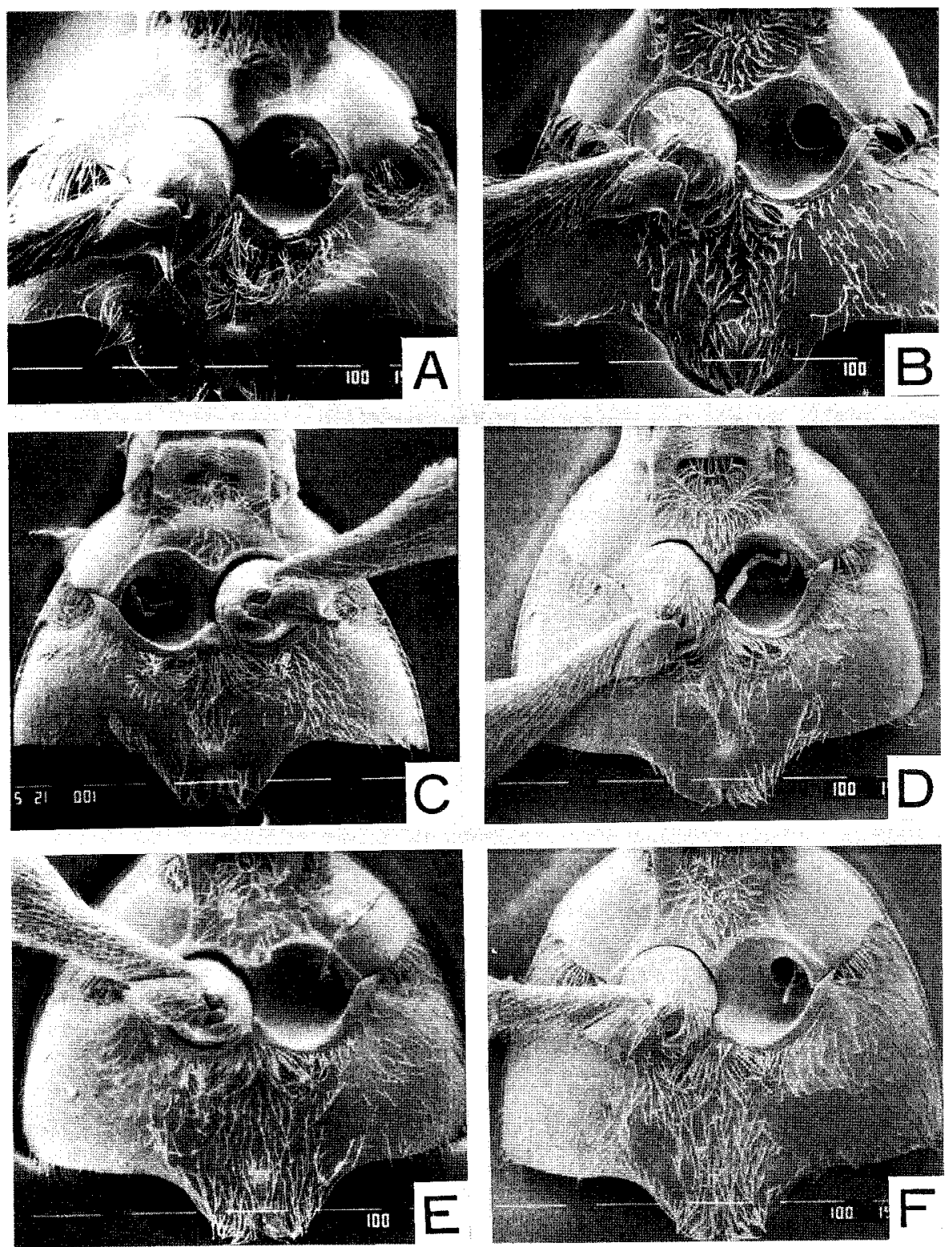
Fig. 22. Schemata of meso- and metathoraces in Batrisceniola semipunctulata (Raffray).

A, meso- and metathoraces in lateral view.

$\mathrm{B}$, metathorax in dorsal view. 

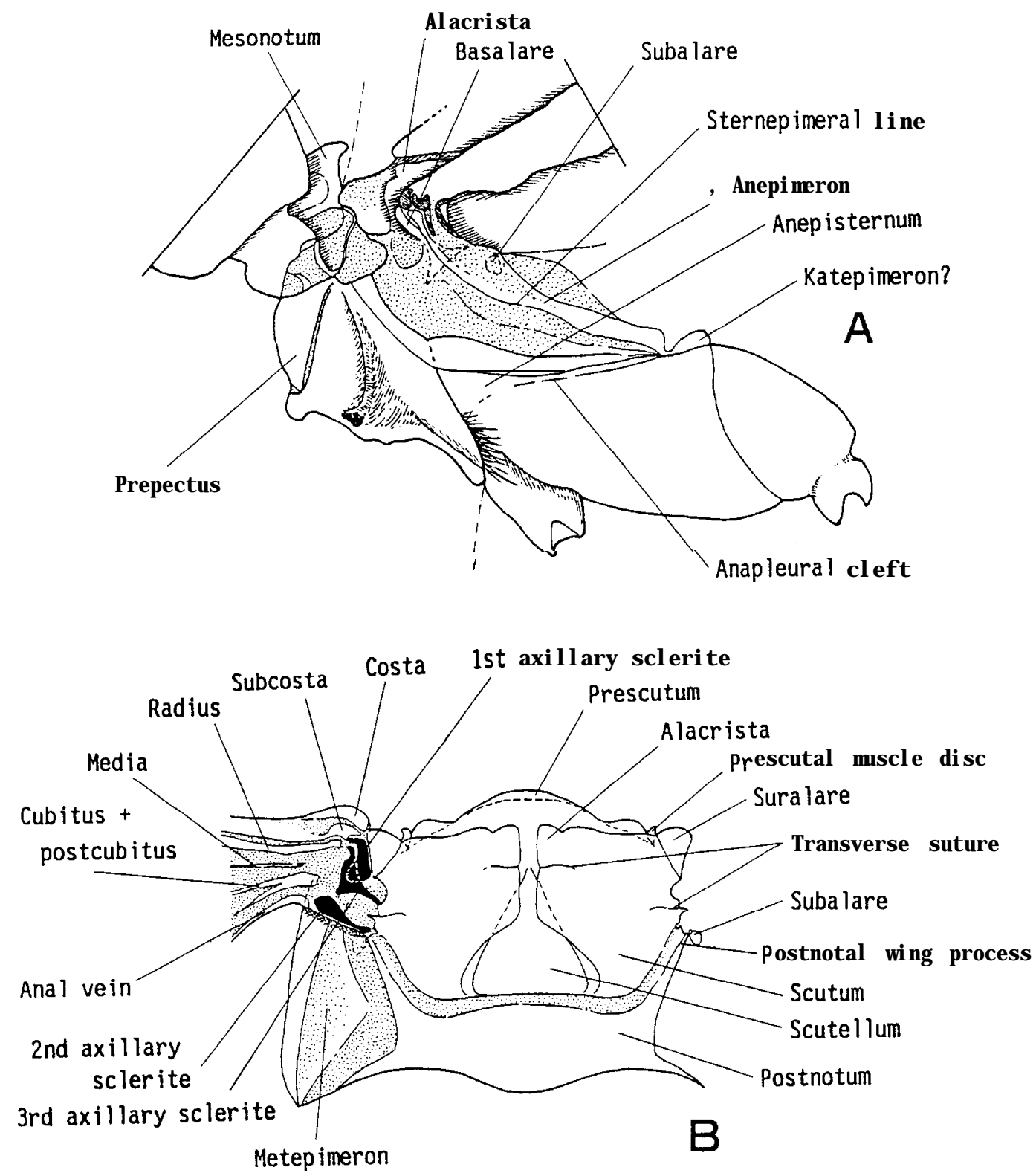
Fig. 23. Metanota and wing bases in dorsal view.

A, Batrisoplisus raffrayi Jeannel, brachypterous male.

B, ditto, brachypterous female.

C, Batriscenellus kujumontanus sp. nov., macropterous male.

$\mathrm{D}$, ditto, brachypterous female. 

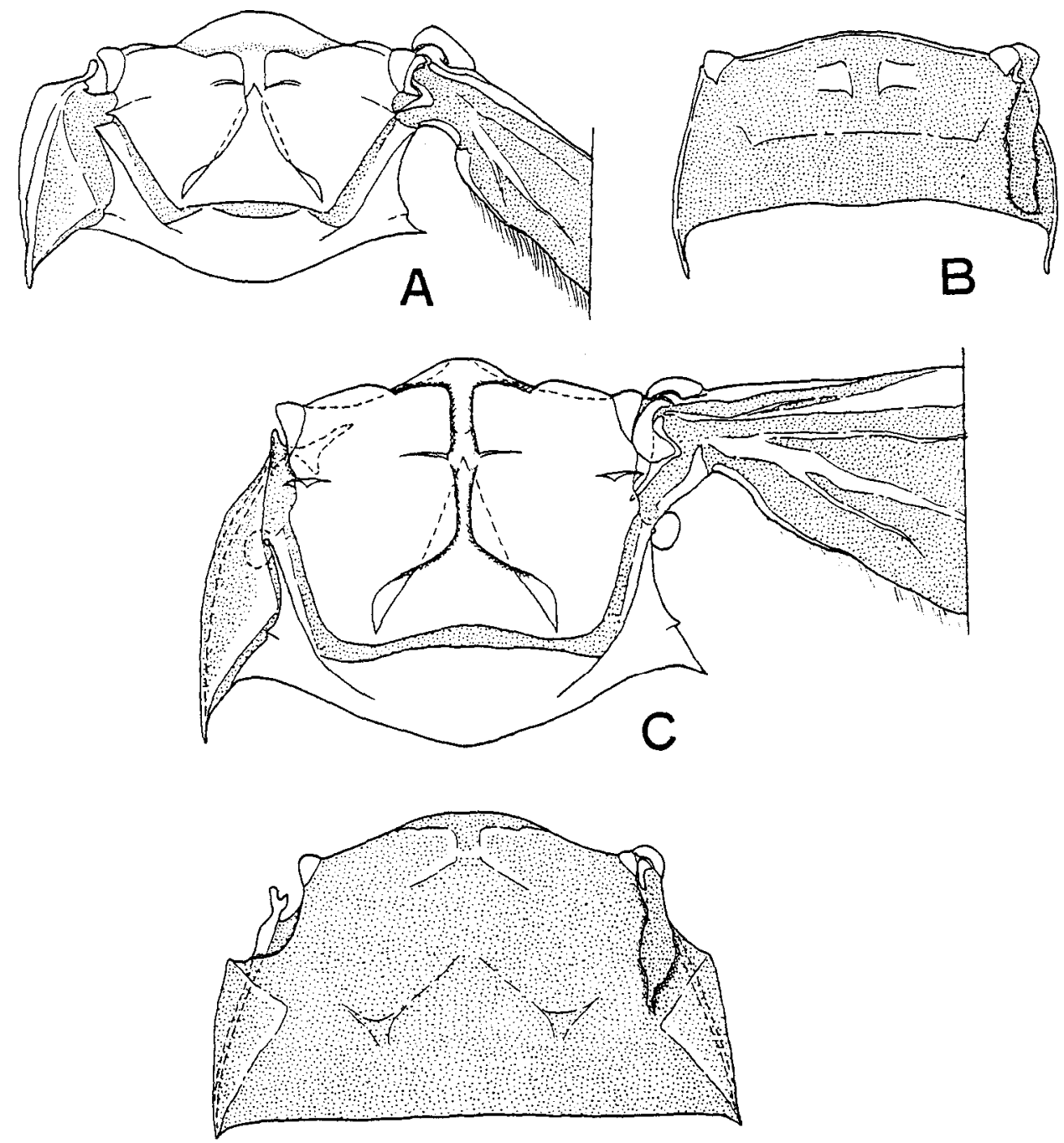

D 
Fig. 24. Metanota and wing bases.
A, C, D, dorsal view.
$\mathrm{B}$, anterior view.
A, B, Cratna abdomimlis Löbl, macropterous male.
C, Batriscenaulax longipes longipes Jeannel, macropterous male.
$\mathrm{D}$, ditto, brachypterous male. 

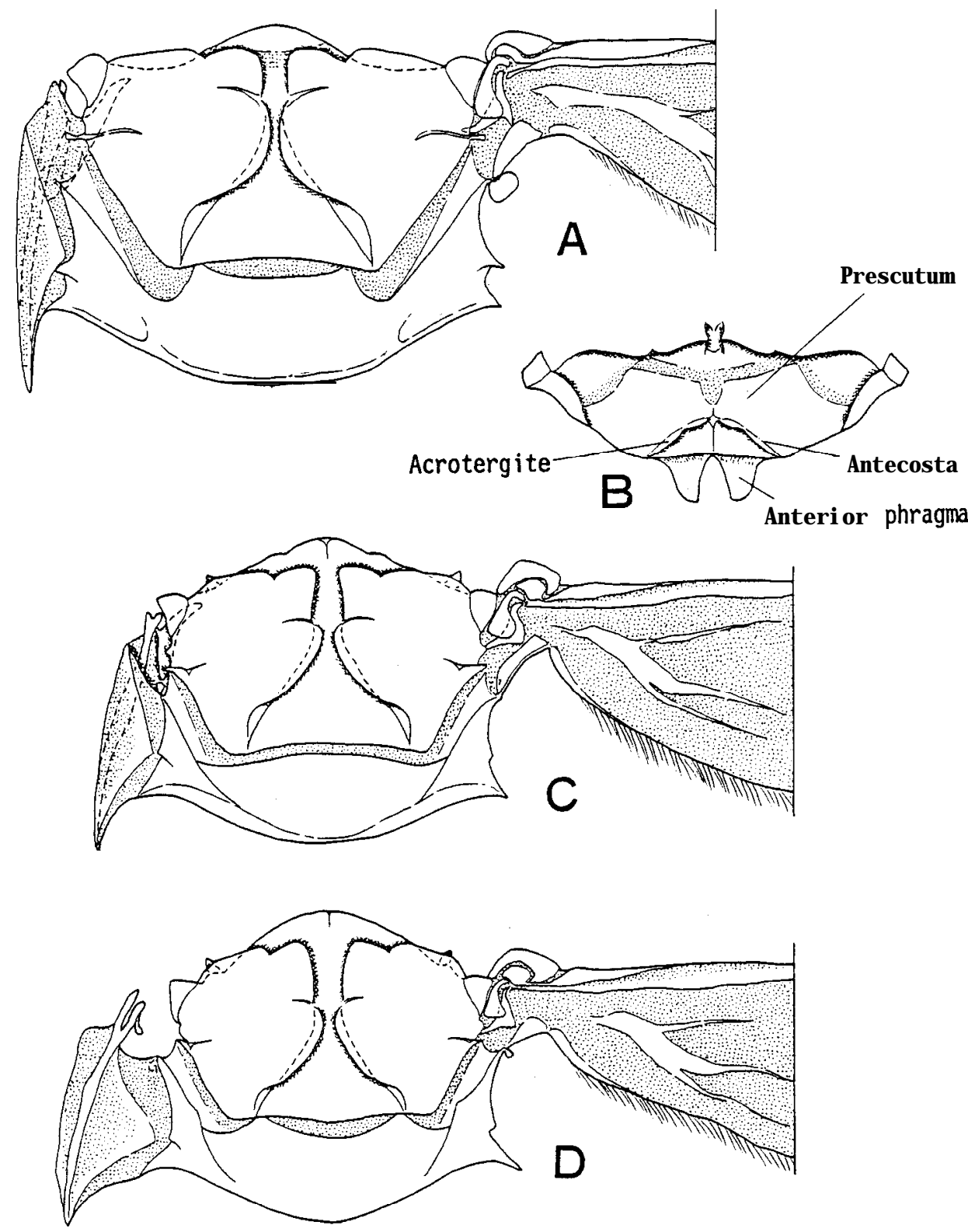
Fig. 25. Metanota, metepimera and wing bases in Batrisceniola dissimilis (Sharp).

$$
\begin{aligned}
& \text { A-C, macropterous male. } \\
& D-F \text {, brachypterous male. }
\end{aligned}
$$

G-I, brachypterous female.
$A, D, G$, metanota in dorsal view.
$B, E, H$, ditto, in anterior view.
C, F, I, metepimera. 

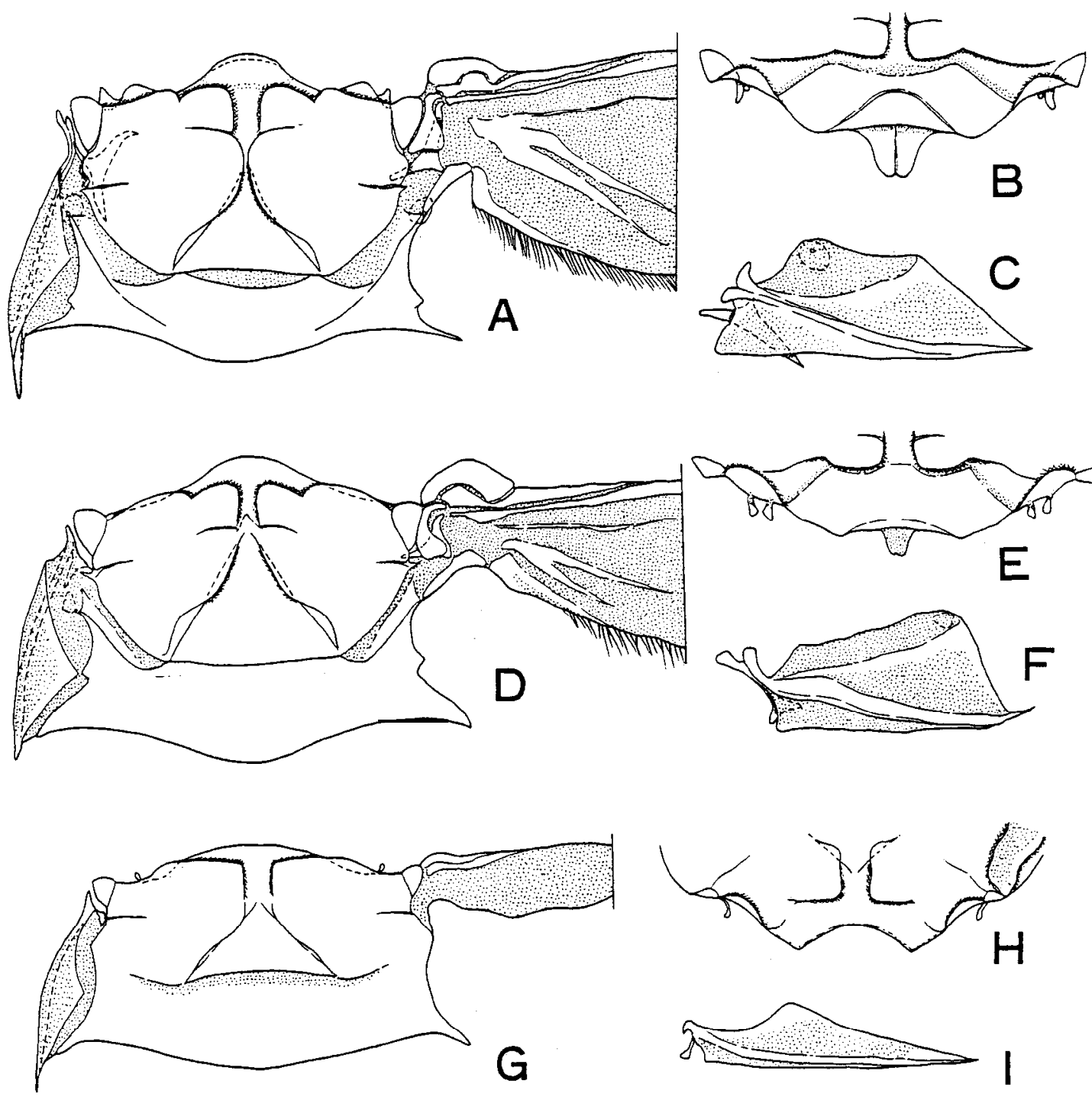
Fig. 26. Elytra in dorsal view.

A. Batrisoplisus raffrayi Jeannel, male.

B. B. uroceratus, male.

C, Cratna abdominalis Löbl, male.

$\mathrm{D}$, Batriscenellus uenoi sp. nov., male.

E, Batriscenaulax longipes longipes Jeannel, male.

F, Physomerinuspedator (Sharp), female. 

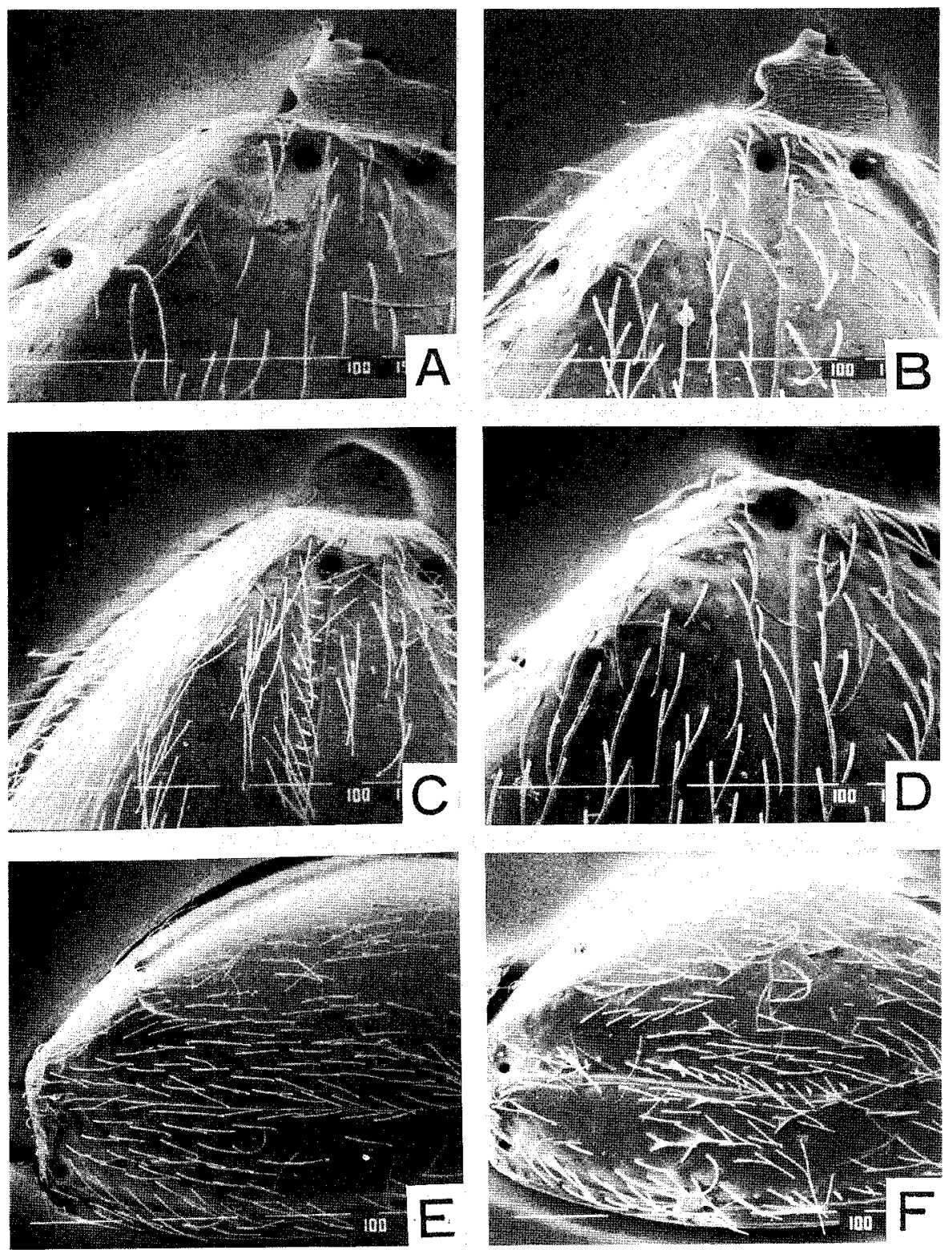
Fig. 27. Elytra in dorsal view.

A, Arthromelodes giganteus sp. nov., male.

$\mathrm{B}, \boldsymbol{A}$. mercurius sp. nov., male.

C, A. saikaiensis sp. nov., male.

D, $A$. crucifer sp. nov., male.

E, Batrisceniola dissimilis (Sharp), male.

F, Coryphomodes spinicollis Jeannel, male (out-group). 

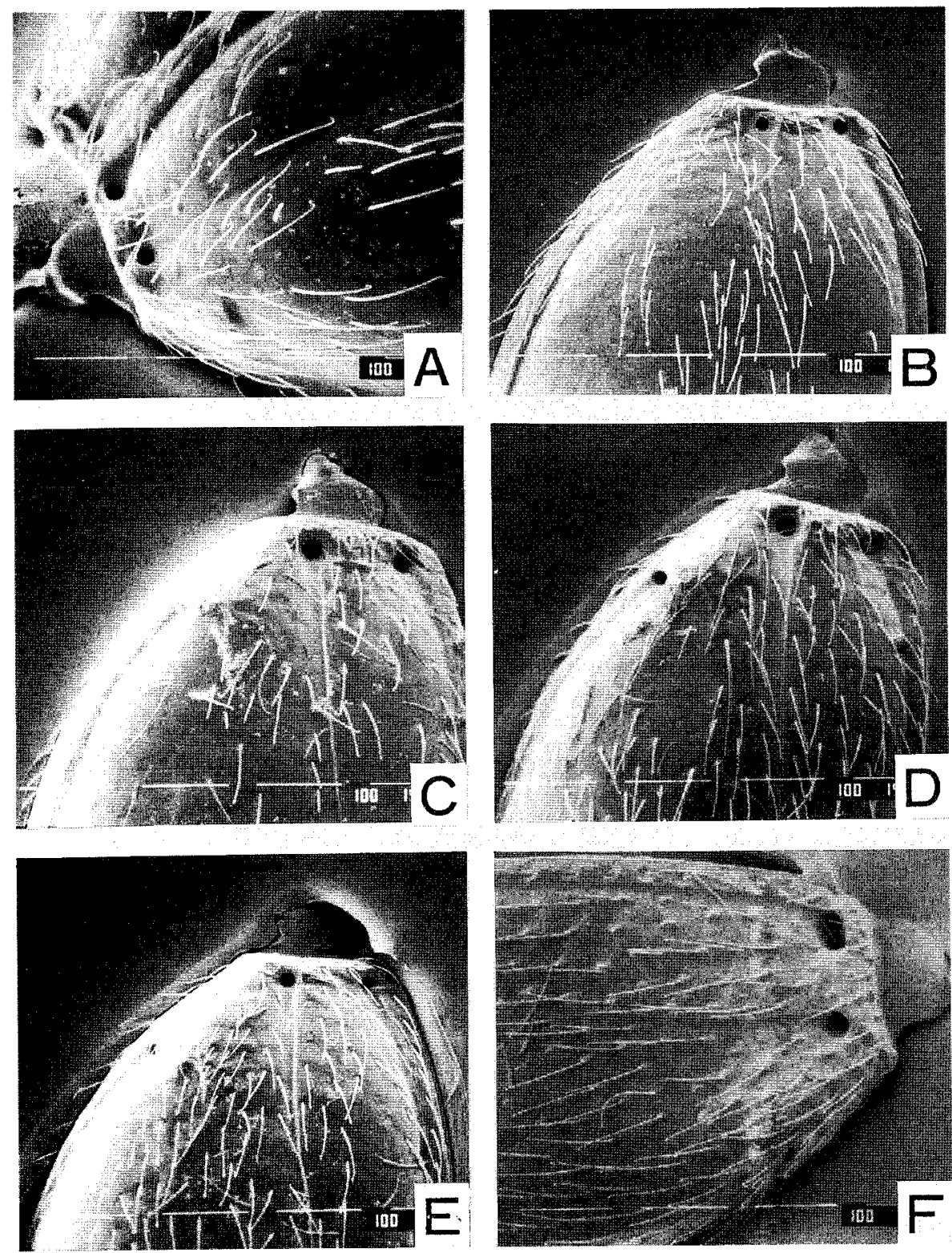
Fig. 28. Elytra in ventral view.

A, Batrisoplisus galloisi Jeannel, male.

B, Batriscenaulax furuhatai (Kubota), female.

C, B. kleinzach sp. nov., male.

$\mathrm{D}$, Arthromelodes giganteus sp. nov., male.

E, $A$. kïensis sp. nov., male.

F, Batrisceniola semipunctulata (Raffray), male. 
BATRISOPLISUS AND ITS ALLIES FROM JAPAN
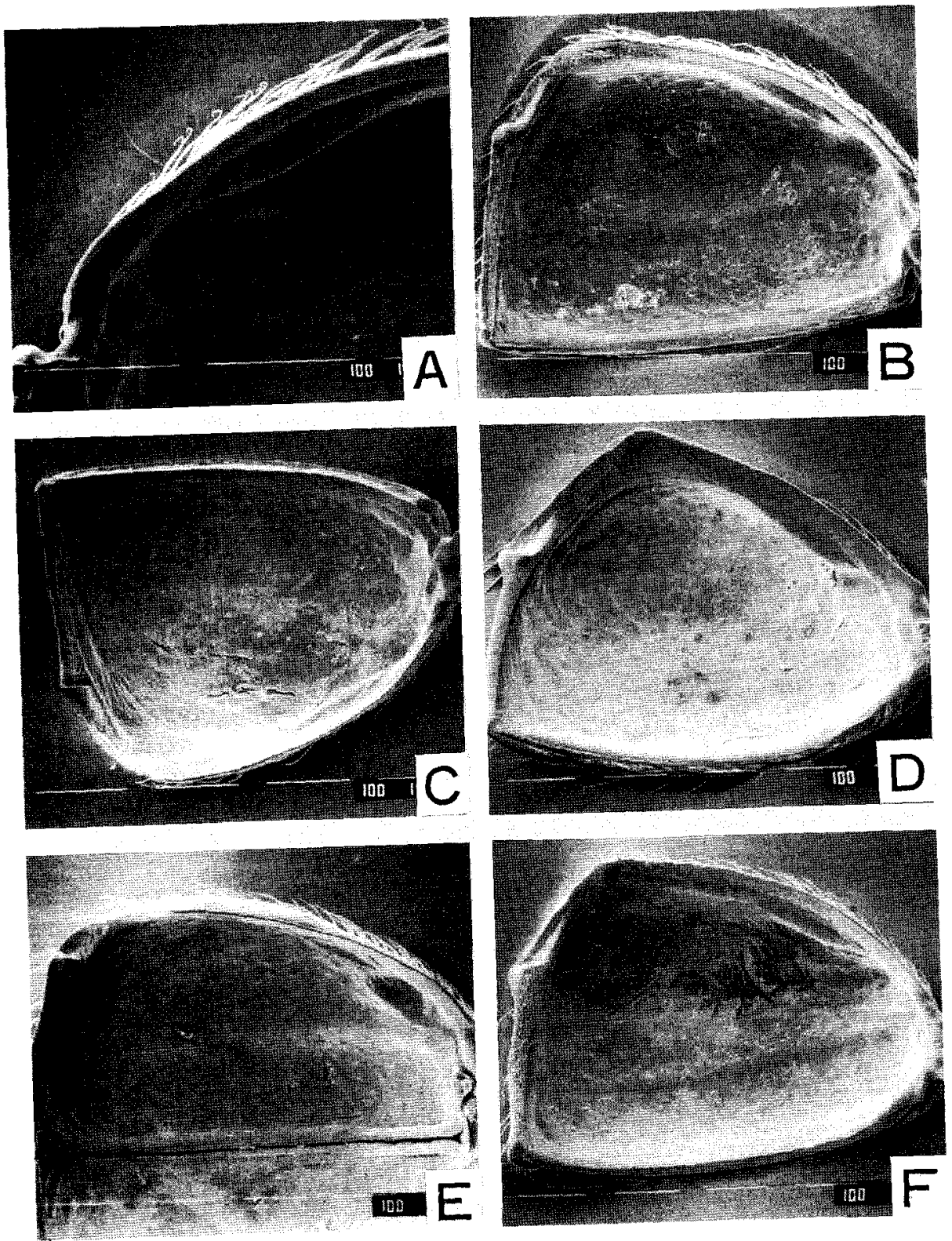
Fig. 29. Schema of locking device of elytra in Batrisceniola semipunctulata (Raffray). 


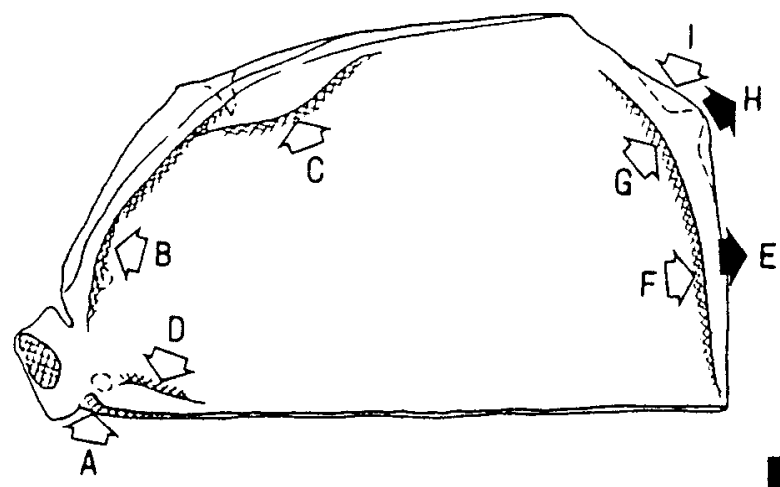

Locking process

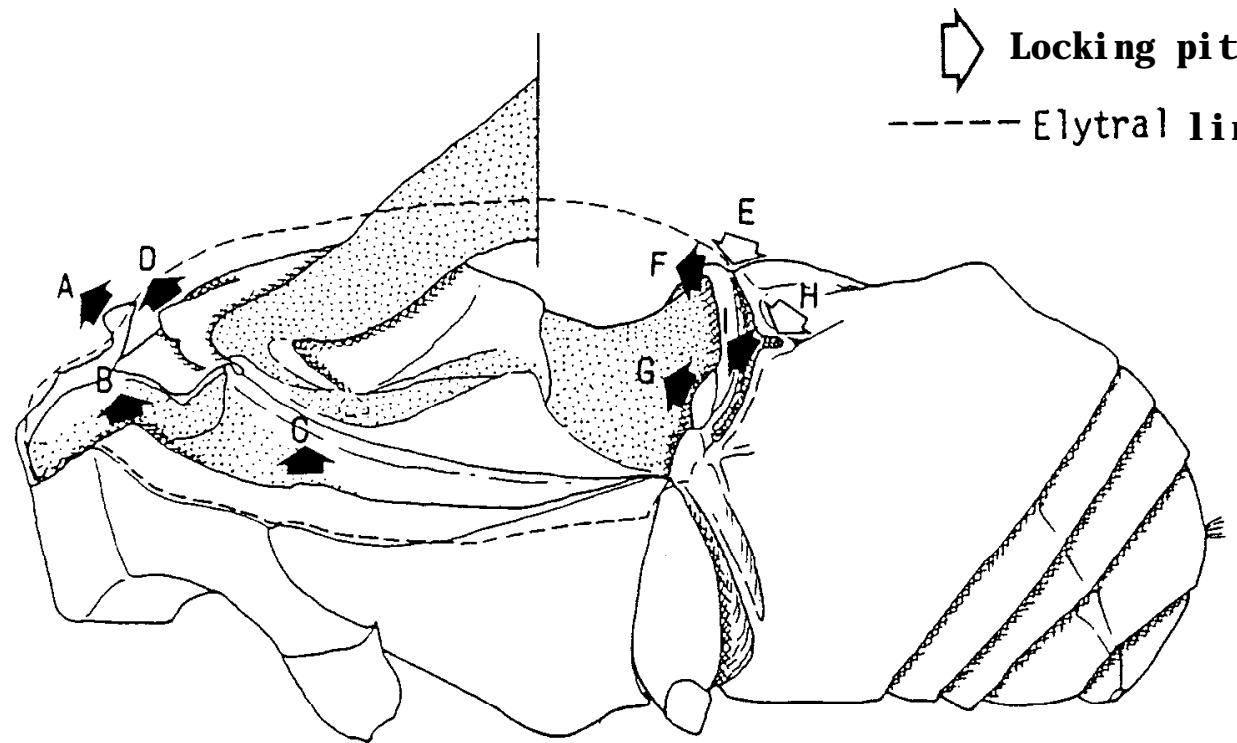


Fig. 30. Locking devices of elytra in Batrisceniola dissimilis (Sharp).

A, C, E, macropterous male.

$\mathrm{B}, \mathrm{D}, \mathrm{F}$, brachypterous male.
A, B, ventral view.
$\mathrm{C}, \mathrm{D}$, posterior view.
E, F, posterolateral parts enlarged. 

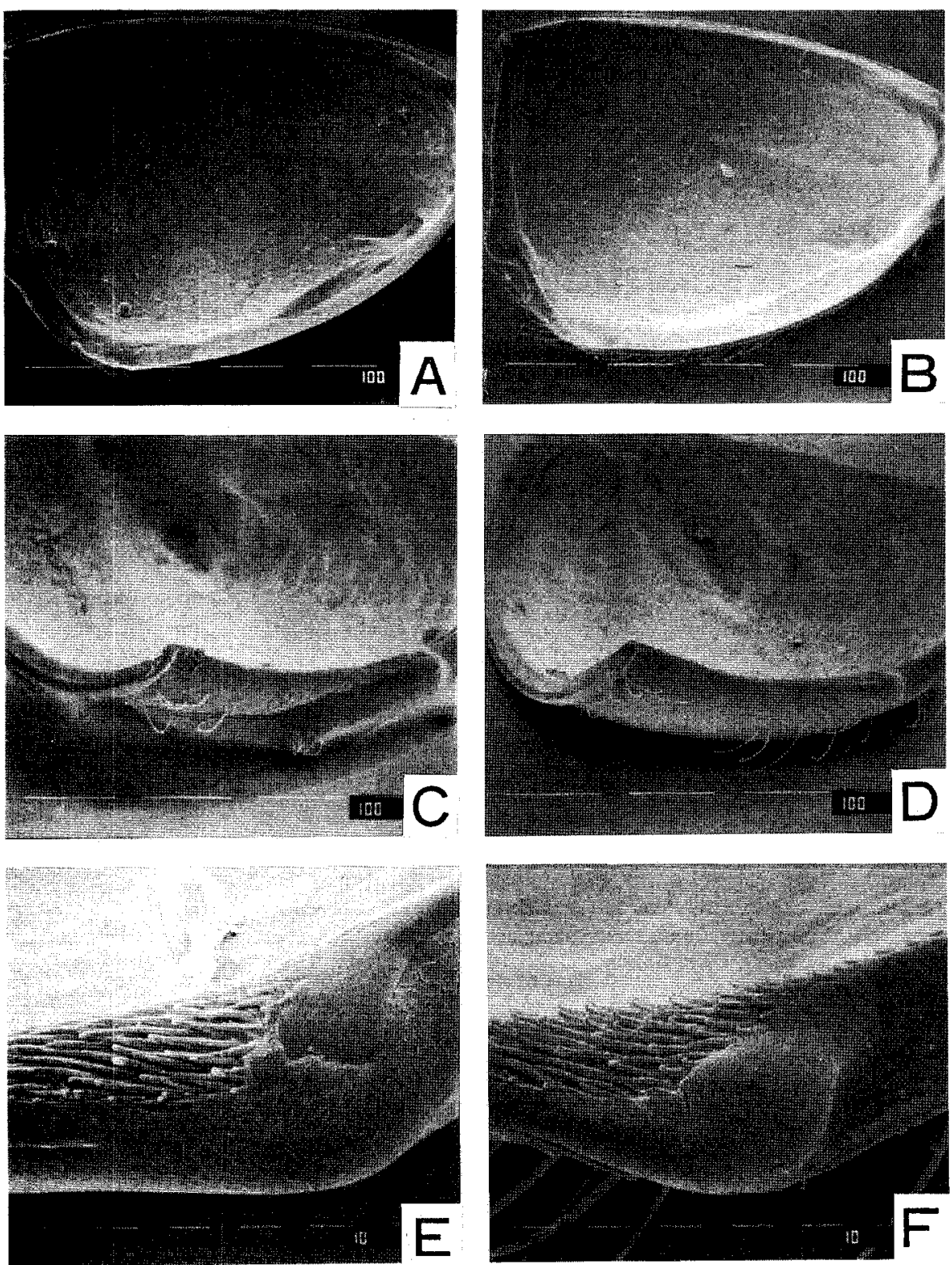
S. NOMURA

Fig. 31. Hind wings.

A, Batrisceniola dissimilis (Sharp), macropterous male.

B, ditto, brachypterous male.

C, Cratna abdominalis Löbl, macropterous male. 

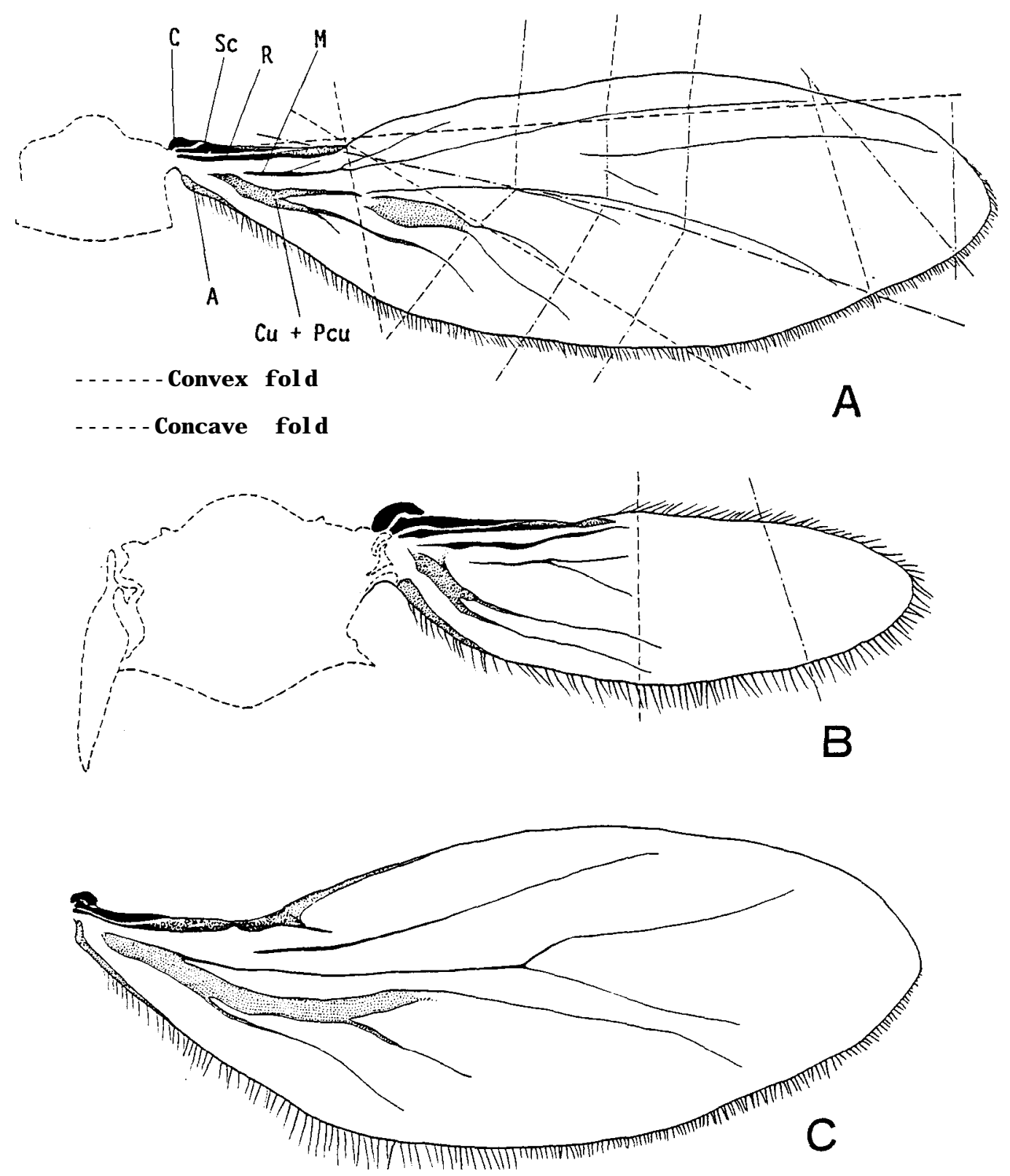
Fig. 32. Ratios of macropterous and brachypterous individuals in two wing dimorphic speck, Batriscenaulax longipes longipes Jeannel and Batrisceniola dissimilis (Sharp). 


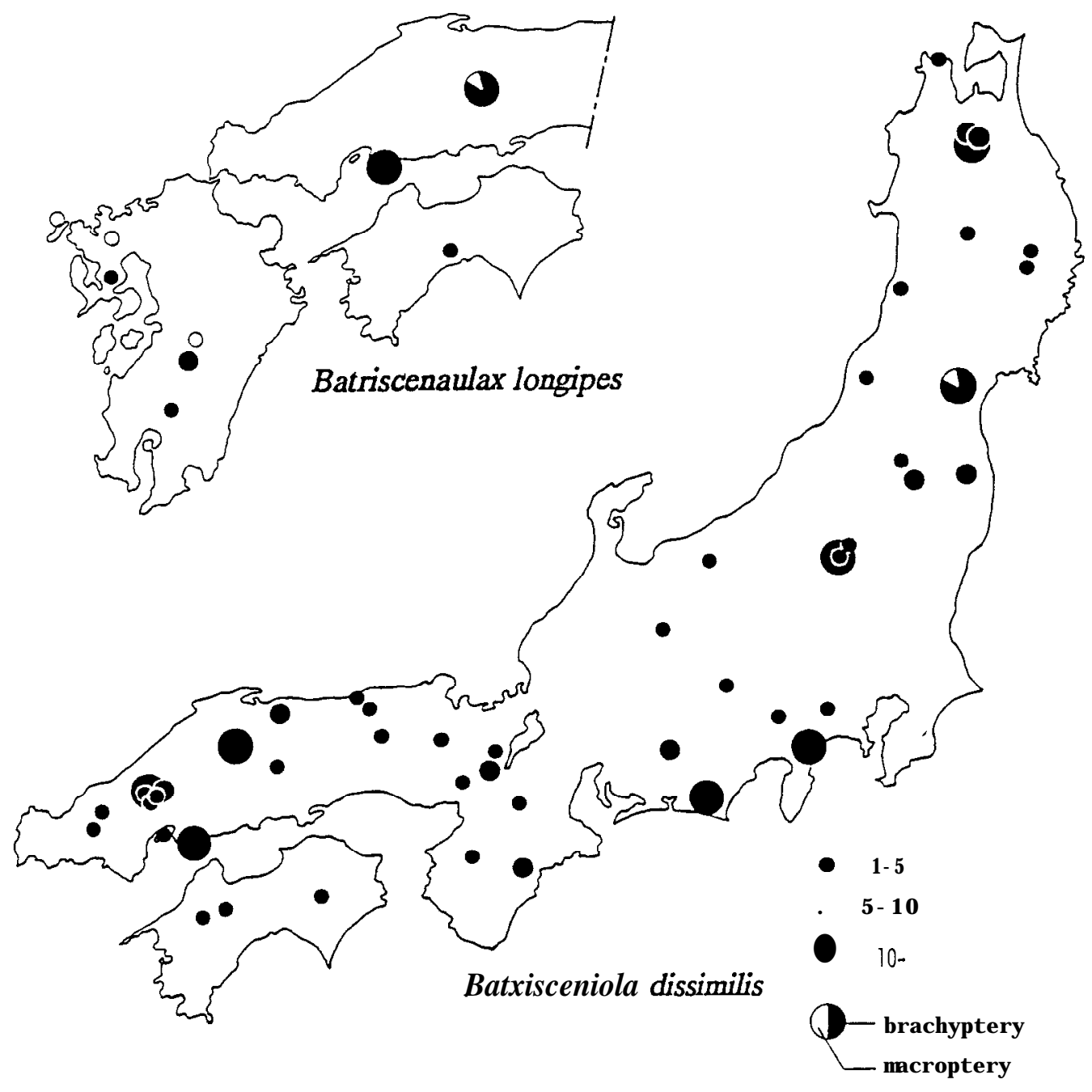


Fig. 33. Frequency distributions of relative wing length in four species of the Batrisocenus complex. 


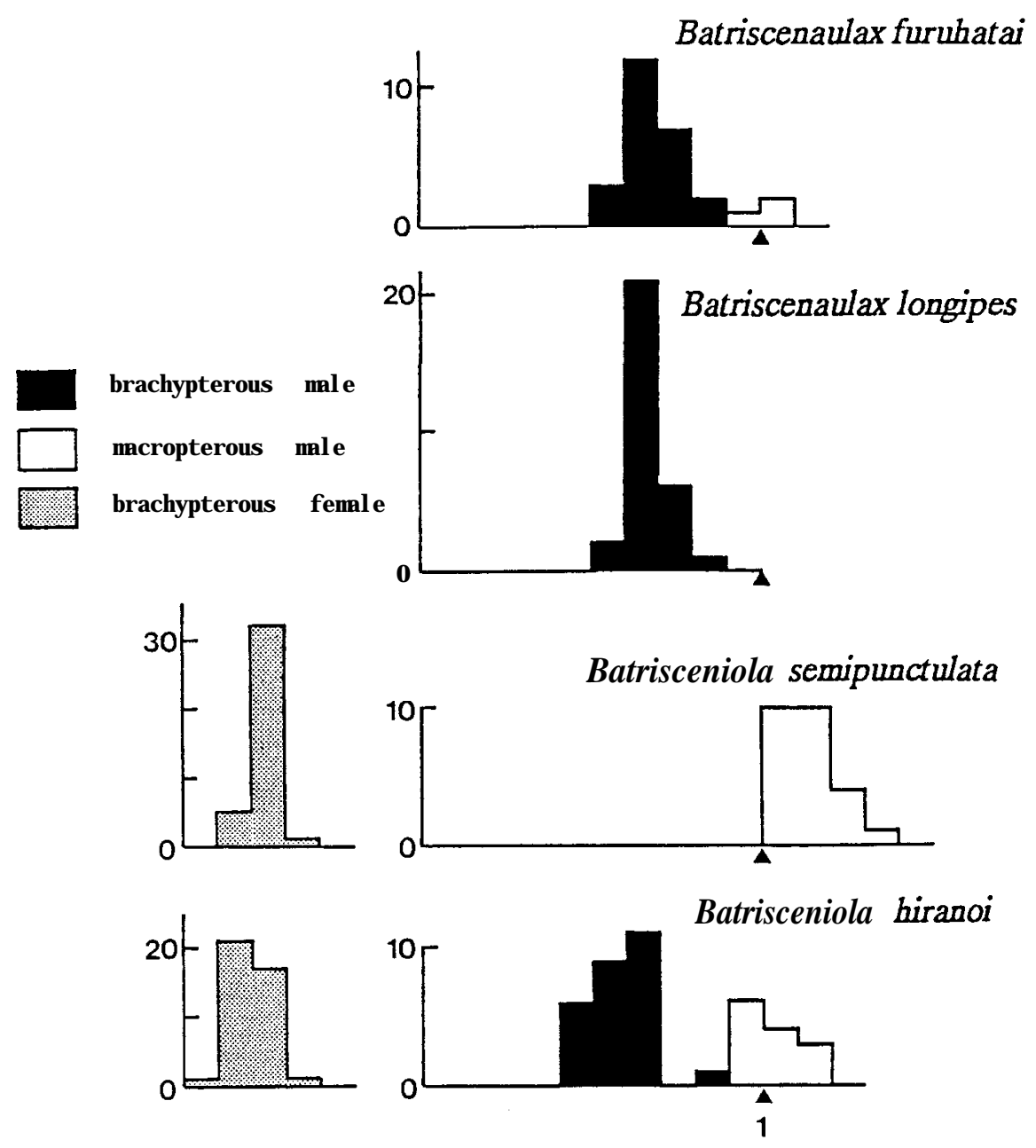


Fig. 34. Frequency distributions of relative wing length in five populations of Batrisceniola dissimilis (Sharp). 


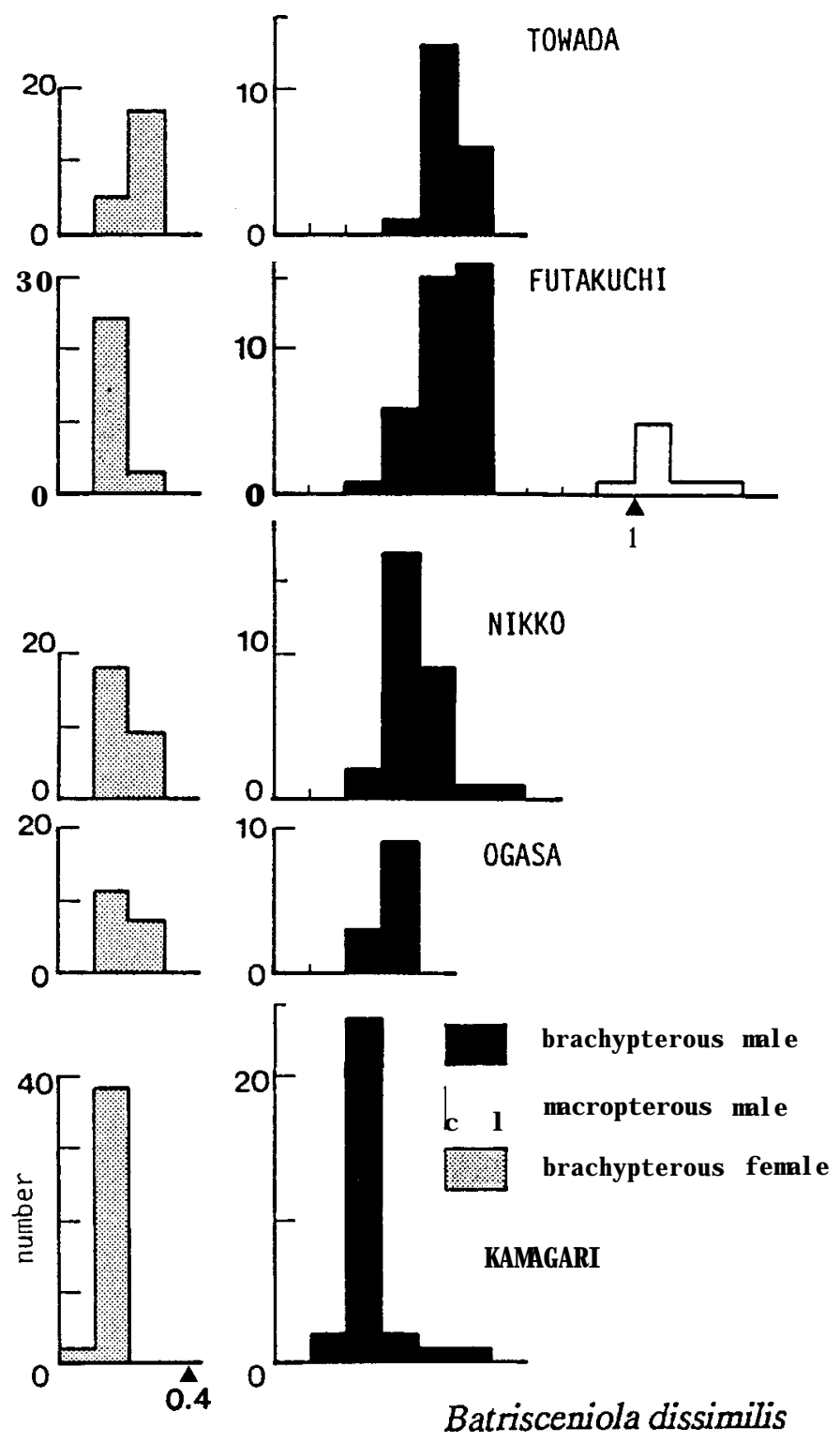


Fig. 35. Schemata of legs in Batriscenellus ohishii sp. nov.

A, fore leg.

$B$, fore tibial base.

$\mathrm{C}$, mid leg.

D, mid tibial base.

$\mathrm{E}$, hind leg.

$\mathrm{F}$, hind tibial base. 


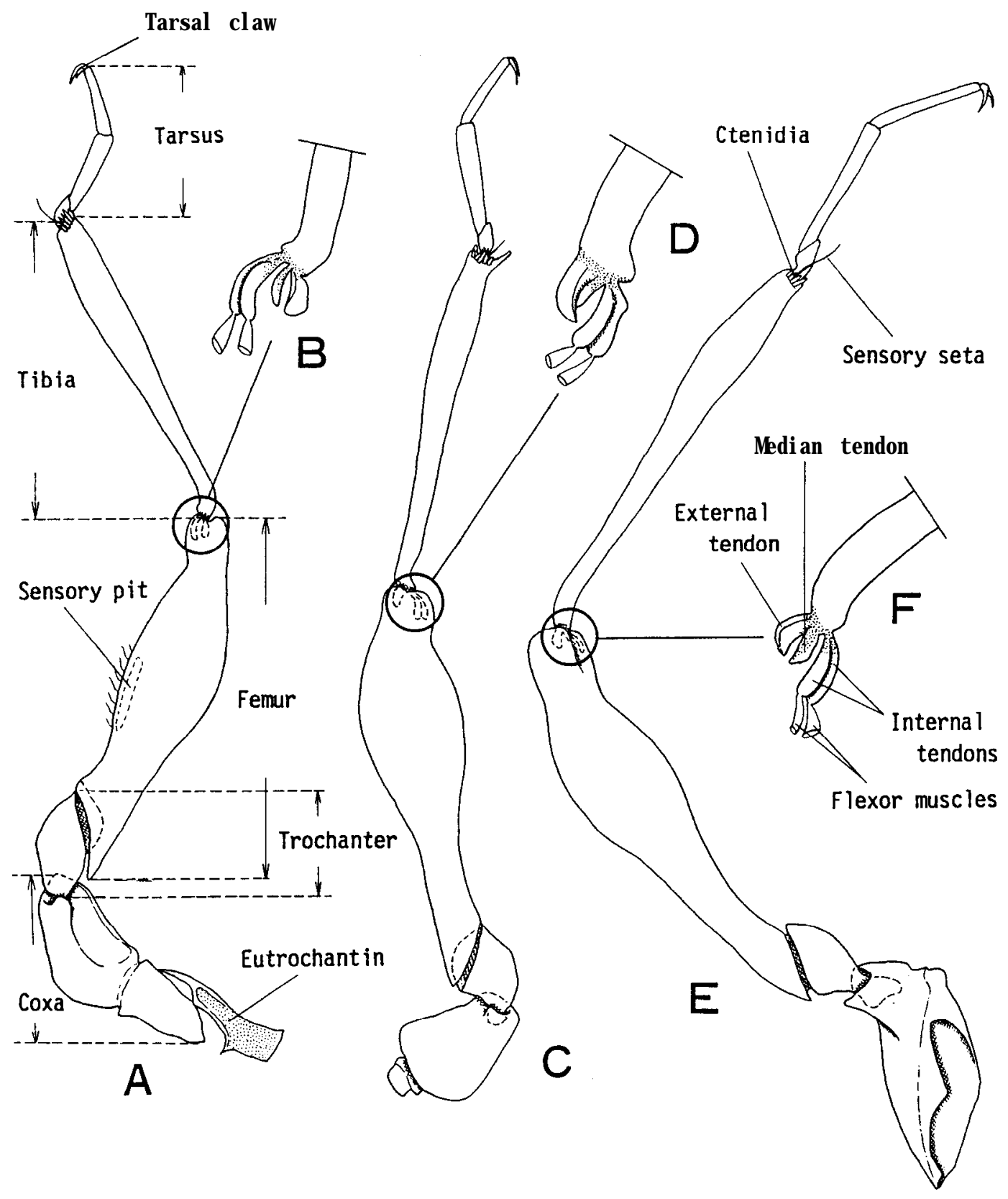


Fig. 36. Legs.
A, B, fore legs.
$\mathrm{C}$, fore femur.
D, fore tarsus.
E, hind tarsus.
A, Batriscenaulax longipes longipes Jeannel, male.
$\mathrm{B}$, Arthromelodes giganteus sp. nov., male.
C, Batrisoplisus uroceratus uroceratus sp. et subsp. nov., male.
D, Cratna abdominalis Löbl, male.
E, Batrisoplisus venustus Jeannel, male. 

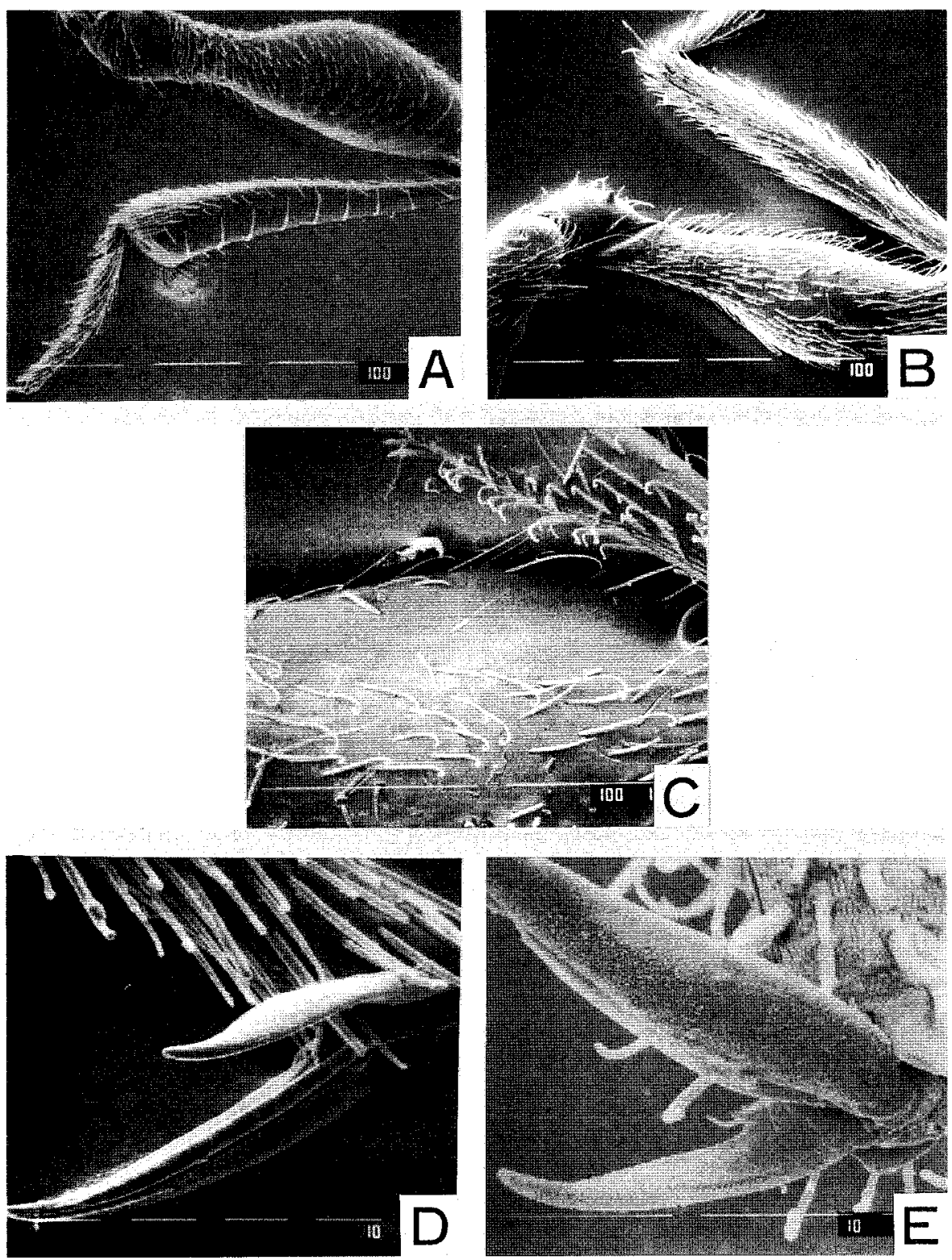
Fig. 37. Trochanters.

A, fore trochanter.

$\mathrm{B}$, mid trochanter.

C-E, hind trochanters.

A, Physomerinus pedator (Sharp), male.

$\mathrm{B}, \mathrm{D}$, Arthromelodes thysanoventris sp. nov., male.

$C$, A. kiiensis sp. nov., male.

E, A. dilatatus daibosatsuanus subsp. nov., male. 

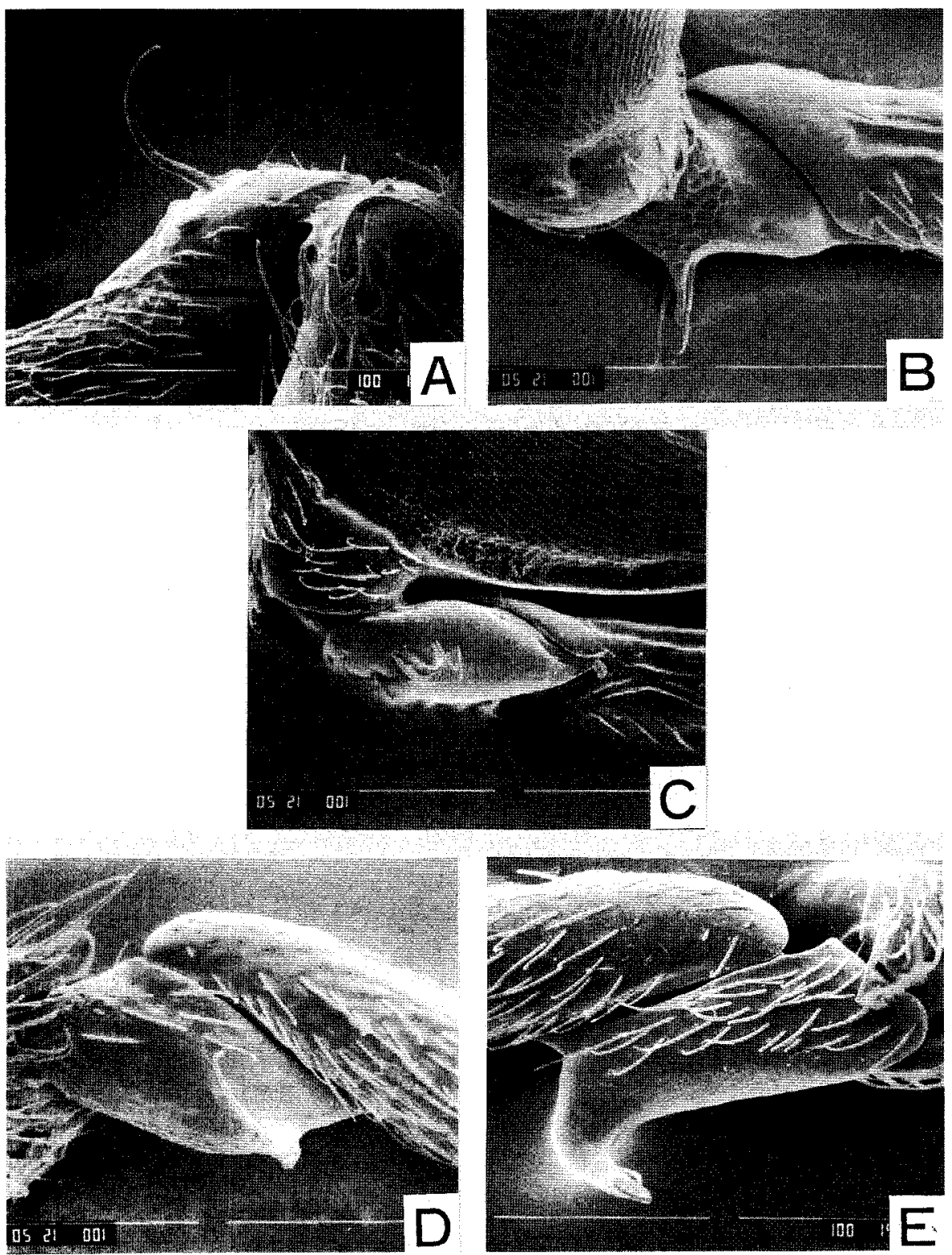
Fig. 38. Fore tibiae.
A, Batrisoplisus uroceratus uroceratus sp. et subsp. nov., male.
B, Batrisceniola furuhatai (Kubota), male.
C, B. kleinzach sp. nov., male.
D, Physomerinus schenklingi (Raffray), male.
E, Arthromelodes crucifer sp. nov., male.
F, Batrisceniola dissimilis (Sharp), male. 

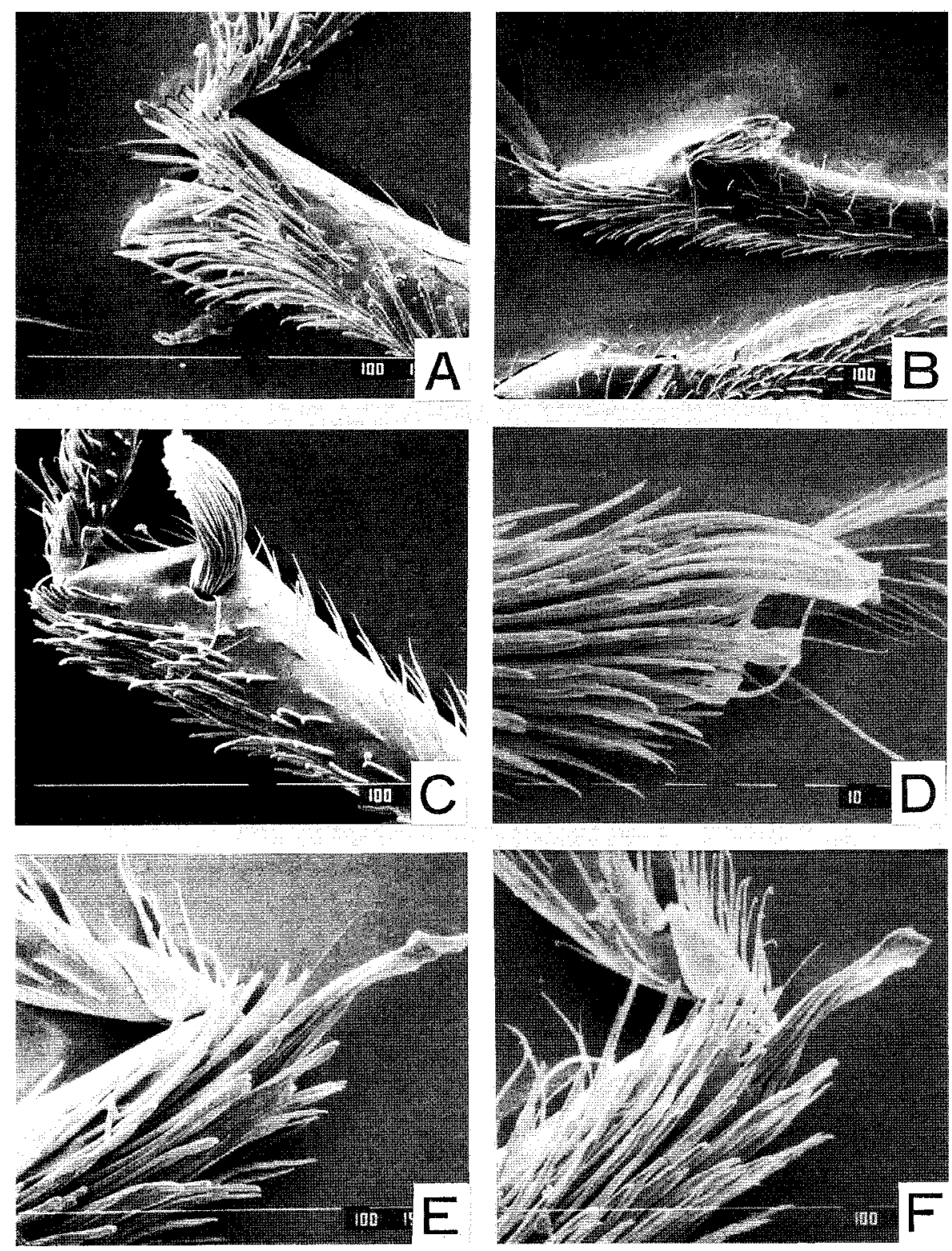


\section{Fig. 39. Mid tibiae.}
A, Batn'soplisus torticomis sp. nov., male.
B, ditto, female.
C, B. uroceratus uroceratus sp. et subsp. nov., male.
D, ditto, female.
E, Batriscenellus ohishii sp. nov., male.
$\mathrm{F}$, ditto, female. 

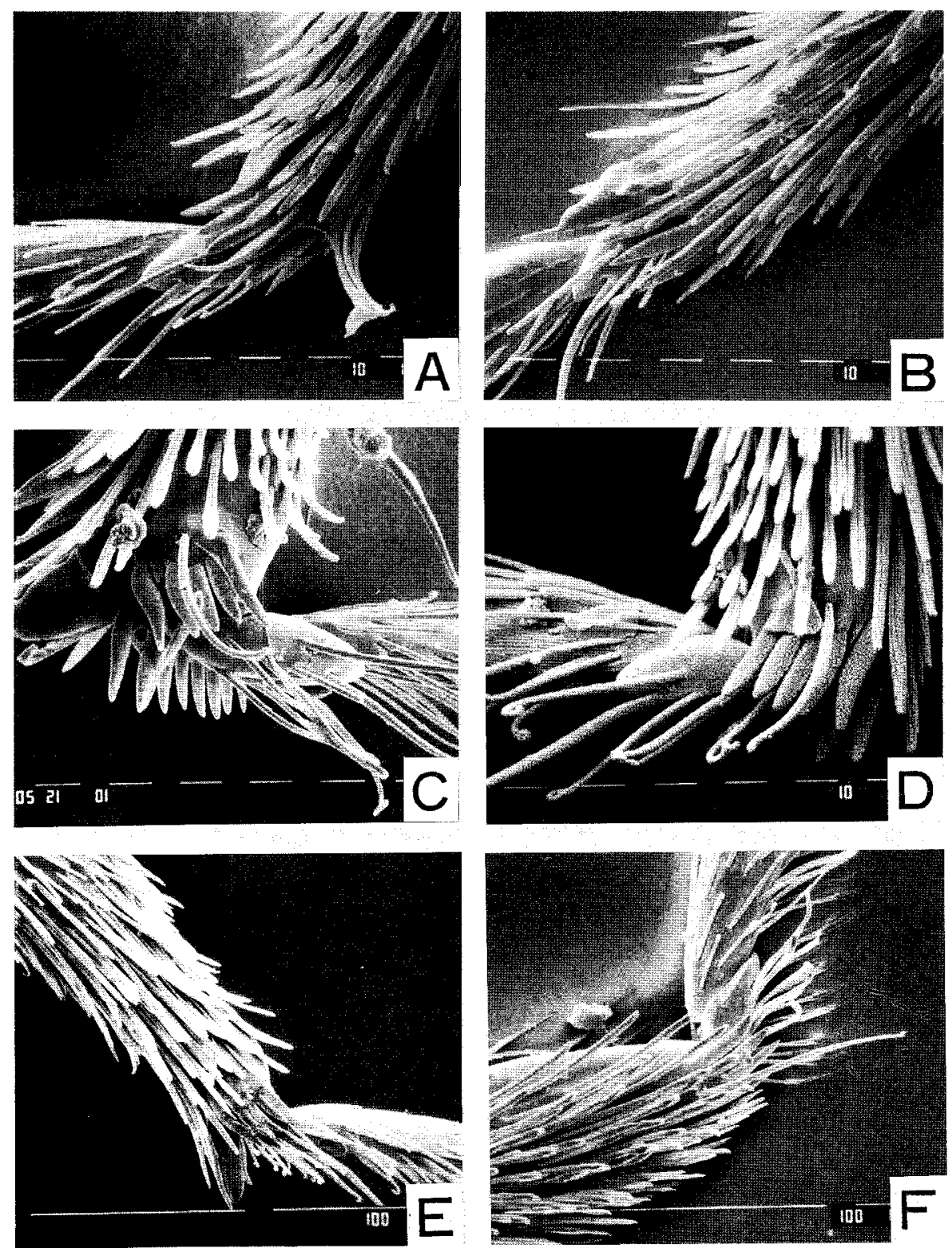
Fig. 40. Mid tibiae.

A, Cratna abdominalis Löbl, male.

B, Physomerinus schenklingi (Raffray), male.

$\mathrm{C}$, Arthromelodes mercurius sp. nov., male.

$\mathrm{D}$, A. dilatatus daibosatsuanus subsp. nov., male.

E, A. saikaiensis sp. nov., male.

F, A. dissimilis (Sharp), male. 

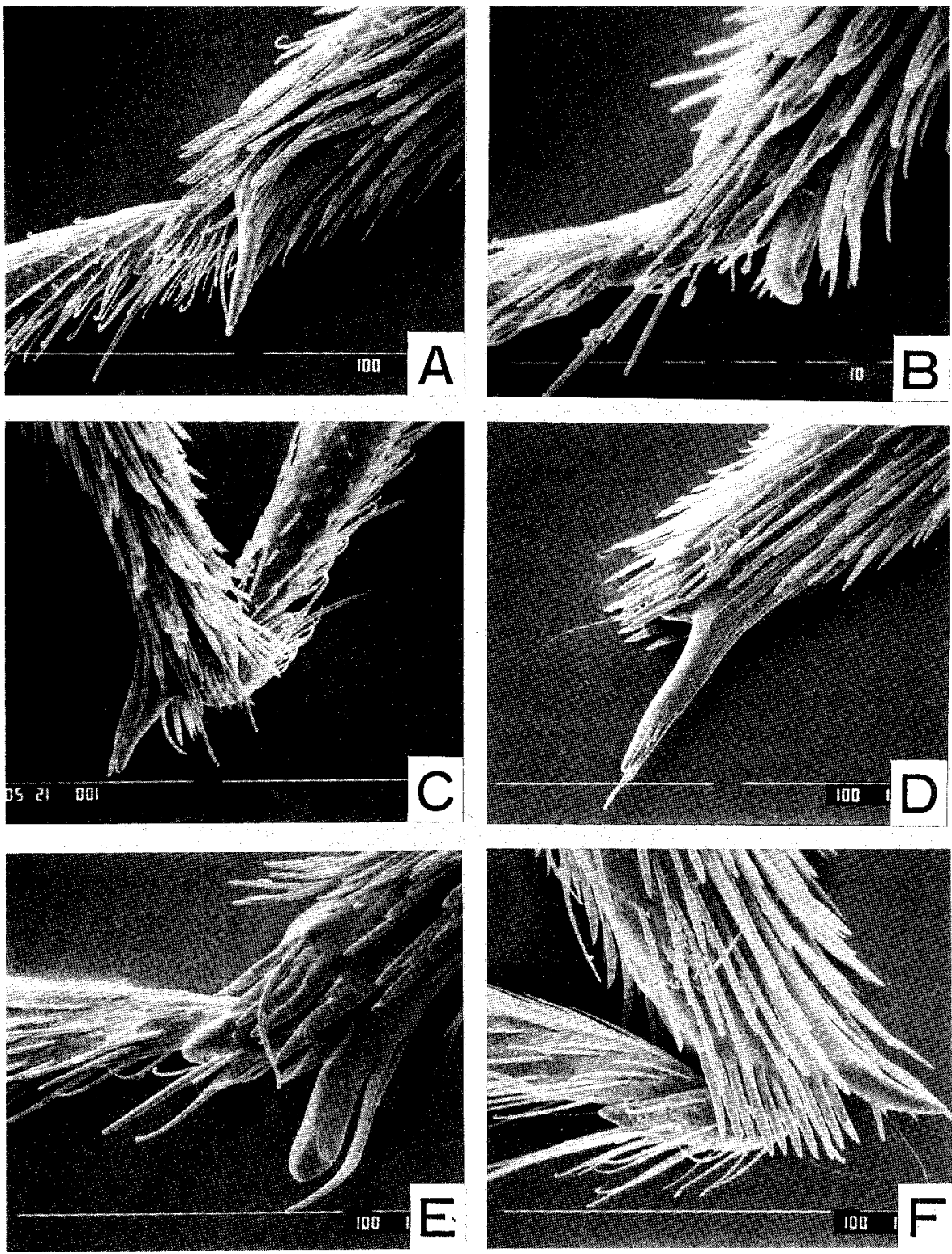
Fig. 41. Fourth abdominal segments.

A-D, dorsal view.

$\mathrm{E}, \mathrm{F}$, lateral view.

A, Batrisoplisus uroceratus uroceratus sp. et subsp. nov., female.

B, B. parallelus sp. nov., female.

C, Batriscenellus ohishii sp. nov., female.

D, Cratna abdominalis Löbl, male.

E, Physomerinus pedator (Sharp), male.

F, Arthromelodes mercurius sp. nov., male. 

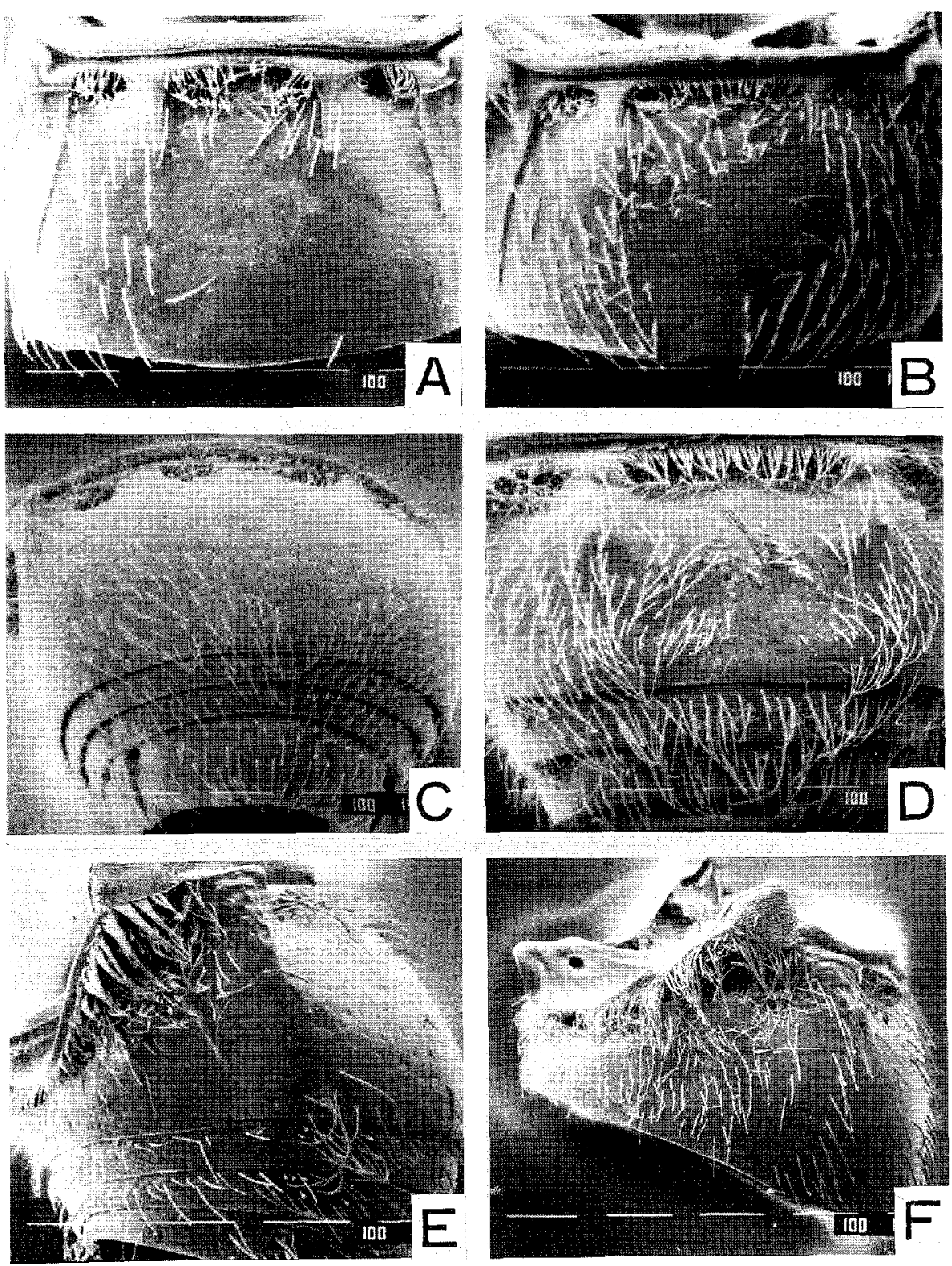
Fig. 42 Fourth abdominal segment in ventral view.

A, Batrisoplisus uroceratus uroceratus sp. ct subsp. nov., male.

B, Batriscenellus uenoi sp. nov., male.

C, Batriscenaulax longipes longipes Jeannel, female.

$\mathrm{D}$, Physomerinus schenklingi (Raffray), male.

E, Arthromelodes saikaiensis sp. nov., male.

$\mathrm{F}$, Batrisceniola dissimilis (Sharp), male. 

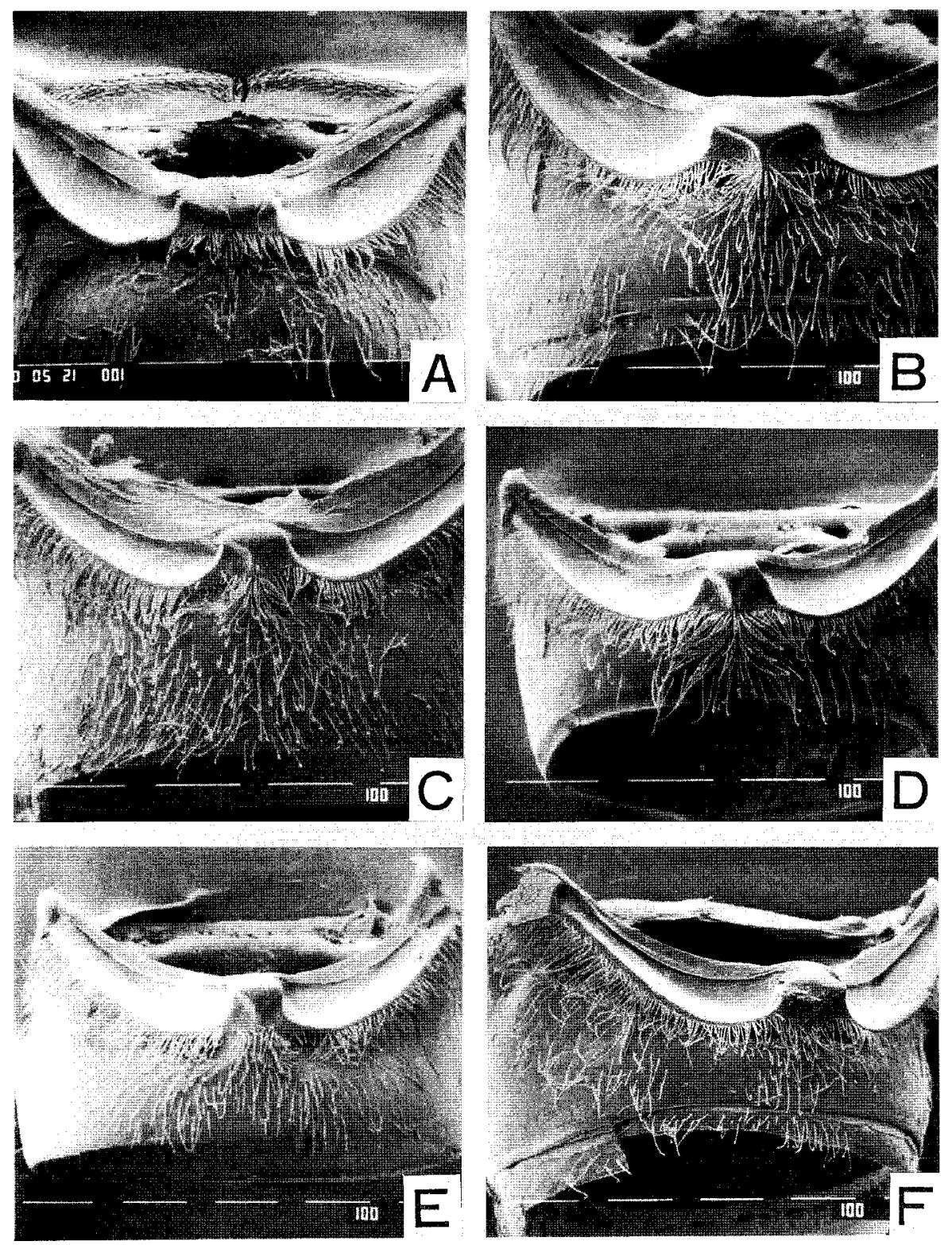
Fig. 43. Fourth abdominal sternites in Batrisoplisus. A-F, male.
A, B. galloisi Jeannel.
$\mathrm{B}, \boldsymbol{B}$. venustus Jeannel.
C, B. okamotoi sp. nov.
D, B. raffrayi Jeannel.
E, B. monostatos sp. nov.
F, B. parallelus sp. nov. 

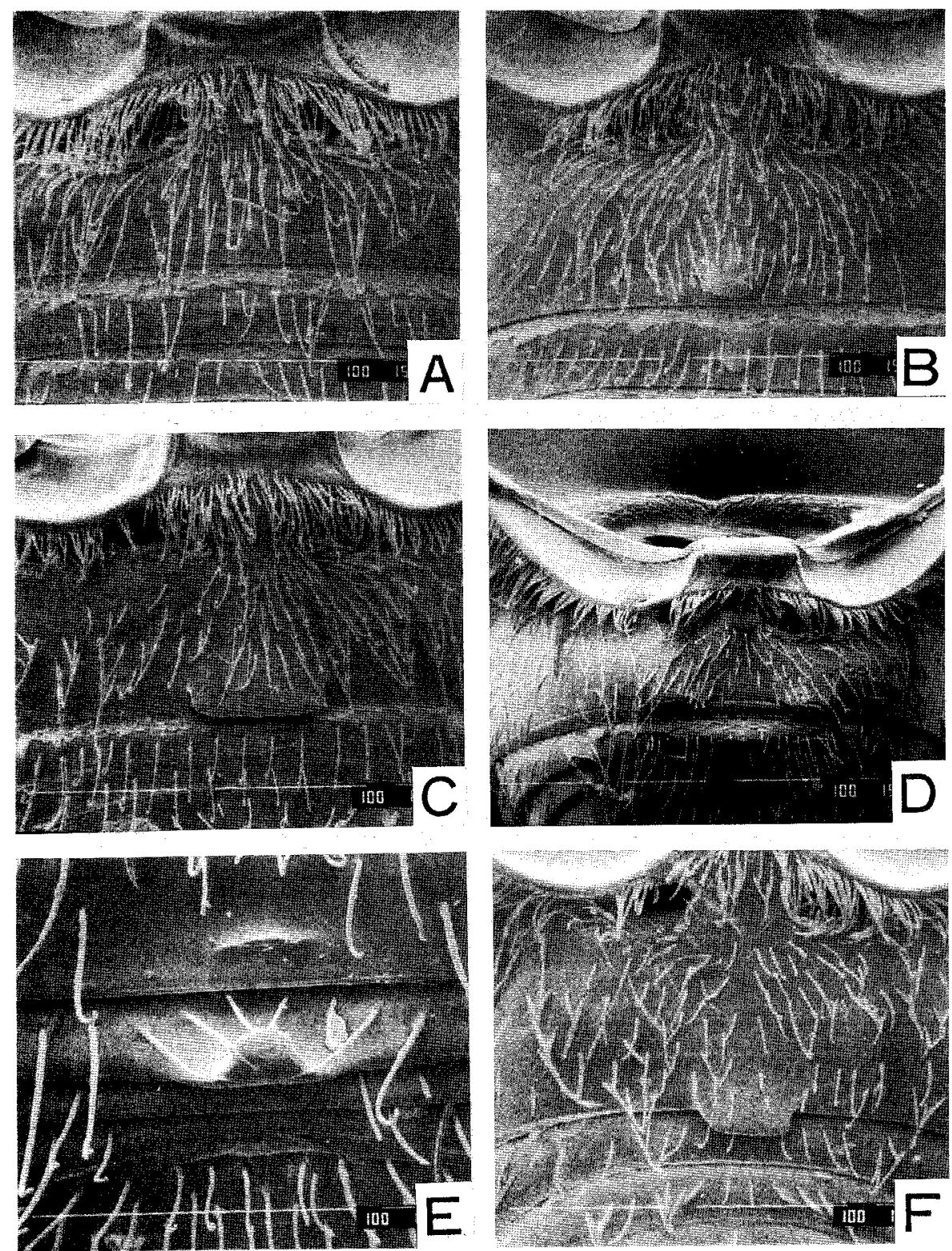
Fig 44. Schema of abdomen and 4th abdominal segments.

A, abdomen lateral view.

B-F, ditto, anterior view.
A, B, Batrisoplisus raffrayi Jeannel.
$\mathrm{C}, B$. parallelus sp. nov.
$\mathrm{D}, B$. uroceratus uroceratus sp. et subsp. nov.
E, Batriscenellus kujumontanus sp. nov.
F, B. uenoi sp. nov. 

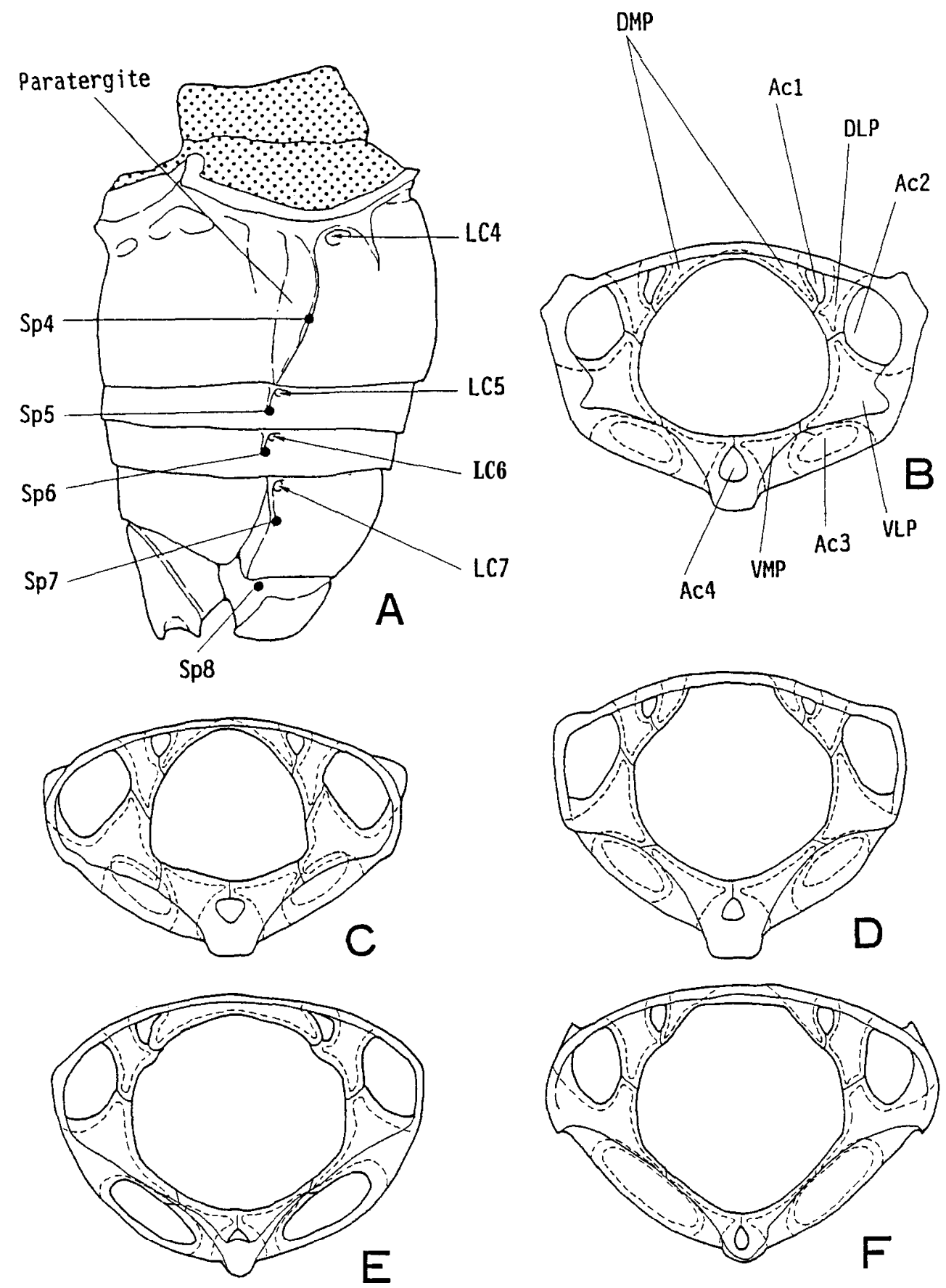
Fig. 45. Fourth abdominal segments in anterior view.
A, Cratna abdominalis Löbl.
B, Batriscenaulax kleinzach sp. nov.
C, B. furuhatai (Kubota).
D, Physomerinus schenklingi (Raffray).
E, Arthromelodes punctifrons sp. nov.
F, A. giganteus sp. nov. 

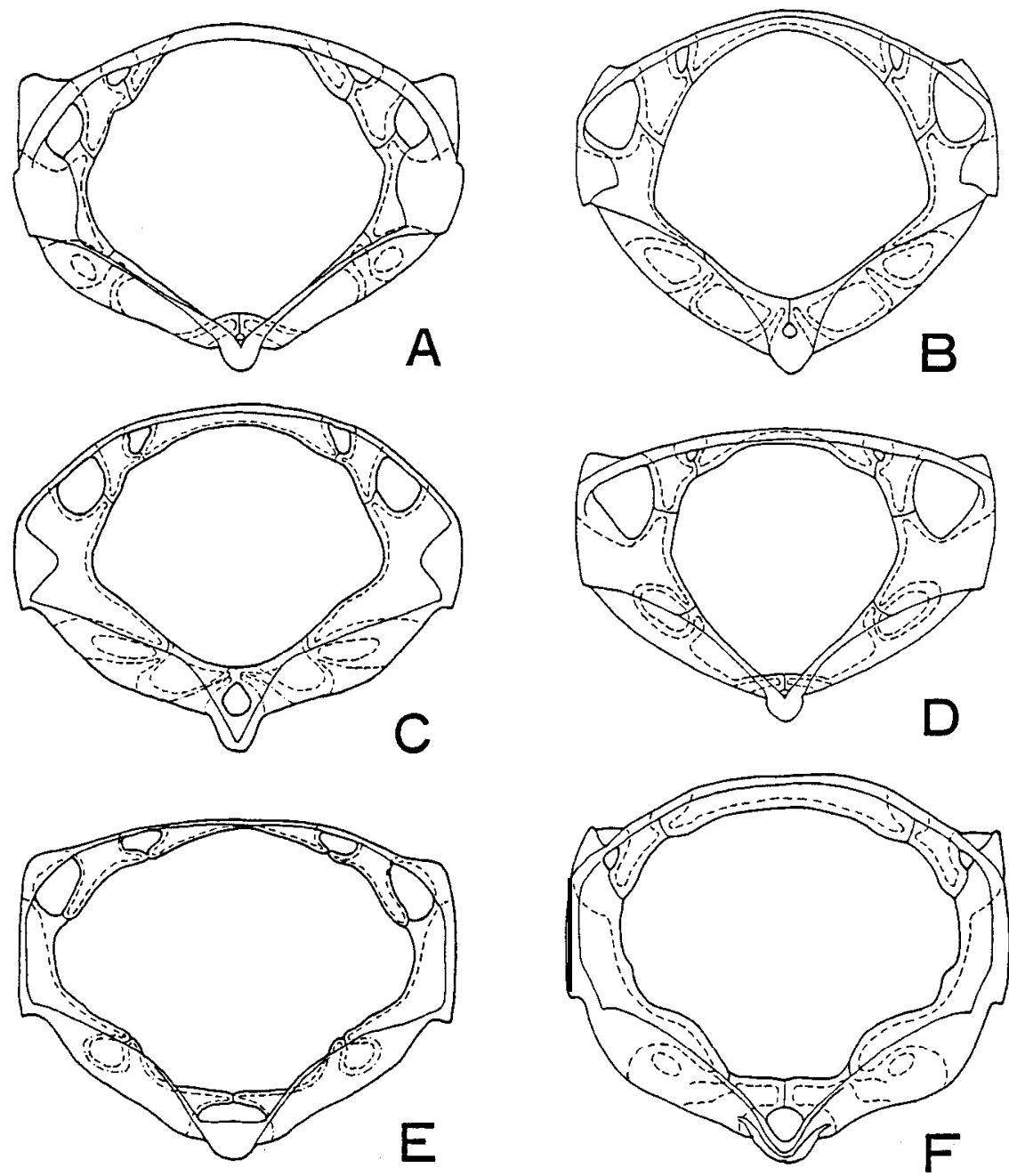
Fig. 46. Fourth abdominal segments in anterior view.

A, Arthromelodes kiiensis sp. nov.

B, A. thysanoventris sp. nov.

C, A. mercurius sp. nov.

D, A. saikaiensis sp. nov.

E, A. crucifer sp. nov.

F, Batrisceniola dissimilis (Sharp).

G, B. semipunctulata (Raffray). 


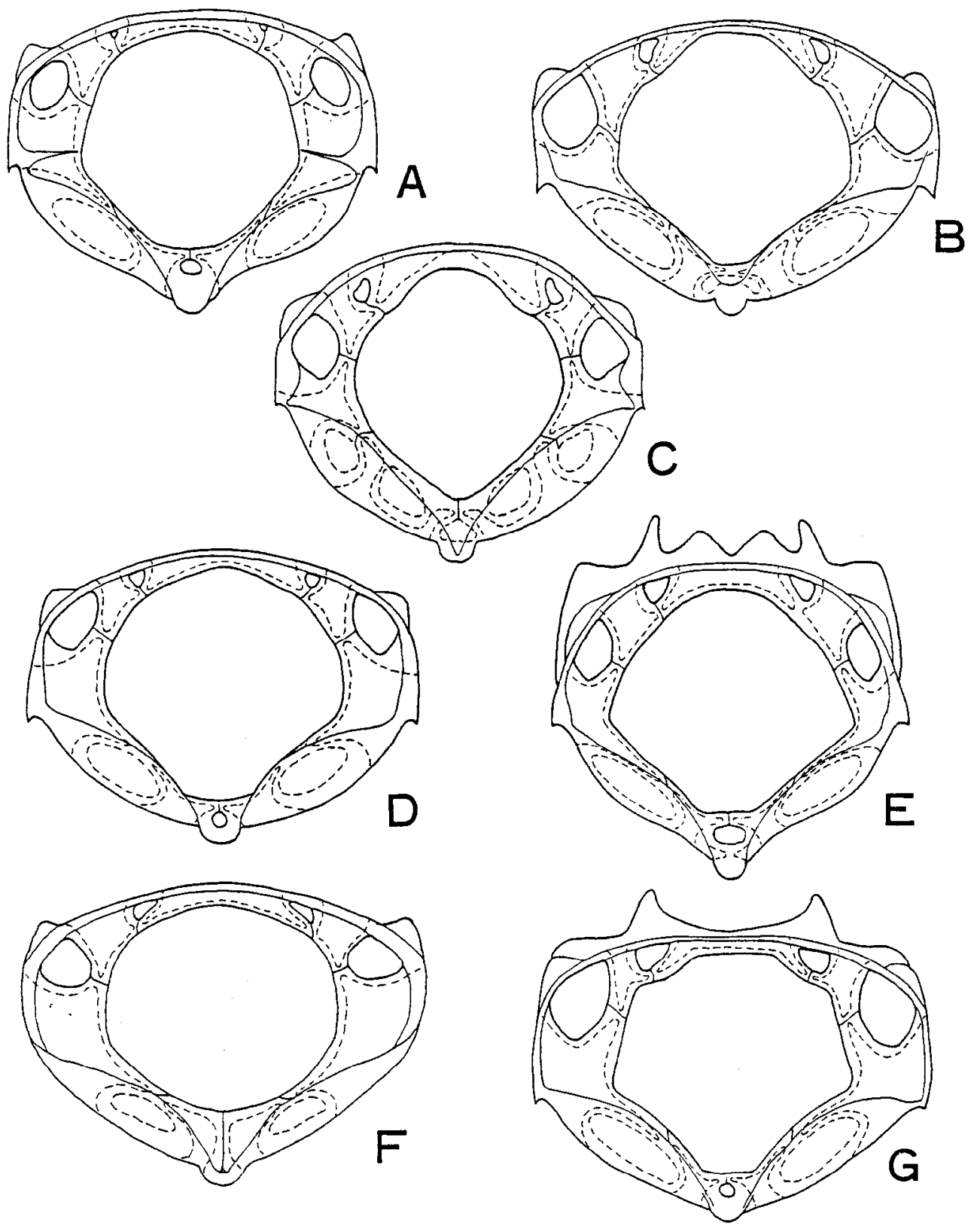


Fig. 47. Fifth to 9th abdominal segments.
A, C, E, dorsal view.
$B, F$, ventral view.
D, lateral view.

A, B, Batrisoplisus torticornis sp. nov., male.

C, D, B. uroceratus uroceratus sp. et subsp. nov., male.

$\mathbf{E}, \mathbf{F}$, ditto, female. 

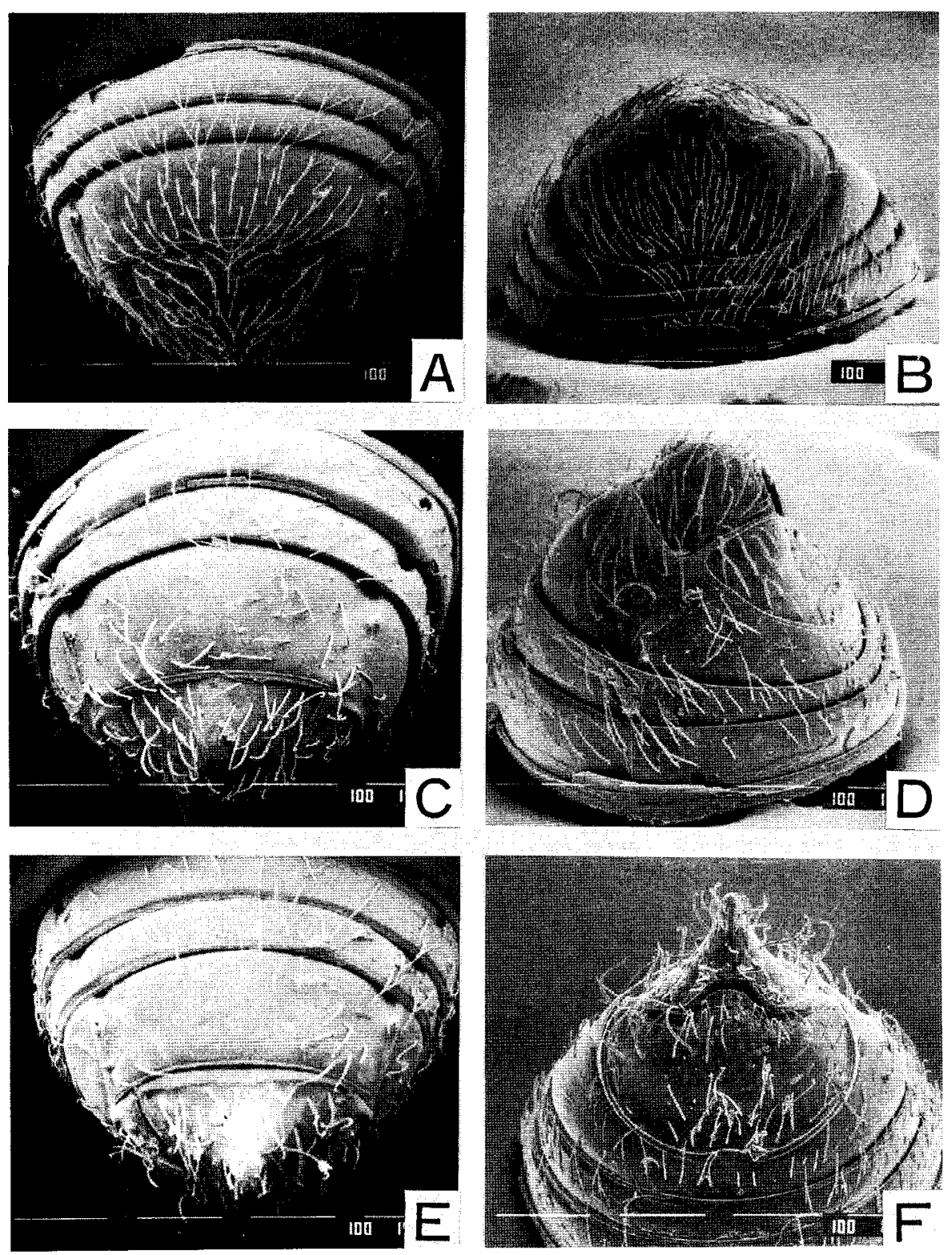
Fig. 48. Fifth to 9th abdominal segments.

A-C, E, F, posterior view.

$\mathrm{D}$, ventral view.

A, Batriscenellus kujumontanus sp. nov., male.

B, B. ohishii sp. nov., male.

C, D, Cratna abdominal\& Löbl, male.

E, Batriscenaulax furuhatai (Kubota), male.

F, B. longipes longipes Jeannel, female. 

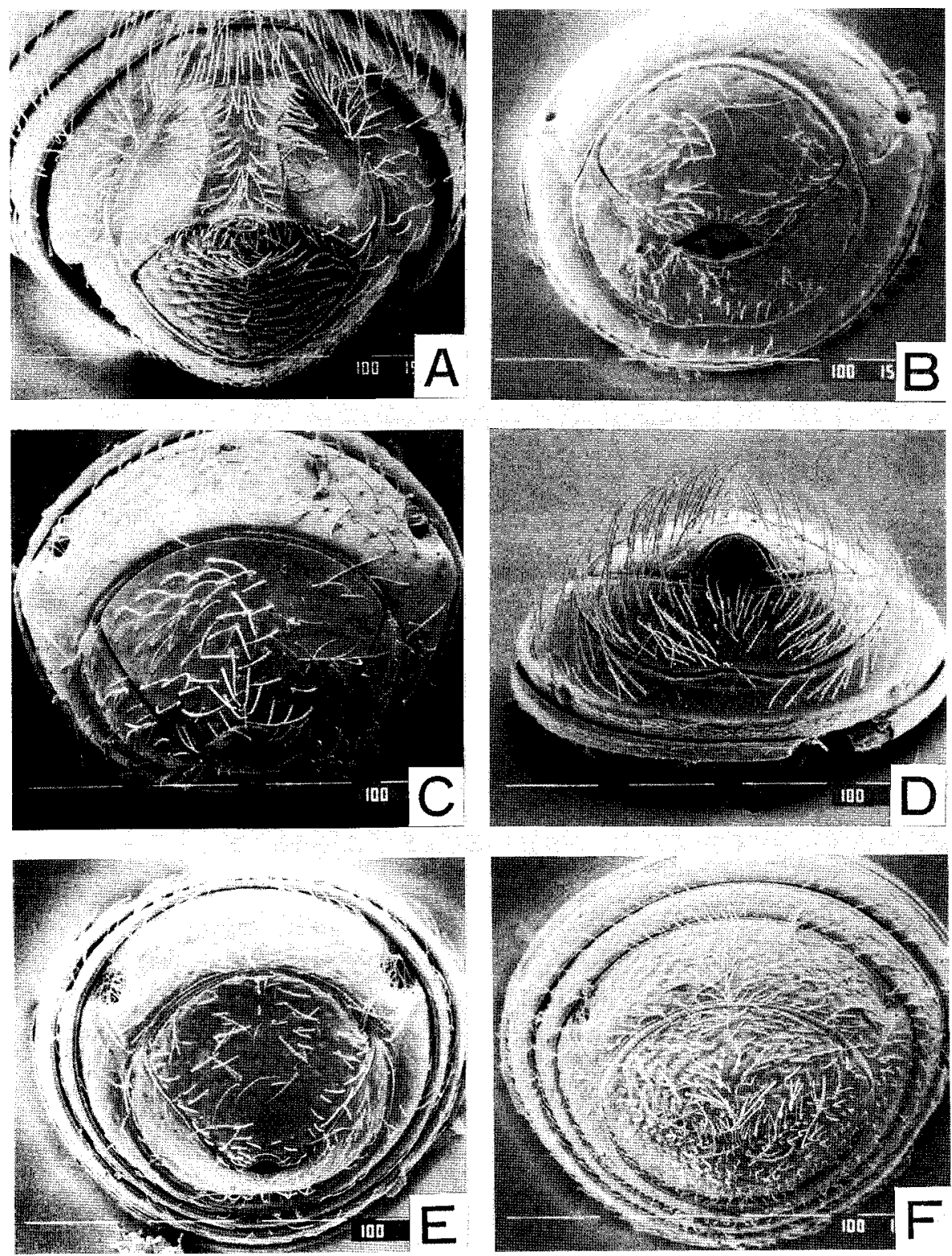
Fig. 49. Fifth to 9th abdominal segments.
A, E, ventral view.
B-D, posterior view.
$\mathrm{F}$, lateral view.
A, Physomerinus schenklingi (Raffray), male.
B, ditto, female.
C, Arthromelodes giganteus sp. nov., male.
D-F, A. mercurius sp. nov., male. 

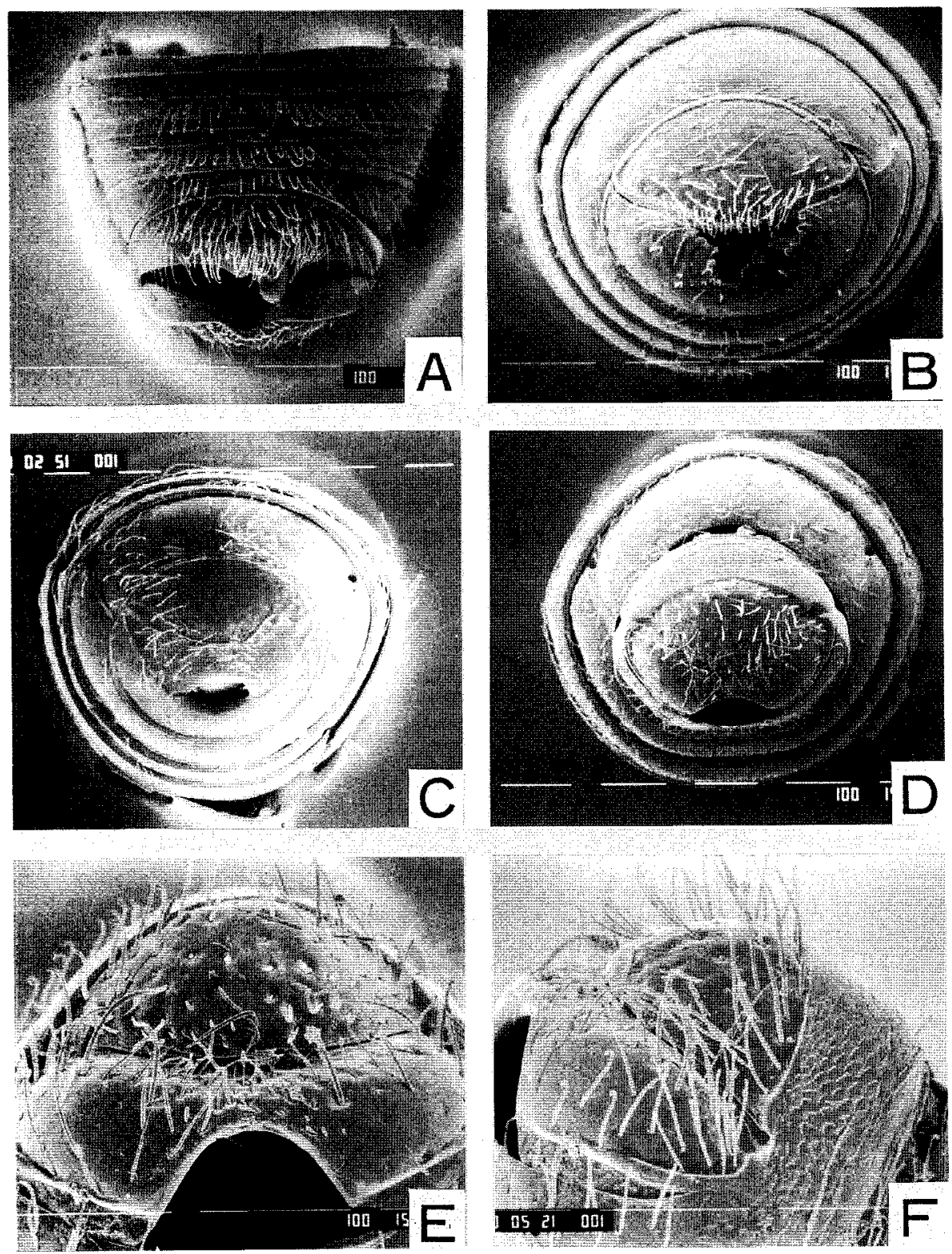
Fig. 50. Abdomen.

A-D, posterior view.

$\mathrm{E}$, lateral view.

$\mathrm{F}$, ventral view.

A, Arthromelodes küensis sp. nov., male.

B, A. dilatatus daibosatsuanus subsp. nov., male.

C, $A$. saikaiensis sp. nov., male.

$\mathrm{D}$, Batrisceniola dissimilis (Sharp), male.

E, Batniodes dorsalis Jeanne1 (out-group), male.

$\mathrm{F}$, Coryphomodes spinicollis (Jeannel) (out-group), male. 

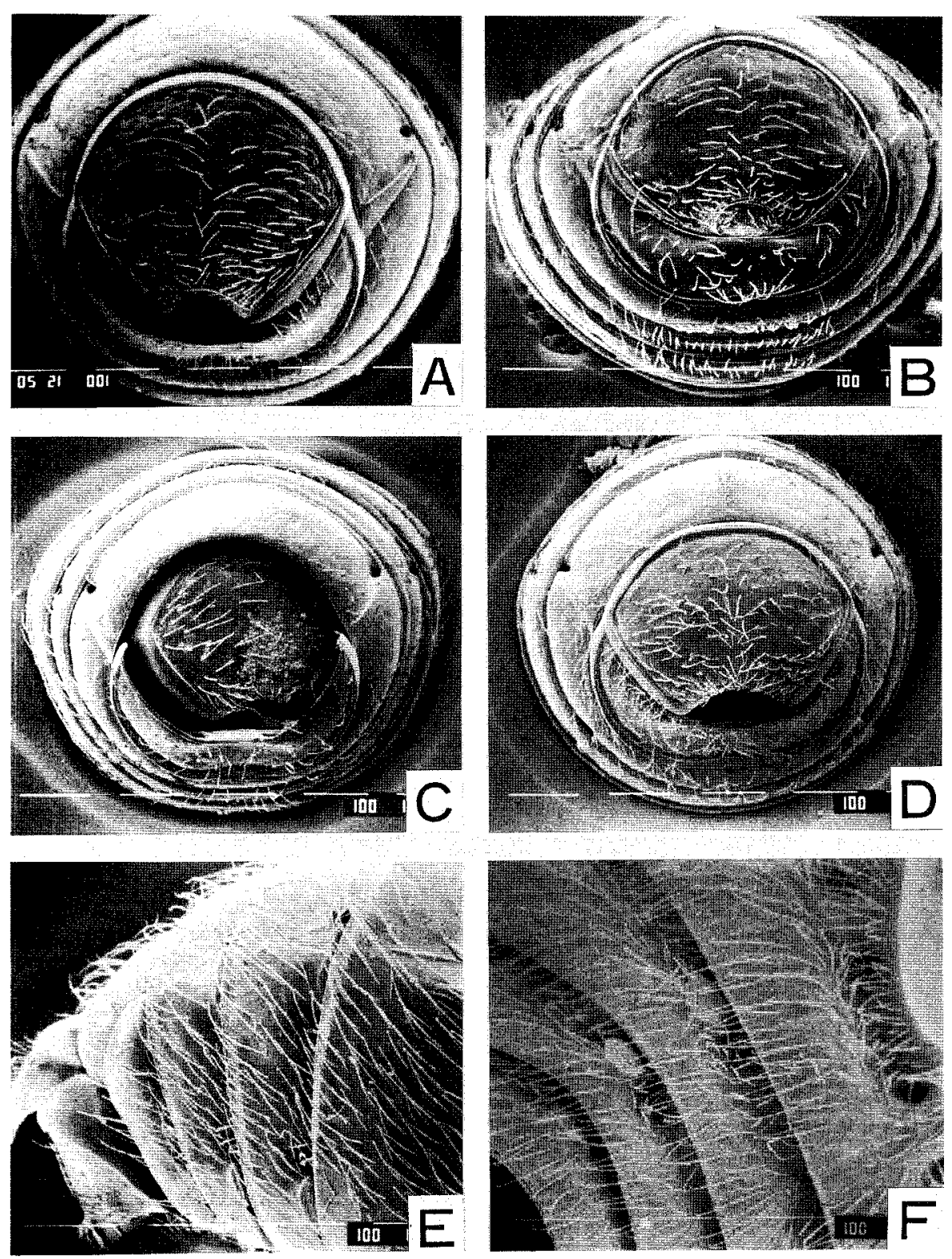
S. NOMURA

Fig. 51. Abdominal spiracles.
A, SP4.
B, Sp5 to $\operatorname{Sp} 7$.
C, $\mathrm{Sp} 7$ to $\mathrm{Sp} 8$.
$\mathrm{D}, 4$ th abdominal segment lateral view (Sp4 is absent).
E, Sp5 to Sp7.

A-C, Batrisoplisus raffrayi Jeannel, female.

D, E, Physomerinus schenklingi (Raffray), female. 

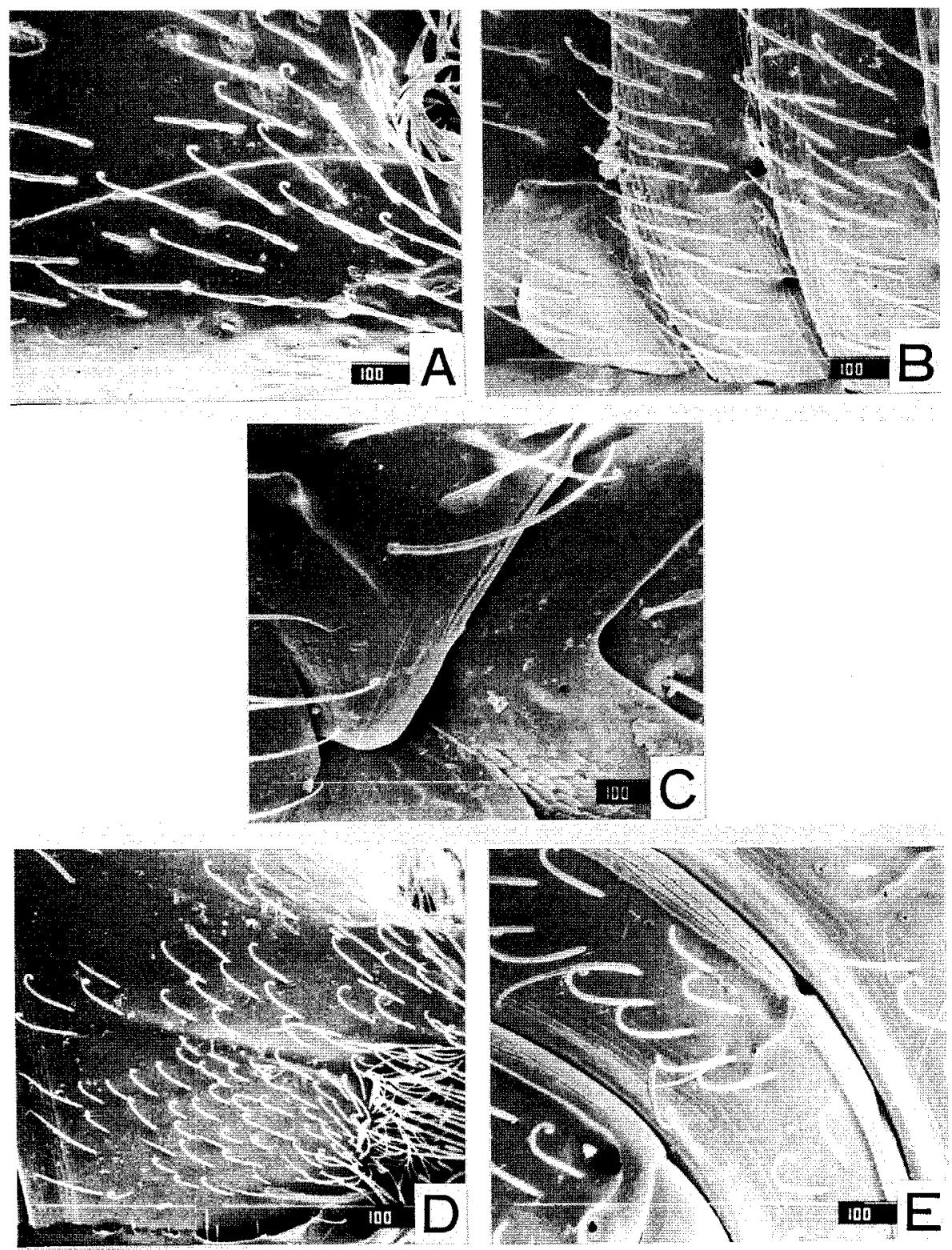
Fig. 52. Abdominal spiracles.
A, C, Sp4.
B, Sp5 to sp7.
D, Sp5.
E, Sp6.
F, Sp7.

A, B, Physomerinus pedator (Sharp), male.

C-F, ditto, female. 

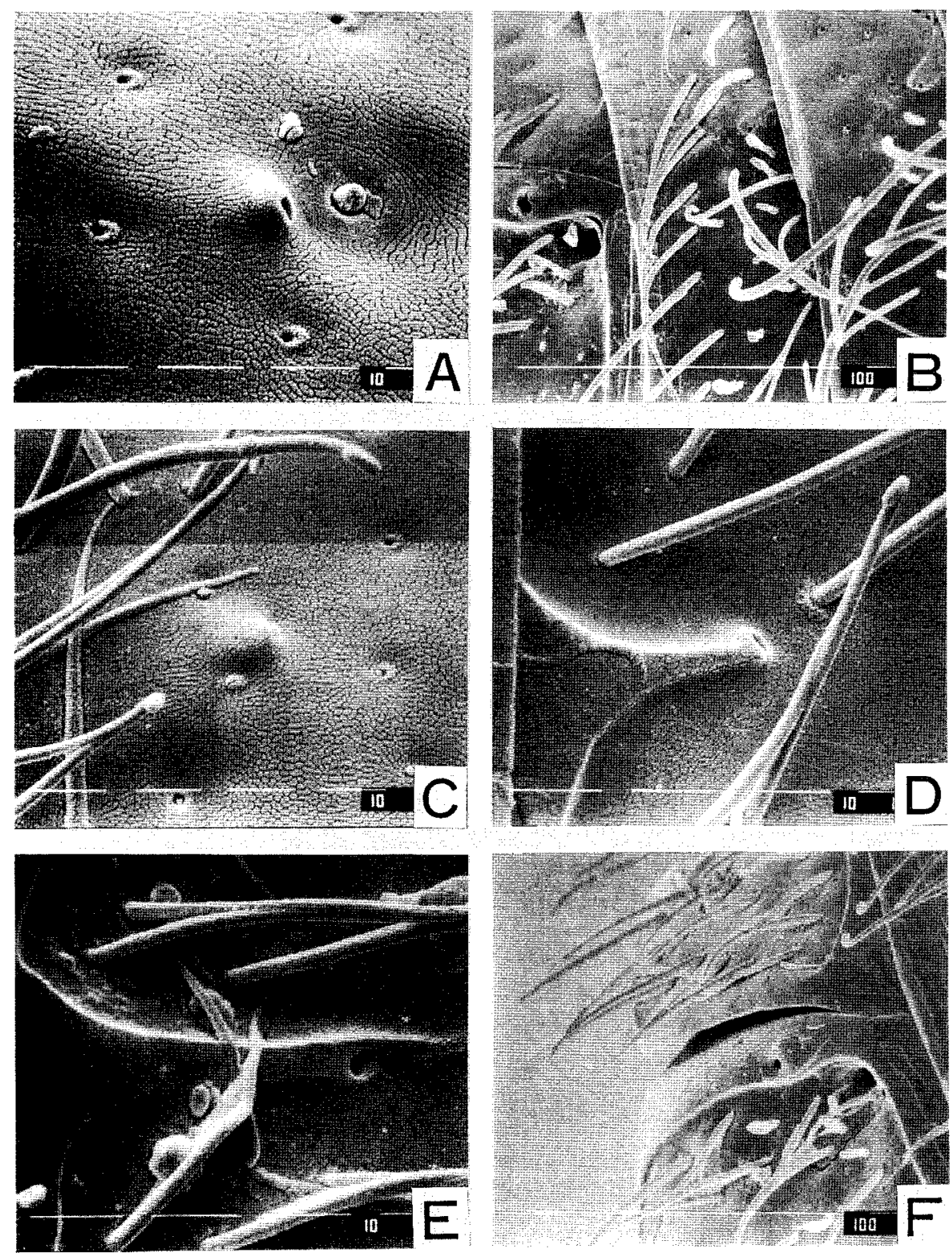
Fig. 53. Abdominal spiracles.

A, C, E, Sp5 to Sp7.

B, Sp8.

$\mathrm{D}, \mathrm{Sp} 4$.

A, B, Batriscenaulax furuhatai (Kubota), female.

C, Batrisceniola hiranoi sp. nov., female.

D, E, Batrisoschema euplectiforme (Sharp), male (out-group). 

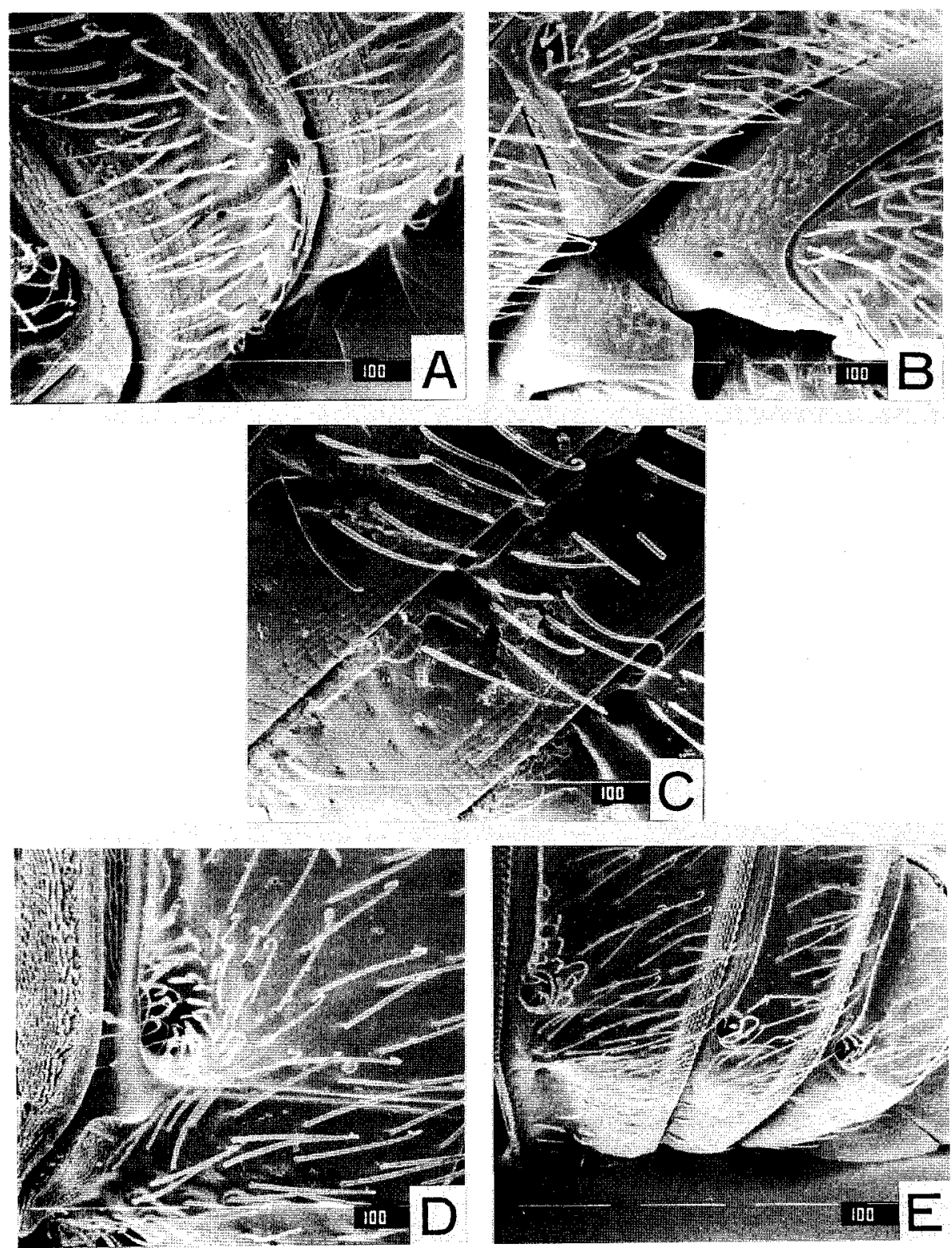
Fig. 54. Abdominal defensive glands in internal view. A, 8th abdominal sternite in external view. $\mathrm{B}-\mathrm{F}$, ditto in internal view
A, Batriscenellus kujumontanus sp. nov., male
$\mathrm{B}$, ditto, female.
C, Batriscenaulax longipes longipes Jeannel, male.
D, Physomerinus schenklingi (Raffray), female.
$\mathrm{E}$, Batrisceniola dissimilis (Sharp), male.
F, ditto, female. 

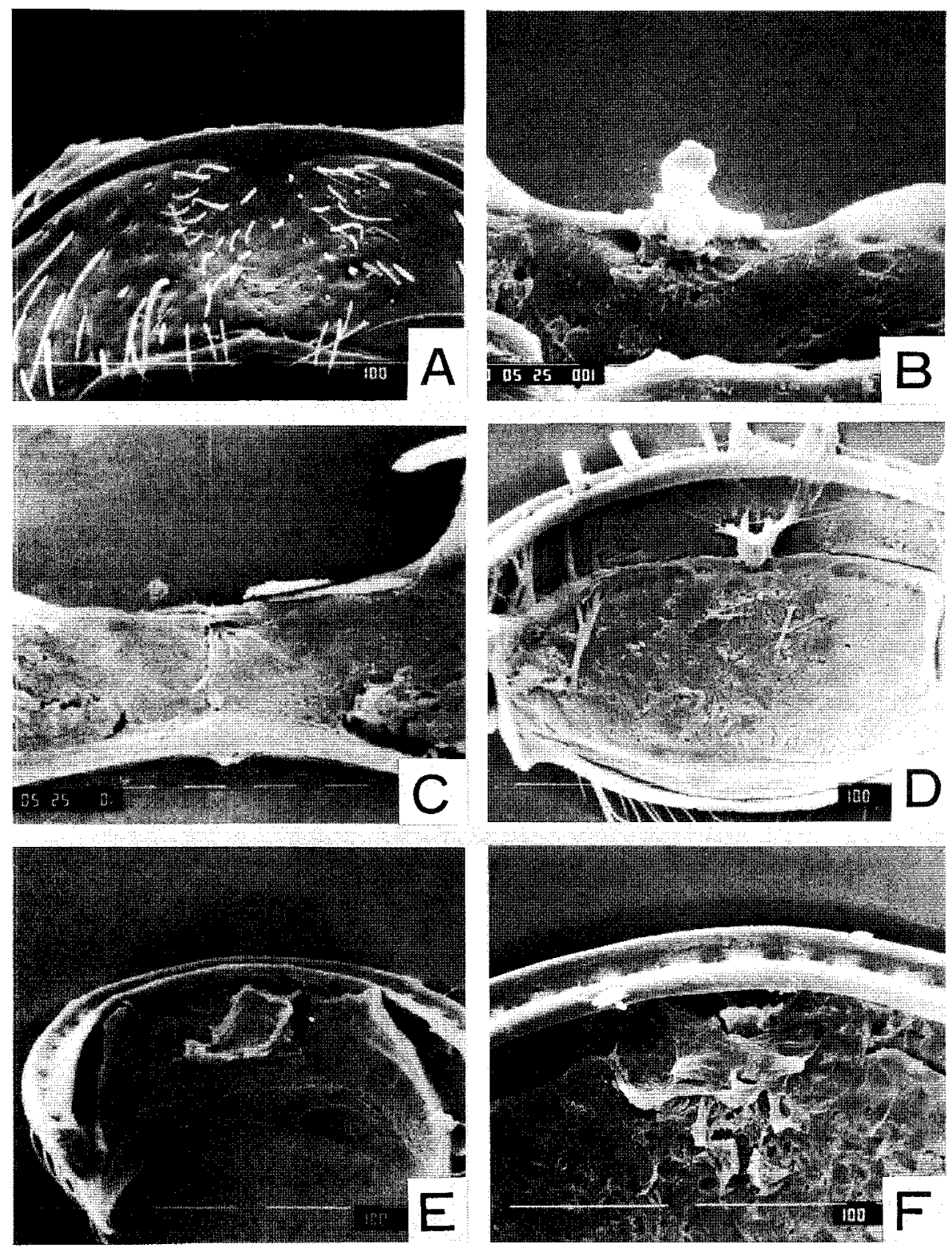
Fig. 55. Schemata of male genitalia
A, aedeagus lateral view.
B, ditto, ventral view.
C, male genitalia lateral view,

A-C, Batrisceniola dissimilis (Sharp). 


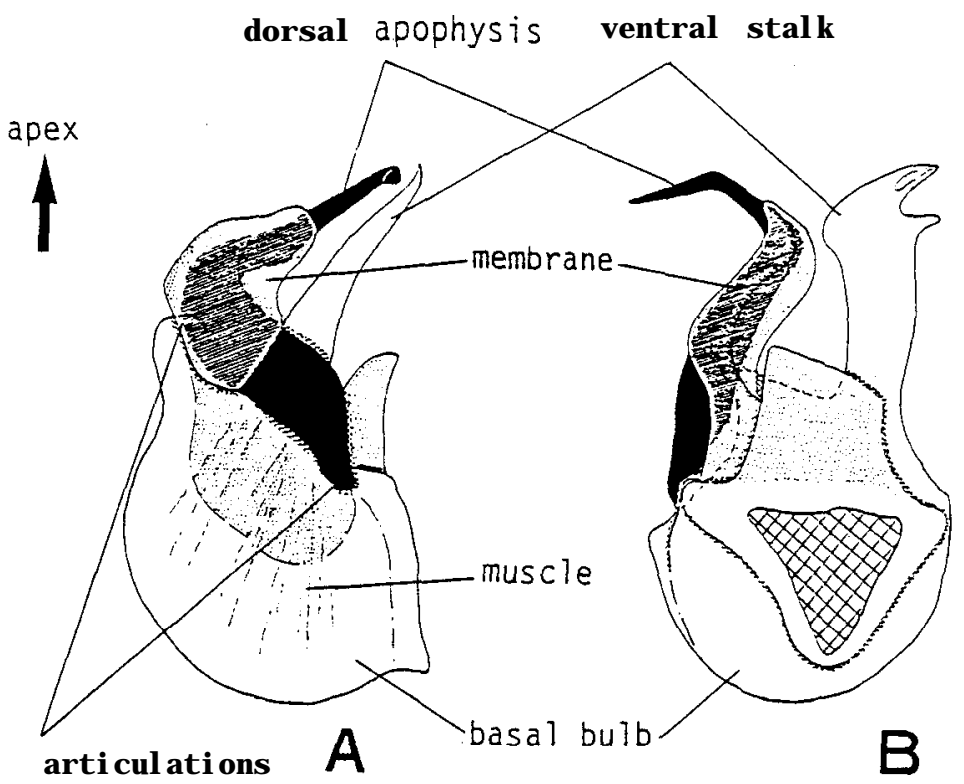

ej acul atory duct

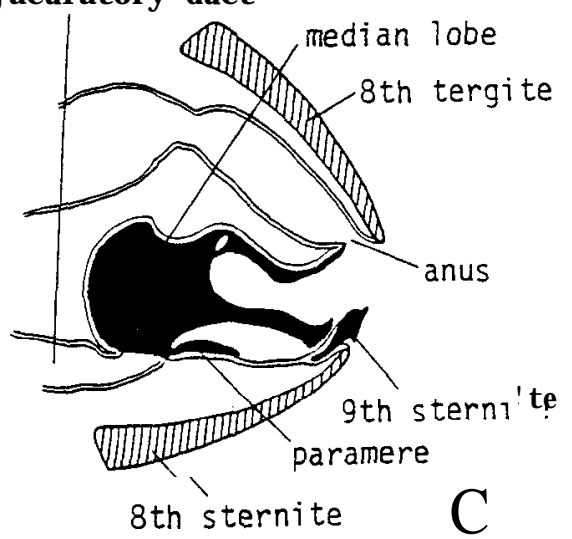


S. NOMURA

Fig. 56. Two types of male genitalia in Batrisceniola dissimilis (Sharp).

$A$, ventral view.

B, dorsal view. 

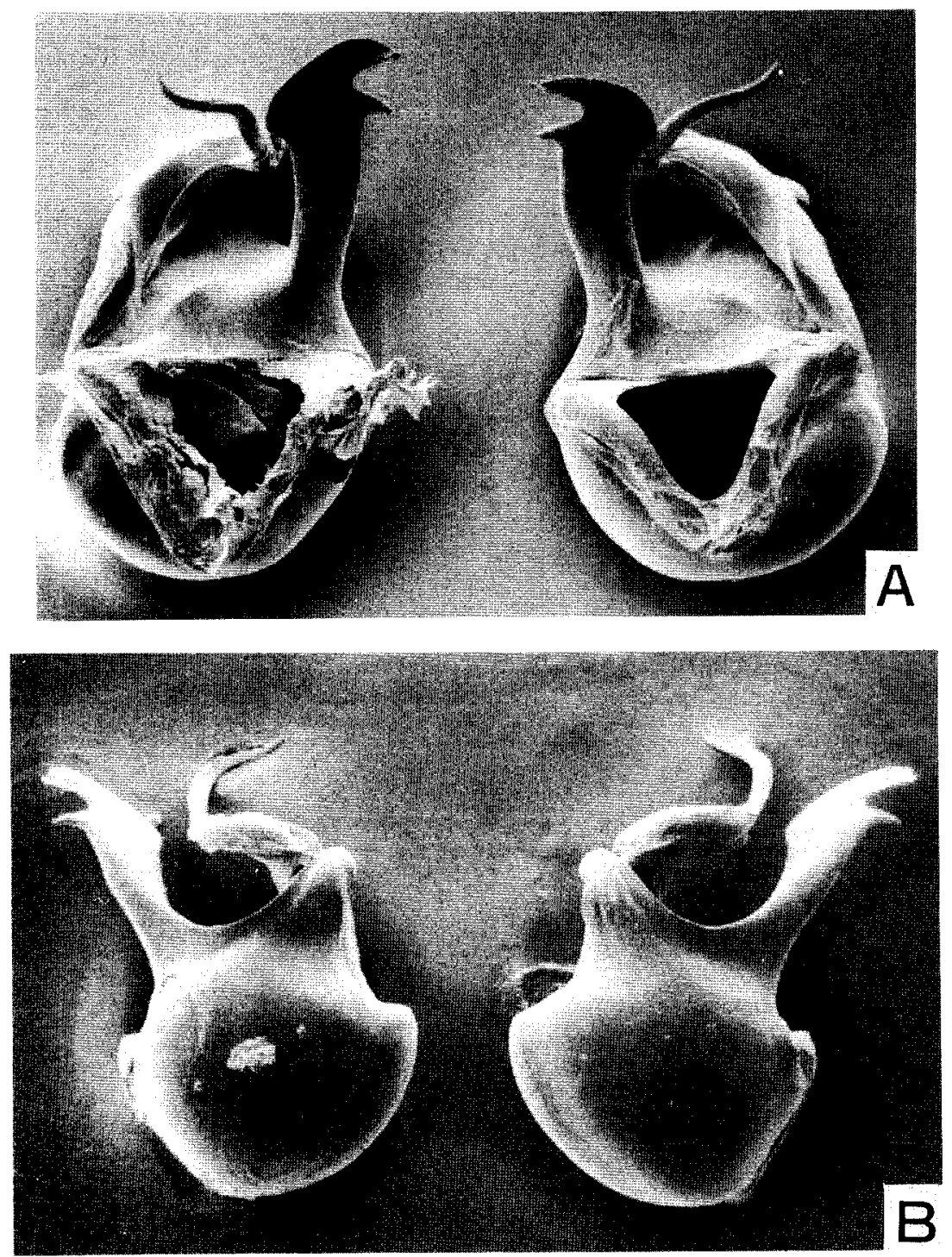
S. NOMURA

Fig. 57. Ratios of left-articulated and right-articulated types in some populations of Batrisceniola dissimilis (Sharp). 


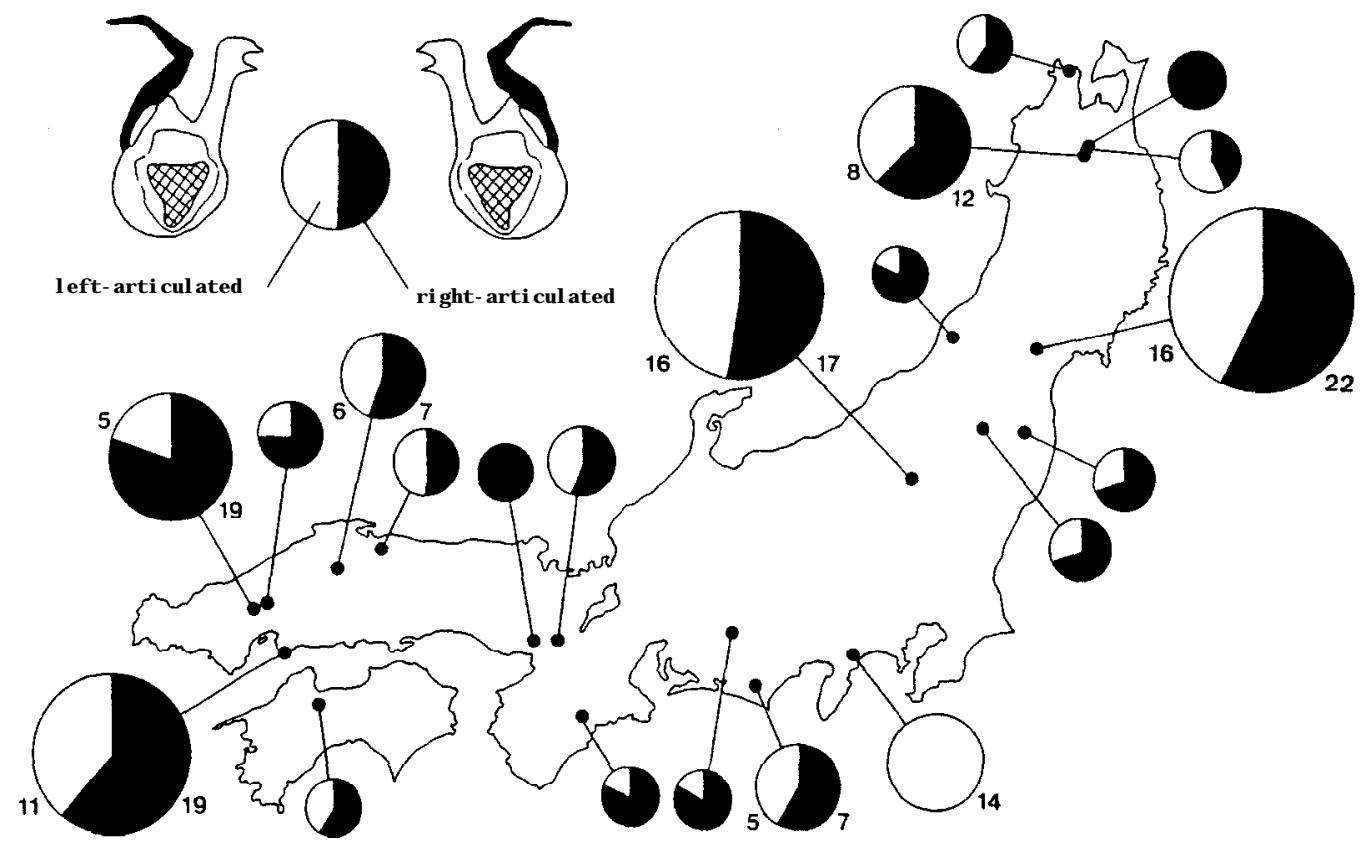


Fig. 58. Sehemata of female genitalia (ovipositor).

A, lateral view.

$\mathrm{B}$, ventral view.

A, B, Batriscenellus kujumontanus sp. nov. 

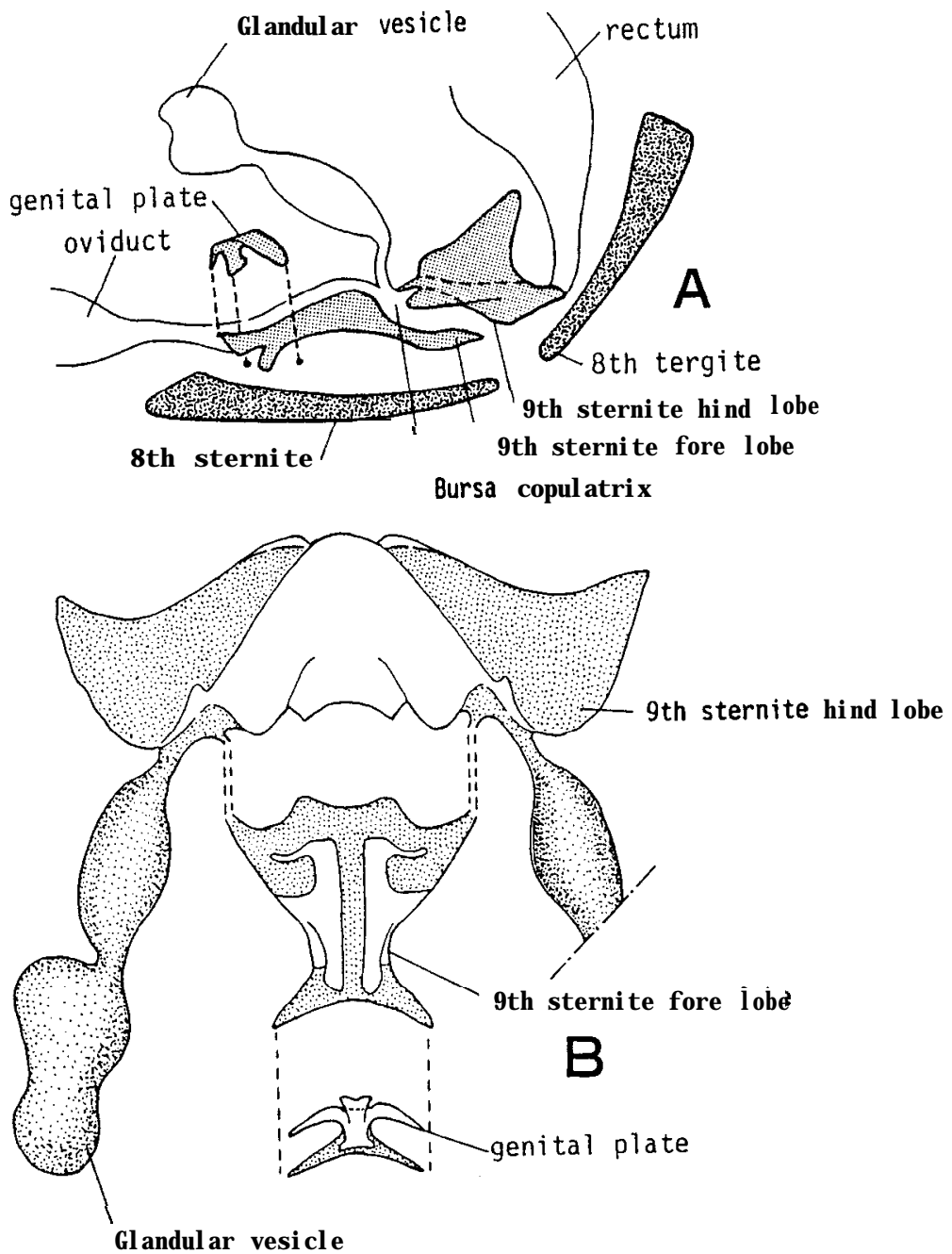
Fig. 59. Arrangements of suberect hairs on dorsal surfaces of bodies in five specks of Arthromelodes.
A, A. punctifrons sp. nov., male.
B, A giganteus sp. nov., female.
C, A. kiiensis sp. nov., male.
D, A. gyoja sp. nov., male.
E, A. pilicollis sp. nov., male. 


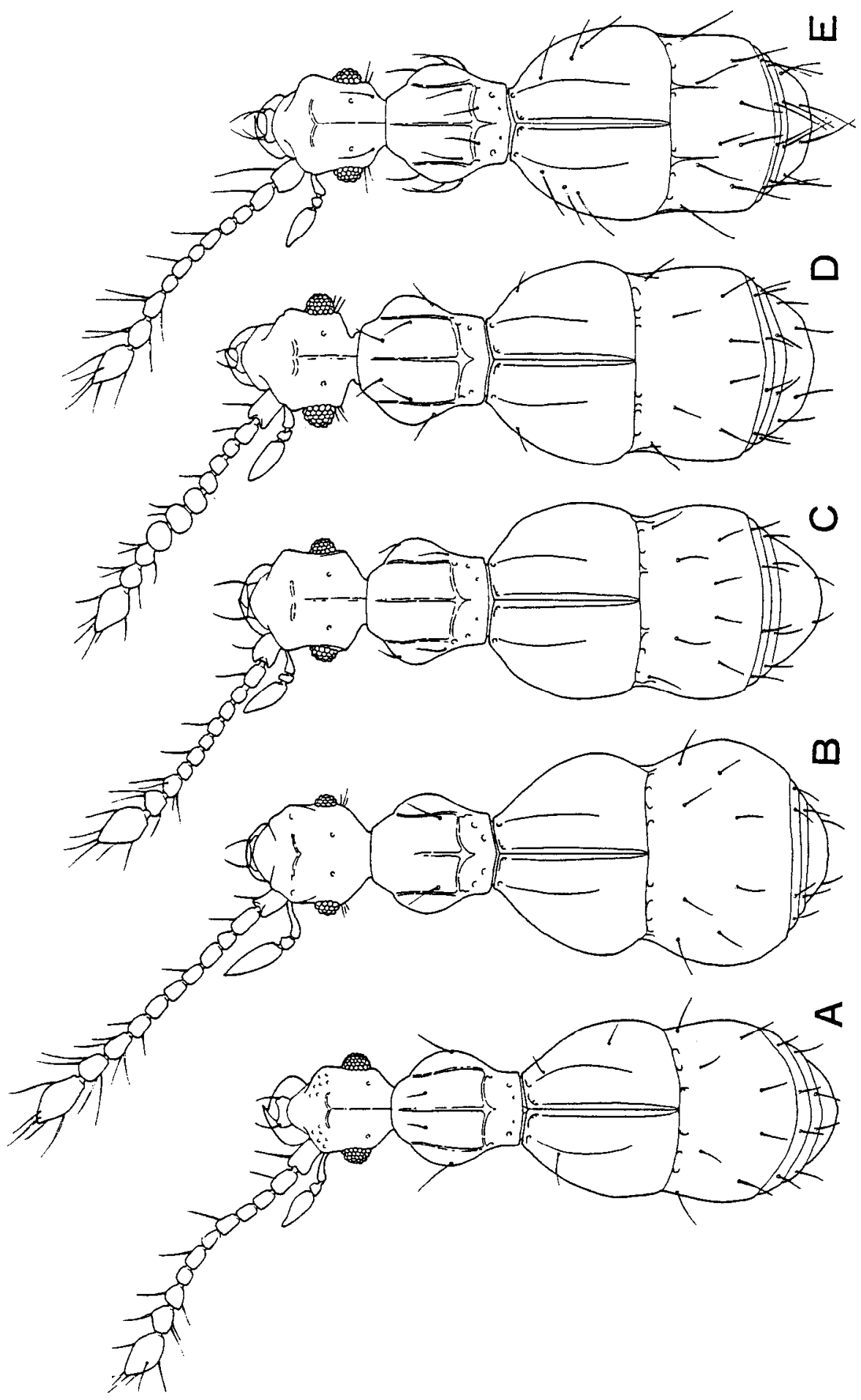


Fig. 60. First antennal segments in lateral view.
A, Batrisoplisus raffrayi Jeannel, male.
B, C, Batriscenellus kujumontanus sp. nov., male.
C, ditto, enlarged.
D, ditto, female.
E, B. similis (Sharp), male.
F, B. ohishii sp. nov. female. 

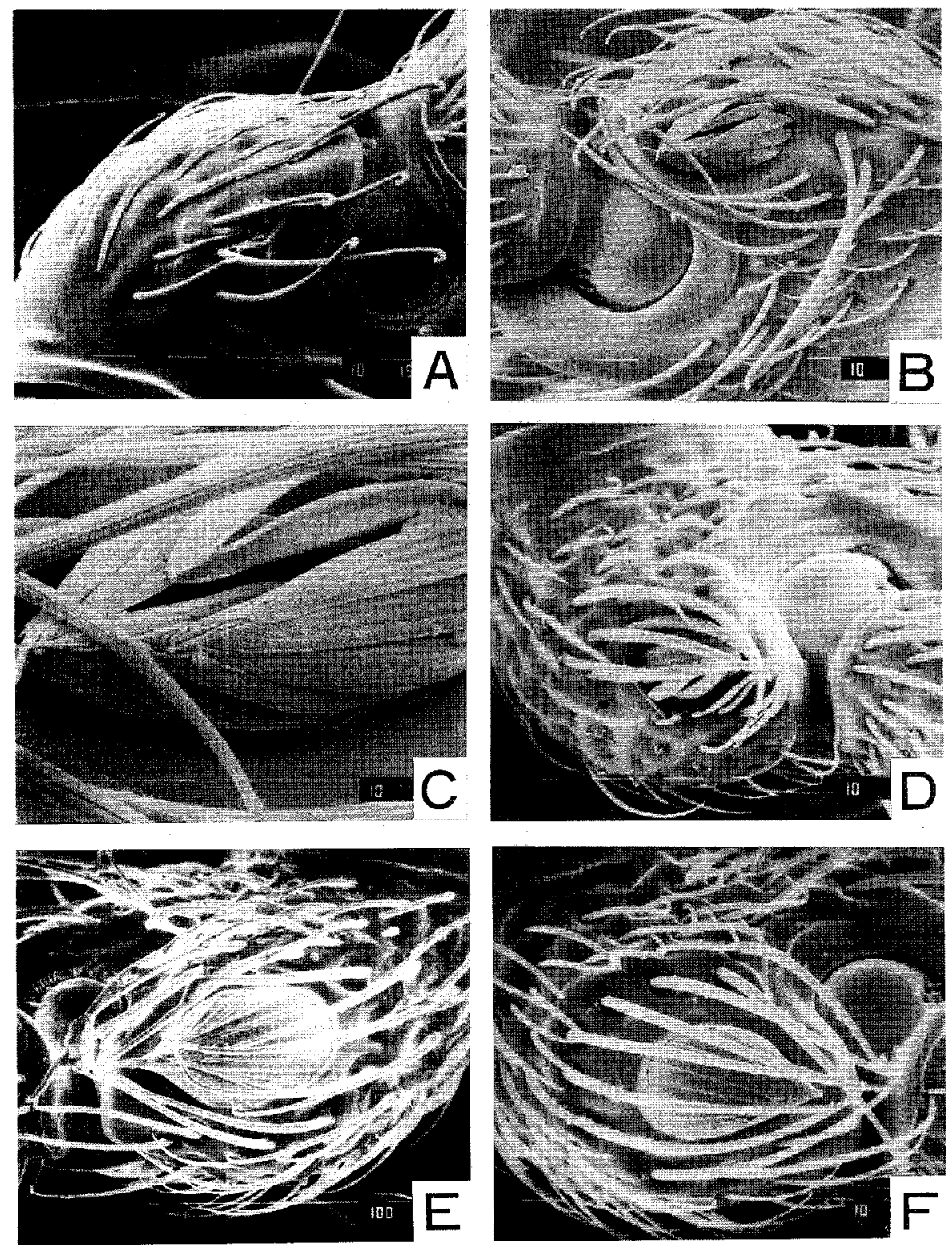
Fig. 61. First antennal segments in lateral view.
A, Cratna abdominalis Löbl, male.
B, ditto, female.
C, Batriscenaulax longipes longipes Jeannel, male.
D, Physomerinus pedator (Sharp), male.
E, Arthromelodes giganteus sp. nov., male.
F, A. kiiensis sp. nov., male. 

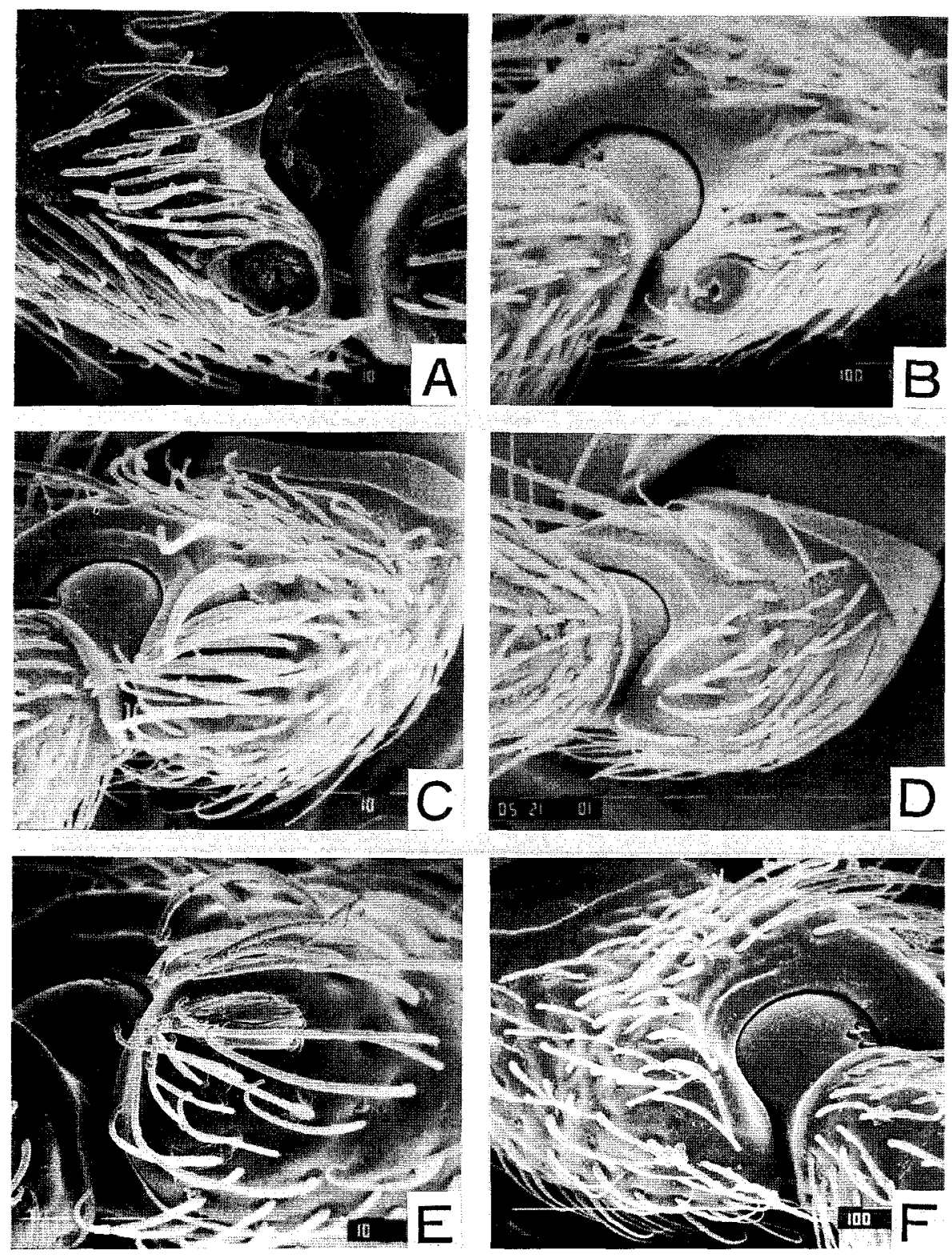
Fig. 62 First antennal segments in lateral view.

A, Arthromelodes mercurius sp. nov., male.

B, A. dilatatus daibosatsuanus subsp. nov., male.

C, $A$. saikaiensis sp. nov., male.

D, A. crucifer sp. nov., male.

E, Batrisceniola dissimilis (Sharp), male.

F, B. semipunctulata (Raffray). 

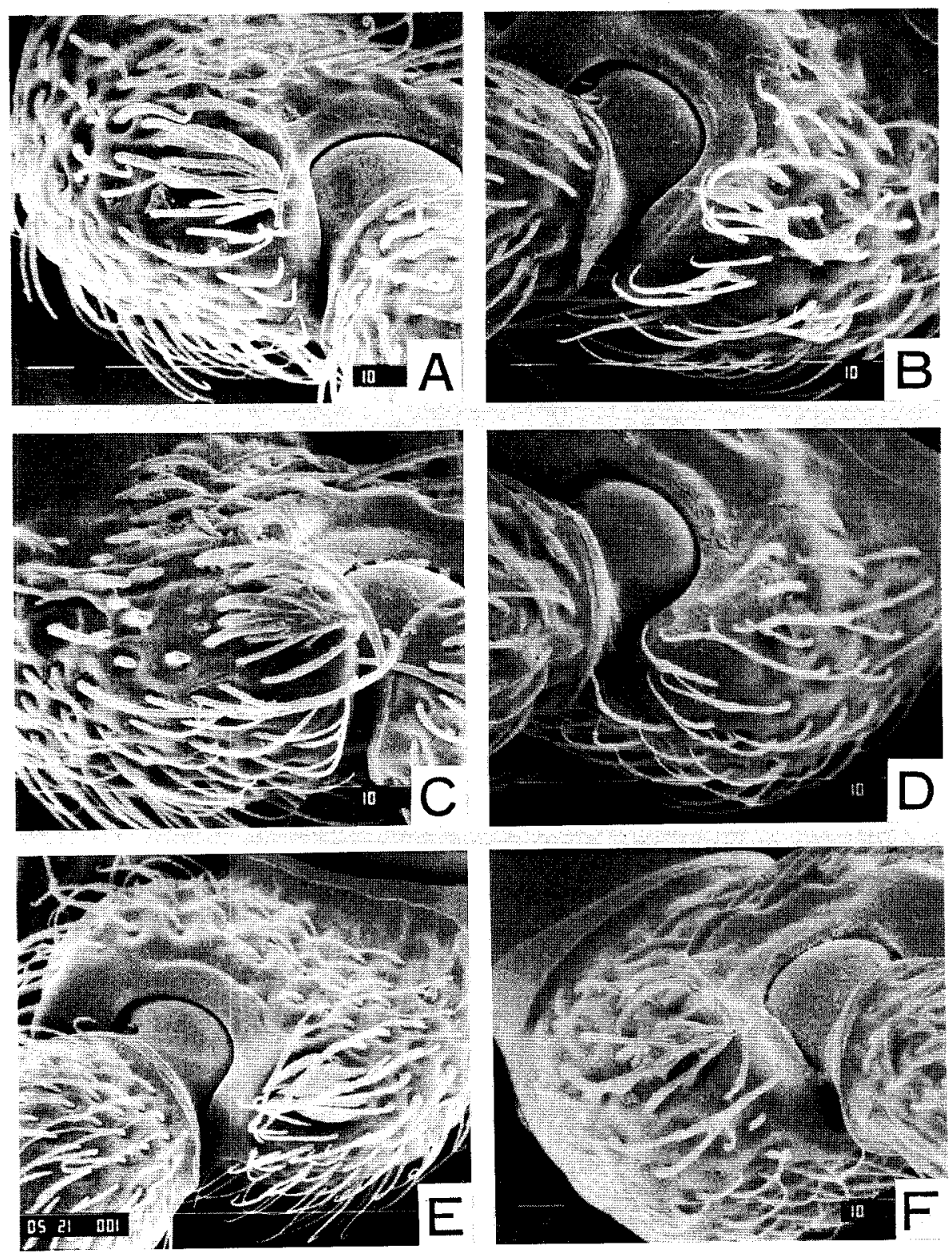
Fig. 63. Trichomes on 4th segments of maxillary palpi.
A, Batrisoplisus raffrayi Jeannel, male.
B, ditto, enlarged.
C, B. uroceratus uroceratus sp. et subsp. nov., male.
D, Batriscenellusohishii sp. nov., male.
E, Arthromelodes mercurius sp. nov., male. 

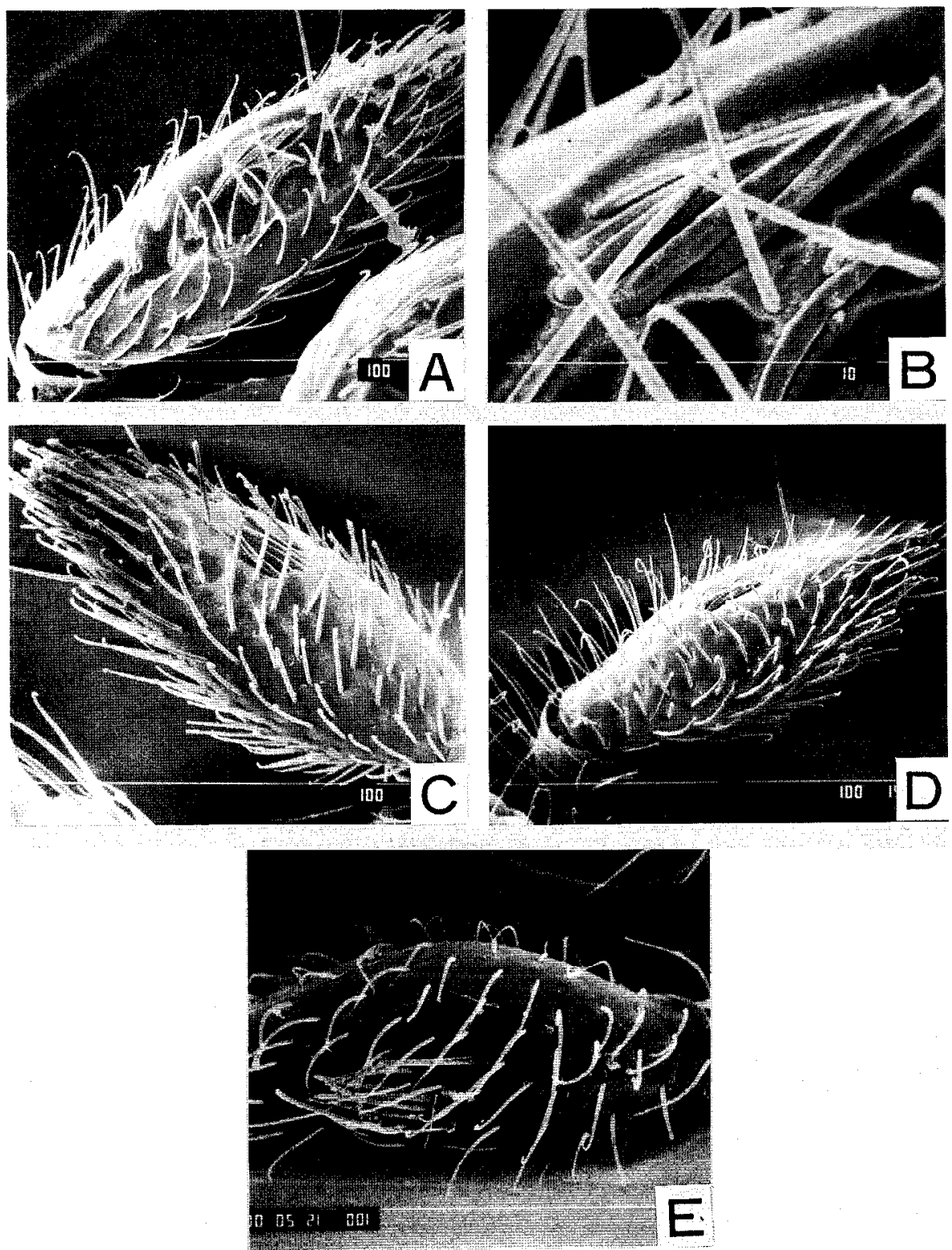
Fig. 64. Sensory pits on fore femora.
A, Batrisoplisus monostatos sp. nov., male.
B, Batriscenellus similis (Sharp), male.
C, B. ohishii sp. nov., female.
D, Cratna torticornis Raffray, male.
$\mathrm{E}, \mathrm{F}$, ditto, female.
G, C. abdominalis Löbl, female. 

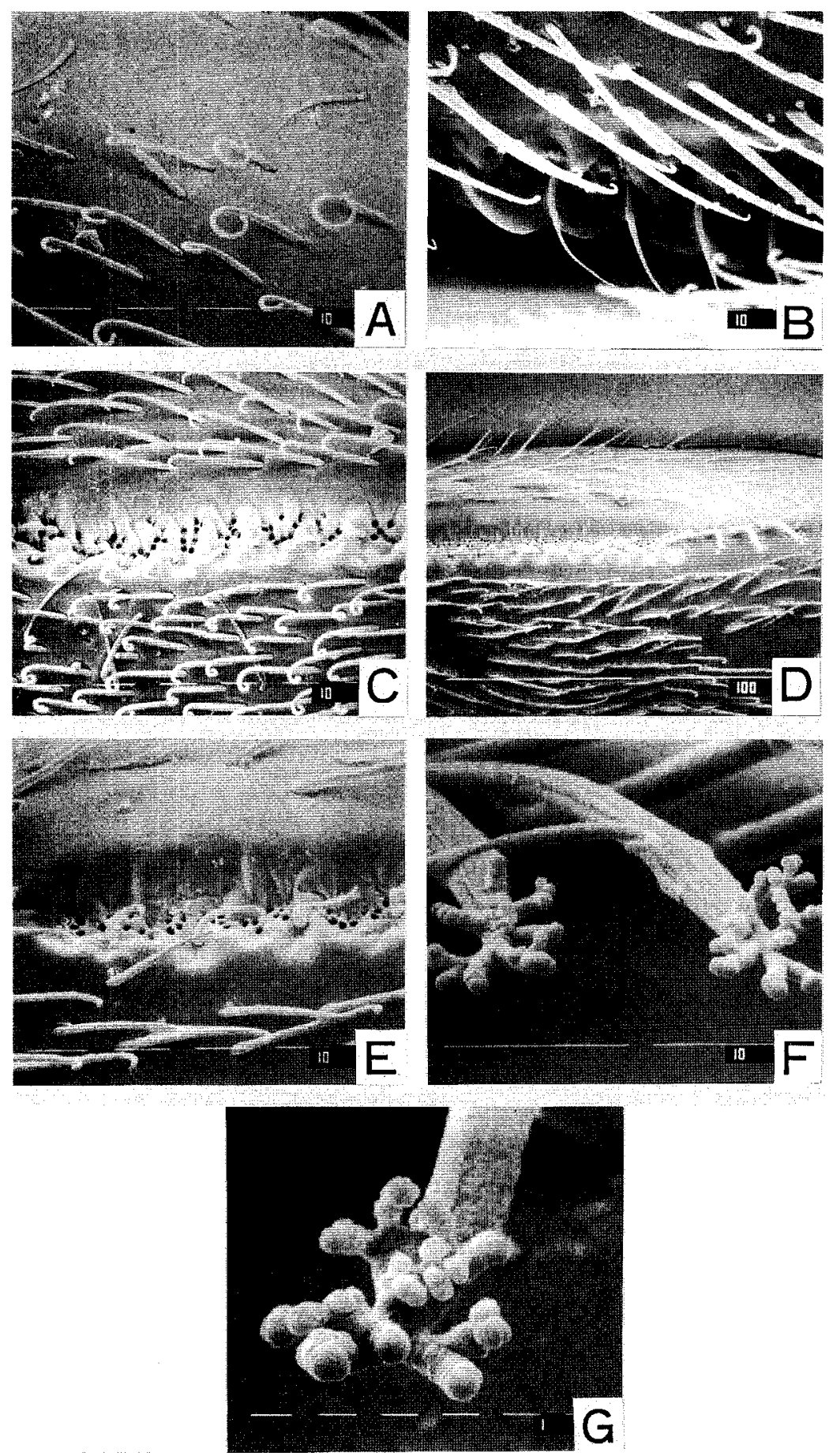
Fig. 65. Sensory pits on fore femora.
A, Batriscenaulax longipes longipes Jeannel, male
$\mathrm{B}$, ditto, female.
C, B. kleinzach sp. nov., male.
$\mathrm{D}$, Physomerinus schenklingi (Raffray), male.
E, P. pedator (Sharp), female.
$\mathrm{F}$, Arthromelodes giganteus sp. nov., male.
G, A. küensis sp. nov., male.
$\mathrm{H}, \mathrm{A}$. mercurius sp. nov., male. 

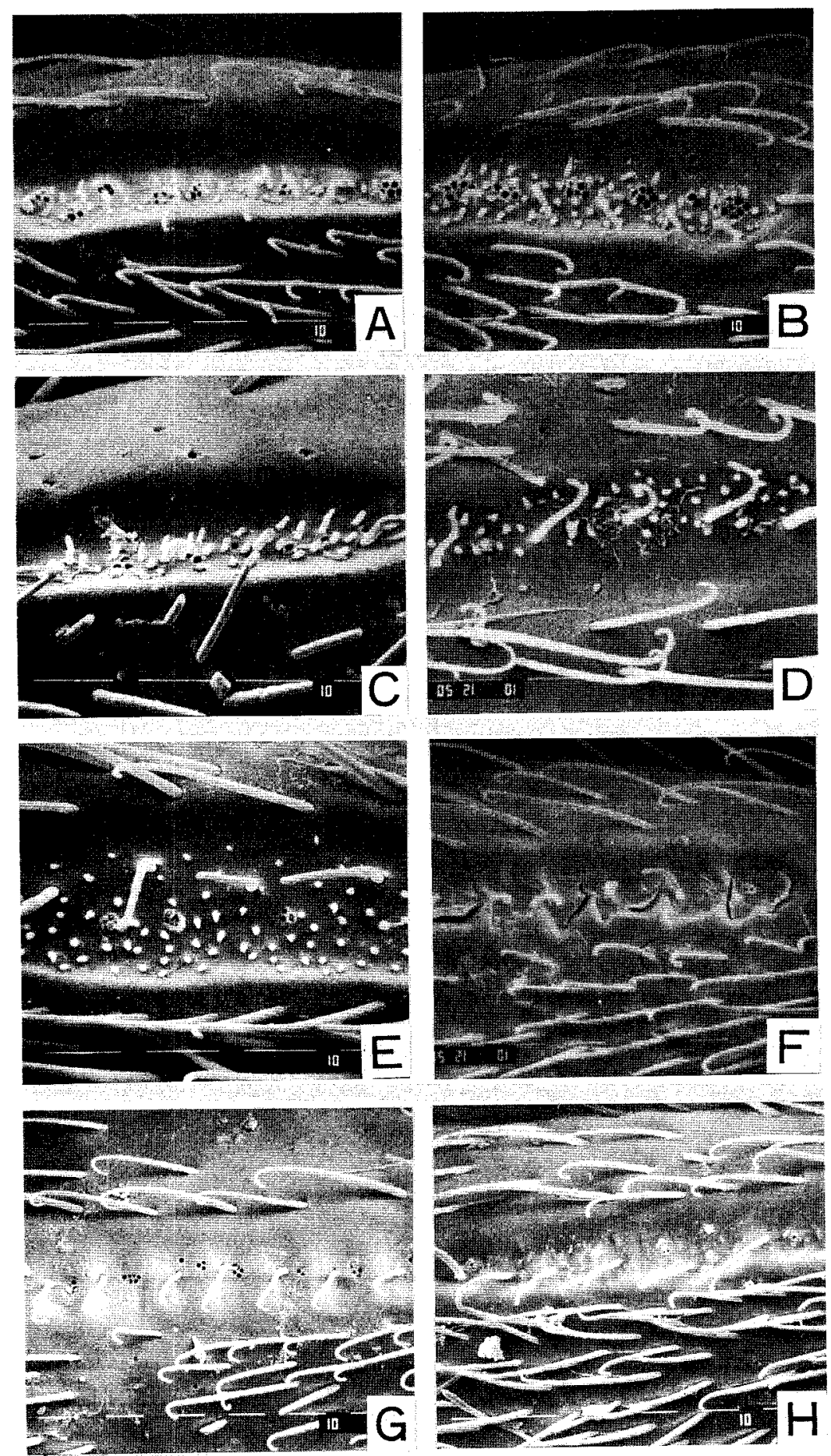
Fig. 66. Sensory pits on fore femora.
A, Arthromelodes dilatatus daibosatsuanus subsp. nov., male.
B, A. saikaiensis sp. nov., male.
C, A. crucifer sp. nov., male.
$\mathrm{D}$, Batrisceniola dissimilis (Sharp), male.
E, B. semipunctulata (Raffray), male.
$\mathrm{F}$, Batrisodes dorsalis Jeanne1 (out-group), male.
$\mathrm{G}$, Coryphomodes spinicollis (Jeannel), male.
$\mathrm{H}$, Batrisoschema euplectiforme (Sharp), male. 

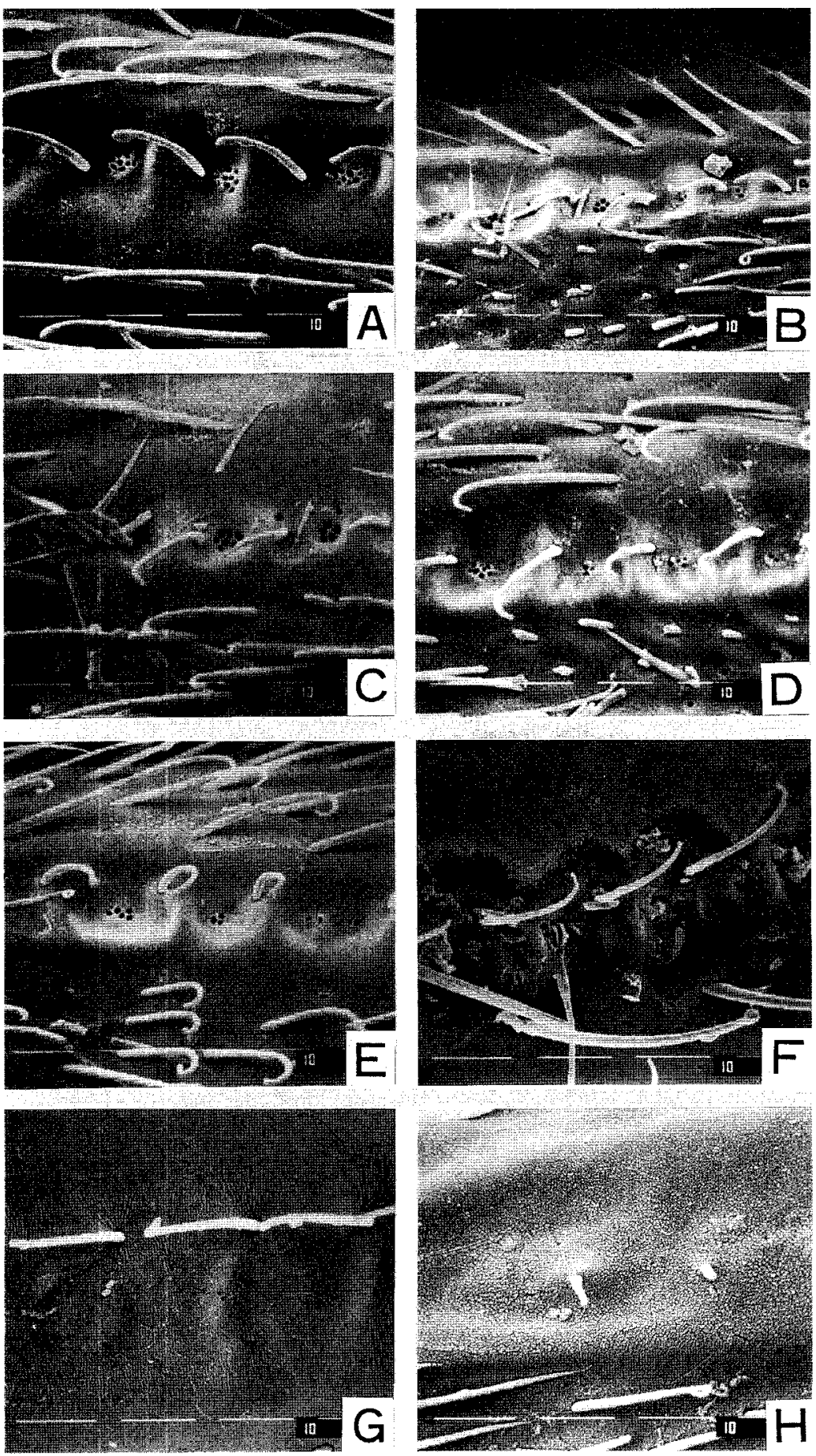
Fig. 67. N on-sexual setiferous structures.

A-C, Trichome on 7th abdominal tergite.

D, lateral cavity of 7 th tergite.

E, prothorax in lateral view.

F, ditto, enlarged.

$\mathrm{G}$, frontal sulcus.
A, Batrisceniola dissimilis (Sharp), male.
B, B. hiranoi sp. nov., male.
C, B. semipunctulata (Raffray), male.
D, Batriscenaulax furuhatai (Kubota), male.
E, F, Cratna abdominalis Löbl, male.
$\mathrm{G}$, ditto, female. 

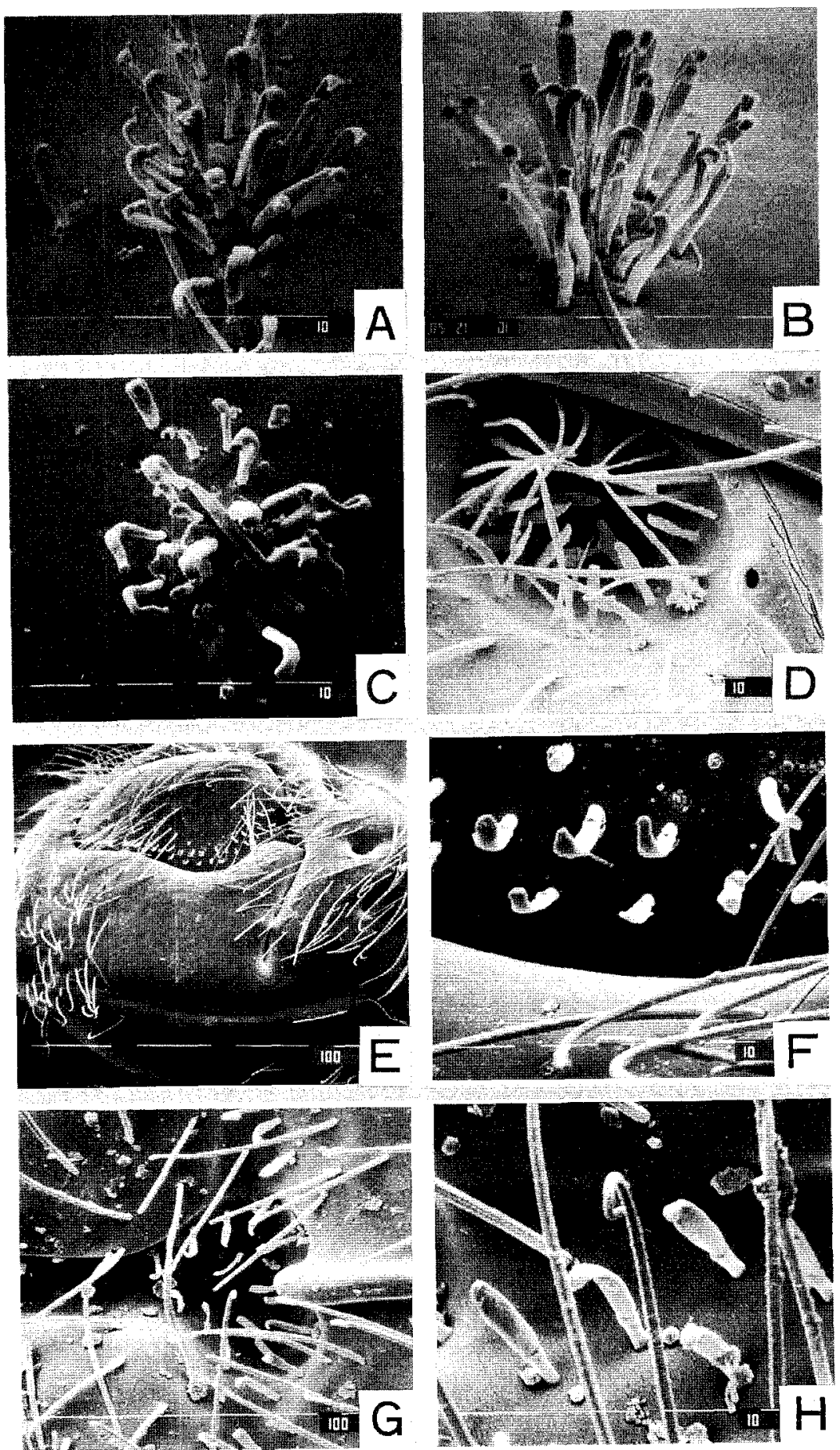
Fig. 68. Schemata of sexual patches in Batrisoplisus.
A, dorsal aspect.
A, B, B. raffrayi Jeannel.
C, $B$. galloisi Jeannel.

B, C, 8th to 9th antennal segments. 


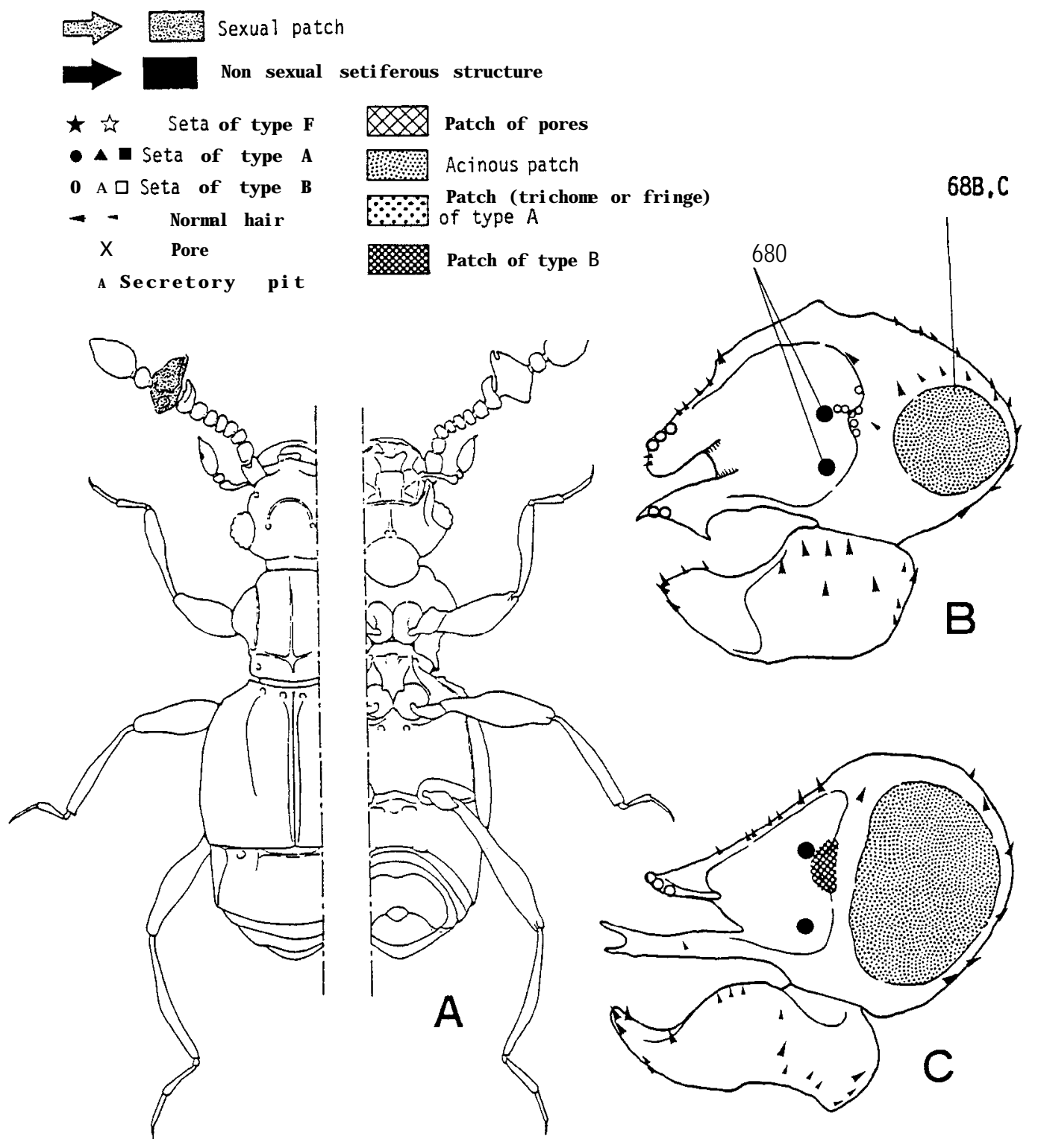


Fig. 69. Schemata of sexual patches in Batrisoplisus.
A, B, 8th to 9th antennal segments.
C, D, 7th to 11th antennal segments.
$\mathrm{E}$, metasternum.
A, B. okamotoi sp. nov.
$\mathrm{B}, \boldsymbol{B}$. venustus Jeanne 1
C, B. monostatos sp. nov.
D, E, B. tortiwmis sp. nov. 

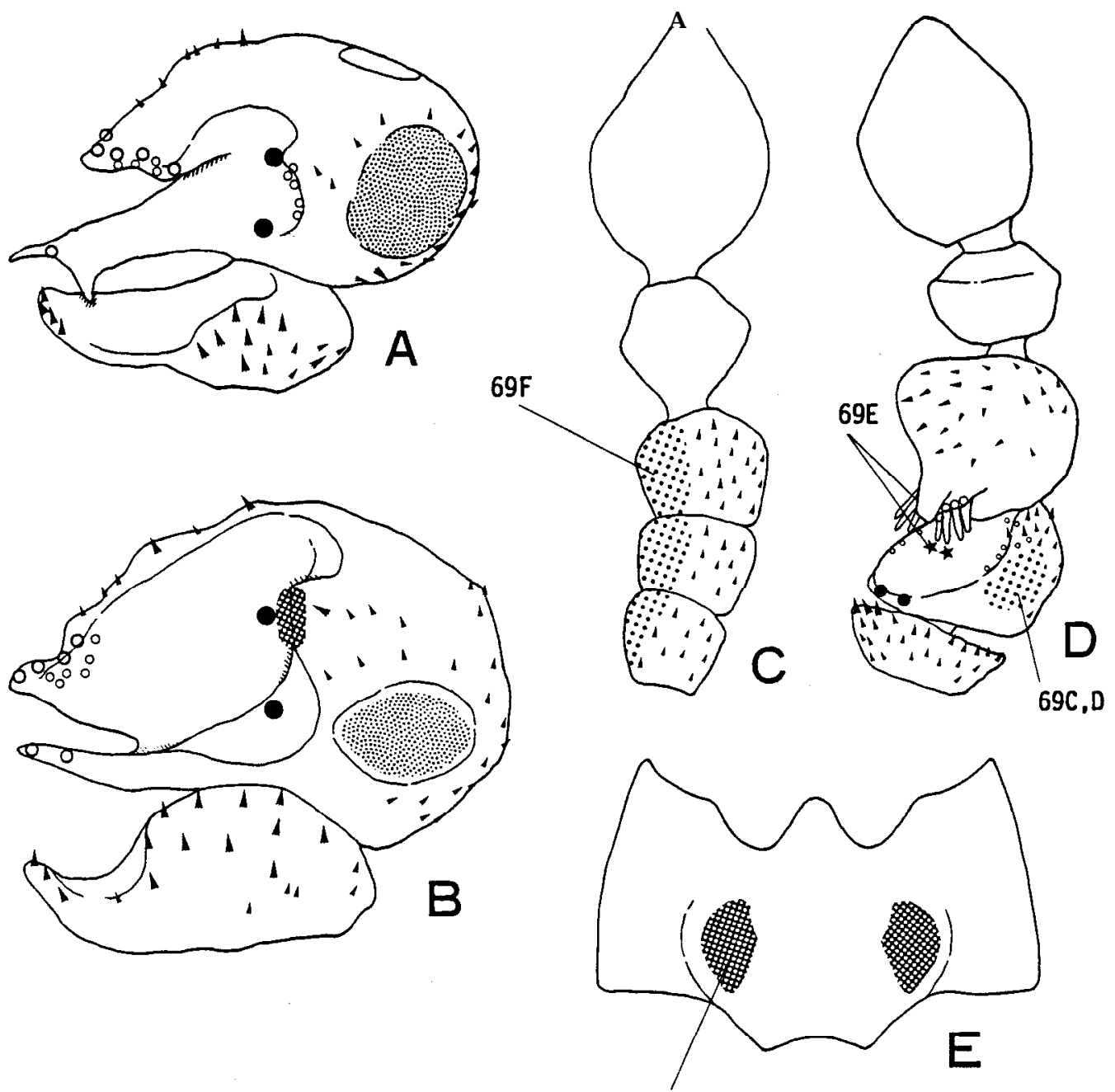

69A.B 
Fig 70. Sexual patches in Batrisoplisus.

A, E-G, 8th to 9th antennal segments in dorsal view.

B-D, 9th antennal segment enlarged.

A-D, B. raffrayi Jeannel.

E, B. galloisi Jeannel.

F, B. okamotoi sp. nov.

$\mathrm{G}, \boldsymbol{B}$. venustus Jeannel. 

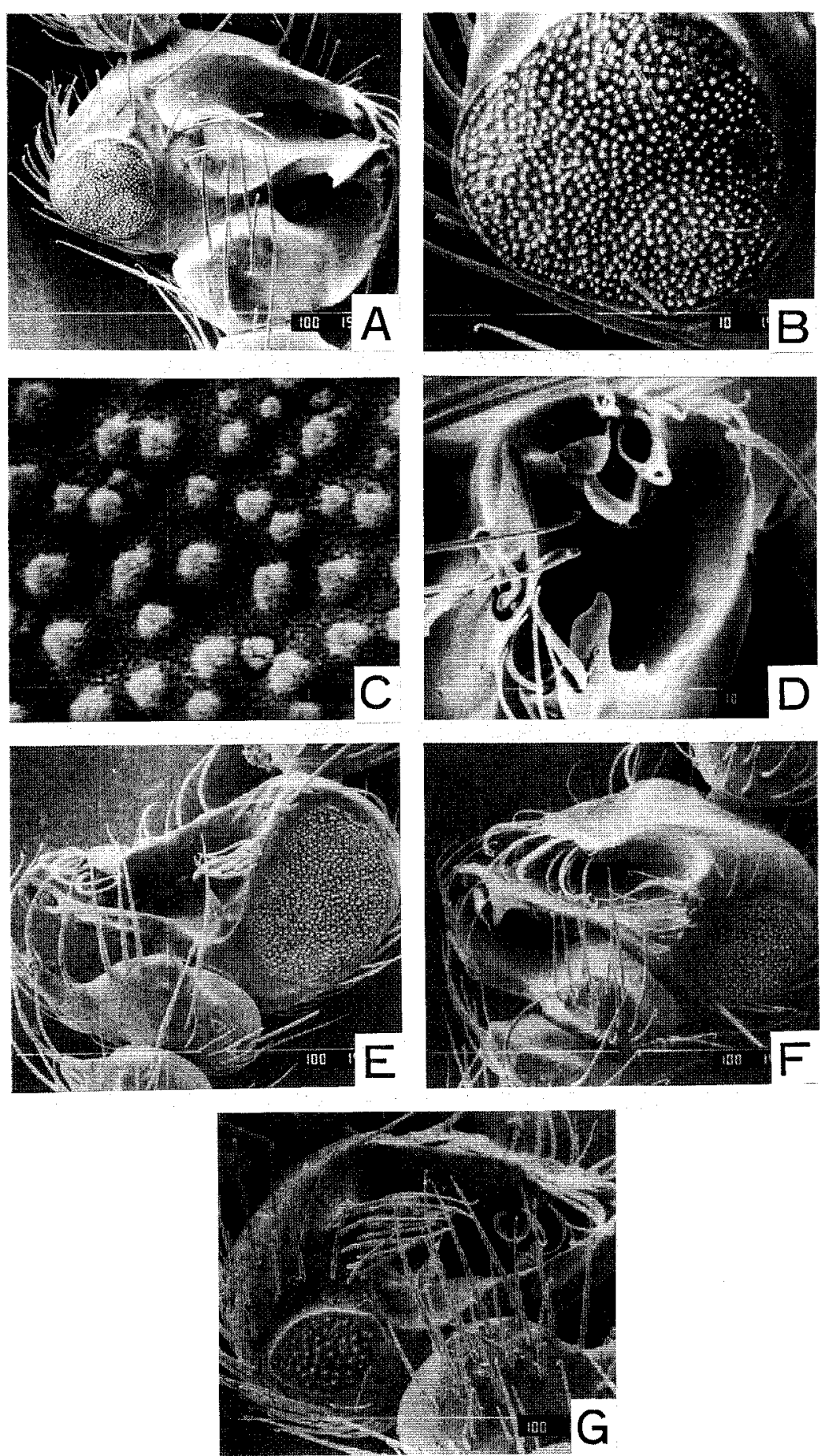
Fig. 71. Sexual patches in Batrisoplisus.
A, metasternum.
B, ditto, enlarged.
C, D, 8th to 9th antennal segments.
E, F, 8th antennal segment enlarged.

A-E, $\boldsymbol{B}$. torticornis sp. nov.

F, B. monostatos sp. nov. 

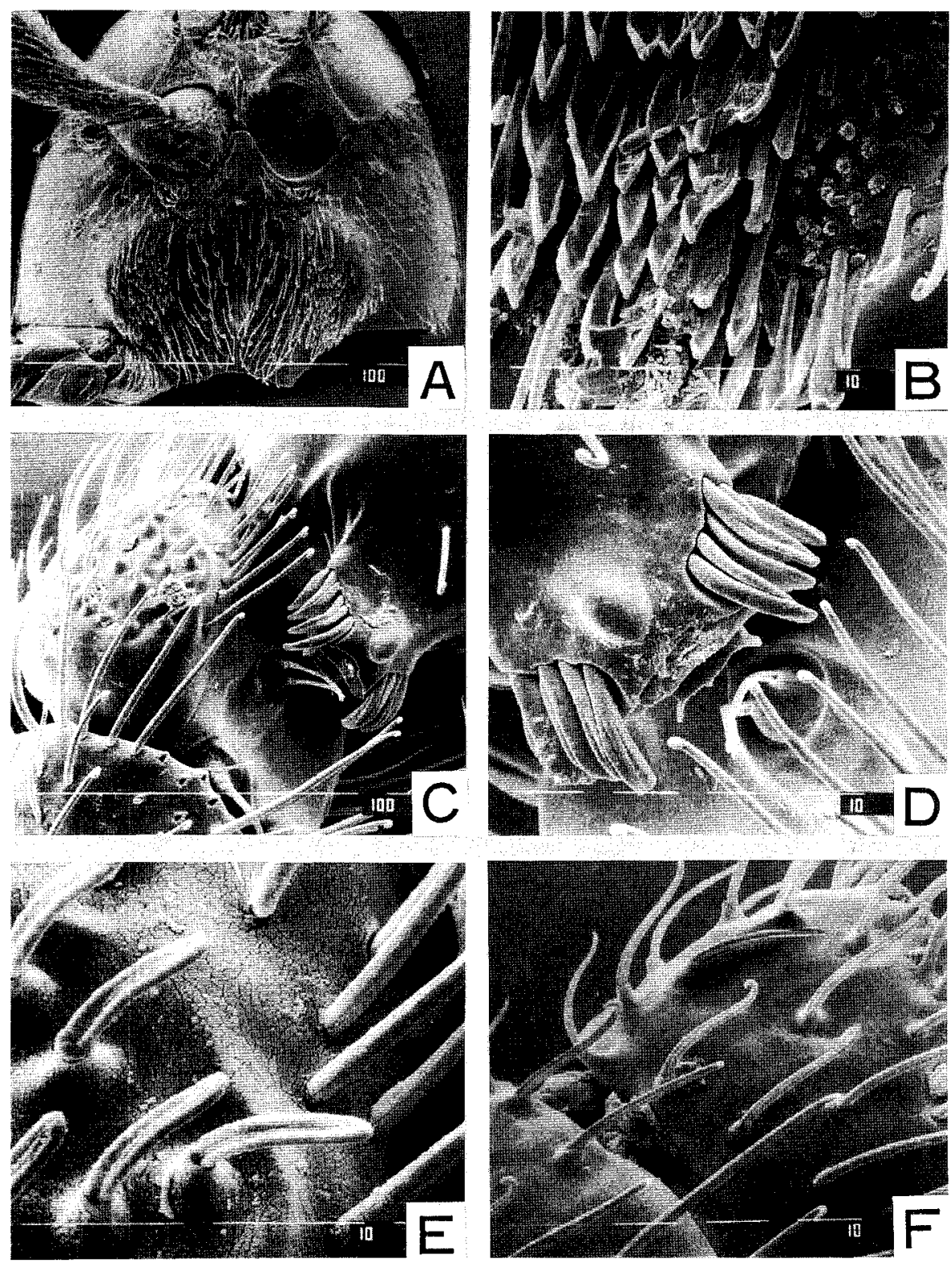
Fig. 72.. Schemata of sexual patches in Batriscenellus.
A, dorsal aspect.
B, D, 5th abdominal tergite.
C, E, 6th tergite.
A-C, B. kujumontanus sp. nov.
D, E, B. fallax (Sharp). 


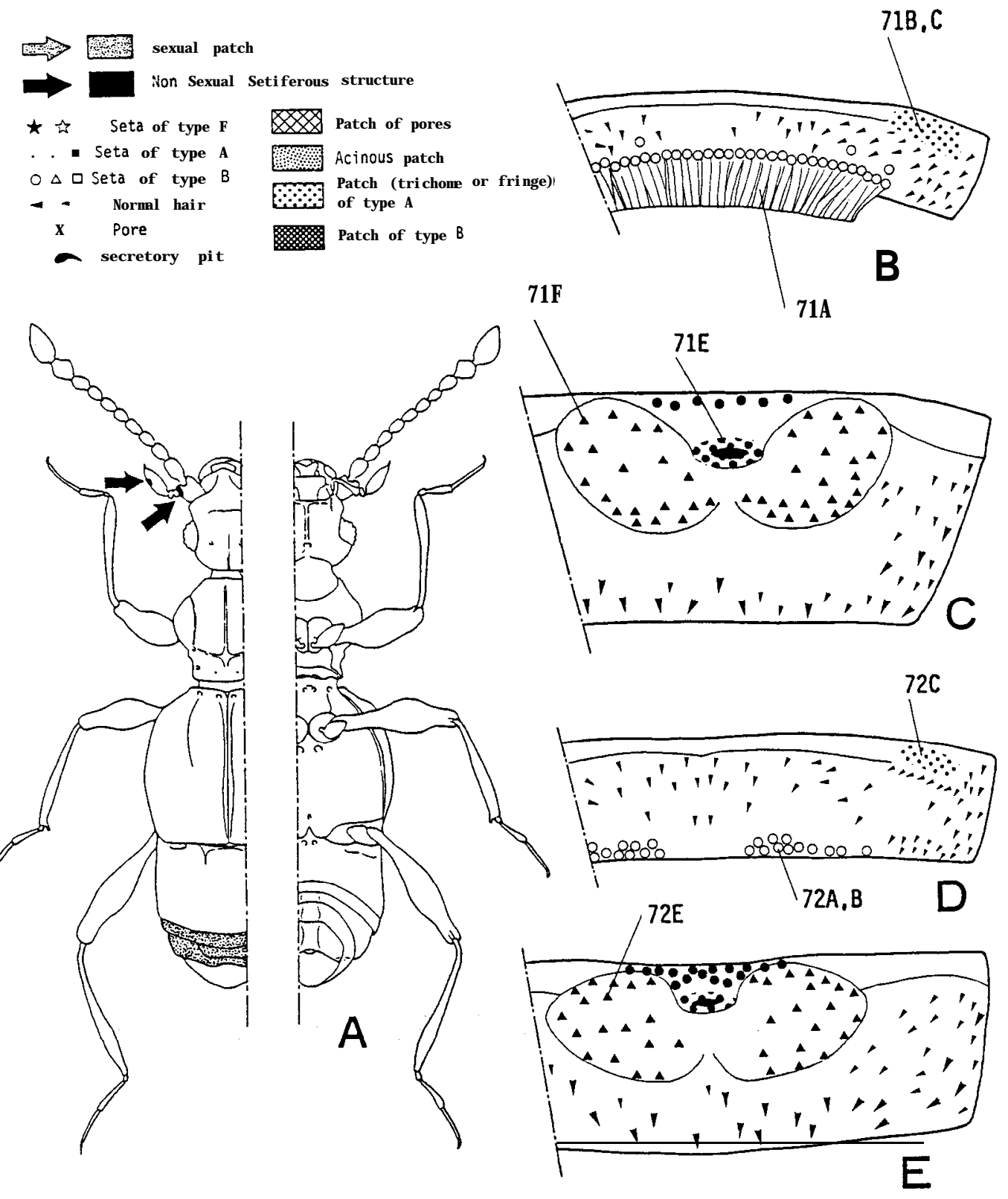


Fig. 73. Sexual patch in Batriscenellus kujumontanus sp. nov.

A-C, 5th abdominal tergite.

D-F, 6th tergite. 

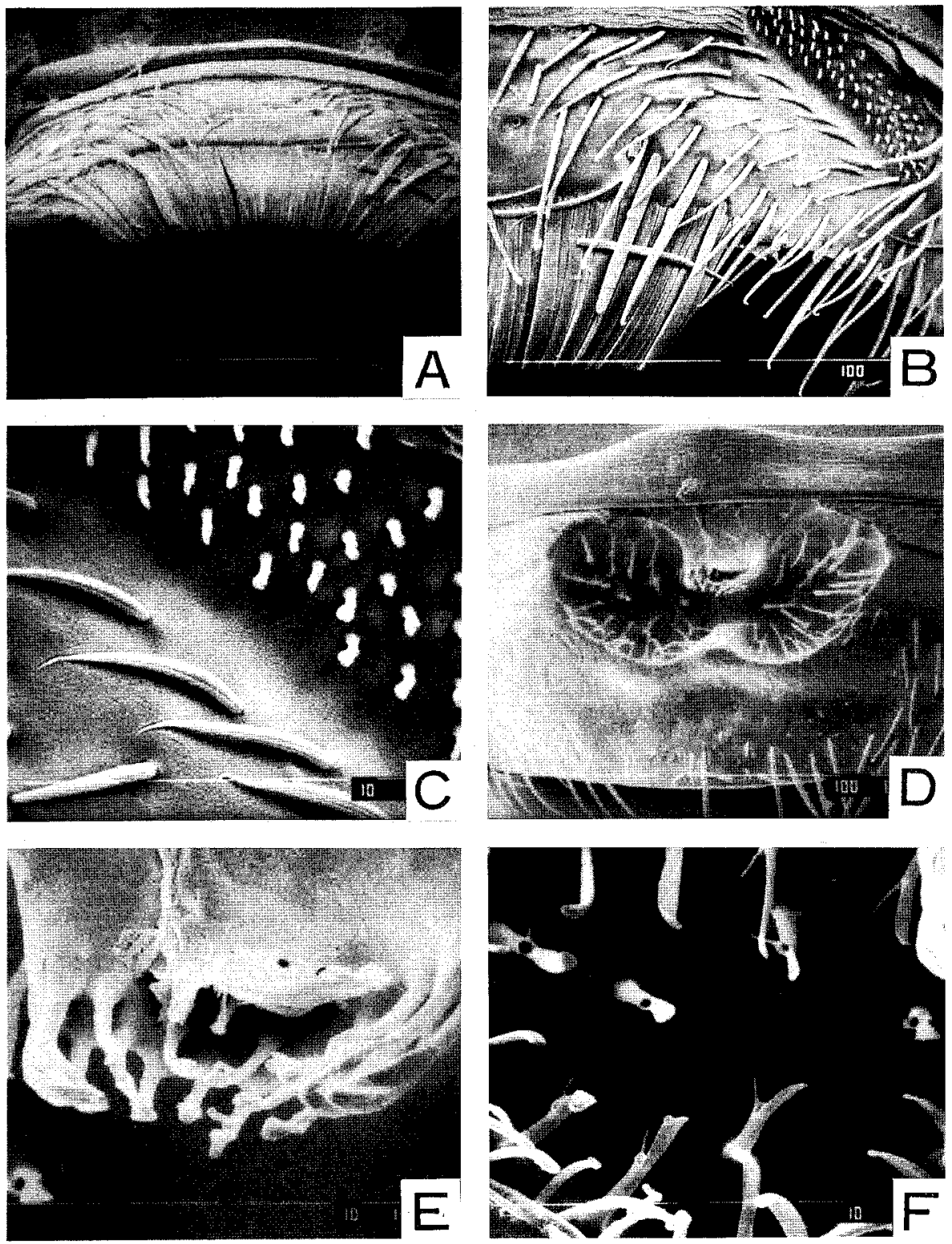
Fig. 74. Sexual patch in Batriscenellus fallax (Sharp).

A-C, 5th abdominal segment.

D, E, 6th abdominal segment. 

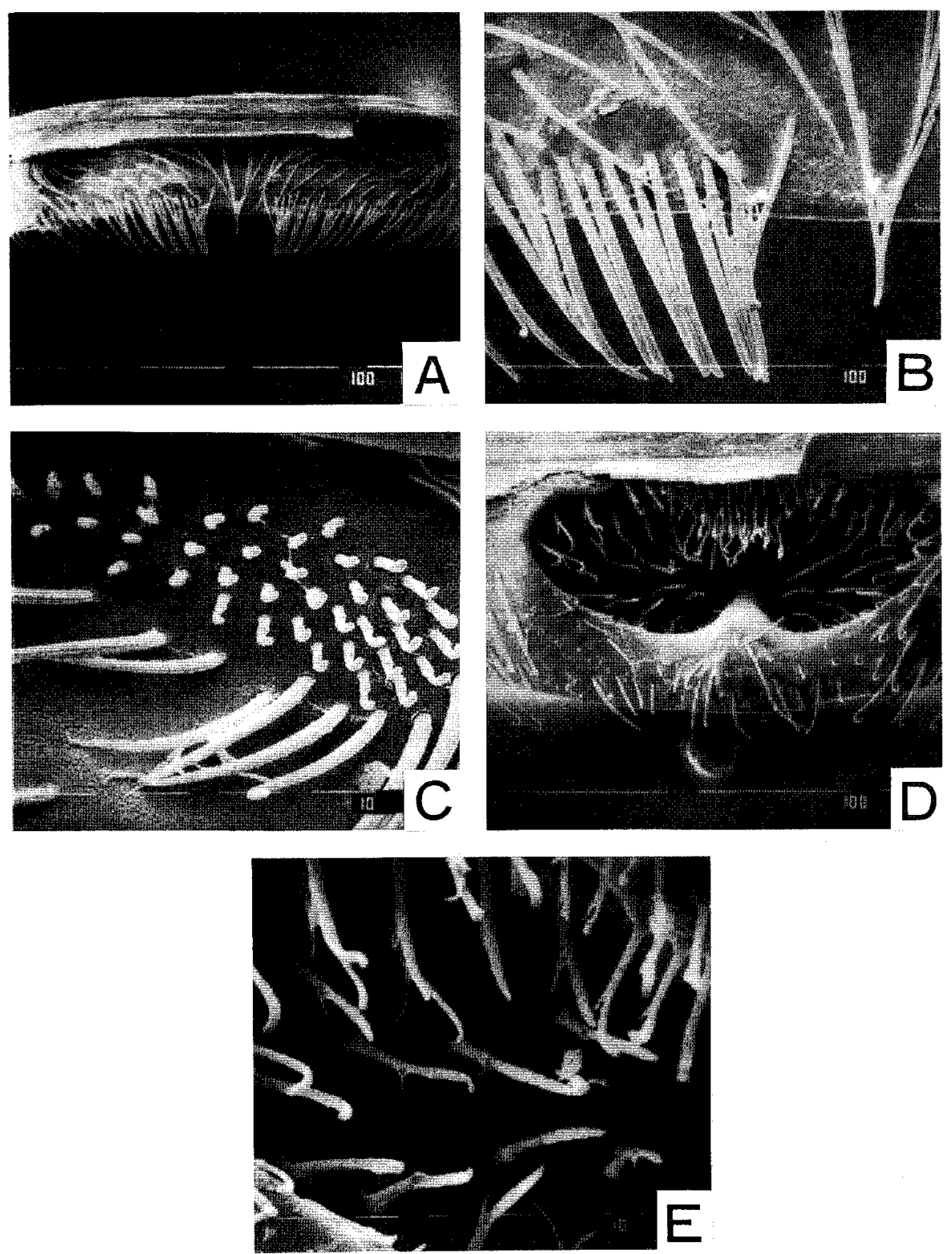
Fig. 75. Schmata of sexual patches in Batriscenellus.
$\mathrm{B}, \mathrm{D}, 6$ th tergite.
$\mathrm{C}$, dorsal aspect.

A, 5th abdominal tergite.

A, B, B. nodulifer sp. nov.

C, D, B. transformis sp. nov. 


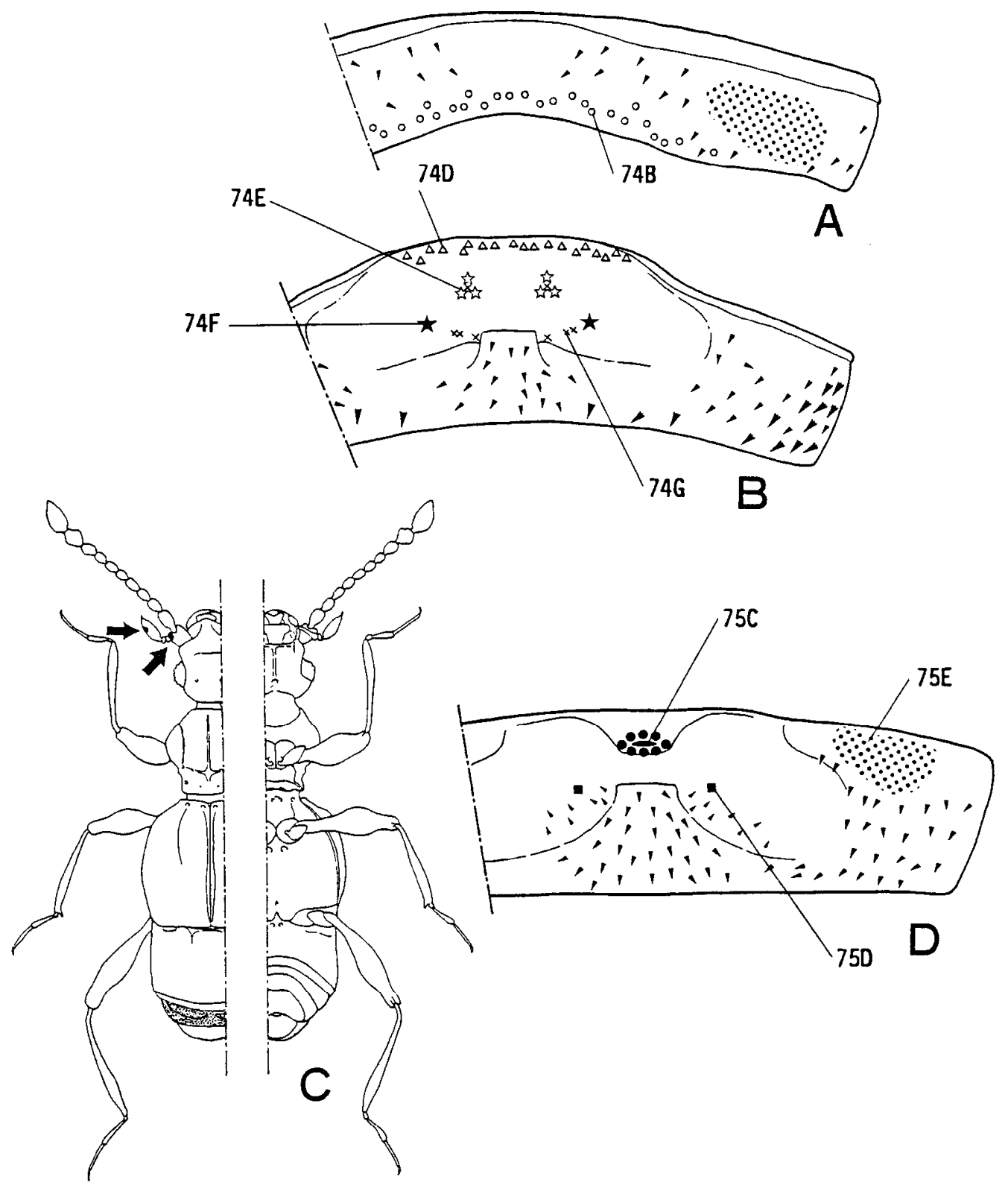


Fig. 76. Sexual patch in Batriscenellus nodulifer sp. nov.

A, B, 5th abdominal tergite.

C-G, 6th tergite. 

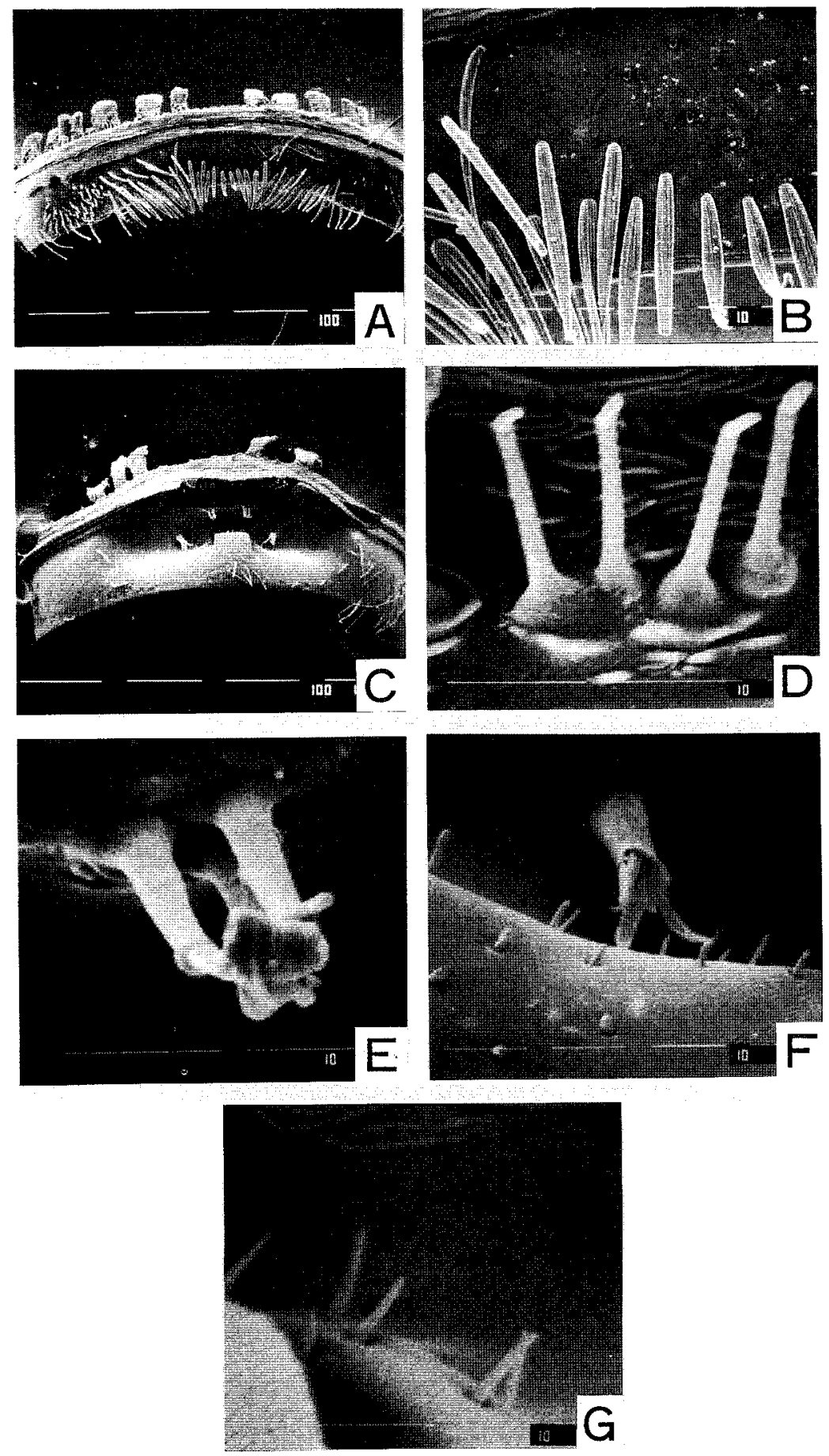
S. NOMURA

Fig. 77 Sexual patch in Batriscenellus transformis sp. nov.

A, 5th abdominal tergite.

B-E, 6th tergite. 

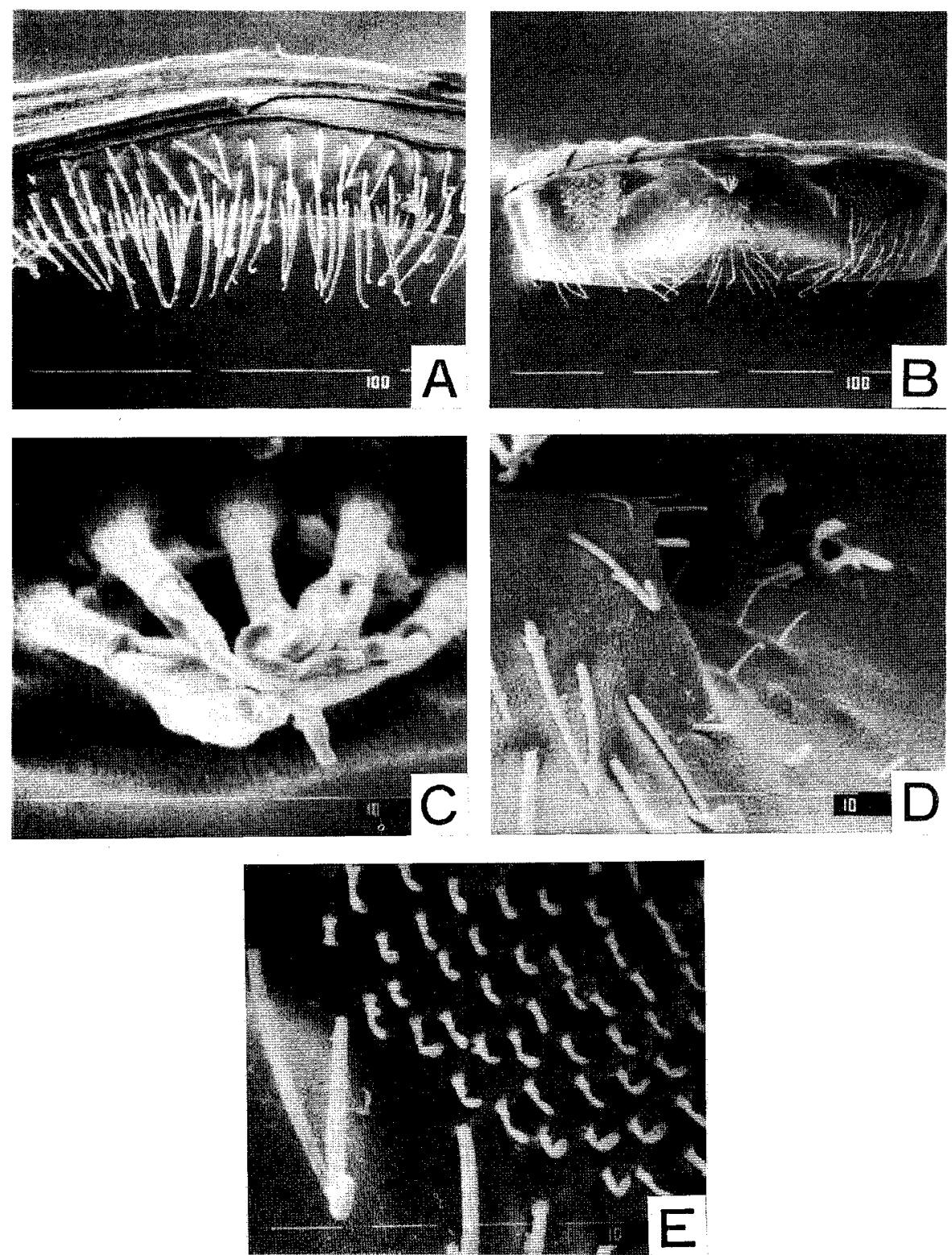
Fig. 78. Schemata of sexual patches in Batriscenellus.
A, dorsal aspect.
B, 5th abdominal tergite.
C, 6th tergite.
D, E, 5th to 6th tergites.

A-C, B. similis (Sharp).

D, B. ohishii sp. nov.

E, B. pilosellus sp. nov. 
$\Rightarrow$ Sexual patch

$\longrightarrow$ iton sexual setiferous structure

$\downarrow \quad$ Seta of type $F$

. . Seta of type A

- $\triangle \square$ Seta of type B

- Nornal hai $r$

$\times \quad$ Pore

- Secretory pit

Patch of pores

Acinous patch

Patch (trichome or fri nge)

$\because \because$ of type $A$

Patch of type B
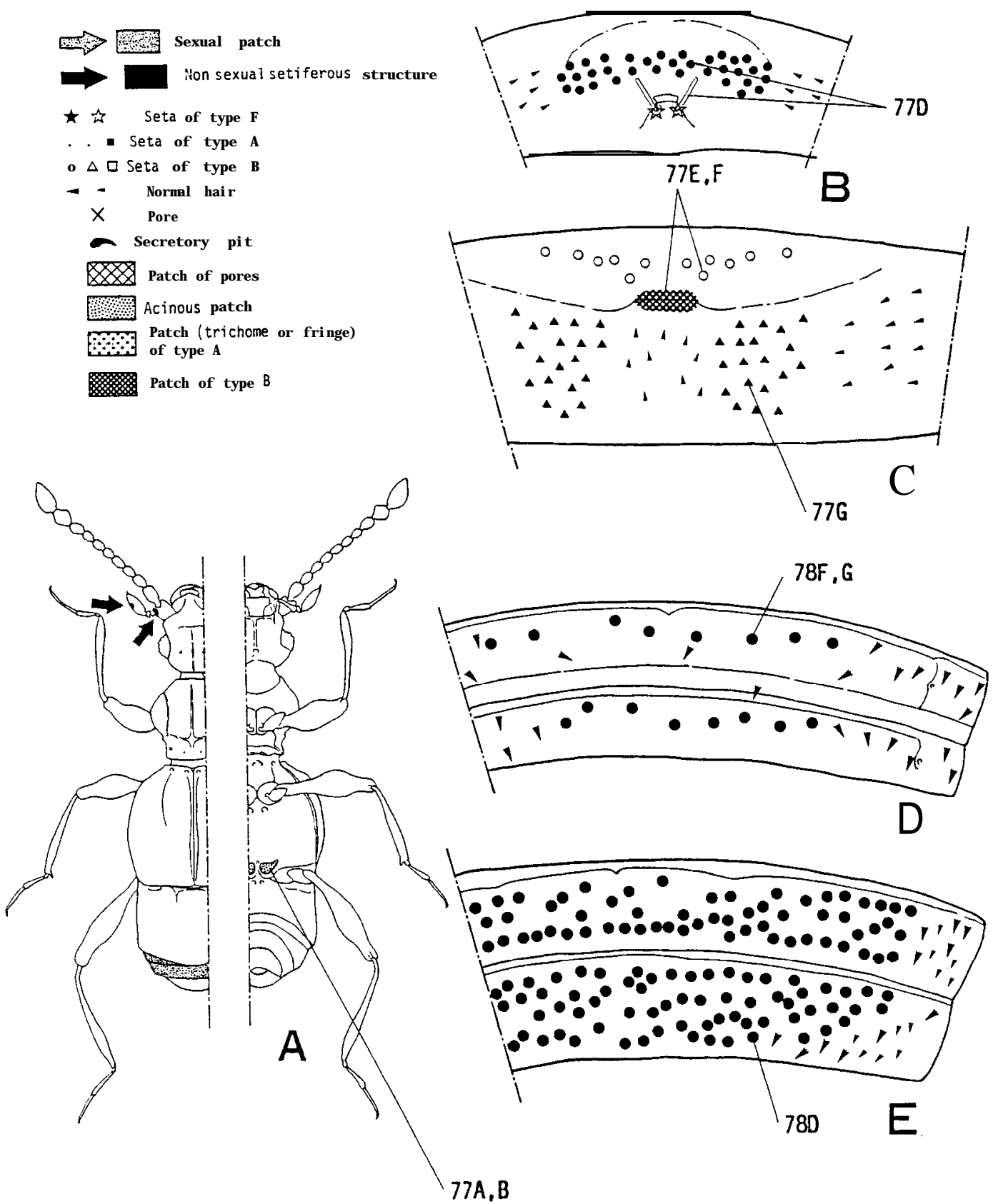

$77 \mathrm{~A}, \mathrm{~B}$ 
Fig. 79. Sexual patch in Batriscenellus similis (Sharp).
A, B, metastemum.
C, D, 5th abdominal tergite.
E-G, 6th tergite. 

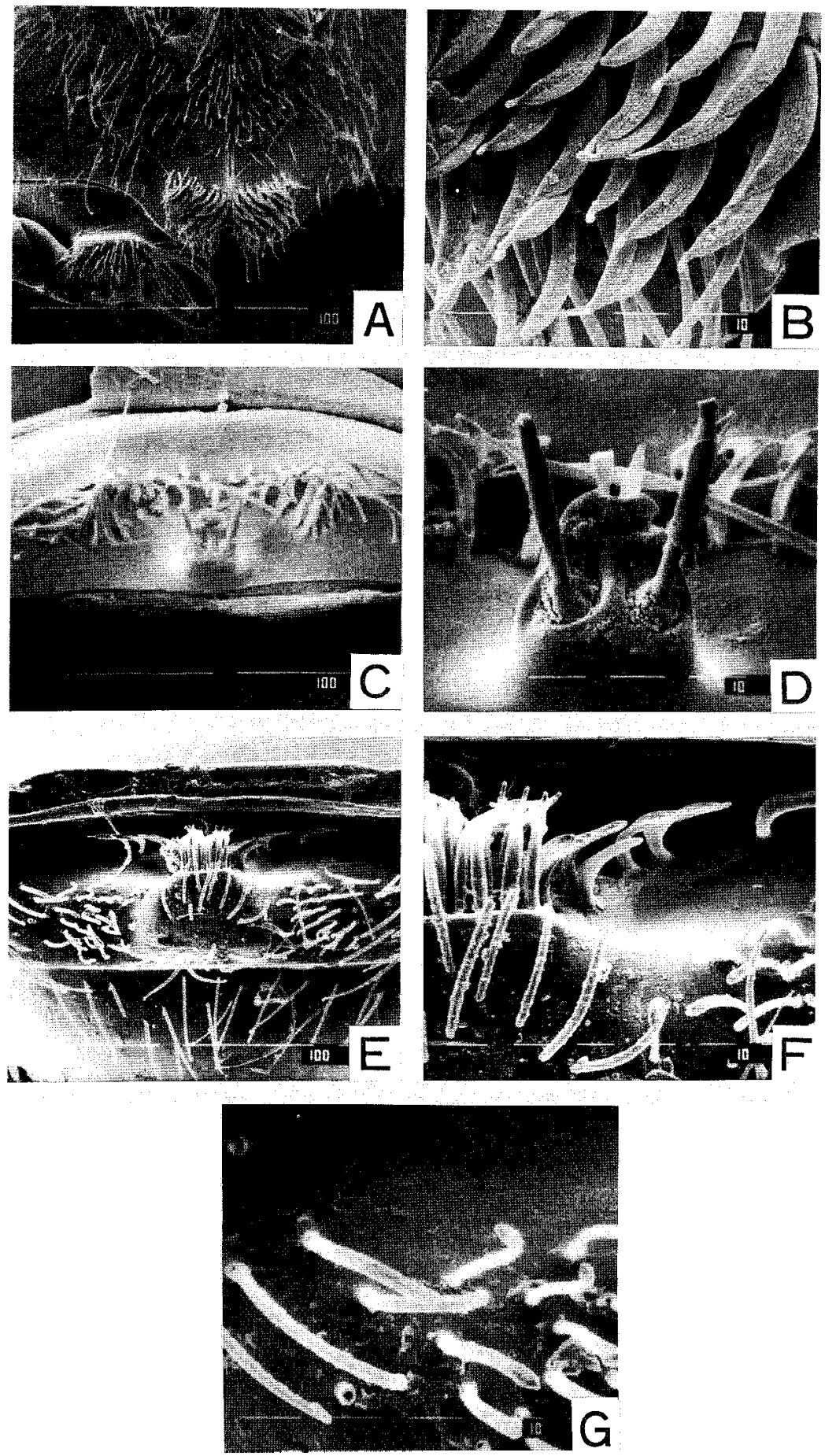
Fig. 80. Sexual patch in Batriscenellus.
A, B, metastemum.
C, E, F, 5th to 6th abdominal tergite.
D, G, secretory setae on 5 th tergite.

A-D, B. pilosellus sp. nov.

E-G, B. ohishï sp. nov. 

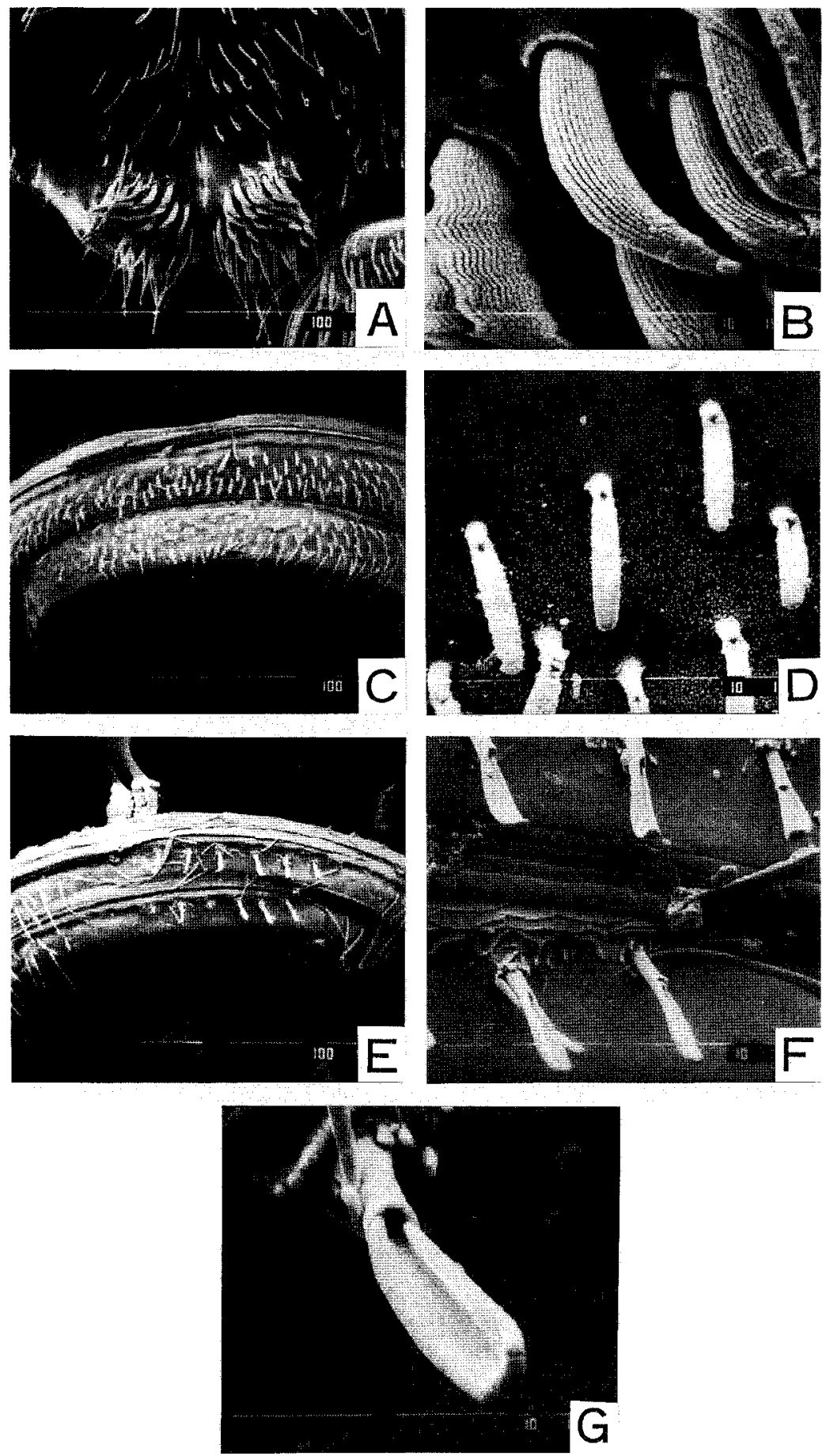
S. NOMURA

Fig. 81. Sexual patch in Batriscenellus uenoi sp. nov.

A, dorsal aspect.

B-E, hind femur. 

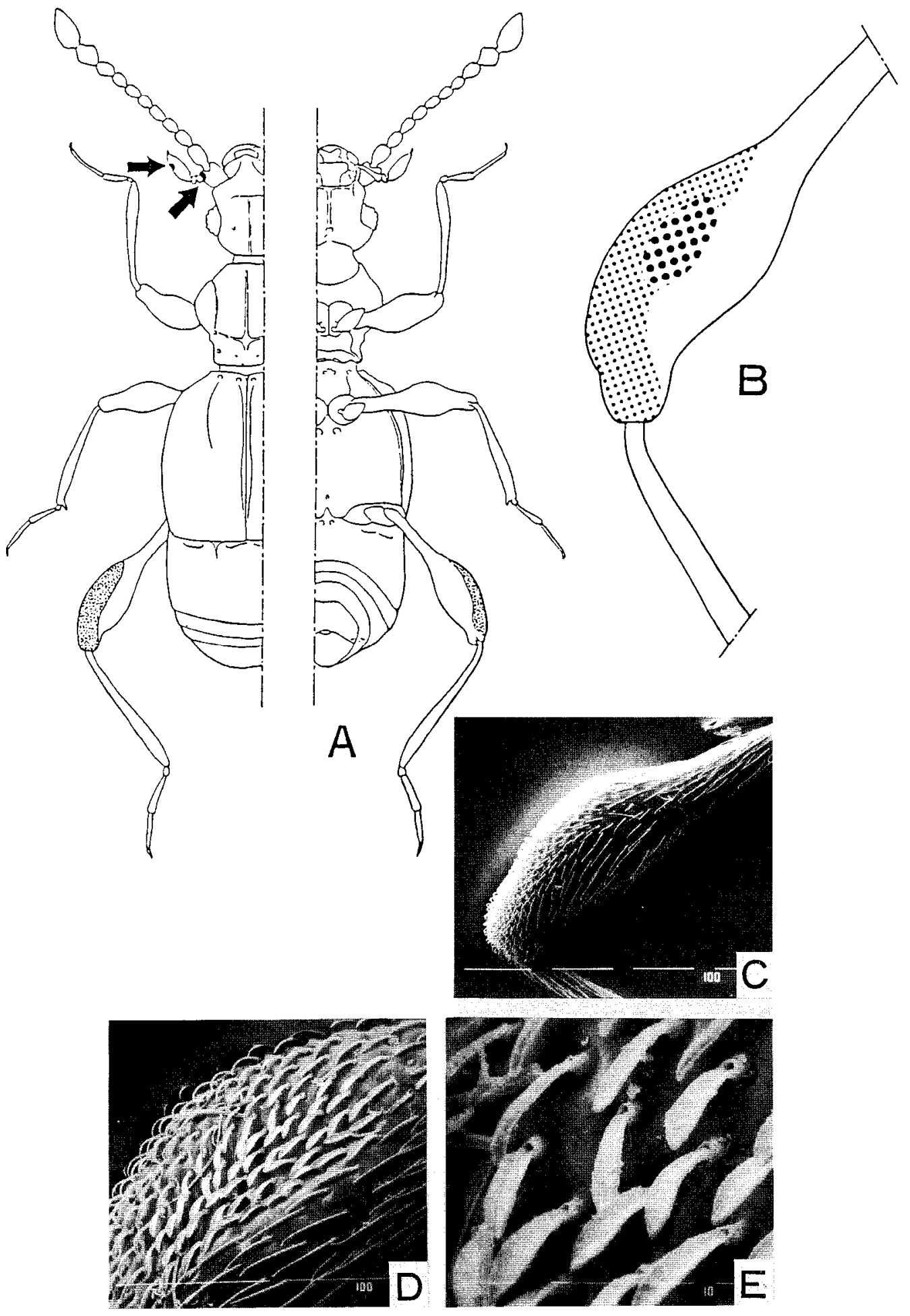
S. NOMURA

Fig.82 Schamata of sexual patches in Physomerinus.

A-C, Hind femur.
A, $P$. pedator (Sharp).
B, P. schenklingi (Raffray).
C, $\boldsymbol{P}$. hasegawai sp. nov. 


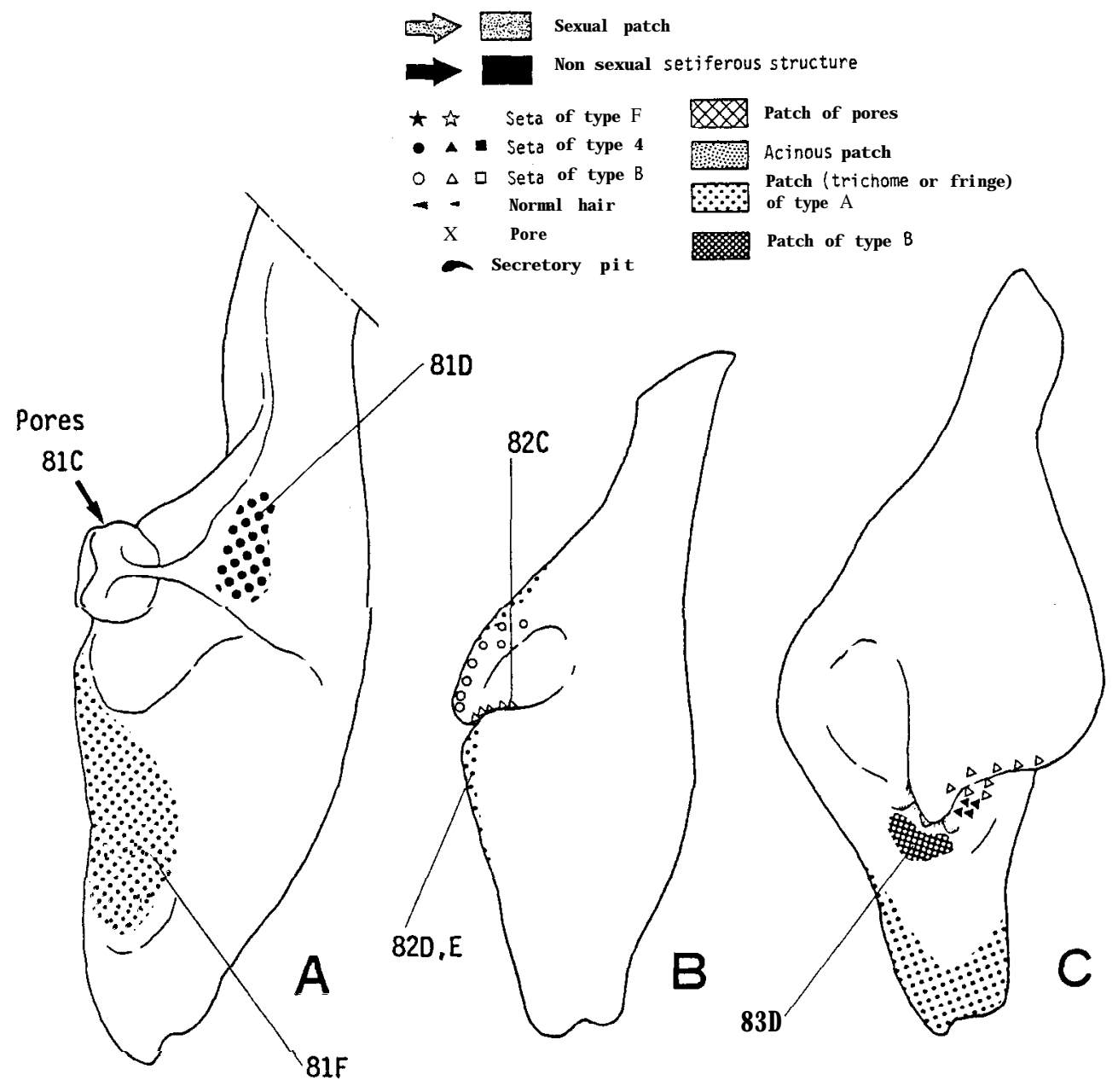


Fig. 83. Sexual patch in Physomerinus pedator (Sharp).
A, B, metasternum.

$\mathrm{C}-\mathrm{F}$, hind femur. 

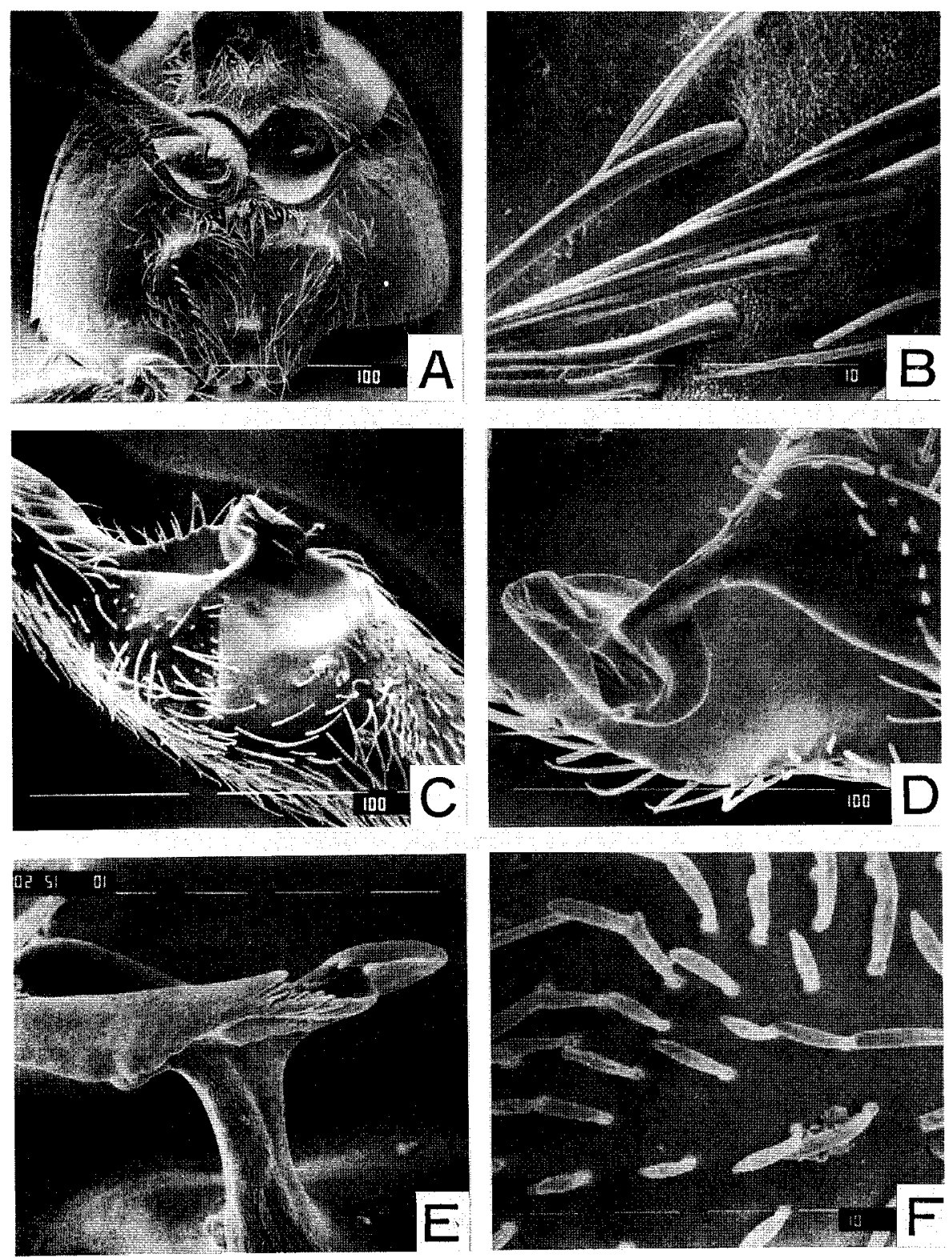
Fig. 84. Sexual patch in Physomerinus schenklingi (Raffray).

A-E, hind femur. 

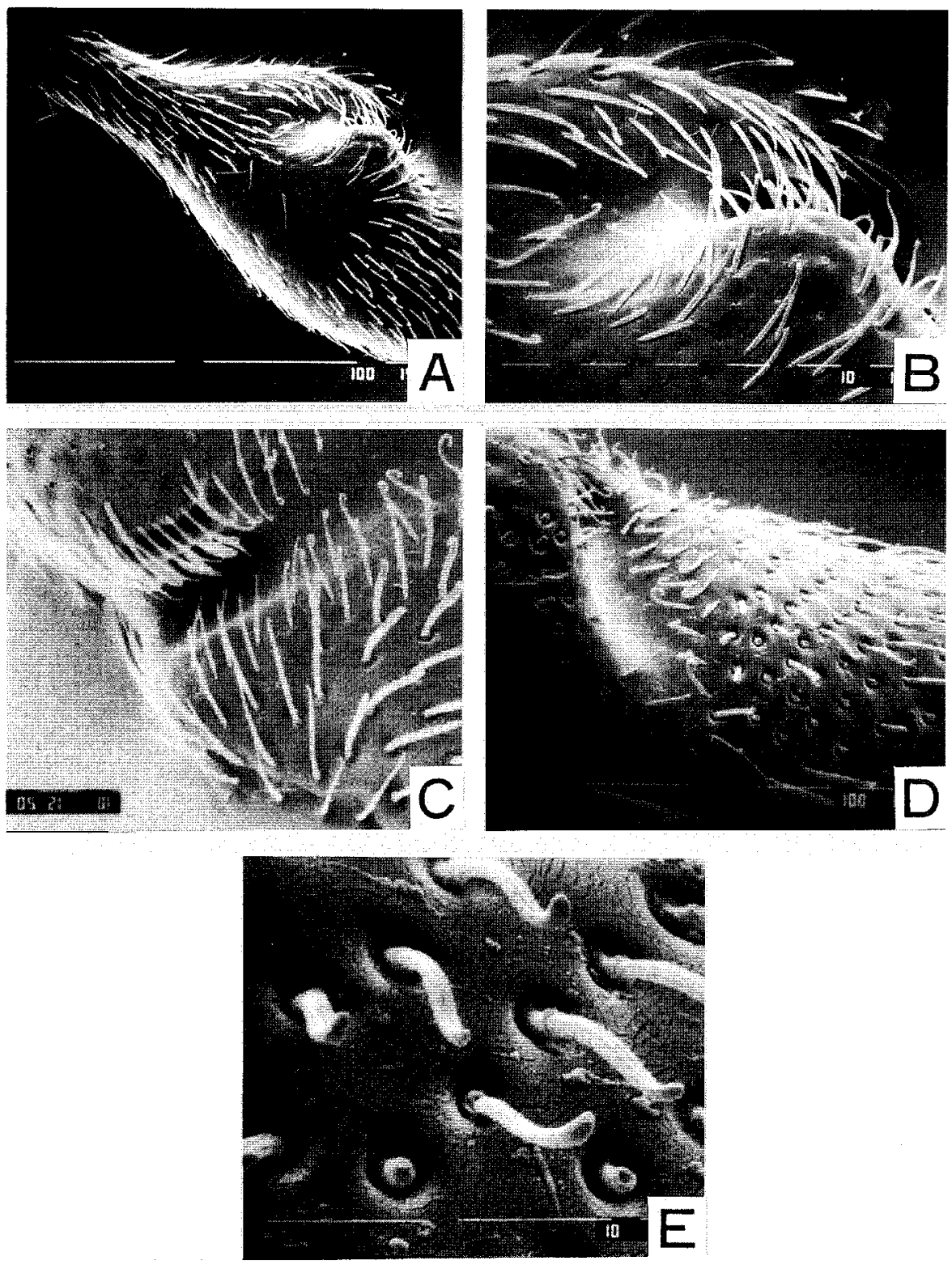
Fig. 85. Sexmal patch in Physomerinus hasegawai sp.nov.

A, fore tibia.

B-D, hind femur. 

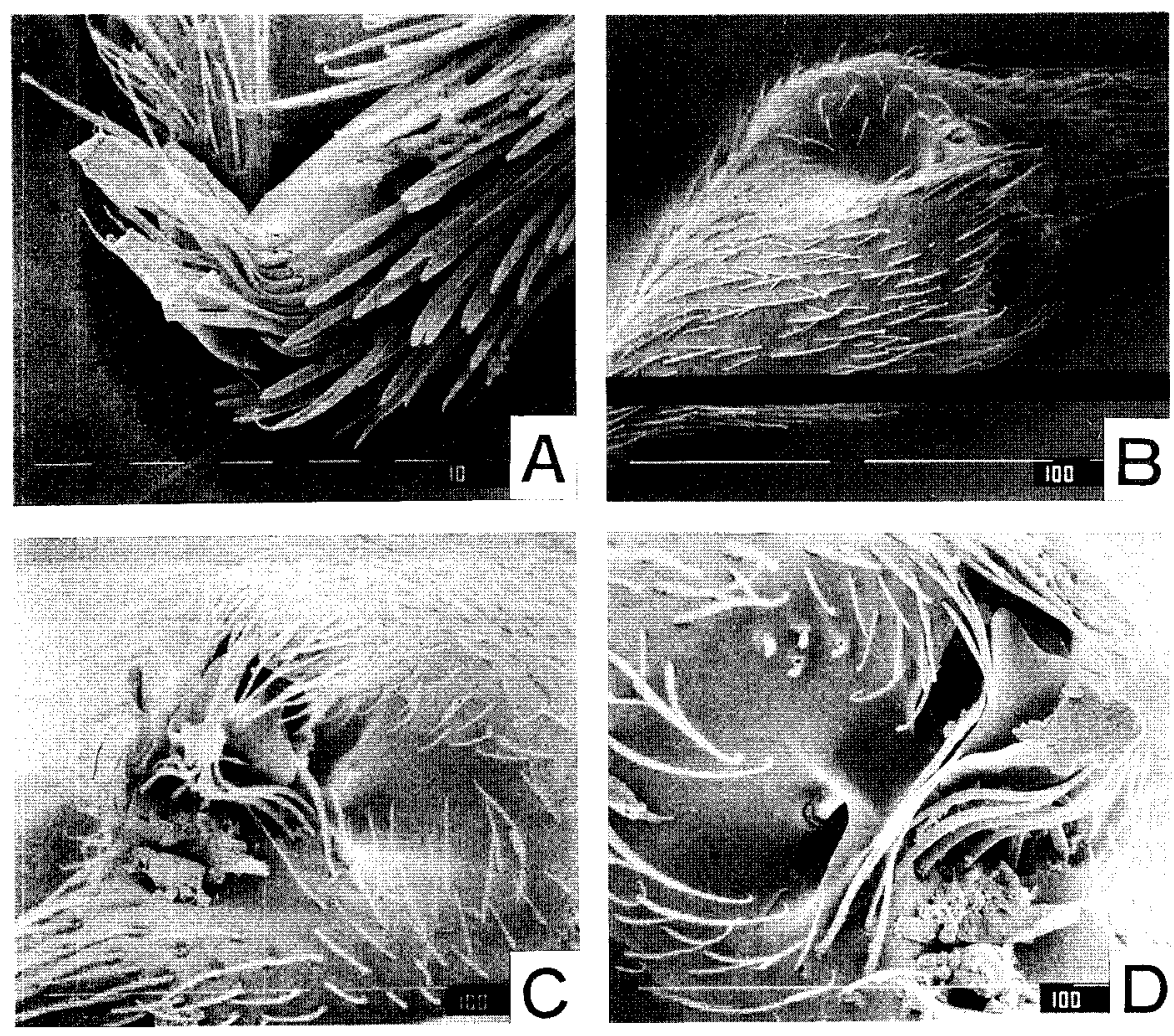
Fig. 86. Scemata of sexual patches in Batriscenaulax.
A, dorsal aspect.
B, C, 4th abdominal tergite.
A, B, B. longipes longipes Jeannel.
C, B. furuhatai (Kubota). 


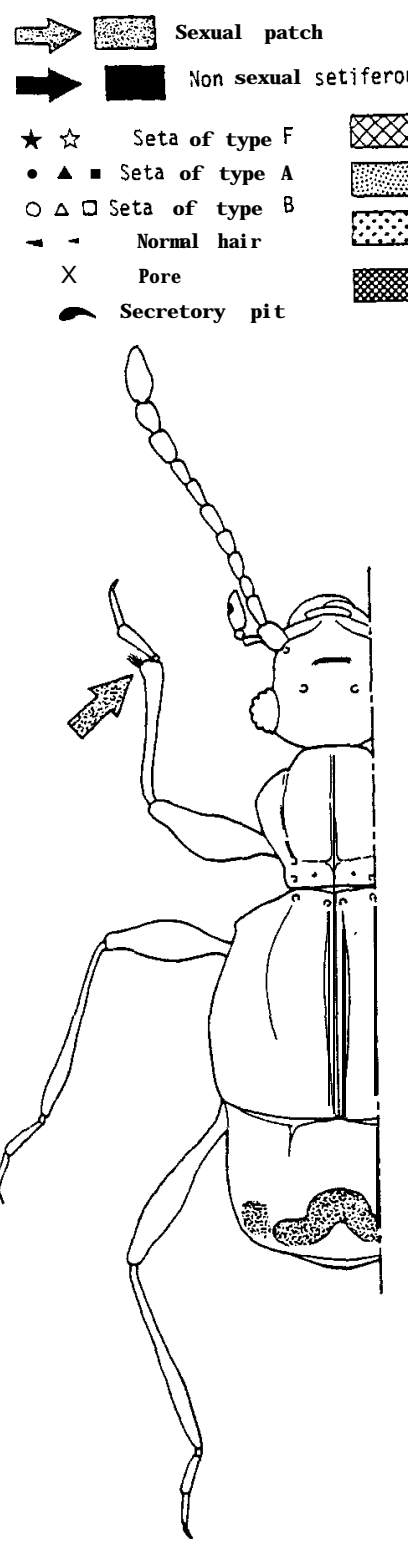

struct ure

Patch of Pores

Acinous patch

of type $A$

Patch of type B
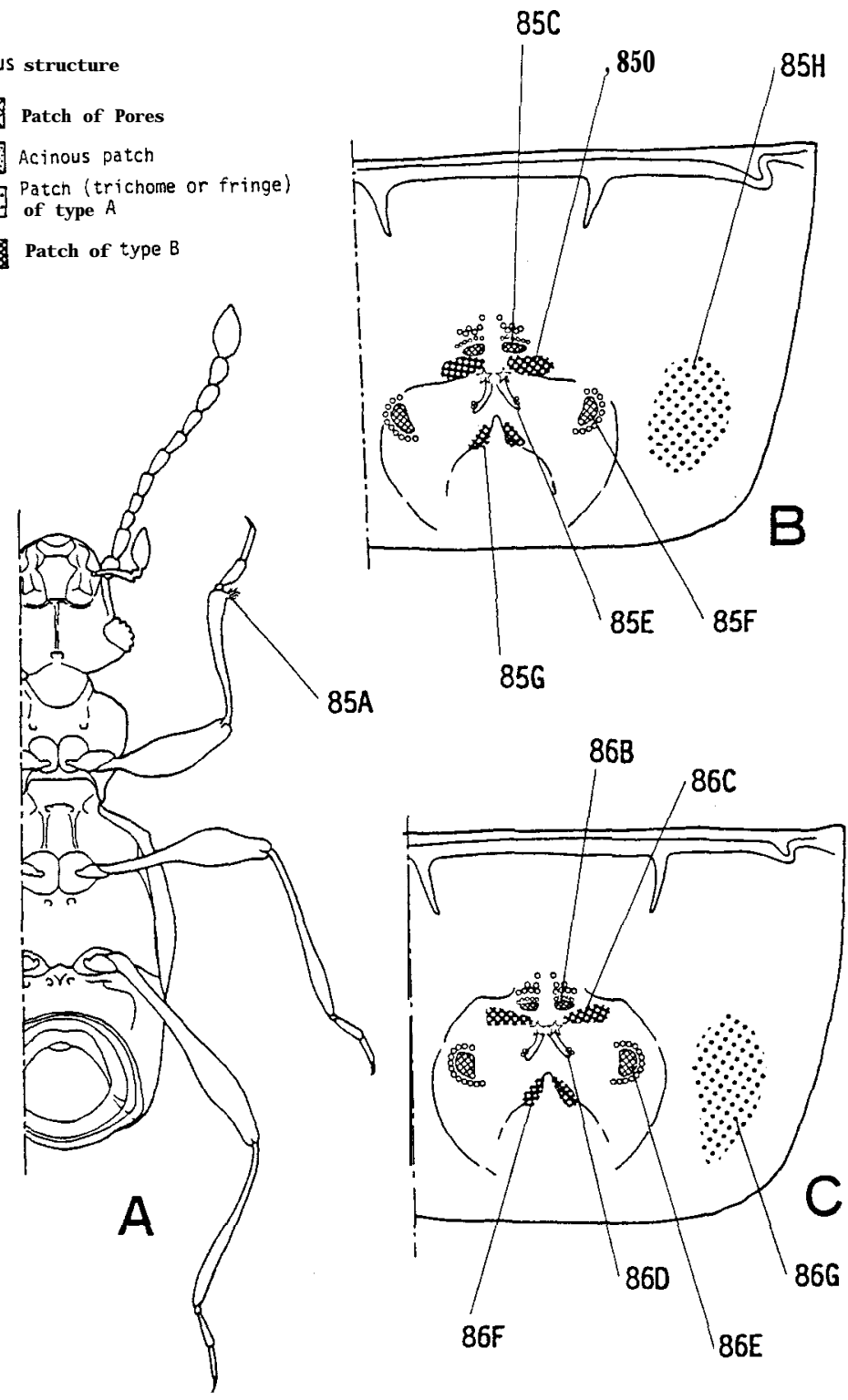
Fig. 87. Sexual patch in Batriscenaulax longipes longipes Jeannel.

A, fore tibia.

B-H, 4th abdominal tergite. 

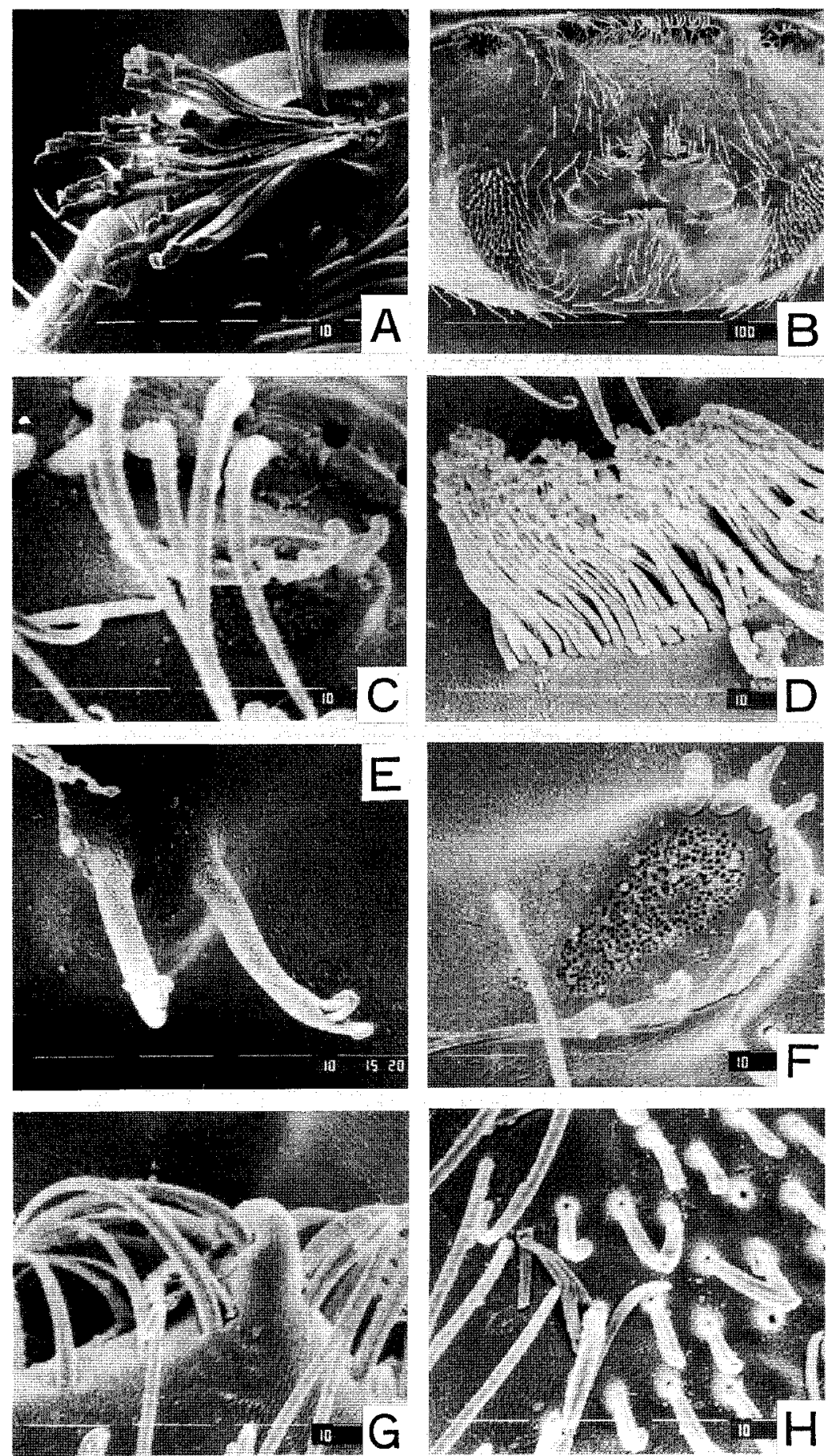
Fig. 88. Sexual patch in Batriscenaulax furuhatai (Kubota).

A, 4th abdominal tergite.

B-G, ditto, enlarged. 

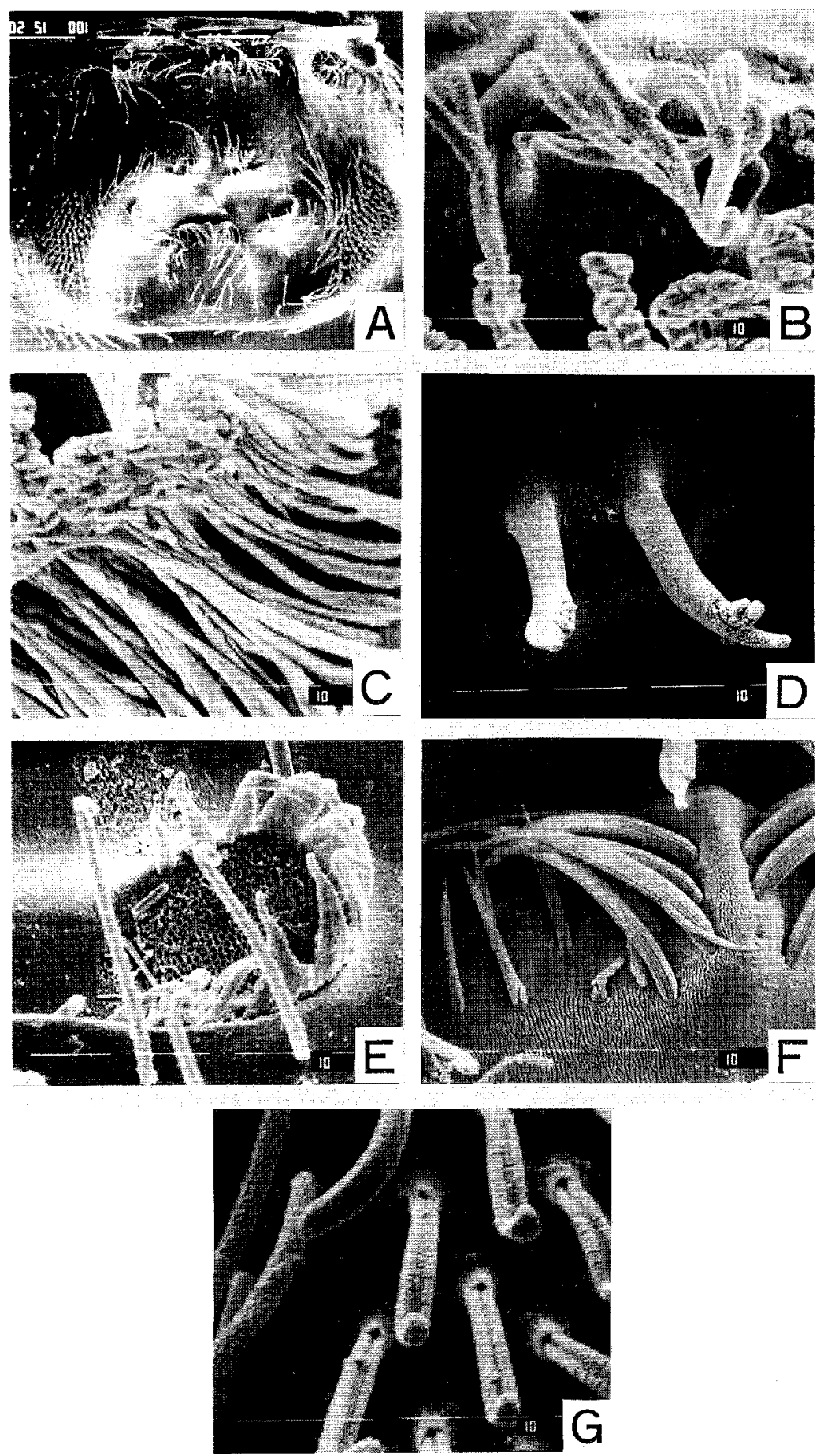
Fig. 89. Schemata of sexual patch in Batriscenaulax kleinzach sp. nov.

$A$, dorsal aspect.

B, 4th abdominal tergite. 


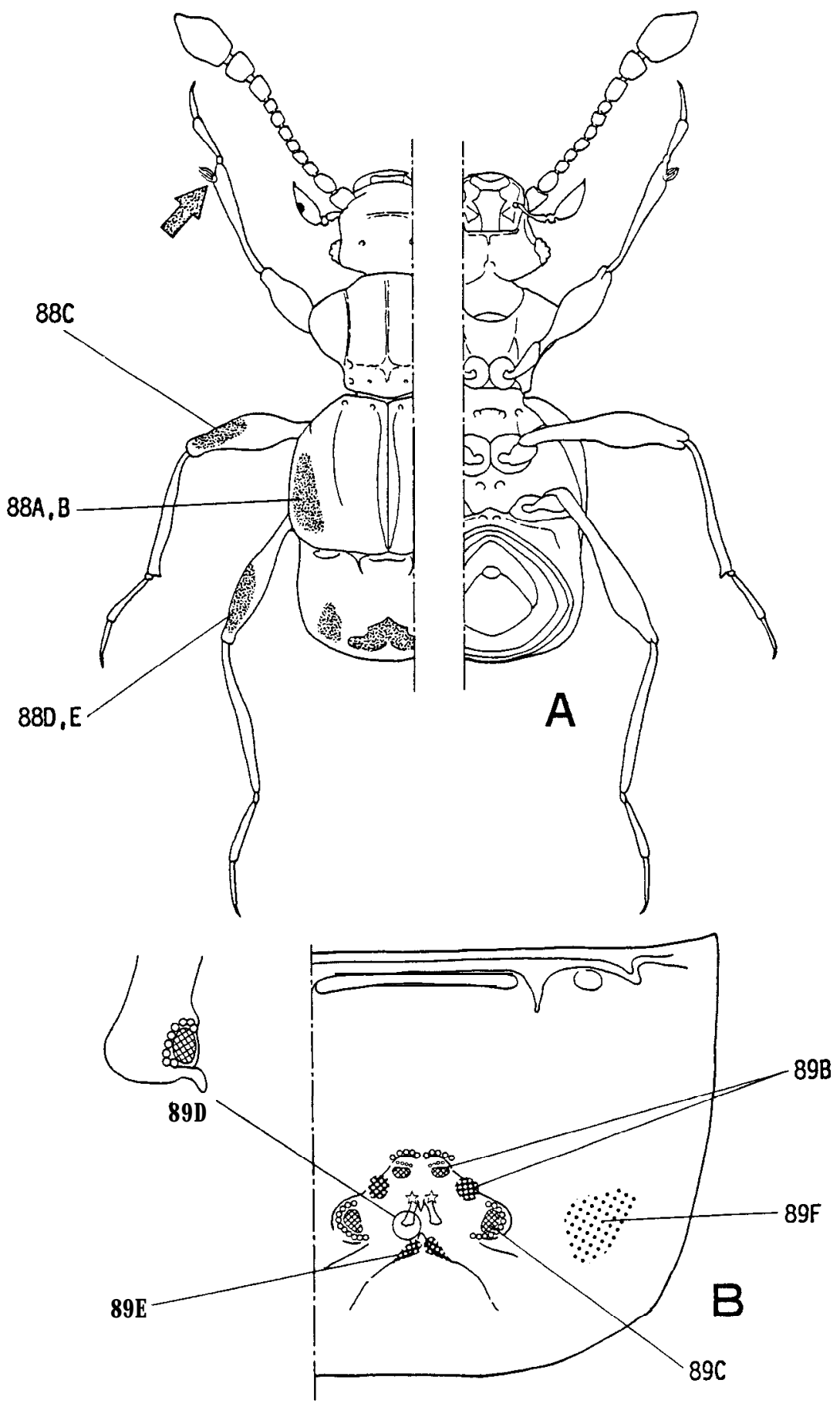


Fig. 90. Sexual patch in Batriscenaulax kleinzach sp. nov.
A, B, elytron.
C, mid femur.
$\mathrm{D}, \mathrm{E}$, hind femur. 

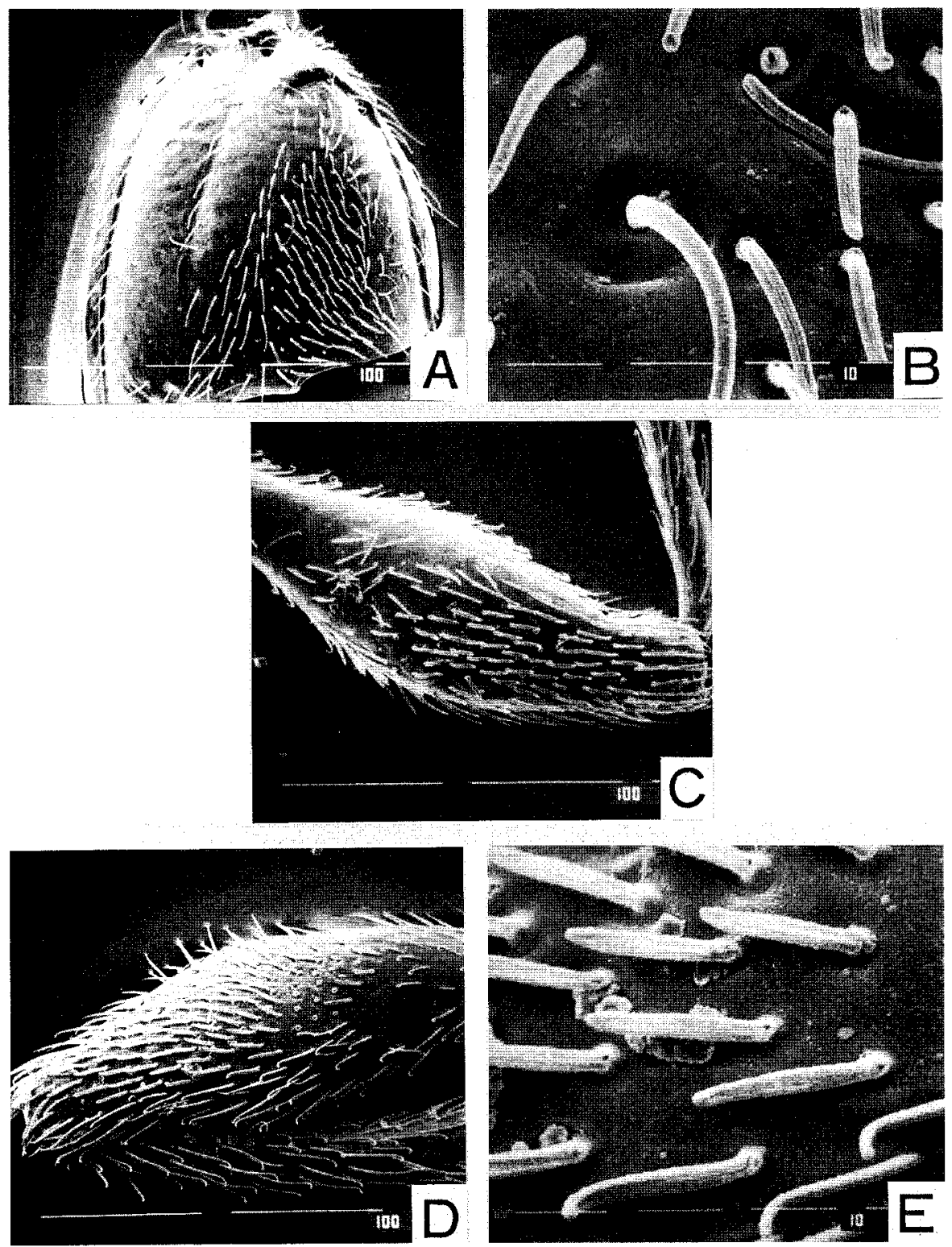
Fig. 91. Sexual patch in Batriscenaulax kleinzach sp. nov.

A, 4th abdominal tergite.

B-F, ditto, enlarged. 

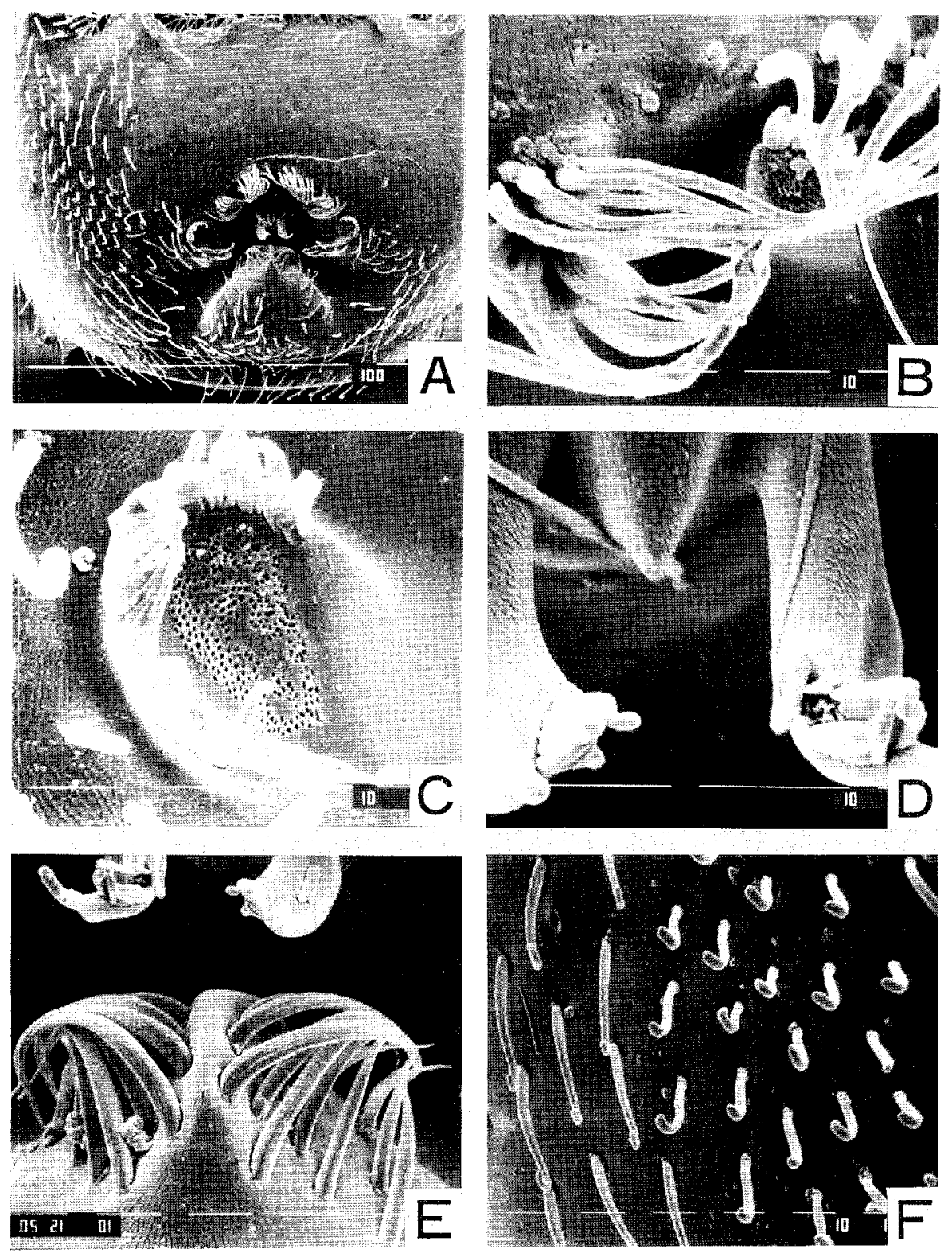
Fig. 92 Schemata of sexual patches in Arthromelodes.

$\boldsymbol{A}$, dorsal aspect.

$\mathrm{B}, 7$ th to 10th antennal segments in ventral view.

$\mathrm{C}$, hind femur in ventral view.

$\mathrm{D}$, hind tibia.

A-C, $A$. giganteus sp. nov.

$\mathrm{D}, \boldsymbol{A}$. mercurius sp. nov. 

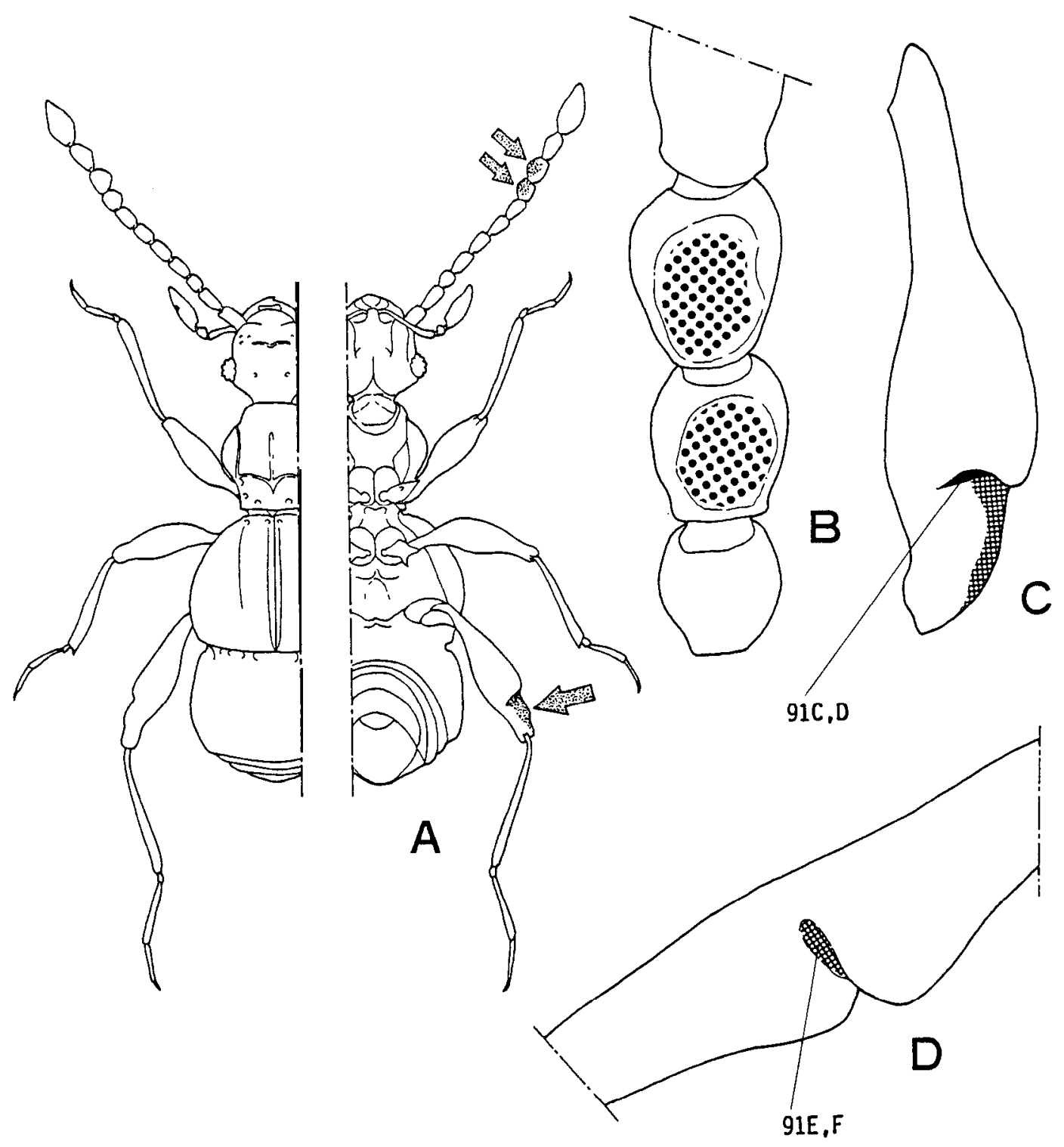
Fig. 93. Sexual patch in Arthromelodes.
A, 8th to 9th antennal segments.
B-D, hind femur.
E, F, hind tibia.

A-D, A. giganteus sp. nov.
E, F, A. mercuriussp. nov. 

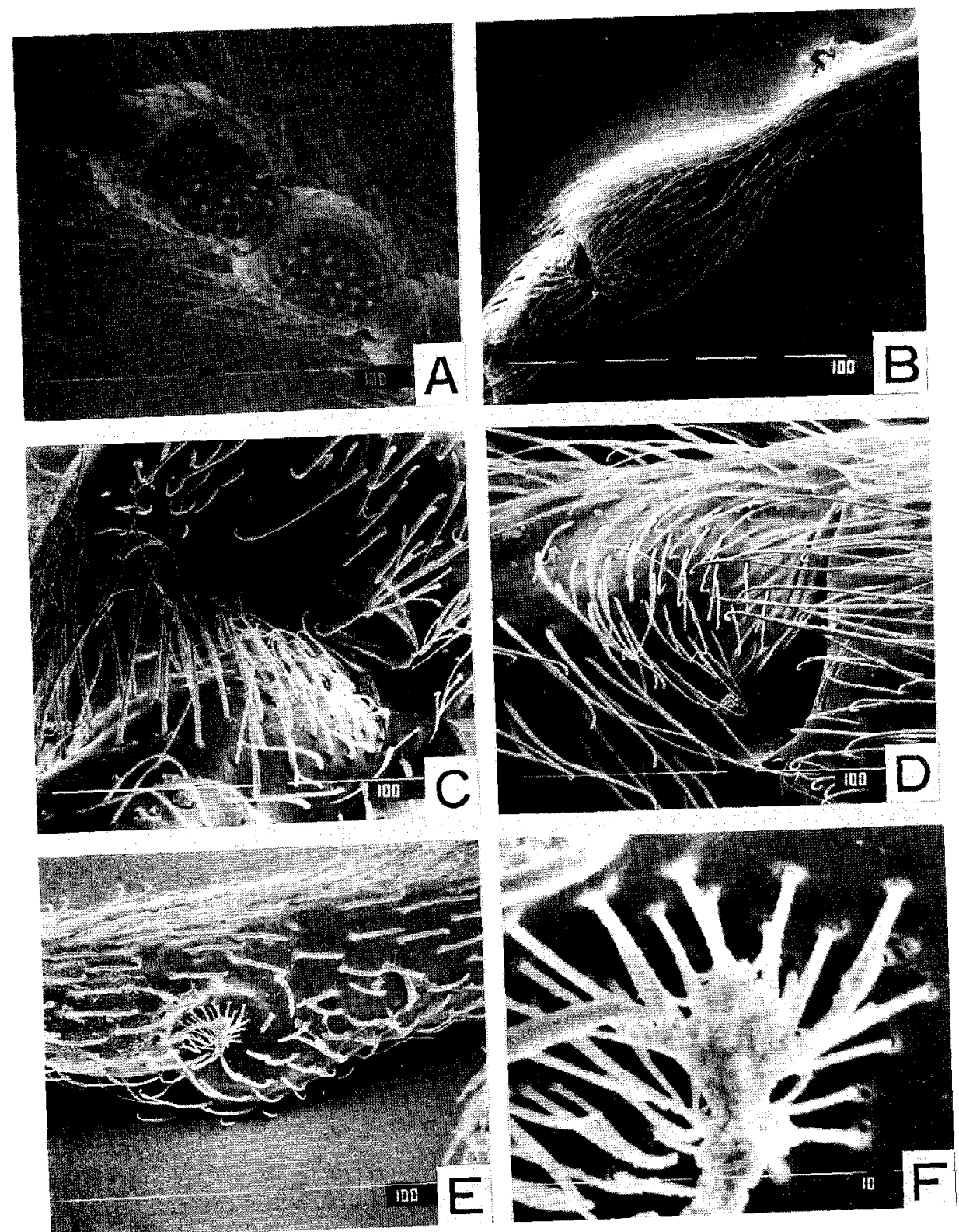
S. NOMURA

\section{Fig. 94. Schemata of sexual patches in Arthromelodes.}

A, 5th abdominal tergite.

B, 6th tergite.

C, 7th tergite.

$\mathrm{D}$, 4th tergite.

A-C, A.thysanoventris sp. nov.

$\mathrm{D}, \mathrm{A}$. dilatatus daibosatsuauus subsp. nov. 


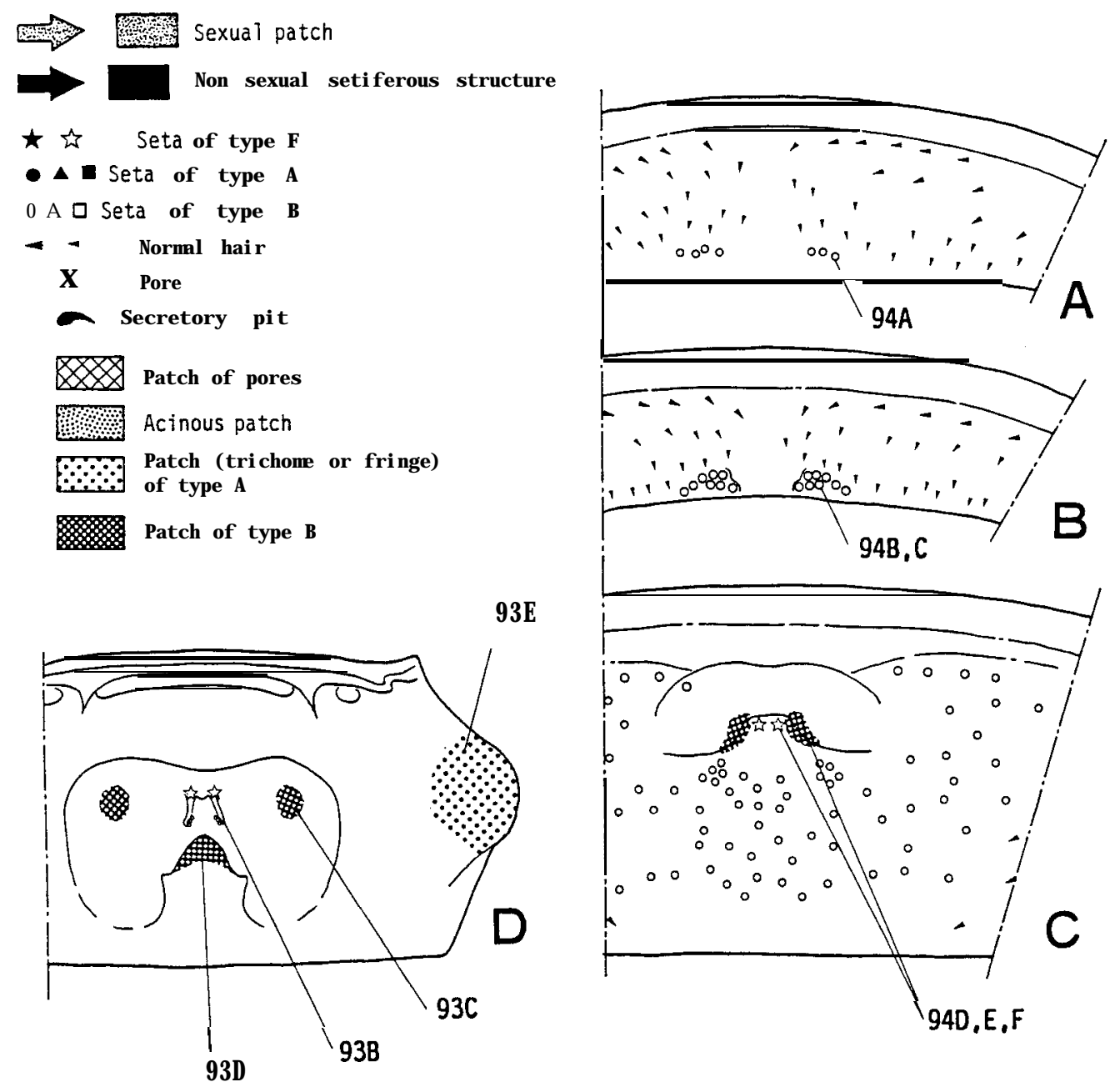


S. NOMURA

Fig. 95. Sexual patch in Arthromelodes thysanoventris sp. nov.
A, 5th abdominal tergite.
$\mathrm{B}, \mathrm{C}, 6$ th tergite.
D-F, 7th tergite. 

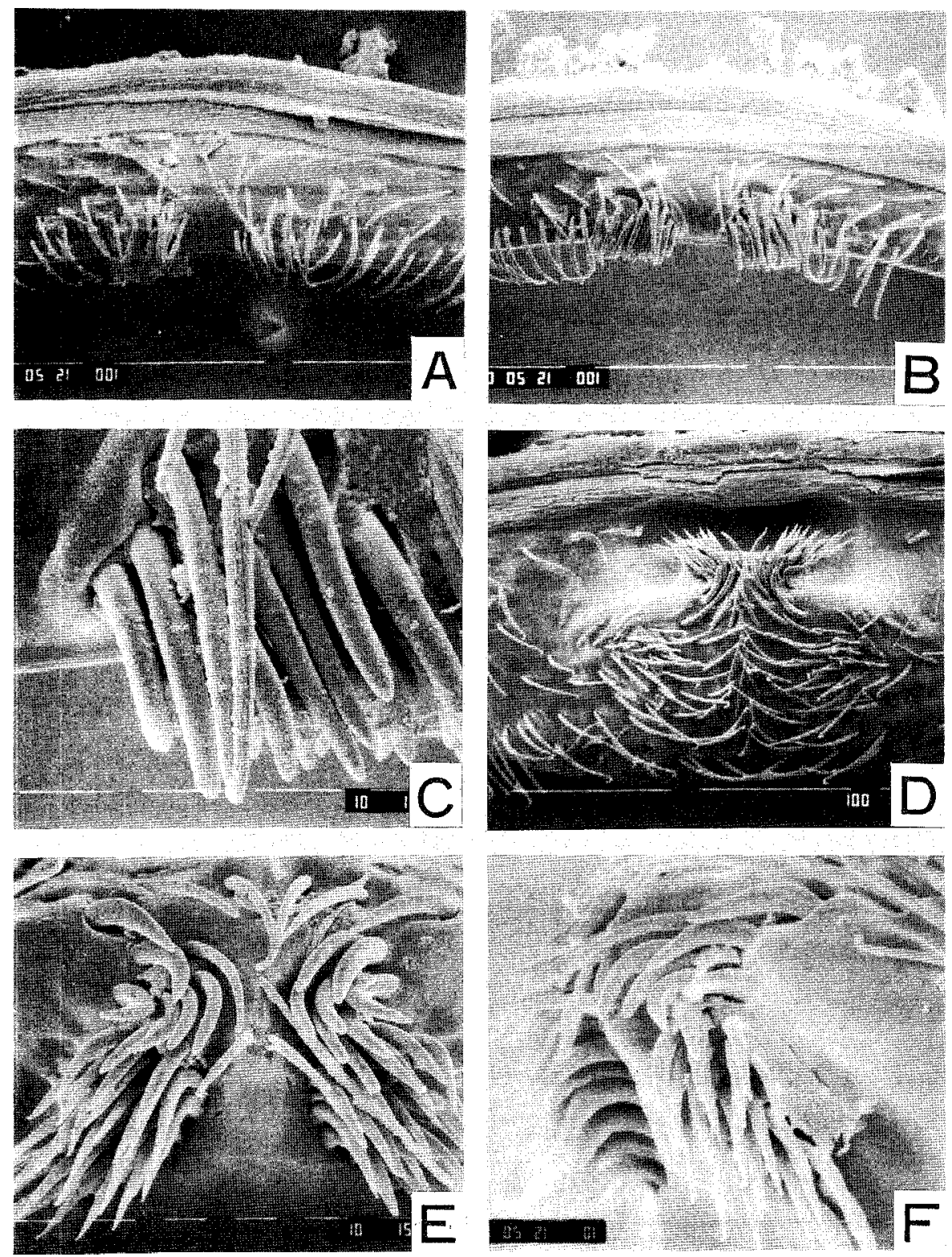
Fig. 96. Sexwal patch in Arthromelodes dilatatus daibosatsuanus subsp. nov. A, 4th abdominal tergite.

B-E, ditto, enlarged. 

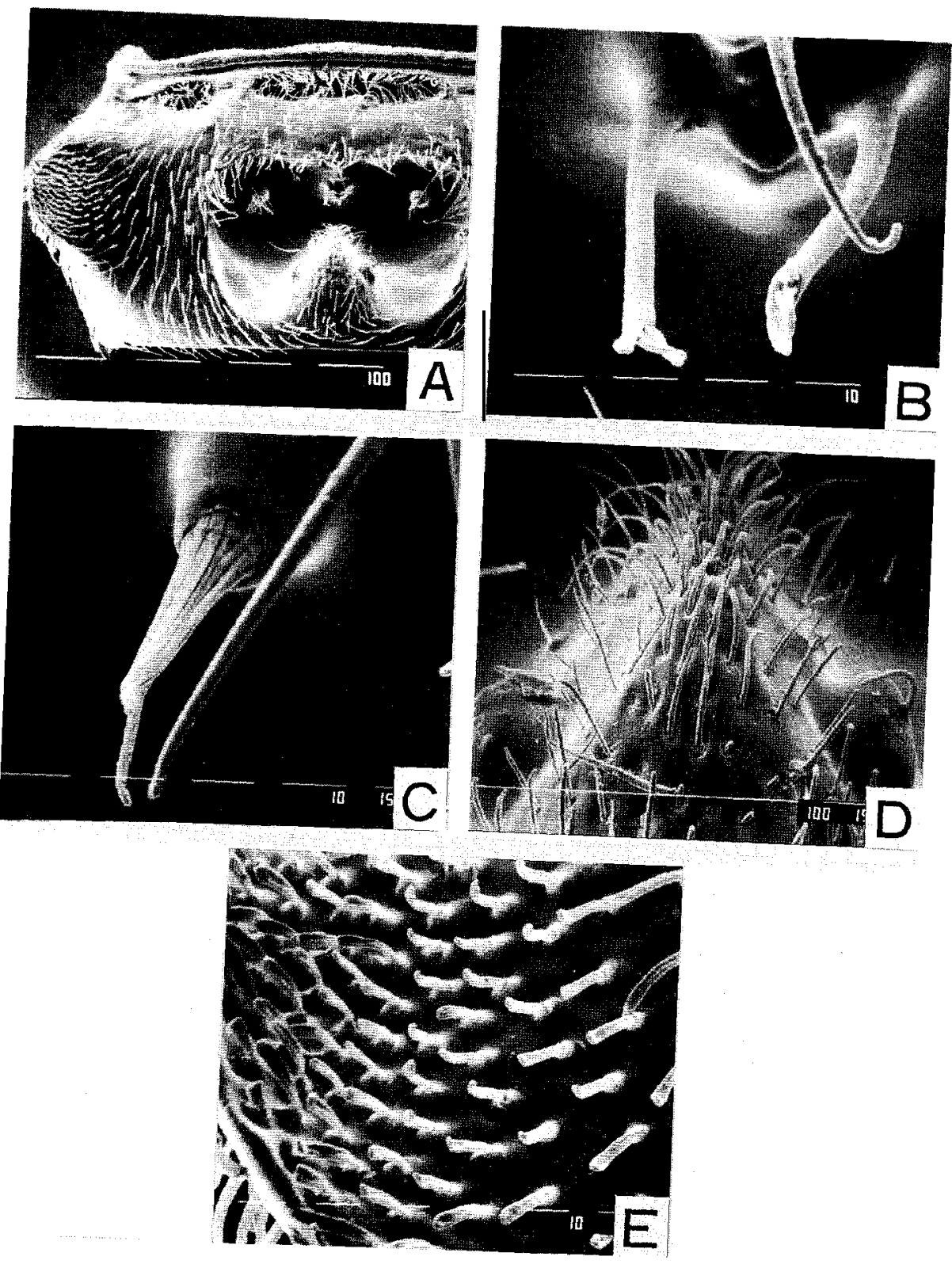
Fig. 97. Schemata of serual patches in Arthromelodes.

A, dorsal aspect.

B, C, 4th abdominal tergite.

A, B, A. cruder sp. nov.

C, A. saikaiensis sp. nov. 

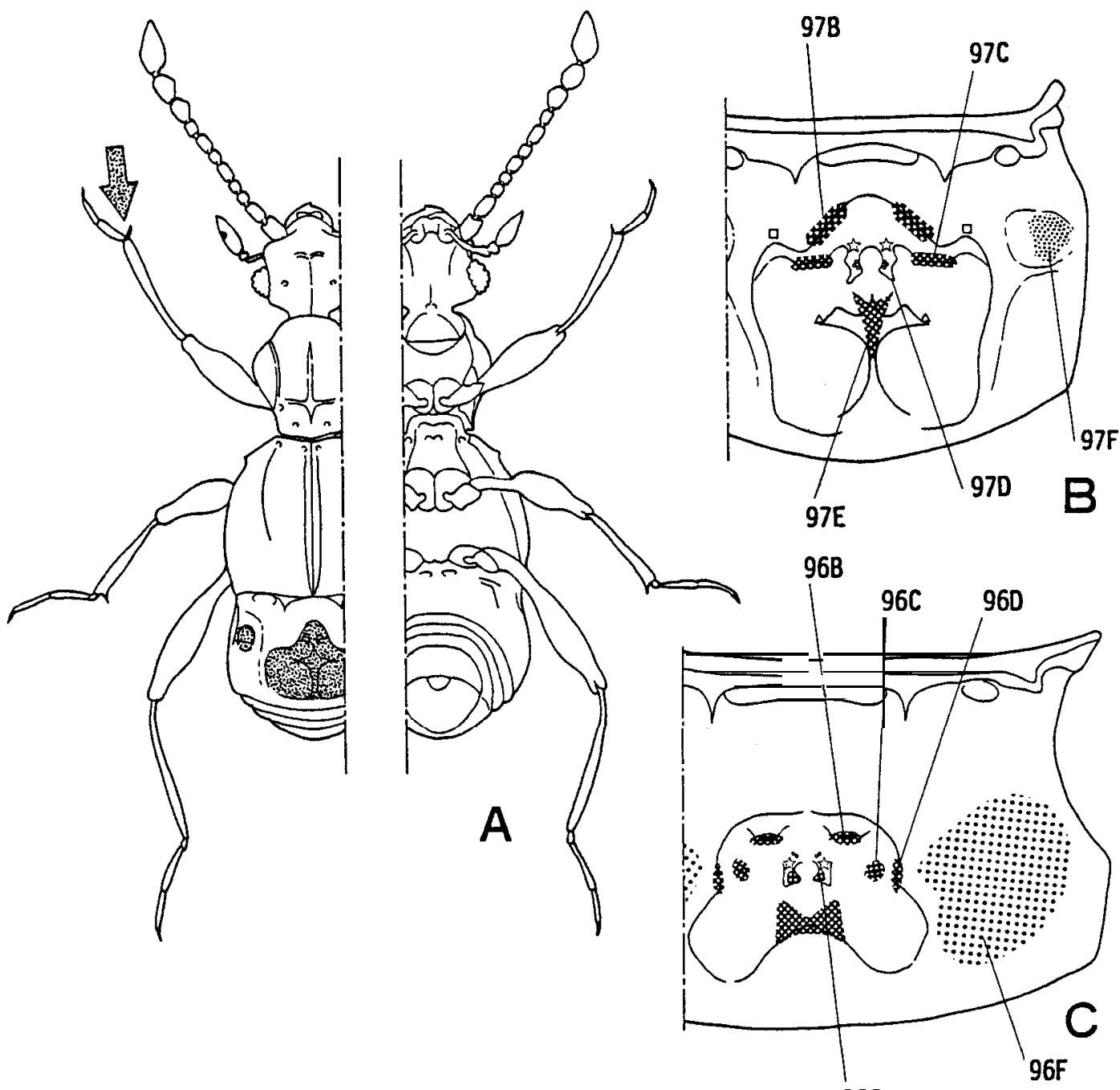

96E 
Fig. 98. Sexual patch in Arthromelodes saikaiensis sp. nov.

A, 4th abdominal tergite.

B-F, ditto, enlarged. 

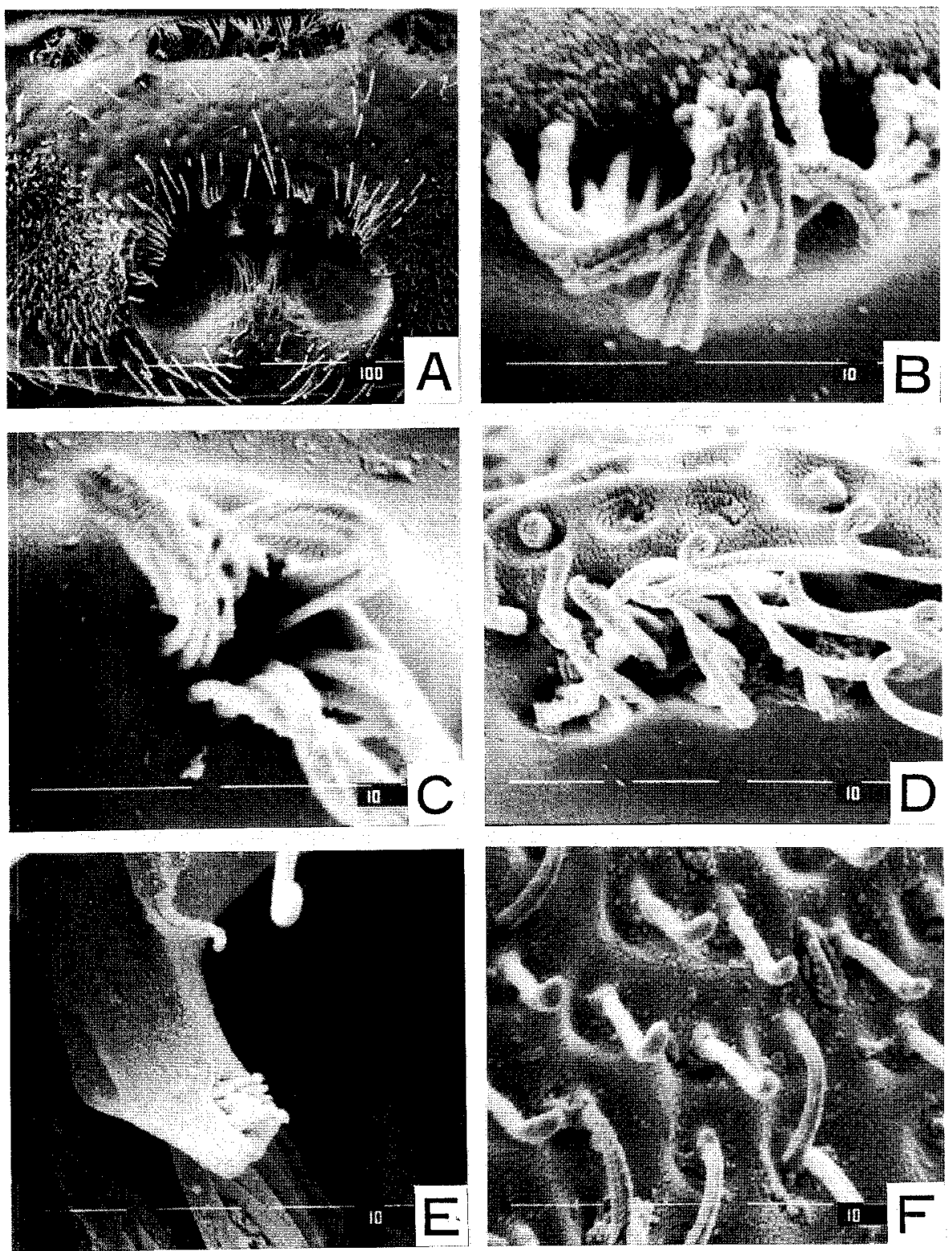
S. NOMURA

Fig. 99. Sexual patch in Arthromelodes crucifer sp. nov.

A, 4th abdominal tergite.

B-F, ditto, enlarged. 

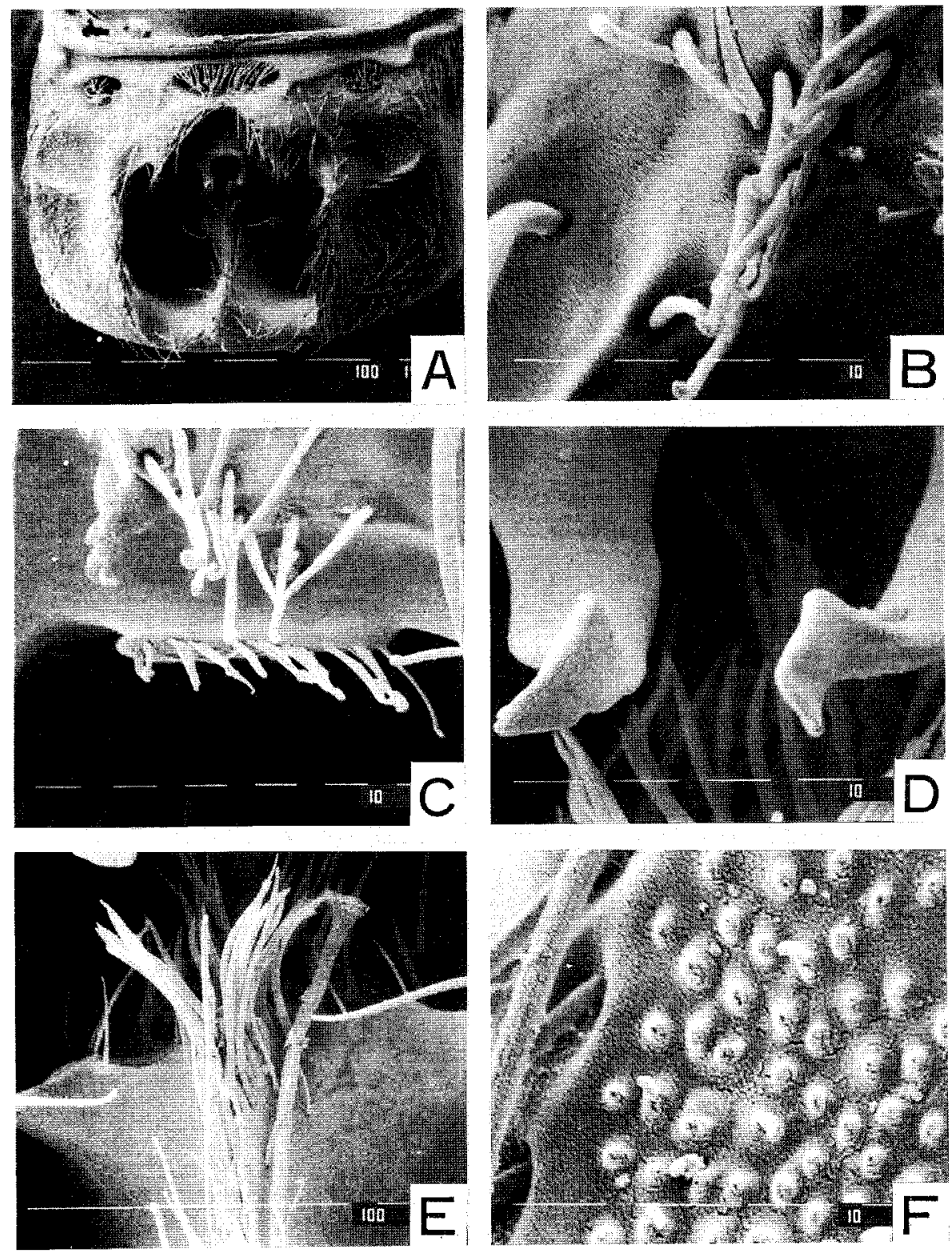
Fig. 100. Schemata of sexual patches in Batrisceniola.
A, 4th abdominal tergite.
$\mathrm{B}, \mathrm{C}$, head in dorsal view.
A, B. semipunctulata (Raffray).
B, B. dissimilis (Sharp).
C, B. hiranoi sp. nov. 


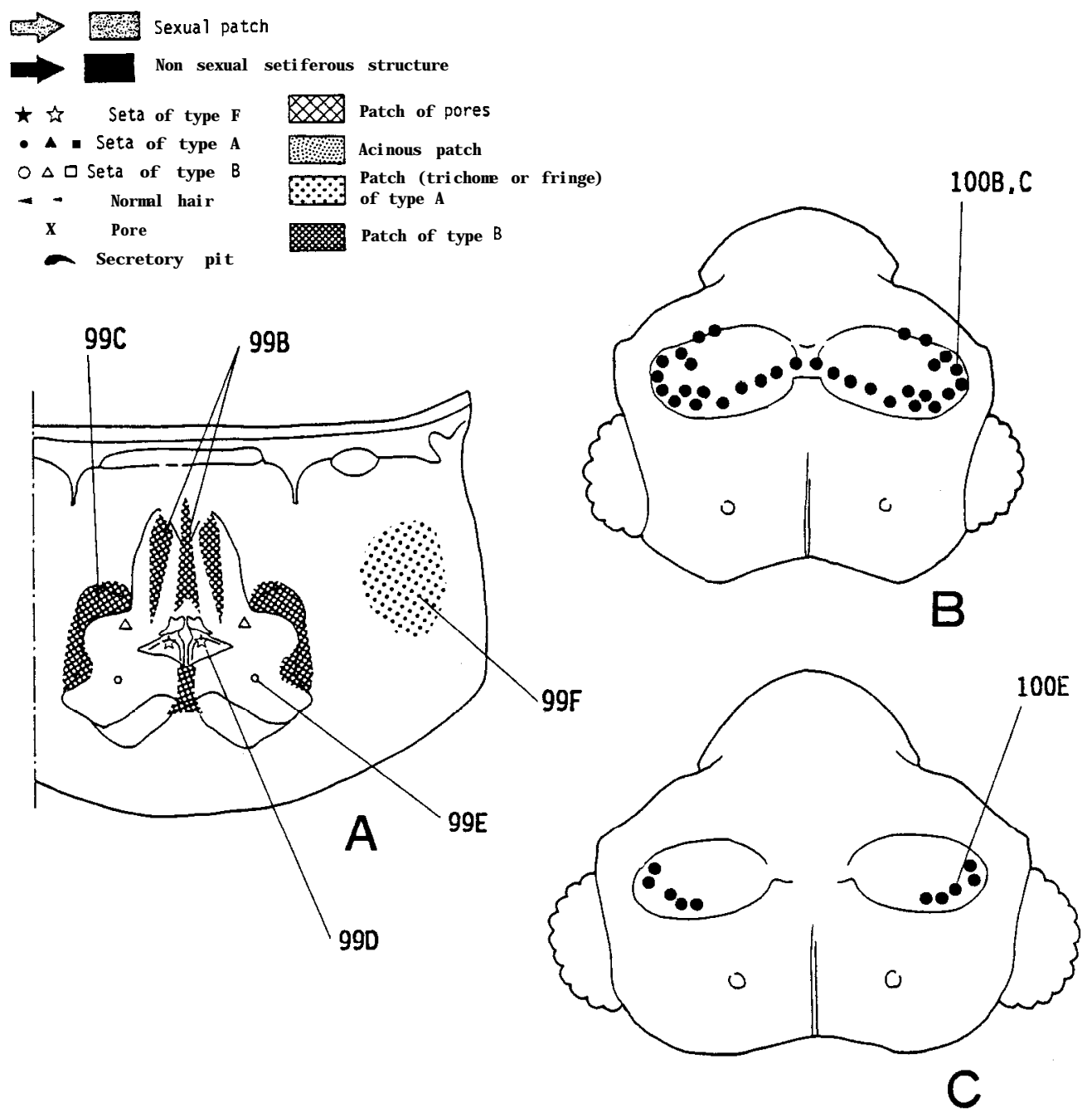


Fig. 101. Sexual patch in Batrisceniola semipunctulata (Raffray).

A, 4th abdominal tergite.

B-F, ditto, enlarged. 

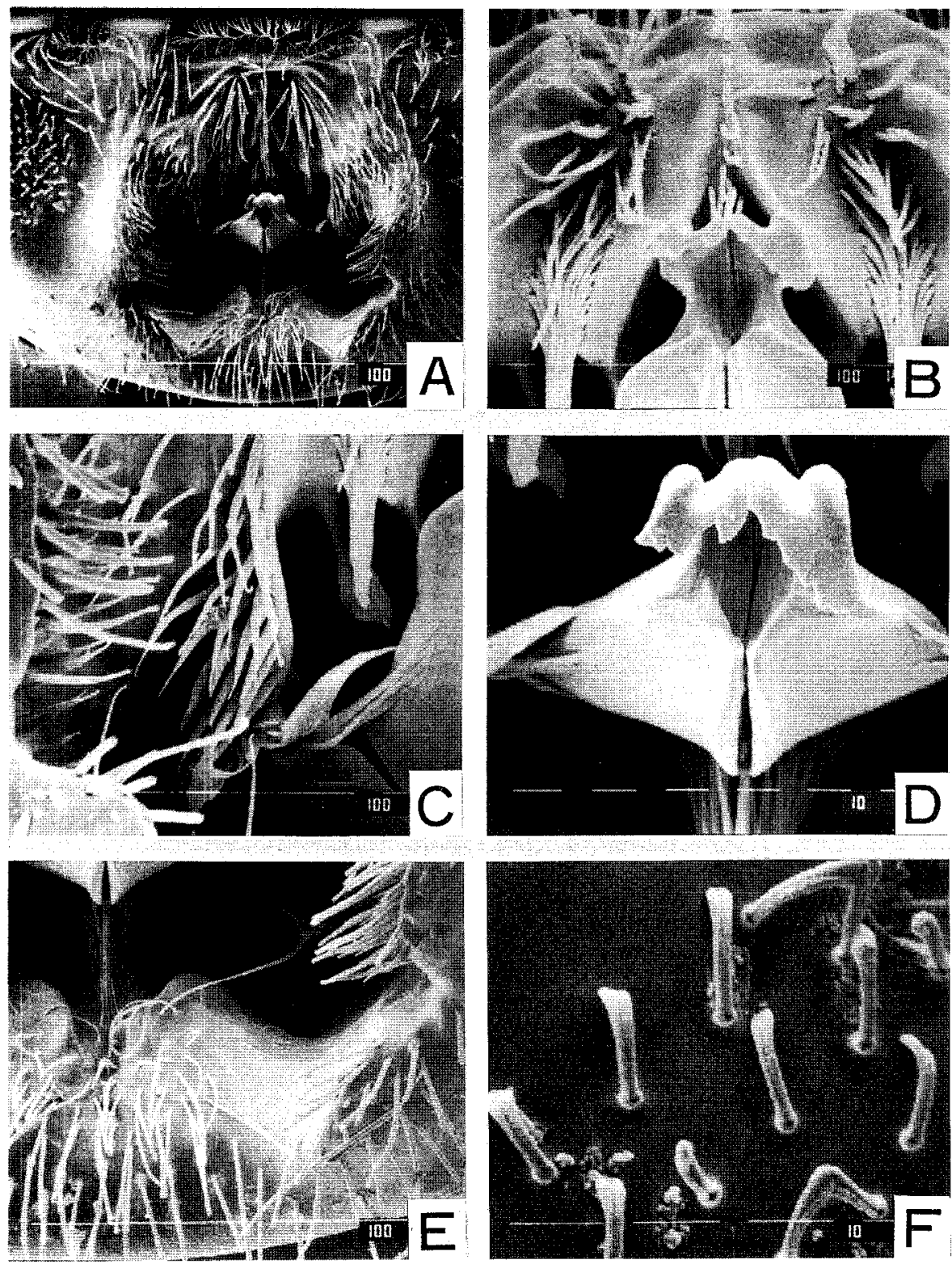
Fig. 102 Sexual patches in Batrisceniola

$A, D$, head in dorsal view.

$B, C, E$, frons enlarged.

A-C, B. dissimilis (Sharp).

D, E, B. hiranoi sp. nov. 

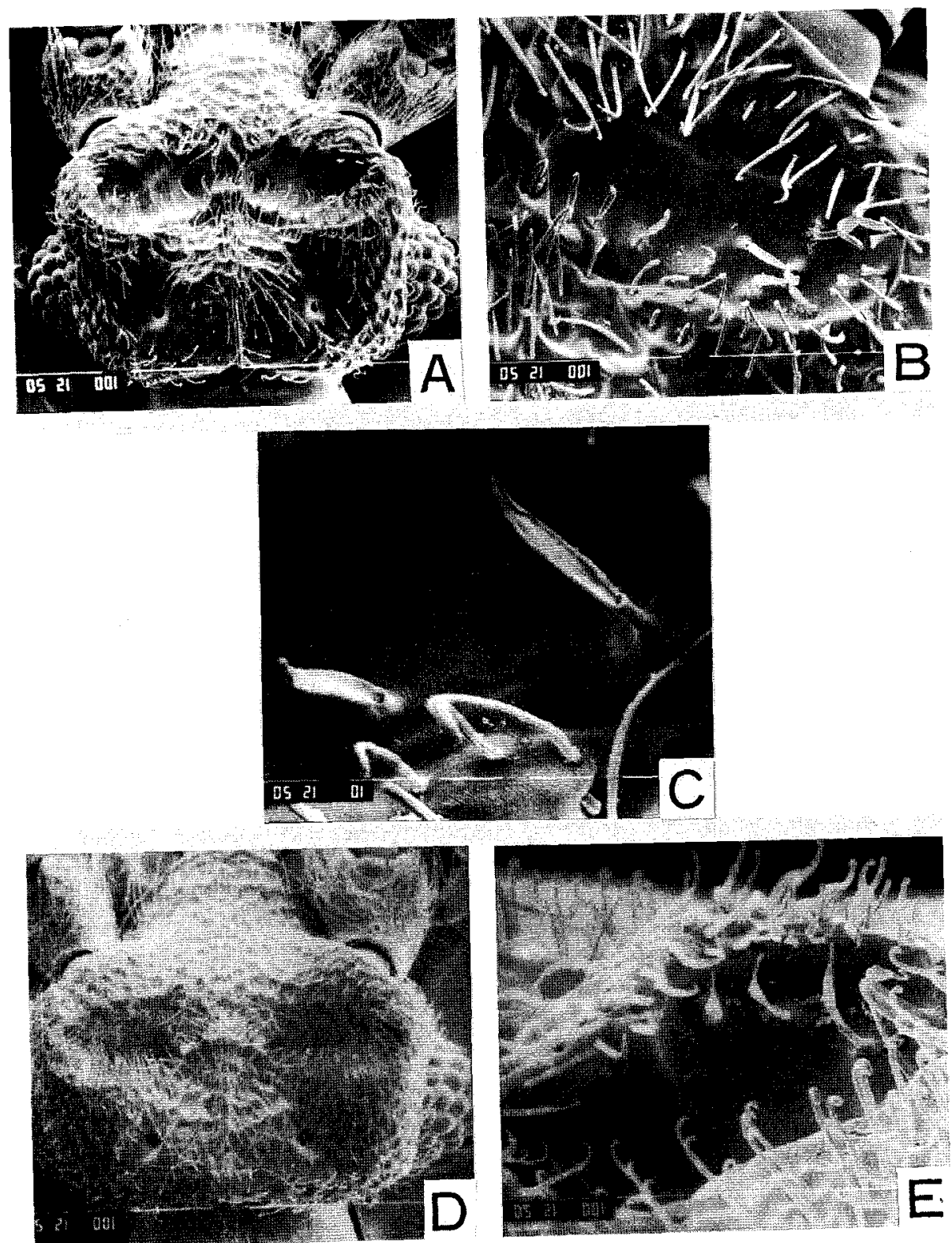
S. NOMURA

Fig. 103. Phylogenetic relationship among genera and some species $\stackrel{\bullet}{\bullet}$ i n Batrisocenus complex. 


\section{Bafrisocenus complex}

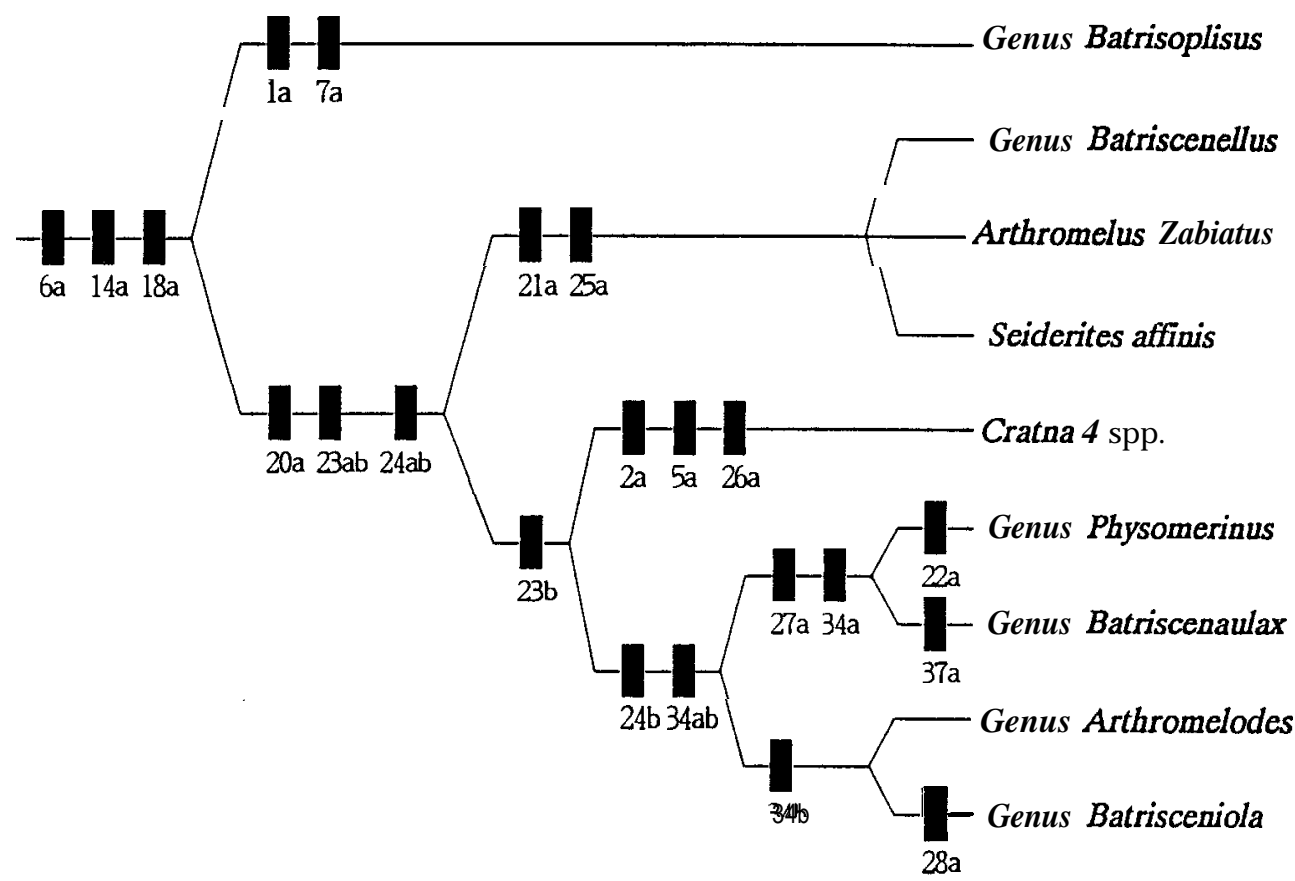


Fig. 104. Phylogenetic relationship among species-groups, species and subspecies in genus Batrisoplisus. 


\section{Genus Batrisoplisus}

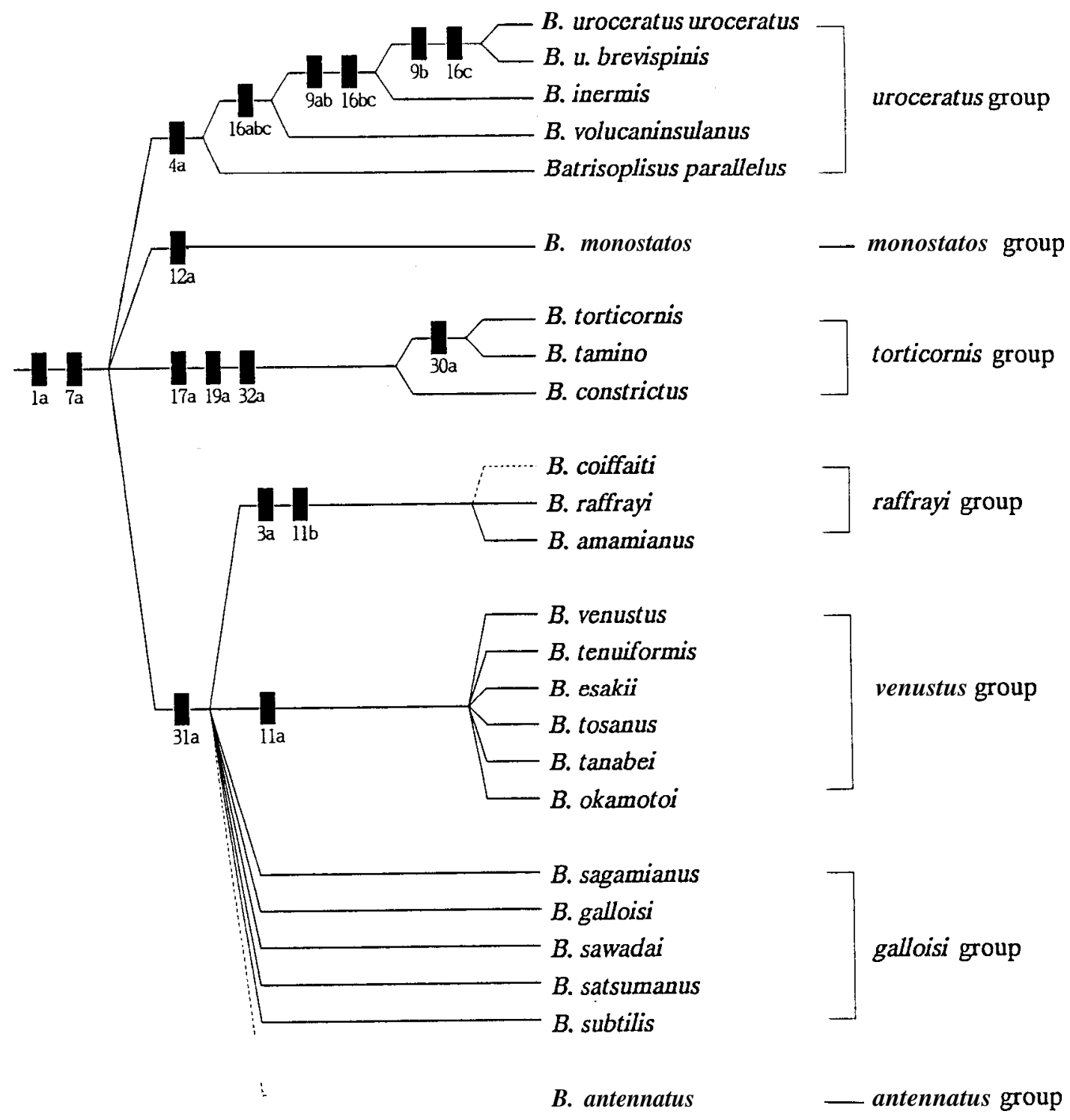


Fig. 105. Phylogenetic relationship among subgenera, species and subspecies in genus Batriscenellus. 


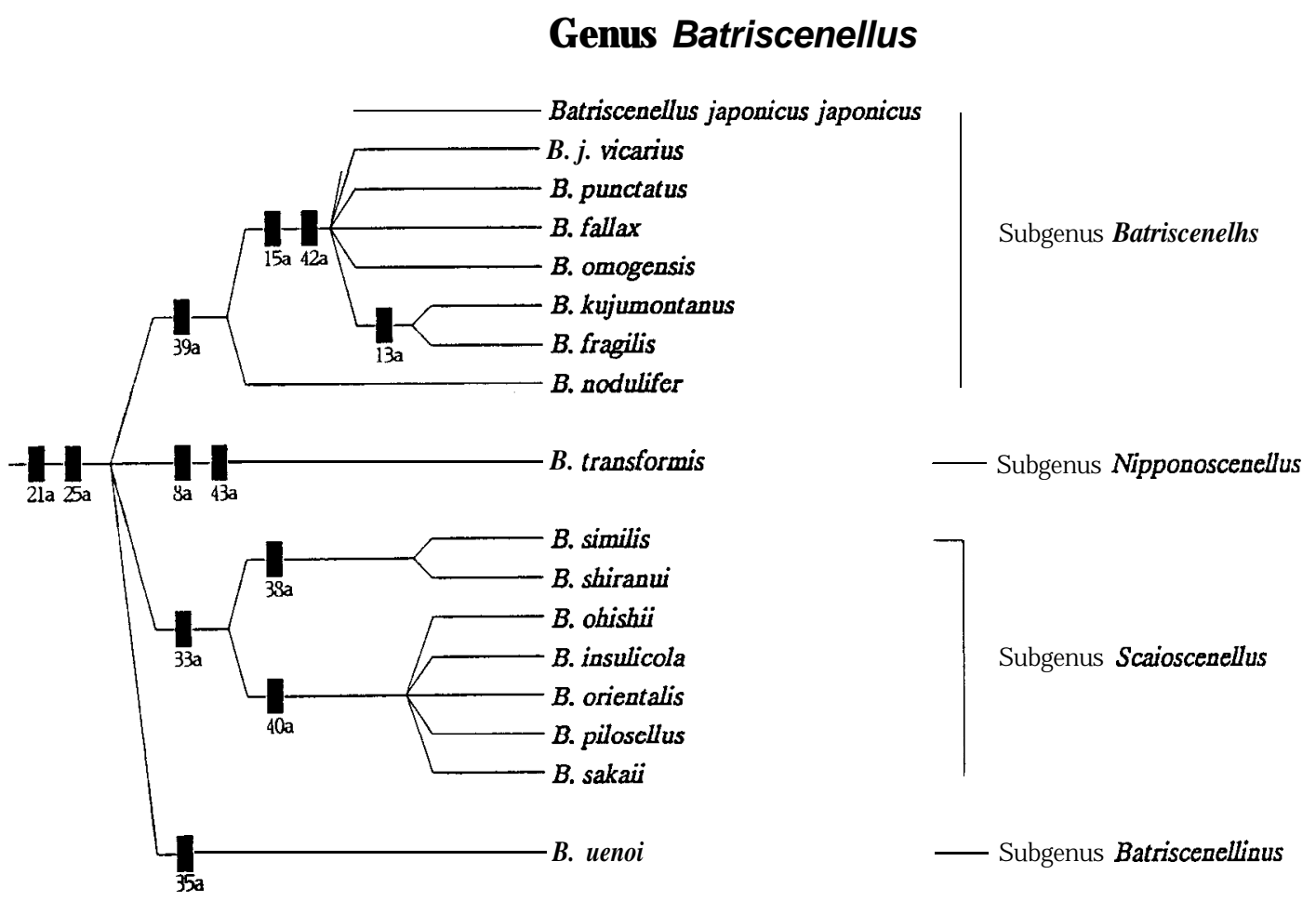


S. NOMURA

Fig. 106. Phylogenetic relationship among species and subspecies in genera Physomerinus, Batriscenaulax, Arthromelodes and Batrisceniola 
Genus Physomerinus

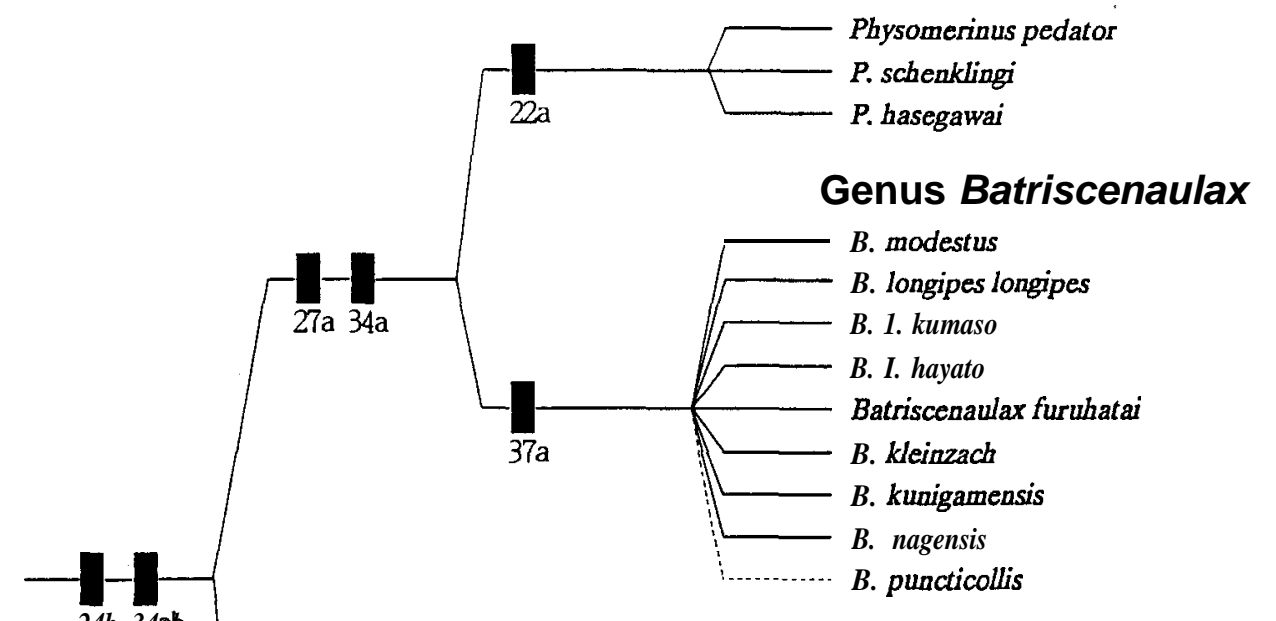

\section{Genus Arthromelodes}

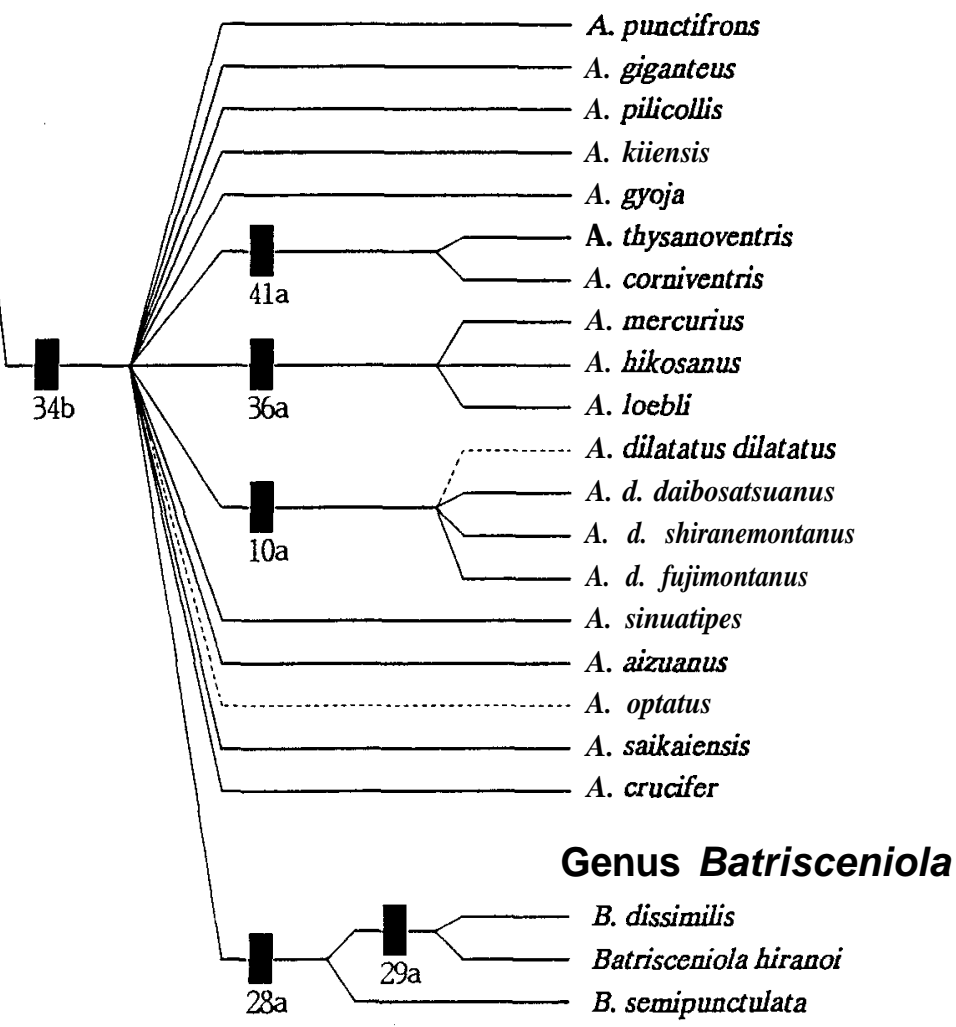




\section{V.SYSTEMATICS}

This chapter presents keys and the descriptions of the genera, subgenera, species-group, species and subspecies of the Batrisocenus complex in Japanese fauna. Six genera, Batrisoplisus, Batriscenellus, Batriscenaulax, Physomerinus, Arthromelodes and Batrisceniola are newly redefined. They contain 6 genera and 67 species and 8 subspecies in all, including 2 new subgenera, 47 new species and 7 new subspecies.

In the first, a key is provided to genera from Japan, together with some from the Oriental region for comparison. The latter genera are in parentheses. The important characters for the systematics are illustrated in the Figs. 107 to 150.

\section{A Key to the Genera of Batrisocenus Complex from Japan (with Some from the Oriental Region Put in Parentheses)}

1. Fourth abdominal segment with a pair of paratergites well-demarcated by 2 pairs of lateral carinae; male genitalia with a broad dorsal apophysis composed of 2 or 3 scleritcs .........Batrisoplis us Raffray

- Fourth abdominal segment without paratergite nor lateral carina; male genitalia with dorsal apophysis composed of single sclerite and membrane

2. Male genitalia with an exposed internal sack free from large dorsal apophysis

(Batrisocenus Raffray)

- Male genitalia with an internal sack fixed or fused with dorsal apophysis.

3. First antennal segment with a conical projection formed by semihyaliue setae; female genitalia composed of slender T-shaped genital plate and broad 9th sternite without posteromedian membranous part

Batriscenellus Jeanne 1

- First antennal segment without conical projection; female genitalia with an ovoid or transverse posteromedian membranous part

4. Frons very large, with a T-shaped sulcus; maxillary palpus conspicuously large and slender with long hairs; 1st antennal segment projected externally and truncate at apex. (Cratn $a$ Raffray)

- Frons with a transverse sulcus; maxillary palpus short; 1st antennal segment without external projection

5. Pronotum without median longitudinal sulcus

. (Trisiniotus Jeannel, Batrisceninus Jeannel, Batriscenodes Jeannel, Batriscenites Jeannel.)

- Pronotum with a median longitudinal sulcus

6. Hind femur strongly swollen near the middle with excavation and setiferous setae in male.

Physomerinus Jeanne 1

- Hid femur simple in male

7. Fore tibia with a brush at apical part in male; 4 th abdominal segment with a large dorsomedian con- 
cavity and a pair of setiferous patch in male; male genitalia small, with an elongate dorsal apophysis longitudinally devided into 2 sclerites by a median longitudinal membrane

Batriscenaulax Jeannel

- Fore tibia with a macrochaeta at apex in male; male genitalia large with a dorsal apophysis covered with membrane in basal part

8. Clypeus broad, hind part of cranium from frons to postgenae shortened; 7th abdominal tergite with a median brush in both sexes Batrisceniola Jeanne 1

- Clypeus short; 7th tergite without median brush Arthromelodes Jeannel

\section{Genns Bamisoplisus Raffray}

Batrisoplisus Raffray, 1908, Coleopt. Psel., Gen. ins., 64: 180; 1911, Psel., Coleopt. Cat., (27): 74; Jeannel, 1958, Mém. Mus. Hist. nat. Paris, (A), 18: 53; Newton \& Chandler, 1989, Field. Zool., (53): 35.

Type species: Batrisus antennatus Weise, by monotypy.

Body dark brown to reddish brown, maxillary palpi and legs reddish brown to light brown, short.

Head nearly square to ovoid, clypeus short, frons weakly concave or flat, vertex convex, with a pair of dorsal tentorial pits connected to each other by a U-shaped or semicircular sulcus, postgenae rounded, eyes convex and ovoid; antennae short, reaching base of elytra at most, 1st segment thick and subcylindrical, 2nd to 7th slender to moniliform, 8th to 9th large and asymmetrical in nodiform male (see remarks), each subglobose to ovoid in moniliiorm male and female, 10th short, subspherical, 11th large and ovoid.

Pronotum wider than long, with a median longitudinal, a pair of lateral longitudinal and a shallow transverse sulci, a pair of indistinct longitudinal carinae between lateral and median longitudinal sulci and a pair of lateral foveae at the ends of lateral longitudinal sulci, antebasal foveae indistinct. Elytra wider than long, rectangular to trapezoid, humeri weakly denticulate, each elytron with 2 dorsal and a lateral foveae and 2 dorsal and a lateral sulci. Mesostemum with a pair of antecoxal projections. Legs short, femora thick, mid tibiae slender, each with a short mucro in general.

Abdomen shorter than elytra in male, longer in female in many species, with one or paird ventral process on 4th or 5th segment in male of some species, 4th segment largest, with a pair of paratergites each narrowed posteriorly, a pair of basidorsal carinae and a pair of basiventral carinae, 5th to 6th short, 7th longer than 6th, 8th tergite transverse, narrowed posteriorly, emarginate or truncate at posteromedian margin in male, arcuate in female, 8th sternite nearly semicircular, depressed or flattened at the median part in male, weakly convex in female, 9 th stemite present in male, small.

Male genitalia with a complex dorsal apophysis composed of 2 sclerites, paramere small and membranous, basal bulb slightly elongate, rounded basally, with a small basal foramen and a ventral stalk.

Female genitalia composed of 9th sternite and genital plate, 9th stemite membranous, genital plate weakly sclerotized and $\mathrm{T}$-shaped in posterior view.

Remarks. The genus Batrisoplisus Raffray is distinct in the division V by the fourth abdominal 
segment with a pair of paratergites. This genus contains two phenotype of the antenna in the male, the nodiform characterized'by the asymmetrical eighth segment and bilobate or setiferous ninth segment, and the moniliform with each subglobose or ovoid eighth to ninth segment?,. This genus is classified into the following six species-groups: the galloisi-group, the venustus-group, the raffrayi-group, the torticornis-group, the monostatos-group and the uroceratus-group by the right mandible, ventral process of the male abdomen, and the structures of the male genitalia. The genotypic species, B.antennatus is unknown to which species-group it belongs.

\section{A Key to the Speck-group, the Species and the Subspecies of the Genus Batrisoplisus from Japan}

1. Right mandible arcuate on outer margin in male 2 .

- Right mendible with a large dent on outer side in male (the uroceratus-group)

2. Fifth abdominal segment with a ventral process on posteromedian part in male (the monostatosgroup). monostatos sp. nov.

- Fifth abdominal segment simple in male

3. Fourth abdominal segment with one or paird ventral process in male..............................................4

- Fourth abdominal segment simple in male …………...............................................................12

4. Fourth abdominal segment with a ventral process on posteromedian part in male (the venustus-

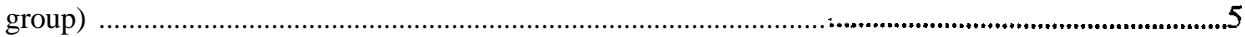

- Fourth abdominal segment with a pair of ventral processes in posterior margin in male (the raf-

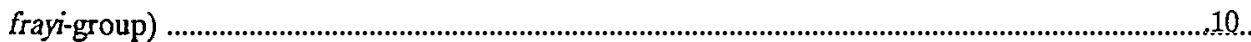

5. Ventral process of 4 th abdominal segment small, narrower than $1 / 10$ width of the segment ..............

- Ventral process of 4 th abdominal segment large, wider than $1 / 10$ width of the segment...................... 8

6. Ninth antennal segment with a large and semicircular acinous patch in male; male genitalia with a large and arcuate left sclerite of dorsal apophysis esakii sp. nov.

- Ninth antennal segment with an ovoid or circular acinous patch in male

7. Ninth antennal segment with a small and ovoid acinous patch being $2 / 5$ times as long as the segment, located at basilateral part in male venustus Jeanne1

- Ninth antennal segment with a large and circular acinous patch being $2 / 3$ times as long as the segment in male tenuiformis sp. nov.

8. Ventral process of 4 th abdominal segment $1 / 8$ times as wide as the segment; male genitalia with a C-shaped right sclerite of dorsal apophysis tosanus sp. nov.

- Ventral process of 4th abdominal segment large, 1/5 to 1/6 times as wide as the segment .9

9. Ventral process of 4th abdominal segment $1 / 5$ times as wide as the segment; male genitalia with a short ventral stalk and a ring-shaped scierite of dorsal apophysis tanabei sp. nov.

- Ventral process of 4th abdominal segment 1/6 times as wide as the segment; male genitalia with a long ventral stalk and an apically sharpened right sclerite of dorsal apophysis .okamoto is sp. nov.

10. Ninth antennal segment strongly projected externally, with a small and transversely ovoid acinous patch in male; male genitalia with a large left sclerite having 2 long spines and a small and arcuate right sclerite amamianus sp. nov.

- Ninth antennal segment expanded externally in male; male genitalia with a broad ventral stalk and a 
small dorsal apophysis $11 \ldots$

11. Head narrowed anteriorly; male genitalia with an almost straight ventral stalk in lateral view

coiffaiti Jeanne 1

Head subparallel-sided; male genitalia with a ventral stalk curved apically and broadened near the middle in lateral view raffrayi Jeannel

12. Ninth antennal segment bilobate at internal part, subspherical at external part, with an acinous patch in male (the galloisi-group)

- Ninth antannal segment subspherical without internal lobe nor acinous patch in male; metastemum concave and densely setose on median part in male (the torticornis-group) . .17

13. Ninth antennal segment smaller than 11th in male subtilis sp. nov. Ninth antennal segment larger than 11th in male .14

14. Ninth antennal segment with a very large semicircular acinous patch in male galloisi sp. nov.

- Ninth antennal segment with a circular or ovoid acinous patch in male .15

15. Ninth antennal segment with a small and circular acinous patch which is half as long as the segment in male sagamianus sp. nov.

- Ninth antennal segment with a larger acinous patch in male .16

16. Male genitalia with a robust basal strut of basal bulb and an apically sharpened right sclerite of dorsal apophysis satsumanus sp. nov.

- Male genitalia with an indistinct basal strut of basal bulb and a L-shaped right sclerite of dorsal apophysis sawadai sp. nov.

17. Antennae moniliform in male constrictus sp. nov.

- Antennae nodiform in male .18 .

18. Antennae long, 9th segment tricarinate on dorsal side, 10th longer than wide, ovoid in male

tamino sp. nov.

- Antennae short, 9th segment strongly projected basilaterally, 10th transverse in male

19. Fourth abdominal segment with a small ventral process in male

torticornis sp. nov.

- Fourth abdominal segment simple on ventral side in male parallelus sp. nov.

20. Fore tibiae without mucro at apex, mid tibiae constricted at apical 1/5 in male; 8th abdominal tergite small and convex in female volcaninsulanus sp. nov.

- Fore tibiae each with a mucro at apex, mid tibiae simple in male; 8th abdominal tergite large and projected posteriorly in female

21. Fore tibiae each with a short mucro which is vertical to basiapical axis in male; 8th tergite rounded at apex of the projection in female inermis sp. nov. Fore tibiae each with a robust mucro in male; 8th tergite acutely projected posteriorly in female ......

22. Fore tibiae successively thickened distally in male; 8th abdominal tergite with a tapering projection uroceratus uroceratus sp. et subsp. nov. Fore tibiae each thickened at the middle and at apex including mucro in male; 8th abdominal tergite with a conical projection. uroceratus brevispinis subsp. nov. 


\section{The galloisi-group}

The galloisi-group is characterized by the ninth antennal segment which is rounded externally and the fourth abdominal segment without ventral process. This group contains B. galloisi Jeannel, $\boldsymbol{B}$. sagamianus sp. nov., B. sawadai sp. nov., B. satsumanus sp. nov. and $\boldsymbol{B}$. subtilis sp. nov.

\section{Batrisoplisus sagamianus sp. nov.}

(Fig. 109A, B)

Male. Length 1.5-1.6 mm. Width $0.6 \mathrm{~mm}$.

Body reddish brown, legs and maxillary paipi light brown, short, head and pronotum narrowed.

Head slightly wider than long, subparallel-sided, densely with coarse punctures on dorsal surface, clypeus short, arcuate and limbate on posterior margin, frons broad and weakly concave, with a pair of lateral foveae, vertex weakly convex, with a fine longitudinal carina and a pair of dorsal tentorial pits connected to each other by a U-shaped sulcus, postgenae rounded. Eyes ovoid and convex, each composed of 25-30 facets. Antennae short, reaching hind margin of pronotum, 1st segment short, thick and subcylindrical, 2nd subglobose, 3rd as long as wide, thickened distally, 4th to 6th subequal in length, each short, wider than long, 7th transverse, expanded internally, 8th as long as 7th, lobate at dorsal and internal parts, 9th largest, 1.67 times as wide as long, thick and rounded on outer side, with a small and circular acinous patch which is half as long as the segment at basilateral part and 2 lobes on inner side, apical lobe short, broad and sinuate on ventral margin, basal lobe elongate and narrow, 10th wider than long, ovoid, expanded internally, 11th large, 1.6 times as long as wide. Maxillary palpi short, 4th segment largest, fusiform in dorsal view.

Pronotum wider than long, widest at the middle, clearly expanded on both sides, with coarse and dense punctures on dorsal surface. Elytra slightly wider than long, weakly convex and sparsely punctate, humeri feebly denticulate, each elytron with 2 dorsal foveae and 2 dorsal sulci, outer dorsal sulci running from the outer dorsal fovea to posterior 1/5. Hind wing reduced. Legs short, femora thick, fore tibiae slender, each with a short denticle at apical $1 / 10$, mid tibiae slender, each with an acute mucro at apex.

Abdomen shorter than elytra, 4th segment largest, 1.8 times as wide as long, weakly convex, with a pair of basidorsal carinae on basal $1 / 3$, a pair of paratergal ridges and a pair of clear tergosternal ridges reaching the hind margin, 5th to 6th subequal in length, each short, 7th large, 1.6 times as long as 6 th, 8 th tergite wider than long, emarginate on posteromedian margin 8th sternite transverse, 9th sternite ovoid in external view.

Male genitalia (Fig. 109A, B) large and well-sclerotized; paramere small and membranous; basal bulb longer than wide, weakly flattened on basal part, ventral stalk elongate and weakly attenuate distally, dorsal apophysis composed of 2 sclerites, right sclerite C-shaped, acute at apex, about as wide as left one, left sclerite elongate, lamellar, about as long as ventral stalk.

Female. Length $1.5 \mathrm{~mm}$. Width $0.6 \mathrm{~mm}$.

Similar to male, but differs as follows: eyes smaller than in male, each composed of about 20 facets; antennae slender, 7th segment subcylindrical, 8th smaller than 7 th, subglobose, 9th to 10th each simply 
ovoid, elytra weakly narrowed anteriorly, humeri rounded and denticulate; hind wings reduced; legs short, fore and mid tibiae without denticle. Abdomen as long as elytra, 4th segment largest, 1.5 times as wide as long.

Distribution. Japan (Honshu).

Holotype, male (Type No. 2804, Kyushu Univ.), Matsuda, Kanagawa Pref., 25. iv. 1979, Y. Hirano leg. Paratypes: 1 male, same locality as holotype, 23. iv. 1978, Y. Hirano leg.; 1 female, same data as holotype; 3 males 4 females, Hiedano, Kyoto Pref., 23. x. 1978, K. Masaki leg.

Remarks. Batrisoplisus sagamianus sp. nov. is closely allied to $\boldsymbol{B}$. galloisi Jeannel, but the ninth antennal segment has a small and circular acinous patch which is half as long as the segment.

\section{Batrisoplisus galloisi Jeannel}

(Fii. 43A, 109D, E)

Batrisoplisus galloisi Jeannel, 1958, Mém. Mus. Hist. nat., Paris, (A), 18: 54.

Male. Length 1.5-1.6 mm. Width 0.6-0.7 mm.

Body reddish brown, maxillary palpi and legs light brown, head and pronotum narrowed.

Head slightly wider than long, weakly narrowed anteriorly, densely with coarse punctures, clypeus short, frons weakly concave, with a pair of lateral foveae, vertex convex, with a pair of dorsal tentorial pits connected to each other by a U-shaped sulcus, postgenae rounded. Eyes ovoid and convex, each composed of 25-30 facets. Antennae almost same structure as in sagamianus, but 9th segment 1.5 times as wide as long, apical lobe longer than sagamianus and more weakly sinuate on ventral margin, acinous patch very large occupying most of the outer dorsal surface. Maxillary palpi short, 4th segment largest, fusiform and flattened on inner side, 2.4 times as long as wide in lateral view.

Pronotum slightly wider than long, widest at the middle, expanded on both anterolateral sides, densely with coarse punctures on dorsal surface. Elytra wider than long, nearly rectangular, humeri expanded, each elytron with 2 dorsal foveae and 2 dorsal sulci, outer dorsal sulci reaching posterior 1/4. Legs short, fore and mid tibiae each with a denticle or a mucro as in sagamianus.

Abdomen weakly narrowed posteriorly, 4th segment largest, 1.8 times as wide as long, with a pair of basidorsal carinae on basal $2 / 5$, 5th to 6th short, subequal in length, 7 th large, as long as 5 th +6 th segments, 8th tergite wider than long, emarginate on posteromedian margin, 8th sternite wider than 8th tergite, transverse and shallowly emarginate on posterior margin, weakly concave at the middle part.

Male genitalia (Fig. 109D, E) urniform, paramere membranous, basal bulb subcylindrical with a slender ventral stalk, dorsal apophysis composed of 2 sclerites, right sclerite C-shaped, acute at apex, left elongate, wider than ventral stalk,

Female. Length $1.5 \mathrm{~mm}$. Width $0.6 \mathrm{~mm}$.

Similar to male except for the following characters: eyes smaller than in male, each composed of about 20 facets; antennae moniliform, 7th to 10th segments each simply ovoid, elytra weakly narrowed anteriorly, humeri flat; hind wings reduced; legs short, fore and mid tibiae without denticle. Abdomen larger than elytra, 4th segment largest, 1.7 times as wide as long, with a pair of basidorsal carinae on basal $1 / 3$, 8th tergite very shallowly emarginate on posteromedian margin, 8th stemite semicircular and 
weakly expanded on posteromedian margin.

Distribution Japan (Honshu).

Specimens examined. 6 males, Fujishima, Yamagata Pref., 20. vi. 1955 (H. Hasegawa); 1 male, Kanomata river, Kurokawa-mura, Niigata Pref., 3. vii. 1985 (S. Nomura); 4 males 5 females, Ukima park, Itabashi-ku, Tokyo Pref., 26. vi. 1985 (Nishimura et Niisato); 1 male, Kurosawaguchi, Mt. Ontake, Nagano Pref., 20. vii. 1952 (S. Ueno).

Remarks. Batrisoplisus galloisi Jeanne1 is closely allied to B. sagamianus in the male genitalia with C-shaped right sclerite of the dorsal apophysis. But this species is separated from the new species by the ninth antennal segment with a long apical lobe and a large acinous patch occupying most of the outer dorsal surface.

Biological notes. One male of this species was caught by light trap at the middle reaches of Kanomata riverside, Niiata Pref.

\section{Batrisoplisus sawadai sp. nov.}

(Fig. 109G, H)

Male. Length 1.5-1.6 mm. Width $0.6 \mathrm{~mm}$.

Body reddish brown, narrowed in head and pronotum.

Head as long as wide, subparallel-sided, densely with coarse punctures, clypeus short, frons weakly concave, with a pair of lateral foveae, vertex convex, with a pair of dorsal tentorial pits connected with each other by a U-shaped sulcus and a fine longitudinal carina. Eyes convex and ovoid, each composed of 25-30 facets. Antennae almost the same structures as in sagamianus, but 9th segment thick, 1.43 times as wide as long, apical lobe short and broad, acinous patch large and ovoid. Maxillary palpi short, 4th segment largest, 2.3 times as long as wide.

Pronotum apparently transverse, widest at posterior 3/7, densely with coarse punctures. Elytra wider than long, nearly rectangular, humeri expanded, each elytron with 2 dorsal foveae and 2 dorsal sulci, outer dorsal sulcus reaching posterior $1 / 4$, feebly incurved. Legs short, fore and mid tibiae each with a denticle as in sagamianus

Abdomen shorter than elytra, weakly narrowed posteriorly, 4th segment largest, 1.9 times as wide as longh, with a pair of basidorsal carinae on basal $1 / 3$, 5th to 6th short, subequal in length, 7 th large, 1.6 times as long as 6 th, 8th tergite transverse, arcuately emarginate on posterior margin 8th sternite wider than 8th tergite, short and transverse, with a pair of suberect hairs on both lateral sides.

Male genitalia (Fig. 109G, H) broadened dorsally; paramere membranous; basal bulb subcylindrical, with a slender ventral stalk, dorsal apophysis consisting of 2 sclerites, right sclerite small and elongate and acute at apex, left as long as ventral stalk, lobate.

Female. Unknown.

Distribution. Japan (Honshu).

Holotype, males (Type No. 2805, Kyushu Univ.), Kawachi-Hiraoka, Osaka Pref.. 10 x. 1952, K. Sawada leg. Paratypes: 1 male, Yono, Higashi-Nose, Osaka Pref., 24. x. 1941, F. Matsumoto leg.

Remarks. Batrisoplisus sawadai sp. nov. is very similar to B. sagamianus sp. nov. in the transverse pronotum, but is distinguished by the ninth antennal segment with a large and ovoid acinous patch on 
the outer dorsal part, and the male genitalia with a small and elongate right sclerite of dorsal apophysis.

\section{Batrisoplisus satsumanus sp. nov.}

(Fig. 109C)

Male. Length $1.6 \mathrm{~mm}$. Width $0.6-0.7 \mathrm{~mm}$.

Body reddish brown maxillary palpi and legs light brown, short, head and pronotum narrowed.

Head as long as wide, weakly narrowed posteriorly, with dense and coarse punctures on dorsal surface, clypeus very weakly limbate, frons almost flat at the middle part, vertex weakly convex, with a pair of dorsal tentorial pits connected to each other by a U-shaped sulcus, postgenae rounded. Eyes ovoid and convex, each composed of about $\mathbf{2 0}$ facets. Antennae short, reaching base of pronotum, very similar to that of galloisi, but 9th segment with a circular acinous patch of $2 / 3$ length of the segment. Maxillary palpi short, 4th segment largest, twice as long as wide, broadened ventrally at the middle part, acute at apex.

Pronotum wider than long, widest at the middle, coarsely punctate on dorsal surface. Elytra transverse, rectangular, humeri expanded and denticulate, each elytron with 2 dorsal foveae and 2 dorsal sulci, outer dorsal sulcus subparallel to inner one, running from outer fovea to posterior 1/9. Legs short, femora thick, mid tibiae slender, each with a very short mucro at apex.

Abdomen shorter than elytra, rounded posteriorly, 4th segment largest, subparallel-sided, with a pair of basidorsal carinae on basal $1 / 3,5$ th to 6 th short, subequal in length, 7 th large, as long as 5 th + 6th, 8th tergite transverse, emarginate in posteromedian part, 8th sternite semicircular, flattened at the middle part, 9th stemite small and semicircular in external view.

Male genitalia (Fig. 109C) reniform in lateral view; paramere short; membranous, basal bulb rounded basally, with a elongate ventral stalk and a short basal strut, dorsal apophysis composed of 2 sclerites, left sclerite elongate, as long as ventral stalk, right sclerite L-shaped, thickened at basal part, acute at apex

Female. Unknown.

Distribution. Japan (Southern Kyushu).

Holotype, male (Type No. 2806, Kyushu Univ.), Sata cape, Kagoshima Pref., 29. iv. 1978, H. Ohishi leg.

Remarks. Batrisoplisus satsumanus sp. nov. is very similar to $\boldsymbol{B}$. galloisi Jeannel, but is separated by the ninth antennal segment with a circular acinous patch which is $2 / 3$ times as long as the segment and the basally rounded male genitalia with clear basal strut.

\section{Batrisoplisus subtilis sp. nov.}

(Fig. 109F)

Male. Length $1.6 \mathrm{~mm}$. Width $0.6 \mathrm{~mm}$.

Body reddish brown, maxillary palpi and legs light brown, short, head and pronotum narrowed.

Head as long as wide, slightly narrowed anteriorly, densely with coarse punctures, clypeus short, 
arcuate on anterior margin, frons feebly depressed at the median part, vertex convex, with a pair of dorsal tentorial pits connected to each other by a U-shaped sulcus, postgenae rounded. Eyes ovoid and convex, each consisting of about 25 facets. Antennae short, reaching base of pronotum, 1st segment thick subcylindrical, 2nd as long as wide, subcylindrical, 3rd slightly narrower than 2nd, weakly thickened distally, 4th to 6th subequal, each slightly wider than long, subglobose, 7th larger than 6th, 8th projected internally, 9th smaller than in gallosi, 1.6 times as wide as long, rounded externally, with 2 lobes on inner side, acinous patch indistinct, 10th thick, wider than long, subglobose, 11th largest, 1.5 times as long as wide, ovoid. Maxillary palpi short, 4th segment largest, 2.2 times as long as wide, fusiform.

Pronotum as long as wide, widest at posterior $2 / 5$, expanded laterally, coarsely punctate on dorsal surface. Elytra wider than long, rectangular, humeri expanded and denticulate, each elytran with 2 dorsal foveae and 2 dorsal sulci, outer dorsal sulcus running subparallel to inner one, reaching posterior 15. Legs short, femora thick, fore tibiae slender, each with a mucro at apex, mid tibiae elongate, each with a short mucro at apex.

Abdomen shorter than elytra, narrowed posteriorly, 4th segment largest, 1.9 times as wide as long, with a pair of basidorsal carinae on basal $1 / 3$, 5th to 6th short, subequal in length, 7 th large, as long as 5 th +6 th, 8th tergite transverse, arcuately emarginate on posteromedian part, 8th stemite nearly crescent, 9th sternite small and semicircular in external view.

Male genitalia (Fig. 109F) reniform; paramere small and membranous; basal bulb rounded basally, with short basal strut and short ventral stalk, dorsal apophysis composed of 2 sclerites, right sclerite broadened at basal part, tapered and sharpened apically, left sclerite small, about 1.4 times as long as right sclerite.

Female. Unknown.

Distribution. Japan (Kyushu).

Holotype, male (Type No. 2807, Kyushu Univ.), Kurusu, Naokawa-mura, Oita Pref., 26. ix. 1984, S. Sasaki leg.

Remarks. Batrisoplisus subtilis sp. nov. is distinct in the galloisi-group by the small ninth antennal segment and the male genitalia with the small left sclerite of the dorsal apophysis.

\section{The venustus-group}

The venustus-group is distinguished from the galloisi-group by the fourth abdominal segment with small ventral process. This group consists of $\boldsymbol{B}$. venustus Jeannel, $\boldsymbol{B}$. tenuiformis sp. nov., B. esakii sp. nov., $\boldsymbol{B}$. tosanus sp. nov., $\boldsymbol{B}$. tanabei sp. nov. and $\boldsymbol{B}$. okamotoi sp. nov.

Batrisoplisus venustus Jeanne 1

(Figs. 43B, 110A, B)

Batrisoplisus venustus Jeannel, 1958, Mém. Mus. Hist. nat., Paris, (A), 18: 55. 
Male. Length 1.5-1.6 mm. Width 0.6 mm.

Body reddish brown, legs and maxillary palpi light brown, short and broad.

Head as long as wide, narrowed anteriorly, trapezoid, densely with coarse punctures on dorsal surface, clypeus very short, arcuate on anterior margin, frons feebly depressed, vertex weakly convex, with a fine longitudinal carina, postgenae rounded. Eyes ovoid and convex, each composed of about 25 facets. Antennae short, reaching base of pronotum, 1st segment subcylindrical, thick, 2nd narrower than 1st, slightly longer than wide, subcylindrical, 3rd to 6th each shorter than wide, spherical, 7th transverse and projected internally, 8th longer than $7 \mathrm{th}$, broadly extended internally, 9th largest, wider than long, rounded on outer side, bilobate on inner side, apical lobe thick and obtuse at apex, basal lobe longer and thinner than apical one, acinous patch ovoid, 2/5 times as long as the segment, located on outer basal part, 10th short and transverse, 11th largest, 1.3 times as long as wide, ovoid. Maxillary palpi short, 4th segment largest, 1.7 times as long as wide in lateral view.

Pronotum wider than long, widest at the middle, coarsely punctate on dorsal surface. Elytra transverse, nearly rectangular, humeri weakly expanded, each with a denticle, each elytron with 2 dorsal foveae and 2 dorsal sulci, outer dorsal sulci reaching posterior 1/4, weakly incurved. Legs short, fore trochanters short, each with a small denticle, fore tibiae slender, each with a short mucro at apex. Hind wing developed or reduced.

Abdomen shorter than elytra, rounded posteriorly, 4th segment largest, about twice as wide as long, with a pair of basidorsal carinae on basal $2 / 5$ and a small ventromedian process, 5th to 6th segments short, subequal in length, 7th large, as long as 5th +6 th, 8 th tergite transverse, arcuately emarginate on posterior margin, 8th sternite semicircular, weakly depressed at central part, 9th sternite ovoid, in external view.

Male genitalia (Fig. 110A, B) reniform in lateral view, paramere small, membranous, basal bulb enlarged dorsally, basal foramen ovoid, with a short basal spine, ventral stalk thick in basal a half, sharpened apically and ventrally curved from the middle, dorsal apophysis composed of 2 sclerite, right sclerite phylliform, sharpened apically, left sclerite elongate, about as long as ventral stalk.

Female. Length 1.5-1.6 mm. Width 0.5-0.6 mm.

Similar to male but differs as follows: Eyes smaller than in male, each composed of about 20 facets; antennae moniliform, 3rd to 11th segments successively enlarged toward apex, each segment simply spherical. Abdomen larger than elytra, 7th segment 1.8 times as long as 6th.

Distribution. Japan (Honshu, Shikoku).

Specimens examined. [Honshu] 1 male, Gohara-machi, Kure City, Hiroshima Pref., 28. xi. 1987 (I. Okamoto); 1 male 2 females, Mt. Noroyama, Kure City, Hiroshima Pref., 18. x. 1987 (I. Okamoto); 1 male, Kurahashi-machi, Aki-gun, Hiroshima Pref., 14. xi. 1987 (I. Okamoto); 2 males 2 females, same locality as above, 9. i. 1988 (I. Okamoto); 1 male, Sandankyo valley, Togouchi-machi, Hiroshima Pref., 3. x. 1987 (I. Okamoto); 1 male, Takiyama valley, 28. vi. 1987 (S. Nomura). [Shikoku] 4 males 5 females, Kusaka, Hidaka-mura, Kochi Pref., 14. v. 1978 (H. Ohishi).

Remarks. Batrisoplisus venustus Jeanne1 differs from the other species of the venusfus-group by the ninth antennal segment with a small and ovoid acinous patch on basilateral part and the male genitalia with a short left sclerite of the dorsal apophysis.

Biological notes. One male was collected by light trap at the riverside of Takiyama valley, Hiroshima Pref. 


\section{Batrisoplisus tenuiformis sp. nov.}

(Fig. 110C)

Male. Length $1.6 \mathrm{~mm}$. Width $0.6 \mathrm{~mm}$.

Body reddish brown maxillary palpi and legs light brown, short, head and pronotum narrowed.

Head as long as wide, slightly narrowed anteriorly, densely with coarse punctures, clypeus short and arcuate on anterior margin, frons weakly depressed at the median part, vertex convex, with a pair of dorsal tentorial pits connected to each other by a U-shaped sulcus, postgenae rounded. Eyes ovoid, convex, each consisting of about 25 facets. Antennae short, reaching base of pronotum, 1st to 8th segments almost same in structure as in venustus, 9 th largest, 1.6 times as wide as long, rounded externally, bilobate on internal side, broadly excavated between the lobes, with a circular acinous patch being $2 / 3$ times as long as the segment on dorsolateral side, 10th transverse, spherical, 11th large, 1.3 times as long as wide, ovoid. Maxillary palpi short, 4th segment largest,

Pronotum slightly longer than wide, round-sided, coarsely punctate on dorsal surface. elytra transversely rectangular, convex, humeri expanded and denticulate, each elytron with 2 dorsal foveae and 2 dorsal sulci, outer dorsal sulcus running from outer fovea to posterior $1 / 5$, weakly incurved; hind wing developed. Legs short, fore tibiae slender, each with a very small denticle near apex, mid tibiae each with a short mucro at apex.

Abdomen as long as elytra, weakly narrowed posteriorly, 4th segment largest, transverse, 1.8 times as wide as long, with a pair of basidorsal carinae on basal $1 / 3,5$ th to 6 th short, subequal in length, 7 th large, 1.8 times as long as 6th, 8th tergite transverse, arcuately emarginate on posteromedian part, 8th sternite semicircular, depressed at the middle part, 9th sternite ovoid in exernal view.

Male genitalia (Fig. 110C) similar to that of venustus, but left sclerite of dorsal apophysis elongate, clearly longer than ventral stalk, right sclerite broadened on basal part, tapered and sharpened at apex.

Female. Length 1.6-1.7 mm. Width $0.6 \mathrm{~mm}$.

Similar to male except for the following characters: eyes smaller than in male, each composed of about 15 facets; antennae moniliform, 9th segment smaller than 10th, subglobose. Elytra shorter than in male, transverse; hind wing reduced; legs short, fore and mid tibiae without modifications as mucro or denticle. Abdomen longer than elytra, weakly narrowed posteriorly, 4th segment largest, 1.4 times as wide as long, 7th large, 1.5 times as long as 6th.

Distribution Japan (Northern Honshu).

Holotype, male (Type No. 2808, Kyushu Univ.), Futakuchi valley, Akiu-machi, Miyagi Pref., 12. vii. 1985, S. Nomura leg. Paratypes: 1 male , same data as holotype; 1 male 4 females, same locality as holotype, 26-29. vii. 1989, S. Nomura leg.

Remarks. Batrisoplisus tenuiformis sp. nov. is closely related to $\boldsymbol{B}$. venustus Jeanne1 in the male genitalia with a ventrally curved ventral stalk, but is separated from the other species by the narrow pronotum and the ninth antennal segment with a large and circular acinous patch which is $2 / 3$ tunes as long as the segment.

Biological notes. This species inhabits the deciduous virgin forest of Futakuchi valley, Miyagi Pref. 


\section{Batrisoplisus esahï sp. nov.}

(Fig. 110D-F)

Male. Length 1.5-1.6 mm. Width $0.6 \mathrm{~mm}$.

Body reddish brown maxillary palpi and legs light brown, elongate, head and pronotum narrowed.

Head as long as wide, weakly narrowed anteriorly, densely with coarse punctures on dorsal surface, clypeus short and arcuate on anterior margin, frons feebly depressed, vertex slightly convex, with a fine longitudinal carina, postgenae rounded. Eyes large and convex, each composed of about 30 facets. Antennae short, reaching base of pronotum, 1st to 8th segments same in structure as in okamotoi, 9th largest, rounded on outer side, bilobate on inner side, broadly excavated between the 2 lobes, apical lobe thin, subparallel-sided and emarginate at apex in distal view, basal lobe longer than apical lobe, slender and acute at apex, acinous patch $5 / 6$ times as long as the segment, longer than wide, semicircular, 10th longer than wide, spherical, 11th 1.3 times as long as wide, ovoid. Maxillary palpi short, 4th segment largest, twice as long as wide in lateral view, broadened near the middle, acute at apex.

Pronotum wider than long, widest at the middle, weakly expanded on both sides, coarsely punctate on dorsal surface. Elytra wider than long, rectangular and convex, humeri expanded and denticulate, each elytron with 2 dorsal foveae and 2 dorsal sulci, outer dorsal sulcus reaching posterior 1/5, weakly incurved. Legs short, fore tibiae slender, each with a small denticle near apex, mid tibiae slender, each with a small mucro at apex.

Abdomen slightly shorter than elytra, 4th segment largest, 1.8 times as wide as long, with a pair of dorsomedian carinae on basal a half and a small ventromedian process, 5th to 6th short, subequal in length, 7th as long as 5th +6 th segments, 8 th tergite transverse, arcuately emarginate on posterior margin 8th stemite semicircular, shallowly emarginate at posteromedian part.

Male ganitalia (Fig. 110D, E) reniform in lateral view; paramere small and membranous; basal bulb narrowed apically with a large basal foramen being weakly denticulate at basal part, ventral stalk long and slender, rectangularly curved apically at basal part, dorsal apophysis consisting of 2 sclerites, right sclerite small, elongate and acute at apex, left sclerite very large, slightly longer than ventral stalk, arcuate and thickened distally.

\section{Female. Unknown.}

Distribution. Japan (Kyushu).

Holotype, male (Type No. 2809, Kyushu Univ.), Mt. Hikosan, Fukuoka Pref., 13.v. 1955, T. Esaki, K. Yasumatsu et Y. Hirashima leg. Paratypes: 4 males, Mt. Hikosan, Fukuoka Pref., 21. v. 1986, S. Nomura leg.; 1 male , Mt. Sobosan, Oita Pref., 23. vii. 1983, S. Nomura leg.; 11 males, Hitoyoshi City, Kumamoto Pref., 16. x. 1977, H. Ohishi leg.; 1 male , Mt. Karakunidake, Kirishima, Miyazaki Pref., 15. ix. 1977, S. Tanaka leg.

Remarks. Batrisoplisus esakii sp. nov. is related to B. venustus Jeanne1 in the fourth abdominal segment with a small process at the ventromedian part. But this species is easily distinguished from the others by the ninth antennal segment with a semicircular acinous patch and the dorsal apophysis of the male genitalia which is composed of the small and elongate right sclerite and the very large and arcuate left one.

Biological notes. This species is an inhabitant of the natural forest or broad-leaved and bamboo 
mixed forest in Mt. Hikosan, Fukuoka Pref.

\section{Batrisoplisus tosanus sp. nov.}

(Fig. 110G)

Male. Length 1.5-1.6 mm. Width $0.6 \mathrm{~mm}$.

Body reddish brown maxillary palpi and legs light brown short, head and pronotum narrowed.

Head as long as wide, feebly narrowed posteriorly, with coarse and dense punctures on dorsal surface, clypeus short, arcuate on anterior margin, frons weakly concave, vertex convex, with a weak longitudianl carina, postgenae rounded. Eyes large and ovoid, each composed of 25-30 facets. Antennae short, reaching base of elytra, 1st segment thick and subcylindrical, 2nd smaller than 1st, as long as wide, subcylindrical, 3rd as long as wide, thickened distally, 4th to 6th each transverse, 7th larger than 6 th, projected internally, 8th broadly extended internally, 9th largest, bilobate, apical lobe short and thick, basal lobe elongate, acinous patch a half as long as the segment, small and circular, 10th small, transverse and spherical, 11th 1.5 times as long as wide, large and ovoid. Maxillary palpi short, 4th segment largest, twice as long as wide in internal view, thickened in the middle, acute at apex.

Pronotum wider than long, widest at the middle, expanded on both sides, coarsely punctate on dorsal surface. Elytra slightly wider than long, rectangular, humeri expanded and denticulate, each elytron with 2 dorsal foveae and 2 dorsal sulci, outer dorsal sulcus reaching posterior $1 / 5$, weakly incurved. Hind wing developed. Legs short, fore trochanters short, each with a small denticle, fore tibiae slender, each with a very small denticle near apex, mid tibiae slender, each with a small mucro at apex.

Abdomen shorter than elytra, 4th segment largest, about twice as wide as long, with a pair of basidorsal carinae on basal $3 / 7$ and a small ventromedian process being 1/8 times as wide as the segment, 5 th to 6th short, subequal in length, 7th large, 1.5 times as long as 6th, 8th tergite transverse, arcuately emarginate on posterior margin, 8th stemite nearly semicircular, depressed at posteromedian part, 9th stemite small and semicircular in external view.

Male genitalia (Fig. 110G) reniform; paramere small and membranous; basal bulb with a broad basal foramen and a basal strut and a slender ventral stalk, dorsal apophysis consisting of 2 sclerites, right sclerite strongly broadened basally, tapered distally and acute at apex, left one longer than ventral stalk, elongate.

Female. Length $1.5 \mathrm{~mm}$. Width 0.5-0.6 mm.

Similar to male except for the following characters: eyes smaller than in male, each composed of 15-20 facets; antennae moniliform, 2nd segment ovoid, 3rd to 8th subequal in length, each slightly wider than long, subspherical, 9th thick, smaller than 10th, slightly wider than long, subglobose. Elytra transverse; hind wing reduced, legs short, fore trochanters, fore tibiae and mid tibiae without modification as mucro nor denticle. Abdomen longer than elytra, 4th largest, 1.6 times as wide as long, 7th large, 1.5 times as long as 6th.

Distribution Japan (Shikoku).

Holotype, male (Type No. 2810, Kyushu Univ.), Ouchi, Ino-cho, Kochi Pref., 15. v. 1978, H. Ohishi leg. Paratypes: 9 males 16 females, same data as holotype.

Remarks. Batrisoplisus tosanus sp. nov. is similar to B. tanabei sp. nov. and B. okamotoi sp. nov. in 
the fourth abdominal segment with a broad ventral process, but is different from the others by the male genitalia with a C-shaped right sclerite of the dorsal apophysis.

\section{Batrisoplisus tanabei sp. nov.}

(Fig. 1101)

Male. Length 1.5-1.6 mm. Width $0.6 \mathrm{~mm}$.

Body redddish brown, maxillary palpi and legs light brown, head and pronotum narrowed.

Head as long as wide, almost rectangular, coarsely punctate on dorsal surface, clypeus very weakly expanded, frons feebly depressed, vertex slightly convex, with a median longitudinal carina, postgenae rounded. Eyes convex and ovoid, each composed of about 25 facets. Antennae short, reaching base of pronotum, almost same in structure as in tosanus. maxillary palpi short, 4th segment largest, twice as long as wide, broadened at the middle, sharpened at apex.

Pronotum slightly wider than long, round-sided, coarsely punctate on dorsal surface. Elytra clearly wider than long, nearly rectangular, sparsely punctate, humeri expanded and denticulate, each elytron with 2 dorsal foveae and 2 dorsal sulci, outer dorsal sulcus running from outer dorsal fovea to posterior 1/5, weakly incurved. Legs short, fore tibiae slender, each with a very small denticle near apex, mid tibiae slender, each with a very short mucro near apex.

Abdomen shorter than elytra, 4th segment largest, 1.8 times as wide as long, with a pair of short basidorsal carinae on basal $1 / 3$ and a broad ventral process being $1 / 5$ times as wide as the segment, 5th to 6th short, subequal in length, 7th large, 1.5 times as long as $6 \mathrm{th}, 8$ th tergite transverse, arcuately emarginate on posterior margin, 8th stemite transverse, distinctly depressed at posteromedian part, 9th sternite ovoid in external view.

Male genitalia (Fig. 1101) reniform in lateral view; paramere small and membranous; basal bulb rounded basally, with an acute basal strut and a short ventral stalk, dorsal apophysis consisting of 2 sclerites, left sclerite elongate and broadened apically, right sclerite larger than ventral stalk in lateral view, almost ring-shaped and pointed at apex.

Female. Unknown.

Distribution Japan (Kyushu).

Holotype, male (Type No. 2811, Kyushu Univ.), Ishiki-cho, Kagoshima City, Kagoshima Pref., 24. iii. 1985, T. Tanabe leg. Paratypes: 1 male, same data as holotype; 1 male, Mt. Unzen, Nagasaki Pref., 17. viii. 1983, H. Harada leg.; 1 male, Buzenbo, Mt. Hikosan, Fukuoka Pref., 2. v. 1983, S. Nomura leg.; 4 males, Hitoyoshi City, Kumamoto Pref., 16. x. 1977, H. Ohishi leg.

Remarks. Batrisoplisus tanabei sp. nov. is closely allied to B. tosanus and B. okamotoi sp. nov., but differs by the fourth abdominal segment with broad ventral process which is $1 / 5$ times as wide as the segment and the male genitalia with a short ventral stalk and a ring-shaped right sclerite of the dorsal apophysis which is larger than the ventral stalk.

\section{Batrisoplisus okamotoi sp. nov.}

(Figs. 43C,110H) 
Male. Length $151.6 \mathrm{~mm}$. Width $0.6 \mathrm{~mm}$.

Body reddish brown, maxillary palpi and legs light brown, short, head and pronotum narrowed.

Head as long as wide, nearly rectangular, densely with coarse punctures, clypeus short and weakly expanded anteriorly, frons feebly concave, vertex convex, with a longitudinal carina, postgenae expanded posterolaterally. Eyes convex and ovoid, each composed of about 30 facets. Antennae and maxillary palpi almost same in structure as in tosanus.

Pronotum wider than long, weakly expanded on both sides, coarsely punctate on dorsal surface. Elytra slightly wider than long, humeri rounded and slightly angular in brachypterous male, expanded in macropterous male, each elytron with 2 dorsal foveae and 2 dorsal sulci, outer sulcus reaching posterior 1/5, weakly incurved. Hind wing developed. Legs short, femora thick, mid tibiae slender, each with a short mucro at apex.

Abdomen shorter than elytra, 4th segment largest, about twice as wide as long, with a pair of basilateral carinae on basal half and a broad ventral process being 1/6 times as wide as the segment, 5th short, slightly longer than 6th, 7th large, 1.8 times as long as 6th, 8th to 9th segments same in structure as in tosanus.

Male genitalia (Fig. 110H) reniform; paramere very smalland membranous; basal bulb rounded basally, with an acute basal strut and a long ventral stalk, dorsal apophysis composed of 2 sclerites, right sclerite as long as ventral stalk in lateral view, broadened on the middle part, sharpened apically, left sclerite slightly longer than ventral stalk, 2.2 times as long as wide.

Female. Length $1.5-1.6 \mathrm{~mm}$. Width $0.6 \mathrm{~mm}$.

Similar to male except for the followings: eyes smaller than in male, each composed of about 15 facets; antennae moniliform, 9th segment smaller than 10th, subglobose. Elytra short and transverse; hind wing reduced; legs short, mid tibiae slender, without mucro. Abdomen longer than elytra, narrowed posteriorly, 4th segment largest, 1.9 times as wide as long, 7 th segment large, as long as 5th +6 th segments.

Distribution. Japan (Honshu).

Holotype, male (Type No. 2812, Kyushu Univ.), Kamagari-cho, Hiroshima Pref., 1. xi. 1987, I. Okamoto leg. Paratypes: 6 males 13 females, same data as holotype; 1 female, same locality as holotype, 7. xi. 1987, I. Okamoto leg.; 5 females, same locality as above, 1. i. 1988, I. Okamoto leg.; 4 males, Nikyu valley, Kure City, Hiroshima Pref., 29. x. 1987, I. Okamoto leg.; 22 males, same locality as above, 16. v. 1989, I. Okamoto leg.; 2 males 3 females, Kurose-machi, Kamo-gun, Hiroshima Pref., 12. xi. 1987, I. Okamoto leg.; 1 male 1 female, same locality as above, 4-12. vi. 1988, I. Okamoto leg.

Remarks. Batrisoplisus okamotoi sp. nov. is closely related to B. tosanus sp. nov. and $\boldsymbol{B}$. tanabei sp. nov., but is separated from the former by the fourth abdominal segment with a broad ventral process, and from the latter by the male genitalia with a long ventral stalk and an apically sharpened right sclerite of the dorsal apophysis. 
The raffrayi-group is characterized by the ninth antennal segment which is strongly expanded externally, and by the fourth abdominal segment with a pair of ventral processes at the posterior margin. This-group consists of $\boldsymbol{B}$. coiffaiti Jeannel, $\boldsymbol{B}$. raffrayi Jeanne1 and $\boldsymbol{B}$. amamianus sp. nov.

\section{Batrisoplisus coiffaiti Jeannel}

Batrisoplisus coiffaiti Jeannel, 1958, Mém. Mus. Hist. nat., Paris, (A), 18: 56.

Remarks. I have examined no type specimen of this species, but this species probably belongs to the raffrayi-group according to the original description. This species is separated from $\boldsymbol{B}$. raffrayi Jeannel by the laterally projected pronotum and the male genitalia with an almost straight ventral stalk after the literature cited.

\section{Batrisoplisus raffrayi Jeannel}

(Figs. 43D, 111A-H, 114-I)

Batrisoplisus raffrayi Jeannel, 1958, Mém. Mus. Hist. nat., Paris, (A), 18: 56.

Male. Length 1.5-1.7 mm. Width 0.6-0.7 mm.

Body reddish brown, maxillary palpi and legs light brown, short.

Head as long as wide, subparallel-sided, sparsely with coarse punctures, clypeus short and arcuate on anterior margin, frons concave, vertex weakly convex, with a pair of dorsal tentorial pits connected to each other by a U-shaped sulcus and a fine median longitudinal carina, postgenae flat. Eyes ovoid and convex, each composed of about 30 facets. Antennae short, reaching base of pronotum, 1st segment thick, subcylindrical, 2nd slightly narrower than lst, as long as wide, subcylindrical, 3rd short, as long as wide, thickened distally, 4th to 6th subequal, each ovoid, slightly wider than long, 7th feebly wider than 6th, ovoid, 8th transverse, extended to form a internal lobe, 9th largest, twice as wide as long, expanded externally, with 2 lobes on internal side, the 2 lobes subequal in length, each sharpened distally, and with a transversely ovoid acinous patch, 10th wider than long, ovoid, 11th large, 1.4 times as long as wide, ovoid. Maxillary palpi short and slender, 4th segment largest, 2.5 times as long as wide, fusiform.

Pronotum almost as long as wide, expanded on both sides, sparsely punctate on dorsal surface. Elytra wider than long, rectangular, humeri expanded and weakly denticulate, each elytron with 2 dorsal foveae and 2 dorsal sulci, outer dorsal sulcus reaching posterior 1/5. Legs short, mid tibiae slender, each with a short mucro at apex, hind femora elongate, each with a shallow longitudinal groove on basilateral part.

Abdomen shorter than elytra, rounded posteriorly, 4th segment largest, twice as wide as long, with a pair of basilateral carinae on basal $1 / 3$, and a pair of ventral processes, 5th to 6th short, subequal in length, 7th large, as long as 5th +6 th segments, 8 th tergite transverse, arcuately emarginate on posteromedian margin, 8th sternite transverse, with a shallow emargination on posteromedian part, 9th sternite small and ovoid on external view. 
Male genitalia (Fig. 111) reniform, paramere short, membranous, basal bulb rounded basally, with an indistinct basal strut and a broad and sinuate ventral stalk, dorsal apophysis consisting of 2 sclerites, right sclerite bifurcate at basal part, sharpened apically, left sclerite elongate, slightly longer than ventral stalk, weakly broadened apically.

Female. Length 1.4-1.6 mm. Width 0.5-0.6 mm.

Similar to male, but differs as follows: head more coarsely and densely punctate than in male; eyes smaller than in male, each composed of 15-20 facets; antennae moniliform, 2nd segment ovoid, 3rd to 8th each slightly longer than wide, ovoid, 9th subglobose. Elytra narrowed anteriorly; legs short, mid tibiae and hind femora each without mucro nor groove. Abdomen longer than elytra, 4th segment largest, subparallel-sided.

Distribution. Japan (Hokkaido, Honshu, Shikoku, Kyushu, Tsushima Is. and Yakushima Is.).

Specimens examined. [Hokkaido] 1 male, Ishikari, Hokkaido, 6. viii. 1962 (Y. Shibata). [Honshu] 2 males, Fujishima, Yamagata Pref., 20. vi. 1955 (H. Hasegawa); 1 male 1 female, Odawara, Kanagawa Pref., 17. ix. 1972 (Y. Hirano); 17 males 27 females, Sengokuhara, Hakone, Kanagawa Pref., 25. x. 1985 (M. Kubota et S. Nomura); 5 males, Gifu Pref., 1. vii. 1980 (A. \& Z, Smetana); 8 males 1 female, same locality as above, 1. viii. 1980 (I. Löbl); 7 males 3 females, Nii valley, Kure City, Hiroshima Pref., 29. x. 1982 (I. Okamoto); 126 males, same locality as above, 16. v. 1989 (I. Okamoto). [Kyushu] 4 males 6 females, Kashinokibaru, Nanayama-mura, Saga Pref., 1. x. 1978 (H. Ohishi); 17 males, Tororo, AmakusaShimojima Is., Kumamoto Pref., 8. viii. 1977 (H. Ohishi). [Tsushima Is.] 2 males 3 females, Izuhara, Tsushima Is. Nagasaki Pref., 8. v. 1979 (H. Ohishi); 1 male , Mt. Mitake, Tsushima Is., Nagasaki Pref., 31. v. 1988 (S. Nomura). [Yaku Is.] 1 male 5 females, Mt. Miyanouradake, Yaku Is., Kagoshima Pref., 23-25. iv. 1985 (T. Tanabe); 2 males 2 females, same locality as above, 18-19. xi. 1985 (T. Tanabe); 1 female, Hanayama, Yaku Is., Kagoshima Pref., 11. xi. 1985 (T. Tanabe); 3 females, Anbo-rindo, Yaku Is., Kagoshima Pref., 14. xi. 1985 (T. Tanabe).

Remarks. Batrisoplisus raffrayi Jeanne1 is broadly distributed and varied geographically in several features and structures of the male genitalia as shown in Fig. 108.

Biological notes. Many specimens of this species were collected from the dead glass spleaded on the field in Hakone, Kanagawa Pref. This species may prefer such dry and open land to the shadowy forest floor.

\section{Batrisoplisus amamianus sp. nov.}

(Fig. 112A, B)

Male. Length $1.6 \mathrm{~mm}$. Width $0.6 \mathrm{~mm}$.

Body reddish brown, maxillary palpi light brown, short, head and pronotum narrowed.

Head as long as wide, subparallel-sided, coarsely punctate on dorsal surface, clypeus very short, arcuate on anterior margin, frons weakly concave, vertex convex, with a pair of dorsal tentorial pits connected to each other by a U-shaped sulcus, postgenae large, almost flat. Eyes convex and ovoid, each composed of about 25 facets. Antennae longer than in raffrayi, reaching base of elytra, 1st segment thick, subcylindrical, 2nd slightly longer than wide, ovoid, 3rd as long as wide, thickened distally, 4th to 6th subequal, each slightly wider than long, subglobose, 7th larger than 6th, projected internally, 8th 
extended and lobate on internal side, 9th largest, transverse, very strongly projected externally, with short and acute 2 lobes on internal side, broadly excavated between the lobes, acinous patch very small and transverse, 2/7 times as long as the segment, located on dorsolateral corner, 10th small, as long as wide, subglobose, 11th large, twice as long as wide, fusiform. Maxillary palpi short, 4th segment largest, twice as long as wide, fusiform.

Pronotum slightly wider than long, projected laterally, sparsely punctate on dorsal surface. Elytra wider than long, convex, almost rectangular, humeri expanded and denticulate, each elytron with 2 dorsal foveae and 2 dorsal sulci, outer dorsal sulcus running from outer dorsal fovea to posterior 1/3, weakly incurved. Metastemum broad, with a pair of robust carinae. Legs elongate, mid tibiae slender, each with a very short mucro at apex.

Abdomen shorter than elytra, rounded posteriorly, with a pair of short basilateral carinae on basal $1 / 4$, and a pair of strongly projected ventral processes, 5th to 6th short, subequal in length, 7th large, as long as 5 th +6 th, 8 th tergite transverse, arcuately emarginate on posteromedian part, 8th sternite semicircular, strongly concave at the middle part, shallowly emarginate on posteromedian margin 9th sternite ahnost circular in external view.

Male genitalia (Fig. 112A, B) reniform; paramere short and membranous; basal bulb rounded basally, with a short basal strut and a short, straight ventral stalk, dorsal apophysis consisting of 2 sclerites, left sclerite broad, longer than the ventral stalk, with 2 long and acute spine at apex, right sclerite small, elongate and arcuate, connected with base of the dorsoapical spine of the left sclerite.

Female. Length $1.5-1.7 \mathrm{~mm}$. Width $0.6 \mathrm{~mm}$.

Similar to male except for the following characters: eyes smaller than in male, each composed of about 15 facets; antennae moniliform, 3rd to 6th segments each subglobose. Elytra shorter than in male, weakly narrowed anteriorly; mid tibiae slender, without mucro. Abdomen longer than elytra, 4th segment largest, subparallel-sided.

Distribution. Japan (Amami-Oshima Is.).

Holotype, male (Type No. 2813, Kyushu Univ.), Hatsuno, Amami-Oshima Is., Kagoshima Pref., 10. viii. 1984, S. Nomura leg. Paratopotype: 2 females, same data as holotype.

Remarks. Batrisoplisus amamianus sp. nov. is easily distinguished from the other species by the ninth antennal segment which is strongly projected externally and is having the small, transverse and ovoid acinous patch at the dorsolateral comer of the segment.

Biological notes. The habitat of this species is the sandy soil on the upper reaches of the stream.

The antennatus-group

This group consists of an uncertainly defined genotypic species, $\boldsymbol{B}$. antennatus (Weise).

\section{Batrisoplisus antennatus (Weise)}

Batrisus antennatus Weise, 1877, Deutsche ent. Zeitschr., 21: 97; Waterhouse, 1882-90, Aid Identif. Ins., 
pl. 146.

Batrisocenus antennatus. Raffray, 1904, Ann. Soc. ent. Fr., 73: 219.

Batrisoplisus antennatus. Raffray, 1908, Coleopt. Psel., Gen. ins., 64: 181; 1911, Psel., Coleopt. Cat., (27): 74; Jeannel, 1958, Mém. Mus. Hist. nat. Paris, (A), 18: 54.

Distribution. Japan (Honshu).

Remarks. I could not examine the type specimen, but this species probably bears the large and bilobate ninth antennal segment according to the original description and the illustration by Waterhouse (1882-90). Jeanne1 (1958) pointed out such key characters of this species that the vertex with a fine median longitudinal carina and the minutely punctate elytra; those characters are, however, found in some species of this genus, and this species cannot be identified to any present species nor speciesgroup.

\section{The monostatos-group}

The monostatos-group is distinct from the other species-group by the fifth abdominal segment with a ventral process, however, it has the same type of the male genitalia as the venustus-group and allied groups. This species-group contains one species, B. monostatos sp. nov.

\section{Batrisoplisus monostatos sp. nov.}

(Fig. 43E)

Male. Length $1.5-1.6 \mathrm{~mm}$. Width $0.6 \mathrm{~mm}$.

Body reddish brown, maxillary palpi light brown, short and elongate.

'Head slightly wider than long, feebly narrowed anteriorly on both sides, densely with coarse punctures on dorsal surface, clypeus short, weakly expanded anteriorly, frons flattened and arcuate on anterior margin, with a pair of conspicuous lateral foveae between the base of antennae and eyes, vertex convex with a pair of dorsal tentorial pits connected to each other by a U-shaped sulcus, postgenae rounded. Eyes convex and ovoid, each composed of about 20 facets. Antennae short, reaching base of pronotum, 1st segment thick and subcylindrical, with 2 apical projections, 2nd slightly longer than wide, ovoid, 3rd as long as 2nd, thickened distally, 4th to 9th successively enlarged, each subglobose, 10th as large as 9 th, subglobose, 11th largest, 1.7 times as long as wide, ovoid. Maxillary palpi short, 4th segment largest, twice as long as wide, broadened on the middle part, acute at apex.

Pronotum slightly wider than long, expanded laterally, with dense and coarse punctures. Elytra slightly wider than long, nearly rectangular, humeri expanded and denticulate, each elytron with 2 dorsal foveae and 2 dorsal sulci, outer dorsal sulcus running from outer fovea to posterior $1 / 3$, weakly incurved. Metasternum concave at the middle part, with a pair of strongly projected short carinae in front of metacoxae. Legs short, femora thick, mid trochanters short, each with a short and acute spine, mid tibiae weakly thickened on the middle part, each with a very short mucro at apex. 
Abdomen shorter than elytra, 4th segment largest, twice as wide as long, with a pair of basidorsal carina on basal $2 / 5,5$ th short, with a small ventral process at posteromedian part of the sternite (Fig. $41 E$ ), 6th slightly shorter than 5th, 7th large, as long as 5th +6 th, 8th tergite transverse, arcuately emarginate on posteromedian part, 9th sternite small, nearly quadrangular in posterior view.

Male genitalia reniform, paramere very small, membranous, basal bulb rounded basally, with a conspicuous basal strut and a ventral stalk broadened distally, dorsal apophysis consisting 2 sclerites, right sclerite elongate, sharpened distally, left sclerite as long as ventral stalk, broadened posteriorly.

Female. Length 1.5-1.6 mm. Width $0.6 \mathrm{~mm}$.

Very similar to male except for the following characters: eyes smaller than in male, each consisting of about 15 facets. Antennae almost same in structure as in male, but more slender than in male. Hind wing reduced, mid tibiae without mucro. Abdomen slightly longer than elytra, 4th segment largest, subparallel-sided, 1.7 times as wide as long, 8th stemite convex, arcuately expanded to fit in the emargination of 8th tergite.

Distribution. Japan (Okinoerabu Is. and Okinawa Is.).

Holotype, male (Type No. 2814, Kyushu Univ.), Ie-rindo, Kunigami-son, Okinawa pref., 14. iii. 1985, S. Nomura leg. Paratypes: 9 males 9 females, same data as holotype; 1 female, same locality as holotype, 11. x. 1988, S. Nomura leg.; 5 males, Mt. Terukubi, Kunigami-son, Okinawa Pref., 19. iv. 1986, S. Nomura leg.; 8 males 7 females, Mt. Yonahadake, Kunigami-son, Okinawa Pref., 20. x. 1987, M. Sakai et Y. Nishikawa leg.; 1 male, Hiji, Kunigami-son, Okinawa Pref., 22. x. 1987, M. Sakai leg.; 1 male 3 females, Mt. Nagodake, Nago City, Okinawa Pref., 11. iii. 1985, S. Nomura leg.; 1 male, Yonashiro, Okinawa Pref., 2. viii. 1971, B. Melin leg, 1 male 2 females, Mt. Oyama, Okinoerabu Is., Kagoshima Pref., 24. iii. 1980, S. Nomura leg.

Remarks. Batrisoplisus monostatos sp. nov. is similar to B.parallelus in the subparallel-sided body and the subglobose ninth antennal segment without sexual patch. But this species is easily distinguished from others by the fifth abdominal segment with a small ventral process.

Biological notes. Several specimens captured by light trap; but, this species usually inhabits the premeval forest floor.

\section{The torticornis-group}

The torticornis-group is characterized by the fourth abdominal segment without ventral process and the male genitalia with a broad ventral stalk, a bifurcate and internally tapered left sclerite of dorsal apophysis and an internally extending and distally thickened right sclerite.

This group contains B. torticornis sp. nov., B. taminosp. nov. and species, B. constrictus sp. nov.

\section{Batrisoplisus torticormis sp. nov.}

(Fig. 113A-C)

Male. Length 1.4-1.5 mm. Width 0.5-0.6 mm.

Body reddish brown, maxillary palpi light brown, short and elongate. 
Head as long as wide, rectangular, sparsely punctate on dorsal surface, clypeus short and arcuate on anterior margin, frons concave, vertex convex, with a pair of dorsal tentorial pits connected to each other by a semicircular sulcus, postgenae rounded. Eyes convex and ovoid, each composed of about 20 facets. Antennae elongate, reaching base of elytra, 1st segment thick, subcylindrical, 2nd as long as wide, subcylindrical, 3rd slightly wider than long, thickened distally, 4th to 6th subequal, each wider than long, subspherical, 7th large, transverse, broadened dorsolaterally, with long and bold setae at external part, 8th thickened on internal part, excavated externally, with small acquinous patch on dorsal side, 9th large and subspherical, strongly projected basilaterally, with bold setae on both sides of the projection, 10th small, wider than long, subglobose, 11th 15 times as long as wide, large and ovoid. Maxillary palpi short, 4th segment largest, twice as long as wide, broadened on the middle part, acute at apex.

Pronotum wider than long, expanded laterally, sparsely punctate on dorsal surface. Elytra wider than long, weakly narrowed anteriorly, humeri denticulate, each elytron with 2 dorsal foveae and 2 dorsal sulci, outer dorsal sulcus reaching posterior $1 / 3$. Metastemum flattened at the median part, both sides of the flat area arcuately carinated, with a pair of densely setiferous patches. Legs short, mid tibiae slender, each with a short and thin mucro at apex.

Abdomen slightly shorter than elytra, rounded posteriorly, 4th segment largest, subparallel-sided, with a pair of basidorsal carinae on basal $1 / 3$, 5th to 6th short, subequal in length, 7 th large, as long as 5 th +6 th, 8th transverse, shallowly emarginate on posteromedian part, 8th stemite nearly semicircular, arcuately emarginate on posteromedian part, 9 th stemite small, transversely fusiform in posterior view.

Male genitalia (Fig. 113A-C) complicate in apical part, rounded in basal part, with a ventral stalk on right or left side; paramere short and membranous; basal bulb reniform, rounded basally, with a short basal strut and a broad ventral stalk angularly curved on basal part, incurved apically, dorsal apophysis composed of 2 sclerites, right sclerite on the same side as the ventral stalk extending to left crossing ventral stalk in ventral view, thick in basal part, sharpened distally, left sclerite twig-shaped, strongly bent to right and bifurcate in apical a half, one arm curved ventrally, the other dorsally.

Female. Length 1.3-1.5 mm. Width OS-O.6 mm.

Similar to male except for the following characters: eyes smaller than in male, each consisting of 15-20 facets. Antennae short and moniliform, 7th segment slightly wider than long, subglobose, 8th shorter than 7th, transverse, 9th subglobose, 10th larger than 9th, as long as wide, spherical 11th largest, 1.5 times as long as wide, ovoid. Metastemum weakly convex at the middle part, moderately pubescent. Legs short, fore and mid tibiae slender, without denticle nor mucro. Abdomen larger than elytra, 8th tergite transverse, arcuate on posterior margin, 8th stemite broad, semicircular.

Distribution. Japan (Ishigalci Is. and Iriomote Is.).

Holotype, male (Type No. 2815, Kyushu Univ.), Mt. Omotodake, Ishigaki Is., Okinawa Pref., 22. iii. 1984, S. Nomura leg. Paratypes: 10 males 12 females, same data as holotype; 3 males 7 females, same locality as holotype, 9-11. iv. 1986, S. Nomura leg.; 1 female, Uehara, Iriomote Is., Okinawa Pref., 22. iii. 1985, K. Nemoto leg.; 2 males 2 females, Kanpiree, Iriomote Is., Okinawa Pref., 13-14. iv. 1986, S. Nomura leg.

Remarks. Batrisoplisus torticornis sp. nov. has the dimorphic male genitalia as in Batrisceniola dissimilis (Sharp).

Biological notes. This species is an inhabitant of the subtropical forest floor. 


\section{Batrisoplisus tamino sp. nov.}

(Fig. 113D-F)

Male. Length $1.7 \mathrm{~mm}$. Width $0.6 \mathrm{~mm}$.

Body reddish brown maxillary palpi light brown elongate.

Head as long as wide, rectangular, coarsely punctate on dorsal surface, clypeus short, arcuate on anterior margin, frons depressed at the median part, vertex convex, with a pair of dorsal tentorial pits connected to each other by a semicircular sulcus, postgenae large, rounded. Eyes small and ovoid, each composed of about 15 facets. Antennae clearly longer than in torticornis, reaching base of elytra, 1st segment thick, subcylindrical, 2nd longer than wide, ovoid, 3rd longer than wide, thickened distally, 4th to 6th subequal, each as long as wide, subglobose, 7th thick, transverse, projected dorsolaterally, 8th thickened ventrally, excavated dorsally, with small setiferous patch, 9th thickest, subspherical, with 3 short longitudinal carinae on basidorsal side, 10th longer than wide, small and ovoid, 11th longest, twice as long as wide, ovoid. Maxillary palpi short, 4th segment largest, 2.4 times as long as wide, thickened on the middle part, acute at apex.

Pronotum wider than long, expanded laterally, coarsely punctate on dorsal surface. Elytra wider than long, narrowed anteriorly, humeri denticulate, each elytron with a weakly incurved outer dorsal sulcus on basal 2/3. Legs elongate, fore tibiae slender, each with a small denticle at apical 1/8, mid tibiae slender, densely pubescent on apical $1 / 4$, with short and thin mucro at apex.

Abdomen slightly longer than elytra, weakly narrowed posteriorly, concave on the ventromedian part, 4th segment largest, 1.8 times as wide as long, subparallel-sided with a pair of short basidorsal carinae on basal $1 / 4,5$ th to 6 th subequal in length, each longer than in torticornis, 7 th large, as long as 5 th +6 th, 8th tergite wider than long, nearly triangular in posterior view, 8th sternite very large, concave at the median part, semicircular, 9th stemite small, transversely fusiform in posterior view.

Male genitalia (Fig. 113D-F) larger than in torticornis with ventral stalk on right side; paramere very small and membranous; basal bulb nearly rectangular, with a triangular basal foramen and an apically broadened ventral stalk extending to right, dorsal apophysis composed of 2 sclerites, left sclerite thick on basal part, rounded at apex with a tapering dorsal spine being bent basidorsally, right sclerite located between the ventral stalk and left sclerite, thickened and rounded apically, with a very slender spine extending externally from the base of the sclerite to ventral side of the ventral stalk.

Female. Length $1.7 \mathrm{~mm}$. Width $0.6 \mathrm{~mm}$.

Similar to male, but differs as follows: Eyes slightly smaller than in male, each composed of 12-13 facets. Antennae shorter than in male, reaching base of pronotum, moniliform, 8th segment shorter than 7 th, slightly thickened distally, 9th longer than wide, ovoid, 10th larger than 9th, subglobose, 11th largest, ovoid. Legs elongate, fore and mid tibiae each slender, without modification as mucro nor denticle. Abdomen moderately convex on ventral side, 7 th smaller than in male, 1.2 times as long as 6th.

Distribution. Japan (Okinawa Is.).

Holotype, male (Type No. 2816, Kyushu Univ.), Ie-rindo, Kunigami-son, Okinawa Is., Okinawa Pref., 11. x. 1988, S. Nomura leg. Paratype: 1 female, same data as holotype.

Remarks. Batrisoplisus tamino sp. nov. belongs to the torticornis-group. This species is separated from $\boldsymbol{B}$. torticornis sp. nov. by the elongate antennae and the ovoid ninth an tennal segment, and by the 
elongate abdomen which is excavated on the ventral side.

Biological notes. The type specimens were extracted from the litter of the subtropical primeval forest.

\section{Batrisoplisus constrictus sp. nov.}

(Fii. 112C, D)

Male. Length 1.6-1.7 mm. Width $0.6 \mathrm{~mm}$.

Body dark brown to reddish brown, maxillary palpi light brown, short and elongate, weakly constricted at base of abdomen.

Head slightly longer than wide, subparallel-sided, densely with coarse punctures on dorsal surface, clypeus short and arcuate on anterior margin, frons almost flat, arcuately expanded anteriorly, vertex weakly convex, with a pair of dorsal tentorial pits connected to each other by a U-shaped sulcus and a tine longitudinal carina, postgenae rounded. Eyes convex and ovoid, each composed of about 20 facets. Antennae short, reaching base of elytra, 1st segment thick and elongate, 2nd as long as wide, subcylindrical, 3rd slightly narrower than 2nd, thickened distally, 4th to 8th moniliform, each segment subglobose, 9th to 11th thick, each ovoid, 9th large, 1.4 times as long as wide, 10th slightly shorter than 9th, 11th largest, about twice as long as wide. Maxillary palpi short, 4th segment largest, 2.2 tunes as long as wide, broadened on the middle part, acute at apex.

Pronotum wider than long, expanded laterally with dense and coarse punctures on dorsal surface. Elytra slightly wider than long, weakly narrowed anteriorly, humeri almost flat, each with a small denticle, each elytron with 2 dorsal foveae and 2 dorsal sulci, outer dorsal sulcus reaching posterior 1/3. Metasternum concave on the middle part, weakly carinated on both sides of the concave area, with a pair of setiferous patch at the concavity. Legs thick in femora, fore tibiae slender, each with a small denticle at apex, mid tibiae thickest at apical 2/5, each with a robust mucro at apex.

Abdomen about as long as elytra, convex on dorsal side, flattened on ventromedian side, 4th segment broadened posteriorly, with a pair of basidorsal carinae on basal $1 / 4$, 5th to 6 th short, subequal in length, 7th large, 1.7 times as long as 6 th, 8 th tergite transverse and nearly trapezoid, 8 th sternite broad and nearly semicircular, concave at the middle part, 9th sternite small, transversely fusiform in posterior view.

Male genitalia (Fig. 112C, D) elongate in lateral view; paramere weakly sclerotized and elongate; basal bulb rounded basally, with transverse basal foramen extending ventrally and a broad and divergentventral stalk, dorsal apophysis consisting of 2 sclerites, left sclerite slender, curved internally on the middle part and bifurcate at apical part, right sclerite broad, thickened and rounded apically with an elongate spine extending from right side of the sclerite to apex of the ventral stalk.

Female. Length $1.7 \mathrm{~mm}$. Width $0.6 \mathrm{~mm}$.

Very similar to male except for the followings: eyes smaller than in male, each composed of about 20 facets. Antennae almost same in structure as in male, but 9th segment distinctly smaller than 10th. Metastemum concave at the middle part, without setiferous patch; fore and mid tibiae without denticie nor mucro. Abdomen longer than elytra, 4th segment weakly divergent posteriorly, 5th to 7th short, 5th as long as 7 th, longer than 6 th, 8th transverse, arcuate on posterior margin, 8th sternite semicircular, 
moderatory convex.

Distribution. Japan (Amami-Oshima Is.).

Holotype, male (Type No. 2817, Kyushu Univ.), Mt. Yuwandake, Amami-Oshima Is., Kagoshima Pref., 11. v. 1983, S. Nomura leg. Paratypes: 1 female, same locality as holotype, 8. v. 1987, S. Nomura leg.; 2 males, Hatsuno, Amami-Oshima Is., Kagoshima Pref., 27. iii. 1978, S. Naomi leg.; 1 female, same locality as above, 10. viii. 1984, S. Nomura leg.; 1 male, Mt. Yuidake, Amami-Oshima Is., Kagoshima Pref., 15. v. 1983, S. Nomura leg.; 1 male, same locality as above, 10. viii. 1984, S. Nomura leg.

Remarks. Batrisoplisus constrictus sp. nov. is similar to B. parallelus sp. nov. in the ovoid ninth antennal segment without sexual patch in the male. But this species is more closely allied to B. torticornis sp. nov. by the fourth abdominal segment without ventral process and the male genitalia with a slender and bifurcate left sclerite of the dorsal apophysis.

Biological notes. This species inhabits the litter layer of the broad-leaved forest.

\section{The uroceratusgroup}

The uroceratus-group is well demarcated from the other species-group by the right mandible with a robust dent in the male. This species-group is composed of $\boldsymbol{B}$. volcaninsulanus sp. nov., B. uroceratus uroceratus sp. et subsp. nov., B. uroceratus brevispinis subsp. nov., B. inermis sp. nov. and B. parallelus sp. nov.

\section{Batrisoplisus volcaninsulanus sp. nov.}

(Fig. 114D)

Male. Length $1.6 \mathrm{~mm}$. Width $0.6 \mathrm{~mm}$.

Body reddish brown maxillary palpi and legs light brown, short and broadened posteriorly.

Head as long as wide, subparallel-sided, coarsely punctate, clypeus short and arcuate on anterior margin frons weakly concave, vertex convex, with a pair of dorsal tentorial pits connected to each other by a semicircular sulcus, postgenae rounded. Eyes convex and ovoid, each composed of about 20 facets. Antennae short, reaching base of pronotum, 1st segment thick and subcylindrical, with 2 acute projections at apex, 2nd longer than wide, 3rd as long as 2nd, thickened distally, 4th slightly shorter than 3rd, 5 th large, as long as $2 \mathrm{nd}$, 6th subequal to $3 \mathrm{rd}$, 7th large, slightly wider than 5 th, 8 th short, subglobose, 9th thick, slightly wider than long, spherical, 10th subequal to 9th, 11th largest, 1.4 times as long as wide, ovoid. Maxillary palpi short, 4th segment largest, 1.8 times as long as wide in lateral view, widest at basal $1 / 3$, sharpened distally on apical $2 / 3$.

Pronotum slightly wider than long, weakly expanded laterally, coarsely punctate on dorsal surface. Elytra 1.2 times as wide as long, broadened posteriorly, humeri denticulate, each elytron with 2 dorsal foveae and 2 dorsal sulci, outer dorsal sulcus faint, reaching posterior 1/5. Legs short, thickened in femora, mid tibiae constricted at apical $1 / 5$ in dorsal view, each with an acute mucro at apex, hind femora each with a dorsal longitudinal carina on basal a half. 
Abdomen broad, about as long as elytra, 4th segment largest, twice as wide as long, weakly narrowed posteriorly with a pair of short basidorsal carinae on basal $1 / 4,5$ th to 6 th short, 5th longer than 6th, 7th large, twice as long as 6th, 8th tergite transverse and arcuately emarginate on posteromedian part, 8th stemite broad and semicircular, flattened at the middle part, 9th sternite small, nearly semicircular in posterior view.

Male genitalia reniform (Fig. 114D) in lateral view; paramere small and membranous; basal bulb rounded basally, with a short basal strut and broad ventral stalk being acute at apex, dorsal apophysis consisting of 2 sclerites, left sclerite broadened apically, right sclerite P-shaped, acute at apex.

Female. Length 1.5-1.6 mm. Width $0.6 \mathrm{~mm}$.

Very similar to male, but differs as follows: eyes smaller than in male, each composed of about 15 facets. Antennae almost same in structure as in male, but 9th segment clearly smaller than 10th. Mid tibiae and hind femora without modification. Abdomen longer than elytra, 4th segment largest, subparallel-sided, 1.6 times as wide as long, 8th tergite transverse and convex, horizontal on posterior margin, 8th sternite semicircular, weakly convex.

Distribution. Japan (Kuchinoerabu Is.).

Holotype, male (Type No. 2818, Kyushu Univ.), Maeda, Kuchinoerabu Is., Kagoshima Pref., 16. xi. 1985, T. Tanabe leg. Paratypes: 3 females, same data as holotype.

Remarks. Batrisoplisus volcaninsulanus sp. nov. is similar to B. parallelus sp. nov. in the subglobose ninth to tenth antennal segments which are subequal in the male. But this species is separated from parallelus by the fourth abdominal segment without ventral process.

\section{Batrisoplisus uroceratus sp. nov. \\ 107, 108A,114A,}

L e n g th $1.7-1.8 \quad \mathrm{~mm}$. W W d th $0.6 \quad \mathrm{~m} \mathrm{~m}$.

palpi $1 \mathrm{ight}$ brown, short, he ad and pronot um naro

Head slightly longer than wide, subparallel-sided, densely with coarse punctures, clypeus short and arcuately expanded anteriorly, frons weakly depressed on median part, vertex convex, with a pair of fine $\mathrm{m}$ e d i a $\mathrm{n}$ lo carina, $\mathrm{u} \mathrm{d}$ i $\mathrm{n}$ a 1

\section{volcaninsulanus. $\mathrm{M}$ a x i l palpi $\mathrm{y}$ fusiform.}

Pronotum wider than long, expanded laterally, coarsely punctate on dorsal surface. Elytra slightly wider than long, nearly rectangular, humeri weakly expanded and denticulate, each elytron with 2 dorsal foveae and 2 dorsal sulci, outer dorsal sulcus reaching posterior $1 / 5$, weakly incurved; metasternum concave at posteromedian part, with a pair of small projections in front of metacoxae. Legs short, femora thick, fore trochanters short, each with a short and acute denticle, mid trochanters short, each with a slender and outcurved spine, fore tibiae (Fig. 108A) thickened distally, each with a large and robust mucro at apex, mid tibiae (Fig. 108D) thickest at the middle, each with a small mucro at apex.

Abdomen shorter than elytra, narrowed posteriorly, 4th segment largest, 1.8 times as wide as long, 5 th to 6 th short, subequal in length, 7 th large, as long as 5 th +6 th, 8 th transverse, strongly convex at 
median part, arcuately emarginate on posteromedian margin, 8th sternite broad and transverse, concave at median part, 9th sternite nearly quadrangular on posterior margin.

Male genitalia (Fig. 114A, B) elongately reniform; paramere small and membranous; basal bulb rounded basally with a small basal foramen and a broad ventral stalk, dorsal apophysis composed of 2 sclerites, left sclerite short and elongate, weakly broadened distally, right sclerite elongate and arcuate, tapered apically.

Female (Fig. 107). Length 1.8-1.9 mm. Width $0.6 \mathrm{~mm}$.

Similar to male except for the following characters: eyes smaller than in male, each consisting of 15-20 facets. Antennae more slender than in male, 9th segment clearly smaller than 10th, subglobose. Legs more slender than in male, fore and mid trochanters and fore and mid tibiae without modification. Abdomen slightly.longer than elytra, 4th segment largest, 1.5 times as wide as long, narrowed posteriorly, 8th tergite transverse in posterior view, arcuately emarginate on posterior margin, with a conspicuously long projection being as long as 7th segment in dorsal view and tapering on apical part, 8th sternite large, nearly semicircular arcuately expanded to fit in the emargination of the 8th tergite.

Distribution. Japan (Kyushu).

Holotype, male (Type No. 2819, Kyushu Univ.), Todoroki valley, Nagasaki Pref., 1. vi. 1987, S. Nomura leg. Paratypes: 2 males 5 females, same data as holotype; 1 male, Ryumon, Nishiarita-cho, Saga Pref., 23. x. 1977, H. Ohishi leg.; 2 males 3 females, Buzenbo, Mt. Hikosan, Fukuoka Pref., 30. iv-2. v. 1983, S. Nomura leg.: 1 female, Mt. Hikosan, 21. v. 1986, S. Nomura leg.; 4 males 7 females, Mt. Ichifusa, Kumamoto Pref., 12-13. v. 1985, S. Nomura leg.; 2 males, Yabakei, Yamaguni-machi, Oita Pref., 30. iii. 1985, S. Nomura leg.; 3 males, Naokawa-mura, Oita Pref., 16. xi. 1985, S. Sasaki leg.; 1 male, Yokogawa, Naokawa-mura, Oita Pref., 19. xi. 1986, S. Sasaki leg.; 1 female, Mt. Inaodake, Tashiro-machi, Kagoshima Pref., 15. viii. 1985, S. Nomura leg.

Remarks. Batrisoplisus uroceratus sp. nov. is a distinct species by the fore tibiae each with a large mucro in the male and the eighth tergite with a long and tapering projection in the female.

Biological notes. This species is found in the litter of the shadowy and wet natural forest in Kyushu.

\section{Batrisoplisus uroceratus brevispinis subsp. nov.}

(Figs. 108B, 114C)

Male. Length $1.8 \mathrm{~mm}$. Width $0.6 \mathrm{~mm}$.

Female. Length $1.8 \mathrm{~mm}$. Width $0.6 \mathrm{~mm}$.

Very similar to the nominate subspecies in general aspect, but differs as follows: fore tibiae (Fig. 108B) more slender than in subsp. uroceratus, widest at the middle and at apex including short mucro in male. Eighth abdominal tergite with robust and conical projection being scarcely tapering on apical part in female.

Distribution. Japan (Kyushu; Amakusa-Shimojima Is.).

Holotype, male (Type No. 2820, Kyushu Univ.), Shimoda, Amakusa-Shimojima Is., Kumamoto Pref., 9. x. 1977, H. Ohishi leg. Paratypes: 1 male 1 female, same data as holotype.

Batrisoplisus inermis sp. nov. 
(Figs. 108C, E, 114E)

Male. Length $1.6 \mathrm{~mm}$. Width $0.6 \mathrm{~mm}$.

Body reddish brown maxillary paipi light brown short, head and pronotum narrowed.

Head as long as wide, subparallel-sided, densely with coarse punctures, clypeus short and arcuate on anterior margin, frons weakly depressed at median part, vertex convex, with a pair of dorsal tentorial pits connected to each other by a U-shaped sulcus and a fine median longitudinal carina, postgenae rounded. Eyes convex and ovoid, each composed of about 25 facets. Antennae almost same in structure as in uroceratus, but 9th to 10th segments thick, each transverse, 9th slightly smaller than 10th, 11th largest, 1.6 times as long as wide. Maxillary palpi short, 4th segment largest, 2.6 times as long as wide, fusiform.

Pronotum wider than long, expanded laterally, coarsely punctate on dorsal surface. Elytra wider than long, nearly rectangular, humeri weakly expanded and denticulate, each elytron with 2 dorsal foveae and 2 dorsal sulci, outer dorsal sulcus reaching posterior 1/6, weakly incurved. Metasternum weakly concave at posteromedian part, with a pair of short carinae before metacoxae. Legs short, femora thick, fore trochanters short, each with a broad denticle on ventral side; mid trochanters short, each with a short and outcurved spine at posterior part, fore tibiae weakly thickened on the middle part, each with a short and acute spine being nearly vertical to basiapical axis at apex, mid tibiae slender on apical part, each with a short mucro at apex

Abdomen shorter than elytra, weakly narrowed posteriorly, almost same in structure as in uroceratus, but 8th tergite weakly convex at median part.

Male genitalia (Fig. 114E) smaller than in uroceratus, paramere small and membranous; basal bulb rounded basally with a very short basal strut and a long ventral stalk, dorsal apophysis consisting of 2 sclerites, left sclerite larger than in uroceratus, broadened apically, right sclerite P-shaped, obtuse at apex.

Female. Length $151.6 \mathrm{~mm}$. Width $0.6 \mathrm{~mm}$.

Similar to male, but differs as follows: eyes smaller than in male, each consisting of 10-15 facets. Ninth antennal segment clearly smaller than 10th, subglobose. Legs more slender than in male, fore and mid trochanters and fore and mid tibiae without modification. Abdomen longer than elytra, 4th segment largest, 1.7 times as wide as long, 5th to 6th short, 6th slightly shorter than 5th, 7th large, twice as long as 6 th, 8th tergite transverse in posterior view, strongly convex on the middle part, shallowly emarginate on posterior margin, 8 th sternite large, semicircular arcuately expanded to fit in the emargination of the 8th tergite.

Distribution. Japan (Shikoku).

Holotype, male (Type No. 2821, Kyushu Univ.), Saruta, Hidaka-mura, Kochi Pref., 14. v. 1978, H. Ohishi leg. Paratypes: 4 females, same data as holotype.

Remarks. Batrisoplisus inermis sp. nov. is very closely related to B. uroceratus sp. nov., but is separated by the fore tibiae each with a small and acute spine in the male and by the eighth abdominal tergite which is strongly convex with obtuse apex (sharpened in uroceratus) in the female.

\section{Batrisoplisus parallelus sp. nov.}


(Fig. 114F-H, J)

Male. Length $1.6 \mathrm{~mm}$. Width $050.6 \mathrm{~mm}$.

Body dark brown to reddish brown, maxillary palpi light brown, elongate and subparallel-sided.

Head as long as wide, slightly narrowed anteriorly, densely with coarse punctures on dorsal surface, clypeus short, weakly expanded anteriorly on the median part, frons feebly depressed at the middle part, vertex convex, with a pair of dorsal tentorial pits connected to each other by a U-shaped sulcus, postgenae large, rounded. Eyes convex and ovoid, each composed of about 20 facets. Antennae short, reaching base of pronotum, 1st segment thick and subcylindrical, with 2 acute apical projection, 2nd narrower than 1st, slightly longer than wide, subcyliidrical, 3rd longer than wide, thickened distally, 4th to 8th moniliform, each segment about as long as wide, subglobose, 9th larger than 8th, subglobose, 10th slightly smaller than 9 th, subglobose, 11th largest, 1.5 times as long as wide, ovoid. Maxillary palpi short, 4th segment largest, twice as long as wide in lateral view, broadened on the middle part, acute at apex.

Pronotum wider than long, expanded laterally, coarsely punctate on dorsal surface. elytra slightly wider than long, weakly rounded on both sides, humeri almost flat, each with a denticle, each elytron with 2 dorsal foveae and 2 dorsal sulci, outer dorsal sulcus running from outer dorsal fovea to posterior $1 / 5$, feebly incurved. Legs short, mid tibiae thickened at the middle, each with an acute and robust mucro at apex.

Abdomen as long as elytra, 4th segment largest, 1.5 times as wide as long, parallel-sided, with a pair of basidorsal carinae on basal $2 / 7$, and a very small ventral process at posteromedian part of the stemite as in veaustus, 5 th to 6th short, subequal in length, 7th large, 1.3 times as long as 6 th, 8 th tergite small, transverse, shallowly emarginate on posteromedian margin, 8th stemite large, depressed at the middle part, nearly semicircular, 9th sternite small, semicircular in posterior view.

Male genitalia (Fig. 114F, G) narrowed posteriorly; paramere small and membranous; basal bulb thickened and rounded basally, with a short basal strut and a very long and slender ventral stalk extending laterally, dorsal apophysis consisting of 2 sclerites, left sclerite elongate, broadened apically, right sclerite slender, acute at apex, divided into 2 pieces by membrane at the basal part.

Female. Length $1.5-1.6 \mathrm{~mm}$. Width $0.5-0.6 \mathrm{~mm}$.

Very similar to male except for the followings: antennae more slender than in male, 3rd to 7th slender, each segment longer than wide, 9th clearly smaller than 10th, subglobose. Elytra transverse, 1.3 times as wide as long, mid tibiae without mucro.

Distribution. Japan (Yaku Is.).

Holotype, male (Type No. 2822, Kyushu Univ.), Shiratani, Yaku Is., Kagoshima Pref., 13. v. 1987, S. Nomura leg. Paratype: 6 males 4 females, same data as holotype; 3 males 3 females, same locality as holotype, 23-25. iv. 1985, T. Tanabe leg; 1 female, same locality as above, 16. v. 1986, T. Yasunaga leg.; 1 female, Hanayama, Yaku Is. Kagoshima Pref., 11. xi. 1985, T. Tanabe leg.; 2 males, same locality as above, 26. iv. 1986, Moroto leg.; 1 female, Yakusugi Land, Yaku Is. Kagoshima Pref., 24. iv. 198.5, T. Tanabe leg.; 2 females, Kurio, Yaku Is. Kagoshima Pref., 10. v. 1987, S. Nomura leg.; 5 males 3 females, Onoaida, Yaku Is., Kagoshima Pref., 11. v. 1987, S. Nomura leg.

Remarks. Batrisoplisusparallelussp. nov. is similar to B. volcaninsulanus sp. nov., B. constrictus sp. nov. and B. monostatos sp. nov. by absence of the sexual patch on the ninth antennal segment. This species belongs, however, to the uroceratus-group by the right mandible with a large dent on the outer 
side and separated from others by the fourth abdominal segment with a small ventral process and the male genitalia with the slender right sclerite of the dorsal apophysis.

Biological notes. This species is commonly found in the litter of the forest floor in Yaku Is.

\section{Genus Batriscenellus Jeannel}

Batriscenellus Jeannel, 1958, Mém. Mus. Hist. nat. Paris, (A), 18: 60; Newton \& Chandler, 1989, Field. Zool., (53): 34. Type species: Batrisus fragilis Sharp, by original designation.

Body reddish brown to right brown, elongate.

Head longer than wide, clypeus short, frons concave, with a transverse sulcus, vertex weakly convex, with a median longitudinal carina running from the middle of frontal sulcus to cervix; eyes large, convex and ovoid; antennae elongate, 1st segment thick, short, with a large subconical trichome consisting of some brownish, semihyaline and bold setae at the external side; maxillary palpi short, 4th segment largest, fusiform.

Pronotum round-sided, with 3 longitudinal and a transverse sulci and 2 pairs of antebasal foveae. Elytra wider than long, convex in macropterous male, humeri weakly pointed, each elytron with 2 dorsal and a lateral foveae and 2 dorsal and a lateral sulci. Legs elongate, mid tibiae slender, each with a mucro at apex in male.

Abdomen subparallel-sided or weakly narrowed posteriorly, 4th segment predominantly large, with a pair of short basidorsal carinae and a pair of tergostemal ridges, 5th to 6th short in general, 7th larger than 6th, 8th tergite wider than long, emarginate on posterior margin in male, arcuate on posterior margin in female, 8th stemite crescent to semicircular, 9th stemite very small, transverse in external view in male, invisible in female.

Male genitalia with dorsal apophysis on dorsal side of basal bulb; paramere small and lamellar; basal bulb broad, rounded on basal side, ventral stalk extendingventroapically, dorsal apophysis elongate, robust, attached to dorsomedian side of basal bulb, close and subparallel to ventral stalk in lateral view, strongly bent on basal part in some species.

Female genitalia composed of 9th stemite and genital plate, 9th stemite divided into 2 lobes, fore lobe narrow, with a pair of sclerites connected to each other by membrane, hind lobe transverse, Simply sclerotyzed, narrowly extending anteriorly on both sides, arcuate on posterior margin; genital plate narrower than 9th sternite, with a pair of short lateral arms sharpened distally.

Remarks. The genus Batriscenellus was defined by the fifth to seventh (?) abdominal segments having sexual patch according to Jeanne1 (1958). But I redifined it in this paper by the first antenna1 segment with a subconical trichome composed of some brownish, hyaline and bold setae.

This genus is very closely related to the genus Batrisiella in the structure of the male genitalia, but the latter genus is so indistinctly defmed that must be revised in detail.

A Key to the Subgenera of the Genus Batriscenellus from Japan 
1. Metasternum with a pair of small setiferous patches between hind coxae in male

- Metastemum simply pubescent between hind coxae in male

Scaioscenellus Jeanne 1

2. Hind femur strongly swollen and covered with secretory setae on apical half in male

Batriscenellinus subgen. nov.

- Hind femur simple, without secretory seta in male

3. Fiih tergite with a pair of setiferous patches on both sides and a fringe at posteromedian part, 6th tergite with a large basimedian excavation in male; basal bulb of male genitalia with a large articulate process

Batriscenellus s. str.

- Fifth abdominal tergite simple, without setiferous patch nor fringe, 6th tergite with a pair of setiferous patches on both sides and a large transverse excavation in male; basal bulb of male genitalia with a small, indistinct articulate process

Nipponoscenellus subgen. nov.

\section{Subgenus Batrisceneflus s. str.}

The nominotypical subgenus is defined by the "inverse" male genitalia, i. e. left-articulated type in this study and the simple fifth abdominal segment in Jeanne1 (19.58). But these two features are not appropriate for the key character, because the dorsal apophysis of the male genitalia is articulated to the same side of median lobe as the other subgenus, and the fifth abdominal segment has two kinds of special setae. So I propose the following two characteristics for this subgenus: 5th abdominal segment with a pair of setiferous patches and a fringe consisting of some long and bold setae at posteromedian part, 6th segment with a deep and transverse median excavation covered with the fringe of 5th segment; basal bulb of male genitalia with a large articulate process.

This subgenus is composed of the following seven species and a subspecies: B. japonicus japonicus (Sharp), B. japonicus vicarius Löbl, B. punctatus sp. nov., B. fallax (Sharp), B. omogensis sp. nov., B. kujumontanus sp. nov., $\boldsymbol{B}$. fragilis (Sharp) and $\boldsymbol{B}$. nodulifer sp. nov.

\section{A Kcy to the Species and the Subspecies of the Subgenus Batriscenellus from Japan}

1. Sixth abdominal tergite with an indistinctly demarcated excavation and a trapezoid nodule, 8th sternite simple, without longitudinal carina nodulifer sp. nov.

- Sixth abdominal tergite with a deep, well-demarcated excavation, 8th sternite with a pair of longitudinal carinae . ............................................................................................................................

2. Head and pronotum with coarse punctures . . . . . . . . .......................................................................... 3

- Head and pronotum sparsely with minute punctures ……………………......................................... 5

3. Sixth abdominal segment large, weakly concave on the posteromedian part ....kujumontanus sp. nov.

- Sixth abdominal segment short, weakly convex on the posteromedian part …………....................... 4

4. Ventral stalk of male genitalia strongly bent ...................................................... punctatus sp. nov.

- Ventral stalk of male genitalia weakly sinuate …….............................................. omogensis sp. nov. 
5. Sixth abdominal segment with a very narrow basimedian excavation fragilis (Sharp)

- Sixth abdominal segment with a large basimedian excavation

6. Fii abdominal segment with a posteromedian fringe divided into 2 small fringes by a narrow median grabrous part

- Fifth abdominal segment with a posteromedian fringe without grabrous part

7. Fourth abdominal segment subparallel-sided; male genitalia with a dorsally expanded basal bulb .....

- Fourth abdominal segment weakly narrowed posteriorly; male genitalia with a dorsally rounded basal bulb japonicus japonicus (Sharp)

\section{Batriscenellus japonicus (Sharp) \\ (Figs. 116A, 118D, 120A, B)}

Batrisus japonicus Sharp, 1883, Trans ent. Soc. London, 1883, p.318.

Batrisocenus japonicus. Raffray, 1904, Annls. Soc. ent. Fr., 73: 218; 1908, Coleopt. Psel., Gen. ins., 64: 173; 1911, Psel., Coleopt. Cat., (27): 70.

Batriscenellus japonicus Jeannel, 1958, Mém. Mus. Hist. nat., Paris, (A), 18: 62.

Male. Length 1.9-2.1mm. Width 0.7-0.8mm. Body reddish brown and shiny, elongate and narrowed in head and pronotum.

Head slightly longer than wide, subparallel-sided, moderately pubescent, clypeus short, arcuate on anterior margin, frons concave on median part, coarsely punctate, with a transverse sulcus being weakly bisinuate, vertex convex, sparsely punctate, with a median longitudinal carina reaching frontal transverse sulcus, postgenae weakly rounded. Eyes large, convex, each composed of about 30 facets. Antennae slender, reaching base of elytra, densely pubescent, 1st segment convex on outer side, with a conical setiferous structure on apical part of the outer expantion, 2nd longer and narrower than 1st, elongate, 3 rd to 4th subequal to each other, each smaller than 2nd, thickened distally, 5th slightly longer than 4th, elongate, 6th shorter than 5th, ovoid, 8th subequal in width to 7th, short and ovoid, 9th to 11th thick, each longer than wide, 9th ovoid, 10th thickened distally, 11th largest, about 1.7 times as long as wide, sharpened toward apex, rounded on basal part.

Pronotum as long as wide, round-sided and convex, sparsely minute punctures, with a median longitudinal sulcus running from anterior $1 / 10$ to posterior 1/8. Elytra slightly wider than long, weakly broadened posteriorly, sparsely punctate, humeri expanded, each elytron with 2 dorsal foveae and 2 dorsal sulci, outer dorsal sulcus subparallel to sutural line reaching posterior 1/8; hind wings developed. Legs slender and densely pubescent, mid tibiae slender, each with a short mucro at apex.

Abdomen (Fig. 116A) rounded posteriorly, 4th segment largest, transverse, weakly narrowed posteriorly in dorsal view, with a pair of angular tergostemal ridges on basal $1 / 3$ and a pair of short basidorsal carinae, and with long and bold hairs on posterolateral margin, 5th short, with a pair of setiferous patches on lateral part covered with the long hairs of 4th segment, with long and bold setae on dorsomedian part of the posterior margin, 6th twice as long as 5th in median part with a transverse and deep median excavation on anteromedian part, posterior margin of the excavation bisinuate, reaching posterior $4 / 9$ of 
the segment, 7th as long as 6th, moderately convex, 8th tergite (Fig. 118D) wider than long, weakly emarginate on posteromedian part, 8th sternite nearly crescent, with a pair of weak longitudinal carinae on its basal part.

Male genitalia (Fig. 120A, B) with a dorsal apophysis on left side; paramere lamellar; basal bulb with narrow basal foramen, ventral stalk broadened on apical $3 / 4$, curved ventrally at basal $1 / 3$, articulate process projected dorsally from right surface of basal bulb, dorsal apophysis bent inward at basal $1 / 5$, thickened on the middle part, curved and sharpened on dorsoapical part with small denticle at apical 2/5 and membrane on apical 2/5.

Female. Unknown.

Distribution Japan (Honshu, Kyushu see remarks).

Specimens examined. 3 males , Byobuyama, Tsugaru Peninsula, Aomori Pref., 6. viii. 1987 (S. Nomura); 2 males, Kusatsu, Gumma Pref., 11. vii. 1981 (Y. Hirano).

Remarks The nominotypical subspecies of Batriscenellus japonicus (Sharp) is characterized by the broad ventral stalk and the thickened and dorsally sharpened dorsal apophysis of the male genitalia. Sharp (1883) recorded this species from Honshu and Kyushu (Nagasaki), but the distribution of this species in Nagasaki is doubtful.

Biological notes. The habitat of this species is not exactly known, but three specimens ware caught by light trap in Tsugaru Peninsula, Aomori Pref.

\section{Batriscenellus japonicus vicarius Löbl}

(Figs. 116B, 118E,120C, D, 125A)

Batriscenellus japonicus vicarius Löbl, 1973, Ann. Zool., Warszawa, 30(9): 322.

Male. Length 2.2-2.3 $\mathrm{mm}$. Width $0.8 \mathrm{~mm}$.

Very similar to the nominate subspecies except for the following characters: Fourth abdominal segment (Fig. 116B) subparallel-sided, 6th larger than in subsp. japonicus, slightly shorter than 7th, with long and bold setae on posterior margin being short on median part. Male genitalia (Fig. 120C, D) similar to subsp. japonicus, but basal bulb expanded dorsally, with short articulate process, ventral stalk broad and flat, obtuse at apex.

Female. Length $2.2 \mathrm{~mm}$. Width $0.7 \mathrm{~mm}$. Head similar to male; eyes smaller than in male, each composed of about 25 facets; antennae moniliform, each segment ovoid, thicker than in male; elytra wider than long, narrowed anteriorly, humeri flat; legs slender, mid tibiae without mucro; abdomen as wide as elytra, 4th segment largest, subparallel-sided, without bold hairs, 5th to 6th short, simple, 6th slightly shorter than 5th, 7th large, 1.5 times as long as 6th on median part, 8th tergite transverse, arcuate on posterior margin, 8th stemite larger than 8th tergite, semicircular, weakly convex.

Female genitalia (Fig. 125A) well-sclerotized; 9th sternite complicate, fore lobe longer than wide, composed of a pair of longitudinal sclerites, with short basal processes divergent anteriorly, hind lobe broad, transverse and emarginate on both sides; genital plate small, T-shaped in ventral view.

Distribution. Japan (Tsushima Is.), North Korea.

Specimens examined. 2 males 1 female, Mt. Mitake, Kamijima, Tsushima Is. (S. Nomura); 1 male, 
Mt. Tatera, Shimojima, Tsushima Is. (S. Nomura).

Remarks. Batriscenellus japonicus vicarius Löbl is recorded from Japan for the first time and the female of this subspecies is firstly described in this study. This subspecies is separated from the nominotypical subspecies by the subparallel-sided fourth abdominal segment and the male genitalia with a dorsally expanded basal bulb.

Biological notes. This species is rarely extracted from the litter of the broad-leaved forest in Tsushima Is.

\section{Batriscenellus punctafus sp. nov.}

(Fig. 116C, 118F, 120E, F, 125B)

Male. Length $2.1 \mathrm{~mm}$. Width $0.7 \mathrm{~mm}$.

Body reddish brown, maxillary palpi and legs light brown, elongate.

Head slightly longer than wide, nearly pentagonal, subparallel-sided, densely with coarse punctures on dorsal surface, clypeus arcuate on anterior margin, frons weakly concave, with a bisinuate transverse sulcus, vertex weakly convex, with a pair of clear dorsal tentorial pits, postgenae short and rounded. Eyes large and ovoid, each composed of 25-30 facets. Antennae slender, reaching base of elytra, 1st segment thick, subcylindrical, 2nd narrower than 1st, longer than wide, ovoid, 3rd to 4th subequal to each other, each short and slightly longer than wide, weakly thickened distally, 5th to 6th subequal to each other, each slightly longer than 4th, ovoid, 7th feebly longer than 6th, longer than wide, 8th short, subglobose, 9th to 11th thick, 9th to 10 th subequal in length, 9th elongate, 10th wider than 9th, 11th largest, 1.4 times as long as wide, ovoid. Maxillary palpi short, 4th segment largest, 2.8 times as long as wide, fusiform.

Pronotum about as long as wide, round-sided and convex, coarsely punctate, with a long median longitudinal sulcus. Elytra slightly wider than long, weakly broadened posteriorly, convex and sparsely punctate, humeri expanded, each elytron with 2 dorsal foveae and 2 dorsal sulci, outer dorsal sulcus running from outer dorsal fovea to posterior $1 / 5$, being weakly incurved; hind wing developed. Legs elongate, thick in femora, fore trochanters short, each with 2 small denticles, mid tibiae slender, each with an acute mucro at apex.

Abdomen (Fig. 116C) narrowed posteriorly, 4th segment largest, weakly convex on dorsal surface, coarsely punctate, with a pair of short dorsomedian carinae on basal 1/5, a pair of angular tergostemal ridges on basal a half and with two groups of long hairs on both sides of the posterior margin, 5th short, with a pair of setiferous patch covered with the long hairs of 4th segment and a fringe consisting of long, bold setae at posteromedian part, 6th slightly longer than 5th, with a deep and transverse median concavity being very similar to japonicus, 7th large, slightly longer than 6th, 8th tergite (Fig. 118F)arrowed distally, arcuately emarginate on posterior margin, 8th sternite crescent, with a pair of weak longitudinal carinae and dense pubescence on outer sides of the carinae.

Male genitalia (Fig. 120E, F) with a dorsal apophysis on left side; paramere lamellar; basal bulb with large basal foramen and large articulate process, ventral stalk strongly bent ventrally and curved to left at the middle, broadened at apex, dorsal apophysis broadest near the middle, covered with membrane on apical $2 / 5$, being bent rightward at basal $2 / 5$ and turned to left at apical $1 / 4$, acute and curved 
dorsally at apex.

Female. Length 2.0-2.1 $\mathrm{mm}$. Width $0.7 \mathrm{~mm}$.

Similar to male except for the following characters: eyes smaller than in male, each composed of about 25 facets; elytra clearly wider than long, narrowed anteriorly, humeri flat; fore trochanters without denticle, mid tibiae without mucro; 4th abdominal segment subparallel-sided, 5th to 6th subequal in length, each short, simple, without excavation nor special seta, 7th clearly longer than 6th, 8th tergite transverse, arcuate on posterior margin 8th stemite semicircular.

Female genitalia (Fig. 125B) weakly sclerotized, 9th sternite slightly wider than long, fore lobe complicate, with a pair of sclerites each projected ventrally, hind lobe broad, transverse, emarginate on both sides; genital plate V-shaped, completely hided behind the hind lobe of 9th sternite in ventral view.

Distribution_ Japan (Honshu, Kyushu).

Holotype, male (Type No. 2823, Kyushu Univ.), Takiyama vall., Hiroshima Pref., 28. vi. 1987, S. Nomura leg. Paratypes: 5 males, Mt. Kurodake, Kuju, Oita Pref., 2. ix. 1982, R. Noda and S. Nomura leg; same locality as above, 29. iv. 1985, S. Nomura leg.; 1 male 2 females, Mt. Shiraiwa, Miyazaki Pref.,6. viii. 1978, H. Ohishi leg.

Remarks. Batriscenellus punctatus sp. nov. is very similar to B. japonicus (Sharp) in the structure of the sexual patch on the fifth to sixth abdominal segments, but is separated by the coarsely punctate pronotum. In addition, this new species is distinguished from the other species by the male genitalia with a strongly bent ventral stalk.

Biological notes. Several specimens were extracted from the litter of the temparate deciduous forest in high altitude of Kyushu. This species was found at the forest floor together with $\boldsymbol{B}$. kujumonta nus in Kuju Mountains, Oita Pref. One male was came up to the light trap at the riverside of Takiyama valley, Hiroshima Pref.

\section{Batriscenellus fallax (Sharp)}

(Fig. 116D, 119A, 121A, B, 125C)

Batrisus fallax Sharp, 1883, Trans. ent. Soc. London, 1883, p. 318.

Batrisocenus fallax Raffray, 1904, Ann. Soc. ent. Fr., 73: 218; 1908, Coleopt. Psel., Gen. ins., 64: 173; 1911, Psel., Coleopt. Cat., (27): 70.

Batriscenellus fallax. Jeannel, 1958, Mtm. Mus. Hist. nat., Paris, (A), 18: 63.

Male. Length $1.9-2.0 \mathrm{~mm}$. Width $0.7 \mathrm{~mm}$.

Body reddish brown, legs and maxillary palpi light brown, elongate.

Head longer than wide, weakly constricted inside eyes, clypeus arcuate on anterior margin, coarsely punctate, frons depressed at median part, with a transverse sulcus, coarsely punctate, vertex weakly convex, sparsely punctate, with an indistinct median longitudinal carina. Eyes ovoid and convex, each composed of 30 facets. Antennae short, reaching hind margin of pronotum, 1st segment short, thick, 2nd narrower than 1st, elongate, ovoid, 3rd to 4th subequal to each other, smaller than 2nd, weakly thickened distally, 5th to 7th subequal in length, 5th larger than 4th, thickened distally, 6th slightly narrower than 5th, ovoid, 7th as wide as 5th, ovoid, 8th short and ovoid, 9th to 11th thick, 9th to 10th subequal in length, 
each swollen externally, 10th wider than 9th, 11th largest, 1.5 times as long as wide, ovoid. Maxillary palpi short, 4th segment largest, 2.6 times as long as wide, fusiform.

Pronotum as long as wide, roundly expanded on both sides, sparsely, minutely punctate, with a long median longitudinal sulcus. Elytra wider than long, widest at posterior $2 / 5$, sparsely wi th minute punctatures, humeri expanded, each elytron with 2 dorsal foveae and 2 dorsal sulci, outer sulcus reaching posterior $1 / 6$, weakly incurved. Legs elongate, mid tibiae slender, each with a very short mucro at apex.

Abdomen (Fig. 116D) weakly narrowed posteriorly, 4th segment largest, weakly convex, coarsely, sparsely punctate, with a pair of short basidorsal carinae, a pair of angular tergostemal ridges and two groups of long and bold hairs on both posterolateral sides, 5th short, with a pair of setiferous patches on basilateral sides covered with the long hairs of 4th segment and a fringe at posteromedian part divided into two small fringes by a narrow median grabrous area, 6th twice as long as 5th with a large, deep, transverse median excavation on basal $2 / 3$ being arcuate on posterior margin, 7 th tergite about as long as 6 th, 7th sternite with a pair of longitudinal carinae, 8th tergite (Fig. 119A) wider than long, weakly convex, shallowly emarginate on posterior margin 8th sternite crescent, with a pair of longitudinal carinae and dense pubescence on outer sides of the carinae, 9th very short and transverse in external view.

Male genitalia (Fig. 121A, B) with a dorsal apophysis on left side; paramere; lamellar, basal bulb broad, with large basal foramen and large articulate process, ventral stalk elongate, simply narrowed toward apex, obliquely truncate at apex, dorsal apophysis elongate, widest at the middle, weakly curved to left in dorsal view.

Female. Length $1.9 \mathrm{~mm}$. Width $0.6 \mathrm{~mm}$.

Similar to male except for the following characters: elytra clearly wider than long, narrowed anteriorly, hind wing reduced; legs elongate, mid tibiae without mucro. Fourth abdominal segment subparallel-sided without bold hair, 5th to 6th subequal in length, each short and simple without fringe nor excavation, 7th slightly longer than 5th +6 th, 8 th tergite transverse, weakly convex and arcuate on posterior margin 8th sternite semicircular and weakly convex.

Female genitalia (Fig. 125C) slightly wider than long, 9th stemite composed of two lobes, fore lobe projected ventrally at posterior part, with a pair of anterior processes, hind lobe broad, transverse, with a pair of broad extention on both sides of the anterior part; genital plate wider than fore lobe, located behind the hind lobe of 9th stemite in ventral view, V-shaped.

Distribution. Japan (Hokkaido, Honshu).

Specimens examined. [Hokkaido] 1 male, Matsuyama, Mt. Taisetsu, Kamikawa, 18. vii. 1952, (H. Ishida); 1 male, Mt. Taisetsu, 17-23. vii. 1968 (H. Takizawa); 1 male, Niisho pass, Tokachi, 1. viii. 1986 (S. Nomura); 1 male, Hakodate, Oshima, 14. vii. 1986 (Y. Hirano). [Honshu] 1 male, Mt. Towada, Aomori Pref., 21. vii. 1980 (H. Takemoto); 1 male, Zenjin, Mt. Chokai, Akita Pref., 19-20. vi. 1980 (S. Naomi); 1 male, Kawarabo, Mt. Hayachine, Iwate Pref., 22-24. vi. 1980 (S. Naomi); 1 male, Nuruyu spa, Hanayama-mura, Miyagi Pref., 22-23. vi. 1983 (K. Morimoto); 3 males 4 females, Futakuchi vall., Miyagi Pref., 26-29. vii. 1989 (S. Nomura); 1 male, Mt. Asakusadake, Oku-Tadami, Fukushima Pref., 22. vii. 1987 (S. Nomura); 1 male, Daibosatsu, Yamanashi Pref., 22. iv. 1984 (H. Sato); 1 male, Kiyosato, Oizumimura, Yamanashi Pref., 19. vii. 1984 (S. Nomura); 1 male, Jigokudani, Mt. Yatsugatake, Yamanashi Pref., 8. vii. 1982 (S. Naomi); 1 male 2 females, Aokigahara, Mt. Fuji, Yamanashi Pref., 23. viii. 1984 (S. Nomura); Minobusan, Yamanashi Pref., 2. vi. 1978 (Y. Hirano); 1 male, same locality as above, 9. vi. 
1982 (Y. Hirano); 1 male, Shirakabako, Nagano Pref., 21-22. vii. 1974 (H. Takizawa).

Remarks. Batriscenellus fallax (Sharp) is very similar to the other species of the subgenus $\mathrm{Ba}$ triscenellus, but is distinguished from them by the fifth abdominal segment with fringe which is divided into two by a median glabrous area and the sixth segment with a large excavation in the male.

Biological notes. This species are often caught by light trap; usually it inhabits the litter of the deciduous forest. One male was discovered under bark of a dead tree in Mt. Asakusadake, Fukushima Pref.

\section{Batriscenellus kujumontanus sp. nov.}

(Fii. 116E, 119B, 121C, D, 125D)

Male. Length 2.0-2.1 mm. Width 0.7-0.8 mm.

Body reddish brown, maxillary palpi and tarsi light brown, elongate.

Head slightly longer than wide, nearly pentagonal, densely with coarse punctures on dorsal surface, clypeus arcuate on anterior margin, frons concave, with a transverse sulcus, vertex convex with a pair of clear dorsal tentorial pits and a weak longitudinal carina, postgenae short, rounded. Eyes large and ovoid, each composed of about 30 facets. Antennae slender, reaching base of elytra, 1st segment short and thick, expanded on outer side, 2nd narrower than 1st, elongate, thickened distally, 3rd to 4th subequal in length, each slightly longer than wide, ovoid, 5th to 7th subequal in length, each slightly longer than 4th, subcylindrical, weakly thickened distally, 8th shorter than 7th, slightly longer than wide, 9th to 11th thick, 9th to 10th subequal in length, 9th larger than 8th, elongate and ovoid, 10th thicker than 9th, 11th largest, 1.7 times as long as wide, ovoid. Maxillary palpi short, 4th segment largest, 2.8 times as long as wide, fusiiorm.

Pronotum as long as wide, round-sided, coarsely punctate on dorsal surface, with a long median longitudinal sulcus. Elytra slightly wider than long, widest at posterior 1/3, convex, sparsely punctate, humeri expanded, each elytron with 2 dorsal foveae and 2 dorsal sulci, outer sulcus reaching posterior 1/5, weakly incurved; hind wing developed. Legs elongate, fore trochanters short, each with a very small denticle on ventral side, mid tibiae slender, each with a mucro at apex.

Abdomen (Fig. 116E) weakly narrowed posteriorly, 4th abdominal segment largest, convex, sparsely punctate, with a pair of dorsomedian carinae on basal 1/4, a pair of tergosternal ridges on basal $2 / 5$ and two groups of long hairs on both sides of its posterior margin, 5th short, with a pair of setiferous patches on basilateral sides covered with the long hairs of 4th segment and a fringe consisting of long, bold setae on posteromedian part, 6th twice as long as 5th, with deep, transverse median excavation reaching basal $4 / 9$, posteromedian part behind the median excavation broad, weakly concave, 7 th tergite as long as 6th, weakly concave on basimedian part, 7th sternite with a pair of short carinae, 8th tergite (Fig. 119B) wider than long, emarginate on apical margin, 8th sternite crescent, with a pair of longitudinal carinae running in subparallel, densely pubescenton outer sides of the carinae, 9th sternite very small.

Male genitalia (Fig. 121C, D) with a dorsal apophysis on left side; paramere lamellar, folded into ventral side; basal bulb with large articulate process on dorsal side, ventral stalk elongate, weakly expanded to right at the middle, broadened and truncate at apex, dorsal apophysis broadest at apical 1/3 
on lateral view, suddenly curved to left on subapical part and sharpened toward apex, covered with membrane on apical part.

Female. Length 1.9-2.0 mm. Width $0.7 \mathrm{~mm}$.

Similar to male except for the follwing characters: eyes smaller than in male, each composed of 20 25 facets; elytra clearly wider than long, narrowed anteriorly, humeri flat; fore trochanters without denticle, mid tibiae without mucro; 4th abdominal segments wide as elytra, subparallel-sided, 5th short, without bold seta, 6th as long as 5th, very weakly concave on basimedian part, 7 th 1.5 times as long as 6 th, 8 th tergite semicircular.

Female genitalia (Fig. 125D) weakly sclerotized; 9th sternite narrowed anteriorly, fore lobe composed of a pair of elongate sclerites and membrane, each sclerite with a short anterior process, hind lobe broad, strongly sclerotized on posterior part, genital plate small and T-shaped, just located behind the anterior processes of 9 th stemite in ventral view.

Distribution Japan (Honshu, Kyushu).

Holotype, male (Type No. 2824, Kyushu Univ.), Mt. Kurodake, Kuju, Oita Pref., 2. ix. 1982, R. Noda and S. Nomura leg. Paratypes: 58 males 141 females, same data as holotype; 20 males 43 females, same locality as holotype, 15. ix. 1985, S. Nomura leg.; 1 male 4 females, same locality as holotype, 29. iv. 1985, S. Nomura leg.; 1 male 1 female, Ura-Hikimi vall., Shimane Pref., 6. vi. 1988, S. Nomura leg.; 1 male, Nakatsuya vall., Yoshiwa-mura, Hiroshima Pref., 8. vi. 1987, S. Nomura leg.; 1 male, Mt. Kanayama, Fukuoka City, Fukuoka Pref., 27. iii. 1983, S. Nomura leg.; 3 males, Mt. Kyogatake, Kashima City, Saga Pref., 19. x. 1986, S. Nomura leg.; 1 female, same locality as above, 24. iv. 1987, S. Nomura leg.; 1 male 2 females, Daisen-rindo, Kuju, Oita Pref., 12.x. 1982, S. Nomura leg.; Mt. Sobosan, Oita Pref., 4. v. 1984, S. Nomura leg.; 3 mates 4 females, same locality as above, 17. v. 1986, S. Nomura leg.; 1 male, Mt. Shiratori, Kumamoto Pref., 27. v. 1978, T. Ogata leg.; 1 male, same locality as above, 21. v. 1985, K. Konishi leg.; 2 males 2 females, Mt. Koshikidake, Kirishima, Miyazaki Pref., 7. v. 1985, S. Nomura leg.

Remarks. Batrisceoellus kujumontanus sp. nov. is closely allied to B. punctatus sp. nov., but is different from the latter by the large sixth abdominal segment which is concave behind the median excavation in the male and by the T-shaped genital plate in the female.

Biological notes. This species commonly inhabits the litter of the broad-leaved forest; about 200 specimens was collected at one time from dead branches fallen on the forest floor in Kuju Mountains.

\section{Batriscenellus omogensis sp. nov.}

(Figs. 116F, 119C, 121E, F)

Male. Length $2.3 \mathrm{~mm}$. Width $0.8 \mathrm{~mm}$.

Body reddish brown, tarsi and maxillary palpi light brown, elongate.

Head longer than wide, subparallel-sided, densely with coarse punctures on dorsal surface, clypeus arcuate on anterior margin, frons concave, with a transverse surcus, vertex weakly convex, with a pair of dorsal tentorial pits and a weak median longitudinal carina, postgenae short and flat. Eyes large, convex, each composed of about 30 facets. Antennae elongate, reaching base of elytra, 1st segment short and thick, weakly expanded on outer side, 2nd elongate and thickened distally, 3rd smaller than 2nd, weakly thickened distally, 4th slightly smaller than 3rd, 5th slightly longer than 3rd, elongate, 6th smaller than 
5th, 7th subequal to 5th, 8th short, slightly longer than wide, 9th to 11th thick, 9th longer than wide, ovoid, 10th wider than 9th, subglobose, 11th largest, 1.6 times as long as wide, ovoid. Maxillary palpi short, 4th segment largest, 2.5 times as long as wide, fusiiorm.

Pronotum slightly longer than wide, round-sided and convex, densely with coarse punctures, with a very weak median longitudinal sulcus. Elytra slightlywider than long, almost rectangular, sparsely punctate, humeri expanded, each elytron with 2 dorsal foveae and 2 dorsal sulci, outer dorsal sulcus reaching posterior 1/5, weakly incurved, hind wing developed. Legs elongate, mid tibiae slender, each with an acute mucro at apex.

Abdomen (Fig. 116F) weakly narrowed posteriorly, 4th segment largest, with a pair of very short dorsomedian carinae, a pair of tergosternal ridges on basal 2/5 and two groups of long setae on posterolateral margin, 5th short, with a pair of setiferous patches on both basilateral sides covered with the long hairs of 4th segments, and a transverse fringe consisting of long and bold setae at posteromedian part, 6th 1.2 times as long as 5th with deep and transverse median excavation on basal $5 / 9,7$ th tergite slightly shorter than 6 th, 7th sternite with a pair of short carinae being divergent posteriorly, 8th tergite (Fig. 119C) wider than long, shallowly emarginate on apical margin 8th sternite crescent, with a pair of longitudinal carinae and dense pubescence on outer side of the carinae.

Male genitalia (Fig. 121E, F) very similar to kujumontanus, but ventral stalk of basal bulb shorter than in kujumontanus.

Female. Unknown.

Distribution. Japan (Shikoku).

Holotype, male, Omogo vall., Ehime Pref., 12. viii. 1980, C. Besuchet leg. The holotype is deposited in Museum d'Histoire Naturelle, Gentve.

Remarks. Batriscenellus omogensis sp. nov. is closely allied to B.kujumontanus sp. nov. in structure of the male genitalia. But is separated from the latter by the weak longitudinal sulcus of the pronoturn and the sixth abdominal segment which is weakly convex on its posteromedian part (concave in

kujumontanus).

\section{Batriscenellus fragilis (Sharp)}

(Figs. 117A, 119B, 122A, B)

Batrisus fragilis Sharp, 1883, Trans, ent. Soc. London, 1883:p. 317.

Batrisocenus fragilis. Raffray, 1904, Arm. Soc. ent. Fr., 73: 218; 1908, Coleopt. Psel., Gen. ins., 64: 173; 1911, Psel., Coleopt. Cat., (27): 70.

Batriscenellus fragilis. Jeannel, 1958, Mém. Mus. Hist. nat., Paris, (A), 18: 63.

Male. Length 2.0-2.1 mm. Width $0.7 \mathrm{~mm}$.

Body reddish brown and shiny, maxillary palpi and tarsi light brown, elongate.

Head longer than wide, subparallel-sided, clypeus arcuate on anterior margin, coarsely punctate, frons depressed at median part, coarsely punctate, with a transverse sulcus, vertex weakly convex, sparsely punctate, postgenae large, almost flat. Eyes large and ovoid, strongly convex, each composed of about 35 facets. Antennae slender, reaching base of elytra, 1st segment thick and weakly swollen externally, 
2nd narrower than 1st, elongate, 3rd to 4th subequal to each other, each smaller than 3nd, short and weakly thickened distally, 5th longer than 4th, elongate, 6th slightly smaller than 5th, 7th as long as 5th, 8th short, slightly longer than wide, 9th to 10th subequal at length, 9th ovoid, 10th wider than 9th, swollen ventrally, 11th largest, 1.8 times as long as wide, ovoid. Maxillary palpi short, 4th segment largest, 2.8 times as long as wide, fusiform.

Pronotum as long as wide, round-sided, sparsely with minute punctures and with a long median longitudinal sulcus. Elytra slightly wider than long, nearly trapezoid and convex, sparsely punctate, humeri expanded, each elytron with 2 dorsal foveae and 2 dorsal sulci, outer sulcus reaching posterior $1 / 4$, subparallel to sutural line; hind wings developed. Legs elongate, mid tibiae slender, each with an acute mucro at apex.

Abdomen (Fig. 117A) weakly narrowed posteriorly, 4th segment largest, weakly convex, sparsely punctate, with a pair of basidorsal carinae on basal $1 / 4$, a pair of indistinct tergosternal ridges on both sides, and some long and bold hairs on posterolateral margin, 5th short and broadly extended posteriorly at posteromedian part, with a fringe consisting of bold setae and a pair of setiferous patches covered with the long hairs of 4th segment, 6th 1.5 times as long as 5th on median part, with transverse and very short excavation on basal $1 / 4,7$ th tergite slightly longer than 6 th, depressed on basimedian part as in kujumontanus, 7th sternite with a pair of short longitudinal carinae, 8th tergite (Fig. 119D) wider than long, shallowly emargiuate on posterior margin, 8th sternite crescent, with a pair of longitudinal carinae running in subparallel, 9th stemite very small and transverse in external view.

Mate genitalia (Fig. 122A, B) with a dorsal apophysis on left side; paramere lamellar, folded ventrally; basal bulb with a large artisulate process, ventral stalk elongate, broadest at apical 1/3, then sharpened toward apex, dorsal apophysis very long, slender, weakly bent ventrally, bifurcate at apex.

Female. Unknown.

Distribution. Japan (Honshu).

Specimens examined. 2 males, Fujishima, Yamagata pref., 20. vi. 1955 (H. Hasegawa); 1 male, Odawara, Kanagawa Pref., 22. vi. 1985 (Y. Hirano); 1 male, same locality as above, 31. v. 1986 (Y. Hirano).

Remarks. Batriscenellus fragilis (Sharp) is closely allied to B. kujumontanus sp. nov. in the seventh abdominal tergite with a weak depression, but this species is easily distinguished from the others by the sixth abdominal segment with a narrow excavation and the male genitalia with a long and slender dorsal apophysis.

\section{Batriscenellus nodulifer sp. nov.}

(Fig. 117B, 119E, 122C)

Male. Length $2.2 \mathrm{~mm}$. Width $0.8 \mathrm{~mm}$.

Body reddish brown, tarsi and maxillary palpi light brown, elongate.

Head longer than wide, nearly pentagonal, densely with coarse punctures on dorsal surface, clypeus arcuate on anterior margin, frons depressed at median part, with a bisinuate transverse sulcus, vertex convex, with a pair of dorsal tentorial pits and a weak median longitudinal carina. Eyes ovoid and convex, each composed of about 30 facets. Antennae slender, 1st segment thick, weakly swollen on the 
outer side, 2nd narrower than 1st, elongate, weakly thickened distally, 3rd to 4th subequal in length, each longer than wide, thickened distally, 5th to 7th elongate and thickened distally, 5th longer than 4th, 6th shorter than 5th, 7th slightly longer than 6th, 8th clearly shorter than 7th, longer than wide, ovoid, 9th to 11th thick, 9th to 11th subequal in length, 9th elongate, 10th thicker than 9th, swollen on outer side, 11th largest, 1.8 times as long as wide, ovoid. Maxillary palpi short, 4th segment largest, 2.7 times as long as wide, fusiiorm.

Pronotum as long as wide, round-sided and convex, densely with coarse punctures, with a long median longitudinal sulcus. Elytra wider than long, convex and weakly broadened posteriorly, sparsely with minute punctures, humeri weakly expanded, each elytron with 2 dorsal foveae and 2 dorsal sulci, outer sulcus reaching posterior 1/5, very weakly incurved. Legs elongate, mid tibiae slender, each with an acute mucro at apex

Abdomen (Fig. 117B) narrowed posteriorly, 4th segment largest, convex and sparsely punctate, with a pair of basidorsal longitudinal carinae on basal $1 / 3$, and a pair of angular tergosternal ridges on basal a half, 5th short, with a pair of setiferous patches on both sides and a fringe consisting of irregular bold setae on posteromedian part, 6th 1.5 times as long as 5 th, with deep, indistinctly demarcated excavation on basimedian part and trapezoid nodule just behind the excavation, 7th about as long as 6th, 8th tergite (Fig. 119E) wider than long, shallowly emarginate on apical margin 8th sternite semicircular, flattened at median part, 9th stemite very small, transverse in external view.

Male genitalia (122C) with a dorsal apophysis on left side; paramere lamellar, folded ventrally; basal bulb broad, with large basal foramen and slender ventral stalk sharpened distally, dorsal apophysis curved to left and hook-shaped at apical part in dorsal view.

Female. Unknown.

Distribution Japan (Kyushu).

Holotype, male (Type No. 2825, Kyushu Univ.), Mt. Kurodake, Kuju, Oita Pref., 2. ix. 1982, S. Nomura leg.

Remarks. Batriscenellus nodulifer sp. nov. is similar to $\boldsymbol{B}$. japonicus and allied species, but differs from them by the sixth abdominal segment with a trapezoid nodule and the eighth stemite without longitudinal carina.

Biological notes. The holotype was caught from the dead branch together with many B.kujumontanus.

\section{Subgenus Nipponoscenellus nov.}

Type species: Batriscenellus transformis sp. nov.

This subgenus is similar to the nominate subgenus, but is separated by the following features: Abdomen with moderately pubescent 5th segment, 6th segment very widely excavated on basal part with a trichome at the basal part and a trapezoid nodule at the posterior part of the excavation, and with a pair of setiferous patches on both basilateral sides of the tergite; male genitalia almost same in structure to subgenus Batriscenellus, but basal bulb with short and indistinct articulate process, dorsal apophysis smaller than in the nominate subgenus; female genitalia composed of 9th sternite divided into 2 lobes 
and a genital plate, fore lobe of 9th sternite broad, membranous on the middle part, with a sclerotized nodule at the anteromedian part, genital plate completely hinded behind the hind lobe of 9th stemite in ventral view.

This new subgenus consists of a new species, B. transformis.

\section{Batriscenellns transformis sp. nov. (Figs. 117C, 119F, 122E, F, 125E)}

Male. Length 2.0-2.2 mm. Width 0.7-0.8 mm.

Body reddish brown, legs and maxillary palpi light brown, elongate.

Head longer than wide, widest between base of antenna and eyes, clypeus arcuate on anterior margin, densely punctate and pubescent, frons depressed at median part, coarsely punctate, with a bisinuate transverse sulcus, vertex weakly convex and sparsely punctate, with a indistinct longitudinal carina, postgenae broad and almost flat. Eyes ovoid, convex, each composed of about 25 facets. Antennae slender, reaching hind margin of pronotum, 1st thick, subcylindrical, weakly expanded externally, 2nd narrower than 1st, elongate, 3rd, 5th and 7th subequal to each other, each elongate, weakly thickened distally, 4th, 6th and 8th subequal in length, each shorter than 3rd, weakly swollen distally, 9th to 10th subequal in length, thick, each ovoid and swollen ventrally, 10th wider than 9th, 11th largest, 1.7 times as long as wide, ovoid. Maxillary palpi short, 4th segment largest, 2.2 times as long as wide.

Pronotum slightly longer than wide, round-sided, sparsely with minute punctures, with a long median longitudinal sulcus. Elytra wider than long, widest at posterior 1/4, convex, sparsely punctate, humeri weakly expanded, each elytron with 2 dorsal foveae and 2 dorsal sulci, outer dorsal sulcus reaching posterior 1/5, weakly incurved. Legs elongate, mid tibiae slender, each with a short mucro at apex.

Abdomen (Fig. 117C) rounded posteriorly, 4th abdominal segment subparallel-sided and convex, sparsely punctate, with a pair of basidorsal carinae on basal $1 / 3$ and a pair of angular tergosternal ridges on basal a half, 5th segment very short, with a fringe composed of long and bold hairs at posteromedian part, 6th large, 2.5 as long as 5th with very broad transverse excavation in its anterior $4 / 5$ indistinctly demarcated in posterior margin, small trapezoid nodule at posteromedian part of the excavation and a pair of setiferous patches on both sides of the excavation, 7th as long as 6th, 8th tergite (Fig. 119F) wider than long, shallowly emarginate on posterior margin, 8th crescent, flattened at the middle part.

Male genitalia $(122 \mathrm{E}, \mathrm{F})$ with a dorsal apophysis on left side; paramere lamellar, folded ventrally; basal bulb with small articulate process, ventral stalk elongate, simply sharpened toward apex, weakly sinuate in apical part, dorsal apophysis nearly straight in dorsal view, its apex close to the apex of ventral stalk, acute and weakly curved dorsally.

Female. Length 1.9-2.2 mm. Width $0.7 \mathrm{~mm}$.

Similar to male except for the followings: eyes smaller than in male, each composed of about 20 facets; elytra shorter than in male, round-sided; hind wing reduced; abdomen slightly longer than in male, 5th to 6th segments subequal in length, each short, simple, 7th large, as long as 5th +6 th, 8th tergite transverse and strongly convex on the middle part, 8th sternite semicircular and convex.

Female genitalia (Fig. 125E) strongly sclerotized, wider than long in ventral view, 9th stemite covered with membrane on anterior part, fore lobe small, with a median nodule and a pair of curled scier- 
ites extending anteriorly and ventrally, hind lobe transverse, weakly constricted on both sides, with a pair of anterior extentions.

\section{Distribution. Japan (Honshu).}

Holotype, male (Type No. 2826, Kyushu Univ.), Futakuchi vall., Miyagi Pref., 26-29. vii. 1989, S. Nomura leg. Paratypes: 8 males 28 females, same data as holotype; 1 male, Tsuta spa, Towada City Aomori Pref., 6. viii. 1987, S. Nomura leg.; 2 males, Tokura, Katashina-mura, Gumma Pref., 22. vii. 1954, A. Habu leg.; 1 male, Kaminikkawa pass, Mt. Daibosatsu, Yamanashi Pref., 15-18. vii. 1982, S. Naomi leg.; 1 male, Mt. Daibosatsu, Yamanashi Pref., 21. v. 1960, Y. Shibata leg.; 1 male, Omonoki pass, Inatake-machi, Aichi Pref., 10. x. 1980, N. Kanie leg.; 1 male, Mt. Kongo, Osaka Pref., 7. viii. 1936, M. Azuma leg.

Remarks. Batriscenellus transformis sp. nov. is easily distinguished from the other species of this genus by the sixth abdominal segment with a large excavation and a pair of setiferous patches in the male. The female of this species is separated from the others by the broad fore lobe of the ninth sternite with an anteromedian nodule and the concealed genital plate behind the hind lobe of the ninth sternite in ventral view.

Biological notes. This species is an inhabitant of the litter of the deciduous forest floor; it was found together with Batyriscenellus fallax, Batrisoplisus tenuiformis and Batrisceniola dissimilis.

\section{Subgenus Scaioscenellus Jeannel}

Scaioscenellus Jeannel, 1958, Mtm. Mus. Hist. nat. Paris, (A), 18: 61. Type species: Batrisus similis Sharp, by monotypy.

The subgenus Scaioscenellus is separated from the nominate subgenus by the "non inverse" male genitalia and the very short fifth abdominal segment in the median part after the original desciption by Jeannel(1958). But these characters are not adequate as already shown in remarks of the nominotypical subgenus. This subgenus is well-defined by the following two characters: The metasternum is with a pair of setiferous patches composed of the bold setae between the hind coxae, and the fifth to sixth abdominal segments covered with some secretory setae in the male. This subgenus is containing the following seven species: $\boldsymbol{B}$. similis (Sharp), B. shiranui sp. nov., B. ohishii sp. nov., B. insulicola sp. nov., B. orientalis (Löbl), B. pilosellus sp. nov. and B. sakaï sp. nov.

\section{A Key to the Species of the Subgenus Scaioscenellus from Japan}

1. Fifth to 6th abdominal segments with a transverse excavation . .2

- Fifth to 6 th abdominal segments without excavation ..................................................................................

2. Head and pronotum sparsely punctate; 5 th abdominal segment depressed at median part similis (Sharp)

- Head and pronotum densely with coarse punctures; 5th abdominal segment with secretory setae on dorsal surface shiranui sp. nov. 
3. Fiih to 6th abdominal segments extremely short, each with secretory setae in one or two lines .......4

- Fiith to 6 th abdominal segments large, each with many secretory setae on dorsal surface $\ldots \ldots \ldots \ldots \ldots 6$

4. Body small $(1.7 \mathrm{~mm})$, head sparsely punctate; male genitalia with a T-shaped ventral stalk $\ldots \ldots \ldots \ldots \ldots$.

orientalis Löbl

- Body large (1.8-2.0 mm), head coarsely punctate $\ldots . .5$

5. Fore femur swollen posteriorly on apical $1 / 3$ in male, mid tibia with a very short mucro in male; male genitalia with a strongly bent and simply sharpened dorsal apophysis ...........insulicola sp. nov.

- Fore femur simple, mid tibia with long and acute mucro; male genitalia with a bifurcate dorsal apophysis on ohishisisp. nov.

6. Sixth abdominal segment longer than 5th in male; dorsal apophysis of male genitalia with a short spine on the left side near apex piloselllus sp. nov.

- Sixth abdominal segment shorter than 5th in male; dorsal apophysis of male genitalia C-shaped in dorsal view and without spine skaiai sp. nov.

\section{Batriscenellus similis (Sharp)}

(Figs. 117D, 123A, B, 126A)

Batrisus similis Sharp, 1883, Trans. ent. Soc. London, 1883, p. 319.

Batrisocenus similis. Raffray, 1904, Arm. Soc. ent. Fr., 73: 218; 1908, Coleopt. Psel., Gen. ins., 64: 173; 1911, Psel., Coleopt. Cat., (27): 70.

Batriscenellus similis. Jeannel, 1958, Mtm. Mus. Hit. nat., Paris, (A), 18: 61.

Male. Length 2.0-2.3 mm. Width $0.8 \mathrm{~mm}$.

Body reddish brown, tarsi and maxillary palpi light brown, elongate.

Head longer than wide, subparallel-sided, clypeus short, arcuate on anterior margin, frons concave and sparsely punctate, with a clear transverse sulcus being almost horizontal, vertex weakly convex, sparsely punctate, with a pair of dorsal tentorial pits and a median longitudinal carina, postgenae flat. Eyes ovoid, convex, each composed of about 25 facets. Antennae elongate, reaching base of elytra, 1st segment thick, expanded and with a large conical trichome on external side, 2nd elongate, a half as wide as 1 st, 3 rd to 5 th subequal to each other, each slightly narrower than 2nd, feebly longer than wide, subcylindrical, 6th slightly narrower than 5th, 7th larger than 6th, elongate, 8th shortest, about as long as wide, 9th to 10th thick, subequal in length, each weakly swollen internally and ovoid, 10th wider than 9th, 11th largest, 1.7 times as long as wide, ovoid. Maxillary palpi short, 4th largest, about 3 times as long as wide, fusiform.

Pronotum slightly longer than wide, round-sided, sparsely with minute punctures, with a weak longitudinal sulcus. Elytra slightly wider than long, widest at posterior $1 / 3$, sparsely punctate, humeri expanded, each elytron with 2 dorsal foveae and 2 dorsal sulci, outer sulcus short, reaching posterior $1 / 3$, weakly incurved; hind wing developed. Metasternum with a pair of setiferous patches between hind coxae. Legs elongate, mid tibiae slender, each with a short mucro at apex.

Abdomen (Fig. 117D) weakly narrowed posteriorly, 4th segment largest, slightly convex and sparsely punctate, with a pair of short, basidorsal carinae on basal $1 / 5$ and a pair of angular tergosternal ridges 
on basal $1 / 4$, 5th short, depressed and invisible on median part in dorsal view, with a pair of median setae, 6th about 1.5 times as long as 5 th, with a transverse excavation on basal 1/2 connecting the depression of 5th, and with a short median trichome at posterior part of the excavation, 7th large, 1.3 times as long as 6th in median part, 8th tergite wider than long, shallowly emarginate on posterior margin, 8th sternite crescent, flattened at the middle part.

Male genitalia (Fig. 123A, B) with a dorsal apophysis on left side; basal bulb broad, with a short basal strut, ventral stalk short and slender, narrowed posteriorly and weakly curved to right, dorsal apophysis very long, curled up into right side of basal bulb in basal part, sharpened and curved to left in apical part.

Female. Length 1.9-2.2 mm. Width $0.7 \mathrm{~mm}$.

Similar to male except for the following characters: eyes smaller than in mate, each composed of 20-25 facets; elytra clearly wider than long, narrowed anteriorly; metastemum simple, without setiferous patch; mid tibiae slender, without mucro; 5th to 6th abdominal segments simple, 8th tergite transverse, convex and arcuate on posterior margin, 8 th sternite semicircular and weakly convex.

Female genitalia (Fig. 126A) composed of 9th sternite and genital plate, 9th sternite broadened in the posterior part, fore lobe membranous on the median part, with a pair of triangular sclerite each narrowed anteriorly, hind lobe transverse, arcuate on posterior margin, constricted on both sides, with a pair of lateral extentions on both anbterolateral sides.

Distribution. Japan (Honshu).

Specimens examined. 10 males 3 females, Arakawa, Sanpoku-machi, Niiata Pref., 5. vii. 1985 (S. Nomura); 1 male 1 female, Gatsugi, Sanpoku-machi, Niigata Pref., 2. vii. 1985 (S. Nomura); 2 males, Nikko, Tochigi Pref., 20. v. 1978 (Y. Hirano); 1 male, Mt. Kumakura, Saitama Pref., 15. x. 1974 (T. Nagashima); 1 male, Mt. Takao, Tokyo Pref., 16. ix. 1960 (Y. Shibata); 1 male, Mt. Oyama, Tanzawa, Kanagawa Pref., 28. v. 1978 (Y. Hirano); 2 males, same locality as above, 15. ix. 1981 (Y. Hirano); 5 males 6 females, Monomi pass, Tanzawa, Kanagawa Pref., 5. viii. 1978 (M. Tao); 5 males 2 females, same locality as above, 15. ix. 1978 (M. Tao); 1 male, Hatajuku, Hakone, Kanagawa Pref., 2. vii. 1983 (Y. Hirano); 1 male, Yamanaka, Yamanashi Pref., 22. vii. 1978 (Y. Hirano); 7 males 22 females, Aokigahara, Mt. Fuji, Yamanashi Pref., 23. vii. 1982 (S. Naomi); 4 females, same locality as above, 23. vii. 1984 (S. Nomura).

Remarks. Batriscenellus similis (Sharp) is similar to the subgenus Batriscenellus in the excavation on the sixth abdominal segment, but is separated from the other species by the metastemum with a pair of setiferous patches and the fifth abdominal segment depressed at the median part in the male.

Biological notes. This species inhabits the litter of the broad-leaved forest.

\section{Batriscenellus shiranui sp. nov.} (Fig. 117E)

Male. Length $2.3 \mathrm{~mm}$. Width $0.8 \mathrm{~mm}$.

Body reddish brown, tarsi and maxillary parpi light brown, elongate.

Head longer than wide, subparallel-sided, densely with coarse punctures on dorsal surface, clypeus short and arcuate on anterior margin, frons weakly concave, with a transverse sulcus being almost hori- 
zontal, vertex weakly convex, with a pair of dorsal tentorial pits and a clear median longitudinal carina, postgenae almost flat. Eyes ovoid and convex, each composed of about 25 facets. Antennae and maxillary palpi in same structure as similis.

Pronotum about as long as wide, round-sided and sparsely punctate, with a clear longitudinal sulcus. Elytra slightly wider than long, widest at posterior $1 / 3$, convex and sparsely punctate, humeri expanded and weakly denticulate, each elytron with 2 dorsal foveae and 2 dorsal sulci, outer dorsal sulcus reaching posterior $1 / 4$, weakly incurved, hind wing developed; metasternum with a pair of setiferous patches between hind coxae. Legs elongate, mid tibiae slender, each with an acute mucro at apex.

Abdomen (Fig. 117E) weakly narrowed posteriorly, 4th segment largest, weakly convex and sparsely punctate, with a pair of short basidorsal carinae and a pair of tergosternal ridges on basal $1 / 3,5$ th weakly projected and with a pair of bold setae at the middle, slightly depressed around the median projection, with some secretory setae on both dorsal sides, 6th 1.5 times as long as 5th in median part, with a deep transverse basimedian excavation on basal a half and a pair of setiferous patches on both sides of the excavation, 7th large, 1.7 times as long as 6th, weakly convex, 8th tergite transverse, shallowly emarginate on posteromedian margin, 8th sternite short and transverse, arcuately emarginate on posterior margin.

Female. Unknown.

Distribution. Japan (Kyushu: Amakusa)

Holotype, male (Type No. 2827, Kyushu Univ.), Amakusa-Shimojima Is., Kumamoto Pref., 7. viii. 1977, H. Ohishi leg.

Remarks. Batriscenellus shiranui sp. nov. is closely allied to B. similis (Sharp), but is different from the latter by the coarsely and densely punctate head and the fifth abdominal segment with secretory setae on the all dorsal surface. The male genitalia of this species could not examined.

\section{Batriscenellus ohishii sp. nov.}

(Figs. 123E, F, 126B)

Male. Length 1.9-2.0 mm. Width 0.7-0.8 mm.

Body reddish brown and shiny, tarsi and maxillary palpi light brown, elongate.

Head slightly longer than wide, subparallel-sided, clypeus short and arcuate on anterior margin, frons weakly concave and coarsely punctate, with an almost horizontal transverse sulcus, vertex weakly convex and sparsely punctate, with a pair of dorsal tentorial pits and a median longitudinal carina, postgenae almost flat. Eyes ovoid and convex, each composed of about 30 facets. Antennae elongate, reaching base of elytra, 1st segment thick, short, 2nd narrower than 1st, elongate and ovoid, 3rd to 4th subequal to each other, each ovoid, 5th slightly larger than 4th, ovoid, 6th as long as 4th, 7th slightly longer than 5th, 8th short, slightly longer than wide, 9th to 10th thick, each ovoid, weakly swollen internally, 10th slightly wider than 9 th, 11th largest, 1.6 times as long as wide, ovoid. Maxillary palpi short, 4th segment largest, 2.3 times as long as wide, fusiform.

Pronotum as long as wide, round-sided and sparsely punctate, with a shallow median longitudinal sulcus. Elytra wider than long, nearly trapezoid, convex and sparsely punctate, humeri weakly expanded and denticulate, each elytron with 2 dorsal foveae and 2 dorsal sulci, outer sulcus reaching posterior $1 / 5$, 
weakly incurved. Legs elongate, mid tibiae slender, with a long and acute mucro at apex.

Abdomen subparallel-sided, 4th segment largest, weakly convex and sparsely punctate on dorsal surface, with a pair of very short basidorsal carinae and a pair of tergosternal ridges on basal $1 / 4,5$ th extremely short with some setae in one or two lines, 6th as long as 5th being same in structure as 5 th, 7th large, 2.5 times as long as 5 th +6 th, 8 th tergite deflected into ventral side, wider than long, arcuately emarginate on posteromedian margin, 8th stemite crescent, 9 th very small.

Male genitalia (Fig. 123E, F) with a dorsal apophysis on left side; paramere very small and lamellar; basal bulb broad and bulbous, ventral stalk thick at base, weakly sinuate and sharpened distally, dorsal apophysis long and thick being curled up rightward, rectangularly curved on basal $1 / 4$, bifurcate and acute at apex.

Female. Length $1.9-2.0 \mathrm{~mm}$. Width $0.7 \mathrm{~mm}$.

Similar to male except for the following features: eyes smaller than in male, each composed of 25 30 facets; elytra wider than long, narrowed anteriorly, humeri weakly rounded; mid tibiae without mucro, 5 th to 6th segment short, each slightly longer than in male, without secretory setae, 7th large, about twice as long as 5 th +6 th, 8 th tergite transverse and convex, arcuate on posterior margin, 8th sternite semicircular and weakly convex.

Female genitalia (Fig. 126B) weakly sclerotized, 9th sternite divided into 2 lobes, fore lobe membranous on median part, with a pair of quadrangular sclerites, hind lobe transverse, arcuate on posterior margin, broadly extended on anteromedian part, narrowly extended on both anterolateral sides.

Distribution. Japan (Kyushu).

Holotype, male (Type No. 2828, Kyushu Univ.), Tsubakiyama, Hamatama-cho, Saga Pref., 19. ix. 1976, H. Ohishi leg. Paratypes: 2 males 3 females, Shin-Yabakei, Yamaguni-machi, Oita Pref., 30. iii. 1985, S. Nomura leg.; 1 male, Mt. Kurodake, Kuju, Oita Pref., 3. ix. 1982, R. Noda leg.; 1 male 3 females, same locarity as above, 28. v. 1986, S. Nomura leg.; 2 males 1 female, Mt. Hijidake, Kuju, Oita Pref., 25. x. 1981, S. Sasaki leg.; 1 male, Mt. Sobosan, Oita Pref., 4. v. 1984, S. Nomura leg.

Remarks. Batriscenellus ohishii sp. nov. unites with $\boldsymbol{B}$. orientalis Löbl and $\boldsymbol{B}$. insulicola sp. nov. to form a species group characterized by the extremely short fifth and sixth segments each having some secretory setae in one or two lines in the male. But this new species is different from them by the mid tibia with a long and acute mucro and the male genitalia with a bifurcate dorsal apophysis in the male, by the fore lobe of ninth sternite with a pair of quadrangular sclerites in the female.

Biological notes. This species inhabits the litter of the natural forest floor.

Batriscenellus insulicalasp. nov.

(Figs. 118A, 123C, D)

Male. Length 1.8-1.9 mm. Width $0.7 \mathrm{~mm}$.

Body reddish brown, tarsi and maxillary palpi light brown, elongate.

Head longer than wide, widest at base of antennae, clypeus short and arcuate on anterior margin, frons weakly concave and coarsely punctate, with a clear transverse sulcus, vertex weakly convex and sparsely punctate, with a pair of dorsal tentorial pits and a median longitudinal carina, postgenae flat. Eyes ovoid and convex, each composed of 25-30 facets. Antennae slender, reaching base of elytra, 1st 
segment thick, swollen distally, 2nd narrower than 1st, elongate, 3rd to 4th subequal in length, each subcylindrical, 5th longer than 4th, elongate, 6th smaller than 5th, 7th as long as 5th, 8th slightly longer than wide, short, 9th to 10th subequal in length, 10th wider than 9th, 11th largest, twice as long as wide. Maxillary palpi elongate, 4th segment largest, 3.5 times as long as wide, elon gate and fusiform.

Pronotum about as long as wide, thick and roundly expanded laterally on anterior part, widest at the middle, then weakly narrowed posteriorly, sparsely with minute punctures, and with a shallow median longitudinal sulcus. Elytra wider than long, convex and sparsely punctate, humeri weakly expanded and denticulate, each elytron with 2 dorsal foveae and 2 dorsal sulci, outer dorsal sulcus running from outer fovea to posterior $1 / 4$, weakly incurved. Legs elongate, fore femora weakly expanded posteriorly in apical 1/3, mid tibiae slender, each with a very short mucro at apex.

Abdomen (Fig. 118A) subparallel-sided and nearly truncate in dorsal view, 4th segment predominantly large, with a pair of short, basidorsal carinae and a pair of angular tergosternal ridges on basal $1 / 3$, 5th extremely short, with some secretory setae in one or two lines, on all dorsal surface, 6th as long as 5 th being same in structure as 5 th, 7 th large, 2.2 times as long as 5 th +6 th, 8 th tergite wider than long, shallowly emarginate on posterior margin, 8th sternite crescent, 9th very small and transverse in external view.

Male genitalia (Fig. 123C, D) with a dorsal apophysis on left side; paramere small and lamellar; basal bulb broad and bulbous, ventral stalk short and slender, simply sharpened distally, dorsal apophysis very thick, curled up rightward in basal part, weakly curved ventrally, suddenly bent to left at apical 1/3, sharpened and crossed with ventral stalk at apex.

\section{Female. Unknown.}

Distribution Japan (Okinoerabu Is.).

Holotype, male (Type No. 2829, Kyushu Univ.), Sumiyoshi, Okinoerabu Is., Kagoshima Pref., 24. iii. 1980, S. Tanaka leg. Paratype: 1 male, same data as holotype.

Remarks. Batriscenellus insuliwla sp. nov. is very similar to $\boldsymbol{B}$. ohishii sp. nov. in the structure of the sexual patch, but is separated from the latter by the swollen fore femora and the male genitalia with a strongly bent and simply sharpened dorsal apophysis.

\section{Batriscenellus orientalis (Löbl) comb. nov.}

(Fig. 117F)

Batrisiella orientalis Löbl, 1973, Ann. Zool., Warzawa, 30(9): 4, comb. nov.

Male. Length $1.7 \mathrm{~mm}$. Width $0.7 \mathrm{~mm}$.

Body light brown to reddish brown, narrowed in head and pronotum.

Head longer than wide, subparallel-sided, clypeus short, arcuate on anterior margin, frons weakly concave and sparsely punctate, with a shallow transverse sulcus, vertex weakly convex, sparsely with minute punctures, and with a weak median longitudinal carina. Eyes large and ovoid, each composed of about 30 facets. Antennae elongate, reaching base of elytra, 1st segment thick, expanded laterally, with a large and conical trichome, 2nd narrower than 1st, elongate, 3rd to 5th subequal to each other, 6th short, 7 th subequal to 5 th, 8 th subequal to 6 th, 9 th to 10 th subequal in length, each thick and ovoid, weakly 
swollen internally, 10th wider than 9th, 11th largest, 1.7 times as long as wide, ovoid and pointed at apex. Maxillary palpi short, 4th segment largest, 2.8 times as long as wide, fusiform.

Pronotum about as long as wide, round-sided, sparsely with minute punctures, with a shallow median longitudinal sulcus. Elytra wider than long, nearly trapezoid, humeri expanded and denticulate, each elytron with 2 dorsal foveae and 2 dorsal sulci, outer dorsal sulcus running in subparallel to sutural line from outer fovea to posterior $1 / 5$. Legs elongate, mid tibiae slender, with a very short mucro at apex

Abdomen (Fig. 117F) weakly narrowed posteriorly, 4th segment largest, with a pair of very short dorsomedian carinae and a pair of weakly angular tergostemal ridges in basal 1/3, 5th extremely short, with some secretory setae in one or two lines, 6th about as long as 7th, same in structure as 5th, 7th large, longer than 5 th +6 th, moderately pubescent, 8 th tergite wider than long, arcuately emarginate on posterior margin, 8th sternite crescent.

Male genitalia was not examined (see original description by Löbl).

Female. Length $1.7 \mathrm{~mm}$. Width $0.6 \mathrm{~mm}$.

Similar to male except for the followings: eyes slightly smaller than in male, each composed of 20 25 facets; elytra clearly wider than long, round-sided and narrowed anteriorly, humeri rounded; mid tibiae slender, without mucro; 5 th to 6th abdominal segments short, each slightly longer than in male, 7 th large, 1.4 times as long as 5 th +6 th segments, 8 th tergite transverse, arcuate on posterior margin, 8th stemite semicircular, weakly convex.

Female genitalia weakly sclerotized, 9th sternite separated two lobes, fore lobe with a pair of elongate sclerites connected by membrane, each projected ventrally on anterior part, hind lobe broadened on posterior part, narrowly extended anterolaterally, arcuate on posterior margin; genital plate transverse, T-shaped in ventral view.

Distribution. Japan (Hokkaido), North Korea.

Specimens examined. 1 male 1 female (paratypes), Akan lakeside, Hokkaido, 1-10. xii. 1907 (H. Sauter).

Remarks. Batriscenellus orientalis (Mbl) is transferred to this genus from the genus Batrisiella in this study by having the conical trichome at the first antennal segment and the setiferous patches at the metasternum. This species is closely allied to $\boldsymbol{B}$. obishii sp. nov. in the extremely short fifth and sixth abdominal segments, but differs from the latter by the small body, the sparsely punctate head and the $\mathrm{T}$ shaped ventral stalk of the male genitalia. The female of this species distinguished from those allied species by the fore lobe of the ninth stemite with a pair of elongate sclerites; the female genitalia of this species is described for the first time.

\section{Batriscenellus pilasellus sp. nov.}

(Fig. 115, 118B, 124A, B, 126C)

Male (Fig. 115). Length $2.1 \mathrm{~mm}$. Width 0.8-0.9 mm.

Body dark brown to reddish brown, tarsi light brown elongate.

Head longer than wide, subparallel-sided and coarsely punctate on dorsal surface, clypeus short and arcuate on anterior margin, frons weakly concave, with a transverse sulcus, vertex weakly convex, 
with a pair of dorsal tentorial pits and a clear median longitudinal carina, postgenae almost flat. Eyes ovoid and convex, each composed of about 30 facets. Antennae elongate, reaching base of elutra, 1st segment thick, subcylindrical, 2nd narrower than 1st, elongate and weakly thickened distally, 3rd to 6th subequal in width, slightly narrower than 2nd, 7th larger than 6th, elongate, 8th short, slightly longer than wide, 9th to 10th thick, subequal in length, each ovoid and weakly swollen internally, 10th slightly wider than 9th, 11th largest, 1.7 times as long as wide, ovoid and pointed at apex. Maxillary palpi short, 4th segment largest, 2.8 times as long as wide, fusiform.

Pronotum slightly longer than wide, round-sided, sparsely with minute punctures, with a clear median longitudinal sulcus. Elytra wider than long, widest at posterior $1 / 3$, convex and sparsely punctate, humeri expanded and denticulate, each elytron with 2 dorsal foveae and 2 dorsal sulci, outer dorsal sulcus running from outer fovea to posterior $1 / 5$, weakly incurved. Legs elongate, mid tibiae slender, each with an acute mucro at apex.

Abdomen (Fig. 118B) weakly narrowed posteriorly, 4th segment largest, convex and sparsely punctate, with a pair of very short basidorsal carinae and a pair of short tergostemal ridges on basal 1/3, 5th short, covered with many secretory setae on dorsal surface, 6th about 1.5 times as long as 5 th, same in structure as 5th, 7th large, as long as 5th +6 th, 8th tergite short, clearly wider than long, shallowly emarginate on posterior margin, 8th sternite semicircular, weakly convex, 9th very short, transverse in external view.

Male genitalia (Fig. 124A, B) with dorsal apophysis on left side; paramere very small, rounded and lamellar, basal bulb broad, with a short basal strut, ventral stalk thick in basal part, narrowed distally, dorsal apophysis thick and elongate, curled up into right side of basal bulb, rounded at apex and with a short spine on left side near apex

Female. Length $1.9 \mathrm{~mm}$. Width $0.7 \mathrm{~mm}$.

Similar to male except for the followings: eyes smaller than in male, each composed of about 25 facets; elytra clearly wider than long, narrowed anteriorly; mid tibiae without mucro; 4th abdominal segment subparallel-sided, 5th slightly longer than in male, simple on dorsal surface, without secretory seta, 6th slightly longer than 5th, moderately pubescent as 5th, 7th large, as long as 5th +6 th, 8th tergite transverse, arcuate on posterior margin, 8th stemite semicircular, weakly convex.

Female genitalia (Fig. 126C) wider than long in ventral view, 9th sternite devided into 2 lobes, fore lobe with a pair of elongate sclerites each broadened posteriorly, narrowed anteriorly, hind lobe arcuate on posterior margin, broadly extended in anteromedian part, very narrowly extended on both anterolateral sides; genital plate biiinuate in ventral view.

Distribution. Japan (Honshu, Kyushu).

Holotype, male (Type No. 2830, Kyushu Univ.), Kamagari-cho, Hiroshima Pref., 29. ii. 1988, I. Okamoto leg. Paratypes: 2 males, same locality as holotype, 13. iii. 1988, I. Okamoto leg.; 6 males, Takiyama vall., Hiroshima Pref., 28. vi. 1987, S. Nomura leg.; 1 male 1 female, Kachiji, Naokawa-mura, Oita Pref., 16. xi. 1985, S. Sasaki leg.

Remarks. Batriscenellus pilosellus sp. nov. is similar to B. ohishii sp. nov. and allied species, but is different from them by the fifth to sixth segments covered with many secretory setae on the dorsal surface (fewer setae in ohishii).

Biological notes. Six males were caught by light trap at the riverside of Takiyama valley, Hiroshima 'Pref; this species might be usually an inhabitant of the middle reaches of the river. 


\section{Batriscenellus sakaii sp. nov.}

(Figs. 118C, 124D, E, 126D)

Male. Length 1.9-2.0 $\mathrm{mm}$. Width $0.7 \mathrm{~mm}$.

Body reddish brown, shiny, tarsi light brown, elongate.

Head longer than wide, subparallel-sided, clypeus short, arcuate on anterior margin, frons weakly concave and coarsely punctate, with an almost horizontal transverse sulcus, vertex weakly convex and sparsely punctate, with a clear median longitudinal carina, postgenae broad and slightly rounded. Eyes ovoid and convex, each composed of about 30 facets. Antennae slender, reaching base of elytra, 1st segment thick and roundly swollen on outer side, 2nd narrower than 1st, elonagte, 3rd to 4th subequal to each other, each thickened distally, 5th slightly larger than 4th, ovoid, 6th slightly narrower than 5 th, 7th elongate, 8th short, 9th to 10th thick, each ovoid, weakly swollen internally, 11th largest, 1.8 times as long as wide, ovoid. Maxillary palpi short, 4th segment largest, about 3 times as long as wide, fusiform.

Pronotum slightly longer than wide, round-sided, sparsely with minute punctures, with a clear median longitudinal sulcus. Elytra wider than long, nearly trapezoid, convex and sparsely punctate, humeri expanded and denticulate, each elytron with 2 dorsal foveae and 2 dorsal sulci, outer dorsal sulcus reaching posterior $1 / 4$, subparallel to sutural line. Legs elongate, mid tibiae slender, with an acute mucro at apex.

Abdomen (Fig. 118C) weakly narrowed posteriorly, 4th segment largest, weakly convex, sparsely with minute punctures, with a pair of very short basidorsal carinae and a pair of short tergosternal ridges on basal 1/3, 5th short and covered with many secretory setae on dorsal surface, 6th slightly shorter than 5 th in the median part, same in structure as 5th, 7th large, 1.8 times as long as 5 th +6 th, moderately pubescent, 8th tergite larger than in pilosellus, slightly wider than long, shallowly emarginate on posterior margin, 8th sternite nearly crescent, 9 th stemite very short.

Male genitalia (Fig. 124D, E) with dorsal apophysis on left side; paramere small, weakly sclerotized, basal bulb broad, with angular basal strut, ventral stalk broadened in basal part, narrowed posteriorly in dorsal view, dorsal apophysis long and thick, C-shaped in dorsal view, curled up into right side of the basal bulb, simply sharpened and crossed with apex of ventral stalk in apical part.

Female. Length $1.8-1.9 \mathrm{~mm}$. Width $0.7 \mathrm{~mm}$.

Similar to male except for the followings: eyes slightly smaller than in male, each composed of about 25 facets; elytra wider than long, narrowed anteriorly, humeri almost flat; mid tibiae without mucro; 4th abdominal segment subparallel-sided, 5th short, without secretory seta, moderately pubescent, 6th shorter than 5th, moderately pubescent, 7th large, 1.6 times as long as 5th +6 th segments, 8 th tergite transverse, arcuate on posterior margin 8 th sternite semicircular.

Female genitalia (Fig. 126D) wider than long in ventral view, 9th sternite divided into 2 lobes, fore lobe weakly sclerotized on the median part, with a pair of small and ovoid sclerites on both posterolateral sides, hind lobe larger than in pilosellus, arcuate on posterior margin, trisinuate on anterior margin, with a pair of anterolateral extentions being shorter than iu pilosellus, genital plate larger than in pilosellus, arcuate in ventral view.

Distribution. Japan (Okinawa Is.). 
Holotype, male (Type No. 2831, Kyushu Univ.), Safa-Utaki, Okinawa Is., Okinawa Pref.,17.iv. 1986, S. Nomura leg. Paratypes: 1 male 2 females, Mt. Nishimedake, Kunigami-son, Okinawa Pref., 19. x. 1987, M. Sakai leg; 1 male 2 females, Mt. Yonahadake, Kunigami-son, Okinawa Pref., 20. x. 1987, Y. Nishikawa leg.; 1 male, Mt. Nagodake, Nago City, Okinawa Pref., 11. iii. 1985, S. Nomura leg.

Remarks. Batrisceoellus sakaiisp. nov. is difficult to distinguish from B. pilosellus sp. nov. in appearance, but the sixth abdominal segment is shorter than fifth segment, and the male genitalia has a C-shaped and simply sharpened dorsal apophysis.

The female of this species differs from the other species of the subgenus Scaioscenellus in having the small and ovoid sclerites at the fore lobe of the ninth abdominal sternite.

Biological notes. The holotype of this species was collected from litter of the broad-leaved forest.

\section{Subgenus Batriscenellinus nov.}

Type species: Batriscenellus uenoi sp. nov.

This new subgenus has no sexual patch in the fifth to sii segments, but is exactly a component of the genus Batriscenellus by having the subconical trichome at the first antenna1 segment and the male genitalia with bent dorsal apophysis. This subgenus is characterized by the followings: Hind femora each tapering on basal half and covered with many secretory setae on the dorsoapical part; male genitalia with strongly bent dorsal apophysis as in subgenus Scaioscenellus.

The subgenus Batriscenellinus is composed of only one species, B. uenoi sp. nov.

Barniscenellus wenoi sp. nov.

(Figs. 124F, G, 126E)

Male. Length 2.0-2.1 mm. Width $0.8 \mathrm{~mm}$.

Body reddish brown, shiny, maxillary palpi and legs yellowish, elongate.

Head longer than wide, widest at base of antennae, clypeus short, arcuate on anterior margin, densely punctate, frons weakly concave and coarsely punctate, with an almost horizontal transverse sulcus, vertex weakly convex, sparsely punctate, with a pair of dorsal tentorial pits and a clear median longitudinal carina, postgenae short, almost flat. Eyes large, ovoid, each composed of about 30 facets. Antennae slender and reaching base of elytra, 1st segment thick, subcylindrical, with a conical trichome at external side, 2nd narrower than 1st, elongate and thickened distally, 3rd to 4th subequal to each other, short, 5th to 8thsubequal in width, each longer than wide, ovoid, 9th ot 10th subequal in length, thick, each ovoid, weakly swollen ventrally, 10th wider than 9 th, 11 th largest, 1.9 times as long as wide, ovoid in basal part, sharpened distally. Maxillary palpi short, 4th segment largest, 2.9 times as long as wide, fusiform.

Pronotum slightly longer than wide, round-sided, sparsely with minute punctures, with a clear median longitudinal sulcus reaching anterior $1 / 10$. Elytra slightly wider than long, nearly rectangular, widest at posterior 1/3, convex, humeri expanded and weakly pointed, each elytron with 2 dorsal foveae 
and 2 dorsal sulci, outer dorsal sulcus running from outer dorsal fovea to posterior 1/5. Legs elongate, mid tibiae slender, each with a short mucro at apex, hind femora tapered on basal a half, then strongly thickened on apical a half, covered with many secretory setae on dorsoapical part.

Abdomen short and rounded posteriorly, 4th segment largest, weakly convex and sparsely punctate, with a pair of short basidorsal carinae and a pair of weakly angular tergosternal ridges on basal 1/3, 5th to 6th short, 6th slightly longer than 5th, 7th large, 1.3 times as long as 5th +6 th, 8th tergite transverse, convex and narrowly emarginate on posteromedian margin, 8th sternite semicircular, 9th sternite very short and transverse in external view.

Male genitalia (Fig. 124F, G) with a dorsal apophysis on left side; paramere small, round, and Iamellar; basal bulb broad, ventral stalk broad on basal part, tapered distally, dorsal apophysis elongate and robust, strongly bent on basal part, broadened at about apical $1 / 4$, then sharpened distally and curved to left and crossed with apex of the ventral stalk.

Female. Length 2.0-2.1 $\mathbf{m m}$. Width $0.7-0.8 \mathrm{~mm}$.

Similar to male, but differs as follows: Eyes smaller than in male, each composed of about 25 facets; elytra wider than long, narrowed anteriorly, humeri weakly pointed; mid tibiae slender, without mucro, hind femora simple, without secretory setae; abdomen slightly narrowed posteriorly, 7th segment as long as 5 th +6 th, 8 th tergite transverse, arcuate on posterior margin, 8th sternite semicircular.

Female genitalia (Fig. 126E) wider than long, 9th sternite divided into 2 lobes, fore lobe with a pair of large sclerites, each sclerite longer than wide, broadened posteriorly, hind lobe arcuate on posterior margin, narrowly extended anteriorly on both sides; genital plate wider than fore lobe of 9th sternite, bisinuate in ventral view.

Distribution. Japan (Hokkaido, Honshu, Kyushu).

Holotype, male (Type No. 2832, Kyushu Univ.), Mesuta, Nakagawa-mura, Nagano Pref., 18. vi. 1952, S. Ueno leg. Paratypes: 1 male, Jyozankei, Hokkaido, 24. vii. 1962, y. Shibata leg.; 1 male, Futakuchi vall., Miyagi Pref., 12. vii. 1985, S. Nomura leg.; 1 male, Suketune-Rindo, Iitate-mura, Fukushima Pref., 21. vii. 1985, S. Nomura leg.; 1 male, Jigokudani, Mt. Yatsugatake, Yamanashi Pref., 8. vii. 1982, S. Naomi leg.; 1 male, Shoji-ko, Mt. Fuji, Yamanashi Pref., 6. viii. 1987, Y. Hirano leg.; 1 male, Nishiyama spa, Yamanashi Pref., 5. viii. 1987, Y. Hirano leg.; Owakudani, Hakone, Kanagawa Pref., 12. v. 1985, Y. Hirano leg.; Kintoki, Hakone, Kanagawa Pref., 12. vii. 1981, Y. Hirano leg.; 1 male, Kurokura, Tanzawa, Kanagawa Pref., 15. ix. 1975, Y. Hirano leg.; 1 male, same locality as above, 10. xi. 1985, Y. Hirano leg.; 1 male, Mikuni pass, Kanagawa Pref., 3. xi. 1984, Y. Hirano leg.; 4 males, Matsuno, Shizuoka City, Shizuoka Pref., 14. xi. 1974, H. Ohishi leg.; 7 males 1 female, Kyoto, 18-20. viii. 1980, C. Besuchet leg.; 1 male, Mt. Ohtosan, Wakayama Pref., 28-29. vi. 1981, S. Naomi leg.; 1 male 3 females, Kirikomi, Ume-machi Oita Pref., 4. iv. 1982, S. Sasaki leg.

Remarks. Batriscenellus uenoi sp. nov. is distinct in the swollen and densely setose hind femora on each apical part. This new species is allied to the subgenus Scaioscenellus in the male genitalia with a strongly bent dorsal apophysis.

Biological notes. One male of this species was collected by light trap at Futakuchi valley, Miyagi Pref.; the other one was extracted from the titter at the riverside of Nitta river, Fukushima Pref. 


\section{Genus Batriscenaulax Jeannel}

Batriscenaulax Jeannel, 1958, Mtm. Mus. Hist. nat. Paris, (A) 18: 57; Newton \& Chandler, 1989, Field. Zool., (53): 33. Type species: Batrisus modestus Sharp, by original designation.

Body reddish brown to light brown, elongate.

Head about as long as wide, subparallel-sided, frons weakly concave with a transverse sulcus, vertex weakly convex with a pair of clear dorsal tentorial pits, postgenae short; eyes ovoid, convex; antennae slender, reaching base of elytra.

Pronotum round-sided with a pair of lateral longitudinal sulci, a median longitudinal sulcus, transverse sulcus and 2 pairs of antebasal foveae. Elytra more or less wider than long, each elytron with a humeral denticle, 2 dorsal sulci, a lateral sulcus, 2 dorsal foveae and a lateral fovea, outer dorsal sulcus very long, slightly outcurved on its apical part; hind wings developed or reduced, legs slender, fore tibiae each swollen on apical part, each with a brush at the swelling in male, mid tibiae each simply terminated.

Abdomen truncate or rounded posteriorly, 4th segment very large with sexual patch composed of a pair of setiferous patch, median concavity and posteromedian nodule in male, 5th to 8th segments deflected ventrally, 5th to 6th very short, 7th large, 8th tergite rounded basally, narrowed posteriorly with small emargination at apex, 8th stemite short, crescent, 9th stemite very small.

Male genitalia small, with a dorsal apophysis on left- or right side; paramere large, weakly sclerotized; basal bulb short, with long ventral stalk, dorsal apophysis slender and sinuate, with membrane on ventral side; female genitalia similar in structure to Physomeriaus.

Remarks. The genus Batriscenaulax is well-defined by the fore tibiae each with a swelling and a brush and the sexual patch on the fourth abdominal segment. This genus is similar to Physomerinus in the setiferous organ on the fore femur, the long outer dorsal sulci on elytra and the male genitalia characterized by the large and weakly sclerotized paramere, the short basal bulb and the slender dorsal apophysis.

A Key to the Species and the Subspecies of the Genus Batriscenaulax from Japan

\section{Key to Males}

1. Head and pronotum sparsely punctate, pronotum strongly expanded laterally . . . ...kleinzach sp. nov.

- Head and pronotum densely with coarse punctures, pronotum slightly wider than long, round-

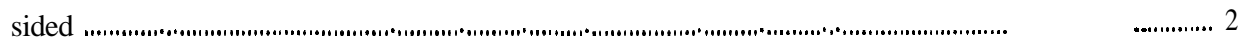

2. Abdomen rounded posteriorly, legs short ..........................................................................................

- Abdomen truncate, legs long ................................................................................................

3. Fore tibiae each widest at apical $1 / 4$, 4 th abdominal segment with broad, transverse median concav-

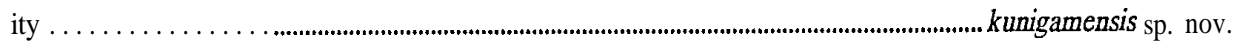

- Fore tibiae each strongly dilated at apical $1 / 3,4$ th abdominal segment with narrow median concavity being a half as wide as 4 th segment ……......................................................... nagensis sp. nov.

4. Fore tibiae each strongly dilated at apical $1 / 3,2$ nd segment of fore tarsus slender, longer than $3 r d$ segment, male genitalia with hook-shaped ventral stalk furuhatai (Kubota)

- Fore tibiae each widest at apical $1 / 4$ to $1 / 8,2$ nd segment of fore tarsus thick, as long as 3rd segment 
or shorter than that segment, male genitalia with slender ventral stalk tapering toward apex..

5. Male genitalia with a dorsal apophysis on right side modestus (Sharp)

- Male genitalia with a dorsal apophysis on left side

6. Fore tarsus short, 2nd segment thick and clearly shorter than 3rd .......... longipes kumaso subsp. nov.

- Fore tarsus elongate, 2nd segment about as long as 3rd

7. Fore tibiae each widest at apical 1/4; male genitalia with a ventral stalk which is widest at the middle

longipes hayato subsp. nov.

- Fore tibiae each widest at apical 1/8; male genitalia with a ventral stalk which is widest at basal $1 / 3$

longipes longipes Jeanne 1

Key to Females

1. Second antennal segment long, about as long as $3 \mathrm{rd}+4$ th segments puncticollis Jeannel

- Second antennal segment shorter than 3rd + 4th segments

2. Head and pronotum sparsely punctate, pronotum clearly transverse kleinzach sp. nov.

- Head and pronotum densely with coarse punctures, pronotum slightly wider than long 3

3. Fourth abdominal segment as wide as elytra, round-sided, with a pair of short dorsomedian carinae

kunigamensis sp. nov.

- Fourth abdominal segment narrower than elytra, subcylindrical with a pair of dorsomedian carinae at basal 1/5

4. Ninth abdomional stemite with a pair of broad ventral processes close to each other

..longipes Jeanne1

- Ninth abdominal sternite with a pair of small ventral processes separated from each other

furuhatai (Kubota)

Batriscenaulax kleinzach sp. nov.

(Figs. 128G, 130A, B, 131C)

Male. Length 1.5-1.6 mm. Width $0.6 \mathrm{~mm}$.

Body testaceus and shiny, compact, legs long and slender.

Head as long as wide, subparallel-sided, clypeus broad and arcuate on anterior margin, densely pubescent, frons short and weakly concave, sparsely with coarse punctures, and with a U-shaped sulcus connected with a pair of dorsal tentorial pits, vertex weakly convex and almost grabrous, postgenae short and rounded. Eyes small and ovoid, each composed of about 15 facets. Antennae slender, 1st segment subcylindrical, 2nd ovoid, as wide as 1st, longer than wide, 3rd to 8th subequal in width, narrower than 2nd, 3rd ovoid, as long as wide, 4th short and subcylindrical, 5th longer than 4th, 6th as large as 4th, 7th subequal to 5 th, 8th short, slightly longer than wide, 9th to 11th thick, 9th ovoid, slightly longer than wide, 10th longer than 9th, ovoid, weakly swollen internally, 11th largest, fusiform, 1.6 times as long as wide. Maxillary palpi large, 4th segment largest, fusiform, 3 times as long as wide.

Pronotum predominantly large, slightly narrower than elytra, 1.2 times as wide as long, widest at anterior $3 / 7$, moderately convex on dorsal fase, strongly expanded on both sides, sparsely punctate. with a pair of lateral longitudinal sulci each located at outer $1 / 4$, and a median longitudinal sulcus distinctly 
running from anterior 1/8 to posterior 1/8. Elytra wider than long, weakly rounded on both sides, humeri rounded and denticulate, each elytron with 2 dorsal foveae and 2 dorsal sulci and a lateral setiferous patch, outer dorsal sulci weakly incurved on anterior part, slightly outcurved on posterior part, reaching to posterior $1 / 5$, setiferous patch longer than wide, located on posterolateral part; hind wings reduced. Legs very slender in tibiae and tarsi, fore tibiae (Fig. 128G) each swollen distally, each with a brush at apical $1 / 8$, mid femora and hind femora each elongate, with a setiferous patch on dorsal side.

Abdomen as wide as elytra, rounded posteriorly, 4th abdominal segment Iargest, with a pair of short dorsomedian carinae on basal part and sexual patch on posterior part, sexual patch composed of a pair of indistinct setiferous patches on posterolateral sides, a small and transverse median concavity with severtal trichomes and a posterior nodule, 5th to 6th very short, 7th large, 2.6 times as long as 5th +6 th in posterior view, 8th tergite slightly wider than long, rounded on basal margin, narrowed posteriorly, with small emargination at apex, 8th stemite very short, crescent, elevated ventrally on posterior margin, 9 th stemite very small, transverse.

Male genitalia (Fig. 130A, B) with a dorsal apophysis on right side; paramere about as long as dorsal apophysis, lamellar; basal bulb short, with transverse basal foramen, ventral stalk longer than dorsal apophysis, slender and weakly sinuate in lateral view, dorsal apophysis elongate and sinuate, with finny membrane on ventral side.

Female. Length $1.5-1.6 \mathrm{~mm}$. Width $0.5-0.6 \mathrm{~mm}$.

Similar to male except for the following characters: antennae moniliform, 2nd to 10th segments each ovoid, slightly shorter than in male. Pronotum narrower than in male; elytra without lateral setiferous patch, legs slightly shorter than in male, fore-, mid- and hind tibiae without modification as brush or setiferous patch. Abdomen longer than in male, 7th segment 1.2 times as long as 5 th +6 th segments, 8th tergite longer than wide, convex, rounded on posterior margin, 8th sternite semicircular, weakly convex.

Female genitalia (Fig. 131C) well-sclerotised; 9th stemite T-shaped, fore lobe with a pair of broad ventral processes, closed to each other, transverse membranous area on posterior part; genital plate as wide as 9th sternite, with a pair of short and robust lateral arms extending laterally.

Distribution Japan (Ryukyu; Ishigaki Is., Iriomote Is.)

Holotype, male ((Type No. 2833, Kyushu Univ.), Mt. Omotodake, Ishigaki Is., Okinawa Pref., 9. iv. 1986, S. Nomura leg. Paratypes: 2 males 7 females, same data as holotype; 1 male, same locality as above, 18. iii. 1984, K. Ogata leg.; 1 male 13 females, same locality as above, 22. iii. 1984, S. Nomura leg.; 1 female, same locality as above, 11. iv. 1986, S. Nomura leg.; 1 male, Kanpiree, Iriomote Is., Okinawa Pref., 18. iii. 1984, S. Nomura leg.; 1 male, same locality as above, 27. iii. 1984, S. Nomura leg.; 3 males 12 females, same locality as above, U-14. iv. 1986, S. Nomura leg.

Remarks. Batriscenaulax kleinzach sp. nov. is easily distinguished from the other species of this genus by the sparsely punctate head and pronotum and the very large pronotum in both sexes, and the elytra, the mid- and hind femora each with the setiferous patch in male.

Biological notes. This species is an inhabitant of the subtropical virgin forest.

Etymology. This species name kleinzach is derived from the gnome "Kleinzach" characterized as a legendary dwarf in the prologue of Offenbach's opera, "Le Conte de Hoffman (The Tales of Hoffman)". 


\section{Batriscenaulax kunigamensis sp. nov.}

(Figs. 127, 128H, 130C, D, 131D)

Male (Fig. 127). Length 1.4-1.5 mm. Width $0.5 \mathrm{~mm}$.

Body testaceus, narrowed in head and pronotum.

Head nearly pentagonal, clypeus short and arcuate on anterior margin, densely with coarse punctures on dorsal surface, frons weakly concave, with transverse sulcus, vertex convex, with a pair of dorsal tentorial pits, postgenae short, rounded. Eyes small, ovoid, each composed of 15-20 facets. Antennae slender, 1st segment subcylindrical, 2nd narrower than 1st, subcylindrical, 3rd to 6th subequal in width, each subcylindrical, weakly thickened distally, 7th slightly larger than 6th, elongate, 8th feebly wider than 7th, 9th to 10th each thick and ovoid, weakly swollen ventrally, 11th largest, 1.8 times as long as wide. Maxillary palpi large, 4th segment thick, fusiform, twice as long as wide.

Pronotum slightly wider than long, round-sided, convex, densely with coarse punctures, with a pair of lateral longitudinal sulci narrowed posteriorly and a median longitudinal sulcus running from anterior 1/8 to posterior 1/8. Elytra slightly wider than long, rounded on both sides, sparsely wi th coarse punctures, humeri almost flat, each with a small denticle, each elytron with 2 dorsal foveae and 2 dorsal sulci, outer dorsal sulcus running from outer dorsal fovea to posterior $1 / 5$, weakly incurved; hind wing reduced. Legs shorter than in kreinzach, fore femora thickened on the middle part, fore tibiae (Fig. 128H) each strongly swollen laterally at apical $1 / 4$, each with a brush at the swelling.

Abdomen as wide as elytra, rounded posteriorly, 4th segment largest, with a pair of short dorsomedian carina at base and sexual patch on posterior part, sexual patch composed of a pair of ovoid setiferous patches on posterolateral sides, large, transverse median concavity with some trichomes and posteromedian nodule, 5th to 6th very short, 7th large, twice as long as 5th +6 th segments in posterior view, 8th tergite wider than long, weakly convex, rounded basally, with small emargination on posterior margin, 8th sternite crescent, elevated ventrally on posterior part, 9th small, transverse.

Male genitalia (130C, D) small, with a dorsal apophysis on left side; paramere large, slightly shorter than dorsal apophysis, lamellar; basal bulb short with a transverse basal foramen, ventral stalk broad, widest at apical 1/3, rounded at apex, dorsal apophysis slender, arcuate in lateral view, with finny membrane on ventral side.

Female. Length 1.4-1.5 mm. Width $0.5 \mathrm{~mm}$. Similar to male except for the followings: fore tibiae very slender, without brush; abdomen simply convex on dorsal surface, 8 th tergite transverse, arcuate on posterior margin, convex, 8th sternite semicircular, weakly convex.

Female genitalia (Fig. 131D) similar in structure to kleinzach, but 9th sternite with small ventral processes; genital plate clearly narrower than 9th sternite, W-shaped with a pair of slender lateral arms.

Distribution. Japan (Okinawa Is.)

Holotype, male (Type No. 2834, Kyushu Univ.), Mt. Terukubi, Kunigami-son, Okinawa Pref., 15. iii. 1985, S. Nomura leg. Paratypes: 2 males 4 females, Mt. Yonahadake, Kunigami-son, Okinawa Pref., 31. xii. 1976, H. Ohishi leg.; 1 male 4 females, same locality as above, 20. x. 1987, Y. Nishikawa leg.; 1 male, Ogimi-son, Okinawa Pref., 28. iii. 1980, S. Tanaka leg.; 1 male, same locality as above, 28. vi. 1982, S. Tanaka leg.

Remarks. Batriscenaulax kunigamensis sp. nov. is similar to $B$. longipes in the head, pronotum and fore tibia, but differs by the short legs and the abdomen rounded posteriorly in the male. The female of 
this new species is distinguished from the other species of this genus by the genital plate has a pair of very short and slender lateral arms.

Biological notes. The holotype of this species was extracted from the soil of the primeval forest of Mt. Terukubi, Okinawa Is.

\section{Bat. ulax nagensis sp. nov.}

(Fig. 128I, 130E, F)

'Male. Length $1.5 \mathrm{~mm}$. Width 0.5-0.6 mm.

Body reddish brown, broadened posteriorly.

Head as long as wide, nearly pentagonal, clypeus very short, densely with coarse punctures on dorsal surface, frons weakly concave, with a transverse sulcus, vertex convex, with a pair of conspicuous dorsal tentorial pits, postgenae short and rounded. Eyes ovoid and convex, each composed of 15-20 facets. Antennae slender, 1st segment subcylindrical, weakly thickened distally, 2nd slightly narrower than 1st, 3rd to 8th subequal in width, each segment subcylindrical, thickened distally, 9th longer than wide, ovoid, 10th slightly wider than 9th, subspherical, 11th largest, twice as long as wide, fusiform. Maxillary palpi large, 4th segment largest, 2.5 times as long as wide, fusiform. Pronotum larger than in kunigamensis, wider than long, round-sided and convex, densely with coarse punctures, with a median longitudinal sulcus from anterior $1 / 7$ to posterior $1 / 8$. Elytra slightly wider than long, weakly broadened posteriorly, convex, humeri each with a denticle, each elytron with 2 dorsal foveae and 2 dorsal sulci, outer dorsal sulcus running from outer dorsal fovea to posterior 1/8, incurved to posterior 1/4 of elytra, then outcurved to the end; hind wings reduced. Legs short, fore femora thickened at the middle parts, fore tibiae (Fig. 1281) each conspicuously swollen, widest at apical 1/3, each with a brush at the swelling at apical $1 / 4$, mid- and hind legs simply slender.

Abdomen as wide as elytra, rounded posteriorly with a pair of short dorsomedian carinae at base and sexual patch at posterior part, sexual patch composed of a pair of round setiferous patch, median concavity and a postmedian nodule, median concavity transverse, smaller than in kunigamensis with trichomes, 5th to 6th short, 7th large, 1.5 times as long as 5th +6 th segments in posterior view, 8th tergite wider than long, convex, arcuate on basal margin, with small emargination on posteromedian part, 8th sternite crescent, elevated ventrally on posterior part.

Male genitalia (Fig. 130E, F) small, with a dorsal apophysis on left side; basal bulb short, with an ovoid basal foramen and a small ventral projection, ventral stalk widest at apical $2 / 5$, sharpened toward apex, dorsal apophysis slightly shorter than ventral stalk, slender and arcuate in lateral view, with membrane on ventral side.

\section{Female. Unknown.}

Distribution. Japan (Okinawa Is.).

Holotype, male (Type No. 2835, Kyushu Univ.), Nago City, Okinawa Pref., 31. iii. 1980, S. Tanaka leg. Paratopotype: 1 male, same data as holotype.

Remarks. Batriscenaulax nagensis sp. nov. is closely allied to $\boldsymbol{B}$. kunigamensis sp. nov., but the fore tibiae are each strongly dilated at the apical $1 / 3$ (apical $1 / 4$ in kunigamensis) and the fourth abdominal segment has a small median concavity which is half as wide as the segment. 


\section{Batriscenaulax furubatai (Kubota)}

(Figs. 128F, 129F, G, 131B)

Batrisocenus furuhatai Kubota, 1943, Trans. Kansai em. Soc., 9: 6.

Batriscenaulax furuhatai : Jeannel, 1958, Mém. Mus. Hist. nat., Paris, (A), 18: 59.

Male. Length 1.7-1.8 mm. Width 0.6-0.7 mm.

Body reddish brown to light brown, elongate, narrowed in head and pronotum.

Head as long as wide, subparallel-sided, densely with coarse punctures on dorsal surface, clypeus short and arcuate on anterior margin, frons weakly concave, with a transverse sulcus, vertex convex, postgenae short and flat. Eyes ovoid and convex, each composed of about 25 facets. Antennae slender, reaching with humeral angles of elytra, 1st segment thick, subcylindrical, 2nd narrower than 1st, ovoid, 3rd to 6th subequal in width, slightly narrower than 2nd, each subcylindrical, thickened distally, 7th larger than 6th, ovoid, 8th short and subequal to 6th, 9th longer than wide, ovoid, 10th slightly wider than 9th, 11th largest, 1.6 times as long as wide, ovoid.

Pronotum round-sided, widest at anterior 2/5, densely with coarse punctures, with a pair of lateral longitudinal sulci running subparallel, and a median longitudinal sulcus from anterior 1/6 to posterior 1/6. Elytraconvex and almost rectangular, sparsely punctate, humeri weakly expanded, each unidenticulate, each elytron with 2 dorsal sulci and 2 dorsal foveae, outer dorsal sulcus reaching to posterior $1 / 7$; hind wings developed or reduced. Legs elongate, fore tibiae (Fig. 128F) each swollen at apical 1/3, each with a brush at the swelling, fore and mid trochanters short, each with a very small denticle.

Abdomen nearly truncate in dorsal view with a pair of dorsomedian carinae on basal $1 / 5$ and sexual patch on posterior part, sexual patch consisting of a pair of setiferous patches on posterolateral sides, a large median concavity containing 3 pairs of trichomes and a posteromedian nodule being setose at its anterior part, 5th to 6th segments very short, 7th large, twice as long as 5th +6 th segments in posterior view, 8th tergite wider than long, weakly convex, rounded on basal margin, narrowed toward apex, weakly emarginate at apex, 8th sternite crescent, elevated ventrally on its posterior part, 9th sternite small.

Male genitalia (Fig. 129F, G) with a dorsal apophysis on left side; paramere slightly shorter than dorsal apophysis, lamellar; basal bulb short and subconical, with a triangular basal foramen, and a small ventral projection, ventral stalk longer than dorsal apophysis, weakly narrowed distally in ventral view, rounded at apex, dorsal apophysis slender, S-shaped in lateral view, membranous on ventral side.

Female. Length $1.7-1.8 \mathrm{~mm}$. Width $0.6 \mathrm{~mm}$. Similar to mele except for the following characters: antennae moniliform, each segment ovoid; elytra weakly rounded on both sides, narrowed anteriorly, humeri flat; fore tibiae slender without swelling nor brush, fore and mid trochanters without denticle; 4th abdominal segment weakly convex without sexual patch, 7th large, 1.5 times as long as 5 th +6 th segments, 8th tergite transverse, convex and semicircular, 8th sternite slightly larger than 8th tergite, weakly convex and semicircular.

Female genitalia (Fig. 131B) wider than long, 9th sternite narrowed anteriorly, fore lobe narrow, with a pair of small ventral processes separated from each other on their posterior part, hind lobe ex- 
tending laterally, divided into 2 sclerite by transverse membrane with ovoid median membranous area; genital plate slightly wider than 9th stemite with a pair of slender lateral arms each thickened at apices.

Distribution. Japan (Honshu, Kyushu).

Specimens examined. [Honshu] 2 males 4 females, Manazuru, Kanagawa Pref., 26. x. 1985 (S Nomura); 3 males 3 females, Gojima, Haruno-cho, Shizuoka Pref., 23. x. 1985 (S. Nomura); 10 males 6 females, Hiedano, Kameyama City, Kyoto Pref., 23. x. 1978 (K. Masaki); 6 males 2 females, Kamagaricho, Hiroshima Pref., 3. iv. 1988 (I. Okamoto); 29 males 14 females, same locality as above, 13. iii. 1988 (I. Okamoto). [Kyushu] 1 male, Mt. Hikosan, Fukuoka Pref., 12. x. 1958 (Y. Murakami); 3 males, same locality as above, 3. v. 1983 (S. Nomura); 1 male 3 females, same locality as above, 21. v. 1986 (S. Nomura); 1 male, Omuta, Fukuoka Pref., 7. ix. 1979 (S. Tanaka); 1 male, Okuhata, Kitakyushu City, Fukuoka Pref., 16. ix. 1979 (S. Tanaka); 1 male 1 female, Mt. Tachibana, Fukuoka City, Fukuoka Pref., 17. iv. 1981 (S. Naomi); 21 males 13 females, Yunoharu, Fuji-cho, Saga Pref, 27. v.-3. vi. 1979 (Baba et C. Okuma); 1 male 2 females, Kuroiwa, Ouchi-machi, Saga Pref., 28. v. 1984 (S. Nomura); 2 males 6 females, Mt. Mifune, Takao City, Saga Pref., 11. iii. 1981 (S. Nomura); 11 males 14 fémales, same locality as above, 10. iv. 1985 (S. Nomura); 23 males, Ryumon Vall., Mt. Kurokami, Saga Pref., 23. x. 1977 (H. Ohishi); 4 males 1 female, Mt. Seira, Imari City, Saga Pref., 28. v. 1984 (S. Nomura); 2 males, same locality as above, 3. iii. 1985 (S. Nomura); 3 males 2 females, same locality as above, 3. iii. 1988 (S. Nomura); 1 male 1 female, Mt. Taradake, Saga Pref., 15. iv. 1984 (S. Nomura); 1 male, Hita City, Oita Pref., 20. xi. 1979 (S. Tanaka); 6 males 8 females, Yabakei, Oita Pref., 30. iii. 1985 (S. Nomura); 2 males, Mt. Yufudake, Oita Pref., 21. xi. 1988 (S. Naomi); 2 males 3 females, Ueki-cho, Kumamoto Pref., 10. iv. 1981 (S. Naomi); 4 males 4 females, same locality as above, 22. xi. 1988 (S. Naomi); 5 males 3 females, Mt. Ichiiusa, Kumamoto Pref., 13. v. 1985 (S. Nomura); 1 male, Saito City, Miyazaki Pref., 12. iii. 1980 (S. Tanaka); 1 male 1 female, Aira-cho, Kagoshima pref., 30. i. 1985 (T. Tanabe); 2 males, Shiroyama, Kagoshima City, Kagoshima Pref., 20. i. 1970 (H. Makihara); 1 male 2 females, same locality as above, 2. ii. 1985 (T. Tanabe).

Remarks. Batriscenaulax furuhatai (Kubota) is very similar to $\boldsymbol{B}$. longipes Jeannel, but is separated by the fore tibiae each dilated at the apical $1 / 3$, the second segment of the fore tarsus which is longer than 3rd segment and the male genitalia with the hook-shaped ventral stalk.

Biological notes. This species mainly inhabits the broad leaved forest; it has ever been rarely found together with $\boldsymbol{B}$. Iongipes.

\section{Batriscenaulax longipes Jeannel}

(Figs. 128A, B, 129A, B, 131A)

Batriscenaulax longipes Jeannel, 1958, Mém. Mus. Hist. nat., Park, (A), 18:57.

Male. Length $1.7 \mathrm{~mm}$. Width 0.6-0.7 mm.

Body reddish brown to light brown, elongate, narrowed in head and pronotum.

Head slightly longer than wide, subparallel-sided, densely with coarse punctures on dorsal surface, clypeus short and arcuate on anterior margin, frons weakly concave with a bisinuate transverse sulcus, vertex slightly convex, postgenae short and rounded. Eyes ovoid and convex, each composed of about 25 facets. Antennae slender, reaching at base of elytra, 1st segment thick, subcylindrical, 2nd narrower than 
1st, subcylindrical, weakly thickened distally, 3rd to 6th subequal in width, 7th larger than 6th, ovoid, 8th short, subequal to 6 th, 9th ovoid, longer than wide, 10th wider than 9th, slightly swollen internally, 11th largest, twice as long as wide, ovoid. Maxillary palpi large, 4th segment largest, 2.6 times as long as wide, fusiform.

Pronotum slightly wider than long, round-sided, widest at anterior $2 / 5$, densely with coarse punctures with a median longitudinal sulcus running from anterior $1 / 6$ to posterior $1 / 6$. Elytra wider than long, slightly broadened posteriorly, convex and sparsely punctate, humeri weakly expanded, each elytron with a humeral denticle, 2 dorsal sulci and 2 dorsal foveae, outer dorsal sulcus reaching to posterior 1/7; hind wing developed or reduced. Legs long and slender, fore tarsi 3-segmented, 1st segment short, 2nd thick, 3rd slender as long as 2nd, fore tibiae (Fig. 128A, B) each slender in basal part, then swollen distally, each with a brush on the swelling at apical 1/8 and some suberect setae in a line on dorsal side from the swelling to base of tibia, fore and mid trochanters short, each with a small denticle.

Abdomen nearly truncate, 4th segment weakly narrowed posteriorly with a pair of dorsomedian carinae on basal 1/5 and sexual patch on posterior part, sexual patch same structure as in furuhatai, 5th to 6th segments very short, 7th large, 2.2 times as long as 5th +6 th, 8 th tergite wider than long, rounded on basal margin narrowed apically, slightly emarginate at apex, 8th sternite crescent, elevated ventrally on posterior part, 9th stemite very small, rounded on apical part.

Male genitalia (Fig. 129A, B) small, with a dorsal apophysis on left- or right side; paramere short and lamellar, weakly folded ventrally; basal bulb short with ovoid basal foramen and a small ventral projection, ventral stalk slender, widest at basal $1 / 3$, then tapering distally, acute and curved internally at apex, dorsal apophysis slightly shorter than ventral stalk, slender, S-shaped in lateral view with membrane and a very thin sclerite on ventral side.

Female. Length $1.6-1.7 \mathrm{~mm}$. Width $0.6 \mathrm{~mm}$.

Similar to male excepting the followings: antennae moniliform, 2nd to 8th segments each ovoid; elytra narrowed anteriorly, humeri flat; hind wing reduced; fore tibiae slender without swelling nor brush, fore and mid trochanters without denticle; abdomen rounded posteriorly, 4th segment simply convex without sexual patch.

Female genitalia (Fig. 131A) very similar in structure to furuhatai, but fore lobe of 9th stemite with a pair of broad ventral processes close to each other, hind lobe with small, ovoid membranous area.

Distribution. Japan (Hokkaido, Honshu, Shikoku, Kyushu).

Specimens examined. [Hokkaido] 1 male, Nanae, Oshima, Hokkaido, 31. vii. 1984 (S. Tanaka). [Honshu] 1 male, Mt. Komuro, Ito City, Shizuoka Pref., 25. x. 1983 (Ohrui); 1 male 2 females, Kibume, Kyoto Pref., 16. ix. 1979 (H. Ohishi); 1 male, Mt. Kurama, Kyoto Pref., 20. x. 1979 (K. Masaki); 2 males, Yaseyuen, Kyoto Pref., 4. viii. 1980 (C. Besuchet); 1 male, Kyoto, 18-20. viii. 1980 (C. Besuchet); 1 male, Takatsuki, Osaka Pref., 13. v. 1973 (K. Sawada); 2 males, Kii-Nagashima, Mie Pref., 29. iii. 1981 (M. Kubota); 8 males 3 females, Ikura, Niimi City, Okayama Pref., 21. v. 1985 (S. Nomura); 12 males 11 females, Mt. Haigamine, Kure City, Hiroshima Pref., 13. iii. 1988 (I. Okamoto); 19 males 21 females, same locality as above, 19-20. iii. 1988 (I. Okamoto). [Shikoku] 1 male 1 female, Mt. Godai, Kochi City, Kochi Pref., 15. v. 1978 (H. Ohishi); 5 males 7 females, Ouchi, Ino-cho, Kochi Pref., 15. v. 1978 (H. Ohishi). [Kyushu] 6 males 8 females, Hiraodai, Kitakyushu City, Fukuoka Pref., 25. iv. 1989 (S. Nomura); 1 male, Mt. Seira, Imari City, Saga Pref., 3. iii. 1988 (S, Nomura); 2 males 1 female, Todoroki vall., Nagasaki Pref., 11. ii. 1985 (S. Nomura); 5 males 2 females, same locality as above, 10. iv. 1988 (S. 
Nomura); 1 male, Mt. Yasumandake, Hirado Is., Nagasaki Pref., 9. xi. 1987 (S. Nomura); 4 males 4 females, Shin-Yabakei, Oita Pref., 30. iii. 1985 (S. Nomura); 1 male 2 females, Sarugajo, Tarumizu City, Kagoshima Pref., 15. iii. 1985 (T.. Tanabe).

Remarks. Three subspecies are recognized in this species. The nominate subspecies of Batriscenaulax longipes Jeannel has the weakly thickened second segment of the fore tarsus which is as long as the third segment, the fore tibiae each with a brush at the apical $1 / 8$ and the ventral stalk of the male genitalia being widest at the basal $1 / 3$, then tapered toward apex.

Biological notes. This species commonly found in the natural forest, but sometimes inhabits the bamboo forest or plantation of Cryptomeria japonica.

\section{Batriscenaulax longipes kumaso subsp. nov.}

(Fig. 128C, 129D)

This new species is very similar to the nominate subspecies in general appearance, but is different from it by the following characters: fore tarsi (Fig. 128C) short, 2nd segment thick, clearly shorter than 3rd segment; ventral stalk of male genitalia (Fig. 129D) narrow, widest at the middle.

Holotype, male (Type No. 2836, Kyushu Univ.), Mt. Sobosan, Oita Pref., 23. vii. 1983, S. Nomura leg. Paratypes: 1 male, same locality as holotype, 4. v. 1984, S. Nomura leg.; 2 males, same locality as above, 17. iv. 1986, S. Nomura leg.; 6 males 4 females, Kikuchi vall., Kumamoto Pref., 11. iv. 1981, S. Naomi leg.; 3 males 4 females, same locality as above, 3. i. 1985, T. Morino leg.; 3 males 6 females, Mt. Shiratori, Kumamoto Pref., 17. xi. 1980, H. Takemoto leg.; 1 male, same locality as above, 5. iv. 1987, S. Nomura leg.; 1 male, Itsuki-mira, Kumamoto Pref., 6. v. 1985, T. Irie leg.; 6 males 7 females, Mt. Ichifusa Kumamoto Pref., 13. v. 1985, S. Nomura leg.

Distribution. Japan (The central mountains of Kyushu).

\section{Batriscenaulax longipes hayaro subsp. nov.}

(Fig. 128D, 129D)

Similar to the other subspecies, but differs from them by the following features: fore tarsi elongate, 2nd segment as long as 3rd, thick; fore tibiae (Fig. 128D) each widest at apical 1/4; male genitalia (Fig. 129D) with a ventral stalk which is broad and widest at the middle.

Holotype, 1 male (Type No. 2837, Kyushu Univ.), Miike, Kirishima, Miyazaki Pref., 8. v. 1985, S. Nomura leg. Paratopotypes: 6 males 6 females, same data as holotype.

Distribution. Japan (Southern Kyushu).

\section{Batriscenaulax modestus (Sharp)}

(Fig. 128E, 129E)

Batrisus modestus Sharp, 1874, Trans. ent. Soc. London, 1874, p. 116.

Batrisocenus modestus : Raffray, 1904, Aм. Soc. ent. Fr., 73: 219; 1908, Coleopt. Psel., Gen. ins., 64: 173; 1911, Psel., Coleopt. Cat., (27): 70. 
Batriscenaulax modestus : Jeannel, 1958, Mém.Mus.Hist. nat., Paris, (A), 18: 58.

Distribution. Japan (Honshu, Kyushu).

Specimens examined. [Honshu] 1 male, Aokigahara, Mt. Fuji, Yamanashi Pref., 23. viii. 1982 (S. Naomi).

Remarks. This species is very similar to longipes in the aspect, but is separated by the male genitaha (Fig. 129E) with a dorsal apophysis on the right side according to the figure in the redescription by Jeannel(1958). B. longipes might be synonymous with this species if the male genitalia have dimorphism as in Batrisceniola dissimilis (Sharp).

\section{Batriscenaulax puncticollis (Sharp)}

Batrisus puncticollis Sharp, 1874, Trans. ent. Soc. London 1874, p. 116; 1883, ibid., 1883, p. 316.

Batrisocenus puncticollis : Raffray, 1904, Ann. Soc. ent. Fr. 73: 221; 1908, Coleopt. Psel., Gen. ins., 64: 174; 1911, Psel., Coleopt. Cat., (27): 71.

Batriscenaulax puncticollis: Jeannel, 1958, Mém. Mus. Hist. nat., Paris, (A), 18: 60.

Distribution. Japan (Honshu).

Remarks. This species is unknown to me.

\section{Genus Physomerinus Jeannel}

Physomerinus Jeannel, 1952, Rev. franc. Ent. 19 (2): 96; 1958, Mém. Mus. Hist. nat. Paris, (A), 18: 52; Newton \& Chandler, 1989, Field. Zool., (53): 39. Type species: Batrisus septemfoveofatus Shaufuss, by monotypy.

Body reddish brown to light brown, head and pronotum narrower than elytra.

Head rounded, clypeus short, frons with a shallow U-shaped sulcus connected with a pair of dorsal tentorial pits, postgenae very short. Eyes large in male, convex and ovoid; antennae short a little; maxillary palpi short.

Pronotum round-sided and sparsely punctate on dorsal surface. Elytra nearly rectangular and humeri expanded in macropterous male; elytra transverse and humeri rounded in apterous female. Metasternum concave at middle part in male. Legs thick in femora, fore tibiae each with a brush of some twisted macrochaetae at apex in male, mid tibiae each with a very short mucro at apex in male, hind femora each broadened near the middle with excavation or setiferous setae in male.

Abdomen weakly narrowed posteriorly, 4th abdominal segment largest, with a pair of short dorsomedian carinae and a pair of short tergosternal ridges. Male genitalia small; paramere large, weakly sclerotized, lamellar; basal bulb small, subconical, with an elongate or twig-shaped ventral stalk at base, dorsal apophysis narrowed on basal part, long and slender, acute at apex and curved proximally. Female 
genitalia well-sclerotized; fore lobe of 9th sternite with a pair of large ventral processes, hind lobe extended anterolaterally, with a large membranous area at apex; genital plate wider than 9th sternite, with a pair of robust lateral arms broadened distally.

Remarks. The genus Physomerinus is characterized by the sexual patch on the hind femora in the male and the male genitalia with slender dorsal apophysis. This genus is related to the genus Batriscenaulax in having the similar small male genitalia and the fore femora each with many small setae on inner side.

\section{A Key to the Species of the Genus Physomerinus from Japan}

Key to Males

1. Fourth segment of maxillary palpus swollen laterally hasegawaisp. nov.

- Fourth segment of maxillary palpus fusiform . .2 ..

2. Hind femora each with large excavation and mushroom like projection on outer side pedator (Sharp)

- Hind femora each with oblique groove at middle part .schenlclingi (Raffray)

Key to Females

1. Pronotum with a long median longitudinal sulcus reaching near anterior margin; 9th abdominal stemite with an ovoid membranous area; genital plate with a pair of broad lateral arms .................

schenklingi (Raffray)

- Pronotum with a short median longitudinal sulcus reaching to anterior $1 / 4$

2. Fore lobe of 9 th abdominal sternite with a pair of short ventral processes, hind lobe with a large and transverse membranous area; genital plate with a pair of slender lateral arms ...pedator (Sharp)

- Fore lobe of 9th abdominal sternites with a pair of long ventral processes, hind lobe with an ovoid membranous area; genital plate with a pair of broad lateral arms hasegawai sp. nov.

\section{Physomerinus pedator (Sharp)}

(Figs. 133A, D, 134A, B, 135A)

Batrisus pedator Sharp, 1883, Trans. ent. Soc. London, 1883; 319.

Batrisocenus pedator: Raffray, 1904, Ann. Soc. ent. Fr. 73: 220; 1908, Coleopt. Psel., Gen. ins., 64: 173; 1911, Psel., Coleopt. Cat., (27): 71.

Physomerinus pedator: Jeannel, 1958, Mém. Mus. Hist. nat., Paris, (A), 18: 52.

Male. Length 1.7-1.9 mm. Width $0.7 \mathrm{~mm}$.

Body reddish brown and shiny, slightly narrowed in head and pronotum.

Head slightly longer than wide, pentagonal and subparallel-sided, clypeus very short, arcuate on anterior margin, frons almost flat at median part, weakly convex in lateral part, sparsely punctate, with U-shaped sulcus connecting dorsal tentorial pits, vertex convex, coarsely punctate, postgenae slightly rounded. Eyes very large, ovoid and convex, each composed of about 30 facets. Antennae slender, 
reaching base of elytra, 1st segment thickened distally, with 2 apical denticles, 2nd subcylindrical, about 1.5 times as long as wide, 3rd slightly narrower than 2 nd, thickened distally, 4th to 6th subequal in width, slightly narrower than 3rd, 4th short, 5th elongate, 6th short, 7th as long as 2nd, elongate, 8th shortest, 9th to 10th each thick, ovoid and swollen ventrally, 11th largest, 3 times as long as wide.

Pronotum slightly wider than long, round-sided and convex, coarsely punctate and densely pubescent, with suberect long hairs, median longitudinal sulcus almost complete. Elytra slightly wider than long, nearly rectangular, coarsely punctate, densely pubescent, with a few suberect hairs, humeri expanded, each denticulate and unisetose, each elytron with 2 dorsal foveae and 2 dorsal sulci, outer dorsal sulcus reaching to posterior $1 / 9$, weakly incurved on basal $3 / 4$, then outcurved on posterior $1 / 4$; hind wing developed. Metastemum strongly concave at middle part, with dense pubescense. Legs thick in femora, fore tibiae slender, each with a brush at apex, mid tibiae slender, each with a very short mucro at apex, hind femora (Fig. 133A, D) thick, each flattened and setose on distal part, with deep excavation on anterolateral side and mushroom-shaped projection at bottom of the excavation.

Abdomen rounded posteriorly with dense pubescense and several long suberect hairs, 4th segment largest, 1.6 times as wide as long in dorsal view, narrowed posteriorly, with a pair of short dorsomedian carinae on anterior $1 / 4$ and indistinct tergosternal ridges on anterior $1 / 3,5$ th to 6 th short, 7 th large, as long as 5 th +6 th in dorsal view, 8th tergite ovoid, wider than long, weakly emarginate at posterior margin, 8th sternite crescent, weakly concave at the middle part.

Male genitalia (Fig. 134A, B) small, with a dorsal apophysis on the right side; paramere weakly sclerotized formed into a broad lobe attached to base of ventral stalk, basal bulb subconical, with a wellstalked narrow ventral stalk, dorsal apophysis longer than basal bulb, tapering and hook-shaped, with finny membrane on basal side.

Female. Length $1.7-1.9 \mathrm{~mm}$. Width $0.6-0.7 \mathrm{~mm}$.

Similar to male except for following characters: antennae slightly thicker than in male; elytra clearly wider than long, humeri flat, hind wing reduced; fore tibiae without brush, mid tibiae without mucro, hind femora simple, without sexual patch; 4th abdominal segment 1.7 times as wide as long with very short dorsomedian carinae and tergosternal ridges, 7th segment shorter than 5 th +6 th segments, 8 th tergite transverse and convex, arcuate posteriorly, 8th sternite semicircular, weakly convex.

Female genitalia (Fig. 135A) well-sclerotixed; 9th sternite T-shaped, fore lobe with a pair of ventral processes running in subparallel, hind lobe transverse, constricted on both sides with a broad membranous area at apical part; genital plate clearly wider than 9th sternite, W-shaped, with a pair of robust lateral arms broadened distally.

Distribution Japan (Honshu, Kyushu, Yaku Is.).

Specimens examined. [Kyushu] 4 males 5 females, Shimoda, Amakusa-shimojima Is., Kumamoto Pref., 7. viii. 1977 (H. Ohishi); 2 males 3 females, Imasato, Nakadori Is., Goto Isls., Nagasaki Pref., 15. viii. 1977 (H. Ohishi); 21 males 47 females, Niri-machi, Imari City, Saga Pref., 10. x. 1976 (H. Ohishi). [Yaku Is.] 1 male 1 female, Kurio, Yaku Is. Kagoshima Pref., 29. iii. 1964 (Y. Shibata).

Remarks. Physomerinus pedator (Sharp) is similar to the other species of this genus, but is different from them by the hind femora each with the mushroom shaped projection on outer side in the male and the genital plate with the slender lateral arms in the female.

Biological notes. The habitat of this species is the humus of the secondary plant community in the lower riverside mainly composed of Miscanthus sinensis (Ohishi, pers. comm.). 


\section{Physomerinus schenklingi (Raffray) comb. nov.}

(Figs. 132, 133B, E, 134C-F, 135B)

Batrisocenus schenklingi Raffray, 1912, Ent. Mitt. 1(4): 105.

Physomerinus akanensis Löbl, 1973, Ann. Zool., Warszawa, 30(9): 324. Syn. nov.

Male (Fig. 132). Length 1.5-1.7mm. Width $0.6 \mathrm{~mm}$.

Body reddish brown shiny, slightly narrowed in head and pronotum.

Head as long as wide, slightly narrowed anteriorly, clypeus short, arcuate on anterior margin, densely pubescent, frons slightly concave, with a U-shaped sulcus connected with dorsal tentorial pits, coarsely punctate in front of the sulcus, vertex weakly convex, with a line longitudinal carina, postgenae very short, rounded. Eyes large and ovoid, each composed of about 30 facets. Antennae short, reaching base of elytra, 1st segment subcylindrical, 2nd as long as 1st, slightly narrower than 1st, ovoid, 3rd to 6th subequal in width, each longer than wide, ovoid, 7th slightly larger than 6th, elongate, 8th short, as long as wide, 9th to 11th large, each ovoid, 9th clearly larger than wide, 10th wider than 9th, slightly longer than wide, 11th largest, 1.3 times as long as wide. Maxillary palpi small, 4th segment fusiform, 2.5 times as long as wide.

Pronotum about as long as wide, weakly expanded laterally, sparsely with minute punctures, with a median longitudinal sulcus from anterior $1 / 8$ to posterior $1 / 7$, a pair of lateral longitudinal sulci running in subparallel to each other. Elytra slightly wider than long, feebly narrowed anteriorly, convex, humeri expanded, each unidenticulate, each elytron with 2 dorsal foveae and 2 dorsal sulci, outer dorsal sulcus reaching posterior $1 / 8$; hind wing developed. Legs thick in femora, fore tibiae each with a brush at apex, mid tibiae each with a short mucro at inner side of apex, hind femora (Fig. 133B, E)each strongly thickened at the middle part, each with an oblique groove just behind the swelling.

Abdomen clearly narrower than elytra, 4th segment weakly narrowed posteriorly with a short dorsomedian carina, 5th to 6th very short, 7th large, twice as long as 5th +6 th in posterior view, 8th tergite ovoid, convex, 8th sternite crescent, flattened on median part, 9th stemite (Fig. 134F) very small, transversein posterior view.

Male genitalia (Fig. 134C, E) small, with a dorsal apophysis on the left side; paramere (Fig. 134E) weakly sclerotized, lamellar; basal bulb subconical with narrow basal foramen, ventral stalk extending outward with elongate inner projection at base, broadened at apex, dorsal apophysis very slender, hookshaped, acute at apex, with finny membrane on basal side.

Female. Length $1.5-1.6 \mathrm{~mm}$. Width $0.6 \mathrm{~mm}$.

Similar to male excepting following characters: eyes smaller than in male, each composed of about 25 facets; elytra clearly wider than long, humeri rounded; fore tibiae without brush, mid tibiae without mucro, hind femora slender, without oblique groove; 4th abdominal segment longer than in male, 8th tergite ovoid, weakly convex, 8th sternite larger than 8th tergite, semicircular, convex.

Female genitalia (Fig. 135B) broadened in basal part; 9th stemite T-shaped, fore lobe with a pair of large and posteriorly divergent ventral process, hind lobe extended anterolaterally, with a transverse membranous area; genital plate as wide as 9th sternite, with robust lateral arms broadened distally. 
Distribution. Japan (Hokkaido, Ishigaki Is. and Iriomote Is.) and Taiwan.

Specimens examined. [Japan] 1 male (Paratype), Akan lakeside, Hokkaido, 1-10. xii. 1907 (H. Sauter); 1 male 1 female, Mt. Omotodake, Ishigaki Is., Okinawa Pref., 20. iii. 1978 (H. Ohishi); 9 males 37 females, same locarity, 22. iii. 1984 (S. Nomura); 2 males 3 females, same locarity, 9. iv. 1986 (S. Nomura); 1 male, Mt. Bannadake, Ishigaki Is., 8. iv. 1986 (S. Nomura); 1 male, Yonehara, Ishigaki Is., 10. iv. 1986 (S. Nomura); 5 males, Kanpiree, Iriomote Is., 12-13. iv. 1986 (S. Nomura). [Taiwan] 4 males, Liu-kui, Kaohsung Hsien, S-Taiwan, 19. ii. 1987 (K. Baba); 17 males, Rengechi, C-Taiwan (Y. Oda).

Remarks. Physomerinus schenklingi (Raffray) is closely allied to F! pedator (Sharp), but differs by the pronotum with a long median longitudinal sulcus which is reaching the anterior and the posterior margins in both sexes, and the hind femora each swollen at the middle part with the oblique groove in male.

Biological notes. One male of Physomerinus schenklingi is captured from the colony of the ant, Pheidole fervida F. Smith nested in the dead wood. But this species usually inhavits in the litter of the primeval forest.

\section{Physomerinus hasegawai sp. nov.}

(Figs. 133C, F, 134G, H, 135C)

\section{Male. Length 1.5-1.7 mm. Width 0.6mm.}

Body reddish brown to light brown, shiny, narrowed in head and pronotum.

Head slightly longer than wide, weakly narrowed anteriorly, clypeus short and arcuate on anterior margin, frons slightly concave, coarsely punctate on lateral parts, with shallow U-shaped sulcus connected with dorsal tentorial pits, vertex convex, sparsely with minute punctures, and with a fme longitudinal carina, postgenae very short and rounded posterolaterally. Eyes very large and convex, each composed of about 30 facets. Antennae short, reaching hind margin of pronotum, 1st segment short, subcylindrical with 2 apical denticles at apex, 2nd longer than wide, subcylindrical, slightly narrower than 1st, 3rd to 4th subequal to each other, each subcylindrical, smaller than 2nd, 5th ovoid, longer than 4th, 6th short, as long as wide, 7 th subequal to 5 th, 8 th short, as long as wide, 9 th to 11 th large, each ovoid, 9th longer than wide, 11th largest, 1.6 times as long as wide.

Pronotum round-sided, as long as wide, sparsely with minute punctures, and with a shallow median longitudinal sulcus from anterior $1 / 5$ to posterior $1 / 7$, a pair of subparallel lateral longitudinal sulci. Elytra slightly wider than long, nearly rectangular and convex, humeri strongly expanded, weakly denticulate, each elytron with 2 dorsal sulci and 2 dorsal foveae, outer sulcus reaching posterior 1/7, incurved on basal 2/3, then outcurved on apical 1/3; hind wing developed. Legs thick in femora, fore tibiae slender, each with a short brush consisting of some twisted setae, mid tibiae each with a very short mucro at apex, hind femora (Fig. 133C, F) each strongly dilated at apical 2/5, each weakly convex on inner side, with broad concavity and complicated sculpture and swelling on outer side.

Abdomen clearly narrower than elytra, rounded posteriorly, 4th abdominal segment largest, weakly narrowed posteriorly, convex, with a pair of broad and short dorsomedian carinae and a pair of indistinct tergosternal ridges, 5th to 6th short, 7th large, 1.3 times as long as 5 th +6 th segments in posterior view, 8th tergite transverse and ovoid, 8th stemite very short and crescent, concave at median part. 
Male genitalia (Fig. 134G, H) small, with a dorsal apophysii on the right side; paramere broad and lameller; basal bulb short, with round basal foramen and a basal strut, ventral stalk slender, weakly dilated and curved basally, widest at apex, dorsal apophysis broad and semitubular, about as long as ventral stalk, weakly narrowed toward apex.

Female. Length $1.5 \mathrm{~mm}$. Width $0.6 \mathrm{~mm}$. Similar to male excepting following characters: Eyes slightly smaller than in male, each composed of about 30 facets; elytra clearly wider than long, narrowed anteriorly, humeri rounded; legs slender, fore tibiae without brush, mid tibiae without mucro, hind femora simple, without swelling or excavation; 4th abdominal segment about as wide as elytra, 8th tergite transverse and ovoid, 8th sternite larger than 8th tergite, semicircular and weakly convex.

Female genitalia (Fig. 135C) narrowed posteriorly; 9th sternite T-shaped, fore lobe longer than wide, with a pair of long ventral processes, hind lobe narrow in anterior part, posterior part strongly extending anterolaterally, with a large and ovoid membranous area; genital plate clearly wider than 9th stemite, transverse, with a pair of large lateral arms broadened distally.

Distribution. Japan (Ishigaki Is.).

Holotype, males (Type No. 2838, Kyushu Univ.), Ishigaki City, Ishigaki Is., Okinawa Pref., 3. iii. 1973, H. Hasegawa leg. Paratypes: 1 male, Hirai, Ishigaki Is., 28. ii. 1973, H. Hasegawa leg.; 1 male, same locality, 3. iii. 1973, H. Hasegawa leg.; 2 males, Hegina, Ishigaki Is., 15. iv. 1974, 0. Tamura leg.; 1 male, same locality as holotype, 14. iv. 1975, H. Ohishi leg.; 1 male 2 females, Mt. Omotodake, Ishigaki Is., 20. iii. 1978, H. Ohishi leg.; 1 male, same locality, 22. iii. 1984, S. Nomura leg.

Remarks. Physomerinus hasegawai sp. nov. is the distinct species in the swollen fourth segment of the maxillary pulpus in the male. The female of this new species is difficult to distinguish from the other species of this genus, but is separated from them by the ninth abdominal sternite with a pair of long ventral processes and an ovoid membranous area, and by the genital plate with a pair of broad lateral arms.

Biological notes. One male was extracted from the litter of the subtropical forest floor together with $P$. schenklingi.

\section{Genus Arthromelodes Jeanne1}

Arthromelodes Jeannel, 1953, Mém. Inst. sci. Madagascar, 4: 247; Newton \& Chandler, 1989, Field. Zool., (53): 33. Type species: Axthromelodes cariei Jeannel, by monotypy.

Pseudobatriscenus Jeannel, 1958, Mém. Mus. Hist. nat. Paris, (A), 18: 66; Newton \& Chandler, 1989, Field. Zool., (53): 39. Syn. nov.

Body dark brown to light brown, head and pronotum narrowed.

Head nearly rectangular on posterior part, clypeus short, arcuate on anterior margin; eyes ovoid, small in some species, antennae slender to moniliform, 1st segment thick, with small, indistinct trichome on anterolateral corner in some species. Pronotum round-sided, with median longitudinal, a pair of lateral, and transverse sulci, median longitudinal sulcus shortened in some species, and with a pair of indistinct antebasal foveae in many species; elytra transverse, convex, each elytron with 2 dorsal and a 
lateral foveae and 2 dorsal and a lateral sulci, lateral foveae absent in some species; legs elongate, fore tibiae each with a bold, twisted macrochaeta at apex in male. Abdomen wider than elytra in some species, 4th segment large, with a pair of basimedian carinae, a pair of tergosternal ridges on basilateral part, 5th to 6th very short, 7th large, 8th tergite more or less deflected posteriorly, with a small emargination on posterior margin in male, 8th sternite crescent in male, semicircular in female, 9th sternite small, located at the emargination of 8th tergite in male. Male genitalia almost same in structure as in $\boldsymbol{B a}$ trisceniola, but with broad dorsal apophysis widely covered with membrane, female genitalia similar in structure to Batrisceniola.

Remarks. This genus is redifined as follows including the type species, Arthromelodes cariei Jeanne1 which I borrowed from Museum Nationale d'Histoire Naturelle de Paris through Dr. C. Besuchet.

The genus Arthromelodes constitutes a large genus group with the genera Batrisceniola and Plocamarthrus by the dorsal apophysis of the male genitalia which is erected on the ventroapical part of the basal bulb distant from the ventral stalk. Arthromelodes is, however, separated from the former genus by absence of the group setae at the seventh tergite (present in both sexes in Batrisceniola); and the latter genus cannot be separable from Arthromelodes according to the present definition.

A Key to the Species and the Subspecies of the Germs Arthromelodes from Japan

\section{Key to Males}

1. Fourth abdominal segment sculptured on dorsal surface 2.

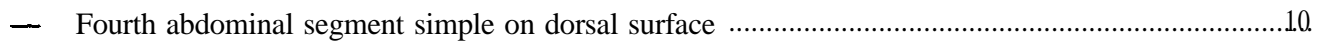

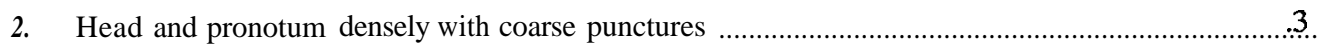
Head and pronotum sparsely ptmctate 4....

3. Fourth abdominal segment strongly constricted at base saikaiensis sp. nov.

- Fourth abdominal segment scarcely constricted, with a very large and deep median concavity.. crucifer sp. nov.

4. Fourth abdominal segment with a pair of large lateral lobes .5

Fourth abdominal segment without lateral lobe ...................................................................................8

5. Fourth abdominal segment with a median concavity being trisinuate on anterior margin; male genitalia with a very long and slender ventral stalk and short dorsal apophysis

dilatatus dilatatus (Raffray)

- Dorsal apophysis of male genitalia longer than ventral stalk with a long spine at left side of the apex

6. Fourth abdominal segment with a pair of large, round setiferous patches and a median concavity being horizontal in anterior margin ...................................................dilatatus daibosatsuanus sp. nov.

- Fourth abdominal segment with a pair of small setiferous patches 7

7. Fourth abdominal segment with a median concavity being bisinuate on anterior margin; male genitalia with narrow and apically sharpened ventral stalk dilatatus shiranemontanus sp. nov.

- Fourth abdominal segment with a median concavity being arcuate on anterior margin; ventral stalk of male genitalia broadened at apical $1 / 3$ dilatatus fujimontanus sp. nov.

8. Fourth abdominal segment with a posteromedian longitudinal carina on bottom of median concavi- 
ty .optatus (Sharp)

- Fourth abdominal segment with a postmedian nodule on bottom of median concavity .9

9. Mid tibiae weakly outcurved externally; 4 th abdominal segment with a round median concavity and a pair of round setiferous patches sinuatipes sp. nov.

- Mid tibiae almost straight; 4th abdominal segment with a transverse concavity and a pair of lengthwise setiferous patches aizuanus sp. nov.

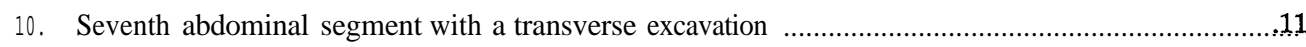

- Seventh abdominal segment without excavation .12

11. Seventh abdominal segment with a round nodule behind the excavation .........thysanoventris sp. nov.

- Seventh abdominal segment with a conical projection behind the excavation ......corniventriis sp. nov.

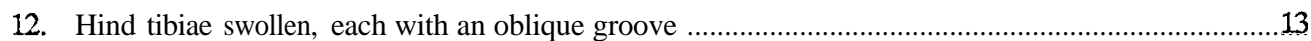

- Hind tibiae slender .......................................................................................................................15

13. Hind tibiae thickest near the middle; 8th abdominal tergite simple .............................. loebli sp. nov.

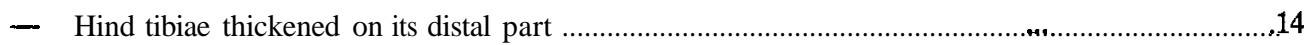

14. Eighth abdominal tergite with a deep transverse groove ........................................mercurius sp. nov.

- Eighth abdominal tergite strongly convex on its basal part, without transverse groove

hikosanus sp. nov.

15. Body large; 9th to 10th antennal segments with setiferous patches; hind femora swollen, each depressed on ventral side giganteus sp. nov.

- Body small; 9th to 10th antennal segments simple; hind femora slender .16

16. Fii to 8th antennal segments swollen gyoja sp. nov.

- Fifth to 8th antennal segment simple, each ovoid . .17

17. Fourth abdominal segment with a pair of long basidorsal carinae on anterior $2 / 5$....pilicolli $s$ sp. nov.

- Fourth abdominal segment with very short basidorsal carinae 18

18. Male genitalia strongly constricted between basal bulb an basal spine kiiensis sp. nov.

- Male genitalia with slender dorsal apophysis tapering on apical part punctifrons sp.nov.

\section{Key to Females}

1. Head slightly narrowed anteriorly; head and pronotum coarsely punctate; elytra with humeral denticles

- Head subparallel-sided to divergent anteriorly; humeri rounded

2. Genital plate of female genitalia with a pair of gradually dilated lateral arms ........saikaiensis sp. nov.

- Genital plate of female genitalia with a pair of lateral arms conspicuously dilated near apex..

crucifer sp. nov.

3. Head, pronotum, elytra and 4th abdominal segment with erect long hair . .4

- Head, pronotum, elytra and 4th abdominal segment without erect long hairs .........................................7

4. Female genitalia weakly sclerotized, with very slender genital plate punctifrons sp. nov.

- Female genitalia strongly sclerotized, genital plate with robust lateral arms

5. Body large; head and pronotum minutely punctate giganteus sp. nov.

- Body small; head and pronotum moderately punctate

6. Ninth sternite clearly longer than wide, with large transverse membranous area, with a pair of elongate ventral processes goja $\boldsymbol{a}$ sp. nov. 
- Ninth sternite with small, ovoid membranous area, each ventral process broadened posteriorly in ventral view

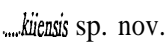

7. Fifth to 8th abdominal segments rounded posteriorly

thysanoventris sp. nov.

- Fifth to 8th abdominal segments subconical

8. Eighth stemite conspicuously convex; ventral process of 9th sternite with a small membranous disc; lateral arm of genital plate weakly narrowed distally

mercurius sp. nov.

- Eighth sternite moderately convex, with dense pubescense on apical part

9. Ventral process of 9th sternite with a very large membranous disc; lateral arm of genital plate clearly dilated distally

loebli sp. nov.

- Ventral process of 9th sternite with a very small membranous disc; genital plate with a pair of narrow lateral arms

hilkosanus sp. nov.

\section{Arthromelodes punctifrons sp. nov.}

(Figs. 139A, B, 146A)

Male. Length 2.1-2.2 mm. Width $0.7 \mathrm{~mm}$.

Body light brown to dark brown shiny, narrowed in head and pronotum.

Head longer than wide, subparallel-sided, pentagonal, clypeus short and arcuately expanded, frons weakly concave and coarsely punctate, vertex weakly convex, with a fine median longitudinal carina, sparsely punctate, postgenae narrowed posteriorly, with long hairs. Eyes small and ovoid, each composed of 10-15 facets. Antennae slender, reaching base of elytra, 1st segment cylindrical, coarsely punctate, 2nd to 9th each subcylindrical, with long hairs, 2nd about as long as 1st, slightly narrower than 1st, thickened distally, 8th shortest, 1.2 times as long as wide, 10th subglobose, slightly wider than 9th, 11th largest, ovoid, 1.8 times as long as wide. Maxillary palpi large, 4th segment longer than 11th antennal segment, about 2.5 times as long as wide, fusiform.

Pronotum about as long as wide, widest at about the middle, convex, sparsely punctate and moderately pubescent, median longitudinal sulcus reaching near anterior margin, lateral longitudinal sulci paired, slightly narrowed anteriorly, transverse sulcus almost horizontal. Elytra wider than long, convex, narrowed anteriorly, humeri flat, pubescent, each elytron with 2 dorsal foveae, and 2 dorsal sulci; hind wings reduced. Metasternum very short, slightly concave at median part. Legs slender, fore tibiae slightly thickened distally, each with a short and thick macrochaeta at apex, mid tibiae tapering, each with a short mucro at apex.

Abdomen slightly narrower than elytra, 4th abdominal segment largest, widest at posterior $1 / 4$, weakly convex, sparsely punctate, pubescent, with a pair of angular tergosternal ridges on basal $3 / 7$, and with some suberect long hairs, 5th to 6th segments short, 7th longer than 5th +6 th in dorsal view, 8th tergite subcircular, weakly convex, arcuately emarginate at posterior margin, with a pair of suberect long hairs, 8th sternite crescent, weakly concave at central part, 9th sternite small and transverse.

Male genitalia (Fig. 139A) with a dorsal apophysis at left side, strongly sclerotized; basal bulb small, with triangular basal foramen, ventral stalk short, extended basally, broadened distally, and beak-shaped as in Batrisceniola dissimilis, articulate process very elongate, dorsal apophysis subtubular on basal $2 / 3$, sharpened apically and curved dorsally in apical part. 
Female. Length 2.0-2.1 $\mathbf{m m}$. Width $0.7-0.8 \mathrm{~mm}$.

Similar to male except for following characters: eyes ovoid, smaller than in male; antennae moniliform; fore and mid tibiae without macrochaeta nor mucro; abdomen shorter than in male, 8th tergite transverse, without emargination, 8th sternite semicircular and weakly convex. Female genitalia (Fig. 146A) weakly sclerotized, 9th sternite T-shaped, broad, almost membranous, genital plate very small, with a pair of very slender lateral arms.

Distribution Japan (Amami-Oshima Is.)

Holotype, male (Type No. 2839, Kyushu Univ.), Yuwandake, Amami-Oshima Is., Kagoshima Pref., 11. v. 1983, S. Nomura leg. Paratypes: 5 females, same data as holotype; 1 female, same locality as holotype, 8. v. 1987, S. Nomura leg.; 2 males, Hatsuno, Amami-Oshima Is., 27. iii. 1978, H. Ohishi leg.; 1 male, same locality as above, 14. v. 1983, S. Nomura leg.; 1 female, Kawauchi river, Amami-Oshima Is., 8. v. 1987, T. Ogata leg.

Remarks. Arthromelodespunctifrons sp. nov. is hardly distinguished in appearance from the females of the other species in this genus, because it does not have any marked male character. Taxonomically, this species is related to A. giganteus sp. nov. and A. kiiensis sp. nov. in the suberect long hairs on dorsal surface. The male genitalia of this species are similar to those in Batrisceniola dissimilis (Sharp) and some species of Procamarthrus in India in the very slender dorsal apophysis, but it differs from others in the long and elongate articulate process and short ventral stalk. The female of this species is separated from others by the weakly sclerotized genitalia.

Biological notes. This species inhabits the litter of the broad leaved forest.

\section{Arthromelodes giganteus sp. nov.}

(Figs. 139C, D, 146B)

Male. Length 2.2-2.3 mm. Width $0.8 \mathrm{~mm}$.

Body reddish brown, shiny, large, thickened posteriorly.

Head round, longer than wide, clypeus arcuate on anterior margin pubescent, frons narrow, weakly concave, sparsely punctate, vertex weakly convex, with a pair of small dorsal tentorial pits, almost glabrous and sparsely pubescent, with a few long suberect hairs, postgenae large, each almost flat. Eyes small and ovoid, each composed of about 15 facets. Antennae long, reaching the middle of elytra, 1st segment subcylindrical, 2nd to 7th each longer than wide, subcylindrical, weakly thickened distally, with long hairs, 8th to 9th each slightly longer than wide, ovoid and swollen ventrally with setiferous patches, 10th ovoid, 11th largest and ovoid, about 2 times as long as wide. Maxillary palpi long, 4th segment about 3 times as long as wide, fusiform and pubescent.

Pronotum longer than head, slightly longer than wide, convex, widest at the middle, almost glabrous and shiny, with 3 longitudinal and a transverse sulci, and with 2 pairs of conspicuous antebasal foveae, median longitudinal sulcus shorter than lateral ones, running from anterior $1 / 3$ to posterior $1 / 3$. Elytra wider than long, widest at posterior $1 / 3$, strongly convex, rounded laterally, each with 2 basal foveae and 2 sulci, outer sulcus running from outer fovea to posterior $1 / 3$. Legs long and densely pubescent, fore trochanters each with short spine, fore tibiae slender, each with a short macrochaeta at apex, mid trochanters with a short spine which is setose at apex, mid tibiae each with a short mucro at apex, hind 
trochanters each with setose spine as in mid one, hind femora each swollen at apical $1 / 3$ with a large, deep pit on ventral side.

Abdomen rounded posteriorly, 4th segment largest, widest at anterior $1 / 3$, sparselypunctate, moderately pubescent, tergosternal ridges and basidorsal carinae completely atrophied, with about 4 pairs of suberect long hairs, 5th to 6th segments very short, 7th and 8th tergite subequal in length in dorsal view, each longer than 5 th +6 th, 8 th tergite convex, arcuately emarginate at apical margin, 8 th stemite short and crescent, 9th tergite transverse and semicircular.

Male genitalia (Fig. 139C) with a dorsal apophysis on left side, strongly sclerotized; basal bulb very large, articulate process extended dorsally, ventral stalk very long, broadened at the middle, dorsal apophysis shorter than basal spine, subtubular, weakly sinuate on basal part, sharpened and curved dorsally on posterior part.

Female. Length 2.2-2.3 $\mathrm{mm}$. Width $0.8-0.9 \mathrm{~mm}$.

Similar to male excepting following characters: eighth to 9th antennal segments without setiferous patch, each subcylindrical, shorter than 7th, 9th ovoid, slightly shorter than 10th, 1.2 times as long as wide; legs slender, trochanters without spine, fore tibiae, mid tibiae and hind femora slender, each without modification as macrochaeta, mucro or pit; 8th abdominal tergite semicircular in posterior view, 8th stemite semicircular and weakly convex.

Female genitalia (Fig. 146B) strongly sclerotized, 9th sternite with a pair of basiventral processes extending ventrally, posterior part transverse, with a pair of deep emargination on both sides, genital plate wider than 9th sternite, W-shaped, with long lateral arms extending basilaterally and tapering apically.

Distribution. Japan (Amami-Oshima Is., Tokunoshima Is.).

Holotype, male (Type No. 2840, Kyushu Univ.), Mt. Yuwandake, Amami-Oshima Is, Kagoshima pref., 11. v. 1983, S. Nomura leg. Paratypes: 1 male 1 female, same data as holotype; 3 males 5 females, same locarity as holotype, 5. v. 1987, S. Nomura leg.; 2 females, Tete, Tokunoshima Is., Kagoshima Pref., 4. v. 1988., S. Nomura leg.

Remarks. Arthromelodesgigaoteus sp. nov. is easily distinguished from the other species of $\boldsymbol{A r}$ thromelodes by the large and shiny body, the sexual patches of the ninth to tenth antennal segments and the swollen hind femur.

Biological notes. This species was found from the litter of the natural forest floor.

\section{Arthromelodes pilicollis sp. nov.}

(Fig. 140A, B)

Male. Length $2.1 \mathrm{~mm}$. Width 0.7-0.8 mm.

Body reddish brown and shiny, narrowed anteriorly.

Head slightly longer than wide, broadened anteriorly, widest at bases of antennae, clypeus arcuately expanded anteriorly, with long hairs, frons broad, weakly concave and coarsely punctate, with a short transverse sulcus, vertex convex, sparsely with coarse punctures, and with a median longitudinal carina, postgenae rounded. Eyes ovoid, each composed of about 20 facets. Antennae short, with long hairs, 1st segment thick and coarsely punctate, 2nd as long as 1st, 2/3 times as wide as 1st, thickened distally, 3rd 
to 4 th short, 5 th about as long as 2 nd, 6th $2 / 3$ times as long as 5 th, 7 th as long as 5 th, 8 th as long as 6 th, 9th to 11th each large and ovoid, longer than wide, 11th largest, 1.7 times as long as wide. Maxillary palpi long, 4th segment fusiform, 3 times as long as wide.

Pronotum as long as wide, convex and scarcely punctate, with 3 pairs of long suberect hairs, median longitudinal sulcus short and shallow. Elytra rounded laterally, convex and sparsely punctate, with 2 pairs of suberect long hairs, humeri almost flat, each elytron with 2 basal foveae and 2 sulci, outer sulcus running from outer fovea to posterior $1 / 4$, weakly curved internally; hind wings reduced. Legs elongate, mid trochanters each with a small spine, mid femora swollen at apical $2 / 5$, mid tibiae each with long mucro at apex.

Abdomen nearly pentagonal in dorsal view, 4th segment largest, 1.7 times as wide as long, slightly broadened posteriorly, tergosternal ridges short, basidorsal carinae long, reaching anterior $2 / 5$, with 4 subelect hairs, 5th to 6th short, 7th longer than 5th +6 th, 8th tergite slightly wider than long, convex, strongly deflected posteriorly, arcuately emarginate at posterior margin, 8th stemite flattened at median part.

Male genitalia (Fig. 140A, B) strongly sclerotized, with a dorsal apophysis on right side; basal bulb small and narrow, ventral stalk very broad on basal part, narrowed and sharpened distally, curved to right, articulate process extended from base of ventral stalk, dorsal apophysis long, broadened at the middle, bifurcated on apical $1 / 3$, curved to right at apical part.

Female. Unknown.

Distribution. Japan (Honshu: Tokai District).

Hoiotype, male (Type No. 2841, Kyushu Univ.), Kuzufu waterfall, Mori-machi, Shizuoka Pref., 24. x 1985, S. Nomura leg. Paratype: 1 male, same data as holotype.

Remarks. Arthromelodes pilicollis sp. nov. is similar to A. kïensis sp. nov. and A. gyoja sp. nov. in having the suberect long hairs on dorsal surface of the body and the eighth abdominal tergite strongly deflected posteriorly, but is easily separated from others by the long dorsomedian carinae and the very long suberect hairs.

Biological notes. The habitat of this species is the litter mixed with sand and gravel in the riverside forest of the upper stream.

\section{Arthromelodes kïensis sp. nov.}

(Figs. 140C, D, 146C)

\section{Male. Length $2.3 \mathrm{~mm}$. Width $0.8 \mathrm{~mm}$.}

Body reddish brown to dark brown, elongate.

Head ovoid, longer than wide, clypeus arcuately expanded anteriorly, coarsely punctate, frons broad and weakly concave, slightly narrowed posteriorly, coarsely punctate, with a shallow transverse sulcus, vertex weakly convex and sparsely punctate, with a median longitudinal carina, postgenae each weakly angulate laterally behind eyes. Eyes small and ovoid, each composed of about 25 facets. Antenna moniliform, reaching base of elytra, 1st segment subcylindrical and coarsely punctate, 2 nd to 11th each ovoid and pubescent, with long hairs, 2nd elongate, 3rd to 4th subequal in length, each smaller than 2nd, 5th 1.2 times as long as 4th, 6th short, as long as wide, 7th as large as 5th, 8th short, as long as 6th, 
9th as large as 2nd, 10th wider than 9th, subglobose, 11th largest, twice as long as wide. Maxillary palpi short, 4th segment largest, 2.5 times as long as wide, fusiform.

Pronotum slightly wider than head, as long as wide, widest at anterior $3 / 7$, sparsely punctate, with 2 pairs of antebasal foveae and a few suberect hairs, median longitudinal sulcus shallow, extending from anterior $1 / 4$ to $3 / 4$ on both sides. Elytra wider than long, round-sided and narrowed anteriorly, each elytron with 2 dorsal foveae, 2 dorsal sulci and a small humeral denticle, outer dorsal sulcus from outer dorsal fovea to basal $2 / 3$, weakly curved internally. Legs elongate, femora thick, fore and mid trochanters each with a small denticle, fore tibiae each with a macrochaeta at apex, mid tibiae each with a short mucro.

Abdomen slightly narrower than elytra, nearly pentagonal in dorsal view, 4th segment largest, weakly convex, subparallel-sided, pubescent, with a pair of clear, short tergosternal ridges, 4 pairs of suberect hairs, basidorsal carinae indistinct, 5th to 6th segments short, 7th very large, 1.4 times as long as 5 th +6 th, 8th tergite strongly deflected on ventral side, very large, slightly wider than long, arcuately emarginate on apical margin, 8th sternite as long as 5th +6 th +7 th sternites, crescent and slightly concave on the median part, 9th stemite small and semicircular in ventral view.

Male genitalia (Fig. 140C, D) very strongly sclerotized, with a dorsal apophysis on right side, constricted between basal bulb and ventral stalk, basal bulb small, rounded on basiventral part, with very small basal foramen, ventral stalk longer than basal bulb, almost straight, extending basiventrally, weakly narrowed apically, but divergent at apex, with acute spine at inner side of apex, dorsal apophysis articulated to base of basal spine, curved ventrally, with 3 elongate spines at apical part, proximal spine covered with membrane, dorsal spine curved to right, apical spine longest, weakly curved basally.

Female. Length $2.2-2.3 \mathrm{~mm}$. Width $0.8 \mathrm{~mm}$.

Very similar to male, but differs as follows: legs more slender than in male, trochanters, fore tibiae and mid tibiae without modification, 7th tergite about as long as 5th +6 th segments, 8th tergite shorter than in male, semicircular, $4 / 7$ times as long as wide, 8th stemite larger than 8th tergite, semicircular.

Female genitalia (Fig. 146C) strongly sclerotized; 9th sternite bilobate, fore lobe membranous on apical part, with a pair of large ventral processes, hind lobe transverse, with a pair of large lobes on both sides and a small ovoid membranous area at the median part, genital plate W-shaped, with a pair of lateral arms which are broadened distally.

Distribution. Japan (Honshu: Kii Peninsula).

Holotype, male (Type No. 2842, Kyushu Univ.), Mt. Odaigahara, Nara Pref., 29-30. v. 1985, S. Nomura leg. Paratypes: 4 males 2 females, same data as holotype; 1 female, same locality as holotype, 25-26. vi. 1981, S. Naomi leg.; 1 female, Mt. Ohto, Wakayama Pref., 28-29. vi. 1981, S. Naomi leg.

Remarks. Arthromelodes kiiensis sp. nov. is allied to A. pilicollis sp. nov. and A. gyoja sp. nov., but the male genitalia of this species has such a special structure that strong constriction between the basal bulb and the ventral stalk associated with the dorsal apophysis.

Biological notes. This species inhabits the litter of the coniferous and deciduous mixed virgin forest at high altitude of Kii Peninsula.

\section{Arthromelodes gyoja sp. nov.}

(Figs. 140E, F, 146D) 
Male. Length $2.5 \mathrm{~mm}$. Width $0.8 \mathrm{~mm}$.

Body reddish brown and shiny, large and elongate.

Head as long as wide, nearly pentagonal and pubescent, clypeus short and coarsely punctate, frons weakly concave and coarsely punctate, with a shallow transverse sulcus, vertex weakly convex and sparsely punctate, with a longitudinal carina, a pair of clear dorsal tentorial pits and a pair of suberect long hairs near its posterior margin, sides of cranium subparallel, postgenae slightly convex and densely pubescent. Eyes ovoid, each composed of about 25 facets. Antennae reaching base of elytra, moniliform, 1st segment subcylindrical and coarsely punctate, 2nd to 10th each ovoid and pubescent, with long hairs, 2nd as long as 1st, 1.5 times as long as wide, 3rd to 4th subequal in length, 3rd as long as wide, 4th slightly wider than $3 \mathrm{rd}$, wider than long, 5th to 8 th each spherical, swollen externally, 5th slightly larger than 4 th, 6th 1.5 times as long as 5th, slightly longer than wide, 7th wider than any other preceding segments, 1.2 times as wide as long, 8th smaller than 7 th, about as wide as 6 th, wider than long, 9th slightly smaller than 8th, swollen internally, wider than long, 10th as wide as 9th, as long as wide, 11th almost fusiform, 1.8 times as long as wide. Maxillary palpi short, 4th segment fusiform, 2.7 times as long as wide.

Pronotum as long as wide, widest at anterior $2 / 5$, round-sided, with complete median longitudinal sulcus, with some suberect long hairs. Elytra short, wider than long, pubescent with some suberect long hairs, each elytron with 2 dorsal foveae and 2 dorsal sulci, outer dorsal sulcus running from outer dorsal fovea to posterior $1 / 3$, weakly curved internally; hind wing reduced. Metastemum concave and coarsely punctate. Legs elongate, fore and mid trochanters each with a short denticle, fore tibiae slender, each with a short macrochaeta at apex, mid tibiae slender, each with an obtuse mucro, hind trochanters each with long spine.

Abdomen very large, slightly narrower than elytra, 4th segment largest, slightly broadened posteriorly, convex and pubescent, with a pair of clear tergostemal ridges on basal $2 / 7$, and with a few suberect long hairs, 5th to 6th short, 7th 1.5 times as long as 5 th +6 th in dorsal view, 8 th tergite slightly wider than long, deflected ventrally, V-notched at posterior margin, 8th sternite almost crescent, weakly concave at median part, 9th small and semicircular in ventral view.

Male genitalia (Fig. 140E,F) strongly sclerotized, with a dorsal apophysis on right side; basal bulb subtubular and twisted, with very narrow basal foramen and basilateral projection, ventral stalk extending basiventrally, very broad on basal part, sharpened distally and curved to right, dorsal apophysis very long and well-stalked, with 2 apical spines each curved to right and acute at apex.

Female. Length $2.3 \mathrm{~mm}$. Width $0.8 \mathrm{~mm}$.

Similar to male except for the following characters: antennae slender, 1st subcylindrical, 2nd to 8th segments each subcylindrical, thickened distally, 9th to 11th each ovoid. Elytra slightly shorter than in male, each elytron with a humeral denticle and a long hair at apex of the denticle. Legs more slender than in male, trochanters, fore tibiae and mid tibiae without such modifications as denticle, spine, macrochaeta nor mucro. 7th abdominal tergite slightly shorter than 5th +6 th segments, 8 th tergite wider than long, projected posteriorly at the middle, 8 th stemite broad and semicircular, almost flat at median part.

Female genitalia (Fig. 146D) strongly sclerotized; 9th sternite longer than wide, fore lobe with a pair of very large ventral processes, each ventral process elongate, widely separated from each other, 
hind lobe T-shaped, with a transverse narrow membranous area; genital plate transverse, clearly wider than 9th stemite, with a pair of lateral arms each broadened distally.

Distribution. Japan (Honshu).

Holotype, male (Type No. 2843, Kyushu Univ.), Mt. Gyojakaeridake, Nara Pref., 15. viii. 1987, H. Ohishi leg. Paratypes: 1 male 2 females, same data as holotype.

Remarks. Arthromelodes gyoja sp. nov. differs from the other species of the germs by the swollen fifth to eighth antennal segments in male. The female of this species is similar to Arthromelodes küensis sp. nov., but the seventh abdominal tergite is strongly convex (almost flat in $\boldsymbol{A}$. kiiensis).

\section{Arthromelodes thysanoventris sp. nov.}

(Figs. 137D, 138E, 141A, B, 146E, F)

Male. Length $2.1 \mathrm{~mm}$. Width 0.7-0.8 mm.

Body light brown to reddish brown.

Head about as long as wide, clypeus short, expanded anteriorly, densely pubescent, frons broad and weakly concave, densely with coarse punctures, with a transverse sulcus, vertex slightly convex and coarsely punctate, with a median longitudinal carina, sides of cranium slightly dilated anteriorly, postgenae each almost flat, with long hairs on ventral side. Eyes small and ovoid, each composed of 20 facets. Antennae short, reaching hind margin of pronotum, 1st segment short, subcyliidrical, 2nd elongate, subcylindrical, 1.7 times as long as wide, slightly thickened distally, 3rd to 6th subequal, clearly narrower than 2nd, each ovoid, slightly longer than wide, 7th 1.2 times as long as 6th, subcylindrical, 1.2 times as long as wide, 8th short and subglobose, 9th 1.3 times as wide as 8th, ovoid, 11th largest, ovoid and pointed at apex. Maxillary palpi short and pubescent, 4th largest, fusiform, 2.5 times as long as wide.

Pronotum convex, about as long as wide, round-sided, sparsely punctate on dorsal surface, median longitudinal sulcus reaching near anterior margin, lateral sulci slightly dilated anteriorly, transverse sulcus on posterior 1/3, antebasal foveae indistinct. Elytra wider than long, convex and pubescent, humeri round, each elytron with 2 dorsal foveae, 2 dorsal sulci, outer dorsal sulcus slightly curved internally; hind wings reduced. Legs thick, densely pubescent, fore tibiae each with a short macrochaeta at apex, mid trochanters each with a short and acute spine, mid tibiae each with a large mucro, hind trochanters each with a spine.

Abdomen (Fig. 138E) about as long as elytra, 4th abdominal segment largest, weakly convex and subparallel-sided, with a pair of clear tergostemal ridges on anterior $2 / 5$, and a pair of short basidorsal carinae on anterior 1/5, 5th to 6th segments short, each tergite with a pair of small fringes composed of some bold setae on postmedian part, 7th large, about as long as 5th +6 th segments with large, transverse excavation on anterior part, and a nodule covered with bold setae just behind the excavation, 8th tergite deflected to ventral side, wider than long, arcuately emarginate at posterior margin, coarsely punctate, 8th sternite crescent, 9th tergite small.

Male genitalia (Fig. 141A, B) with a dorsal apophysis on left side; basal bulb nearly conical, narrowed toward articulate process, with long basal strut, ventral stalk long, constricted on its apical $1 / 5$, curved to left and sharpened apically, dorsal apophysis covered with membrane on basal part, bifurcate on apical part, one apex extending ventrally and the other to left. 
Female, Length $2.1-2.2 \mathrm{~mm}$. Width $0.7-0.8 \mathrm{~mm}$.

Similar to male except for the following characters: antennae shorter than in male, 7 th antenna1 segment as long as wide, 8th short, transverse, 9th subglobose. Legs slender, fore tibiae, mid and hind trochanters and mid tibiae without modification. Fiih to 6th abdominal segments without bold seta, 7th about as long as 5 th +6 th, without excavation nor bold seta, 8 th tergite transverse, weakly convex, 8 th sternite larger than 8th tergite, semicircular and almost flat.

Female genitalia (Fig. 146E) strongly sclerotized, 9th sternite almost triangular, narrowed anteriorly, with a large transverse membranous area at its posterior part, with a pair of narrow ventral processes on its anterior part; genital plate as wide as 9th sternite, W-shaped, with a pair of lateral arms weakly broadened distally.

Distribution Japan (Shikoku).

Holotype, male, Mt. Ishizuchi, Ehime Pref., 13-14. viii. 1980, C. Besuchet and I. Löbl leg. Paratypes: 4 males 1 female, same data as holotype; 2 males 3 females, same locality as holotype, 11-18. viii. 1980, S. and J. Peck leg.; 1 male, same locality as holotype, 16. vi. 1981, S. Naomi leg.; 3 females, Mt. Tsurugi, Tokushima Pref., 15-17. x. 1980, S. Naomi leg. The holotype and 11 paratypes are deposited in the Museum d'Histoire Naturelle, Genève.

Remarks. Arthromelodes thysanoventris sp. nov. is similar to Batriscenellus species in structure of the sexual patch in appearance, but is different in its position (fifth to sixth abdominal segments in $B$ triscenellus). This new species is closely allied to Arthromelodes pilicollis sp. nov. or A.gyoja sp. nov. in structure of the male and female genitalia.

\section{Arthromelodes corniventris sp. nov. \\ (Figs. 137E, 138F, 141C, D)}

\section{Male. Length $2.2 \mathrm{~mm}$. Width $0.8 \mathrm{~mm}$.}

Body reddish brown, elongate, narrowed in head and pronotum.

Head longer than wide, subparallel-sided, densely with coarse punctures on dorsal surface, clypeus short, arcuately expanded anteriorly and densely pubescent, frons weakly concave, with a shallow transverse sulcus, vertex weakly convex, with a median longitudinal carina, postgenae almost flat, with long hairs on ventral side. Eyes ovoid and convex, each composed of 15 facets. Antennae elongate, reaching base of elytra, 1st segment thick and round-sided, 2nd to 8th each subcylindrical, thickened distally, 2nd elongate, 1.8 times as long as wide, 3rd narrower than 2 nd, 4 th shorter than $3 \mathbf{r d}$, as long as wide, 5 th elongate, 1.5 times as long as wide, 6th subequal in length to 4 th, 7 th elongate, subequal to 5 th, 8 th short, slightly longer than wide, 9th to 11th each ovoid, longer than wide, 11th largest, twice as long as wide. Maxillary palpi thick and pubescent, 4th segment fusiform, 2.8 times as long as wide.

Pronotum convex, about as long as wide, round-sided, sparsely punctate on dorsal surface, median longitudinal sulcus reaching near anterior margin, lateral sulci slightly dilated anteriorly, transverse sulcus located on posterior 1/3, antebasal foveae indistinct. Elytra wider than long, convex and pubescent, humeri rounded, each elytron with 2 dorsal foveae and 2 dorsal sulci, outer sulcus slightly curved internally; hind wings reduced, metasternum concave at median part. Legs longer than in thysanoventris, densely pubescent, fore trochanters each with a very small denticle on ventral side, fore tibiae each 
with a short macrochaeta at apex, mid trochanters each with a short and acute spine, mid tibiae each with a large mucro, hind trochanters each with a spine, hind tibiae (Fig. 137E) each with a mucro at apex.

Abdomen (Fig. 137F) about as long as elytra, 4th abdominal segment largest, weakly convex, subparallel-sided, with a pair of clear tergosternal ridges on anterior $1 / 4$, and a pair of short basidorsal carinae on anterior $1 / 7,5$ th to 6 th segments short, each with a few bold setae on postmedian margin, 7th large, as long as 5th +6 th segments, with large, deep and transverse excavation on anterior part, and a conical projection covered with bold setae at its apex just behind the excavation, 8th tergite deflected to ventral side, wider than long, arcuately emarginate at posterior margin, coarsely punctate, 8th sternite crescent, 9th tergite small.

Male genitalia $(141 \mathrm{C}, \mathrm{D})$ very similar in structure to thysanoventris, with a dorsal apophysis on left side; basal bulb roundly expanded dorsoapically, nearly subcylindrical, with obtuse basidorsal projection, ventral stalk short and tapering apically, dorsal apophysis with 2 apical spines, both strongly curved to left.

Female. Unknown.

Distribution. Japan (Honshu: Chugoku District).

Holotype, male (Type No. 2844, Kyushu Univ.), Nakatsuya vall., Yoshiwa-mura, Hiroshima Pref., 8. vi. 1987, S. Nomura leg.

Remarks. Arthromelodes corniventris sp. nov. is closely allied to A. thysanoventris sp. nov., but is separated by the seventh abdominal tergite with a conical projection and the hind tibiae each with an apical mucro in the male.

Biological notes. This species was discovered in the litter of the deciduous forest in the upper riverside.

\section{Arthromelodes mercurius sp. nov.}

(Figs. 137B, 142A-C, 147A, B)

Male. Length $2.1 \mathrm{~mm}$. Width $0.8 \mathrm{~mm}$.

Body reddish brown and shiny, thickened posteriorly.

Head as long as wide, widest at anterior $2 / 5$, nearly pentagonal, clypeus arcuately expanded anteriorly, coarsely punctate, frons broad, weakly concave, coarsely punctate, with a shallow transverse sulcus, vertex weakly convex, sparsely punctate, with a median longitudinal carina, sides of cranium weakly narrowed posteriorly, postgenae slightly rounded. Eyes small and convex, each composed of 15-20 facets. Antennae reaching base of elytra, 1st segment very thick, weakly rounded on both sides, coarsely punctate, 2nd to 11th sparsely punctate, with long hairs, 2nd elongate, as long as 1st, slightly thickened distally, 3rd about $2 / 3$ as long as 2 nd, 4 th subequal to 3 rd in length. 5th about 1.2 times as long as 4 th, 6 th short, 1.2 times as long as wide, 7th subequal to 5 th, 8 th short, subequal to 6 th, 9 th to 11 th thick and ovoid, 9th 1.3 times as long as wide, 10th wider than 9 th, as long as wide, 11th largest, 1.8 times as long as wide, conical on apical part. Maxillary palpi short, with short and long hairs, 4th segment largest, fusiform, about 2.8 times as long as wide.

Pronotum slightly larger than head, slightly longer than wide, convex and sparsely punctate, with a 
deep and long median longitudinal sulcus and 2 pairs of indistinct antebasal foveae. Elytra clearly wider than long, convex and narrowed anteriorly, sparsely punctate and pubescent, each elytron with 2 foveae and 2 sulci, outer sulcus running from outer fovea to posterior $2 / 7$, weakly curved internally on posterior $2 / 3$. Legs thick, fore tibiae slender, each with a thick seta at apex, mid trochanters each with a short spine, mid tibiae slender, each with a long mucro at apex, hind tibiae (Fig. 137B) thicker than hind femora, each tibia simply dilated distally on basal $3 / 4$, then with an oblique groove and setiferous patch on ventral side, densely setose on internal side of apical $1 / 4$.

Abdomen wider than elytra, 4th segment largest, $3 / 5$ as long as wide, slightly divergent posteriorly, convex, sparsely punctate, with a pair of indistinct tergosternal ridges and a pair of obscure basidorsal carinae, 5th to 8th segments conjointly subconical, 5th to 6th segments short, 7th clearly longer than 5th +6th segments, 8th tergite (Fig. 142C) wider than long, strongly convex, with a deep transverse groove at the middle, arcuately emarginate at posterior margin, 8th sternite semicircular, flattened at the median part.

Male genitalia (Fig. 142A, B) with a dorsal apophysis on right side; basal bulb large, rounded, ventral stalk subparallel-sided on basal $2 / 3$, hook-shaped on apical $1 / 3$, with a short spine at outside of base of the hook, dorsal apophysis slightly shorter than ventral stalk, broadened basally, acute at apex.

Female. Length 1.9-2.1 mm. Width 0.7-0.8 mm.

Similar to male except for the following characters: antennae moniliform; legs more slender, fore tibiae and mid trochanters without spine, mid tibiae without modification, hind tibiae more slender than hind femora, without groove nor setiferous patch, 7th tergite about as long as 5th +6 th, 8th tergite convex, without transverse groove nor emargination, 8th sternite (Fig. 147B) strongly convex at apical part, flattened at basal part.

Female genitalia (Fig. 147A) composed of 9th stemite and genital plate; fore lobe of 9th sternite with a pair of ventral processes extended ventroapically, broadened apically in ventral view, each with a small and ovoid membranous disc, hind lobe broad and constricted at the middle, with an ovoid membranous area; genital plate $\mathrm{W}$-shaped, with a pair of robust lateral arms, which is extended basiventrally, broadened distally.

Distribution. Japan (Central Kyushu).

Holotype, male (Type No. 2845, Kyushu Univ.), Mt. Shiratori, Kumamoto Pref., 5. iv. 1987, S. Nomura leg. Paratypes: 2 males 12 females, same data as holotype; 1 male 3 females, Mt. Sobosan, Oita Pref., 16. iv. 1986, S. Nomura leg.

Remarks. Arthromelodes mercurius sp. nov. is closely related with A. hikosanus sp. nov. and A. loeblisp. nov. to form a species group characterized by the hind tibiae each with swellings and the oblique groove in the male. $\boldsymbol{A}$. mercurius is easily distinguished from the other species of this species group by the transverse groove of eighth abdominal tergite in the male.

Biological notes. This species is an inhabitant of the temperate deciduous forest at about $1200 \mathrm{~m}$ altitude of Kyushu Mountains.

Arthromelodes hikosanus sp. nov. (Figs. 137C,142D-G, 147C, D) 
Male. Length $2.0 \mathrm{~mm}$. Width $0.7 \mathrm{~mm}$.

Body reddish brown and shiny, narrowed anteriorly.

Head as long as wide, clypeus arcuately expanded anteriorly, coarsely punctate, frons broad, weakly concave and coarsely punctate, with a shallow transverse sulcus, vertex weakly convex and sparsely punctate, with a longitudinal carina running from frontal transverse sulcus to cervix, sides of cranium subparallel, postgenae weakly rounded. Eyes ovoid, each composed of about 15 facets. Antennae more slender than in mercurius, 1st segment thick and coarsely punctate, 2nd to 8th each longer than wide, thickened distally and sparsely punctate, with long hairs, 2nd as long as 1st, 3rd to 4th subequal in length, 4th slightly narrower than 3rd, 5th 1.2 times as long as 4th, 6th short, 1.2 times as long as wide, 7th elongate, as long as 5 th, 8 th short, as long as 6 th, 9 th to 11 th each ovoid, thick, 9 th 1.3 times as long as wide, 10th slightly shorter and wider than 9th, 11th largest, 1.5 times as long as wide. Maxillary palpi short and pubescent, with long hairs, 4th segment largest, 2.7 times as long as wide, fusiform.

Pronotum slightly larger than head, slightly longer than wide, convex and sparsely punctate, with a deep and long median longitudinal sulcus, 2 pairs of antebasal foveae indistinct. Elytra clearly wider than long, convex, narrowed anteriorly, sparsely punctate and pubescent, each elytron with 2 foveae and 2 sulci, outer sulcus running from outer fovea to posterior $2 / 7$, weakly curved internally on posterior $2 / 3$. Legs thick, fore tibiae slender, each with a thick seta at apex, mid trochanters each with a short spine, mid tibiae slender, each with a long mucro at apex, hind tibiae (Fig. 137C) more slender than hind femora, each slightly delated distally on basal $5 / 7$, then strongly constricted and weakly swollen on apical 27.

Abdomen wider than elytra, 4th segment largest, $3 / 5$ as long as wide, slightly divergent posteriorly, convex and sparsely punctate, with a pair of indistinct tergosternal ridges and a pair of obscure basidorsal carinae, 5th to 8th segments conjointly subconical, 5th to 6th segments short, 7th clearly longer than 5 th +6 th segments, 8th tergite (Fig. 142F) 3/4 times as long as wide, arcuately emarginate at posterior margin strongly convex on basimedian part,

Male genitalia (Fig. 142D, E) showing almost tha same structure as in mercurius, but outer projection of ventral stalk clearly bifurcate and median spine of dorsal apophysis acute and longer than in mercurius.

Female. Length $2.1-2.2 \mathrm{~mm}$. Width $0.7-0.8 \mathrm{~mm}$.

Similar to male except for the following characters: antennae moniliform, legs more slender, fore tibiae, mid trochanters and mid tibiae without modification, hind tibiae more slender than hind femora, without constriction nor setiferous patch, 7th tergite about as long as 5th +6 th tergites, 8 th tergite (Fig. 147D) convex and semicircular, 8th stemite moderately convex, densely pubescent on apical part.

Female genitalia (Fig. 147C) composed of 9th sternite and genital plate; 9th sternite broad, fore lobe with a pair of ventral processes extending ventroapically, each with a very small membranous disc at ventral part, hind lobe T-shaped and constricted on apical part, with large membranous area; genital plate W-shaped, with a pair of long divergent lateral arms.

Distribution. Japan (Northern Kyushu).

Holotype, male (Type No. 2846, Kyushu Univ.), Buzenbo, Mt. Hikosan, Fukuoka Pref., 27. viii. 1988, S. Nomura leg. Paratype: 4 females, same locality as holotype, 30. iv. 1983, S. Nomura leg.; 1 female, same locality as holotype, 2. v. 1983, S. Nomura leg.

Remarks. Arthromelodes hikosanus sp. nov. is the most closely related to A. mercurius, but is 
separated by absence of the transverse groove on the eighth abdominal tergite and the hind tibiae each swollen at apical $2 / 7$ in the male, which is more slender than A. mercurius. The female of this species is distinguished from others by the small membranous disc on the ninth abdominal sternite.

Biological notes. This species inhabits the deciduous forest mainly composed of Fraxinus Spaethiana.

\section{Arthromelodes loebli sp. nov.}

(Fii. 137A, 142H-L, 147E, F)

\section{Male. Length $2.2 \mathrm{~mm}$. Width $0.7 \mathrm{~mm}$.}

Body right brown to dark brown, head and pronotum narrower than elytra.

Head slightly wider than long, clypeus weakly expanded anteriorly, frons broad, weakly concave and coarsely punctate, with a shallow transverse sulcus, vertex weakly convex, sparsely punctate, with a median longitudinal carina, sides of cranium slightly narrowed posteriorly, postgenae almost flat. Eyes small and convex, each composed of 15-20 facets. Antennae longer than those in mercurius, reaching the middle of elytra, slender, 1st segment very thick, wider than any other segments, 2nd elongate, about 1.6 times as long as wide, thickened distally, 3rd to 8th each subcylindrical, slightly thickened distally, 3rd to 4th subequal in length, 5th elongate, 1.3 times as long as 4 th, 6th as large as 4th, 7th elongate, as large as 5 th, 8 th shortest, $5 / 8$ as long as 7 th, slightly longer than wide, 9th to 11th each ovoid, longer than wide, 9th elongate, as long as 7th, 10th wider and shorter than 9th, 11th largest, twice as long as wide. Maxillary palpi short, 4th segment largest, 2.5 times as long as wide, fusiform.

Pronotum slightly larger than head, slightly longer than wide, convex and sparsely punctate, median longitudinal sulcus long and deep, 2 pairs of antebasal foveae indistinct. Elytra clearly wider than long, convex, narrowed anteriorly, sparsely punctate and pubescent, each elytron with 2 dorsal foveae and 2 dorsal sulci, outer dorsal sulcus running from outer fovea to posterior $2 / 7$, weakly curved internally on posterior $2 / 3$. Legs longer than in mercurius, fore tibiae slender, each with a macrochaeta at apex, mid trochanters each with a short spine, mid tibiae slender, each with a long mucro at apex, hind tibiae (Fig. 137A) about as wide as hind femora, each widest at the middle, swollen onventrolateral side, with oblique depression.

Abdomen as wide as elytra, 4th segment subparallel-sided,

5 th to 8 th segments conjointly subconical, 5th to 6th segments short, 7th clearly longer than 5 th +6 th segments, 8 th tergite (Fig. 142K) $3 / 4$ times as long as wide, arcuately emarginate at posterior margin, moderately convex.

Male genitalia (Fig. 142H-J) with a dorsal apophysis on left or right side; basal bulb large and rounded basidorsally, with an acute projection at dorsal base of basal foramen, ventral stalk clearly dilated distally, simply acuminate on inner side of apex, bidenticulate on outer side, dorsal apophysis very broad at the middle, covered with large membrane on its apical half, with median spine tapering outward and bifurcate at apex.

Female. Length $2.2-2.3 \mathrm{~mm}$. Width $0.7-0.8 \mathrm{~mm}$.

Similar to male except for the following characters: antennae moniliform, legs more slender, fore tibiae and mid trochanters without spine, mid tibiae without modification, hind tibiae more slender than hind femora, without depression nor setiferous patch, 7 th tergite about as long as 5 th +6 th, 8 th tergite 
(Fig. 147F) semicircular and convex, 8th stemite weakly convex and densely pubescent on apical part.

Female genitalia (Fig. 147E) composed of 9th sternite and genital plate; 9th sternite very large, fore lobe broadened posteriorly, with a pair of well-sclerotized ventral processes, each process separated from each other and with a very large and ovoid membranous disc at posterior part, hind lobe transverse and constricted on apical part, with a very large and ovoid membranous area; genital plate almost Vshaped, with a pair of long lateral arms broadened distally.

Distribution. Japan (Shikoku).

Holotype, male, Mt. Ishizuchi, Ehime Pref., 13-14. viii. 1980, I. Löbl and C. Besuchet leg. Paratypes: 12 males 4 females, same data as holotype; 1 male, Omogo vall., Ehime Pref., 18-25. viii. 1980, S. and J. Peck leg.; 1 male, Mt. Kotsu, Masyoku-gun, Tokushima Pref., 8. v. 1977, H. Ohishi leg. The holotype and 17 paratypes are deposited in Museum d'Histoire Naturelle, Genève.

Remarks. Arthromelodes loebli sp. nov. is closely allied to A. mercurius sp. nov. and A. hikosanus sp. nov., but differs from them in the hind tibiae each swollen at the middle in the male and the very large membranous disc of 9th abdominal stemite in the female. The dimorphism of the male genitalia is observed in this species like Batrisceniola dissimilis, etc.

\section{Arthromelodes dilatatus (Raffray) comb. nov.}

Batrisocenus dilatatus Raffray, 1909, Ann. Soc. ent. Fr., 78: 25; 1911, Psel., Coleopt. Cat., (27): 70. Pseudobatriscenus dilatatus: Jeannel, 1958, Mém. Mus. Hist. nat., Paris, (A), 18: 66, comb. nov.

Distribution. In the original description, the distribution is indistinctly referred to as "Japan or Y unnan".

Remarks. Arthromelodes dilatatus (Raffray) is a distinct species in having the bilobed fourth abdominal segment. This species is related to Arthromelodes gyoja sp. nov. and its allied species in the structure of the male genitalia, i. e. the internally curved ventral stalk and the out-curved apical spines of the dorsal apophysis.

According to the original description by Raffray (1909) and the redescription by Jeanne1 (1958), the nominotypical subspecies is characterized by the followings: fourth abdominal segment with a pair of lateral lobes, each with very large and ovoid setiferous patch, and a median concavity being trisinuate on its anterior margin; male genitalia consisting of a subconical basal bulb, a very long and slender ventral stalk and a short dorsal apophysis.

This subspecies has not been recorded except for the type specimens, but the other three subspecies are newly described below.

\section{Arthromelodes dilatatus daibosatsuanus subsp. nov.}

(Figs. 138B, 143A, B)

Male. Length 1.9-2.2 mm. Width 0.8-0.9 mm.

Body reddish brown, shiny, broadened posteriorly.

Head longer than wide, clypeus arcuately expanded anteriorly, densely pubescent, frons broad and 
concave, with a transverse sulcus, sparsely with coarse punctures on lateral part, scarcely punctate on median part, vertex weakly convex, with an angular median longitudinal carina, sides of cranium slightly dilated anteriorly, postgenae large and each almost flat, with long hairs just behind eyes. Eyes ovoid and convex, each composed of 15-20 facets. Antennae slender, reaching the base of elytra, 1st segment subcylindrical, 2nd narrower than 1st, elongate and ovoid, 3rd and 4th subequal to each other, each ovoid, 1.2 times as long as wide, 5th to 7th each elongate, subcylindrical, 8th short, slightly longer than wide, 9th to 11th each large, ovoid, 11th largest, pointed at apex, 1.7 times as long as wide. Maxillary palpi large, densely pubescent, 4th segment fusiform, 2.7 times as long as wide.

Pronotum as long as wide, round-sided, sparsely punctate on dorsal surface, median longitudinal sulcus reaching near anterior margin, antebasal foveae indistinct. Elytra wider than long, convex and round-sided, widest at posterior $2 / 5$, with small humeral denticles, each elytron with 2 dorsal sulci and 2 dorsal foveae, outer dorsal sulcus running from outer dorsal fovea to posterior $1 / 4$, weakly curved internally; hind wings reduced. Legs elongate, fore tibiae slender, each with a short macrochaeta at apex, mid tibiae slender, each with a long, sharp and ciliate mucro, hind trochanters short, each with a hooked, ciliate spine at apical part.

Abdomen short, 4th segment (Fig. 138B) extended dorsolaterally and lobate on both sides along the tergostemal ridges, with a pair of very short basidorsal carinae and a pair of large and round setiferous patches on the lateral lobes, and deeply excavated on posteromedian part, the excavation large and ovoid, glabrous on its bottom and almost horizontal on anterior margin, with a posteromedian nodule and 2 pairs of secretory setae at anterior part, 5th to 6th very short, subequal in length to each other, 7th large, 1.3 times as long as 5 th +6 th segments, 8 th stemite longer than wide, weakly convex, with a small arcuate emargination at posterior margin 8th stemite crescent and weakly concave on median part, 9th tergite very small.

Male genitalia (Fig. 143A, B) small and strongly sclerotized, with a dorsal apophysis on left side; basal bulb small and subtubular, with a long basal strut, ventral stalk broad on basal part, feebly curved to left, widest at basal 1/3, acute at apex, dorsal apophysis longer than ventral stalk, with 2 apical spines bent toward left.

Female. Unknown.

D istribution Japan (Central Honshu: Buko mountains)

Holotype, male (Type No. 2847, Kyushu Univ.), Kaminikkawa pass, Mt. Daibosatsu, Yamanashi Pref., 15-18. vii. 1982, S. Naomi leg. Paratypes: 6 males, same data as holotype.

Remarks. Arthlomelodes dilatatus daibosatsuanussubsp. nov. is similar to the nominotypical subsp.dilatatus, but the lateral lobe is very large, the anterior margin of the median concavity is almost horizontal on the fourth abdominal segment and the basal spine of the male genitalia is widest at the basal 13 .

\section{Arthromelodes dilatatus shiranemontanus subsp. nov.}

(Figs. 138D, 143E, F)

Similar to subsp. daibosatsuanus in appearance, but differs from the other subspecies by the follow ing characters: fourth abdominal segment (Fig. 138D) with well-developed lateral lobes and a pair of small setiferous patches on the lobes and broad median concavity being bisinuate on anterior margin; 
ventral stalk of male. genitalia (Fig. 143E, F) elongate, widest at basal 2/5, then sharpened toward apex, dorsal apophysis with large, dorsoapical spine hook-shaped in lateral view.

Distribution. Japan (Central Honshu: Akaishi mountains).

Holotype, male (Type No. 2848, Kyushu Univ.), Hirogawara, Mt. Shirane, Yamanashi Pref., 9-U. vii. 1982, S. Naomi leg. Paratypes: 2 males, same data as holotype.

\section{Arthromelodes dilatatus fü̈montanus subsp. nov.}

(Fii. 138C, 143C, D)

Similar to subsp. daibosatsuanus except for the following characters: fourth abdominal segment (Fig. 138C) with a pair of small lateral lobes, a pair of small setiferous patches on the lobes and round median concavity being arcuate on anterior margin; basal bulb of male genitalia (Fig. 143C, D) with very long basal strut, ventral stalk short, broadened on apical half, dorsal apophysis large, with 2 apical spine, one curved ventrally, the other toward left, acute at apex.

Holotype, male (Type No. 2849, Kyushu Univ.), Okuniwa, Mt. Fuji, Yamanashi Pref., 21. vii. 1982, S. Naomi leg. Paratypes: 3 males, Aokigahara, Mt. Fuji, Yamanashi Pref., 23. vii. 1982, S. Naomi leg.

\section{Arthromelodes sinuatipes sp. nov.}

(Figs. 137F, 138A, 141A, B)

Male. Length $2.0 \mathrm{~mm}$. Width $0.7 \mathrm{~mm}$.

Body reddish brown maxillary palpi and tarsi light brown.

Head clearly longer than wide, subparallel-sided, clypeus large, arcuately expanded anteriorly, frons broad and clearly concave, elevated and coarsely punctate on lateral parts, very sparsely punctate on median part, with V-shaped transverse sulcus, vertex weakly convex, coarsely ptmctate, with a median longitudinal carina, postgenal areas large, each almost flat, with long hairs. Eyes ovoid and convex, each composed of 15 facets. Antennae slender, reaching humeri of elytra, 1st segment short and thick, roundsided and coarsely punctate, 2nd to 8th each subcylindrical, thickened distally, 2nd elongate, 1.7 times as long as wide, 3rd to 7th subequal in width to each other, each longer than wide, 8th shortest, 1.2 times as long as wide, 9 th to 11 th each thick and nearly ovoid, 9 th and 10th subequal in length to each other, each swollen in ventral part, 11th largest, 1.8 times as long as wide, pointed at apex. Maxillary palpi small and densely pubescent, 4th segment fusiiorm, 3 times as long as wide.

Pronotum round-sided, as long as wide, sparsely punctate, with suberect long hairs, median longitudinal sulcus shallow and running from anterior 1/9 to posterior 1/7. Elytra convex and rounded laterally, each elytron with an unisetose humeral denticle, 2 dorsal fovea and 2 dorsal sulci, outer dorsal sulci weakly curved internally, running from outer dorsal fovea to posterior 1/3; hind wings reduced. Legs elongate and densely pubescent, fore tibiae slender, each with a macrochaeta at apex. mid trochanters short, each with a small and obtuse denticle, mid tibiae (Fig. 137F) curved externally at the middle, each with a ciliate long mucro at apex, hind trochanters short, each with a ciliate long spine on posterior side being curved apically.

Abdomen narrower than elytra, 4th segment (Fig. 138A) narrowed posteriorly, with median concav- 
ity and a pair of setiferous patch; median concavity broad and round, glabrous on the bottom, with a pair of macrochaetae, a pair of trichomes and a posteromedian setose nodule on its bottom, tergosternal ridges and basidorsal carinae very short, 5th to 6th segments very short, subequal in length to each other, 7 th very large, twice as long as 5 th +6 th in dorsal view, 8th tergite slightly longer than wide, nearly circular, with small emargination at posterior margin, 8th sternite crescent and weakly concave on the median part.

Male genitalia (Fig. 141A, B) strongly sclerotized, with a dorsal apophysis on right side; basal bulb short and nearly conical, with very long basidorsal projection, ventral stalk large, slightly longer than dorsal apophysis, broadened basally, with elongate membranous area, dorsal apophysis elongate and subtubular, with long, hook-shaped spine curved to right.

Female. Unknown.

Distribution. Japan (Honshu: Kanto District).

Holotype, male (Type No. 2850, Kyushu Univ.), Yushin, Tanzawa, Kanagawa Pref., 26. v. 1984, Y. Hirano leg. Paratype: 1 male, same data as holotype.

Remarks. Arthromelodes sinuatipes sp. nov. is most closely related to A. dilatatus (Raffray), but is easily distinguished by the outcurved mid tibiae and the fourth abdominal segment without lateral lobes.

\section{Arthromelodes aimanus sp. nov.}

(Figs. 136, 144C, D)

Male (Fig. 136). Length $2.3 \mathrm{~mm}$. Width $0.8 \mathrm{~mm}$.

Body reddish brown and shiny, narrowed in head and pronotum.

Head subparallel-sided, clypeus short, arcuately expanded anteriorly, coarsely punctate, frons concave and coarsely punctate on lateral parts, sparsely punctate on median part, with a shallow transverse sulcus, vertex convex, with angular median longitudinal carina, postgenae large, each almost flat, with long hairs on ventral side. Eyes ovoid and convex, each composed of 17 facets. Antennae slender, reaching humeri of elytra, with long hairs, 1st segment thick, subcylindrical and coarsely punctate, 2nd elongate, twice as long as wide, weakly thickened distally, 3rd to 7th subequal in width to each other, each longer than wide, thickened distally, 8th short, 1.2 times as long as wide, 9th to 11th each large and ovoid, longer than wide, 10th subequal in length to 9th, wider than 9th, 11th largest, pointed at apex, twice as long as wide. Maxillary palpi densely pubescent, 4th segment fusiform, 2.8 times as long as wide.

Pronotum longer than wide, round-sided, median longitudinal sulcus short and shallow, running from anterior $2 / 7$ to posterior $1 / 5$, transverse sulcus shallow and weakly sinuate. Elytra wider than long, convex and narrowed anteriorly, humeri each with an unisetose denticle, each elytron with 2 dorsal foveae and 2 dorsal sulci; hind wings reduced. Legs densely pubescent, femora thick, fore trochanters short, each with a small denticle, fore tibiae slender, each with a bold and long macrochaeta at apex, mid trochanters short, each with an unisetose denticle, mid tibiae slender, each with a long mucro, hind trochanters short, each with a short denticle.

Abdomen slightly narrower than elytra, round-sided, 4th segment largest, widest at anterior $2 / 5$, with deep and transverse median concavity, and a pair of setiferous patches, median concavity glabrous 
on its bottom, with a pair of macrochaetae, a pair of trichomes, a pair of truncate projections, and a posteromedian nodule on its bottom, tergosternai ridges angular on anterior half, basidorsal carinae short on anterior $1 / 5$, 5th to 6th segments very short, subequal in length to each other, 7 th large, 1.8 times as long as 5 th +6 th segments, 8 th tergite slightly wider than long, almost circular, with small emargination at posterior margin, 8th stemite wider than 8th tergite, crescent and weakly concave on the middle part.

Male genitalia (Fig. 144C, D) with a dorsal apophysis on right side; basal bulb subconical, with very long basal strut extending ventrally, ventral stalk raised from left side of basal bulb, very broad on basal part, weakly narrowed distally, dorsal apophysis about as long as ventral stalk, subtubular, with a large and basally bent spine on right side of the apex.

Female. Unknown.

Distribution. Japan (Honshu: Tohoku District).

Holotype, male (Type No. 2851, Kyushu Univ.), Mt. Asakusadake, Okutadami, Fukushima Pref., 22. vii. 1987, S. Nomura leg.

Remarks. Arthromelodes aizuanus sp. nov. is very closely allied to $\boldsymbol{A}$. dilatatus (Raffray) and $\boldsymbol{A}$. sinuatipes sp. nov., but is separated from the former by absence of the lateral lobes on fourth abdominal segment, and from the latter by the straight mid tibiae and the fourth abdominal segment with a pair of large setiferous patches and a pair of truncate projections.

Biological notes. The type specimens were discovered under bark of the dead tree (Aesculus turbinata) together with Batriscenellus fallax and Batrisceniola dissimilis.

\section{Arthromelodes optatus (Sharp)}

Batrisus optatus Sharp, 1874, Trans. ent. Soc. London, 1874, p. 112; 1883, ibid, 1883, p. 321.

Batrisocenus optatus. Raffray, 1904, Ann. Soc. ent. Fr., 73: 218; 1909, Coleopt. Psel., Gen. ins., 64: 173; 1911, Psel., Coleopt. Cat., (27): 70.

Arthromefodes optatus Jeannel, 1958, Mém. Mus. Hist. nat., Paris, (A), 18: 51.

Remarks. Arthromelodes optatus (Sharp) has not been recorded additionally after Sharp (1874) described it. But this species is clearly related to A.dilatatus and allied species in the structure of the male genitalia and median concavity of the fourth abdominal segment in the male judging from the original description and the redescription by Jeanne1 (1958).

\section{Arthromelodes saikaiensis sp. nov.}

(Figs. 145A, B, 147G)

Male. Length 2.0-2.1 mm. Width 0.7-0.8 mm.

Body reddish brown and shiny, elongate.

Head longer than wide, subparallel-sided, clypeus short and arcuate on anterior margin, densely pubescent, frons slightly concave and coarsely puncrate, with a transverse sulcus, vertex slightly convex 
and coarsely punctate, with an angular median longitudinal carina, postgenae rounded, with long hairs. Eyes convex and ovoid, each composed of about 20 facets. Antennae short, reaching hind margin of pronotum, 1st segment short and thick, round-sided and coarsely punctate, 2nd to 11th nearly moniliform, each segment ovoid, with long hairs, 2nd 1.2 times as long as wide, thickened distally, 3rd to 4th narrower than 2nd, subequal to each other, each as long as wide, 5th 1.3 times as long as 4th, 6th sübequal in length to 4 th, short, 7 th subequal to 5 th, elongate, 8th slightly wider than long, 9th to 10th subequal in length, each as long as wide, swollen internally, 11th largest, 1.5 times as long as wide. Maxillary palpi short and densely pubescent, 4th segment fusiform, 2.6 times as long as wide.

Pronotum wider than long, coarsely punctate on dorsal surface, median longitudinal sulcus reaching anterior $1 / 6$, transverse sulcus located on posterior $2 / 7$, almost horizontal, antebasal foveae indistinct. Elytra wider than long, nearly trapezoid, humeri weakly expanded, each with an unisetose humeral denticle, each elytron sparsely punctate, with 2 dorsal foveae and 2 dorsal sulci, outer dorsal sulcus running from outer dorsal fovea to posterior $1 / 6$, weakly curved internally; hind wings reduced; metasternum weakly concave on median part. Legs short and thick, fore tibiae slender, each with a bold macrochaeta at apex, mid trochanters short, each with a short spine, mid tibiae weakly thickened on apical 2/5, each with a long mucro, hind trochanters short, each with a short spine.

Abdomen strongly constricted at base, 4th segment with a pair of glabrous lateral excavations forming the basal constriction, and with a median concavity and a pair of setiferous patches; median concavity round, deep, with a pair of macrochaetae, 3 pairs of trichomes and a weak nodule covered with setae and pubescense on anterior part, tergostemal ridges running along dorsal margins of lateral excavations from base to the middle, basidorsal carinae short, 5th to 6th segments short, subequal in length to each other, 7th large, 1.2 times as long as 5 th +6 th segments, 8th tergite slightly wider than long, almost circular, with a small emargination at posterior margin, 8th sternite crescent and weakly depressed on median part.

Male genitalia (Fig. 145A, B) strongly sclerotized, with a dorsal apophysis on left side; basal bulb tubular, with small basidorsal projection, ventral stalk slightly shorter than dorsal apophysis, broadened basally and acute at apex, with an elongate membranous area, dorsal apophysis subtubular, with 2 acute apical spines, one spine extending basally, the other to the left.

Female. Length $1.9-2.0 \mathrm{~mm}$. Width $0.7 \mathrm{~mm}$.

Similar to male except for the following characters: antennae shorter than in male; fore tibiae, mid trochanters, mid tibiae and hind trochanters without modification; 4th abdomional segment simple, without lateral excavation nor median concavity, 7th segment slightly shorter than 5 th +6 th segments, 8th tergite wider than long, arcuate on poaterior margin 8th stemite longer than 8th tergite, semicircular and convex.

Female genitalia (Fig. 147G) well-sclerotized; 9th stemite broadened posteriorly, fore lobe nearly triangular with a pair of large ventral processes dilated posteriorly, hind lobe transverse, constricted on both sides, with a transverse membranous area at posterior part; genital plate about as wide as 9th sternite, W-shaped, with a pair of slender lateral arms slightly broadened distally.

Distribution. Japan (Western Kyushu).

Holotype, male (Type No. 2852, Kyushu Univ.), Mt. Seira, Saga Pref., 3. iii. 1985, S. Nomura leg. Paratypes: 1 female, same locality as holotype, 28. v. 1984, S. Nomura leg.; 15 males, Ryumon vall... Mt. Kurokami, Saga Pref., 23. x. 1977, H. Ohishi leg.; Mt. Taradake, Saga Pref., 15. iv. 1984, S. Nomura leg.; 2 
males 1 female, same locality, 10. iv. 1988, S. Nomura leg.; 3 males 7 females, Todoroki vall., Nagasaki Pref., 10. iv. 1988, S. Nomura leg.; 4 males 6 females, Mt. Iwaya, Nagasaki City, Nagasaki Pref., 29. v. 1987, S. Nomura leg.; 1 male 1 female, Shimoda, Amakusa-shimojima Is., Kumamoto Pref., 7. viii. 1977, H. Ohishi leg.; 1 female, same locality, 9. x. 1977, H. Ohishi leg.

Remarks. Arthromelodes saikaiensis sp. nov. is related to A. dilatatus (Raffray) in the structure of the male genitalia; this species is distinctly separable from the others by the strongly constricted abdomen in the male.

Biological notes. This species inhabits the sand mixed with humus at the upper riverside.

\section{Arthromelodes crucifer sp. nov.}

(Figs. 145C, D, 147H)

Male Length $2.0 \mathrm{~mm}$. Width $0.7 \mathrm{~mm}$.

Body reddish brown, maxillary palpi and tarsi light brown narrowed in head and pronotum.

Head weakly narrowed anteriorly, densely with coarse punctures on dorsal surface, clypeus short and arcuate on anterior margin, frons slightly narrow, weakly convex, with a shallow transverse sulcus, vertex weakly convex, with a median longitudinal carina, postgenae broad and weakly rounded, with long hairs. Eyes ovoid and convex, each composed of about 20 facets. Antennae moniliform, reaching humeri of elytra, 1st segment thick and subcylindrical, coarsely punctate, 2nd to 8th each ovoid, with long hairs, 2nd 1.3 times as long as wide, weakly thickened distally, 3rd to 4th narrower than 2 nd, subequal to each other, 5th larger than 4th, 6th subequal to 4 th, 7 th slightly larger than 5 th, 8th subequal to 4th, 9th to 11th large, each ovoid, 9th and 10th subequal in length, each swollen internally, 11th largest, 1.2 times as long as wide. Maxillary palpi short and densely pubescent, 4th segment fusiform, 3 times as long as wide.

Pronotum slightly longer than wide, densely with coarse punctures on dorsal surface, with suberect long hairs on both sides, median longitudinal sulcus short and shallow, running from anterior $3 / 7$ to posterior $1 / 8$, lateral sulci weakly narrowed posteriorly, transverse sulcus bisinuate, being at posterior $1 / 4$, antebasal foveae indistinct. Elytra narrowed anteriorly, convex and sparsely punctate, humeri flat, each with an unisetose denticle, each elytron with 2 dorsal foveae, and 2 dorsal sulci, outer dorsal sulcus running from outer dorsal fovea to posterior $1 / 5$, weakly curved internally; hind wings reduced. Legs thick in femora, trochanters short, each with a small denticle, fore tibiae slender, each with a long and ciliate mucro at apex.

Abdomen slightly narrower than elytra, nearly pentagonal in dorsal view, 4th segment slightly broadened posteriorly, flattened laterally, with a median concavity and a pair of acinous patches; median concavity very large, deep, slightly longer than wide, with a pair of macrochaeta at basal part, and crossed carina on its bottom, the carina covered with setae and pubescense, both sides of concavity elevated, a pair of aciuous patches small and round, located on basilateral sides of the segment, a pair of tergosternal ridges indistinct, a pair of basidorsal carinae very short, 5th to 6th very short, subequal in length to each other, 7 th large, twice as long as 5 th +6 th segments in dorsal view, 8th tergite wider than long, rounded, with small emargination at posterior margin, 8th sternite crescent, weakly depressed at the middle part. 
Male genitalia (Fig. 145C, D) with a dorsal apophysis on right or left side; basal bulb subtubular, with basidorsal projection, ventral stalk conspicuously broadened basally, acute at apex, dorsal apophysis narrowed distally, bifurcate at apex.

Female. Length $2.0 \mathrm{~mm}$. Width $0.7 \mathrm{~mm}$.

Similar to male except for legs being shorter and more slender than in male, without modification and 4th abdominal segment without median concavity nor acinous patches. Eighth tergite wider than long, slightly convex and rounded at posterior margin, 8th sternite larger than 8th tergite, convex and semicircular, densely pubescent along posterior margin.

Female genitalia (Fig. 147H) weakly sclerotized; fore lobe of 9th sternite narrowed anteriorly in ventral view, with a pair of lobate ventral processes, hind lobe large and transverse, with a rectangular membranous area at posterior part; genital plate wider than 9th sternite, with a pair of long lateral arms broadened distally.

Distribution Japan (Yaku Is.).

Holotype, male (Type No. 2853, Kyushu Univ.), Shiratani-Unsuikyo, Yaku Is., Kagoshima Pref., $13-$ 14. v. 1987, S. Nomura leg. Paratypes: 5 males 19 females, same data as holotype; 1 female, same locality, 16. v. 1986, T. Yasunaga leg.; 1 male 2 females, Shikanosawa, Yaku Is., 11. xi. 1985, T. Tanabe leg.; 1 female, Miyanoura, Yaku Is., 29. vii. 1986, T. Tanabe leg.

Remarks. Arthromelodes crucifer sp. nov. is easily distinguished from the other Arthromelodes species in having the predominantly large median concavity in the male, and by the narrow frons and the coarsely and densely punctate head and pronotum in the female. The male genitalia are dimorphic in male of this species as in Batrisceniola dissimilis, etc.

Biological notes. This species is an inhabitant of the broad-leaved forest at low to middle altitude in Yaku Is.

\section{Genus Batriscemiola Jeannel}

Batrisceniola Jearmel, 1958, Mtm. Mus. Hist. nat., Paris, (A), 18: 65; Newton \& Chandler, 1989, Field.
Zool
$53)$
34
Batrisuscidissimilismonotypy.

Body reddish brown, head and pronotum narrower than elytra.

Head wider than long, clypeus very large and arcuately expanded anteriorly, frons broad, with a pair of large excavations in male and with very small ones in female, vertex with a median longitudinal carina. Eyes large and ovoid, antennae moniliform; maxillary palpi long, 4th segment fusiform. Pronotum as long as wide, convex and coarsely punctate on dorsal surface, with 3 longitudinal and 2 pairs of transverse sulci, with a pair of basilateral and a basimedian foveae. Elytra wider than long, sparsely punctate. Abdomen subcylindrical, 4th abdominal segment largest, with a median, a pair of lateral, a pair of ventromedian and a pair of ventrolateral foveae, with a pair of basimedian carinae and a pair of tergosternal ridges on basal $2 / 3,7$ th tergite with some secretory setae on its dorsoapical part in both sexes, 8th tergite wider than long, arcuately emarginate at posterior margin in male, nearly circular in female, 8th sternite crescent in male, semicircular in female, 9th sternite visible externally, very small in 
male.

Male genitalia consisting of paramere and median lobe; paramere lamellar and weakly sclerotized; median lobe composed of basal bulb and dorsal apophysis, basal bulb rounded on dorsoapical side, with a large ventral stalk and distinct articulate process, dorsal apophysis attached to right or left side of the basal bulb, narrowed distally, curved outward.

Female genitalia composed of 9th stemite and genital plate; 9th sternite divided into two lobes, fore lobe with a pair of large ventral processes, hind lobe transverse, with a large transverse membranous area at its posterior part, genital plate with a pair of long lateral arms, muscle raising from each ventral process and inserting to each apex of lateral arms.

Remarks. The genus Batrisceniola was defined by the frons with a pair of large excavation in the male according to the original description (Jeannel, 1958). But this genus is redifined by the large clypeus and the seventh tergite with a group of setae in the present study. This genus is very close to the genus Arthromelodes in having the fore tibiae each with a twisted macrochaeta in the male and the broad abdomen, but clearly separated by the nonsexual characters mentioned above.

\section{A Key to the Species of the Genus Batrisceniola from Japan}

Key to Males

1. Frons with a pair of large and deep excavations

- Frons without excavation; 4th abdominal tergite with a deep concavity and a pair of setiferous patches semipunculata (Raffray)

2. Frontal excavations contiguous dissimilis (Sharp)

- Frontal excavations distant from each other biranoi sp. nov.

\section{Key to Females}

1. Head and pronotum densely with coarse punctures

- Head and pronotum sparsely punctate semipunctuata (Raffray)

2. Frons broad; vertex convex; 4th segment of maxillary palpus thick and nearly ovoid; 9th abdominal stemite with sclerotized median nodule dissimilis (Sharp)

- Frons transverse; vertex almost flat; 4th segment of maxillary palpus slender and fusiform, 9th abdominal stemite with membranous median nodule biranoi sp. nov.

\section{Batrisceniola dissimilis (Sharp) \\ (Figs. 148, 149A-C, 150A)}

Batrisus dissimilis Sharp, 1874, Trans. ent. Soc. Lond. 1874, p. 116; ibid., 1883, p. 316.

Batrisocenus dissimilis. Raffray, 1904, Ann. Soc. ent. Fr., 73: 221; 1908, Coleopt. Psel., Gen. ins., 64: 174; 1911, Psel., Coleopt. Cat., (27): 71.

Batrisceniola dissimilis. Jeannel, 19.58, Mém. Mus. Hist. nat., Paris, (A), 18: 65.

Male (Fig. 148). Length 2.0-2.4 mm, Width 0.8-0.9 mm. 
Body reddish brown, head and pronotum narrow.

Head slightly wider than long, thick, clypeus large, arcuately expanded, frons concave on its median part, elevated in lateral parts, coarsely punctate and moderately pubescent, with a pair of large excavations separeted by a narrow median carina, each excavation transverse, ovoid and glabrous on the bottom, and with about 10 bold secretory setae on its basal margin, vertex convex, with a median carina and a pair of dorsal tentorial pits. Eyes large and ovoid, each composed of about 40 facets. Antennae long and slender, 1st segment as long as wide, thick, 2nd short, slightly longer than wide, 3rd clearly larger than 2nd, ovoid, longer than wide, 4th shortest, 5th to 8th each ovoid, 9th larger than 8th, as large as 3rd, 10th slightly larger than 9th, 11th largest, ovoid. Maxillary palpi as long as head, 1st segment short, slightly curved, 2nd elongate, tapering on basal 2/3, then thickened distally, 3rd short, 4th largest and fusiform, 2.5 times as long as wide.

Pronotum as long as wide, convex, median longitudinal sulcus present from anterior $1 / 5$ to posterior $2 / 5$, a pair of lateral longitudinal sulci running from anterior $1 / 6$ to basilateral foveae at posterior $1 / 3$, and a transverse sulci running from each outer basilateral foveae to basimedian fovea at posterior $1 / 5$, coarsely punctate on dorsomedian surface. Elytra wider than long, sparsely punctate, humeri weakly expanded, with a pair of humeral denticles, each elytron with 2 dorsal foveae and 2 dorsal sulci; hind wing developed or reduced; metasternum flat at the middle part. Legs elongate, fore tibiae each with a macrochaeta at apex, mid tibiae each with a short mucro.

Abdomen very thick, 4th abdominal segment largest, 5th to 6th segments short, 7th segment longer than 5 th +6 th segments, with a group of setae on dorsoapical part, 8th tergite slightly wider than long, weakly convex, arcuately emarginate at apical margin, 8th sternite crescent and weakly concave, 9th sternite (Fig. 149C) ovoid and transverse in external view, located behind emargination of 8th tergite.

Male genitalia (Fig. 149A, B) with a dorsal apophysis on right or left side; basal bulb rounded on dorsal side, with triangular basal foramen, ventral stalk long and broadened distally, with two acute projections on outer side of the apex, like as the beak of a bird, dorsal apophysis very slender, covered with membrane on basal $2 / 3$, then strongly bent outward, acute at apex.

Female. Length $1.9-2.4 \mathrm{~mm}$. Width $0.8 \mathrm{~mm}$.

Frons slightly concave, with a pair of shallow excavation which is far smaller than in male. Third antennal segment slightly larger than 2nd, as wide as 2nd. Elytra shorter than abdomen, convex and transverse, humeri weakly expanded. Legs without macrochaeta nor mucro. Eighth abdominal tergite wider than long, arcuate on hind margin, 8th stemite larger than 8th tergite, semicircular.

Female genitalia (Fig. 150A) large and strongly sclerotized; fore lobe of 9th stemite complicate in structure, with a pair of lateral longitudinal processes and a large nodule on ventromedian part, hind lobe T-shaped, with very large and ovoid membranous area at apical part, genital plate wider than 9th sternite, with a pair of lateral arms which are broadened distally and strongly curved ventrally.

Distribution. Japan (Honshu, Shikoku).

Specimens examined. 846 examples from the following localities: [HONSHU] Tsunashirazu seashore, Osore-zan, Towada-Oirase, Mt. Towari, Tsuta spa, Shirakami-Oirase river (Aomori Pref.); Nyuto spa (Akita Pref.); Mt. Chokai (Yamagata Pref.); Kadoma near Mt. Hayachine, Kawarabo (Iwate Pref.); Futakuchi valley (Miyagi Pref.); Iitate-mura, Mt. Atatara, Mt. Asakusadake, Mt. Azuma (Fukushima Pref.); Sanpoku-cho, Kurokawa-mura (Niigata Pref.); Chuzenjilakeside, Nikko-Yumoto, Okukinu (Tochigi Pref.); Mt. Takao (Tokyo Pref.); Hakone-Miyagino (Kanagawa Pref.); Kaminikkawa pass, 
Aoki-kosen, Mt. Yatsugatake, Fuji-Aokigahara (Yamanashi Pref.); Mt. Ogasa (Shizuoka Pref.); Mt. Togakushi, Neba-mura (Nagano Pref.); Hirayu spa (Gifu Pref.); Kibune, Mt. Kurama, Iwakura, Mizuhocho (Kyoto Pref.); Mt. Odaigahara, Yoshinoyama (Nara Pref.); Mt. Koyasan, Mt. Ohto (Wakayama Pref.); Minoo (Osaka Pref.); Onzui vall., Mt. Hyonosen (Hyogo Pref.); Ikura vall., (Okayama Pref.); Mt. Daisen, Mt. Kyusho, Kokufu-cho (Tottori Pref.); Takano-cho, Yawatahara, Geihoku-cho, Nakatsuya vall., Yoshiwa-mura, Sandankyo vall., Kamagari-cho, Kurose-machi, Kure City, Itsukushima Is., Fukudomi-cho (Hiroshima Pref.); Hikimi (Shimane Pref.); Chomonkyo vall., Tokusa (Yamaguchi). [SHIKOKU] Mt. Otaki (Kagawa Pref.); Mt. Tsurugi (Tokushima Pref.); Omogo vall., Mt. Ishizuchi (Ehime Pref.).

Remarks. The wing is dimorphic in the male specimens from Futakuchi valley in Miyagi Prefecture, but the macropterous male is not found in the other populations. The dimorphism of male genitalia is also recognized in the almost local populations. These two kinds of dimorphisms are discussed in the chapter of the general morphology in detail.

Biological notes. This species mainly inhabits the natural forest; but one male was captured from the liverworts at the riverside, two males were found under bark of the dead tree, and one macropterous male came up to the light trap in Futakuchi valley, Miyagi Pref.

\section{Batrisceniola hiranoi sp. nov.}

(Figs. 149D-F, 150B, D)

\section{Male. Length $2.0-2.1 \mathrm{~mm}$. Width $0.8 \mathrm{~mm}$.}

Body reddish brown and shiny, narrowed in head and pronotum.

Head (Fig. 150D) clearly wider than long, coarsely punctate and moderately pubescent, clypeus broader than in dissimilis, arcuately expanded anteriorly, frons strongly elevated in level on both sides, with a pair of large excavations separeted from each other, each excavation ovoid and transverse, glabrous on the bottom, with 5-7 bold secretory setae on its posterior margin, median part between the excavations broad. Eyes large and ovoid, each composed of about 40 facets. Antennae slender, with long hairs, 1st segment subcylindrical and thick, 2nd short, slightly longer than wide, 3rd slightly larger than 2nd, 4th shortest, subglobose. Maxillary palpi as long as head, 4th segment fusiform, 3 times as long as wide.

Pronotum as long as wide, convex, modified as in dissimilis. Elytra clearly longer than abdomen, humeri weakly expanded; hind wings developed; metasternum slightly concave on median part. Legs elongate, tarsi longer than in dissimilis, fore tibiae each with a macrochaeta at apex, mid tibiae slender, each with a short mucro.

Abdomen thick and subcylindrical, 4th segment largest, but very short on ventral part, 5th to 6th short, 7th longer than 5 th $+6 \mathrm{th}$, with some secretory setae on dorsoapical part. Male genitalia (Fig. 149D-F) very similar in structure to dissimilis, with a dorsal apophysis on right or left side; basal bulb very large, with an ovoid basal foramen, ventral stalk shorter than in dissimilis, about half as long as basal bulb in basal view, beak-shaped as in dissimilis, dorsal apophysis long, slender on apical part, but bolder than in dissimilis in apical part.

Female. Length $2.0-2.1 \mathrm{~mm}$, width $0.8 \mathrm{~mm}$. 
Frons slightly concave, with a pair of shallow excavations which are far smaller than in male. Elytra convex, shorter than abdomen, humeri weakly expanded. Legs without macrochaeta nor mucro. Eighth abdominal tergite wider than long, hind margin rounded, 8th sternite larger than 8th tergite, semicircular.

Female genitalia (Fig. 150B) strongly sclerotized, similar in structure to dissimilis, hind lobe of 9th sternite transverse, constricted on both sides, with very large membranous area, basal lobe with a pair of twisted ventral processes and a very large membranous median nodule on ventral side; genital plate transverse, with a pair of lateral arms strongly curved ventrally, each arm simply narrowed distally.

Distribution. Japan (Honshu).

Holotype, male (Type No. 2854, Kyushu Univ.), Kuji vall., Iwate Pref., 11. viii. 1984, Y. Hirano leg. Paratypes: 1 male same data as holotype; 2 males, Byobusan, Tsugaru peninsula, Aomori Pref., 6. viii. 1987, S. Nomura leg.; 1 male, Yachi spa, Aomori Pref., 11. viii. 1985, Y. Hirano leg.; 1 male, Yasato, Ibaragi Pref., 9. v. 1983, S. Tanaka leg.; 3 females, Kyoto, 7-8. viii. 1980, C. Besuchet leg.; 5 males 6 females, Hiedano, Kameyama, Kyoto Pref., 23. x. 1978, K. Masaki leg.; 1 male, Ashiya, Osaka Pref., 18. vi. 1942, K. Suzuki leg.; 7 males 18 females, Mt. Gagyu, Okayama Pref., 28. viii. 1977, H. Ohishi leg.; 2 males 1 female, Nanatsukahara, Shobara City, Hiroshima Pref., 2. v. 1987, I. Okamoto leg.; 7 males 2 females, same locality, 14. viii. 1987, I. Okamoto leg.; 4 males 6 females, same locality, 4. x. 1987, I. Okamoto leg.; 4 males 2 females, Mt. Takanosu, Fukudomi-cho, Hiroshima Pref., 29. xii. 1987, I. Okamoto leg.; 723 exs., Kurose-machi, Kamo-gun, Hiroshima Pref., 2. xii. 1987 to 29. v. 1988, I. Okamoto leg.

Remarks. Batrisceniola hiranoi is closely allied to $\boldsymbol{B}$. dissimilis, but is separated from the latter by the frons with a pair of excavations which are distant from each other in the male, and the ninth abdominal sternite with a membranous median nodule in the female (strongly sclerotized in dissimilis).

The wings and male genitalia are dimorphic in the male of this species as in $\boldsymbol{B}$. dissimilis. The ratio of the macropterous male to brachypterous one is clearly larger than in $\boldsymbol{B}$. dissimilis.

Biological notes. Many specimens of this species were collected from the bamboo and pine mixed forest in Hiroshima Pref. This species has not ever been discovered together with $\boldsymbol{B}$. dissimilis. One macropterous male was caught by light trap at Byobusan, Aomori Pref.

\section{Batrisceniola semipunctulata (Raffray) comb. nov.}

(Figs. 149G-I, 150C)

Batrisocenus semipunctatus Raffray, 1909, Ann. Soc. ent. Fr., 78: 25.

Batrisocenus semipunctulatus. Raffray, 1911, Psel., Coleopt. Cat., (27): 70.

Arthlomerinus semipunctulatus. Jeannel, 1958, Mtm. Mus. Hist. nat., Paris, (A), 18: 64.

Batrisiella semipunctulata: Jeannel, 1960, Bull. Brit. Mus. ent., 9(9): 426, comb. nov.

Male. Length 1.9-2.0mm. Width 0.7-0.8mm.

Body reddish brown, narrowed in head and pronotum.

Head slightly longer than wide, clypeus large, arcuately expanded anteriorly, coarsely punctate, frons slightly concave, with a shallow transverse sulcus, vertex weakly convex, with a median longitudinal carina and a pair of dorsal tentorial pits. Eyes large and ovoid, each composed of about 45 facets. 
Antennae moniliform, with long hairs, 1st segment subcylindrical, 2nd ovoid, 1.5 times as long as wide, 3rd smaller than 2nd, 4th to 6th subequal, each ovoid, slightly longer than wide, 7th about I.2 times as long as 6th, 8th shortest, subglobose, 9th about 1.7 times as long as 8th, longer than wide, 10th slightly larger than 9th, 11th largest, ovoid, 1.5 times as long as wide. Maxillary palpi long, 4th segment largest, fusiform, 3 times as long as wide.

Pronotum about as long as wide, widest at the middle, convex and sparsely punctate on dorsal surface, with 3 longitudinal and a transverse sulci, median longitudinal sulcus running from anterior 1/8 to posterior 1/8. Elytra slightly longer than abdomen, convex and weakly broadened posteriorly, humeri gently expanded. Legs elongate, fore tibiae swollen on apical $2 / 3$, each with a macrochaeta at apex, mid tibiae each with a short mucro.

Abdomen as wide as elytra, widest at basal 1/5, 4th abdominal segment largest, with a large and deep concavity and a pair of circular setiferous patches, 5th to 6th segments short, 7 th longer than 5 th + 6th, with a group of setae at dorsomedian part, 8th tergite slightly convex, wider than long, arcuately emarginate on posteromedian margin 8th stemite short and crescent, 9th sternite small (Fig. 1491).

Male genitalia (Fig. 149G, H)with a dorsal apophysis on left side; basal bulb rounded dorsoapically, with a large and triangular basal foramen, ventral stalk long and weakly broadened distally, acute on right side of the apex, articulate process extending to left, dorsal apophysis about as long as basal spine, tapering distally, bifurcate and acute at apex.

Female. Length $1.9 \mathrm{~mm}$. Width $0.7 \mathrm{~mm}$.

Similar to male excepting following characters: elytra narrowed anteriorly, fore tibiae about as wide as mid tibiae, without macrochaeta, mid tibiae without mucro. Fourth abdominal segment without concavity nor secretory patch, 8th tergite shorter than sternite, arcuate on posterior margin 8th sternite semicircular.

Female genitalia (Fig. 150C) strongly sclerotized; apical lobe of 9th stemite T-shaped, constricted on its apical part, with large transverse membranous area, basal lobe with a pair of longitudinal ventral processes; genital plate wider than 9th sternite, with a pair of slender lateral arms extending basilaterally.

Distribution. Japan (Hokkaido, Honshu).

Specimens examined. [Hokkaido] 43 males 63 females, Higashi-Onuma, Oshima, 15-17. vi. 1986 (S. Nomura).

Remarks. Batrisceniola semipunctulata (Raffray) is similar in appearance to some species of $A r$ thromelodes, Batrisiella or Batriscenaulax in having a sexual patch on 4th abdominal segment. But the structure and arrangement of setae are different from these three genera. This species is easily distinguished from the other species of the genus Batrisceniola by sexual patch in the male, and the pronotum with a long median longitudinal sulcus reaching anterior $1 / 8$ and the sparsely punctate head and pronotum in the female.

Biological notes. Many individuals were found among dead hard glass of the hygrophile glassland at Onuma lakeside in Hokkaido. 
FIGURES FOR THECHAPTERS OF SYSTEMATICS

(Figs 107-150) 
Fig. 107. Batrisoplisus uroceratus uroceratus sp. et subsp. nov, female dorsal aspect. 


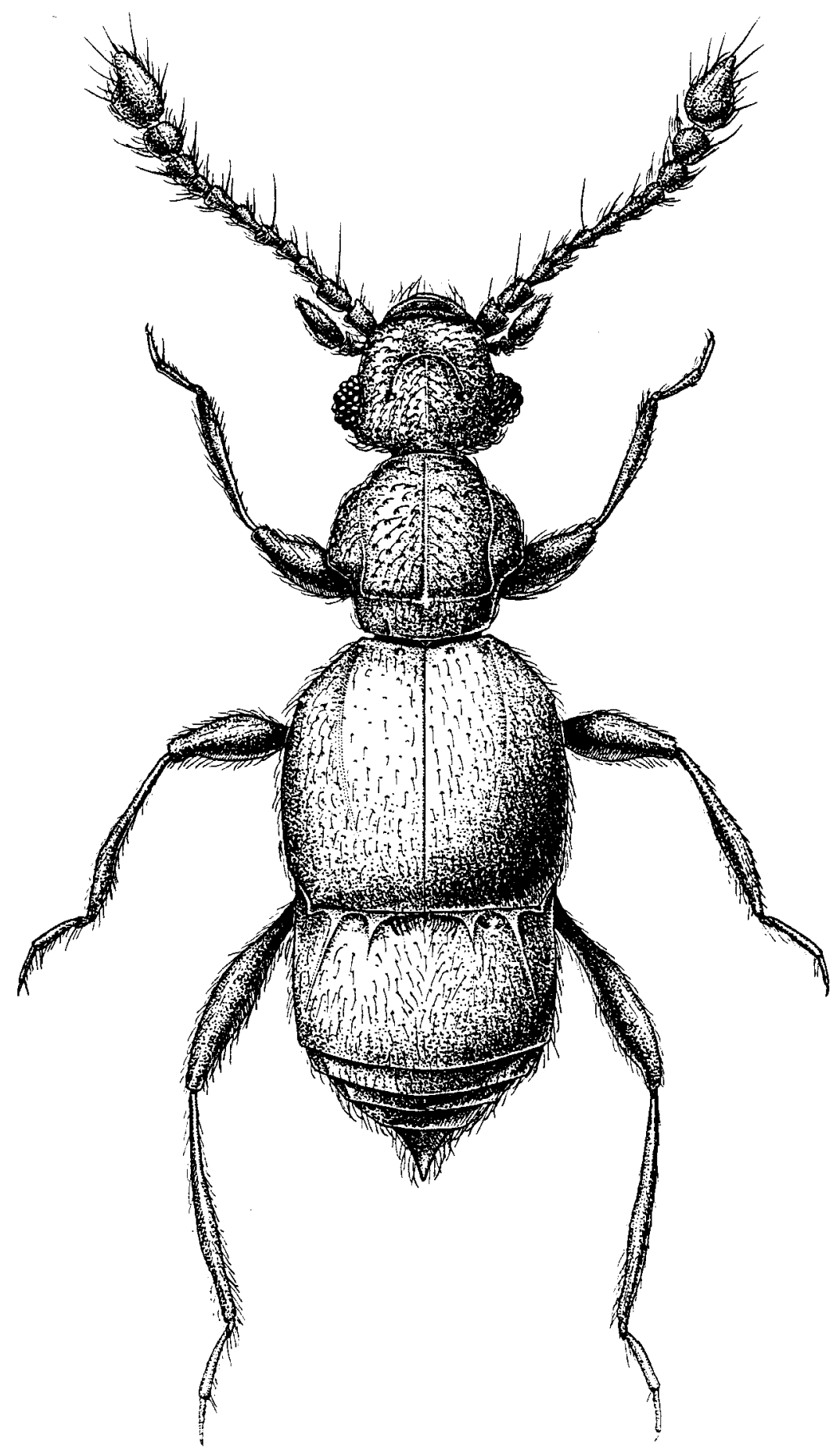


Fig. 108. Fore and mid legs in males of Batrisoplisus. A-C, fore leg.

D, E, mid leg.

$A, D, B$. uroceratus uroceratus sp. et subsp. nov.

B, $B$. uroceratus brevispinis subsp. nov.

$C, E, B$. inermis sp. nov. 

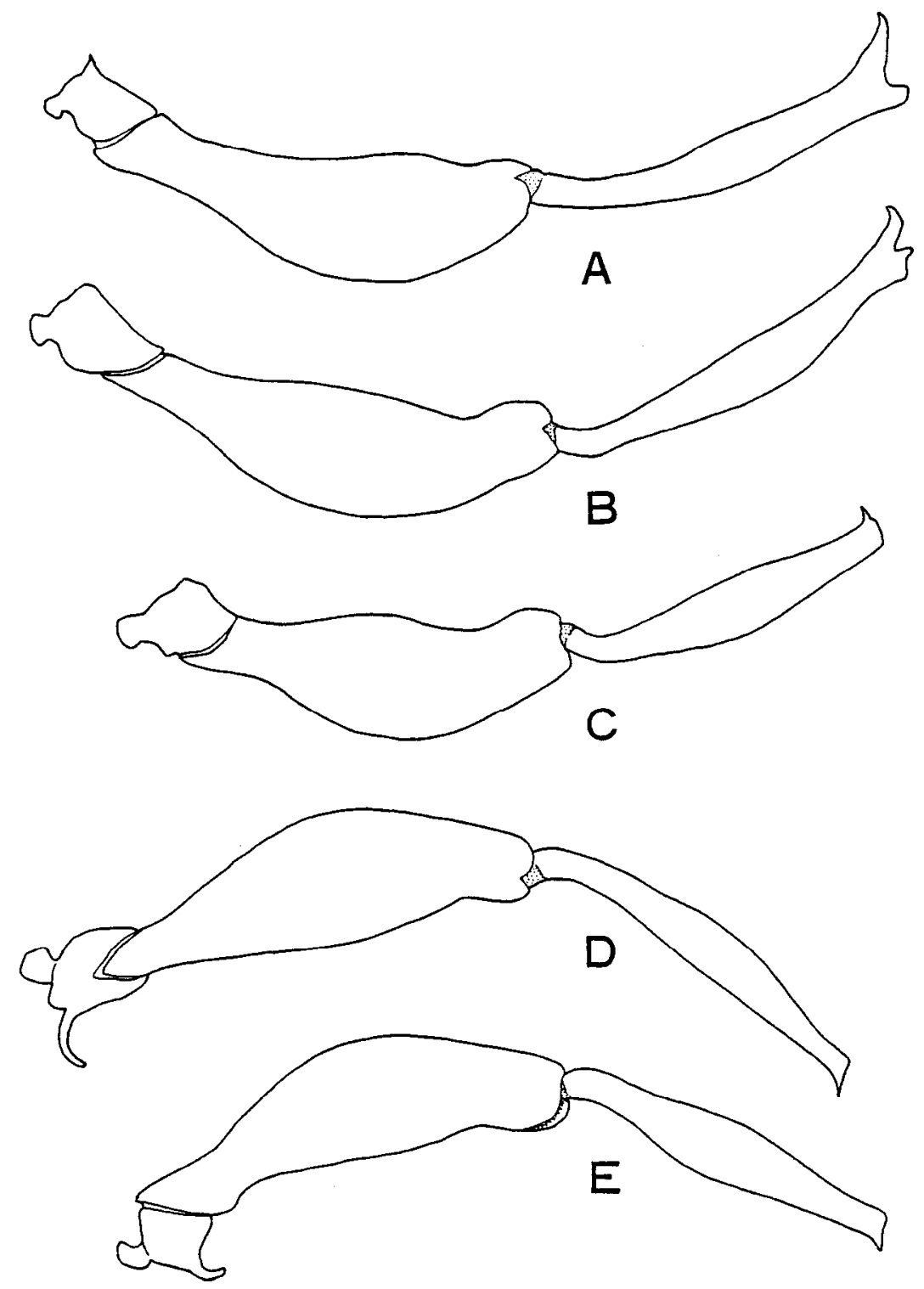
Fig. 109. Male genitalia of Batrisoplisus in lateral view.

A, B. sagamianus sp. nov., from Matsuda, Kanagawa Pref.

B, ditto, from Hiedano, Kyoto Pref.

C, B. satsumanus sp. nov.

D , B $\quad$ B galloisi Jeanne1 from Ukima Park, Tokyo Pref.

E, ditto, from Fujishima, Yamagata Pref.

$\mathrm{F}$, B. subtilis sp. nov.

G, B. sawadai sp. nov., from Hiiaoka, Osaka Pref.

H, ditto, from Yono, Osaka Pref. 
BATRISOPLISUS AND ITS ALLIES FROM JAPAN

371
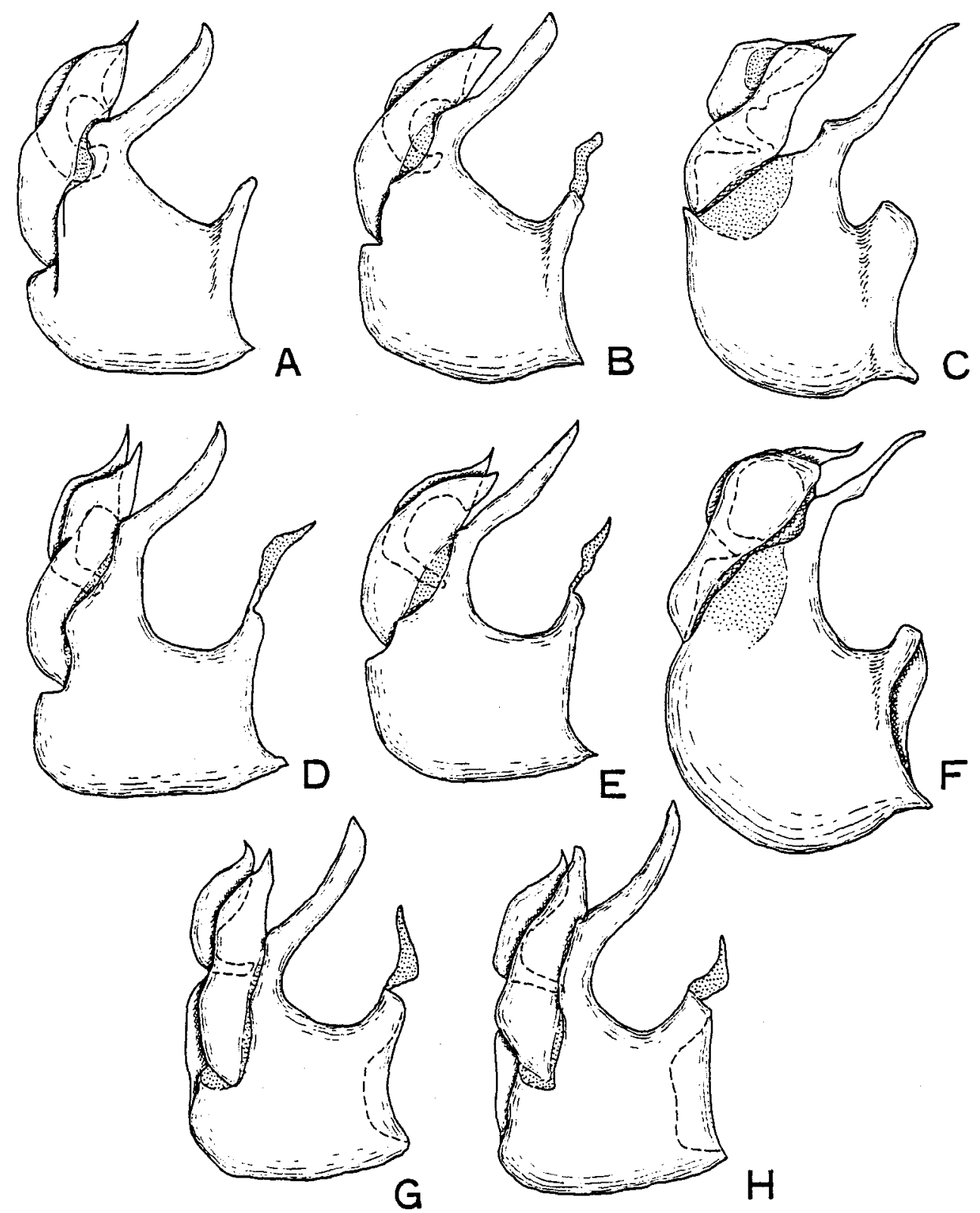
Fig 110. Male genitalia in lateral view and 9th abdominal stemite of Batrisoplisus.

$A$, B. venustus Jeannel, from Gohara-machi, Hiroshima Pref.

B, ditto, from Kusaka, Kochi Pref.

C, B. tenuiformis sp. nov.

D, B. esakii sp. nov., from Mt. Hikosan, Fukuoka Pref.

E, F, ditto, from Hitoyoshi, Kumamoto Pref.

G, B. tosanus sp. nov.

$\mathrm{H}, \boldsymbol{B}$. okamotoi sp. nov.

I, B. tanabei sp. nov.

A-E, G-I, male genitalia.

F, 9th abdominal stemite. 

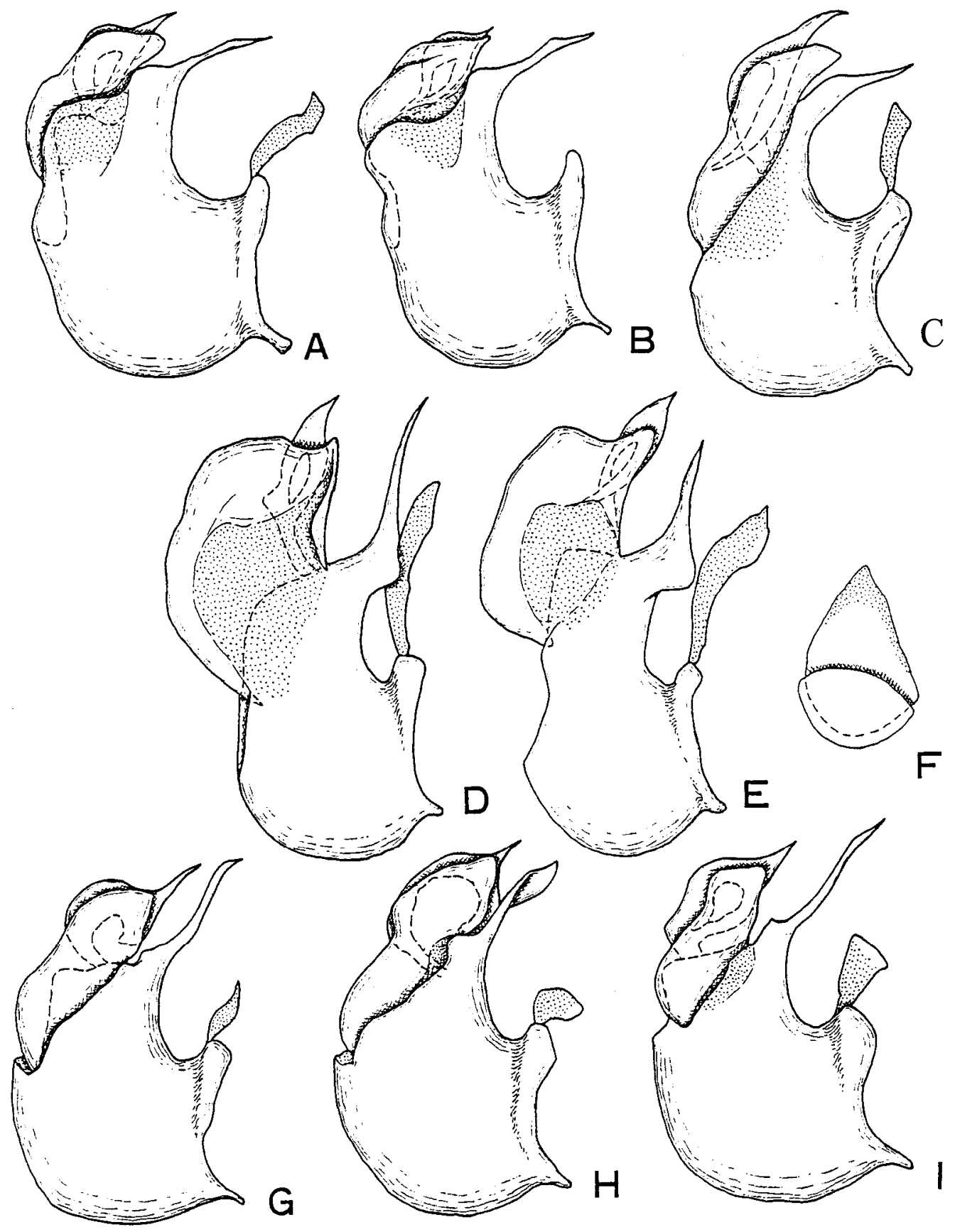
Fig. 111. Male genitalia of Batrisoplisus raffrayi in lateral view.

A, Sengoku-hara, Hakone, Kanagawa Pref.

B, Fujishima, Yamagata Pref.

C, Gifu, Gifu Pref.

D, Nii vall., Hiroshima Pref.

E, Izuhara, Tsushima Is.

F, Kashinokibaru, Saga Pref.

G, Tororo, Amakusa-Shimojima Is.

H, Mt. Miyanouradake, Yaku Is. 


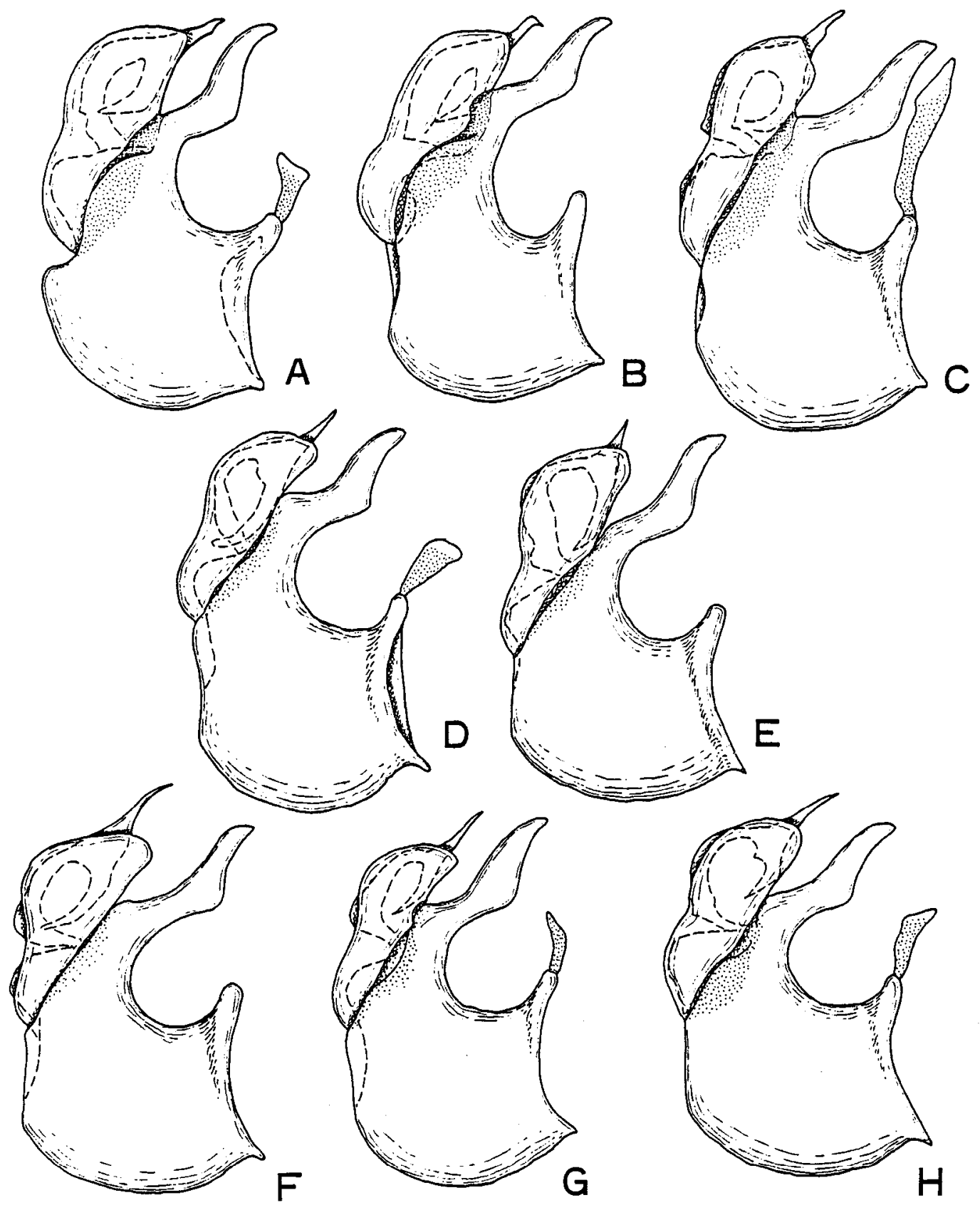


Fig. 112. Male genitalia of Batrisoplisus.

A, B, B. amamianus sp. nov.
C, D, B. constrictus sp. nov.

A, left side in lateral view.

$\mathrm{B}$, right side; $\mathrm{C}$, dorsal view.

$\mathrm{D}$, ventral view. 

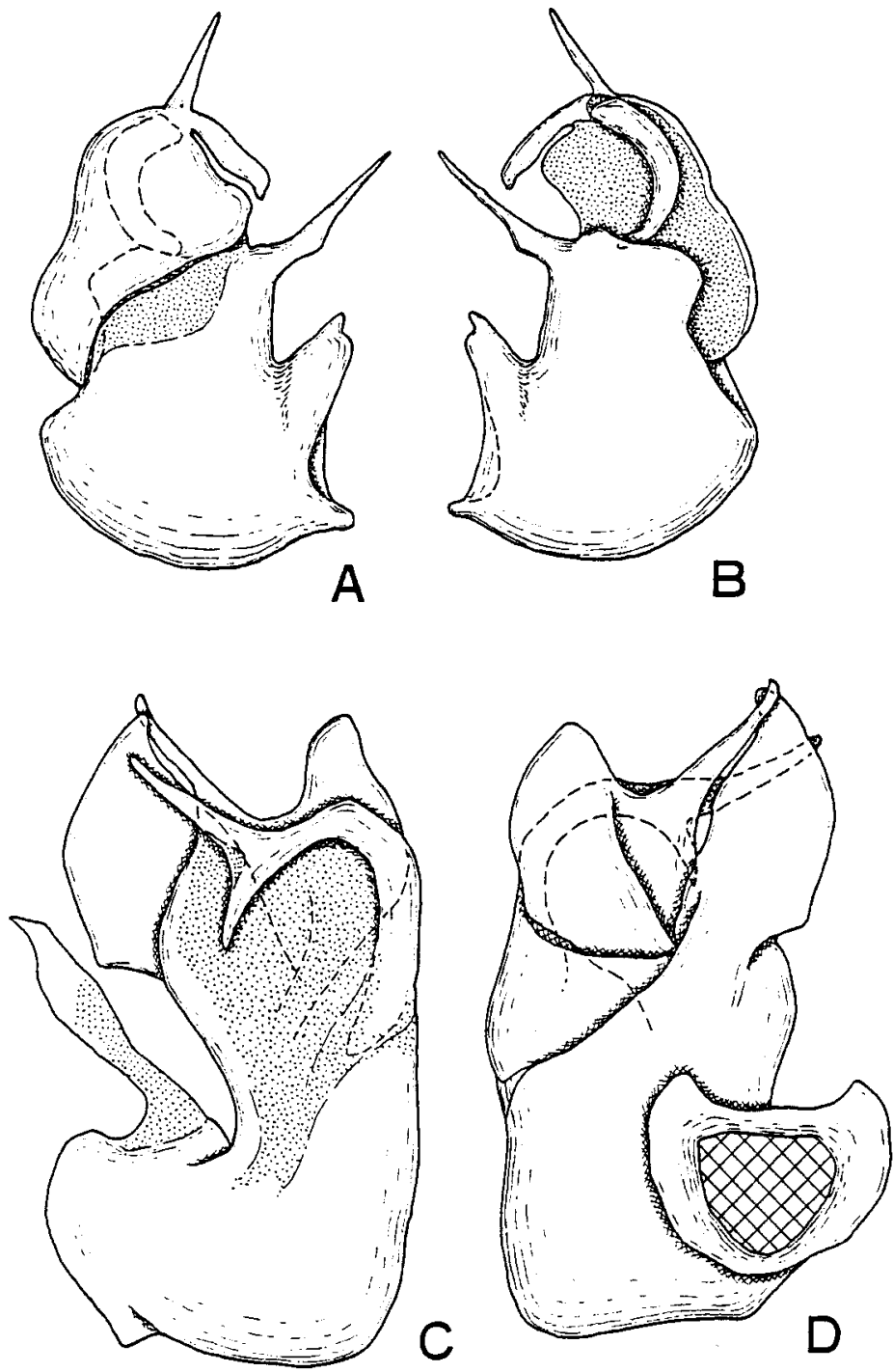
Fig. 113. Male genitalia of Batrisoplisus.

A-C， B. torticornis sp. nov.

D-F, B. tamino sp. nov.
$A, D$, dorsal view.
$B, E$, ventral view.
C, $F$, lateral view. 

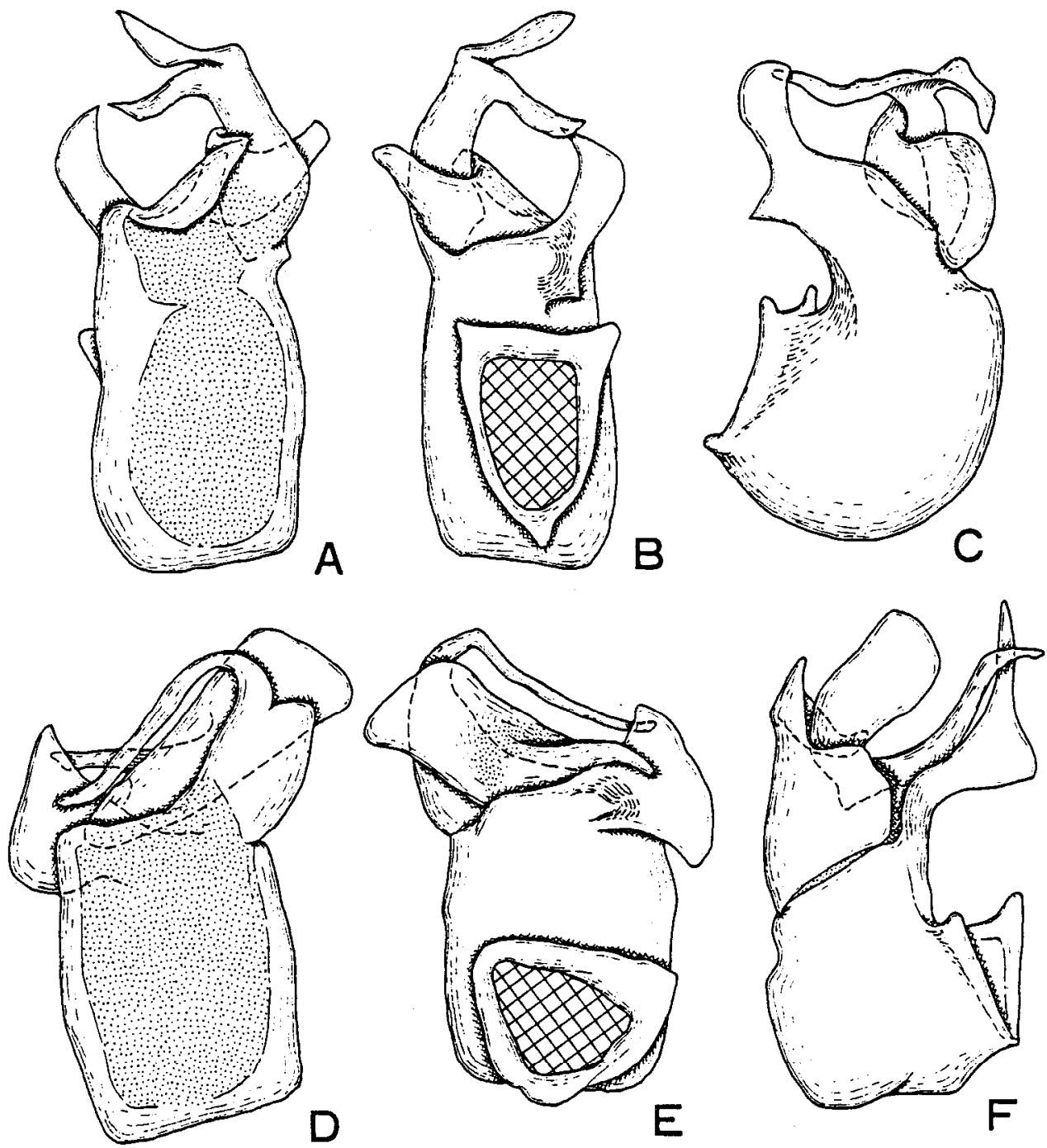
Fig. 114. Male genitalia, 9th abdominal sternite and female genitalia of Batrisoplisus.

A, B. uroceratus uroceratus sp. et subsp. nov., from Buzenbo, Fukuoka Pref.

B, ditto, from Mt. Ichifusa, Kumamoto Pref.

C, B. u.brevispinis subsp. nov.

D, B. volucaninsulanus sp. nov.

E, B. inermis sp. nov.

$\mathrm{F}-\mathrm{H}, \mathrm{J}, \boldsymbol{B}$. parallelus sp. nov.

I, $B$. raffrayi sp. nov.

A-E, G, male genitalia in lateral view.

$\mathrm{F}$, ditto, dorsal view.

$\mathrm{H}, 9$ th abdominal sternite.

I, J, female genitalia in ventral view. 

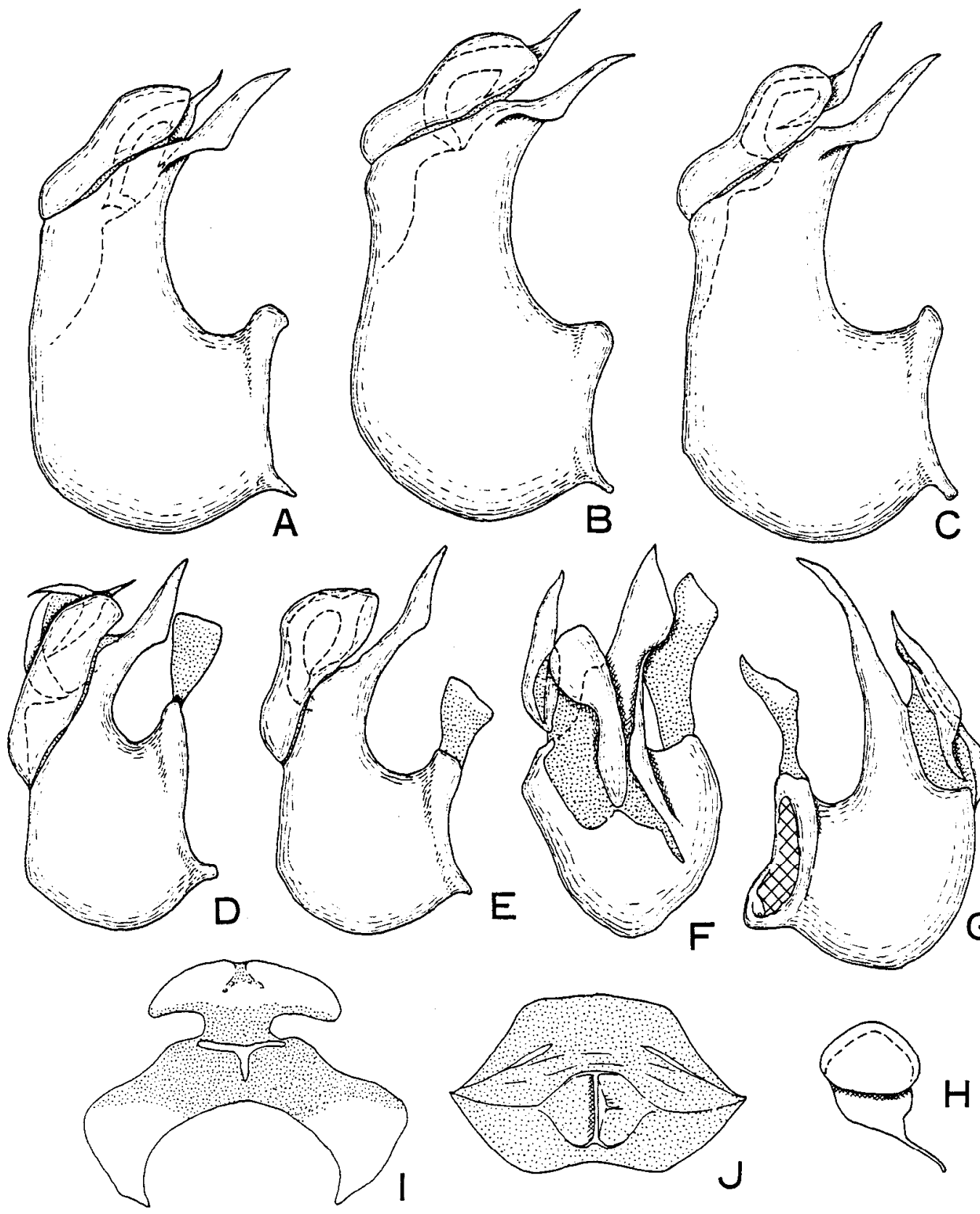
S. NOMURA

Fig. 115. Batriscenellus pilosellus sp. nov., male dorsal aspect. 


$$
\text { 悉 }
$$


Fig. 116. Fourth to8thabdominalsegmentsinmak.s of Batriscenellus in dorsal new.
A, B. japonicus japonicus (Sharp).
$\mathrm{B}, \boldsymbol{B} . \boldsymbol{j}$. vicarius Löbl.
C, B. punctatus sp. nov.
D, B. fallax (Sharp).
E, B. kujumontanus sp. nov.
F, B. omogensis sp. nov. 
BATRISOPLISUSAND ITS ALLIES FROM JAPAN
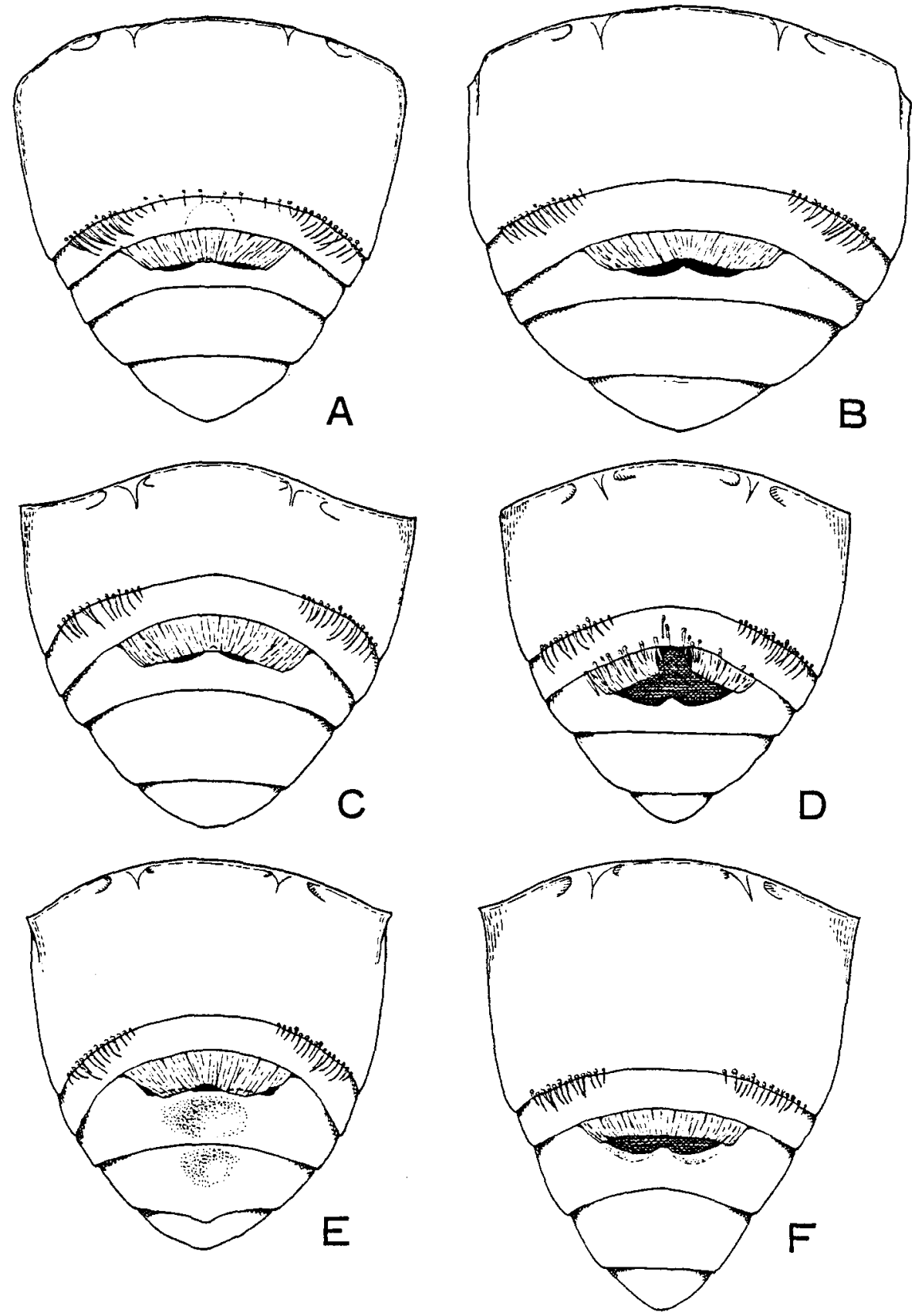
Fig. 117. Fourth to 8th abdominal segments in males of Batriscenellus in dorsal new.
A, B. fragilis (Sharp).
$\mathrm{B}, B$. nodulifer sp. nov.
C, B. transformis sp. nov.
$\mathrm{D}, B$. similis (Sharp)
E, B. shiranui sp. nov.
$\mathrm{F}$, B. orientalis (Löbl). 

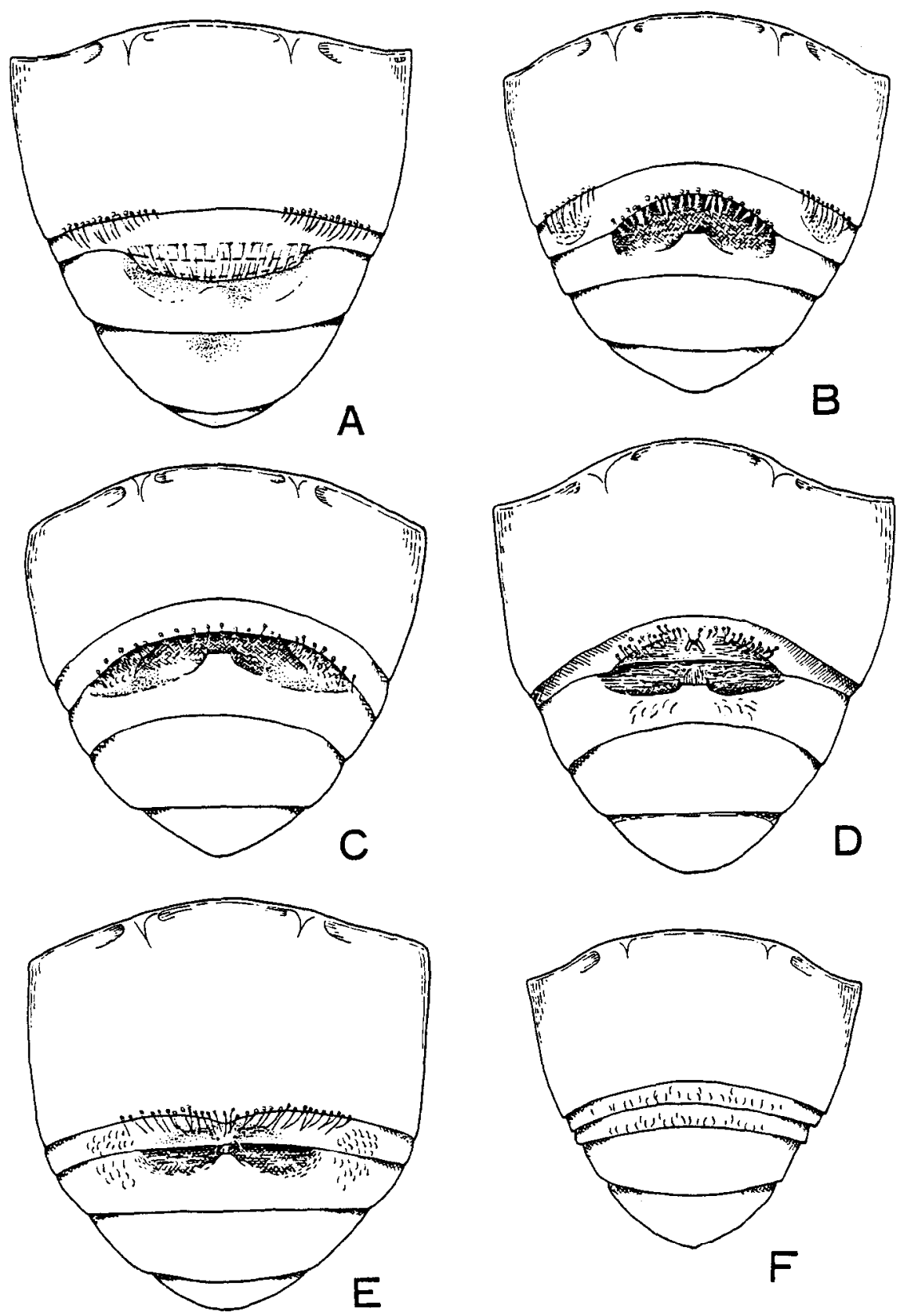
Fig. 118. Fourth to 9th abdominal segments in males of Batriscenellus.
$A$, B. insulicola sp. nov.
B, B. pilosellus sp. nov.
C, B. sakaiisp. nov.
D, B. japonicus japonicus (Sharp)
E, B. j. vicarius Löbl.
F, B. punctatus sp. nov.
A-C, 4th to 8th segments in dorsal view.
D-F, 7th to 9th segments in posterior view. 


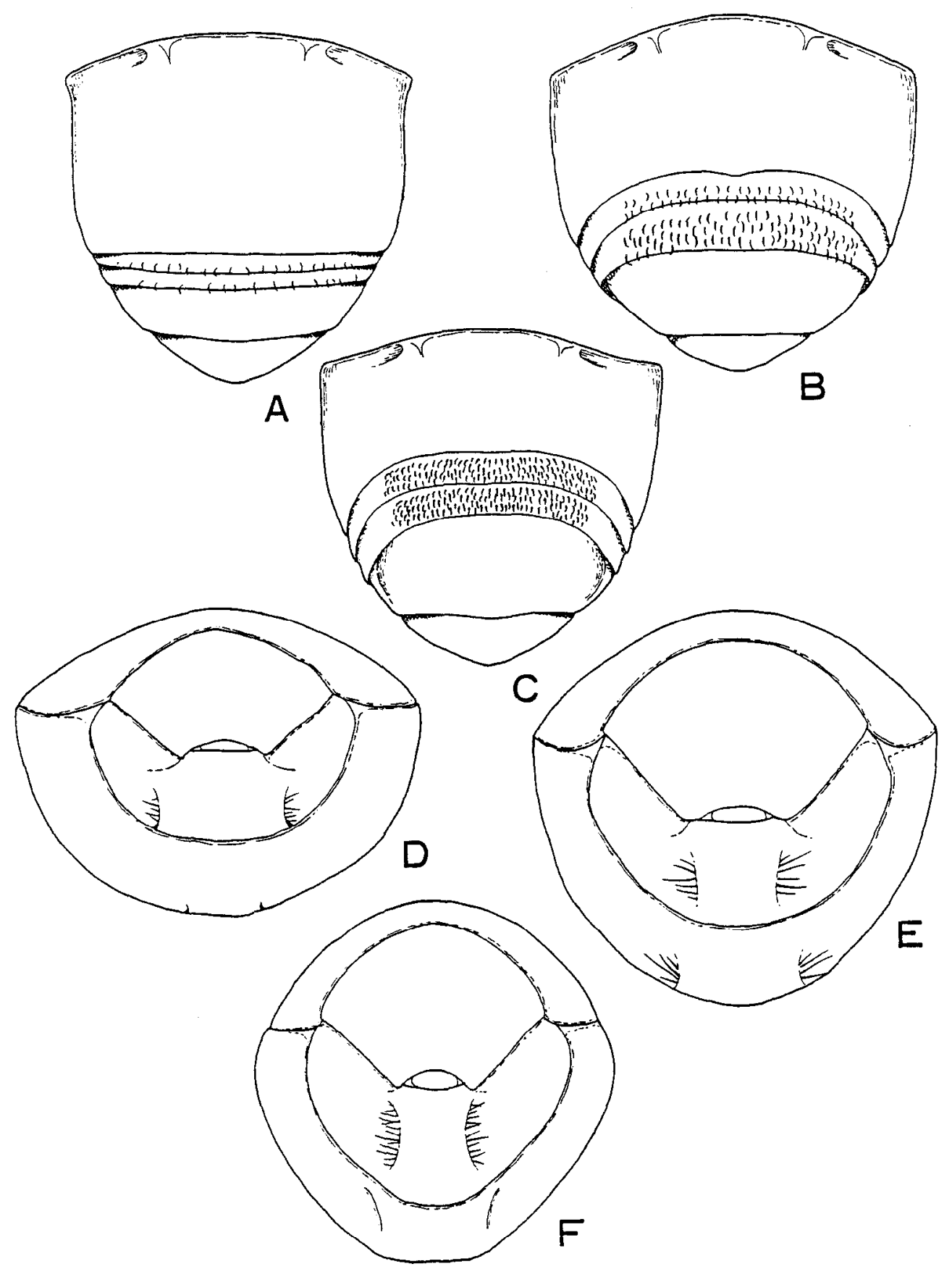


Fig. 119. Seventh to 9th abdominal segments in males of Batriscenellus in posterior vew.
A, B. fallax (Sharp).
B, B. kujumontanus sp. nov.
C, B. omogensis sp. nov.
D, B. fragilis (Sharp).
E, B. nodulifer sp. nov.
F, B. transformis sp. nov. 

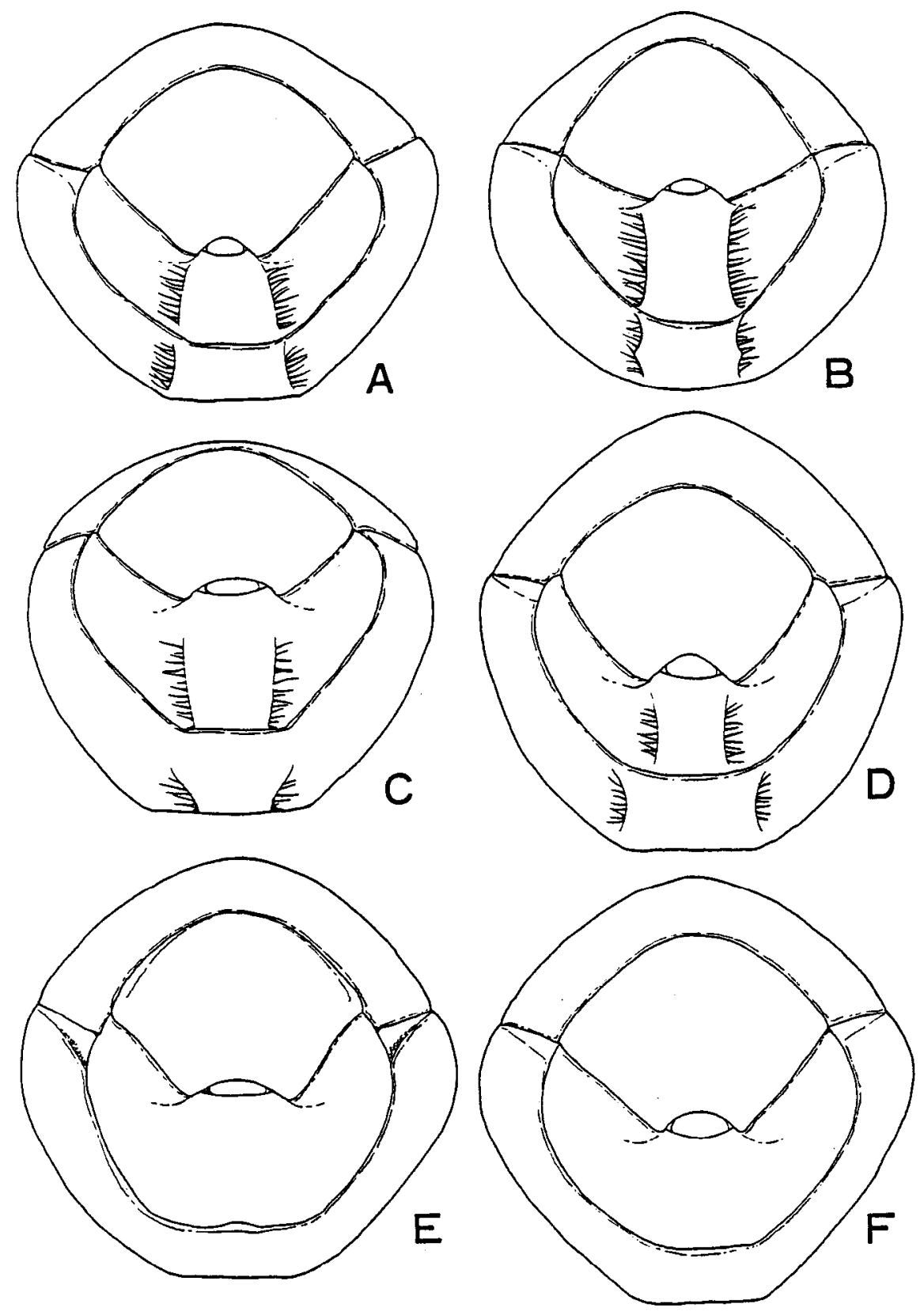
Fig. 120. Male genitalia of Batriscenellus.
A, B, B. japonicus japonicus (Sharp)
$\mathrm{C}, \mathrm{D}, \boldsymbol{B} . \boldsymbol{j}$. vicarius Löbl.
E, F, B. punctatus sp. nov.
A, C, E, lateral view.
$\mathrm{B}, \mathrm{D}, \mathrm{F}$, dorsal view. 


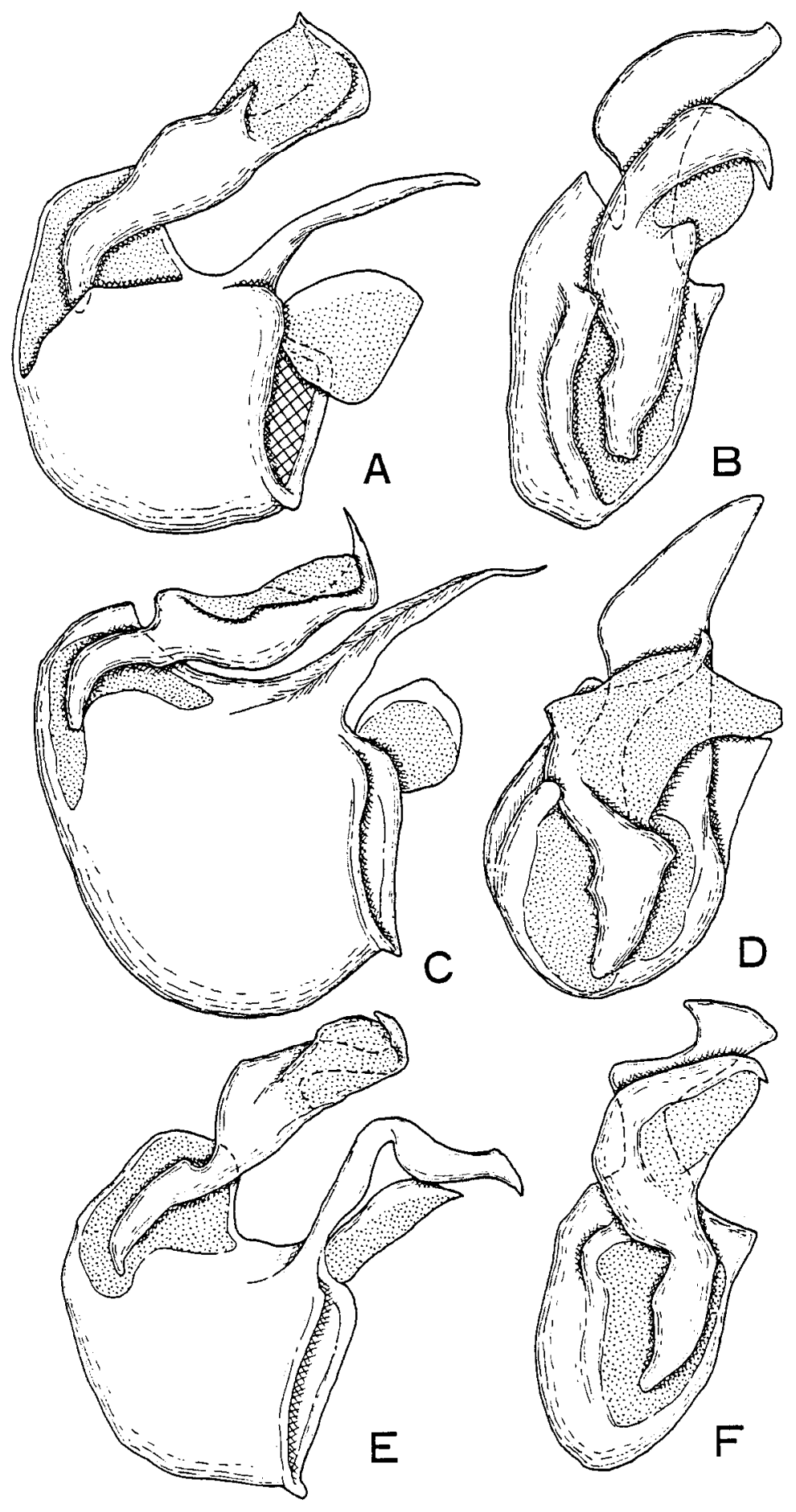


S. NOMURA

Fig. 121. Male genitalia of Batriscenellus.

$A$, B, B. fallax (Sharp)

C, D, B. kujumontanus sp. nov.

E, F, B. omogensii sp. nov.

A, C, E, lateral view.

$\mathrm{B}, \mathrm{D}, \mathrm{F}$, dorsal view. 


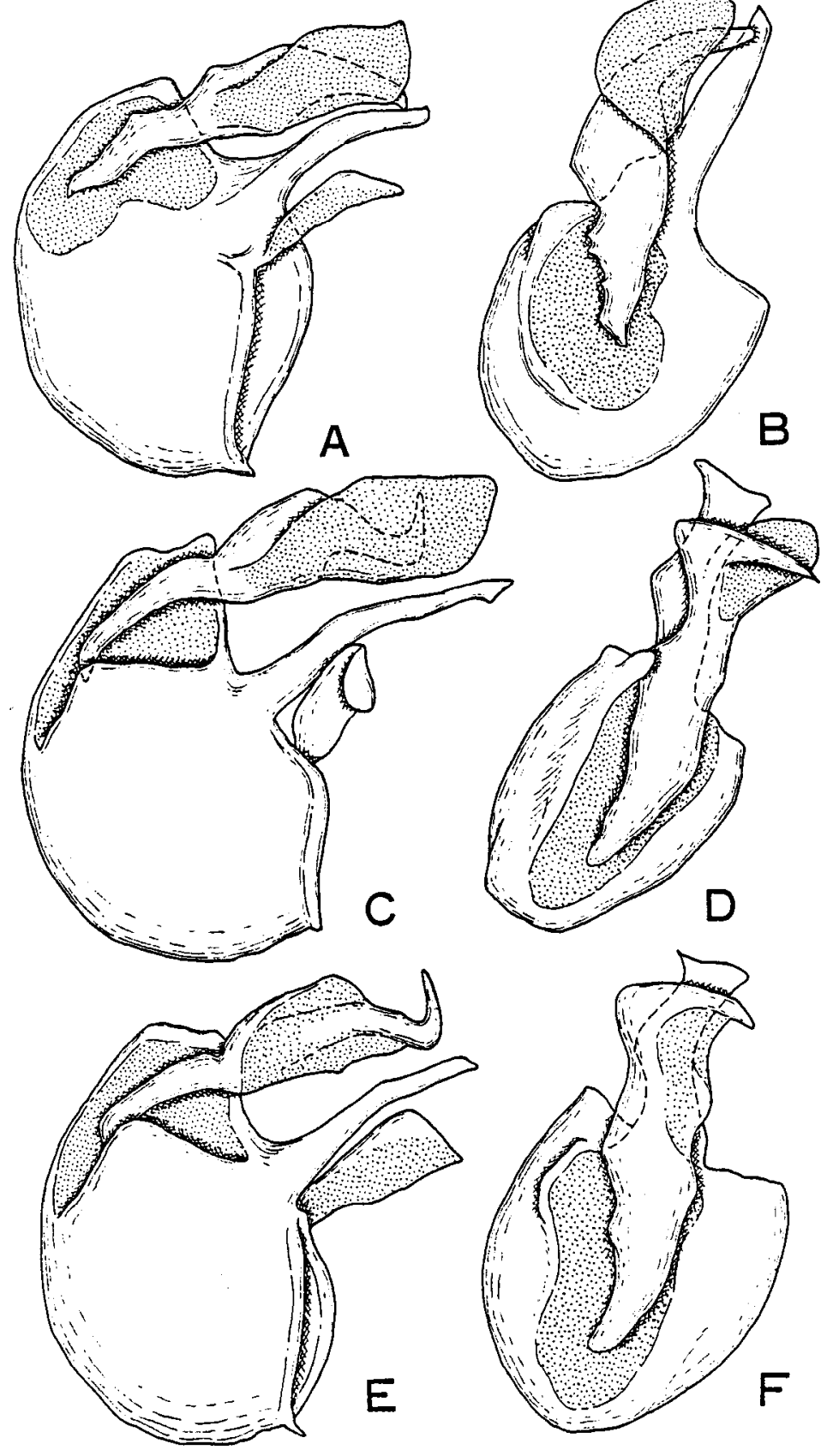


Fig. 122 Male genitalia of Batriscenellus.
A, B, B. fragilis (Sharp).
C, D, B. nodulifer sp. nov.
E, F, B. transformis sp. nov.

A, C, E, lateral view.

$\mathrm{B}, \mathrm{D}, \mathrm{F}$, dorsal view. 


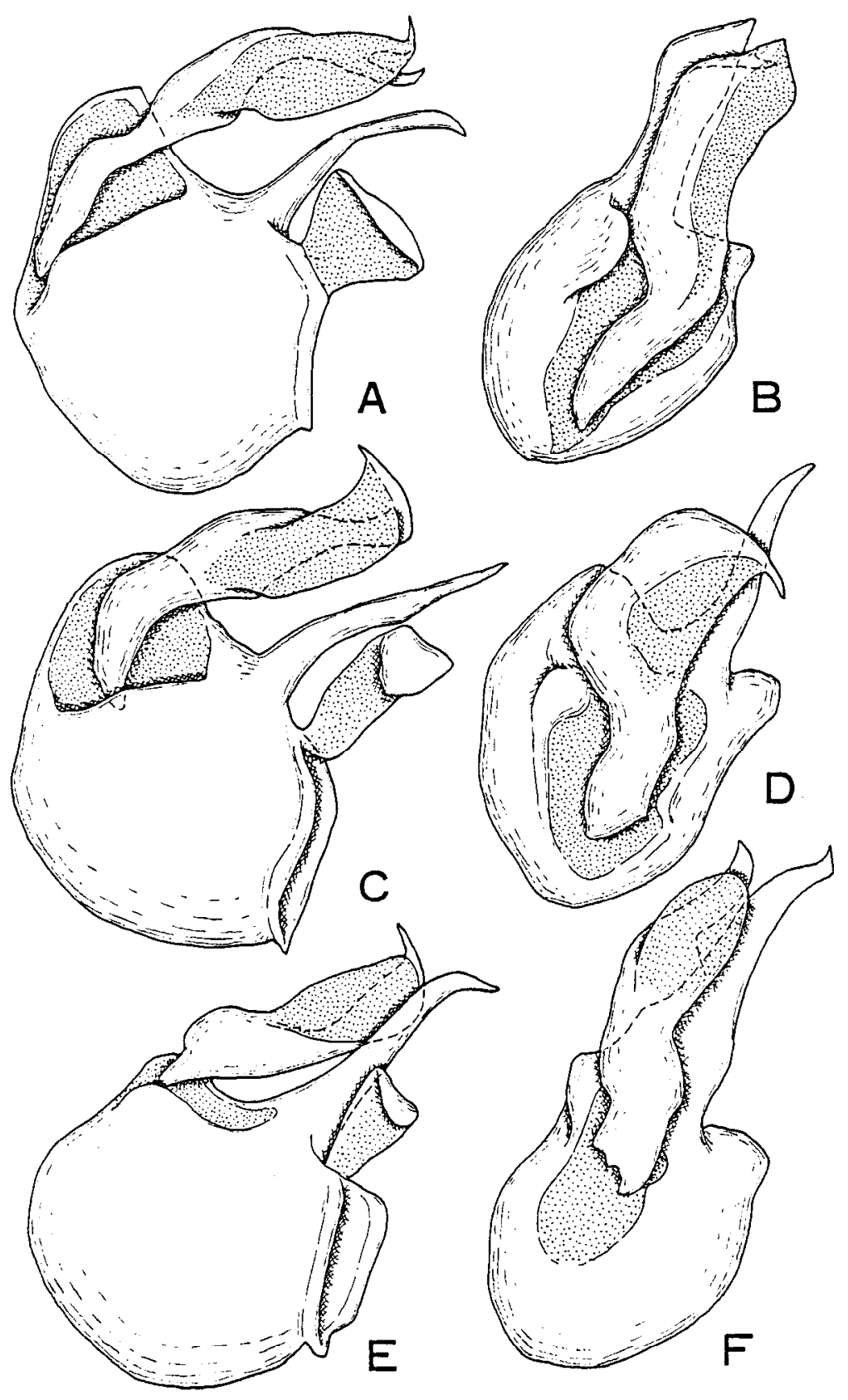


Fig. 123. Male genitalia of Batriscenellus.
A, B, B. similis (Sharp).
C, D, B. insulicola sp. nov.
E, F, B. ohishï sp. nov.
A, C, F, lateral view.
$\mathrm{B}, \mathrm{D}$, dorsal view.
$\mathrm{E}$, ventral view. 

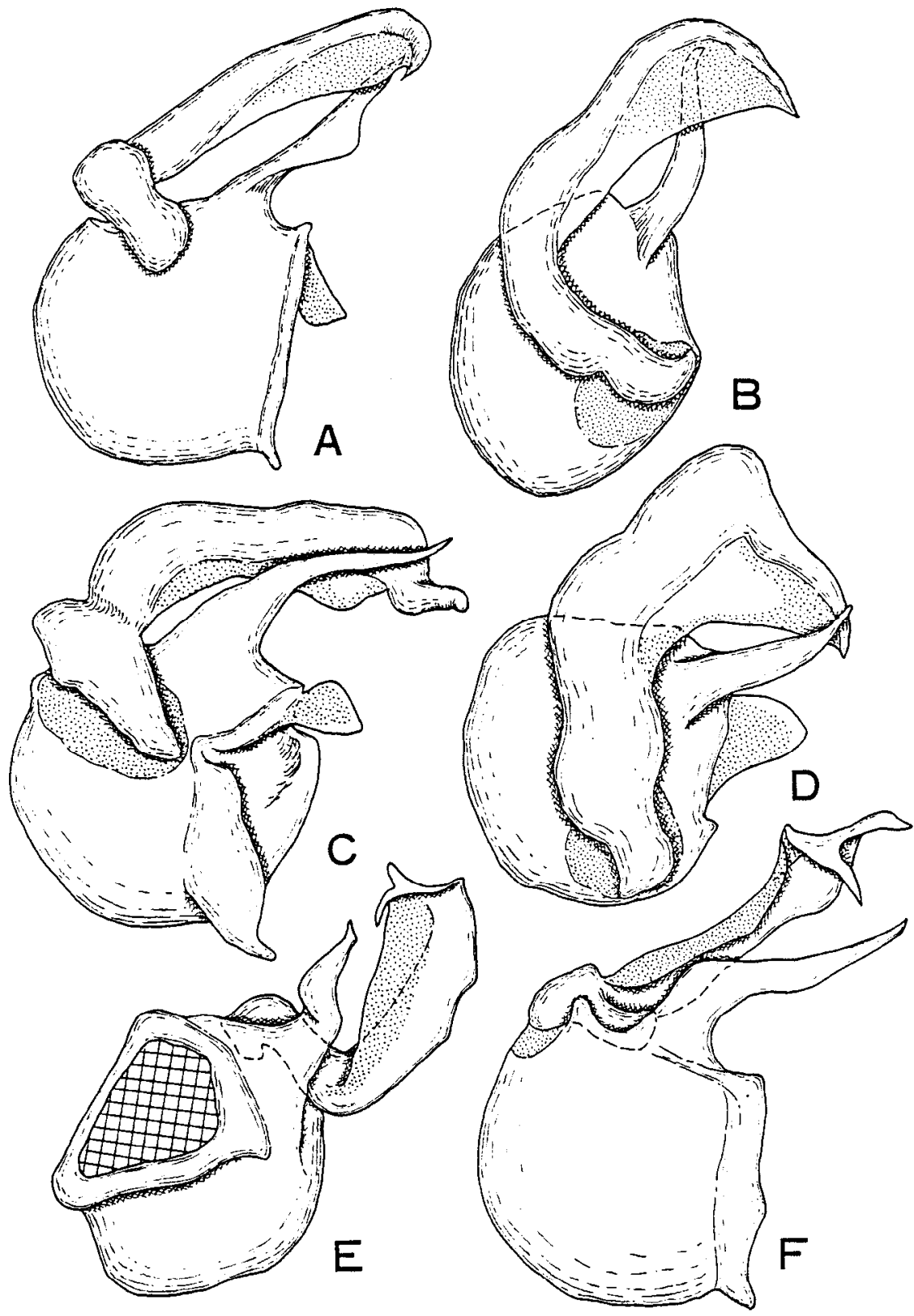
Fig. 124. Male genitalia of Batriscenellus.
A, B, B. pilosellus (Sharp)
C, D, B. sakaii sp. nov.
$\mathbf{E}, \mathbf{F}, \boldsymbol{B}$. uenoisp. nov.
A, C, E, lateral view.
B, D, F, dorsal view. 


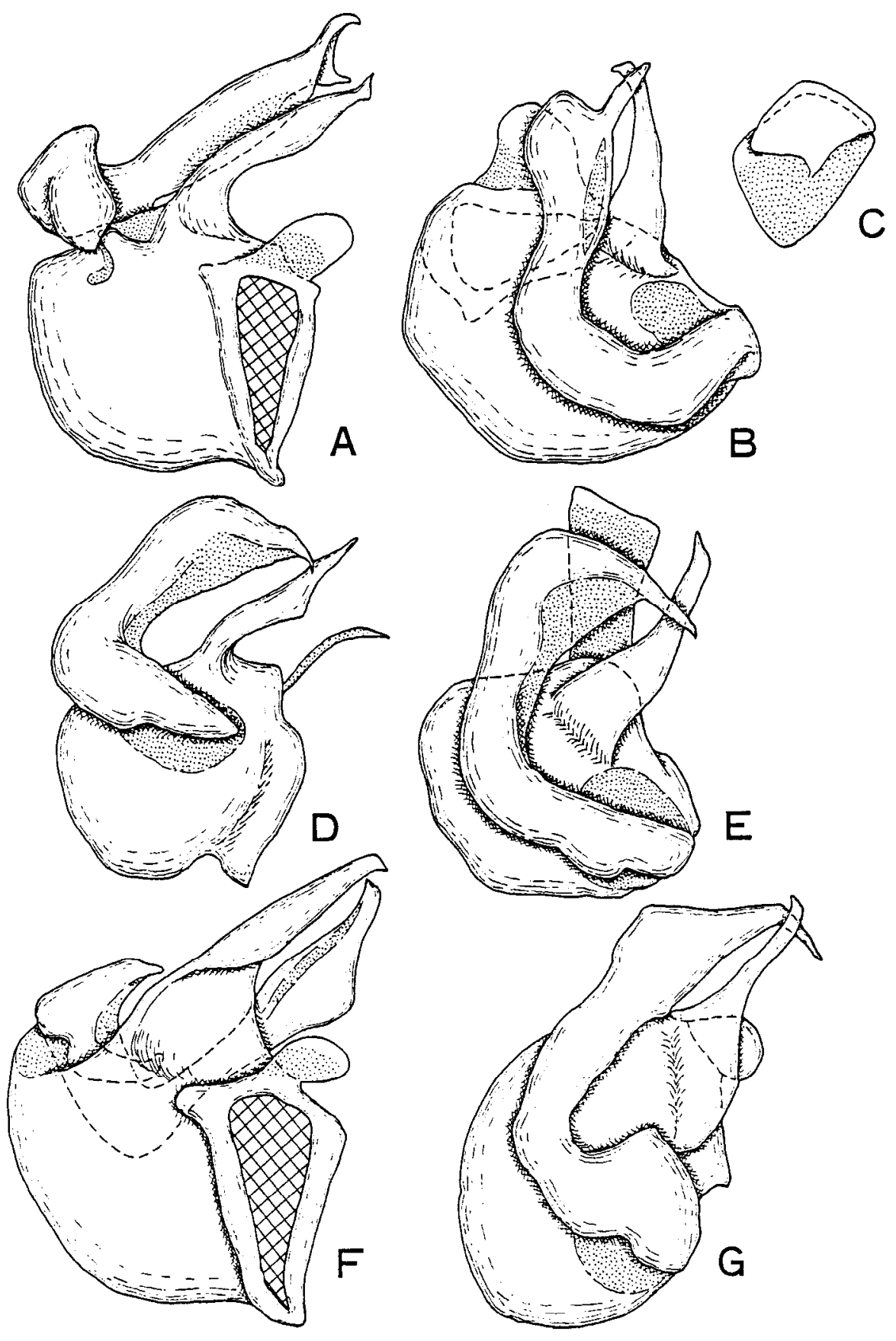


S. NOMURA

Fig. 125. Female genitalia of Batriscenellus in ventral view.
$A, B$. japonicus vicarius Löbl
B, $B$. punctatus sp. nov.
C, B. fallax (Sharp)
D, B. kujumontanus sp. nov.
E, B. transformis sp. nov. 

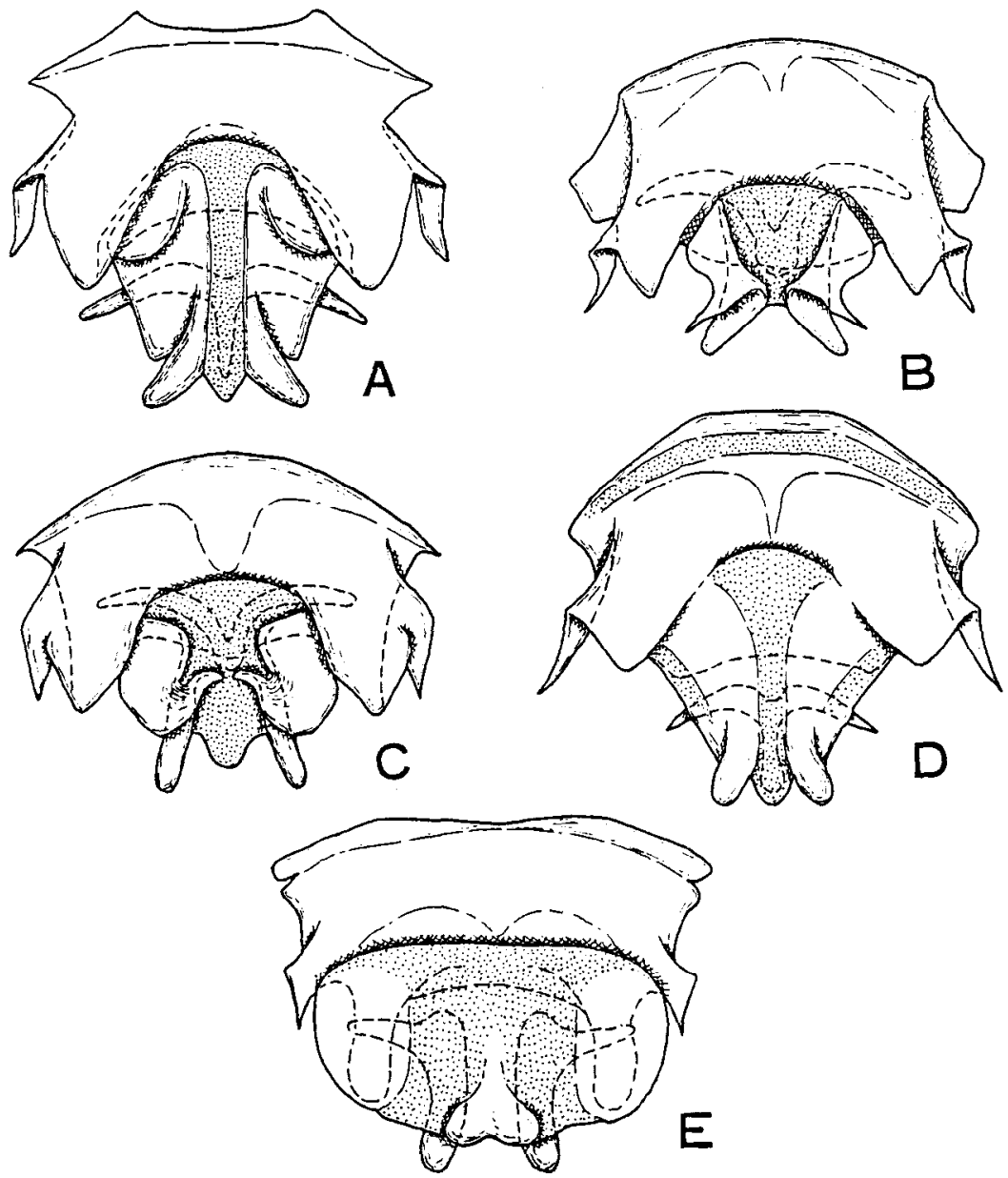
Fig. 126. Female genitalia of Batriscenellus in ventral view.
$A$, similis
$B$.
B .pilosellus
B. s a k a $i$ i
$B$. 

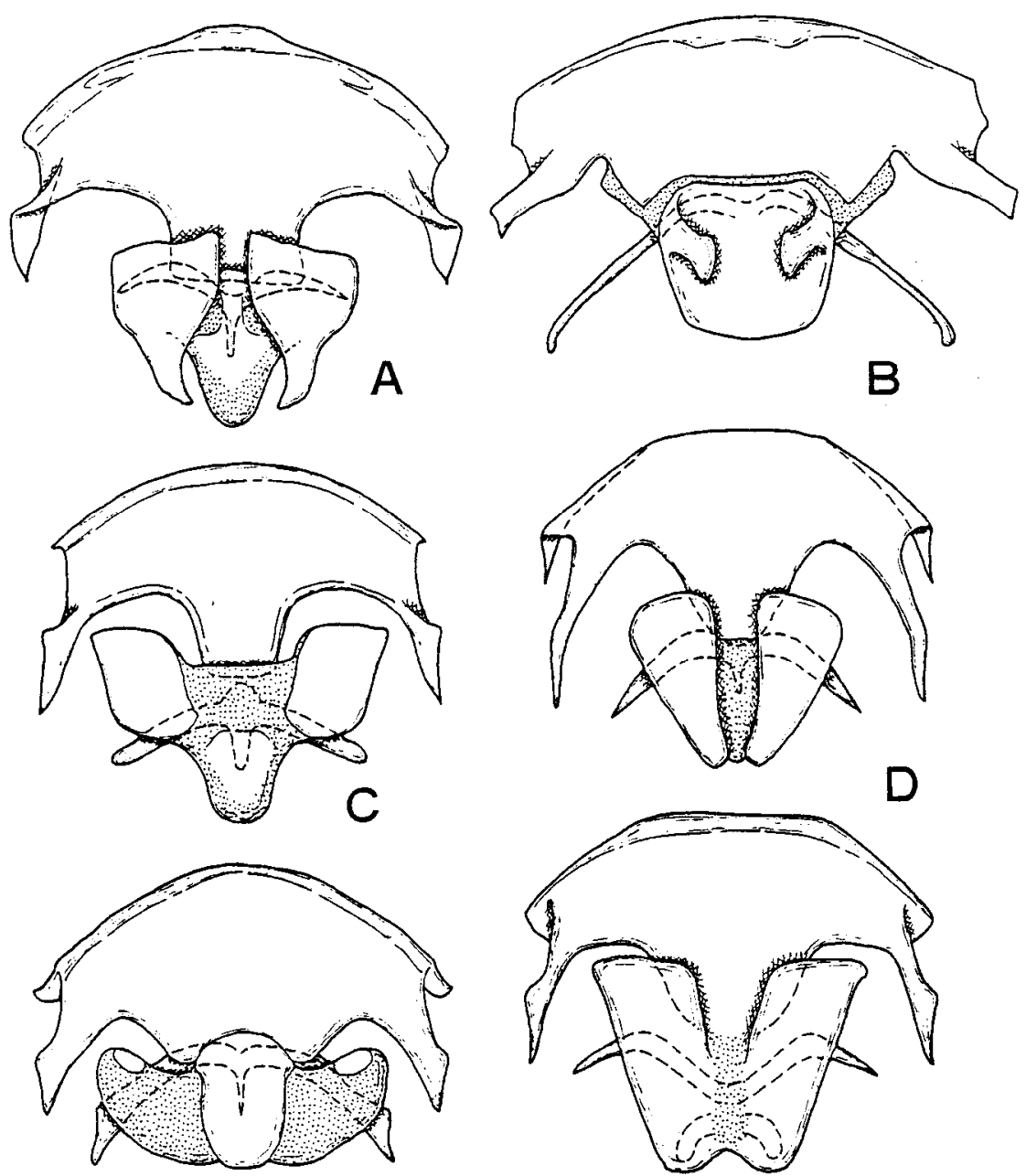

$\mathrm{E}$

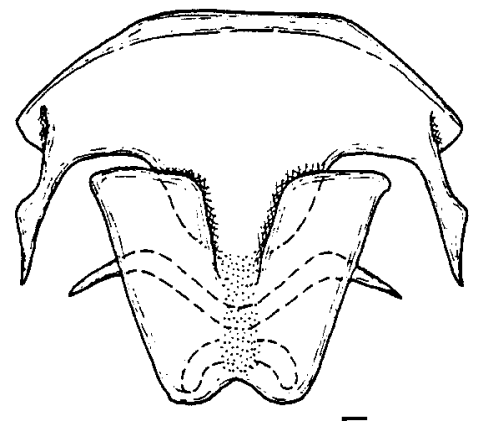

$F$ 
S. NOMURA

Fig. 127. Batriscenaulax kunigamensis sp. nov., male dorsal aspect. 


$$
\text { 渴 }
$$


Fig. 128. Fore tibiae and tarsi of Batriscenaulaxin males.
$A, B$. longipes longipes Jeannel from Mt. Haigamine, Hiroshima Pref.
B, ditto, from Ouchi, Kochi Pref.
C, B. 1. kumaso subsp. nov.
D, B. 1. hayato subsp. nov.
E, B. mcdestus (Sharp).
F, B. furuhatai (Kubota)
G, B. kleinzach sp. nov.
$\mathrm{H}, \boldsymbol{B}$. kunigamensis sp. nov.
I, $\boldsymbol{B}$. nagensis sp. nov. 


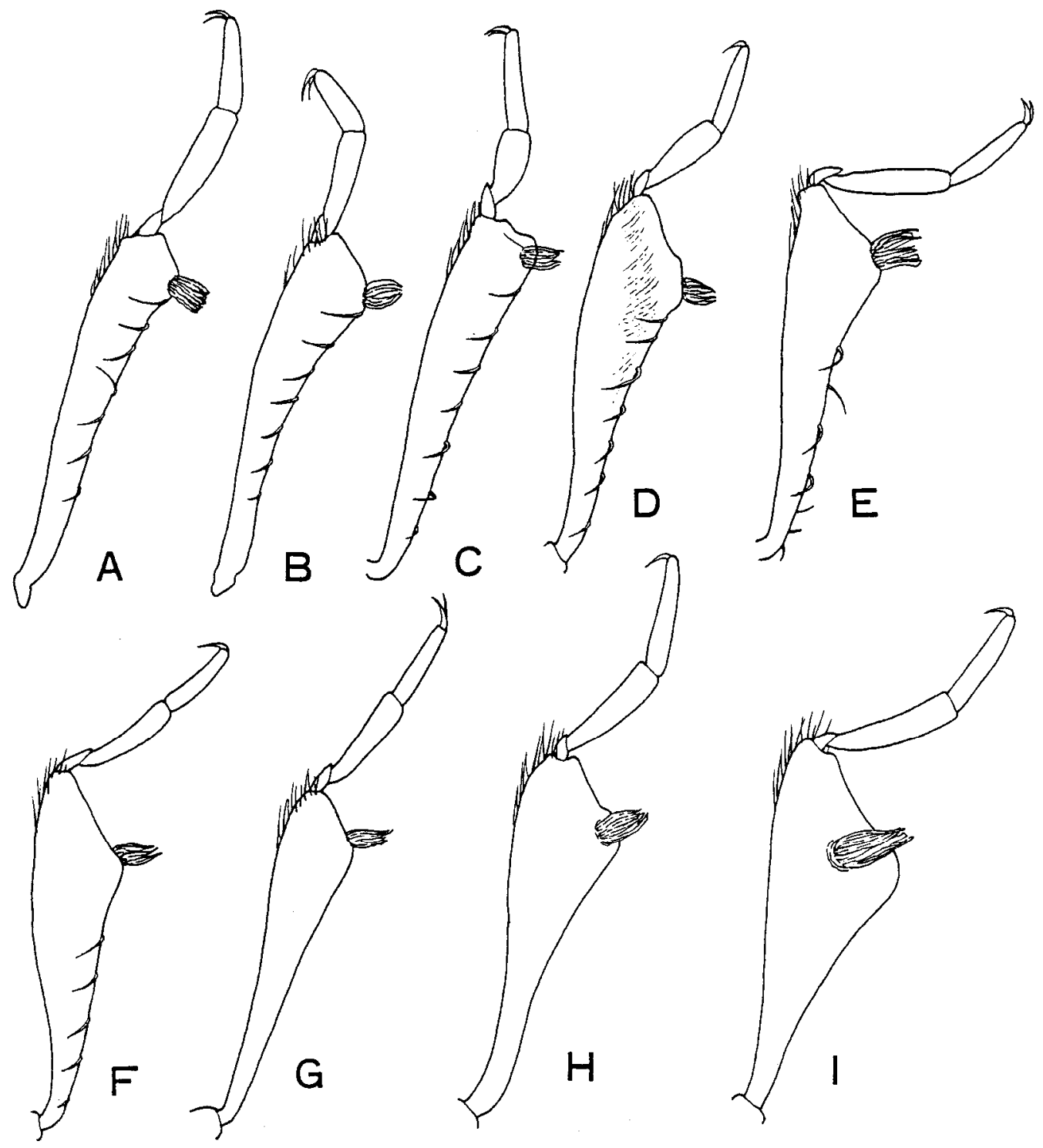


Fig. 129. Male genitalia of Batriscenaulax
A, B, B. longipes longipes Jeannel
C, B. 1. hayato subsp. nav.
D, B. 1. kumaso subsp. nov.
E, $\boldsymbol{B}$. modestus (Sharp)
F, G, B. furuhatai (Kubota).
A, F, lateral view.
B-E, G, ventral view. 

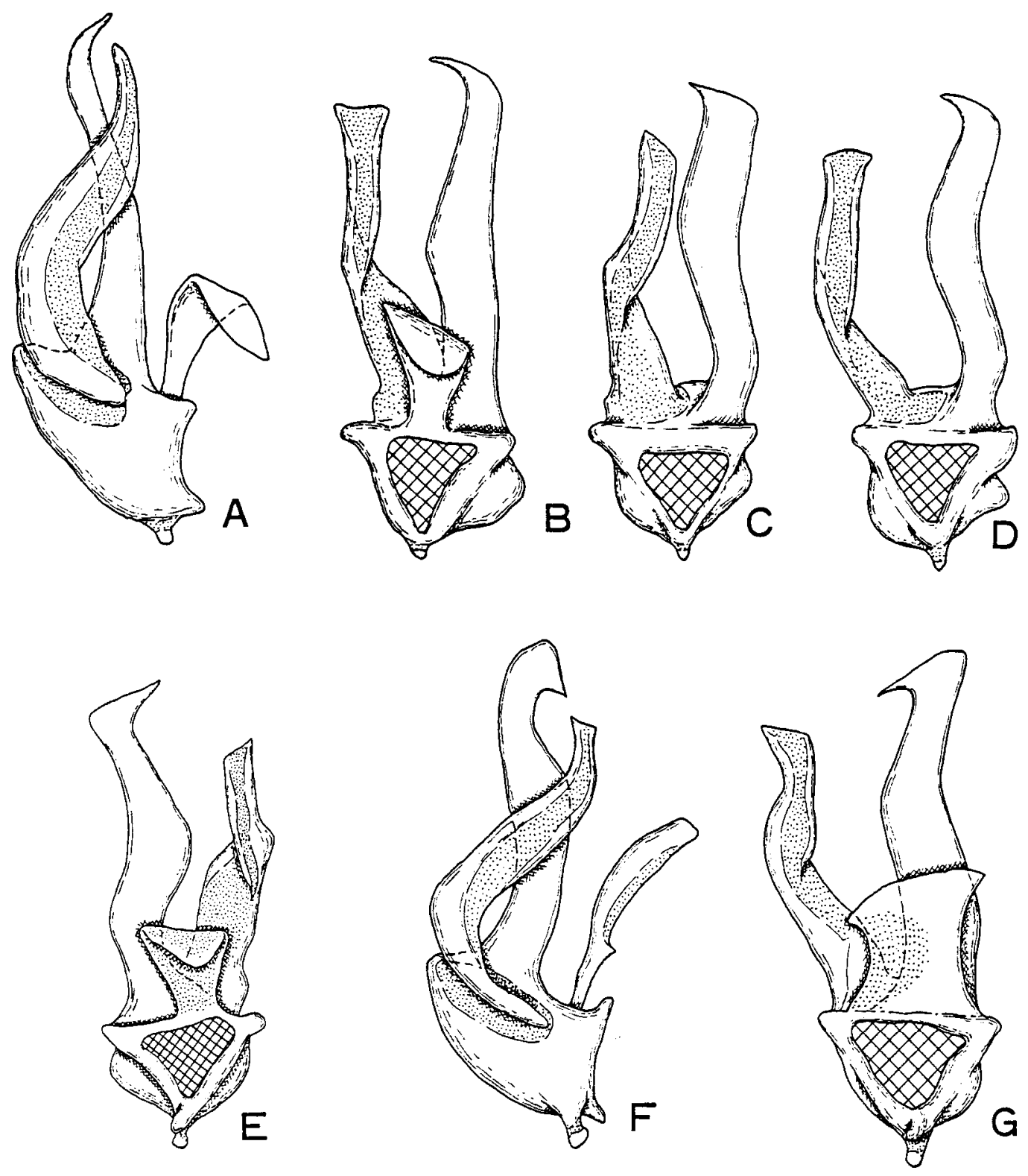
Fig. 130. Male genitalia of Batriscenaulax
A, B, B. kleinzach sp. nov.
C, D, B. kunigamensis sp. nov.
E, F, B. nagensis sp. nov.

A, C, E, ventral view.
B, D, F, lateral view. 


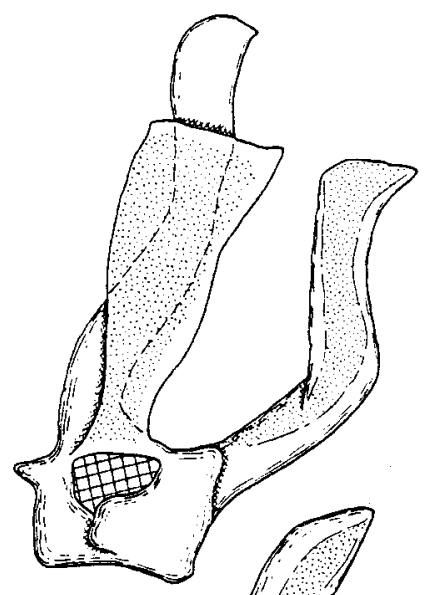

A
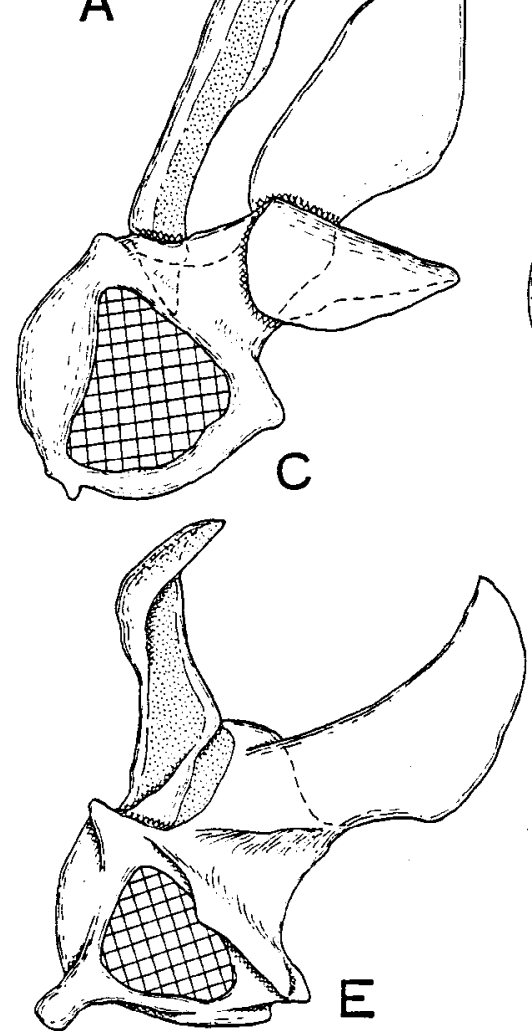
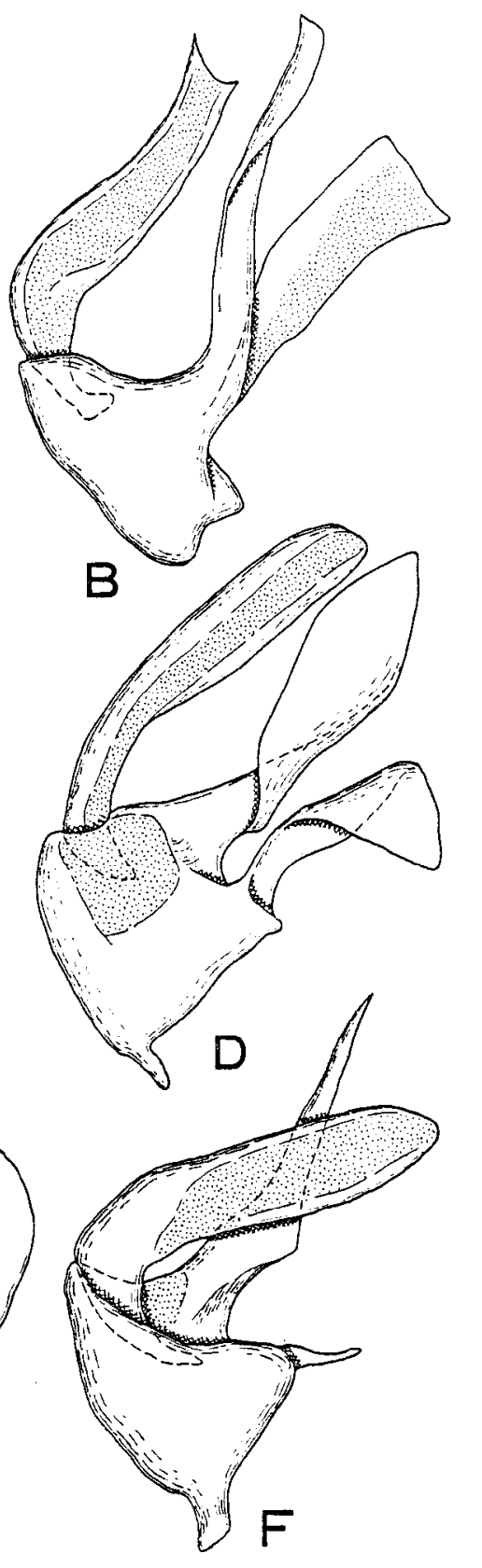
Fig. 131. Female genitalia of Batriscenaularin ventral view.
A, B. longipes longipes Jeannel.
B, B. furuhatai (Kubota).
C, B. kleinzach sp. nov.
D, B. kunigamensis sp. nov. 


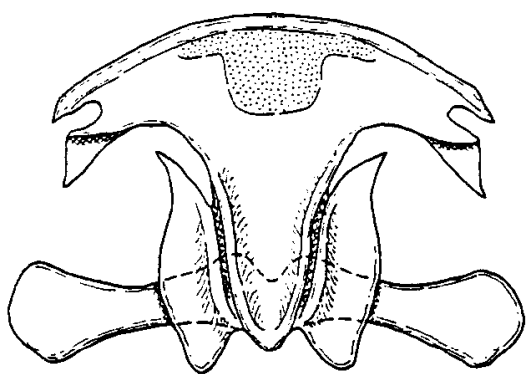

A

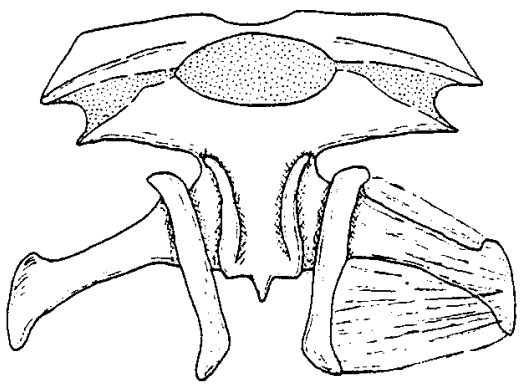

B
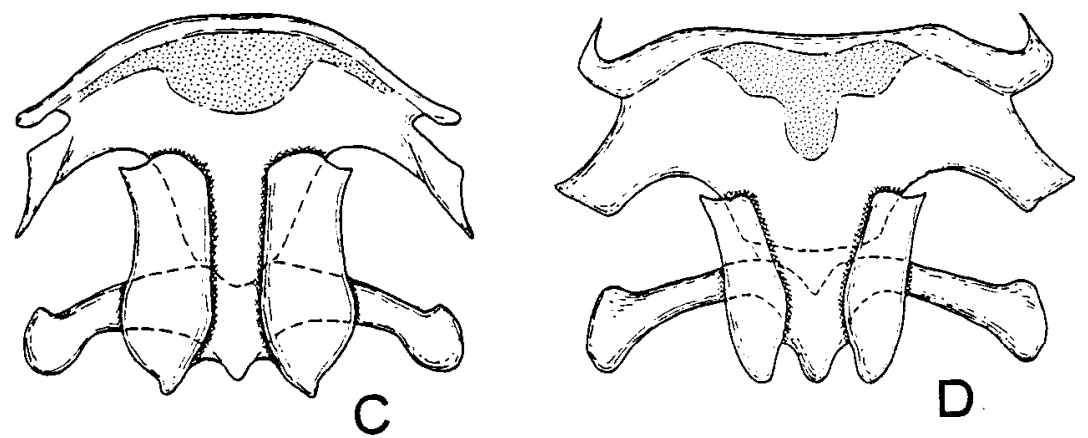
Fig. 132. Physomerinus schenklingi (Raffray), male dorsal aspect. 
BATRISOPLISUS AND TTS ALLIES FROM JAPAN

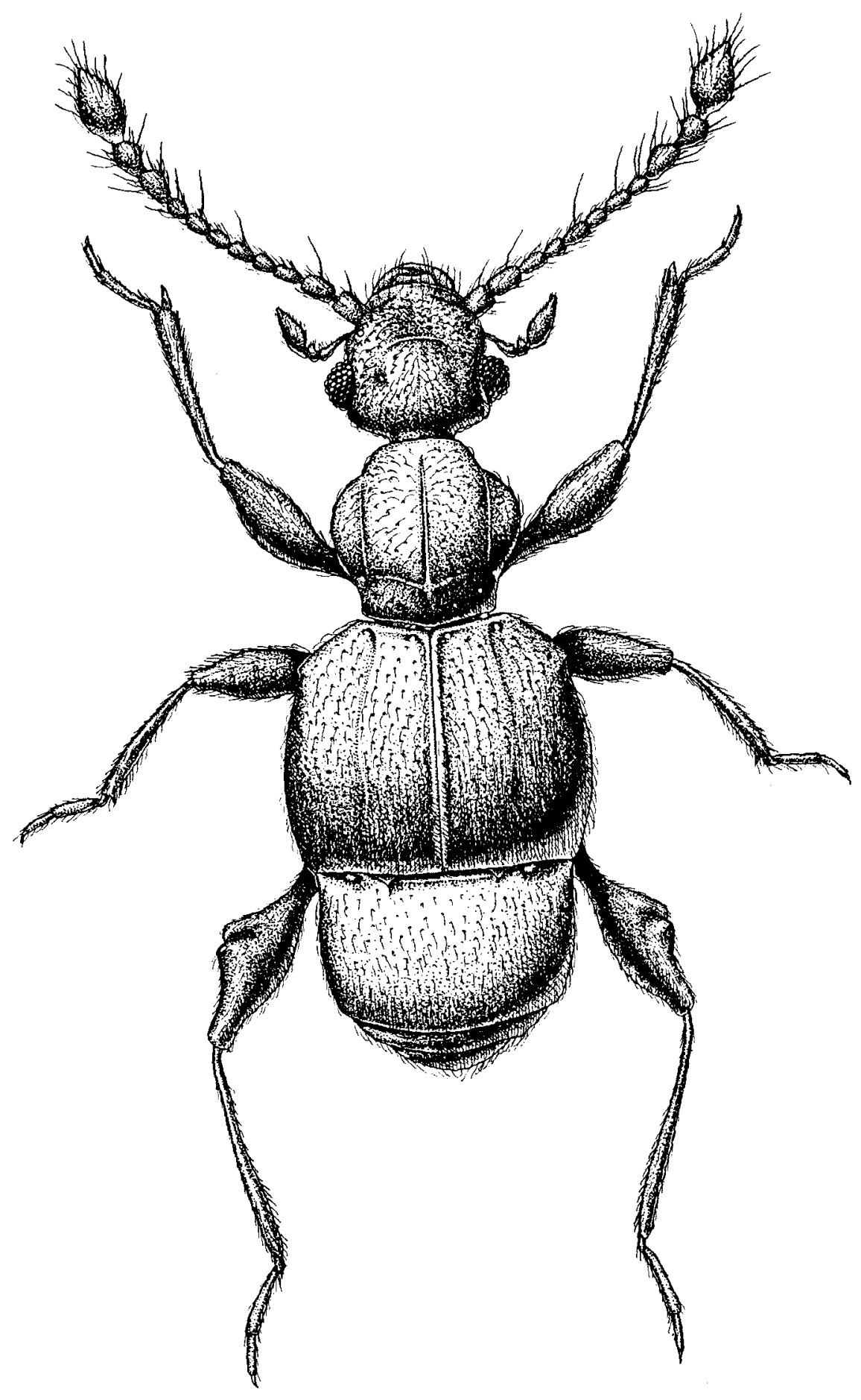


Fig. 133. Hind femora of Physomerinus in males.
A, D, P. pedator (Sharp).
B, E, P. schenklingi (Raffray).
C, F, P. hasegawai sp. nov.

A-C, dorsal view.

D-F, ventral view. 


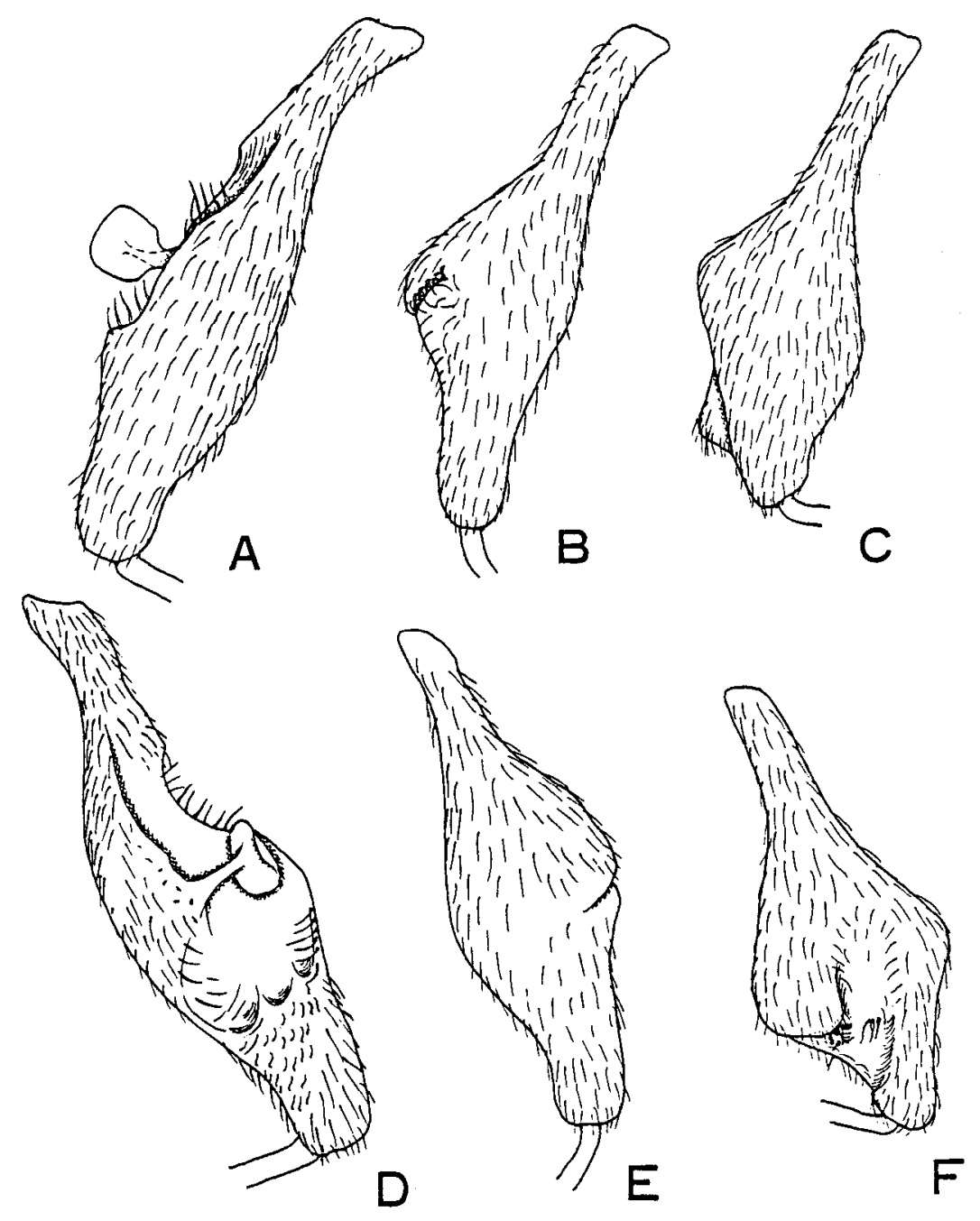


Fig. 134. Male genitalia and 9th abdominal sternite of Physomerinus.

A, B, P. pedator (Sharp).

C-F, P. schenklingi (Raffray).

G, H, P. hasegawai sp. nov.

A, C, G, male genitalia in ventral view.

$\mathrm{B}, \mathrm{D}, \mathrm{H}$, ditto, lateral view.

$\mathrm{E}$, parameres.

F, 9th abdominal stemite. 


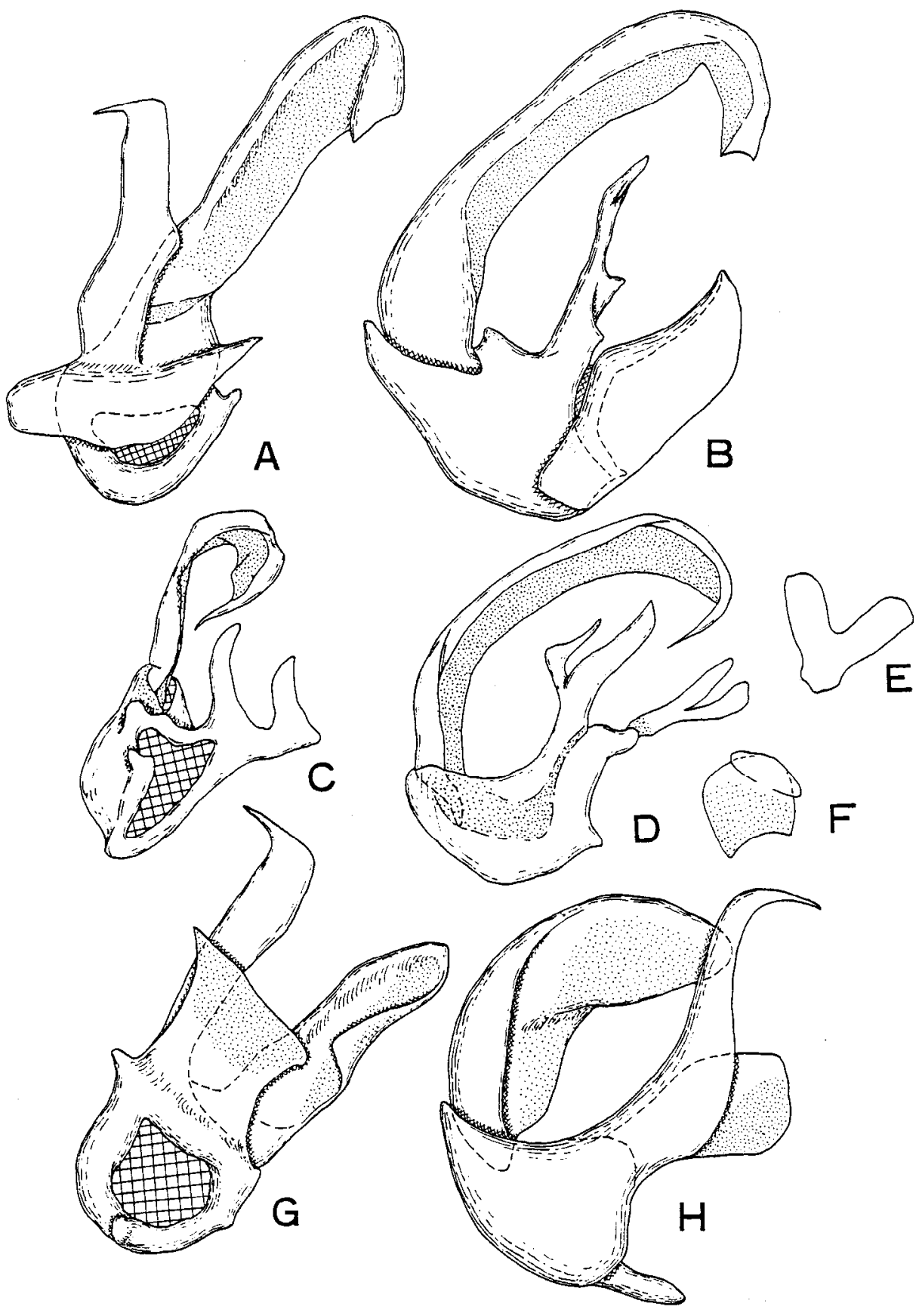


Fig. 135. Female genitalia of Physomerinus in ventral view.
A, P. pedator (Sharp).
B, P. schenklingi (Raffray).
C, P. hasegawai sp. nov. 


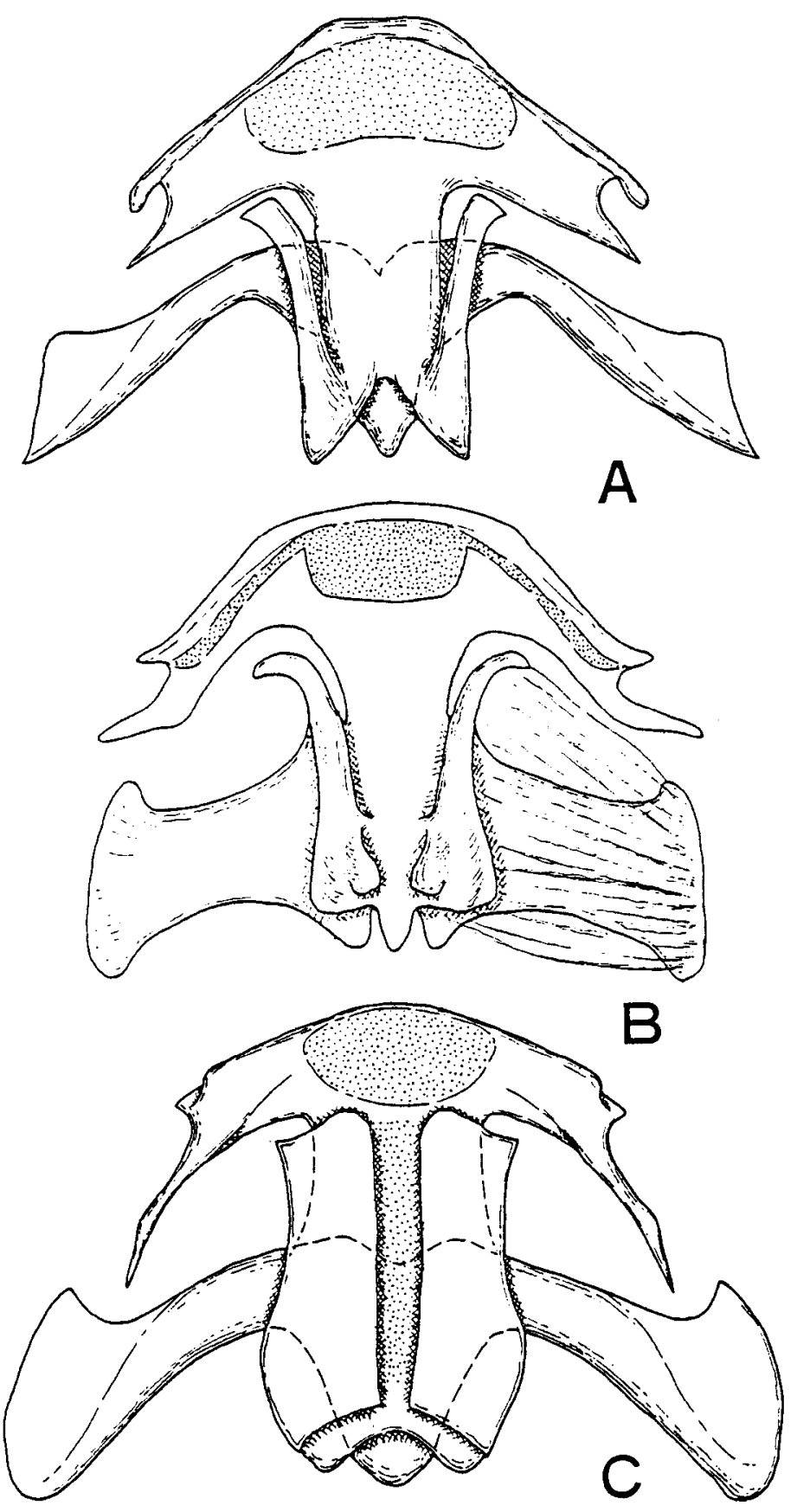


Fig. 136. Arthromelodes aizuanus sp. nov., male dorsal aspect. 


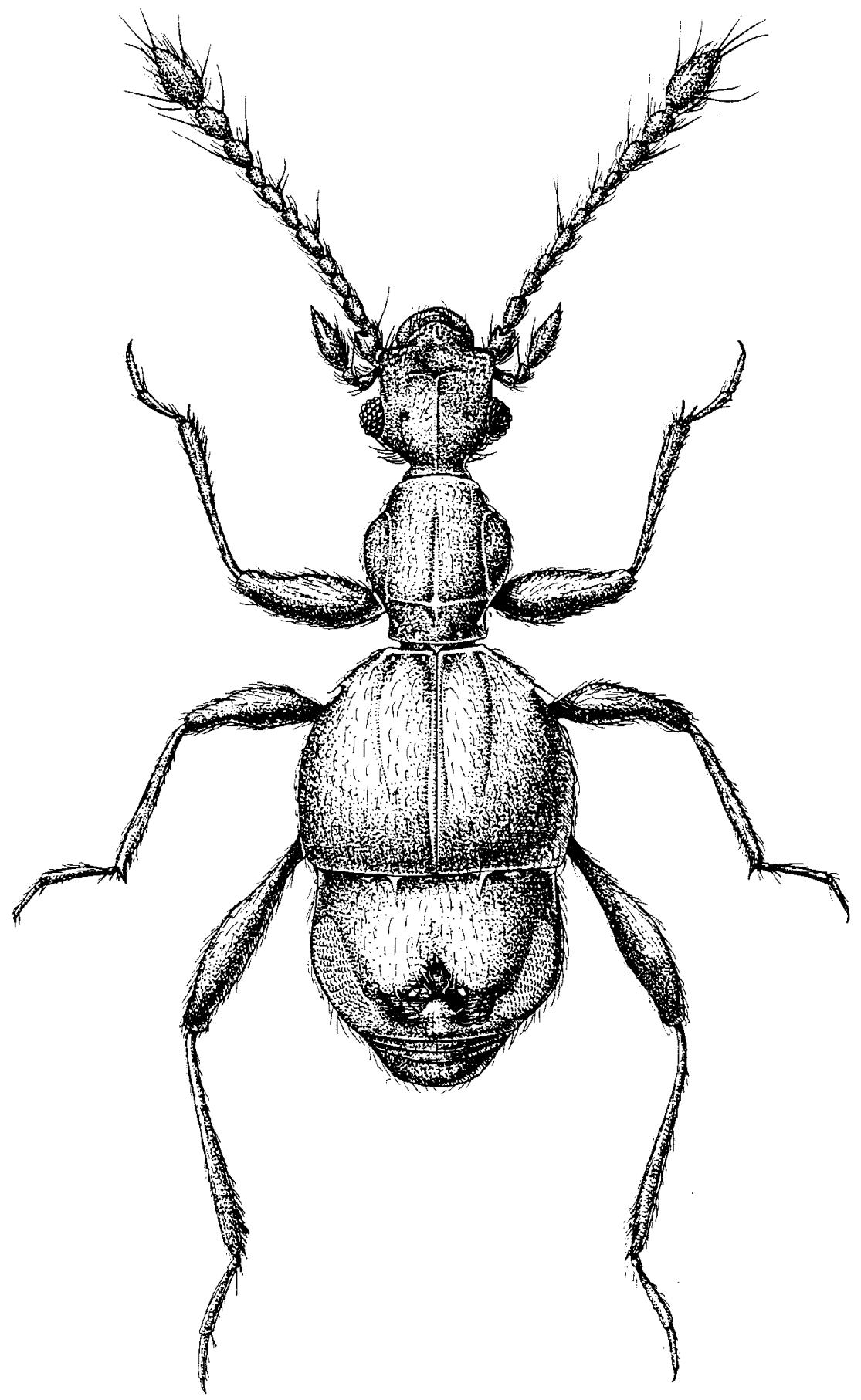


Fig. 137. Legs of Arthromelodes in males.
A, A. loebli sp. nov.
B, A. mercurius sp. nov.
c, A. hikosanus sp. nov.
D, A. thysanoventris sp. nov.
E, A. corniventris sp. nov.
F, A. sinuatipes sp. nov.
A, hind leg.
$\mathrm{B}, \mathrm{C}$, hind femur.
D, E, hind tibia.
F, mid tibia.sp. nov. 


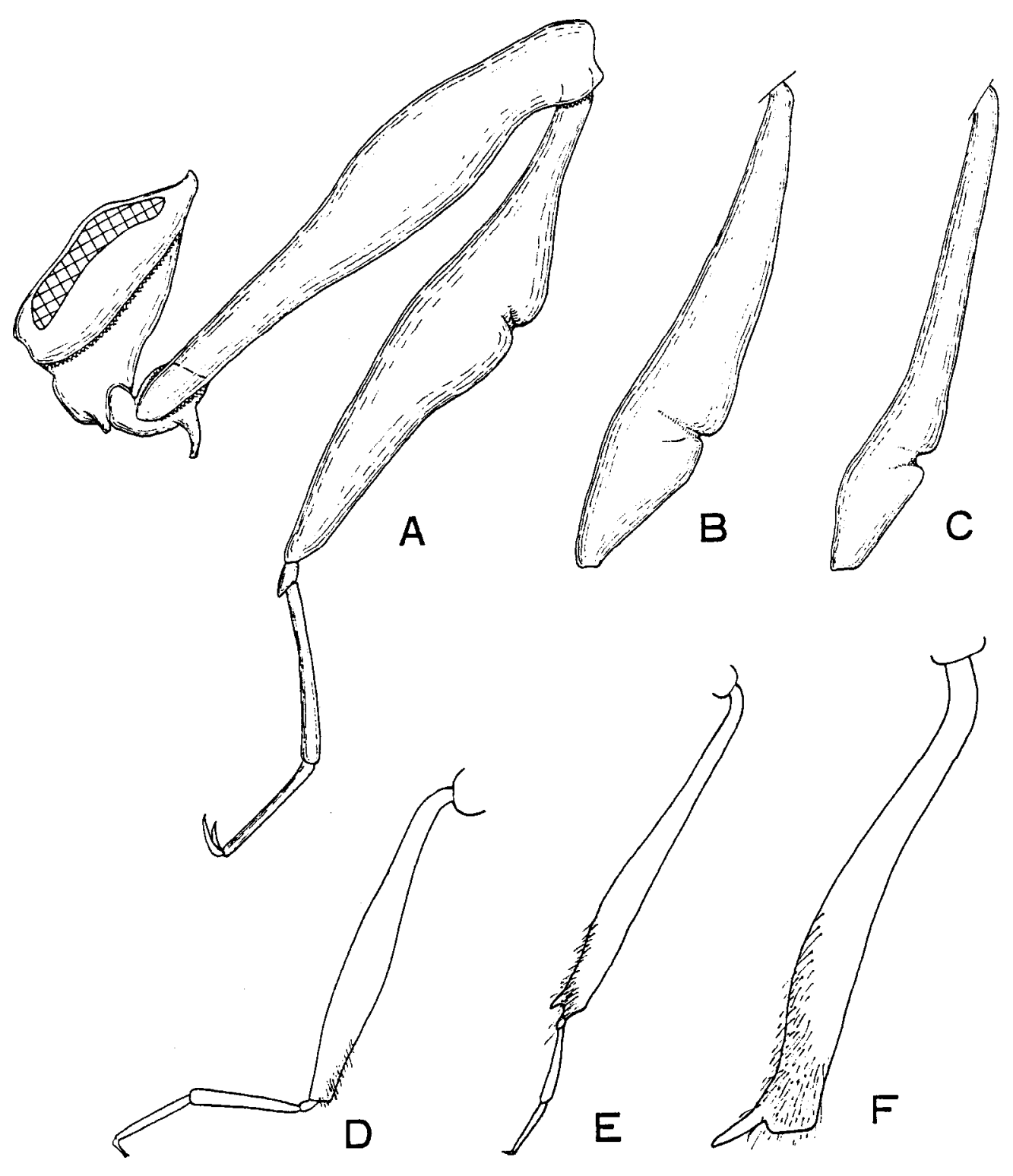


Fig. 138. Fourth to 8th abdominal segments of Arthromelodes in males.
A, $A$. sinuatipes sp. nov.
$\mathrm{B}, A$. dilatatus daibosatsuanus subsp. nov.
C, $A$. d. fujimontanus subsp. nov.
$\mathrm{D}, \boldsymbol{A}$. $\boldsymbol{d}$. shiranemontanus subsp. nov.
E, A. thysanoventris sp nov.

A-D, dorsal view.
E, F, lateral view. 

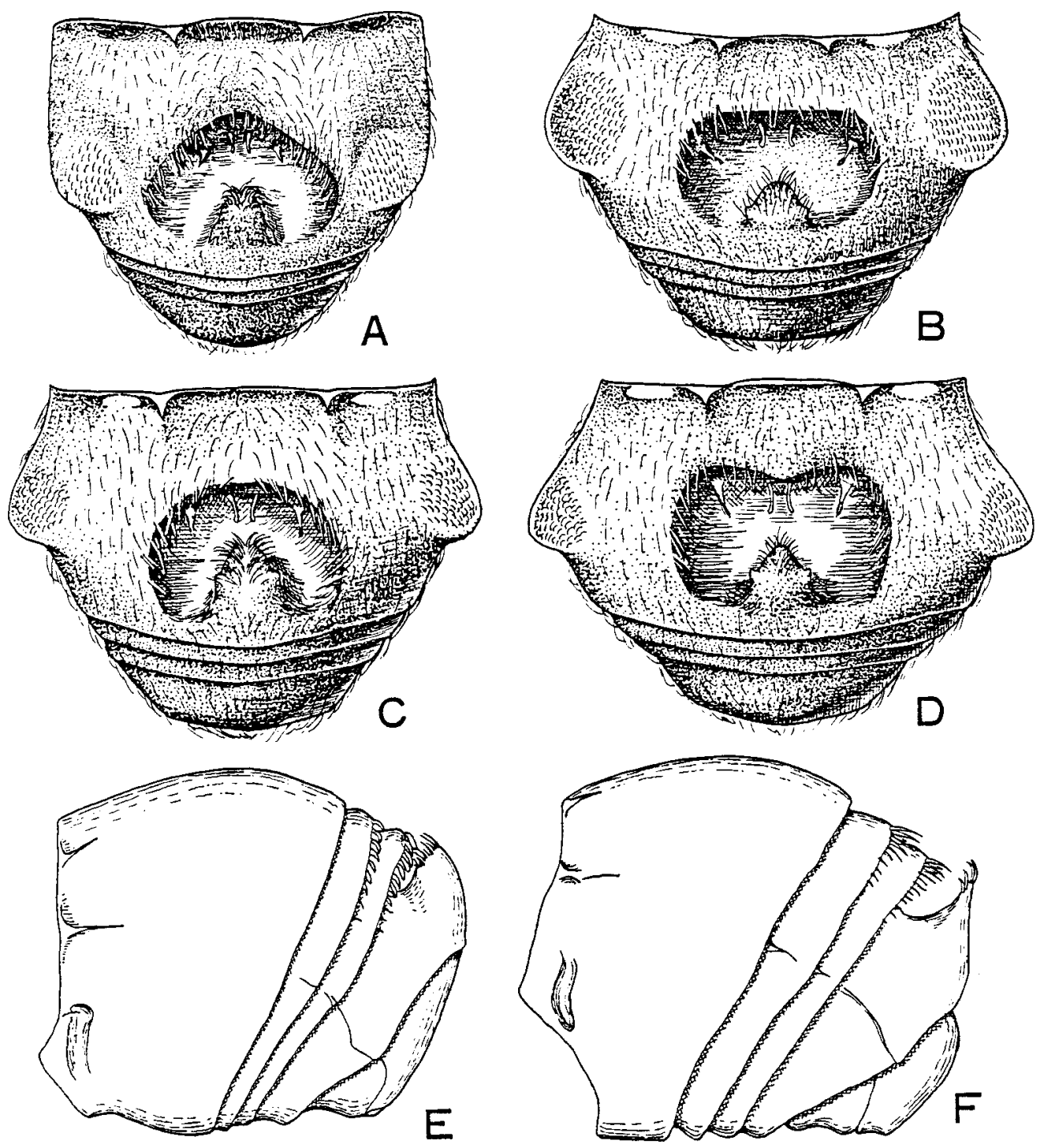
Fig. 139. Male genitalia of Arthromelodes.

A, B, A. punctifrons sp.nov.

C, D, A. giganteus sp. nov.
$A, C$, ventral view.
$\mathrm{B}$, lateral view.
$\mathrm{D}$, dorsal view. 


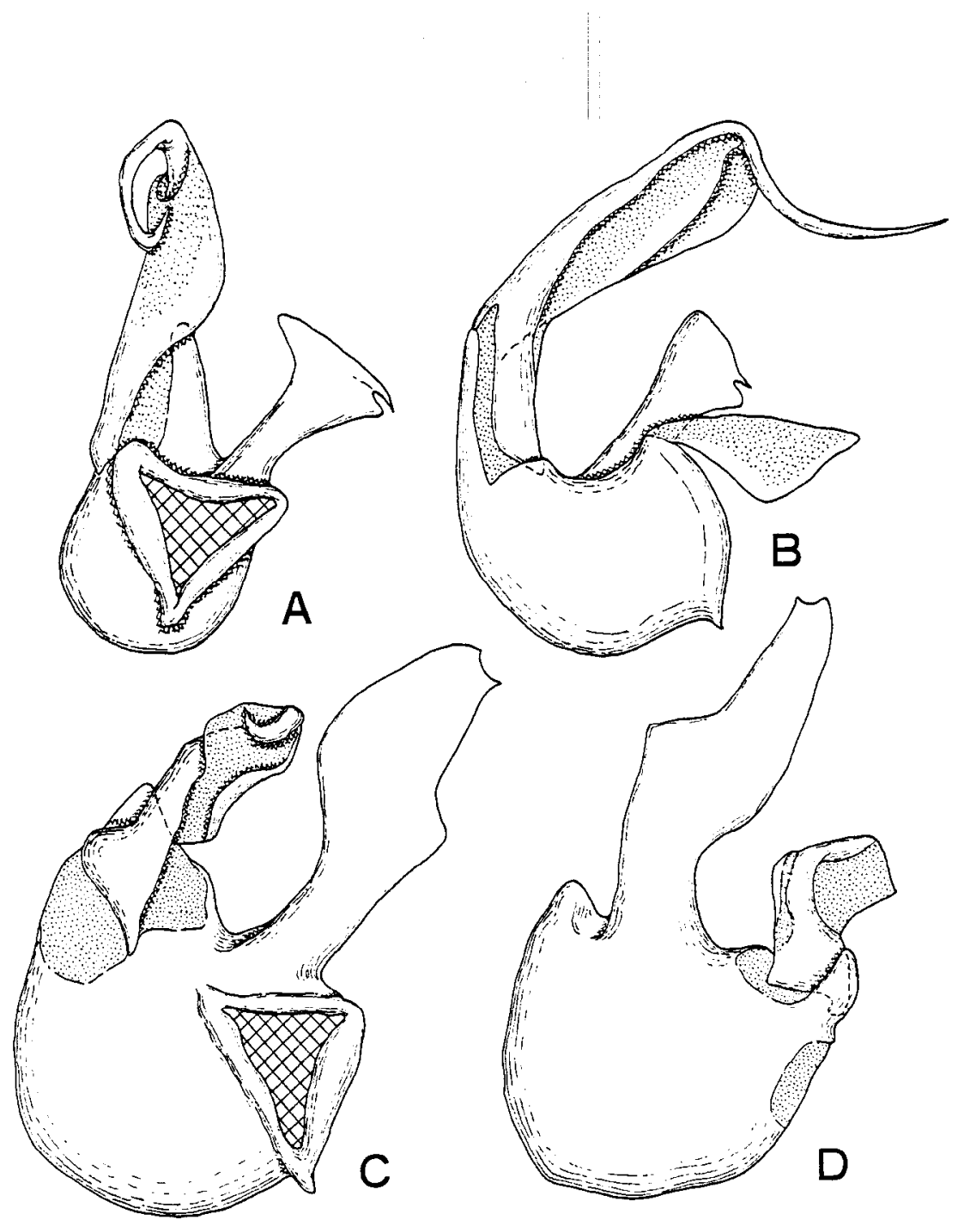


Fig. 140. Male genitalia of Arthromelodes.
A, B, A. pilicollis sp. nov.
C, D, A. kiiensis sp. nov.
E, F, A. gyoja sp. nov.

A, C, E, ventral view.

$\mathrm{B}, \mathrm{D}, \mathrm{F}$, lateral view. 


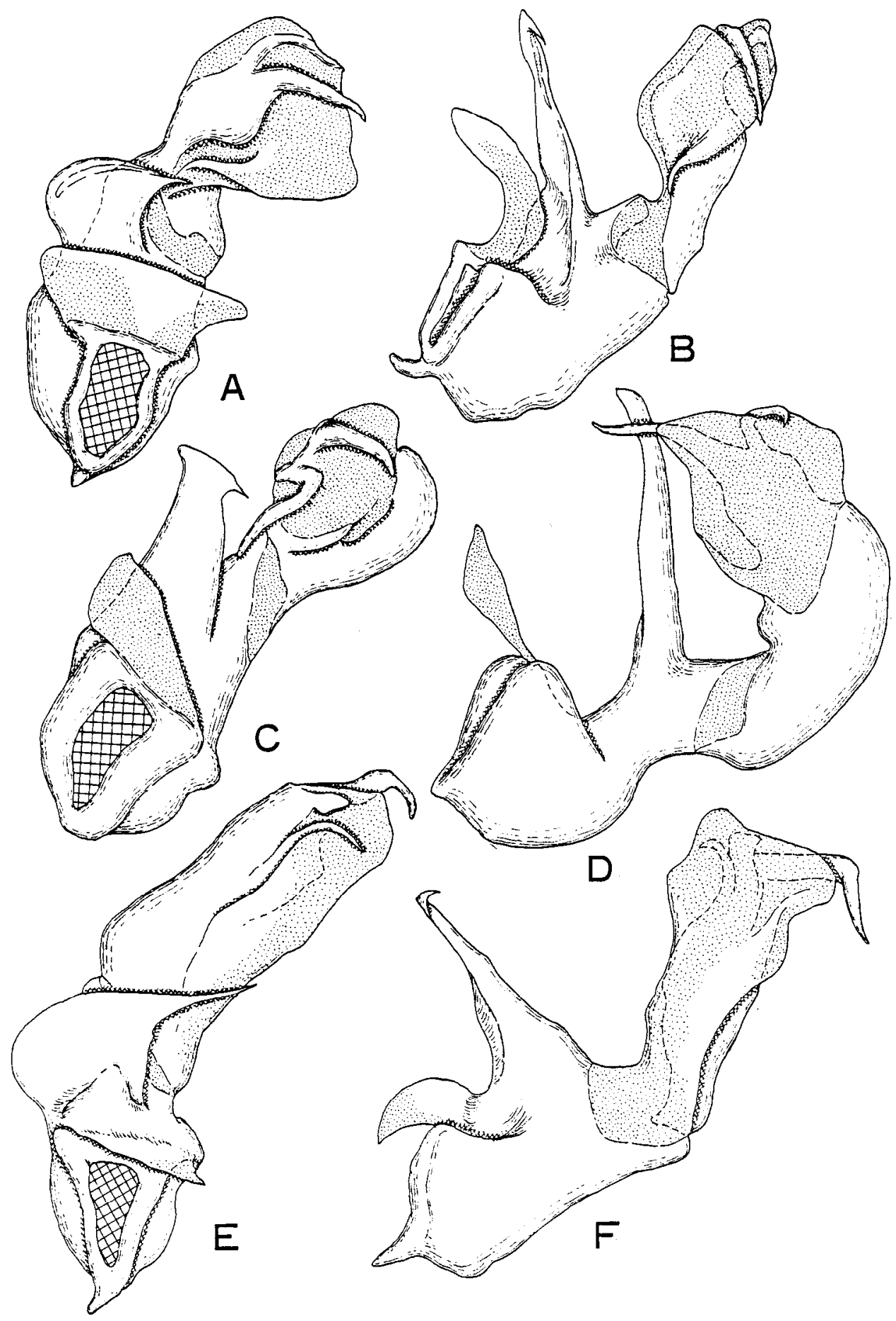


Fig. 141. M ale genitalia of Arthromelodes

A, B, A. thysanoventris sp. nov. C, D, A. corniventris sp. nov.

$A, C$, ventral view.

$B, D$, lateral view. 

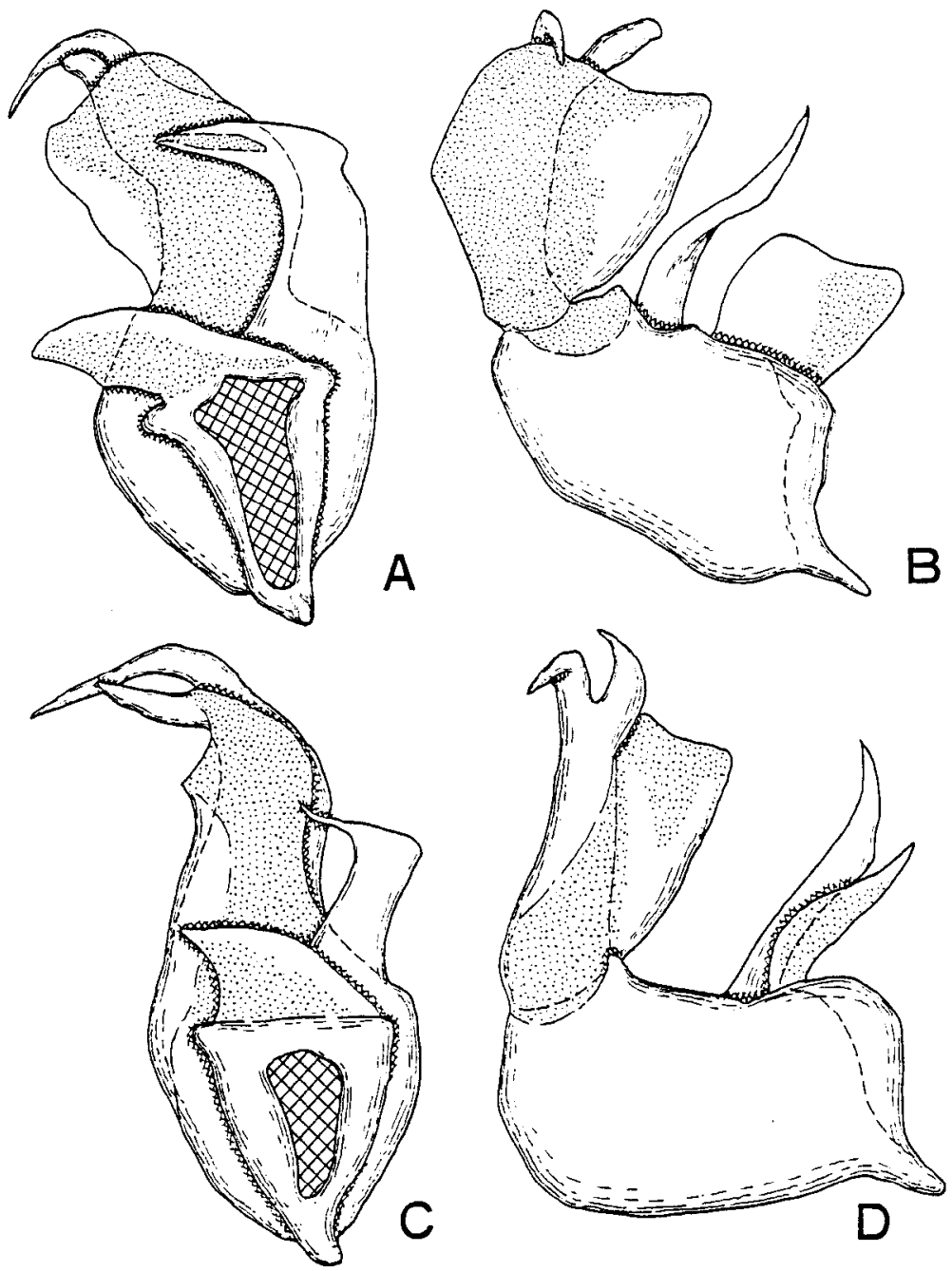
Fig. 142 Male genitalia and 8th to 9th abdominal segments of Arthromelodes. A-C, A. mercurius sp. nov. D-G, $A$. hikosanus sp. nov. H-L, A. loebli sp. nov.

A, D, H, I, male genitalia in ventral view.

$\mathrm{B}, \mathrm{E}, \mathrm{J}$, ditto, lateral view.

$\mathrm{C}, \mathrm{F}, \mathrm{K}, 8$ th tergite in lateral view.

G, L, 9th stemite. 


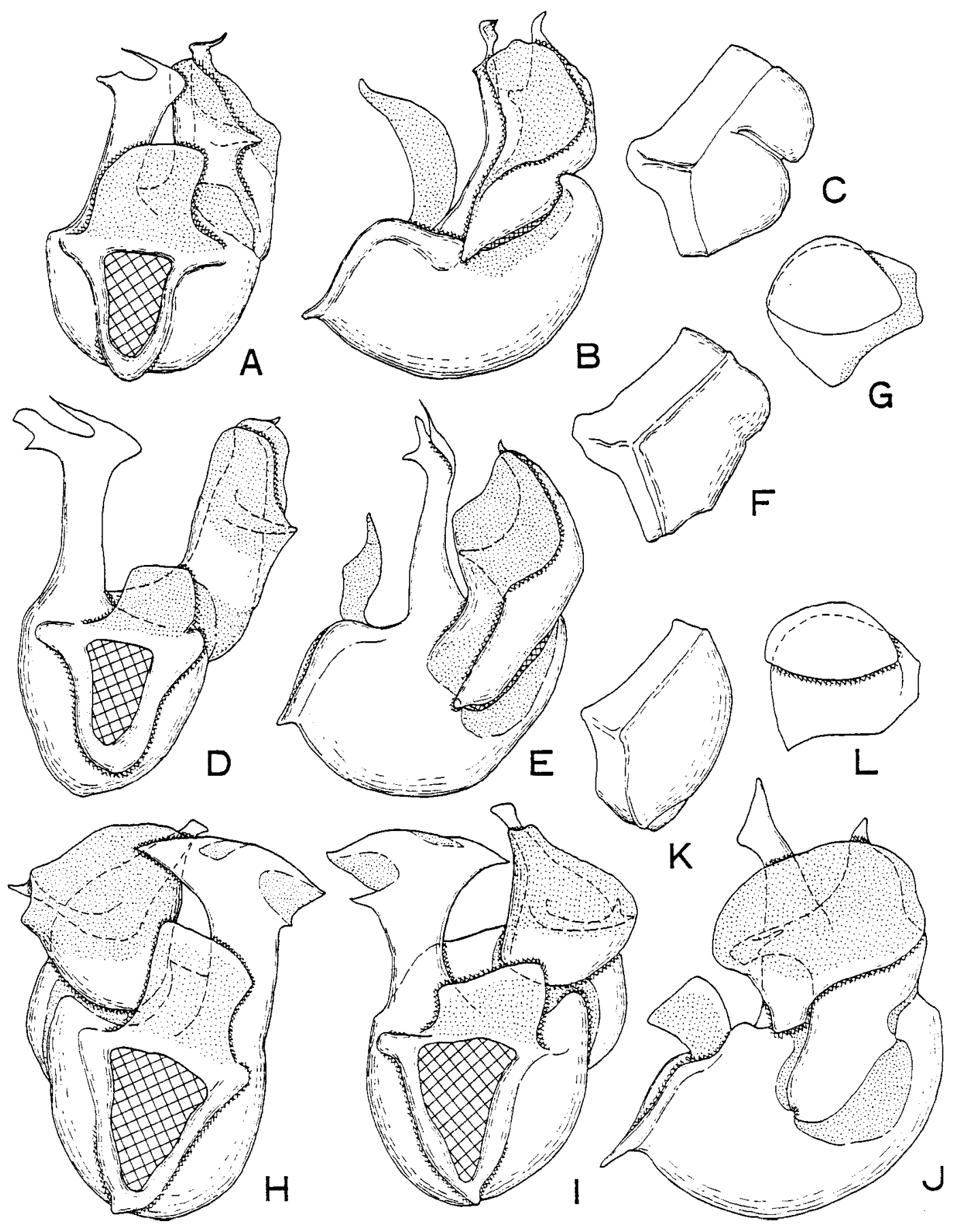


Fig. 143. Male genitalia of Arthromelodes.

A, B, A_ dilatatus daibosatsuanus subsp. nov.

C, D, A. d. fujimontanus subsp. nov.

E, F, A.d. shiranemontanus subsp. nov.

A, C, E, ventral view.

$\mathrm{B}, \mathrm{D}, \mathrm{F}$, lateral view. 


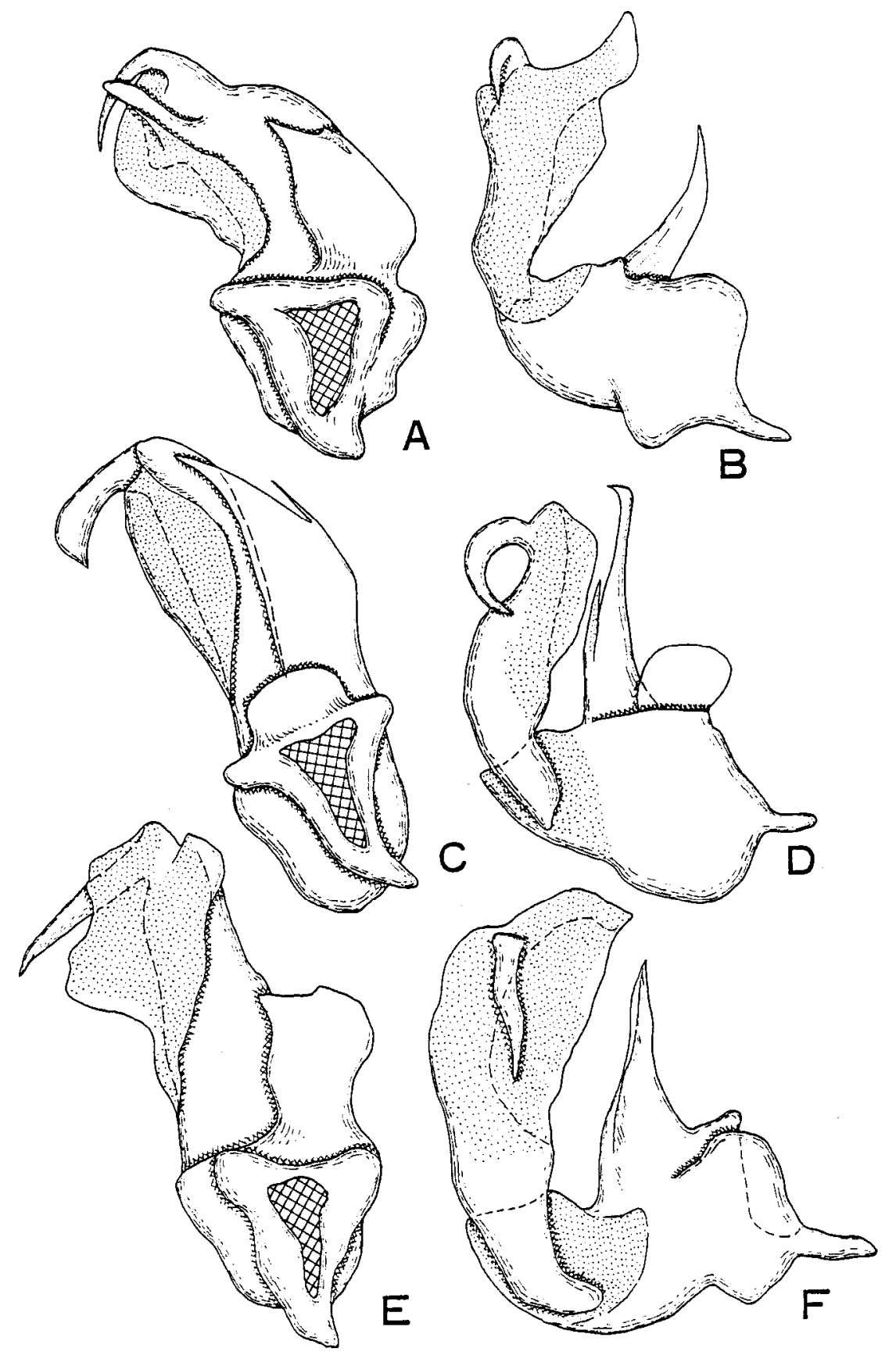


Fig. 144. Male genitalia of Arthromelodes

A, B, A. sinuatipes sp. nov.

$\mathrm{C}, \mathrm{D}, \mathrm{A}$. aizuanus sp. nov.

A, C, ventral view.

B, D, lateral view. 

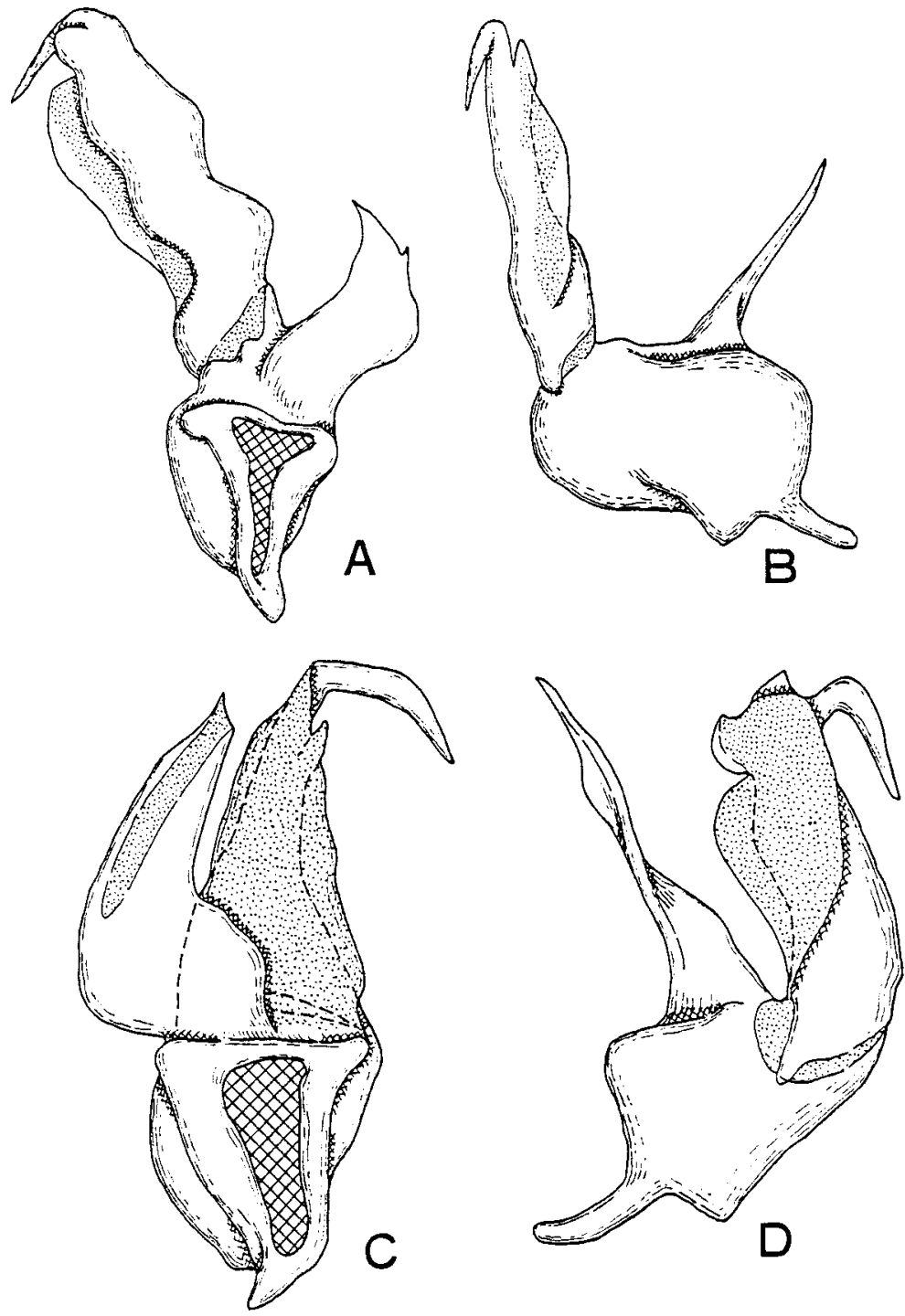
Fig. 145. Male genitalia of Arthromelodes.
A, B, A. saikaiensis sp. nov.

C, D, A. crucifer sp. nov.

$A, C$, ventral view.

$B, D$, lateral view. 


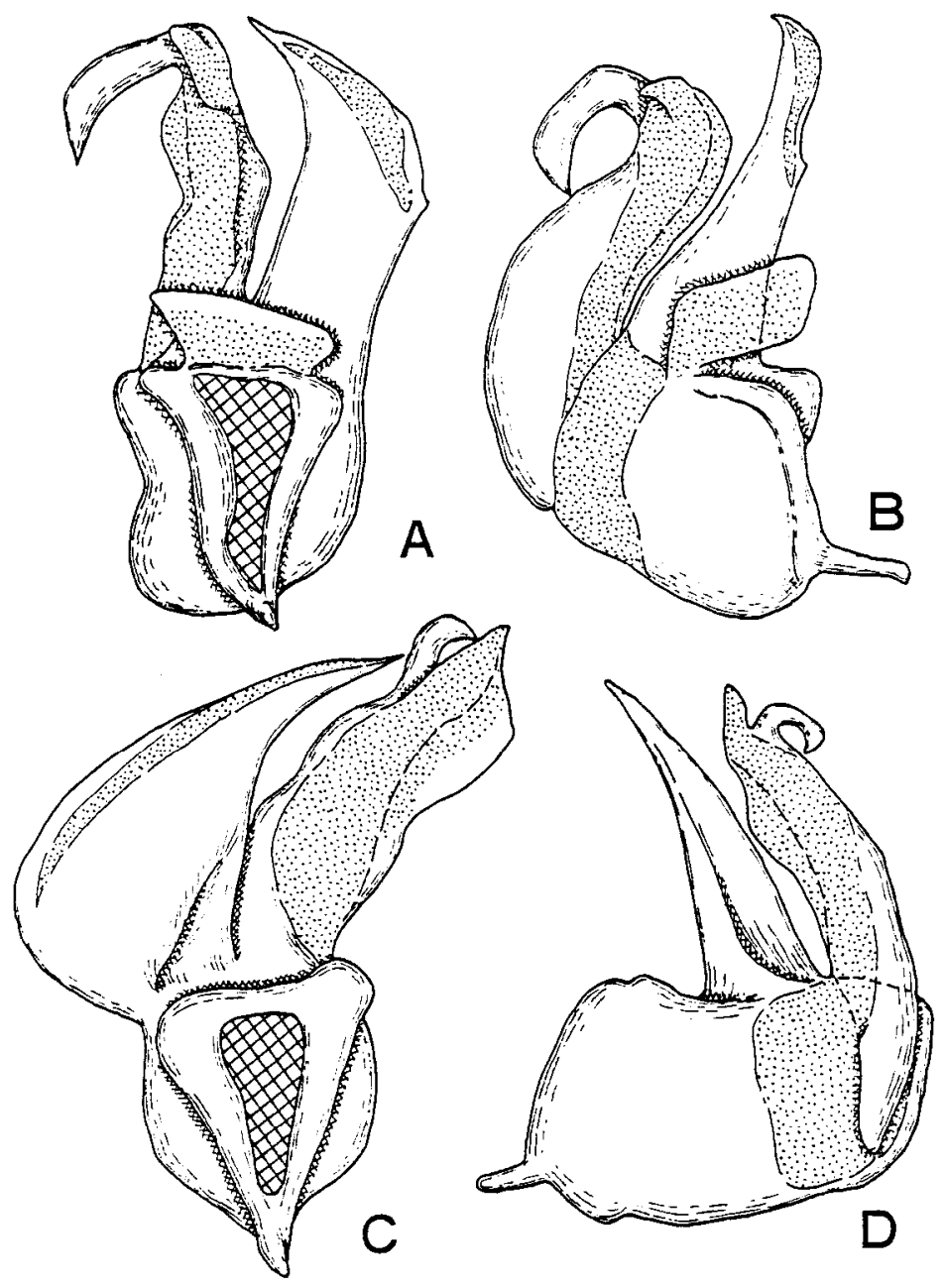


Fig. 146. Female genitalia and 8th abdominal segment of Arthromelodes.
A, A. punctifrons sp. nov.
$\mathrm{B}, \boldsymbol{A}$. giganteus sp. nov.
C, A. kiiensis sp. nov.
D, A. gyoja sp. nov.
E, F, A. thysanoventris sp. nov

A-E, female genitalia in ventral view.

$\mathrm{F}$, 8th abdominal segment in lateral view 

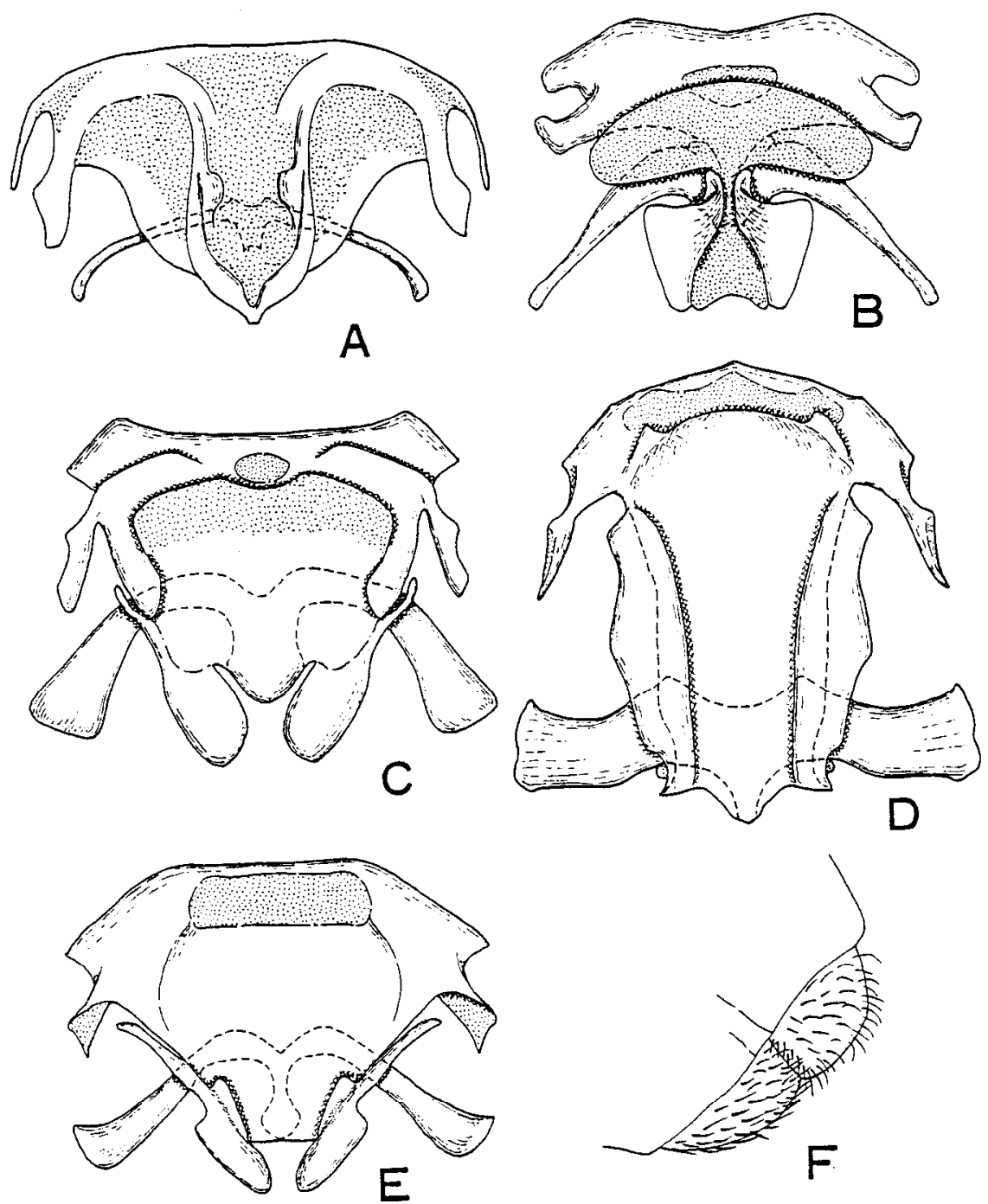
Fig. 147. Female genitalia and 8th abdominal segments of Arthromelodes.
A, B, A. mercurius sp. nov.
C, D, A. hikosanus sp. nov.
E, F, A. loebli sp. nov.
$\mathrm{G}, \boldsymbol{A}$. saikaiensis sp. nov.
E, F, A. crucifer sp. nov.

A, C, E, G, H, female genitalia in ventral view

B, D, F, 8th abdominal segment in lateral view. 

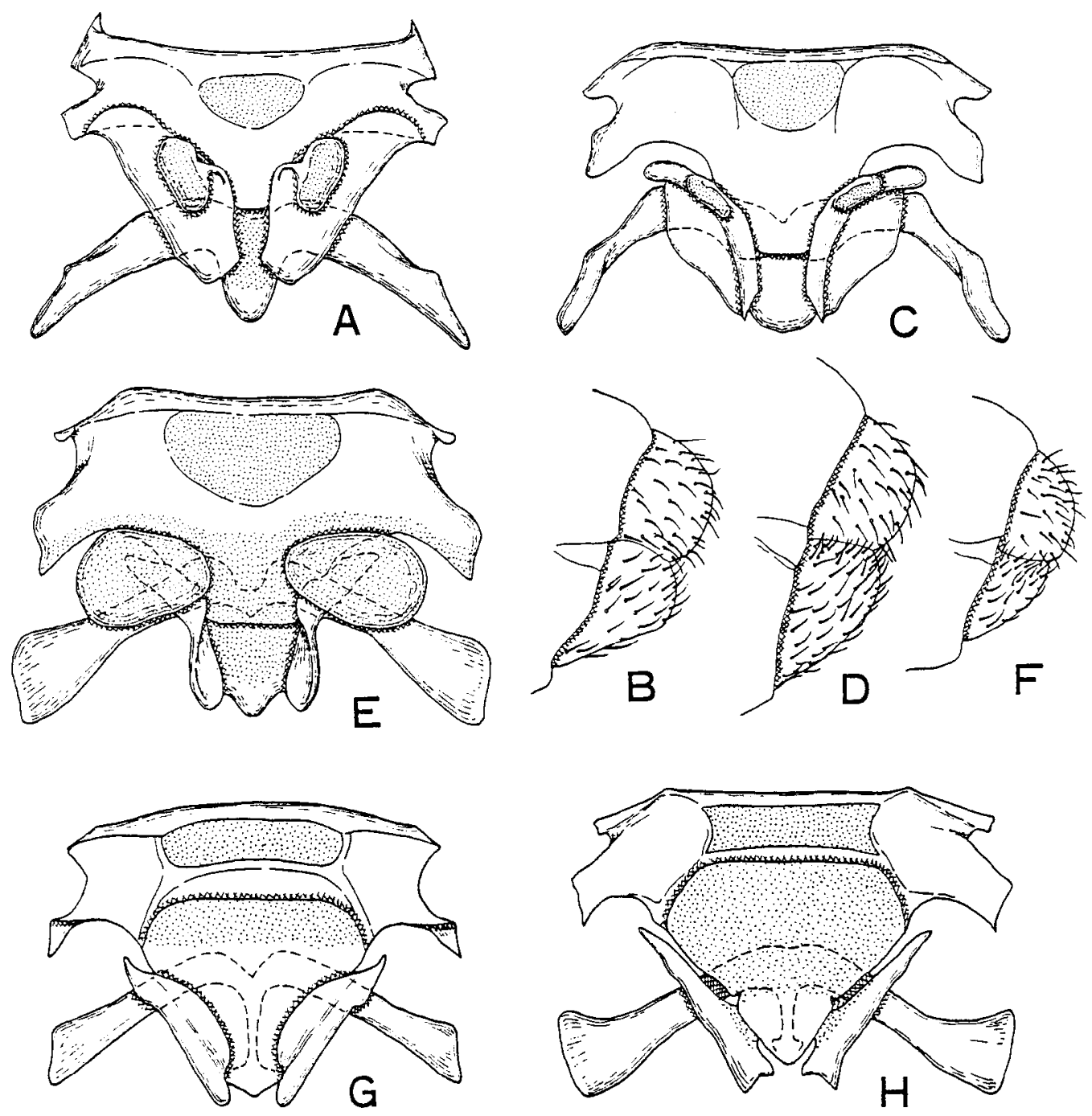
Fig. 148. Batrisceniola dissimilis (Sharp), male dorsal aspect. 


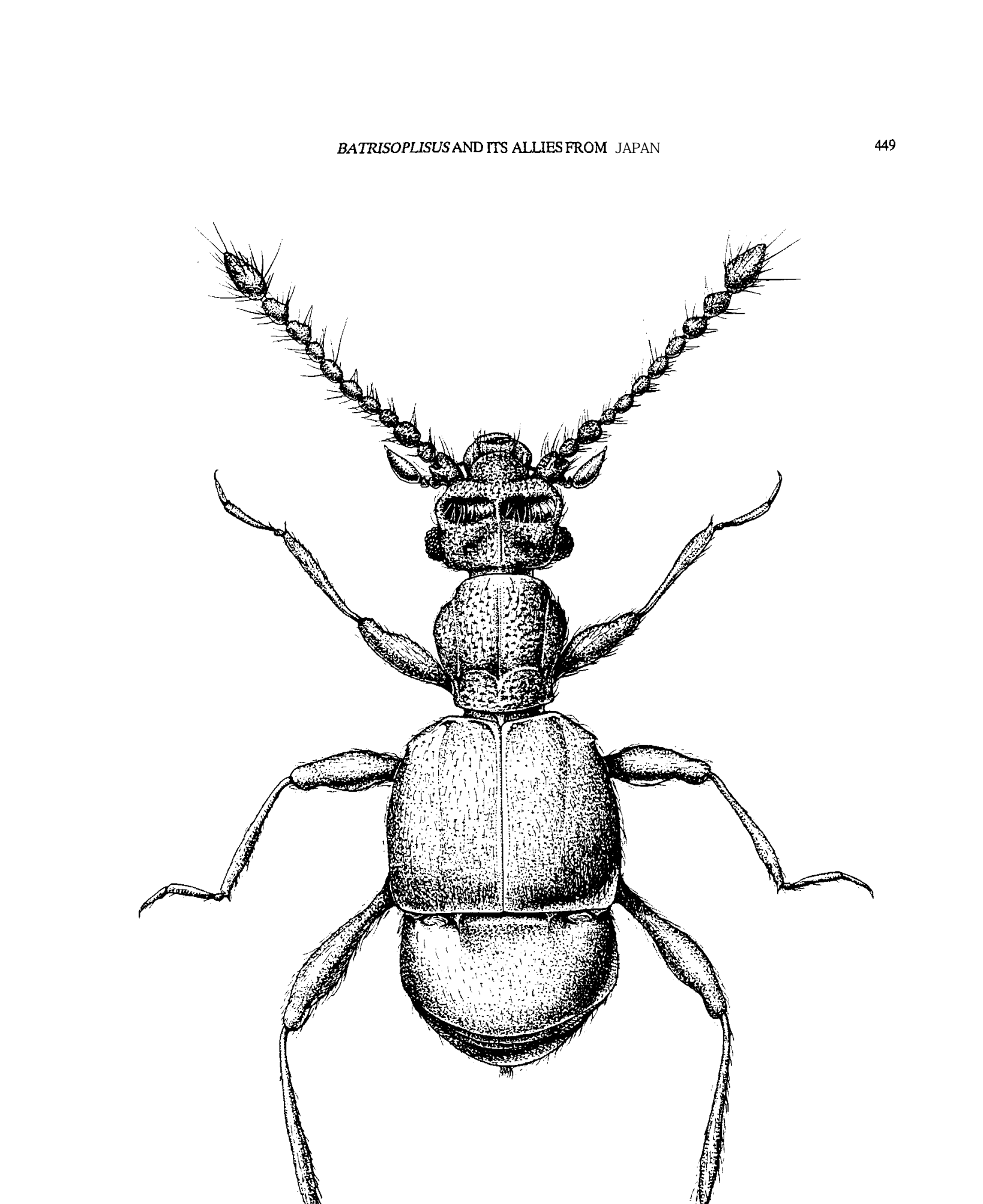


Fig. 149. Male genitalia and 9th abdominal sternites of Batrisceniola.

A-C, B. dissimilis (Sharp).

D-F, B. hiranoi sp. nov.

G-I, B. semipunctulata (Raffray).
A, D, E, G, male genitalia in ventral view.
$\mathrm{B}$, ditto, in dorsal view.
$\mathrm{F}, \mathrm{H}$, ditto, in lateral view.
C, I, 9th stemite. 


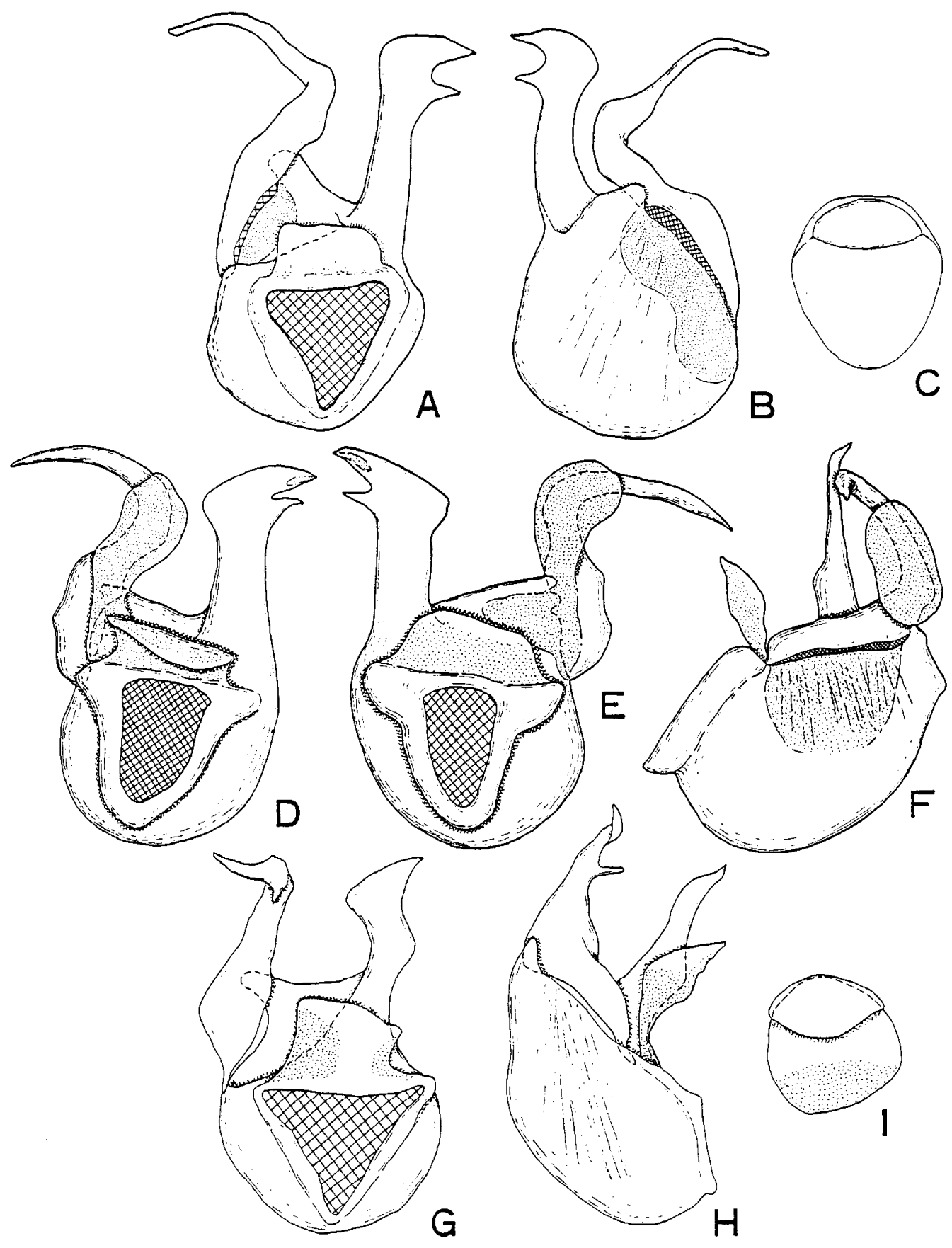


Fig. 150. Female genitalia, and head and pronotum of Batrisceniola in male.
A, B. dissimilis (Sharp).
B, D, B. hiranoi sp. nov.
C, B. semipunctulata (Raffray).

A-C, female genitalia in ventral view.

$\mathrm{D}$, head and pronotum of male in dorsal view. 


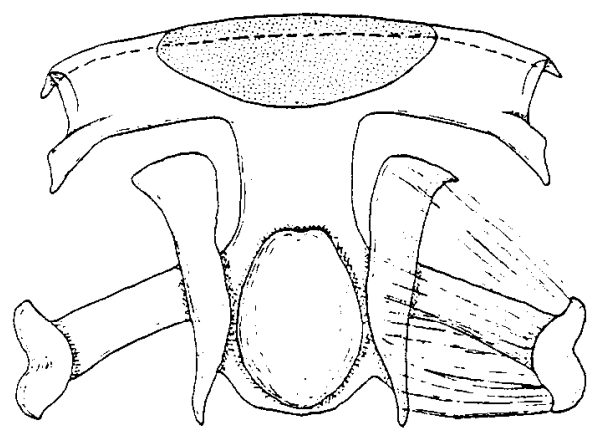

A

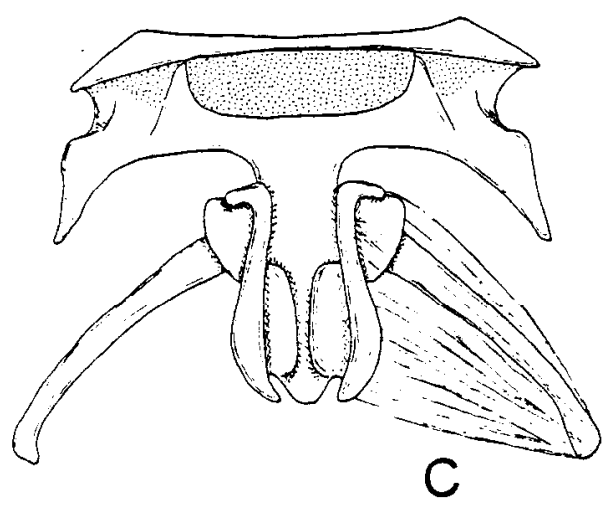

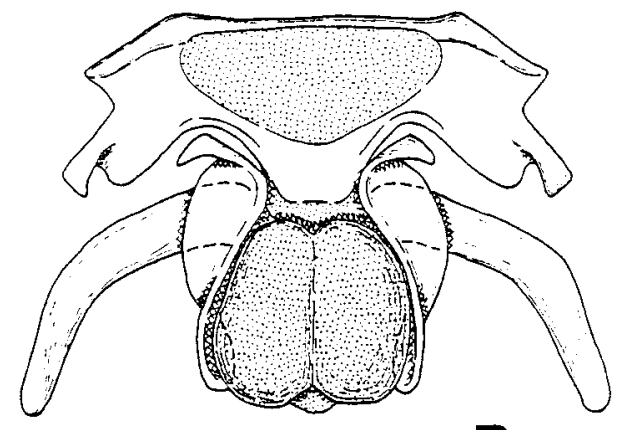

B

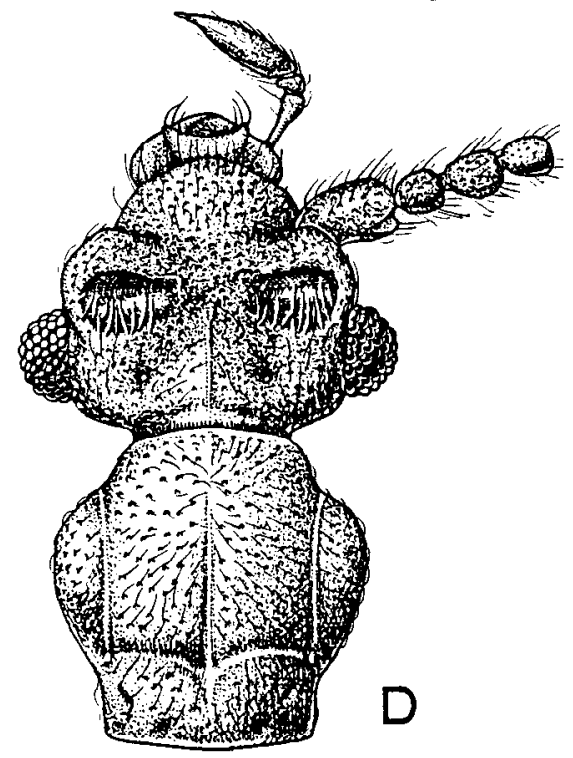




\section{VL ACKNOWLEDGEMENT}

I am most grateful to Professor Katsura Morimoto of Entomological Laboratory, Kyushu University for his continuous kind guidance in the course of my study and critical reading of the manuscript. I express my sincere gratitude to Professor Emeritus Yoshihiro Hirashima of the Entomological Laboratory, Faculty of Agriculture, Kyushu University for his constant guidance and encouragement. My cordial thanks are due to Professor Yozo Murakami of the Institute of Biological Control, Faculty of Agriculture, Kyushu University, Associate Professor SatoshiShiraishi of the Zoological Laboratory, Faculty of Agriculture, Kyushu University, and Associate Professor Osamu Tadauchi of the Entomological Laboratory, Faculty of Agriculture, Kyushu University for critical review of the manuscript and helpful comments for the present study. I am also much indebted to Dr. S. Naomi (Natural History Museum and Institute, Chiba) for his reading of the manuscript and kind help in various ways. My hearty thanks are also due to Dr. I. Löbl and Dr. C. Besuchet (Museum d'Histoire Naturelle, Gentve) and Dr. D. S. Chandler (Entomology Department, University of New Hampshire) for their helpful suggestions and giving me an opportunity to examine the type specimens and their collections. I extend special thanks to Dr. S. Ueno (National Science Museum, Tokyo), Dr. A. F. Newton (Division of Insects, Field Museum of Natural History) and Mr. M. Kubota (Odawara City, Kanagawa Pref.) for their kind encouragement and guidance. I am very grateful to Dr. K. Baba (Niigata Pref.), Mr. I. Okamoto (Hiroshima Pref.), Mr. H. Ohishi (Kyoto Pref.), Mr. Y. Hirano (Kanagawa Pref.), Dr. M. Sakai (Ehime Univ.), Mr. S. Sasaki (Oita Pref.) and Mr. T. Tanabe (Tokushima Pref.) for their gifts or loans of the materials used in this work. I am also indebted to Assoc. Prof. M. T. Chûjô (Hiiosan Biological Laboratory, Kyushu Univ.), Dr. C. Okuma (Entomological Laboratory, Kyushu Univ.), and K. Ogata (Institute of Tropical Agriculture, Kyushu Univ.) for their kindness in various ways in the course of this study. 


\section{REFERENCES}

Blackwelder, R. E., 1936. Morphology of the Coleopterous Staphylinidae.Smith. Misc. coll., 94(13): 1102

Cammaerts, R., 1973. Le systéme glandulaire tegumentaire du Coléoptère myrmecophile Claviger testa ceus Preyssler, 1790 (Pselaphidae). Z Morph. Tiére, 77: 187-219.

Carlton, C. E., 1983. Revision of the genus Conoplectus Brendel (Coleoptera: Pselaphidae). Coleopt. Bull., 37(1):55-80.

Chandler, D. S., 1988a. A revision of the Nearctic genus Cylindrarctus (Coleoptera: Pselaphidae). Trans. Amer. ent. Soc, 114: 129-146.

- 1988b. A cladistic analysis of the world genera of Tychini (Coleoptera: Pselaphidae). Trans. Amer. ent. Soc, 114: 147-165.

- 1988c. Foveae of Pselaphidae - their primitive pattern, usefullness in systematics, and probable function (Coleoptera). Proc. XVIII int.Congr. Ent., Vancouver : 50.

Darlington, Jr., P. J., 1936. Variation and atrophy of flying wings of some carabid beetles. Ann. ent. Soc. Amer. 29:136-179.

Den Boer, P. J., T. H. P. Van Huizen, W. Den Boer-Daanje, B. Aukema \& C. F. M. Den Bieman, 1980. Wing polymorphism and dimorphism in ground beetles as stages in an evolutionary process (Coleoptera: Carabidae). Entomol. gener., 6(2/4): 107-134.

Faustini, D. L. \& D. G. H. Halstead, 1982. Setiferous structures of male Coleoptera. Journ. Morph., 173143-72.

Grigarick, A. \& R. 0. Schuster, 1980. Discrimination of genera of Euplectini of North and Central America (Coleoptera, Pselaphidae). Univ. California Publ. Ent., 87: l-56.

Hennig, W., 1966. Phylogenetic systematics. University of Illinois Press, Urbana. 263pp.

Jeanne $\backslash$ R., 1941. Coléoptères, Carabidae, premiere partie. Faune de France, 39: l-571.

—, 1949a. Les Pselaphides de l'Afrique orientale (Coleoptera). Mém. Mus. Hist. nat., Paris, n. s., 29: l-226.

- 1949b. Faune du Congo Belge et du Ruanda-Urúndi, II: Pselaphidae. Ann. Mus. Congo Belge, Tervuren (Sér. 8”, Sci.Zool.), 2: l-275.

— 1950. Coléoptères Pselaphides. Faune de France, 53: i-iii, 1-421.

—, 1951a. Evolution de l'organe copulateur male des Arthromelus Jeannel (Coleoptera, Pselaphidae). Rev. franç. Ent., 18: 49-55.

-1951b. Pselaphides recueillis par N. Leleup au Congo Belge. Ann. Mus. Congo Belge,Tervuren (Ser. 8, Sci.Zool.), 10: 1-80.

----, 1952. Pselaphides de Saigon. Rev. franç. Ent., 19:69-112.

—, 1954. Les Pseiaphidae de Madagascar. Mém. Inst sci. Madagascar (Sér. E, Ent.), 4:151-344.

, 1955. L'édeage, initiation aux recherches sur la systématique des Coléoptères. Publ. Mus. Hist. nat., Paris, (16): 1-15.5.

— 1958 . Revision des Pselaphides du Japon. Mém. Mus. Hist. nat., Paris, (Sér. A, Zool.), 18:1138. 
- 1959. Revision des Pstlaphides de l'Afrique intertropicale. Ann. Mus. r. Congo Beige, Tervuren(Sér. $8^{\circ}$, Sci. Zool.), 75: 1-742.

- $196 \Omega$ Sur les Pstlaphides (Coleoptera) de l'Inde septentrionale. Bull Brit. Mus. (nat. Hist.), Ent., 9: 403-456.

—, 1961. Sur les Pstlaphides de Ceylan. Bull. Brit. Mus. (nat. Hist.), Ent., 10: 423-456.

Kavanaugh, 1985. On wing atrophy in carabid beetles (Coleoptera: Carabidae), with special reference to Nearctic Nebria. In G. E. Ball (ed.), Taxonomy, Phylogeny and Zoogeography of Beetles and Ants., W. Junk Publ., Dordrecht., pp. 408-431.

Klinger, R. \& U. Maschwitz, 1977. The defensive gland of Omaliinae (Coleoptera, Staphylinidae) I. $J$. chem. Ewl., 3: 401-410.

Klüger, E., 1910. Beitrage zur Anatomie und Biologie der Claviger testaceus Preyssler. Zs. wiss. Zool., 95: $327-381$.

Kubota, M., 1943. New and little known Pselaphidae from Japan. Trans. Kansai. ent. Soc, 9(1): 6-11.

Larsen, O., 1966. On the morphology and function of the locomotor organs of the Gyrinidae and other Coleoptera. Opus. Ent. Suppl., 30: l-242.

Lawrence, J. F. \& A. F. Newton, Jr., 1982. Evolution and classification of beetles. Ann. Rev. Ecol. Syst., 13: $261-290$.

Liidroth, C. H., 1946. Inheritance of wing dimorphism in Pterostichus anthracinus Ill. Heleditas, 32 : 37-40.

Löbl, I., 1973. Beitrag zur Kenntnis der Pselaphidae (Coleoptera) der Koreanischen Volksdemokratis chen Republik, Japan und des Ussuri-Gebietes. Ann. Zool., Warszawa, 30(9): 319-334.

— 1.979a. Revision du genre Sathytes Westwood (Coleoptera, Pselaphidae). Rev. suisse Zool., 86(1): 285-307.

-, 1979b. Deux Batrisini nouveaux de l'Asie tropicale (Coleoptera, Pselaphidae). Arch. Sc Genève, 32(2): 189-198.

— 1986. Über die Arten der Gattung Cratna Raffray (Coleoptera, Pselaphidae) aus dem Gunung Mulu National Park, Sarawak. Mitt schweiz ent. Ges., 59: 221-225.

Matsuda, R., 1970. Morphology and evolution of the insect thorax. Mém. ent. Soc. Canada, (76): 1-431. , 1976. Morphology and evolution of the insect abdomen. Pergamon Press, Oxford. 534pp.

Naomi, S., 1985. The phylogeny and higher classification of the Staphylinidae and their allied groups (Coleoptera, Staphylinoidea). Esakia, (23): 1-27.

- 1987a. Comparative morphology of the Staphylinidae and the allied groups (Coleoptera, Staphylinoidea) I. Introduction, head sutures, eyes and ocelli. Kontyû, 55(3):450-458.

-1987b. Ditto, II. Cranial sutures and tentorium. Ibid., 55(4): 666-675.

- 1988a. Ditto, III. Antennae, labrum and mandibles. Ibid., 56(1): 67-77.

—, 1988b. Ditto, IV. Maxillae and labium. Ibid., 56(2): 241-250.

—, 1988c. Ditto, V. Cervix and prothorax. Ibid., 56(3): 506-513.

- 1988d. Ditto, VI. Mesothorax and metathorax. Ibid., 56(4): 727-738.

—_, 1989a. Ditto, VII. Metendosternite and wings. Jpn. J. Ent., 57(1): 82-90.

__, 1989b. Ditto, VIII. Thoracic legs. Ibid., 57(2): 269-277.

— 1989c. Ditto, IX. General structure, lateral plates, stigmeta and 1st to 7th segments of abdomen. Ibid., 57(3): 517-526. 
, 1989d. Ditto, X. Eighth to 10th segments of abdomen. Ibid., 57(4): 720-733.

— 1990. Ditto, XI. Abdominal glands, male genitalia and female spermatheca. Ibid., 58(1): 16-23. Newton, Jr., A. F. \& D. S. Chandler, 1989. World catalog of the genera of Pselaphidae (Coleoptera). Field. Zool., 53: 1-93.

Newton, Jr., A. F. \& M. K. Thayer, 1988. A critique on Naomi's phylogeny and higher classification' of Staphylinoidea and allies (Coleoptera). Entomol. Gener., 14(1): 63-72.

Nomura, S., 1988a. A revision of the subtribe Acetaliina (Coleoptera, Pselaphidae) from Japan. Part I. Kontyû, 56(2): 251-260.

— 1988b. Ditto, Part II. Ibid., 56(3):515-521.

- 1988c. Ditto, Part III. Ibid., 56(4): 739-751.

Ohishi, H., 1986. Consideration of internal morphology for the taxonomy of Pselaphidae. Pap. Ent. pres. Nakane :111-130.

Raffray, R., 1904. Genera et catalogue des Psblaphides. Ann. Soc ent. Fr., 73: l-400.

- 1908. Coleoptera. Fam. Pselaphidae. In Whytsmann, P., ed., Gen. Ins., 64th fax., Rome, 487 pp.

- 1909. Nouvelles tspeces de Pselaphides. Ann.Soc. ent. Fr., 78: 15-52.

- 1911. Pselaphidae. In Schenlding, S., ed., Coleopt. Cat., pars 27. W. Junk, Berlin, 222 pp.

— 1912. H. Sauter's Formosa-Ausbeute. Pselaphidae (Coleoptera). Ent. Mitt. 1(4): 103-109.

Schaufuss, L. W., 1877. Pselaphiden Siam's Ferdinand Thomass, Dresden, 25 pp.

Sharp, D., 1874. The Pselaphidae and Scydmaenidae of Japan. Trans ent. Soc. London, 1874: 105-130.

—, 1883. Revision of the Pselaphidae of Japan. Ibid., 1883: 291-331.

_ and F. Muir, 1912. The comparative anatomy of the male genital tube in Coleoptera. Ibid., 1912: 477-562.

Tanokuchi, Y., 1989. Some Pselaphidae inhabiting the mangrove forests of Singapore and Thailand, with description of a new genus and eight new species. Raffles Bull. Zool., 37(1/2): 87-115.

Thayer, M. K., 1987. Biology and phylogenetic relationships of Neophonus bruchi, an anomalous south Andean staphilinid (Coleoptera). Syst. Ent., 12:389-404.

Waterhouse, C. O., 1882-90. Aids to identification of insects. E. W. Janson ed., London, 189 pls.

Watrous, L. E. \& Q. D. Wheeler, 1981. The out-group comparison method of character analysis. Syst. Zool., 30: 1-11.

Weise, J., 1877. Japanische Staphylinidae und Pselaphidae. Deutsch. ent. Zs., 21: 88-100.

Wiley, E. O., 1981. Phylogenetics. John Wiley \& Sons, Inc. USA, 439 pp. 


\section{INDEX}

Synonyms and invalid names are in parenthesis, page numbers of the main description or red\&ription are in boldface and those of figures in italic.

A

abdominalis, Cratna, 6, 8,11, 12,15, 27, 28, 41, 43, $55,57,64,82,96,104,108,118,128,136,138$, $146,152,178,184,190$,

Acetalius, 25,

affinis, Seidelites, 6, 39, 48, 263,

aizuanus, Arthromelodes, 6, 19, 35, 43, 55, 57, 269, $339,355,356,424,440$.

(akanensis, Physomerinus), 335.

amamianus, Batrisoplisus, 5, 34, 54, 56, 265, 273, 286, 287, 288, 376.

antennatus, Batrisoplisus, 49, 265, 272, 273, 288, 289.

antennatus-group, Batrisoplisus, 273,288.

Arthromelodes, 4, 6, 8, 25, 27, 32, 36, 38, 39, 41, 43, $44,47,48,49,50,51,55,57,240,242,244,250$, $263,268,269,271,272,337,338,342,359,360$, $364,426,428,430,432,434,436,438,440,442$, 444.

Arthromelus, 4, 6, 37, 50,

Arthromelus, subgenus, 4, 37,

B

Barbiera sp., 6,

Basitrodes sp., 6, 33,

Batraxis, sp., 6, 25,

Batriscenaulax, 4, 6, 8, 12, 17, 27, 28, 32, 36, 38, 39, $40,41,43,44,47,48,49,50,55,57,2.28,263$,

$268,269,271,272,323,333,364,408,410,412$, 414.

Batriscenellinus, subgenus, 5, 267, 300, 321.

Batriscenellus, 4, 5, 8, 12, 17, 18, 25, 27, 28, 29, 32, $34,37,38,39,40,42,44,46,48,50,54,56,200$, $206,212,216,263,266,267,271,299,321,347$, $384,386,388,390,392,394,396,398,400,402$,
404.

Batriscenellus, subgenus, 4, 5, 42, 50, 300, 306, 314. Batrisceninus, 4, 10, 11,271.

Batrisceniola, 4, 6, 8, 17, 25, 27, 32, 36, 38, 39, 41, $47,48,49,50,51,256,260,263,268,269,271$, $272,338,359,360,450,452$.

Batriscenites, 4, 10, 11, 271.

Batriscenodes, 4, 10, 11, 271.

Batrisiella, 4, 50, 299, 318, 364.

Batrisocenus, 4, 32, 33, 50, 271.

Batrisocenus spp., 33 .

Batrisoplisus, 4, 5, 8, 9, 10, 12, 13, 14, 17, la, 23, 25, $27,28,32,33,34,37,38,39,40,42,44,46,48$, 49, 54, 56, 192, 194, 196,198, 263, 264, 265, $271,272,370,372,376,378,380$.

Batrisoschema, 28.

Batristhenes, 4, 11.

brevispinis, subsp., Batrisoplisus, uroceratus, 5, 24, $34,54,56,265,274,296,368,380$.

Bryaxis spp., 6 ,

\section{C}

cariei, Arthromelodes, 6, 37, 51, 337, 338.

coiffaiti, Batrisoplisus, 42, 49, 265, 274, 286.

Conoplectus, 5 ,

constrictus, Batrisoplisus, 5, 18, 34, 42, 44, 46, 49, 54, 56, 265, 274, 290, 293, 294, 298, 376.

corniventris, Arthromelodes, 6, 19, 35, 43, 51, 55, $57,269,339,347,348,426,434$.

Coryphomodes, 15 ,

Cratna, 4, 6, 8, 10, 27, 38, 39, 40, 43, 44, 55, 57, 271.

Cratna sp. (spp.), 44, 48, 55, 57, 263,

crucifer, Arthromelodes, 6, 19, 27, 35, 36, 43, 44, $47,55,57,70,110,132,148,180,188,250,254$, $269,338,339,358,359,442,446$. 
D

daibosatsuanus, subsp., Arthromelodes dilatatus, 6, 9, 35, 55, 57, 66, 130, 136, 156, 180, 188, 244, $248,269,338,352,353,354,428,438$.

denticornis, Cratna, 6.

dilatatus, Arthromelodes, 6, 8, 15, 43, 44, 47, 51, $338,352,355,356,358$.

dilatatus, subsp., Arthromelodes dilatatus, 271,340, 354,355 .

dissimilis, Batrisceniola, 6, 11, 13, 16, 17, 19, 20, 21, $22,27,28,30,31,35,36,39,43,47,51,58,60$, $74,78,80,90,98,106,110,116,118,120,124$ 132. 136, 140,148,156,164,166,168,170,180, $188,190,256,260,269,291,312,332,340,341$, $355356,359,360,362,363,448,450,452$. dorsalis, Batrisodes, 6, 40,156, 188, dubius, Acetalius, 6, 8, 60,

$\mathbf{E}$

elegans, Mina, 6, 11,

esakii, Batrisoplisus, 5, 18, 34, 54, 56, 265, 273, 279, 282,372

Eubatrisus, 4,

euplectiforme, Batrisoschema, 6, 14, 30, 76, 92, 162 , 188 ,

Euplectus, 12, 14,

Euplectus sp., 6, 92 ,

Euthiomelus, subgenus, 4,

F

fallax, Batriscenellus, $5,18,34,46,54,56,200,204$, $267,300,301,304,306,312,356,384,390,394$, 402.

fragilis, Batriscenellus, 6, 18, 34, 50, 54, 56, 267, $299,300,301,308,309,386,396$.

fujimontanus, subsp., Arthromelodes dilatatus, 6, $19,35,55,57,269,338,354,428,438$. furuhatai, Batriscenaulax 6, 17, 19, 20, 21, 22, 27, 30, 31, 35, 47, 55, 57, 70, 76, 96, 112, 123, 132 146, 152,162, 190, 228, 232, 269, 323, 324, 328, 329,330, 408, 410, 414.
G

galloisi, Batrisoplisus, 5, 18, 34, 46, 54, 56, 62, 94, 112 , 142 , 192, 196, 265, 274, 275, 276, 277, 278, $279,370$.

gdoisi-group, Batrisoplisus, 10, 23, 42, 49, 50, 265 , 273, 275, 279.

giganteus, Arthromelodes, 6, 8, 15, 19, 27, 28, 35, $43,44,47,55,57,66,70,78,84,98,110,112$ $128,146,154,174,178,186,240,242,259,339$, $341,342,430,444$.

gyoja, Arthromelodes, 6, 9, 35, 43, 55, 57, 174,269, $339,343,344,346,347,352,432,4.44$.

\section{H}

hasegawai, Physomerinus, 6, 10, 18, 35, 41, 46, 55, $57,64,220,226,269,333,336,337,418,420$ 422

hayato, subsp., Batriscenaulax longipes, 6, 19, 35, 55, 57, 269, 324, 331, 409, 410.

hikosanus, Arthromelodes, 6, 35, 43, 51, 55, 57, 269 , $339,340,349,350,352,426,436,446$.

hiranoi, Batrisceniola, 6, 17, 19, 20, 21, 22, 30, 35, $36,39,43,47,51,55,57,123,162,190,256$, $260,269,360,362,363,450,452$.

I

insulicola, Batriscenellus, 6, 34, 42, 54, 56, 267, 312, $313,316,317,388,398$.

inermis, Batrisoplisus, 5, 18, 23, 29, 34, 49, 54, 56, $265,274,296,297,368,380$.

\section{$\mathrm{J}$}

japonicus, Batriscenellus, 5, 300, 301, 302, 303, 304, 310.

japonicus, subsp., Batriscenellus japonicus, 5, 18, $34,54,56,267,301,302,384,388,392$

$\mathbf{K}$

kiiensis, Arthromelodes, 6, 19, 27, 35, 43, 55, 57, 66, $70,98,112,130,148,156,174,178,186,269$, $339,340,341,343,344,346,432,444$.

kleinzach, Batriscenaulax, 6, 8, 19, 27, 35, 36, 43, 47, 
$339,340,341,343,344,346,432,444$.

kleinzach, Batriscenaulax, 6, 8, 19, 27, 35, 36, 43, 47, $51,55,57,64,70,84,86,112,132,146,186$, $234,236,238,269,323,324,325,408,412,414$. kujumontanus, Batriscenellus, 5, 11, 13, 17, 18, 20, $21,22,27,30,34,44,46,50,54,56,62,68,76$, $82,86,90,96,104,144,152,164,172,176,200$, $202,267,300,304,306,307,308,309,384,390$, 394,402

kumaso, subsp., Batriscenaulax longipes, 6, 19, 35, $55,57,269,324,331,408,410$.

kunigamensis, Batriscenaulax, 6, 19, 35, 55, 57, 269, $323,324,326,327,406,408,415414$.

\section{L}

labiatus, Arthromelus, 6, 39, 48, 263,

Lasinus, 12 ,

loebli, Arthromelodes, $6,19,35,36,43,51,55,57$, $269,339,340,349,351,352,426,436$.

longicornis, Tribasodes, 6, 33,

longipes, Batriscenaulax, 6, 8, 11, 17, 20, 21, 22, 31, $36,47,123,324,326,329,331,332$.

longipes, subsp., Batriscenaulax longipes, 6, 19, 35 , $5,57,64,82,90,104,108,120,128,140,152$, $164,178,186,228,230,269,324,329,408,410$, 414.

\section{M}

Megabatrus, 40.

mercurius, Arthromelodes, 6, 15, 27, 28, 29, 35, 43, $47,51,55,57,66,84,98,110,136,138,148$, $154,180,182,186,339,348,349,350,351,352$, $426,436,446$.

Mina, 25.

modestus, Batriscenaulax, $6,35,36,55,57,269,323$, 324, 331, 408, 410.

monostatos, Batnsoplisus, 5, 18, 34, 46, 49, 54 , 56 , 94, 142, 184, 194, 198, 265, 273, 289, 290, 298. monostatos-group, Batrisoplisus, 42, 49, 265, 273 289.

morulus, Batriscenites, 33,
$\mathrm{N}$

nagensis, Batriscenaulax, 6, 35, 55, 57, 269, 323, $327,408,412$.

Nebria, 22,

Nipponobythus, 8 ,

Nipponoscenellus, subgenus, $6,14,50,267,300$, 310.

nodulifer, Batriscenellus, 6, 34 44, 46, 50, 54, 56, $206,208,267,300,309,310,386,390,396$.

0

ohishii, Batriscenellus, 6, 18, 22, 30, 34, 42, 46, 54, $56,62,82,96,126,134,138,152,176,182,184$, $212,216,267,312,313,315,316,317,318,319$, 398, 404.

okamotoi, Batnsoplisus, 5, 18, 34, 46, 54, 56, 142, 194, 196, 265, 273, 279, 283, 284, 285, 373.

omissus, Nipponobythus, 6 ,

omogensis, Batriscenellus, 5, 34, 54, 56, 267, 300,

307, 308, 384, 394.

optatus, Arthromelodes, 271, 339, 356.

orientals, Batriscenellus, $6,34,42,54,56,267,312$, $313,316,317,318,386$.

$\mathrm{P}$

Parabatrisus, 33.

parallelus, Batrisoplisus, 5, 18, 27, 28, 29, 34, 49, 54, $56,60,72,74,82,86,94,138,142,144,265$, $274,290,294,295,297,298,380$.

Paraplectus, 12,

pedator, Physomerinus, 6, 29, 35, 46, 55, 57, 64, 84, $96,108,130,138,160,178,186,220,222,269$, $333,334,336,418,420,422$

Philoscotus spp., 6,

Physomerinus, 4, 6, 8, 9, 12, 17, 18, 28, 32, 33, 35, $38,39,40,41,43,46,48,49,50,51,55,57,220$, $263,268,269,271,323,332,333,418,420,422$ picticornis, Tribasodites, 6, 32, 33, pilicollis, Arthromelodes, 6, 19, 25, 35, 43, 55, 57, $174,269,339,342,343,344,347,432$ pilosellus, Batriscenellus, $6,18,34,42,46,54,56$, $212,216,267,312,313,318,319,320,321,382$, 
politus, Batristilbus, 6.

Probatrisus, 38.

(Pseudobatriscenus ), 4, 337.

punctatus, Batriscenellus, 5, 18, 34, 54, 56, 267, 300,

$303,304,307,384,388,392,402$

puncticollis, Batriscenaulax, 50, 269, 324, 332.

punctifrons, Arthromelodes, 6, 19, 27, 28, 35, 38,

$43,55,57,146,174,269,339,340,341,430$,

444.

\section{Q}

quinquesulcatus, Batrisodes? ?, 6, 40,

\section{$\mathrm{R}$}

raffrayi, Batn'soplisus, 5, 11, 13, 18, 27, 28, 30, 31, $34,46,54,56,68,72,76,78,80,90,94,102$, $108,142,144,158,176,182,192,196,265,274$, $286,287,374,382$

raffrayi-group, Batrisophsus, 10, 42, 49, 265, 273, $285,286$.

risor, Batrisodellus, 6, 40,

rufipes, Pterostichus, 37.

\section{S}

sagamianus, Batrisophsus, 5, 18, 34, 54, 56, 265, 274, 275, 276, 277,370.

saikaiensis, Arthromelodes, 6, 15,19, 35, 43, 47, 55, 57, 66, 70, 84, 86, 98,110,136, 140,148, 156, $180,188,250,252,269,338,339,356,358,442$, 446.

sakaii, Batriscenellus, 6, 34, 42, 54, 56, 267, 312, $313,320,321,388,400,404$.

Sathytes, 40.

satsumanus, Batrisoplisus, 5, 34, 54, 56, 265,274, $275,278,370$.

sawadai, Batrisoplisus, 5, 18, 34, 54, 56, 265, 274, $275,277,370$.

Scaioscenellus, subgenus, 4, 6, 267, 300, 312, 321, 322.

Scaiomelus, subgenus, 4, 37,

schenklingi, Physomerinus, 6, 18, 27, 31, 32, 33, 35, $44,46,55,57,64,68,72,132,136,140,146$,
$154,164,186,220,224,269,333,335,336,337$, 416, 418, 420,422

Seidehies, 4, 6, 11, (semipunctatus, Batrisocenus ), 363.

semipunctulata, Batrisceniola, 6, 17, 19, 27, 35, 43, $44,47,51,55,57,58,60,66,74,80,84,86,88$, $92,98,164,186,220,224,269,360,363,364$, 450,452

(semipunctulatus, Batrisocenus /Arthromelinus ), 363.

septemfoveolatus, Physomerinus, 332.

shiranemontanus, subsp., Arthromelodes, dilatatus, $6,9,35,55,57,269,338,354,428,438$.

shiranui, Batriscenellus, 6, 42, 50, 54, 56, 267,312, $314,316,386$.

similis, Batriscenellus, 6, 18, 34, 42, 46, 50, 54, 56, $62,68,76,176,184,212,214,267,312,313$,

$314,315,386,398,404$.

sinuatipes, Arthromeiodes, 6, 19, 35, 43, 55, 57, 269, $339,354,355,356,426,428,440$.

spinicollis, Coryphomodes, 6, 15, 110, 156, 188, splendida, Batraxis, 6 ,

subtilis, Batrisoplisus, 5, 34, 54, 56, 265, 274, 275 , 278, 279, 370.

$\mathrm{T}$

Takaorites, 8 .

tamino, Batrisophsus, 5, 34, 49, 54, 56, 265, 274, 290, 292, 378.

tanabei, Batrisoplisus, 23, 33, 42, 54, 56, 265,273, $279,283,284,285,372$

tenuiformis, Batrisoplisus, 5, 34, 54, 56, 265, 273, $279,281,312,372$.

testaceus, Claviger, 37.

thysanoventris, Arthromelodes, 6, 15, 19, 24, 27, 28, $35,36,43,47,51,55,57,130,148,244,246$, $269,339,340,346,347,348,426,428,434,444$. torticornis, Batrisophsus, 5, 10,18, 33, 34, 46, 49, 54, 56, 62, 68, 72, 74, 76, 134, 150,194, 198, $165,274,290,291,292,294,378$.

torticornis, Cratna, 6, 55, 57, 184, torticornis, Takaorites, 6 , 
torticornis, Cratna, 6, 55, 57, 184,

torticornis, Takaorites, 6 ,

torticornis-group, Batrisoplisus, 23, 33, 42, 44, 49, 265, 273, 290, 292.

tosanus, Batrisoplisus, 5, 18, 34,,54, 56, 265,273, $279,283,284,285,372$

transformis, Batriscenellus, 6, 14, 18, 31, 34, 42, 46, $54,56,68,86,206,210,267,310,311,386,390$, 396,402

\section{Trisinarthrus, 4.}

Trisiniotus, 4, 6, 11, 271.

typographus, Ips, 15.

$\mathbf{U}$

uenoi, Batriscenellus, $6,27,28,34,42,44,46,54$ $56,96,108,140,144,218,267,321,322,400$, 404.

uroceratus, Batrisoplisus, 5, 25, 27, 28, 29, 49, 274, 295, 296, 297.

uroceratus, subsp., Batrisoplisus uroceratus, 5, 18, $23,34,54,56,62,72,74,94,108,128,132,134$, $138,140,144,150,182,265,274,295,296,366$, 368,380 .

uroceratus-group, Batrisoplisus, 9, 10, 17, 29, 42, 49, 50, 265, 273, 294, 298.

venustus, Batrisoplisus, 5, 18, 34, 46, 54, 56, 82,128 , $142,194,196,265,273,279,280,281,282,372$ venustus-group, Batrisoplisus, 49, 50, 267, 273,279, 280, 289.

vicarius, subsp., Batriscenellus japonicus, 5, 18, 34, $54,56,267,300,301,302,303,384,388,392$,

402

volucaninsulanus, Batrisoplisus, 5, 18, 29, 34, 54, 56, 265, 274, 294, 296, 298, 380. 